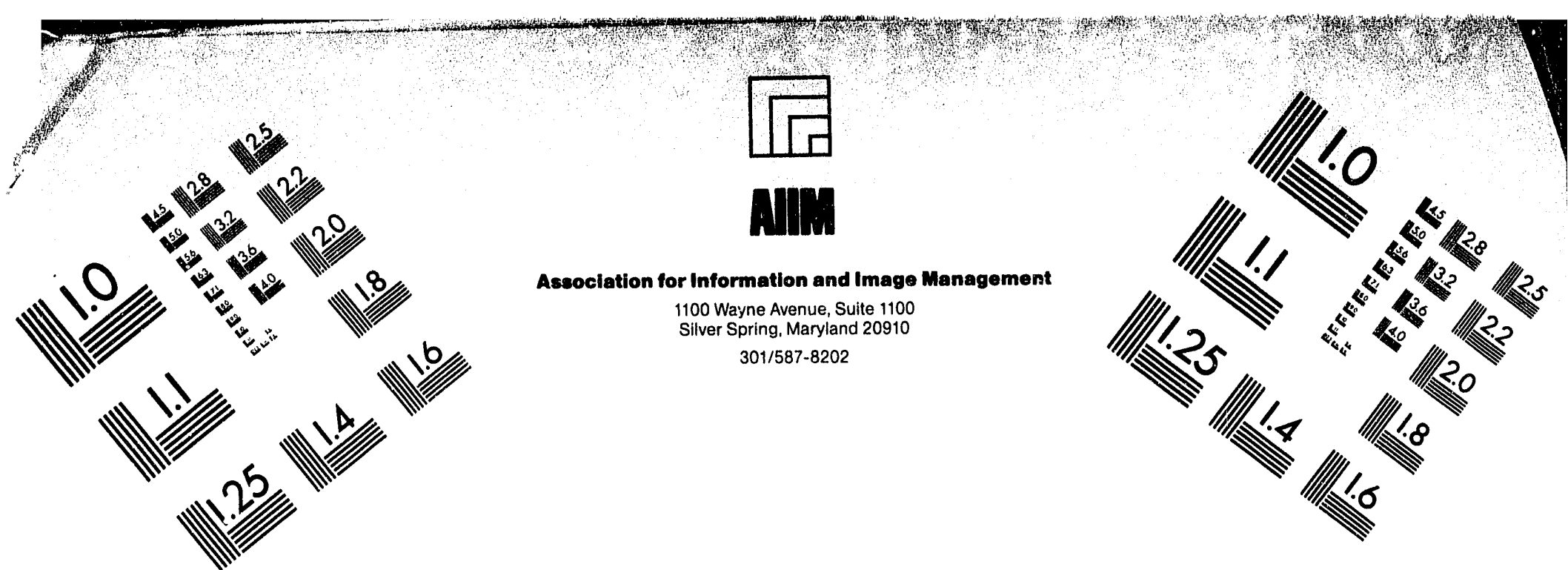

Centimeter

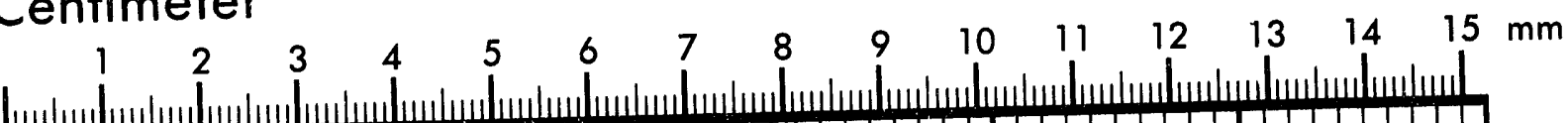

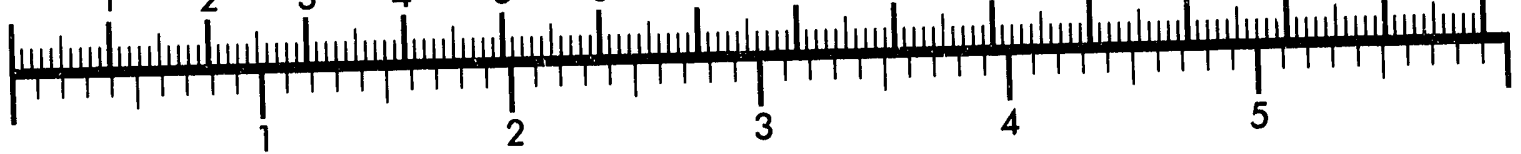
Inches
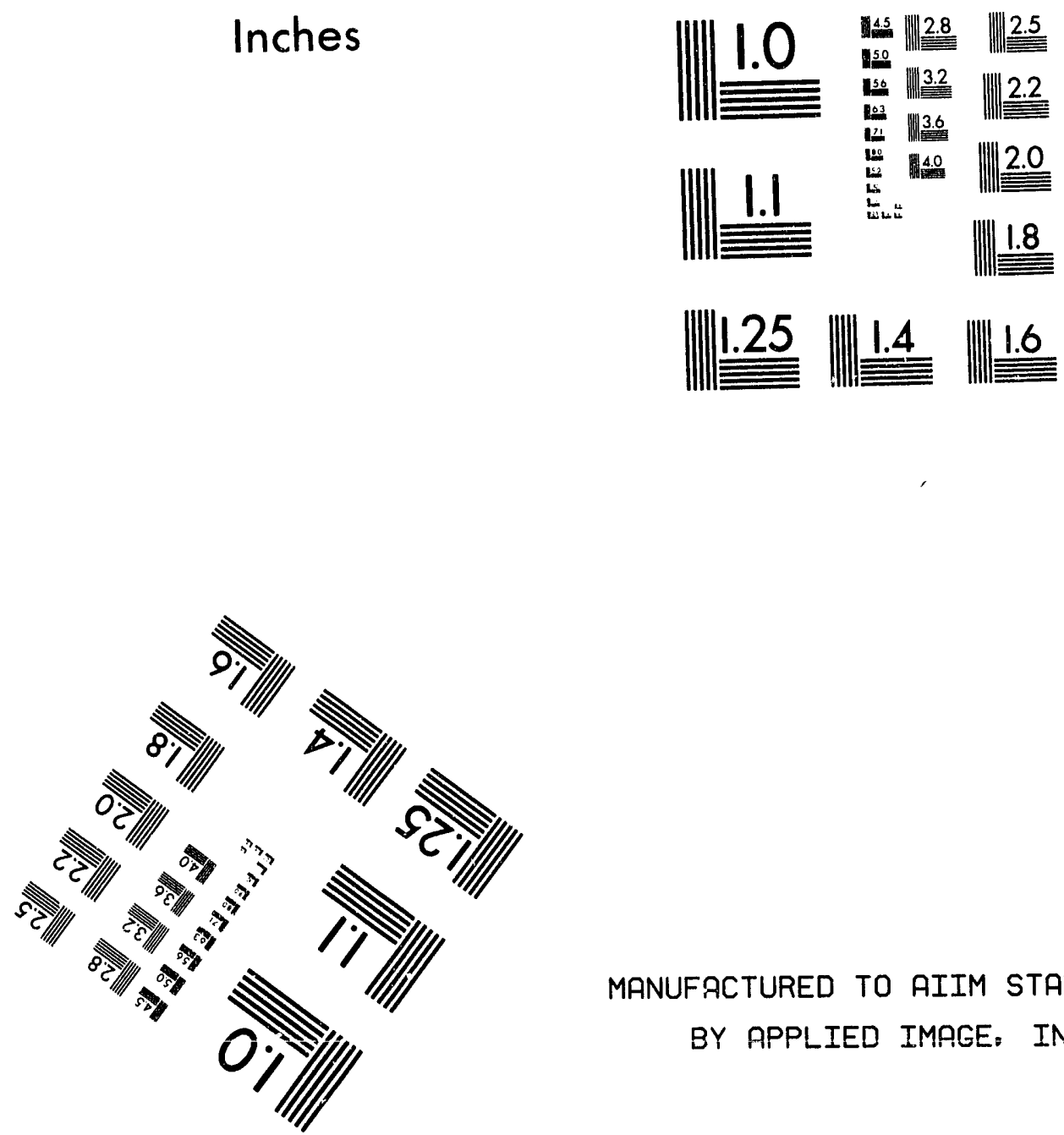

MANUFACTURED TO AIIM STANDARDS BY APPLIED IMPGE: INC.

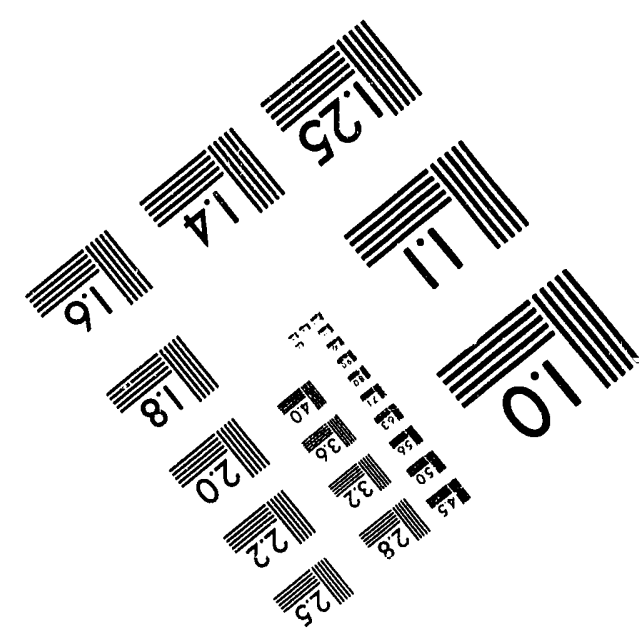



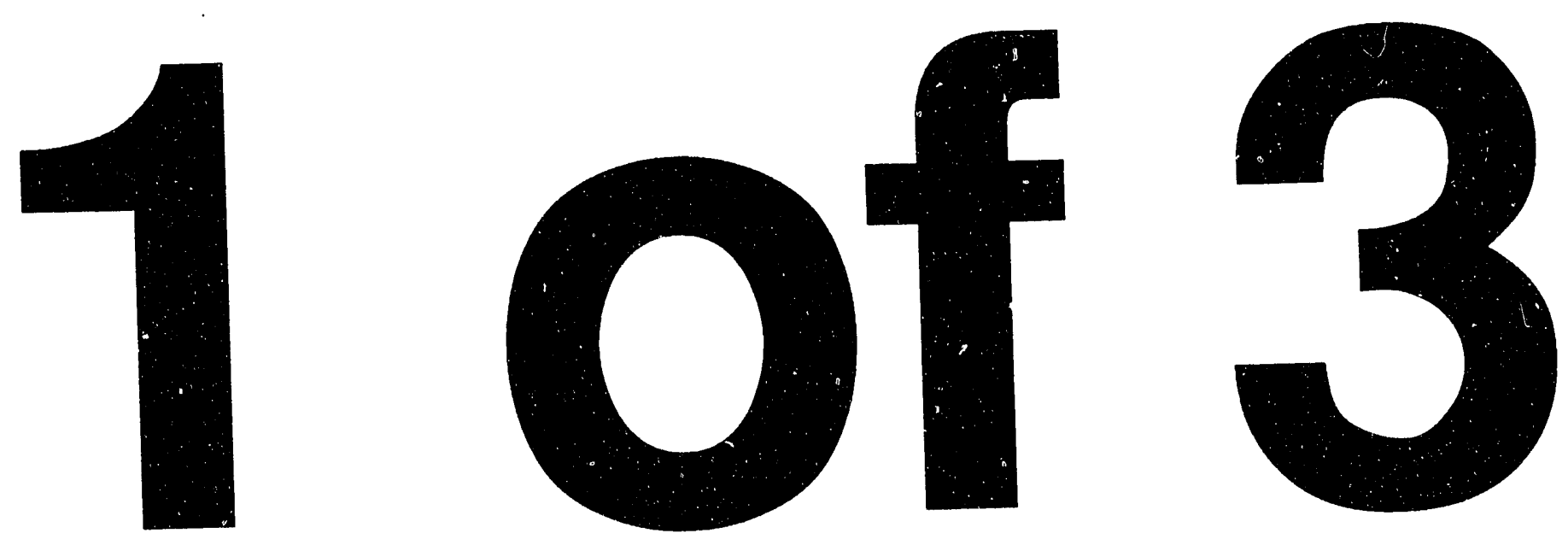
PNL-8559

UC-

902

\section{Numerical Simulation of Jet Mixing Concepts in Tank 241-SY-101}

D. S. Trent

T. E. Michener

March 1993

Prepared for

the U.S. Department of Energy

under Contract DE-AC06-76RLO 1830

Pacific Northwest Laboratory

Richland, Washington 99352

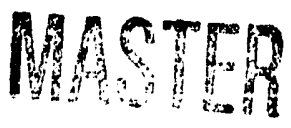




\section{Executive Summary}

The episodic gas release events (GREs) that have characterized the behavior of Tank 241-SY-101 for the past several years are thought to result from gases generated by the waste material in it that become trapped in the layer of settled solids at the bottom of the tank. Several concepts for mitigating the GREs have been proposed.

One concept involves mobilizing the solid particles with mixing jets. The rationale behind this idea is to prevent formation of a consolidated !ayer of settled solids at the bottom of the tank, thus inhibiting the accumulation of gas bubbles in this layer.

The purpose of jet mixing in this application is not to achieve uniformity of the tank contents but, instead, to prevent a thick layer of consolidated solid particles from forming at the bottom of the tank that can trap gas bubbles. A variety of jet mixing concepts have been proposed that might achieve this goal, ranging from vertical jets and draft tubes to horizontal dischargers that are stationary or rotating.

Numerical simulations were conducted using the TEMPEST computer code to assess the viability and effectiveness of the proposed jet discharge concepts and operating parameters. Before these parametric studies were commenced, a series of turbulent jet studies were conducted that established the adequacy of the TEMPEST code for this application. Configurations studied for Tank 241-SY-101 include centrally located downward discharging jets, draft tubes, and horizontal jets that are either stationary or rotating. Parameter studies included varying the jet discharge velocity, jet diameter, discharge elevation, and material properties. A total of 18 simulations were conducted and are reported in this document. The effect of gas bubbles on the mixing dynamics was not included within the scope of this study.

Results from this work indicate that high velocity jets discharging horizontally near the bottom of the tank are more effective mixing devices than vertical downward discharging jets located at the center of the tank. A centrally located vertical jet or draft tube would require an unreasonably large discharge rate to mobilize the settled solids near the outer wall of the tank. The TEMPEST simulations indicate that an incrementally rotated horizontal jet located 2- to 3-feet above the tank floor appears to be the most effective jet mixing option. 


\section{Contents}

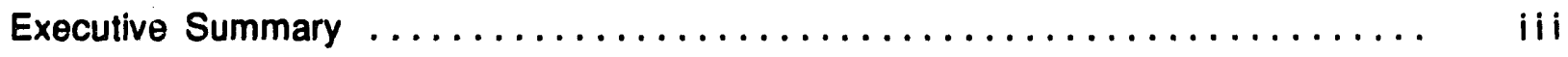

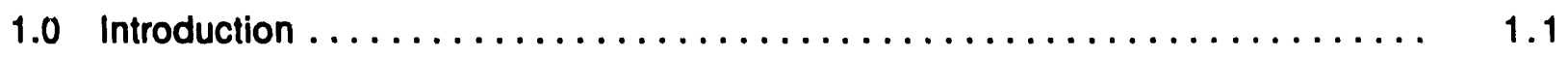

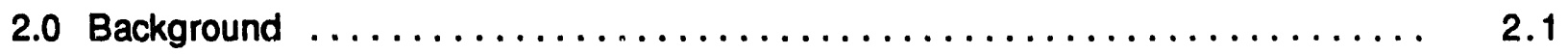

2.1 Description of the Tank $\ldots \ldots \ldots \ldots \ldots \ldots \ldots \ldots \ldots \ldots \ldots \ldots, 2.1$

2.2 Description of Jet Mixing Concepts $\ldots \ldots \ldots \ldots \ldots \ldots \ldots \ldots \ldots, 2.3$

2.2.1 Vertical Jets $\ldots \ldots \ldots \ldots \ldots \ldots \ldots \ldots \ldots \ldots \ldots \ldots \ldots, 2.3$

2.2.2 Liquid Piston $\ldots \ldots \ldots \ldots \ldots \ldots \ldots \ldots \ldots \ldots \ldots \ldots \ldots, 2.3$

2.2.3 Horizontal Jets $\ldots \ldots \ldots \ldots \ldots \ldots \ldots \ldots \ldots \ldots \ldots \ldots, \quad 2.4$

2.2.4 Material Mobilization and Recirculation ............... 2.6

3.0 Numerical Modeling $\ldots \ldots \ldots \ldots \ldots \ldots \ldots \ldots \ldots \ldots \ldots \ldots \ldots \ldots \ldots \ldots \ldots \ldots, \quad 3.1$

3.1 The TEMPEST Computer Code $\ldots \ldots \ldots \ldots \ldots \ldots \ldots \ldots \ldots \ldots \ldots, \quad 3.2$

3.1.1 TEMPEST T2 Equation Set $\ldots \ldots \ldots \ldots \ldots \ldots \ldots \ldots \ldots \ldots, \quad 3.2$

3.1.2 Constitutive Relationships $\ldots \ldots \ldots \ldots \ldots \ldots \ldots \ldots \ldots \ldots \ldots, \quad 3.5$

3.1.3 Rheology Model ........................... 3.6

3.1.4 Particle Settling Model $\ldots \ldots \ldots \ldots \ldots \ldots \ldots \ldots \ldots \ldots \ldots, \quad 3.7$

3.2 Model Testing and Verification $\ldots \ldots \ldots \ldots \ldots \ldots \ldots \ldots \ldots \ldots \ldots, 3.8$

3.2.1 Momentum Jets $\ldots \ldots \ldots \ldots \ldots \ldots \ldots \ldots \ldots \ldots \ldots \ldots, \quad 3.10$

3.2.2 Momentum Jet Using the Tank Coordinate System .......... $\quad 3.27$

4.0 TEMPEST Jet Mixing Simulations $\ldots \ldots \ldots \ldots \ldots \ldots \ldots \ldots \ldots \ldots \ldots \ldots \ldots \ldots \ldots \ldots, 4.1$

4.1 Vertical Jets $\ldots \ldots \ldots \ldots \ldots \ldots \ldots \ldots \ldots \ldots \ldots \ldots \ldots \ldots, 4.1$

4.1.1 Case \#1: Vert. $1 \ldots \ldots \ldots \ldots \ldots \ldots \ldots \ldots \ldots \ldots \ldots \ldots, 4.4$

4.1.2 Cases \#2-4: Vert. 2 - Vert. $4 \ldots \ldots \ldots \ldots \ldots \ldots \ldots \ldots, \quad 4.20$ 


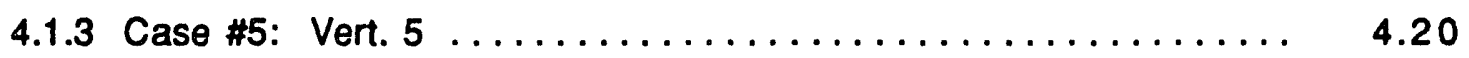

4.1.4 Cases $\# 6$ and 7: Vert. 6 and Vert. $7 \ldots \ldots \ldots \ldots \ldots \ldots \ldots \ldots, 4.28$

4.1.5 Cases \#8-10: Vert. 8 - Vert. $10 \ldots \ldots \ldots \ldots \ldots \ldots \ldots \ldots \ldots$

4.1.6 Case \#11: Vert. $11 \ldots \ldots \ldots \ldots \ldots \ldots \ldots \ldots \ldots \ldots \ldots \ldots \ldots \ldots$

4.1.7 Case \#12: Vert. $12 \ldots \ldots \ldots \ldots \ldots \ldots \ldots \ldots \ldots \ldots \ldots \ldots .4 .40$

4.1.8 Cases \#13 and 14: Vert. 13 and Vert. $14 \ldots \ldots \ldots \ldots \ldots \ldots . \ldots \ldots$

4.2 Horizontal (Radial) Jets $\ldots \ldots \ldots \ldots \ldots \ldots \ldots \ldots \ldots \ldots \ldots \ldots \ldots . \ldots \ldots$

4.2.1 Horiz. 1, Horiz. 2, and Horiz. $3 \ldots \ldots \ldots \ldots \ldots \ldots \ldots \ldots \ldots . \ldots 4$

4.2.2 Horiz. $4 \ldots \ldots \ldots \ldots \ldots \ldots \ldots \ldots \ldots \ldots \ldots \ldots \ldots \ldots \ldots .4 .68$

5.0 Conclusions $\ldots \ldots \ldots \ldots \ldots \ldots \ldots \ldots \ldots \ldots \ldots \ldots \ldots \ldots \ldots \ldots \ldots \ldots \ldots$

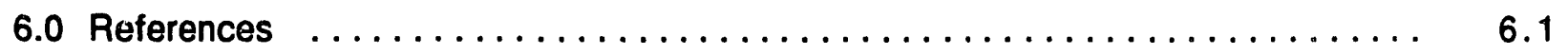




\section{Figures}

2.1 Cross-Section View of Tank 241 -SY-101 $\ldots \ldots \ldots \ldots \ldots \ldots \ldots \ldots \ldots$

2.2 Vertical Jet and Draft Tube Arrangement $\ldots \ldots \ldots \ldots \ldots \ldots \ldots \ldots$

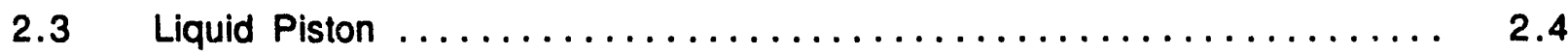

2.4 Horizontal Jet Arrangement (Two Opposing Jets) $\ldots \ldots \ldots \ldots \ldots \ldots \ldots \ldots$

3.1 Jet Discharge Flow Regimens $\ldots \ldots \ldots \ldots \ldots \ldots \ldots \ldots \ldots \ldots \ldots \ldots \ldots \ldots \ldots \ldots$

3.2 Centerline Velocity of a Momentum Jet $\ldots \ldots \ldots \ldots \ldots \ldots \ldots \ldots \ldots \ldots$

3.3 Jet Core Computational Cell Structure $\ldots \ldots \ldots \ldots \ldots \ldots \ldots \ldots \ldots \ldots$

3.4 Momentum Jet Test: Case A.9 $\ldots \ldots \ldots \ldots \ldots \ldots \ldots \ldots \ldots \ldots \ldots \ldots \ldots \ldots \ldots \ldots$

3.5 Momentum Jet Axial Velocity Distributions (Case A.9) . . . . . . . . . . 3.15

3.6 Downstream Velocity: Red $=$ High Velocity, Blue $=$ Low Velocity, and White $=$ Zero Velocity $\ldots \ldots \ldots \ldots \ldots \ldots \ldots \ldots \ldots \ldots \ldots \ldots \ldots \ldots \ldots \ldots \ldots \ldots$

3.7 Downstream Velocity (Expanded Scale): Red $=$ High Velocity, Blue $=$ Low Velocity, and White $=$ Zero Velocity $\ldots \ldots \ldots \ldots \ldots \ldots \ldots \ldots \ldots \ldots \ldots \ldots$

3.8 Magnitude of Lateral Velocity Showing: Red $=$ High Positive Velocity, Blue $=$ High Negative Velocity, and Green $=$ Very Low Flow $\ldots \ldots \ldots \ldots$

3.9 Magnitude of Lateral Velocity Showing: Red = Positive Flow and

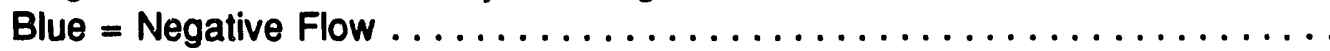

3.10 Case B; Computed Momentum Jet Centerline Velocity Using Three Radial Cells in the Zone of Flow Establishment ....................

3.11 Case C; Computed Momentum Jet Centerline Velocity Using one Radial Cell in the Zone of Flow Establishment . . . . . . . . . . . . . . . . . . . . .

3.12 Plan View of Computational Grid System $(r-\theta$ plane) $\ldots \ldots \ldots \ldots \ldots \ldots \ldots .27$

3.13 Computed Momentum Jet Centerline Velocity Using Tank Coordinates . . . . . 3.28

4.1 Vertical Jet and Draft Tube Arrangement $\ldots \ldots \ldots \ldots \ldots \ldots \ldots \ldots \ldots . \ldots$

4.2 TEMPEST Computational Grid for Tank 241-SY-101, Case \#1: Vert. $1 \ldots$.. 4.5 
4.3 Volumetric Concentration, Vert. 1, Vertical Jet, $9.14 \mathrm{~m} / \mathrm{s}(30 \mathrm{ft} / \mathrm{sec})$

Nozzle Velocity, @ time $=15$ sec ......................... 4.6

4.4 Volumetric Concentration, Vert. 1, Vertical Jet, $9.14 \mathrm{~m} / \mathrm{s}(30 \mathrm{ft} / \mathrm{sec})$

Nozzle Velocity, @ time=60 sec

4.5 Volumetric Concentration, Vert. 1, Vertical Jet, $9.14 \mathrm{~m} / \mathrm{s}(30 \mathrm{ft} / \mathrm{sec})$

Nozzle Velocity, @ time=120 sec

4.6 Volumetric Concentration, Vert. 1, Vertical Jet, $9.14 \mathrm{~m} / \mathrm{s}(30 \mathrm{ft} / \mathrm{sec})$

Nozzle Velocity, @ time=240 sec

4.7 Volumetric Concentration, Vert. 1, Vertical Jet, $9.14 \mathrm{~m} / \mathrm{s}(30 \mathrm{ft} / \mathrm{sec})$

Nozzle Velocity, @ time=480 sec

4.8 Volumetric Concentration, Vert. 1, Vertical Jet, $9.14 \mathrm{~m} / \mathrm{s}$ (30 ft/sec)

Nozzle Velocity, @ time=600 sec

4.9 Volumetric Concentration, Vert. 1, Vertical Jet, $9.14 \mathrm{~m} / \mathrm{s}(30 \mathrm{ft} / \mathrm{sec})$

Nozzle Velocity, @ time $=900 \mathrm{sec} . . . \ldots \ldots \ldots \ldots \ldots . \ldots \ldots$

4.10 Velocity Vector, Vert. 1, Vertical Jet, $9.14 \mathrm{~m} / \mathrm{s}(30 \mathrm{ft} / \mathrm{sec})$ Nozzle

Velocity, @ time=15 sec

4.11 Velocity Vector, Vert. 1, Vertical Jet, $9.14 \mathrm{~m} / \mathrm{s}(30 \mathrm{ft} / \mathrm{sec})$ Nozzle

Velocity, @ time=60 sec.

4.12 Velocity Vector, Vert. 1, Vertical Jet, $9.14 \mathrm{~m} / \mathrm{s}(30 \mathrm{ft} / \mathrm{sec})$ Nozzle

Velocity, @ time=120 sec

4.13 Velocity Vestor, Vert. 1, Vertical Jet, $9.14 \mathrm{~m} / \mathrm{s}(30 \mathrm{ft} / \mathrm{sec})$ Nozzle

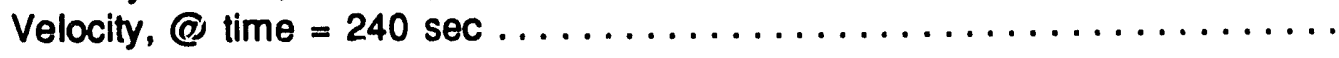

4.14 Velocity Vector, Vert. 1, Vertical Jet, $9.14 \mathrm{~m} / \mathrm{s}(30 \mathrm{ft} / \mathrm{sec})$ Nozzle

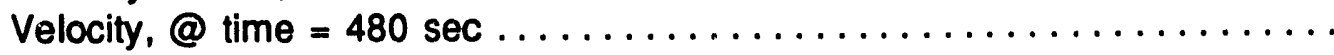

4.15 Velocity Vector, Vert. 1, Vertical Jet, $9.14 \mathrm{~m} / \mathrm{s}(30 \mathrm{ft} / \mathrm{sec})$ Nozzle

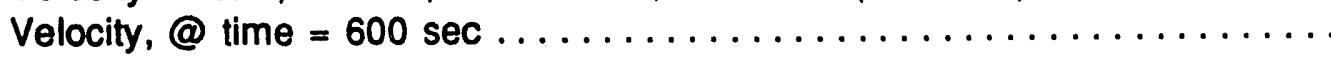

4.16 Velocity Vector, Vert. 1, Vertical Jet, $9.14 \mathrm{~m} / \mathrm{s}(30 \mathrm{ft} / \mathrm{sec})$ Nozzle

Velocity, @ time= 900 sec

4.17 Volumetric Concentration, Vert. 5, Vertical Jet, $9.14 \mathrm{~m} / \mathrm{s}$ (30 ft/sec)

Nozzle Velocity, @ time=15 sec

4.18 Volumetric Concentration, Vert. 5, Vertical Jet, $9.14 \mathrm{~m} / \mathrm{s}(30 \mathrm{ft} / \mathrm{sec})$

Nozzle Velocity, @ time=60 sec 
4.19 Volumetric Concentration, Vert. 5, Vertical Jet, $9.14 \mathrm{~m} / \mathrm{s}(30 \mathrm{ft} / \mathrm{sec})$ Nozzle Velocity, @ time=120 sec.

4.20 Volumetric Concentration, Vert. 5, Vertical Jet, $9.14 \mathrm{~m} / \mathrm{s}(30 \mathrm{ft} / \mathrm{sec})$

Nozzle Velocity, @ time=240 sec

4.21 Volumetric Concentration, Vert. 5, Vertical Jet, $9.14 \mathrm{~m} / \mathrm{s}(30 \mathrm{ft} / \mathrm{sec})$

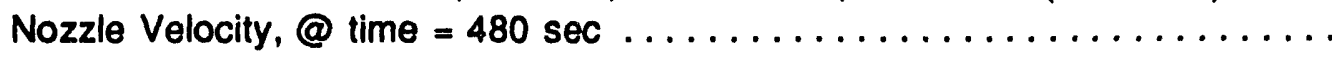

4.22 Volumetric Concentration, Vert. 5, Vertical Jet, $9.14 \mathrm{~m} / \mathrm{s}(30 \mathrm{ft} / \mathrm{sec})$

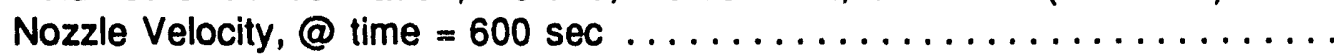

4.23 Volumeiric Concentration, Vert. 5, Vertical Jet, $9.14 \mathrm{~m} / \mathrm{s}(30 \mathrm{ft} / \mathrm{sec})$

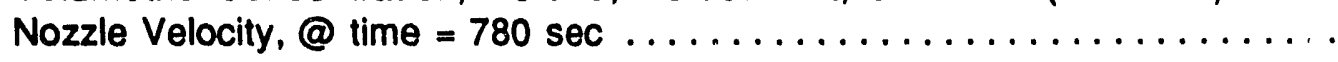

4.24 Velocity Vector, Vert. 5 , Vertical Jet, $9.14 \mathrm{~m} / \mathrm{s}(30 \mathrm{ft} / \mathrm{sec})$ Nozzle

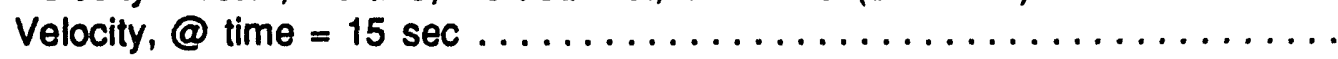

4.25 Velocity Vector, Vert. 5, Vertical Jet, $9.14 \mathrm{~m} / \mathrm{s}(30 \mathrm{ft} / \mathrm{sec})$ Nozzle

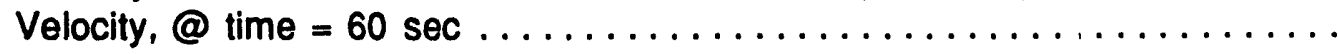

4.26 Velocity Vector, Vert. 5, Vertical Jet, $9.14 \mathrm{~m} / \mathrm{s}(30 \mathrm{ft} / \mathrm{sec})$ Nozzle

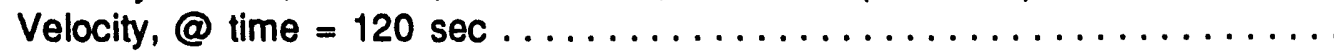

4.27 Velocity Vector, Vert. 5, Vertical Jet, $9.14 \mathrm{~m} / \mathrm{s}(30 \mathrm{ft} / \mathrm{sec})$ Nozzle

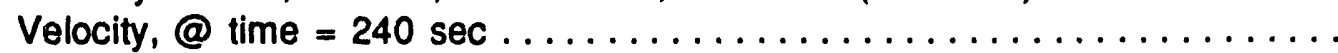

4.28 Velocity Vector, Vert. 5, Vertical Jet, $9.14 \mathrm{~m} / \mathrm{s}(30 \mathrm{ft} / \mathrm{sec})$ Nozzle

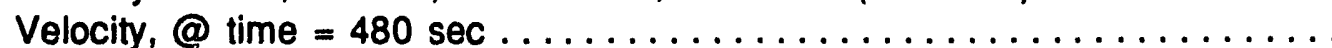

4.29 Velocity Vector, Vert. 5, Vertical Jet, $9.14 \mathrm{~m} / \mathrm{s}(30 \mathrm{ft} / \mathrm{sec})$ Nozzle

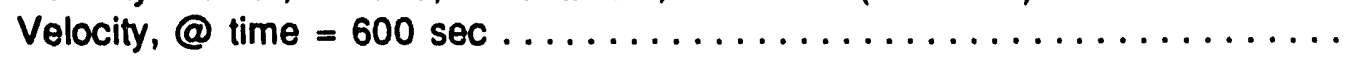

4.30 Velocity Vector, Vert. 5, Vertical Jet, $9.14 \mathrm{~m} / \mathrm{s}(30 \mathrm{f} / \mathrm{sec})$ Nozzle

Velocity, @ time=780 sec.

4.31 Volumetric Concentration, Vertical Jet Grid Study, $75 \times 60$ grid cells,

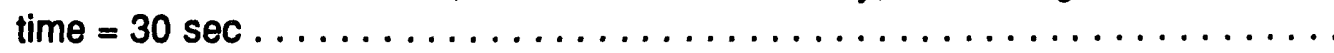

4.32 Volumetric Concentration, Vertical Jet Grid Study, $44 \times 31$ grid cells,

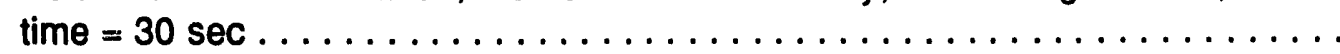

4.33 Volumetric Concentration, Vertical Jet Grid Study, $36 \times 22$ grid cells,

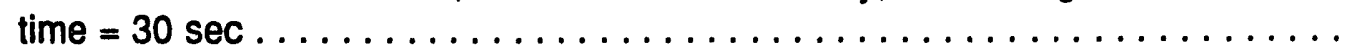


4.35 Volumetric Concentration, Vert. 12, Vertical Jet, $9.14 \mathrm{~m} / \mathrm{s}(30 \mathrm{ft} / \mathrm{sec})$

Nozzle Velocity, @ time=5 sec

4.36 Volumetric Concentration, Vert. 12, Vertical Jet, $9.14 \mathrm{~m} / \mathrm{s}$ (30 ft/sec)

Nozzle Velocity, @ time=30 sec

4.37 Volumetric Concentration, Vert. 12, Vertical Jet, $9.14 \mathrm{~m} / \mathrm{s}(30 \mathrm{ft} / \mathrm{sec})$

Nozzle Velocity, @ time=60 sec

4.38 Velocity Vector, Vert. 12, Vertical Jet, $9.14 \mathrm{~m} / \mathrm{s}(30 \mathrm{ft} / \mathrm{sec})$ Nozzle

Velocity, @ time=5 sec

4.39 Velocity Vector, Vert. 12, Vertical Jet, $9.14 \mathrm{~m} / \mathrm{s}(30 \mathrm{ft} / \mathrm{sec})$ Nozzle

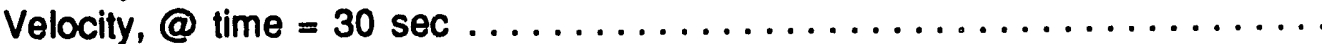

4.40 Velocity Vector, Vert. 12, Vertical Jet, $9.14 \mathrm{~m} / \mathrm{s}(30 \mathrm{ft} / \mathrm{sec})$ Nozzle

Velocity, @ time=60 sec

4.41 Volumetric Concentration, Vert. 14, Vertical Jet, $9.14 \mathrm{~m} / \mathrm{s}$ (30 ft/sec)

Nozzle Velocity, @ time=5 sec

4.42 Volumetric Concentration, Vert. 14, Vertical Jet, $9.14 \mathrm{~m} / \mathrm{s}(30 \mathrm{ft} / \mathrm{sec}$ )

Nozzle Velocity, @ time=60 sec

4.43 Volumetric Concentration, Vert. 14, Vertical Jet, $9.14 \mathrm{~m} / \mathrm{s}$ (30 ft/sec)

Nozzle Velocity, @ time=120 sec

4.44 Volumetric Concentration, Vert. 14, Vertical Jet, $9.14 \mathrm{~m} / \mathrm{s}$ (30 ft/sec)

Nozzle Velocity, (1) time $=240 \mathrm{sec}$

4.45 Volumetric Concentration, Vert. 14, Vertical Jet, $9.14 \mathrm{~m} / \mathrm{s}$ (30 ft/sec)

Nozzle Velocity, @ time = 360 sec

4.46 Volumetric Concentration, Vert. 14, Vertical Jet, $9.14 \mathrm{~m} / \mathrm{s}$ (30 ft/sec)

Nozzle Velocity, @ time=480 sec

4.47 Vector Velocity, Vert. 14, Vertical Jet, $9.14 \mathrm{~m} / \mathrm{s}$ (30 ft/sec) Nozzle

Velocity, @ time=600 sec

4.48 Vector Velocity, Vert. 14, Vertical Jet, $9.14 \mathrm{~m} / \mathrm{s}(30 \mathrm{ft} / \mathrm{sec})$ Nozzle

Velocity, @ time=5 sec

4.49 Vector Velocity, Vert. 14, Vertical Jet, $9.14 \mathrm{~m} / \mathrm{s}$ (30 ft/sec) Nozzle

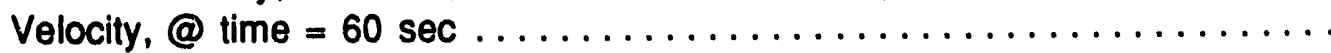

4.50 Vector Velocity, Vert. 14, Vertical Jet, $9.14 \mathrm{~m} / \mathrm{s}(30 \mathrm{ft} / \mathrm{sec})$ Nozzle

Velocity, @ time=120 sec 
4.51 Vector Velocity, Vert. 14, Vertical Jet, $9.14 \mathrm{~m} / \mathrm{s}(30 \mathrm{ft} / \mathrm{sec})$ Nozzle

Velocity, @ time $=240 \sec \ldots \ldots \ldots \ldots \ldots \ldots \ldots \ldots \ldots \ldots \ldots . \ldots . . \ldots . . \ldots 8$

4.52 Vector Velocity, Vert. 14, Vertical Jet, $9.14 \mathrm{~m} / \mathrm{s}(30 \mathrm{ft} / \mathrm{sec})$ Nozzle

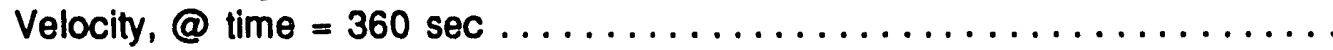

4.53 Vector Velocity, Vert. 14, Vertical Jet, $9.14 \mathrm{~m} / \mathrm{s}$ (30 ft/sec) Nozzle

Velocity, @ time=480 sec

4.54 Vector Velocity, Vert. 14, Vertical Jet, $9.14 \mathrm{~m} / \mathrm{s}(30 \mathrm{ft} / \mathrm{sec})$ Nozzle

Velocity, @ time=600 sec

4.55 Volumetric Concentration, Horiz. 1, Radial Jet, $4.57 \mathrm{~m} / \mathrm{s}$ (15 ft/sec)

Nozzle Velocity, @ time=15 sec

4.56 Volumetric Concentration, Horiz. 2 Radial Jet, $13.7 \mathrm{~m} / \mathrm{s}$ (45 ft/sec)

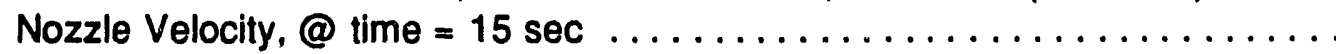

4.57 Volumetric Concentration, Horiz. 3, Radial Jet, $26.5 \mathrm{~m} / \mathrm{s}(87 \mathrm{ft} / \mathrm{sec})$

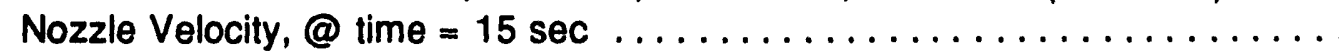

4.58 Volumetric Concentration, Horiz. 1, Radial Jet, $4.57 \mathrm{~m} / \mathrm{s}(15 \mathrm{ft} / \mathrm{sec})$

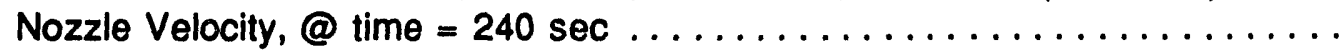

4.59 Volumetric Concentration, Horiz. 2, Radial Jet, $13.7 \mathrm{~m} / \mathrm{s}$ (45 ft/sec)

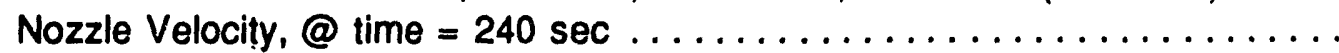

4.60 Volumetric Concentration, Horiz. 3, Radial Jet, $26.5 \mathrm{~m} / \mathrm{s}(87 \mathrm{ft} / \mathrm{sec})$

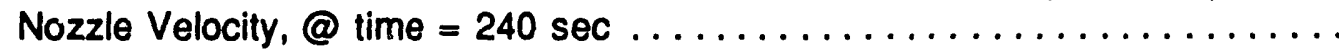

4.61 Velocity Vector, Radial Jet, $18.3 \mathrm{~m} / \mathrm{s}(60 \mathrm{ft} / \mathrm{sec})$ Nozzle Velocity,

$\varnothing=0^{\circ}$, @ time=10 sec

4.62 Volumetric Concentration, Radial Jet, $18.3 \mathrm{~m} / \mathrm{s}(60 \mathrm{ft} / \mathrm{sec})$ Nozzle

Velocity, $\varnothing=0^{\circ}$, @ time = $10 \mathrm{sec}$

4.63 Velocity Vector, Radial Jet, $18.3 \mathrm{~m} / \mathrm{s}(60 \mathrm{ft} / \mathrm{sec})$ Nozzle Velocity,

at Jet Exit Level, @ time=10 sec.

4.64 Volumetric Concentration, Radial Jet, $18.3 \mathrm{~m} / \mathrm{s}(60 \mathrm{ft} / \mathrm{sec})$ Nozzle

Velocity, at Jet Exit Level, @ time=10 sec

4.65 Velocity Vector, Radial Jet, $18.3 \mathrm{~m} / \mathrm{s}$ (60 ft/sec) Nozzle Velocity,

$\emptyset=0^{\circ}$, @ time=80 sec

4.66 Volumetric Concentration, Radial Jet, $18.3 \mathrm{~m} / \mathrm{s}(60 \mathrm{ft} / \mathrm{sec})$ Nozzle

Velocity, $\varnothing=0^{\circ}$, @ time=80 sec 
4.67 Vector Velocity, Radial Jet, $18.3 \mathrm{~m} / \mathrm{s}(60 \mathrm{ft} / \mathrm{sec})$ Nozzle Velocity, at Jet Exit Level, @ time=80 sec ............................

4.68 Volumetric Concentration, Radial Jet, $18.3 \mathrm{~m} / \mathrm{s}(60 \mathrm{ft} / \mathrm{sec})$ Nozzle

Velocity, at Jet Exit Level, @ time=80 sec.

4.69 Velocity Vector, Radial Jet, $18.3 \mathrm{~m} / \mathrm{s}(60 \mathrm{ft} / \mathrm{sec})$ Nozzle Velocity, $\emptyset=0^{\circ}$,@ time=100

4.70 Volumetric Concentration, Radial Jet, $18.3 \mathrm{~m} / \mathrm{s}(60 \mathrm{ft} / \mathrm{sec})$ Nozzle

Velocity, $\varnothing=0^{\circ}$, @ time = $100 \mathrm{sec}$

4.71 Vector Velocity, Radial Jet, $18.3 \mathrm{~m} / \mathrm{s}(60 \mathrm{ft} / \mathrm{sec})$ Nozzle Velocity, at

Jet Exit Level, @ time=100 sec

4.72 Volumetric Concentration, Radial Jet, $18.3 \mathrm{~m} / \mathrm{s}(60 \mathrm{ft} / \mathrm{sec})$ Nozzle

Velocity, at Jet Exit Level, @ time =100 sec ...................

4.73 Velocity Vector, Radial Jet, $18.3 \mathrm{~m} / \mathrm{s}(60 \mathrm{ft} / \mathrm{sec})$ Nozzle Velocity,

$\varnothing=0^{\circ}$,@ time=260 sec

4.74 Volumetric Concentration, Radial Jet, $18.3 \mathrm{~m} / \mathrm{s}(60 \mathrm{ft} / \mathrm{sec})$ Nozzle

Velocity, $\varnothing=0^{\circ}$, @ time = $260 \mathrm{sec}$

4.75 Vector Velocity, Radial Jet, $18.3 \mathrm{~m} / \mathrm{s}(60 \mathrm{ft} / \mathrm{sec})$ Nozzle Velocity, at

Jet Exit Level, @ time=260 sec

4.76 Volumetric Concentration, Radial Jet, $18.3 \mathrm{~m} / \mathrm{s}(60 \mathrm{ft} / \mathrm{sec})$ Nozzle

Velocity, at Jet Exit Level, @ time=260 sec

4.77 Velocity Vector, Radial Jet, $18.3 \mathrm{~m} / \mathrm{s}(60 \mathrm{ft} / \mathrm{sec})$ Nozzle Velocity,

$\emptyset=30^{\circ}$, @ time=280 sec

4.78 Volumetric Concentration, Radial Jet, $18.3 \mathrm{~m} / \mathrm{s}$ (60 ft/sec) Nozzle

Velocity, $\varnothing=30^{\circ}$, @ time $=280 \mathrm{sec}$.

4.79 Vector Velocity, Radial Jet, $18.3 \mathrm{~m} / \mathrm{s}(60 \mathrm{ft} / \mathrm{sec})$ Nozzle Velocity, at Jet Exit Level, @ time=280 sec

4.80 Volumetric Concentration, Radial Jet, $18.3 \mathrm{~m} / \mathrm{s}(60 \mathrm{ft} / \mathrm{sec})$ Nozzle

Velocity, at Jet Exit Level, @ time=280 sec

4.81 Velocity Vector, Radial Jet, $18.3 \mathrm{~m} / \mathrm{s}(60 \mathrm{ft} / \mathrm{sec})$ Nozzle Velocity,

$\varnothing=30^{\circ}$, @ time=350 sec .

4.82 Volumetric Concentration, Radial Jet, $18.3 \mathrm{~m} / \mathrm{s}(60 \mathrm{ft} / \mathrm{sec})$ Nozzle

Velocity, $\varnothing=30^{\circ}$, @ time=350 sec... 
4.83 Vector Velocity, Radial Jet, $18.3 \mathrm{~m} / \mathrm{s}(60 \mathrm{ft} / \mathrm{sec})$ Nozzle Velocity, at Jet Exit Level, @ time = 350 sec ...................................

4.84 Volumetric Concentration, Radial Jet, $18.3 \mathrm{~m} / \mathrm{s}(60 \mathrm{ft} / \mathrm{sec})$ Nozzle

Velocity, at Jet Exit Level, @ time = $350 \mathrm{sec} \ldots \ldots \ldots \ldots \ldots \ldots \ldots \ldots . . \ldots . . . \ldots 2$

4.85 Velocity Vector, Radial Jet, $18.3 \mathrm{~m} / \mathrm{s}(60 \mathrm{ft} / \mathrm{sec})$ Nozzle Velocity,

$\emptyset=30^{\circ}$, @ time=380 sec.

4.86 Volumetric Concentration, Radial Jet, $18.3 \mathrm{~m} / \mathrm{s}(60 \mathrm{ft} / \mathrm{sec})$ Nozzle

Velocity, $\varnothing=30^{\circ}$, @ time $=380 \mathrm{sec} \ldots \ldots \ldots \ldots \ldots \ldots \ldots \ldots . \ldots . \ldots . . \ldots 4$

4.87 Vector Velocity, Radial Jet, $18.3 \mathrm{~m} / \mathrm{s}(60 \mathrm{ft} / \mathrm{sec})$ Nozzle Velocity, at

Jet Exit Level, @ time=380 sec

4.88 Volumetric Concentration, Radial Jet, $18.3 \mathrm{~m} / \mathrm{s}(60 \mathrm{ft} / \mathrm{sec})$ Nozzle

Velocity, at Jet Exit Level, @ time=380 sec

4.89 Velocity Vector, Radial Jet, $18.3 \mathrm{~m} / \mathrm{s}(60 \mathrm{ft} / \mathrm{sec})$ Nozzle Velocity,

$\emptyset=30^{\circ}$, @ time=540 sec .

4.90 Volumetric Concentration, Radial Jet, $18.3 \mathrm{~m} / \mathrm{s}(60 \mathrm{ft} / \mathrm{sec})$ Nozzle

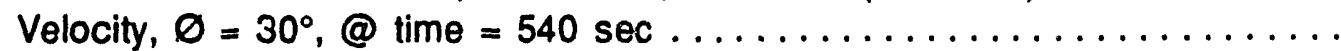

4.91 Vector Velocity, Radial Jet, $18.3 \mathrm{~m} / \mathrm{s}(60 \mathrm{ft} / \mathrm{sec})$ Nozzle Velocity, at

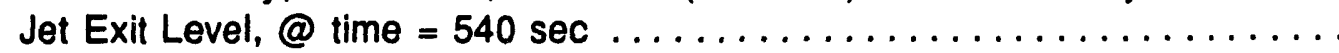

4.92 Volumetric Concentration, Radial Jet, $18.3 \mathrm{~m} / \mathrm{s}(60 \mathrm{ft} / \mathrm{sec})$ Nozzle

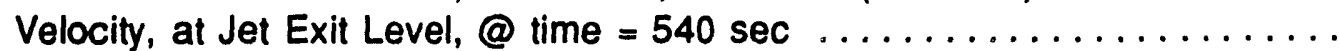

4.93 Velocity Vector, Radial Jet, $18.3 \mathrm{~m} / \mathrm{s}(60 \mathrm{ft} / \mathrm{sec})$ Nozzle Velocity,

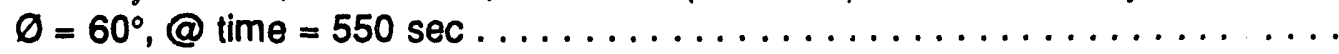

4.94 Volumetric Concentration, Radial Jet, $18.3 \mathrm{~m} / \mathrm{s}(60 \mathrm{ft} / \mathrm{sec})$ Nozzle

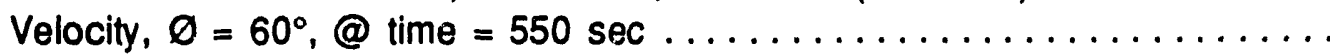

4.95 Vector Velocity, Radial Jet, $18.3 \mathrm{~m} / \mathrm{s}(60 \mathrm{ft} / \mathrm{sec})$ Nozzle Velocity, at Jet Exit Level, @ time=550 sec

4.96 Volumetric Concentration, Radial Jet, $18.3 \mathrm{~m} / \mathrm{s}(60 \mathrm{ft} / \mathrm{sec})$ Nozzle

Velocity, at Jet Exit Level, @ time = 550 sec .....................

4.97 Velocity Vector, Radial Jet, $18.3 \mathrm{~m} / \mathrm{s}(60 \mathrm{ft} / \mathrm{sec})$ Nozzle Velocity,

$\emptyset=60^{\circ}$, @ time=620 sec.

4.98 Volumetric Concentration, Radial Jet, $18.3 \mathrm{~m} / \mathrm{s}(60 \mathrm{ft} / \mathrm{sec})$ Nozzle

Velocity, $\varnothing=60^{\circ}$, @ time =620 sec 
4.99 Vector Velocity, Radial Jet, $18.3 \mathrm{~m} / \mathrm{s}(60 \mathrm{ft} / \mathrm{sec})$ Nozzle Velocity, at

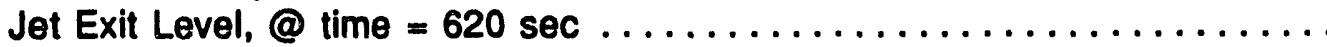

4.100 Volumeiric Concentration, Radial Jet, $18.3 \mathrm{~m} / \mathrm{s}$ (60 ft/sec) Nozzle

Velocity, at Jet Exit Level, @ time=620 sec

4.101 Velocity Vector, Radial Jet, $18.3 \mathrm{~m} / \mathrm{s}$ (60 ft/sec) Nozzle Velocity, $\emptyset=60^{\circ}$, @ time = $640 \mathrm{sec}$

4.102 Volumetric Concentration, Radial Jet, $18.3 \mathrm{~m} / \mathrm{s}$ (60 ft/sec) Nozzle

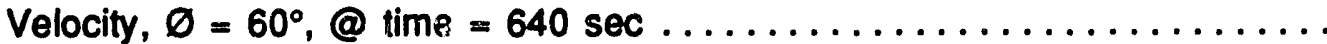

4.103 Vector Velocity, Radial Jet, $18.3 \mathrm{~m} / \mathrm{s}$ (60 fusec) Nozzle Velocity, at Jet Exit Level, @ time=640 sec

4.104 Volumetric Concentration, Radial Jet, $18.3 \mathrm{~m} / \mathrm{s}$ (60 ft/sec) Nozzle Velocity, at Jet Exit Level, @ time=640 sec

4.105 Velocity Vector, Radial Jet, $18.3 \mathrm{~m} / \mathrm{s}(60 \mathrm{ft} / \mathrm{sec})$ Nozzle Velocity, $\emptyset=60^{\circ}$, @ time=800 sec

4.106 Volumetric Concentration, Radial Jet, $18.3 \mathrm{~m} / \mathrm{s}$ (60 ft/sec) Nozzle

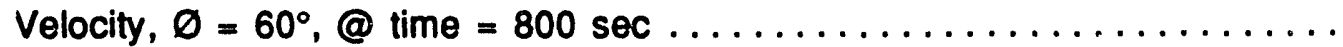

4.107 Vector Velocity, Radial Jet, $18.3 \mathrm{~m} / \mathrm{s}(60 \mathrm{ft} / \mathrm{sec})$ Nozzle Velocity, at Jet Exit Level, @ time =800 sec ..........................

4.108 Volumetric Concentration, Radial Jet, $18.3 \mathrm{~m} / \mathrm{s}(60 \mathrm{ft} / \mathrm{sec})$ Nozzle Velocity, at Jet Exit Level, @ time=800 sec

4.109 Velocity Vector, Radial Jet, $18.3 \mathrm{~m} / \mathrm{s}$ (60 ft/sec) Nozzle Velocity, $\emptyset=90^{\circ}$, @ time=820 sec.

4.110 Volumetric Concentration, Radial Jet, $18.3 \mathrm{~m} / \mathrm{s}(60 \mathrm{ft} / \mathrm{sec})$ Nozzle

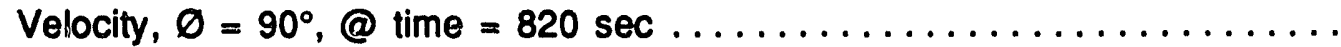

4.111 Vector Velocity, Radial Jet, $18.3 \mathrm{~m} / \mathrm{s}(60 \mathrm{ft} / \mathrm{sec})$ Nozzle Velocity, at

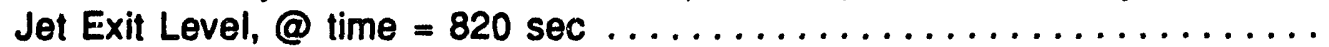

4.112 Volumetric Concentration, Radial Jet, $18.3 \mathrm{~m} / \mathrm{s}(60 \mathrm{ft} / \mathrm{sec})$ Nozzle

Velocity, at Jet Exit Level, @ time = $820 \mathrm{sec}$

4.113 Velocity Vector, Radial Jet, $18.3 \mathrm{~m} / \mathrm{s}(60 \mathrm{ft} / \mathrm{sec})$ Nozzle Velocity, $\emptyset=90^{\circ}$, @ time=890 sec

4.114 Volumetric Concentration, Radial Jet, $18.3 \mathrm{~m} / \mathrm{s}(60 \mathrm{ft} / \mathrm{sec})$ Nozzle

Velocity, $\varnothing=90^{\circ}$, @ time = $890 \mathrm{sec}$ 
4.115 Vector Velocity, Radial Jet, $18.3 \mathrm{~m} / \mathrm{s}$ (60 ft/sec) Nozzle Velocity, at

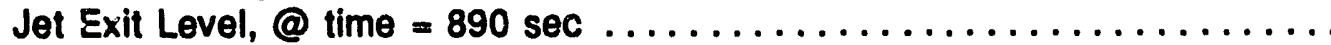

4.116 Volumetric Concentration, Radial Jet, $18.3 \mathrm{~m} / \mathrm{s}(60 \mathrm{ft} / \mathrm{sec})$ Nozzle

Velocity, at Jet Exit Level, @ time = 890 sec ...................

4.117 Velocity Vector, Radial Jet, $18.3 \mathrm{~m} / \mathrm{s}(60 \mathrm{ft} / \mathrm{sec})$ Nozzle Velocity,

$\emptyset=90^{\circ}$, @ time = 920 sec

4.118 Volumetric Concentration, Radial Jet, $18.3 \mathrm{~m} / \mathrm{s}(60 \mathrm{ft} / \mathrm{sec})$ Nozzle

Velocity, $\varnothing=90^{\circ}$, @ time = 920 sec

4.119 Vector Velocity, Radial Jet, $18.3 \mathrm{~m} / \mathrm{s}(60 \mathrm{ft} / \mathrm{sec})$ Nozzle Velocity, at Jet Exit Level, @ time=920 sec.

4.120 Volumetric Concentration, Radial Jet, $18.3 \mathrm{~m} / \mathrm{s}(60 \mathrm{ft} / \mathrm{sec})$ Nozzle

Velocity, at Jet Exit Level, @ time=920 sec

4.121 Velocity Vector, Radial Jet, $18.3 \mathrm{~m} / \mathrm{s}(60 \mathrm{ft} / \mathrm{sec})$ Nozzle Velocity,

$\emptyset=90^{\circ}$, @ time = $1080 \mathrm{sec}$

4.122 Volumetric Concentration, Radial Jet, $18.3 \mathrm{~m} / \mathrm{s}(60 \mathrm{ft} / \mathrm{sec})$ Nozzle

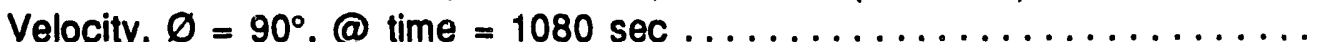

4.123 Vector Velocity, Radial Jet, $18.3 \mathrm{~m} / \mathrm{s}$ (60 ft/sec) Nozzle Velocity, at

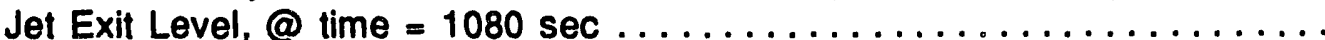

4.124 Volumetric Concentration, Radial Jet, $18.3 \mathrm{~m} / \mathrm{s}(60 \mathrm{ft} / \mathrm{sec})$ Nozzle Velocity, at Jet Exit Level, @ time = $1080 \mathrm{sec}$

4.125 Velocity Vector, Radial Jet, $18.3 \mathrm{~m} / \mathrm{s}(60 \mathrm{ft} / \mathrm{sec})$ Nozzle Velocity, $\emptyset=120^{\circ}$,@ time=1090 sec

4.126 Volumetric Concentration, Radial Jet, $18.3 \mathrm{~m} / \mathrm{s}(60 \mathrm{ft} / \mathrm{sec})$ Nozzle Velocity, $\varnothing=120^{\circ}, @$ time $=1090 \mathrm{sec} \ldots \ldots \ldots \ldots \ldots \ldots \ldots . \ldots \ldots$

4.127 Vector Velocity, Radial Jet, $18.3 \mathrm{~m} / \mathrm{s}(60 \mathrm{ft} / \mathrm{sec})$ Nozzle Velocity, at Jet Exit Level, @ time=1090 sec

4.128 Volumetric Concentration, Radial Jet, $18.3 \mathrm{~m} / \mathrm{s}(60 \mathrm{ft} / \mathrm{sec})$ Nozzle Velocity, at Jet Exit Level, @ time=1090 sec .....................

4.129 Velocity Vector, Radial Jet, $18.3 \mathrm{~m} / \mathrm{s}(60 \mathrm{ft} / \mathrm{sec})$ Nozzle Velocity, $\varnothing=120^{\circ}$, @ time=1160 sec

4.130 Volumetric Concentration, Radial Jet, $18.3 \mathrm{~m} / \mathrm{s}(60 \mathrm{ft} / \mathrm{sec})$ Nozzle Velocity, $\varnothing=120^{\circ}$, @ time=1160 sec 
4.131 Vector Velocity, Radial Jet, $18.3 \mathrm{~m} / \mathrm{s}$ (60 ft/sec) Nozzle Velocity, at Jet Exit Level, @ time=1160 sec.

4.132 Volumetric Concentration, Radial Jet, $18.3 \mathrm{~m} / \mathrm{s}(60 \mathrm{ft} / \mathrm{sec})$ Nozzle

Velocity, at Jet Exit Level, @ time=1160 sec

4.133 Velocity Vector, Radial Jet, $18.3 \mathrm{~m} / \mathrm{s}$ (60 ft/sec) Nozzle Velocity, $\emptyset=120^{\circ}$, @ time = $1180 \mathrm{sec}$

4.134 Volumetric Concentration, Radial Jet, $18.3 \mathrm{~m} / \mathrm{s}(60 \mathrm{ft} / \mathrm{sec})$ Nozzle

Velocity, $\varnothing=120^{\circ}, @$ time $=1180$ sec $\ldots \ldots \ldots \ldots \ldots \ldots \ldots \ldots$

4.135 Vector Velocity, Radial Jet, $18.3 \mathrm{~m} / \mathrm{s}$ (60 ft/sec) Nozzle Velocity, at Jet Exit Level, @ time=1180 sec .........................

4.136 Volumetric Concentration, Radial Jet, $18.3 \mathrm{~m} / \mathrm{s}$ (60 ft/sec) Nozzle

Velocity, at Jet Exit Level, @ time = $1180 \mathrm{sec} \ldots \ldots \ldots \ldots \ldots \ldots . . . \ldots$.

4.137 Velocity Vector, Radial Jet, $18.3 \mathrm{~m} / \mathrm{s}(60 \mathrm{ft} / \mathrm{sec})$ Nozzle Velocity, $\emptyset=120^{\circ}$, @ time=1340 sec

4.138 Volumetric Concentration, Radial Jet, $18.3 \mathrm{~m} / \mathrm{s}$ (60 ft/sec) Nozzle

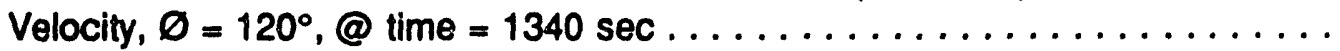

4.139 Vector Velocity, Radial Jet, $18.3 \mathrm{~m} / \mathrm{s}(60 \mathrm{ft} / \mathrm{sec})$ Nozzle Velocity, at Jet Exit Level, @ time=1340 sec ............................

4.140 Volumetric Concentration, Radial Jet, $18.3 \mathrm{~m} / \mathrm{s}(60 \mathrm{ft} / \mathrm{sec})$ Nozzle Velocity, at Jet Exit Level, @ time =1340 sec ....................

4.141 Velocity Vector, Radial Jet, $18.3 \mathrm{~m} / \mathrm{s}(60 \mathrm{ft} / \mathrm{sec})$ Nozzle Velocity, $\emptyset=150^{\circ}$, @ time = $1360 \mathrm{sec}$

4.142 Volumetric Concentration, Radial Jet, $18.3 \mathrm{~m} / \mathrm{s}(60 \mathrm{ft} / \mathrm{sec})$ Nozzle Velocity, $\varnothing=150^{\circ}$, @ time $=1360 \mathrm{sec}$.

4.143 Vector Velocity, Radial Jet, $18.3 \mathrm{~m} / \mathrm{s}$ (60 ft/sec) Nozzle Velocity, at Jet Exit Level, @ time=1360 sec

4.144 Volumetric Concentration, Radial Jet, $18.3 \mathrm{~m} / \mathrm{s}(60 \mathrm{ft} / \mathrm{sec})$ Nozzle Velocity, at Jet Exit Level, @ time=1360 sec

4.145 Velocity Vector, Radial Jet, $18.3 \mathrm{~m} / \mathrm{s}(60 \mathrm{ft} / \mathrm{sec})$ Nozzle Velocity, $\emptyset=150^{\circ}$, @ time=1430 sec

4.146 Volumetric Concentration, Radial Jet, $18.3 \mathrm{~m} / \mathrm{s}(60 \mathrm{ft} / \mathrm{sec})$ Nozzle Velocity, $\varnothing=150^{\circ}$, @ time = $1430 \mathrm{sec}$ 
4.147 Vector Velocity, Radial Jet, $18.3 \mathrm{~m} / \mathrm{s}(60 \mathrm{ft} / \mathrm{sec})$ Nozzle Velocity, at Jet Exit Level, @ time $=1430 \mathrm{sec} . . . \ldots \ldots \ldots \ldots \ldots \ldots \ldots \ldots \ldots \ldots . \ldots \ldots$

4.148 Volumetric Concentration, Radial Jet, $18.3 \mathrm{~m} / \mathrm{s}$ (60 ft/sec) Nozzle Velocity, at Jet Exit Level, @ time $=1430 \mathrm{sec} \ldots \ldots \ldots \ldots \ldots \ldots \ldots \ldots .4 .156$

4.149 Velocity Vector, Radial Jet, $18.3 \mathrm{~m} / \mathrm{s}(60 \mathrm{ft} / \mathrm{sec})$ Nozzle Velocity, $\emptyset=150^{\circ}$, @ time = 1460 sec

4.150 Volumetric Concentration, Radial Jet, $18.3 \mathrm{~m} / \mathrm{s}$ (60 ft/sec) Nozzle Velocity, $\varnothing=150^{\circ}$, @ time = $1460 \mathrm{sec}$

4.151 Vector Velocity, Radial Jet, $18.3 \mathrm{~m} / \mathrm{s}$ (60 ft/sec) Nozzle Velocity, at Jet Exit Level, @ time = 1460 sec

4.152 Volumetric Concentration, Radial Jet, $18.3 \mathrm{~m} / \mathrm{s}(60 \mathrm{ft} / \mathrm{sec})$ Nozzle Velocity, at Jet Exit Level, @ time = $1460 \mathrm{sec}$

4.153 Velocity Vector, Radial Jet, $18.3 \mathrm{~m} / \mathrm{s}(60 \mathrm{ft} / \mathrm{sec})$ Nozzle Velocity, $\varnothing=150^{\circ}$, @ time=1620 sec

4.154 Volumetric Concentration, Radial Jet, $18.3 \mathrm{~m} / \mathrm{s}(60 \mathrm{ft} / \mathrm{sec})$ Nozzle Velocity, $\varnothing=150^{\circ}$, @ time = $1620 \mathrm{sec}$

4.155 Vector Velocity, Radial Jet, $18.3 \mathrm{~m} / \mathrm{s}(60 \mathrm{ft} / \mathrm{sec})$ Nozzle Velocity, at Jet Exit Level, @ time=1620 sec

4.156 Volumetric Concentration, Radial Jet, $18.3 \mathrm{~m} / \mathrm{s}(60 \mathrm{ft} / \mathrm{sec})$ Nozzle Velocity, at Jet Exit Level, @ time = $1620 \mathrm{sec}$ 


\section{Tables}

$3.1 \quad$ Nomenclature $\ldots \ldots \ldots \ldots \ldots \ldots \ldots \ldots \ldots \ldots \ldots \ldots \ldots \ldots \ldots, \quad 3.3$

3.2 Momentum Jet Text Case Summary $\ldots \ldots \ldots \ldots \ldots \ldots \ldots \ldots \ldots \ldots, \quad 3.12$

4.1 Summary of Vertical Jet Cases $\ldots \ldots \ldots \ldots \ldots \ldots \ldots \ldots \ldots \ldots \ldots, 4.2$

4.2 Summary of Horizontal Jet Cases $\ldots \ldots \ldots \ldots \ldots \ldots \ldots \ldots \ldots \ldots, 4.165$

4.3 Horiz. 4 Figure Index $\ldots \ldots \ldots \ldots \ldots \ldots \ldots \ldots \ldots \ldots \ldots \ldots \ldots, 4.166$ 


\subsection{Introduction}

The episodic gas release events that have characterized the behavior of Tank 241-SY-101 for the past several years are thought to result from the entrapment of gases generated in the settled solids (i.e., "slurry") layer of the tank. These gases, generated by complicated and poorly understood radiological and chemical processes, are thought to remain trapped in the settled solids layer in the tank until their accumulation causes a buoyant upset of the settled materials. This upset is a rather dramatic event in that a large amount of the trapped gas is released from the tank in a short time. During this episode, hydrogen gas concentration in the tank dome increases and could reach the lower flammability limit, posing a potential for ignition.

If the gases were continuously released from the settled layer, the possibility of attaining flammable concentrations of hydrogen in the tank dome atmosphere would be significantly diminished. One concept for preventing its accumulation is to mobilize the settled materials with jet mixing. It is suggested that continual agitation of the settled solids would free the bubbles so that they could continually escape, thus mitigating the potential for attaining flammable concentrations.

Therefore, this document reports on initial numerical studies of Tank 241-SY-101 jet mixing concepts conducted with the TEMPEST code. Concepts that have been addressed are

- vertical jets/draft tubes

- liquid piston

- horizontal jets.

Consideration of gas bubbles trapped in the slurry, and therefore the influence of gas bubble dynamics on the slurry motion, was irot included in the scope of this study.

The studies were conducted using the TEMPEST fluid dynamic computer code(a). TEMPEST solves the three-dimensional time-dependent equations that govern the turbulent transport of momentum, energy and mass. TEMPEST is ideally suited for the tank mixing numerical analysis because of demonstrated capability for accurately simulating the dynamic behavior of highspeed jets, including turbulent kinetic energy, entrainment, and circulation.

(a) This report is a draft document by D. S. Trent and L. L. Eyler. 1993. IEMPEST - A Computer Program for Three-Dimensional. Time-Dependent Computational Fluid Dynamics: Theory Manual. Version T, Mod 3. Pacific Northwest Laboratory, Richland, Washington. 


\subsection{Background}

By way of background, presented in this section is a basic description of the Tank 241-SY-101 and the three jet mixing concepts to be addressed in this report. The physical character of the tank, with details on various gas release events, has been documented in a variety of documents (see Allemann et al. 1991, Bryan et al. 1991, Simpson(a), Tingey(b)). Jet mixing concepts, on the other hand, are described in Babad et al. (1992) report.

\subsection{Description of the Tank}

The physical characier of Tank 241-SY-101, along with details of the various gas release events, has been documenied in varisty of reports. A review of this information is not contained in this document, but may be found in (Allemann et al. 1991, Bryan et al. 1991, Simpson(a), Tingey(b)).

Figure 2.1 illustrates the geometry and physical characteristics of Tank 241-SY-101 that are relevant to this study.

Illustrated in the figure is the configuration of materials in the tank believed to exist when the solid particles are fully settled and have formed the non-convecting slurry layer. This was the situation in the days just before the initiation of an upset episode. The layered arrangement shown in Figure 2.1 was to be deduced from the vertical thermal profile recorded by the thermocouple tree. The layer labeled "mushy crust" exhibits a linear temperature profile typical of heat flow through non-heat generating solid material, whereas the layer labeled "convecting liquid" exhibits only a minor temperature difference from top to bottom, which is typical of a naturally convecting liquid. The bottom layer exhibits a temperature profile that is characteristic of non-convecting heat generating materials. It is in this bottom layer that gases generated by radiological and chemical process are thought to be trapped.

Current belief is that the buoyant motion of gas bubbles generated in the slurry layer are severely restrained because of the material viscosity, or yield strength, and their possible attachment to solid particles. Thus, the continued growth and accumulation of these bubbles

\footnotetext{
(a) This report is a draft document by D. E. Simpson, R. T. Allemann, D. A. Reynolds, T. M. Burke, and G. P. Johnson. 1992. Assessment of Gas Accumulation and Retention Tank 241-SY-101. WHC-EP-0576, Westinghouse Hanford Company, Richland, Washington.

(b) This report is a draft document by Tingey, J. M. 1992. Physical Characterization of Iank 101-SY Core Samples From Window C. Pacific Northwest Laboratory, Richland, Washington.
} 


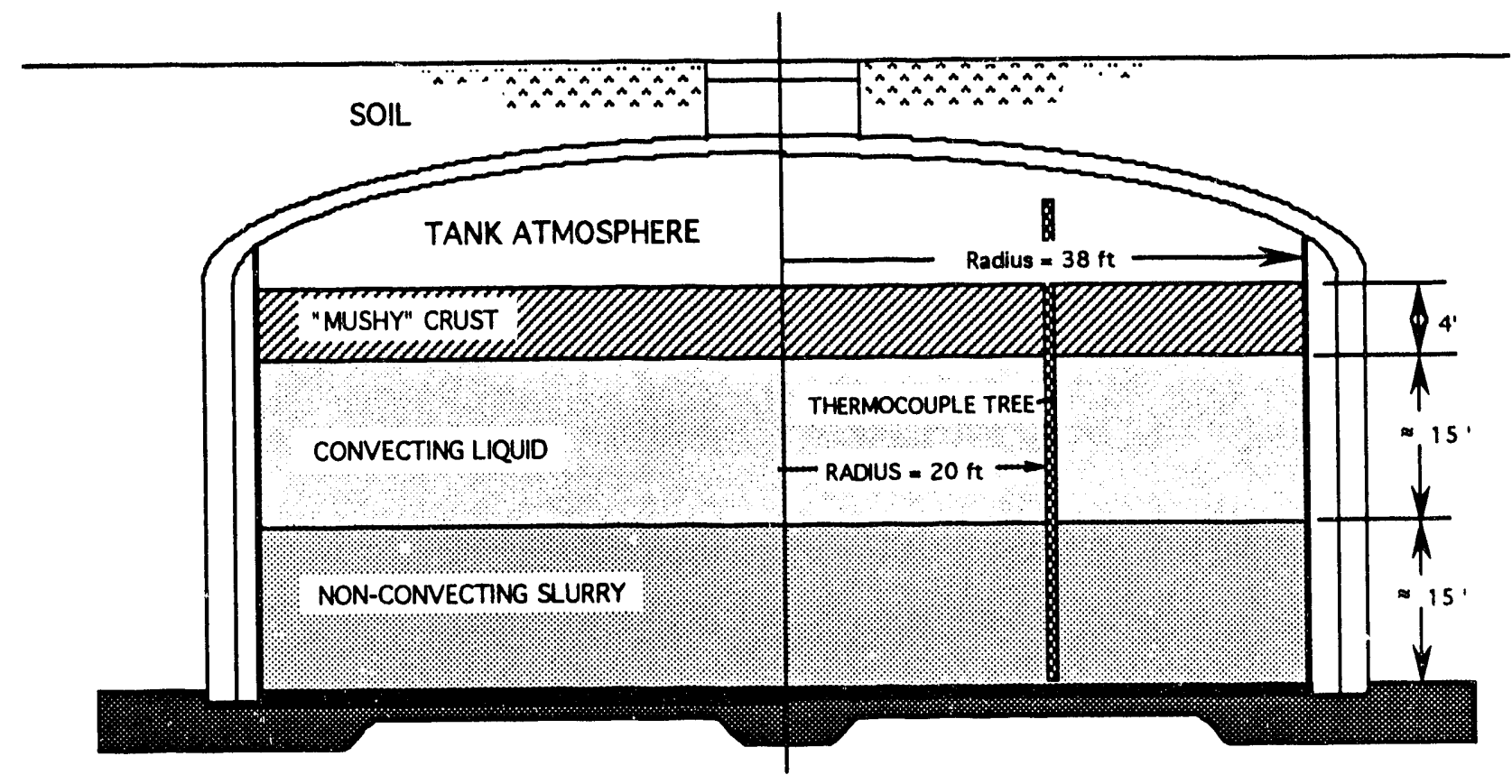

Figure 2.1. Cross-Section View of Tank 241-SY-101

eventually leads to a density "upset" that releases the trapped gases in a rather dramatic gas release event (GRE) called a "burp." Associated with the GRE is the release of a significant amount of hydrogen gas which might momentarily increase the concentration of hydrogen in the tank atmosphere to the lower flammability limit and pose a potential for ignition.

There is no evidence that gas bubbles accumulate in the convecting liquid layer, and thus it is assumed that all gases generated in this region migrate to the top surface and continually escape to the vented tank atmosphere causing only a slight increase in the hydrsgen concentration. The rationale for jet mixing of the non-convecting layer is to force some degree of convection and agitation of the slurry so that the bubbles in this layer will continuously release and migrate to the liquid surface, escaping to the vented tank atmosphere. If this can be accomplished, then the possibility of major GRE will be significantly reduced, mitigating the possibility of flammable concentrations of hydrogen developing in the tank atmosphere.

Jet mixing concepts along with other possible mitigation concepts are discussed in the Babad et al. (1992) report. Three of these concepts are addressed in this report:

- vertical jets/draft tubes

- liquid piston

- horizontal jets. 


\subsection{Description of Jet Mixing Concepts}

The following contains a basic description of the three concepts.

\subsubsection{Vertical Jets}

One of the simplistic mixing concepts is to place a vertical draft tube through the center of the tank. Then a downward directed jet draws fluid through a draft tube from near the top of the liquid level and discharges it near the bottom of the tank.

There are a variety of ways one might position a centrally located jet in attempting to mobilize the non-convecting layer. The general layout of a vertical jet/draft tube arrangement is illustrated in Figure 2.2.

In this figure, $z_{d}$ is the jet discharge elevation, $z_{i}$ is the elevation of the intake, and $D_{j}$ is the discharge diameter. Additional design parameters include the discharge velocity, $U_{j}$, and whether the jet is operated continuously or intermittently.

\subsubsection{Liquid Piston}

The liquid piston concept is also simple and has advantage of having no moving mechanical parts located inside the tank. The concept is similar to a "tire pump" in that a central tube is filled with liquid by gravity, which is then ejected by air pressure through jets located near the tank bottom. When the liquid in the tube has been evacuated at the "bottom of the stroke," the air pressure is released and the tube again gravity fills with liquid. This process is then repeated.

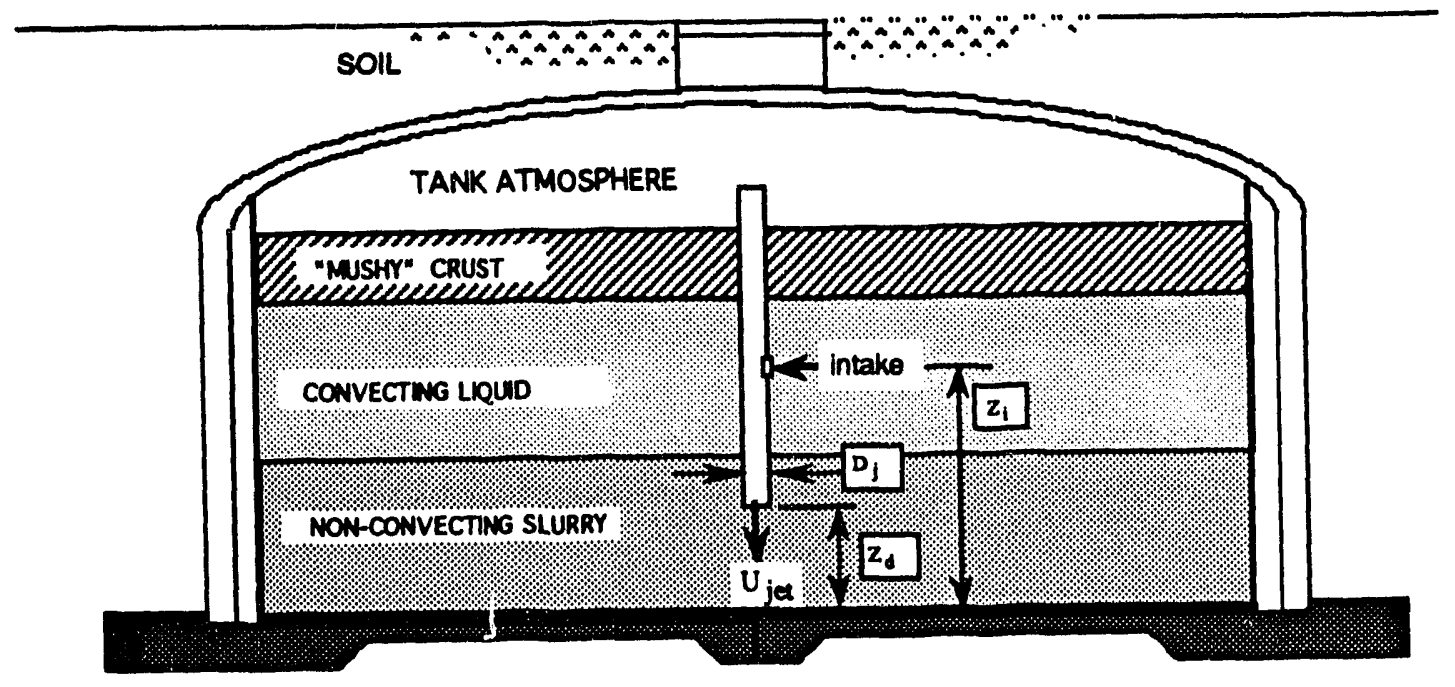

Figure 2.2. Vertical Jet and Draft Tube Arrangement 
The liquid piston concept and certain design parameters are illustrated is: Figure 2.3. The piston operation is a cyclic process with the maximum frequency determined in large part by the filling time. Because the piston would most likely be stationary, a number of jet orifices arranged along the periphery would be required. The piston could be operated so that the jets could be preferentially pulsed.

\subsubsection{Horizontal Jets}

The horizontal jet concept involves a centrally located pump with a fluid intake near the tank liquid surface and discharging through horizontal high-speed jets located near the bottom of the tank. This concept has the advantage of imparting a highly energetic turbulent flow to the slurry layer which may be required to cause thorough agitation of the slurry.

The horizontal jet dischaige concept differs from the liquid piston in that a submerged pump is used to circulate the material from the upper liquid region, discharging it at high velocity to the lower level of the non-convecting layer, as shown in Figure 2.4. There are several design parameters that can be optimized. These jets are expected to be 1.5 to 3.0 in. in diameter and discharge recirculated waste material at high speed, in the range of 60 to $125 \mathrm{ft} / \mathrm{sec}$. A minimum of two jets discharging simultaneously and in opposite directions to balance a cantilever loads on the pump arrangement would be employed. It is anticipated that

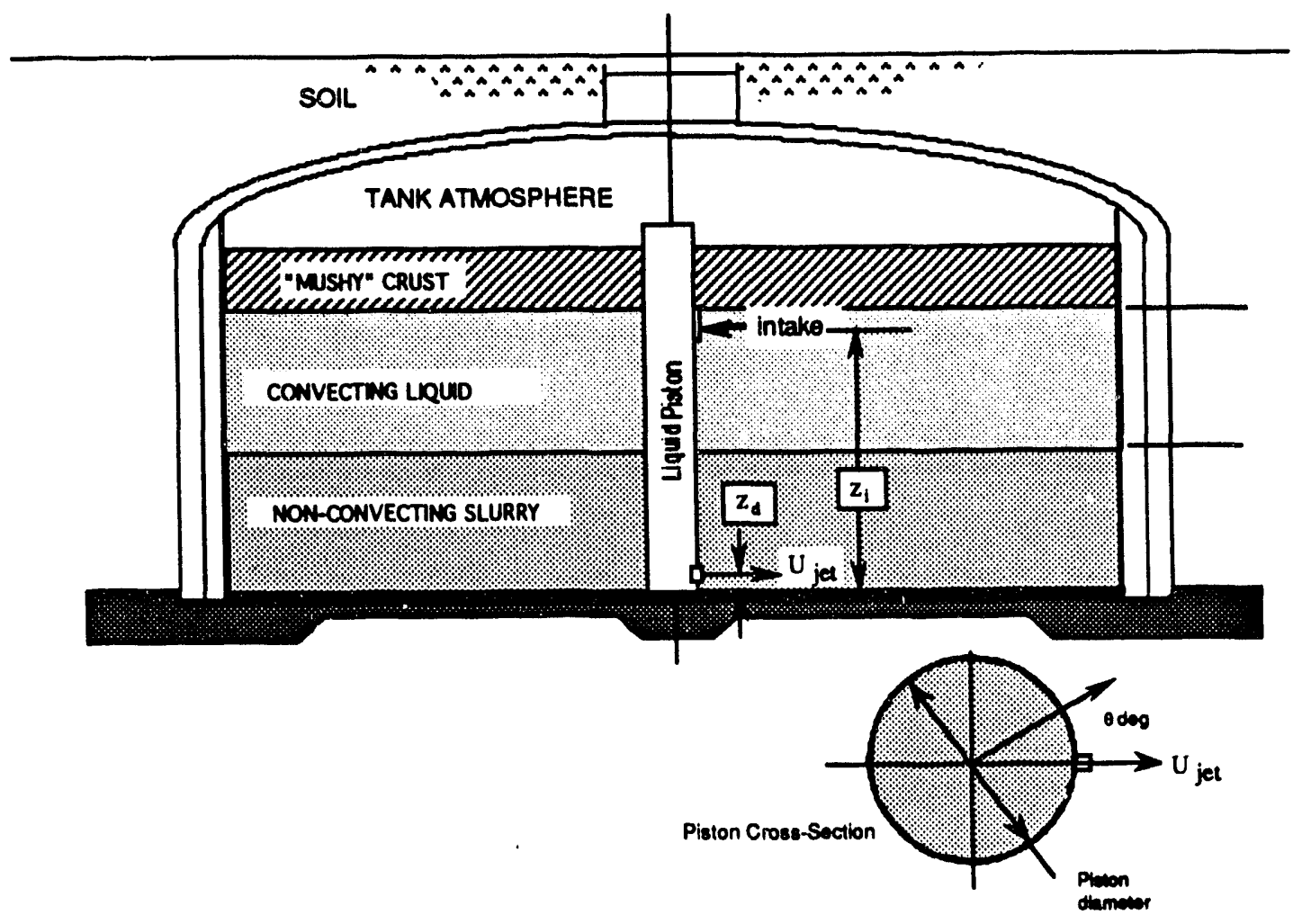

Figure 2.3. Liquid Piston 
the jets would be located 1 to $3 \mathrm{ft}$ above the tank bottom, and the intake would be located near the top of the convecting liquid, but deep enough to prevent possible vortex formation. The jet discharge azimuth $(\theta)$ would likely be changed during operation, either by continuous rotation or incremental steps. It may not be necessary to operate the pump continuously, but rather operate it for a period of time followed by a rest period. The operational mode would depend on the slurry mobilization effectiveness of the jets.

It is felt that the high-speed discharge will impart the level of momentum and kinetic energy necessary to adequately mobilize the non-convecting layer. It is also felt that the best operational mode might be to change the direction of the jet through incremental steps. In this case, the momentum and kinetic energy of the jet would be maintained along one path for a period time, providing better opportunity to overcome any yield strength that the solid layer might have and penetrate to the tank wall. It is possible that under continuous rotation the jet's turbulent kinetic energy and 'nomentum may be dissipated in a central well-mixed core region without disturbing the material along the tank radius, extending to the wall.

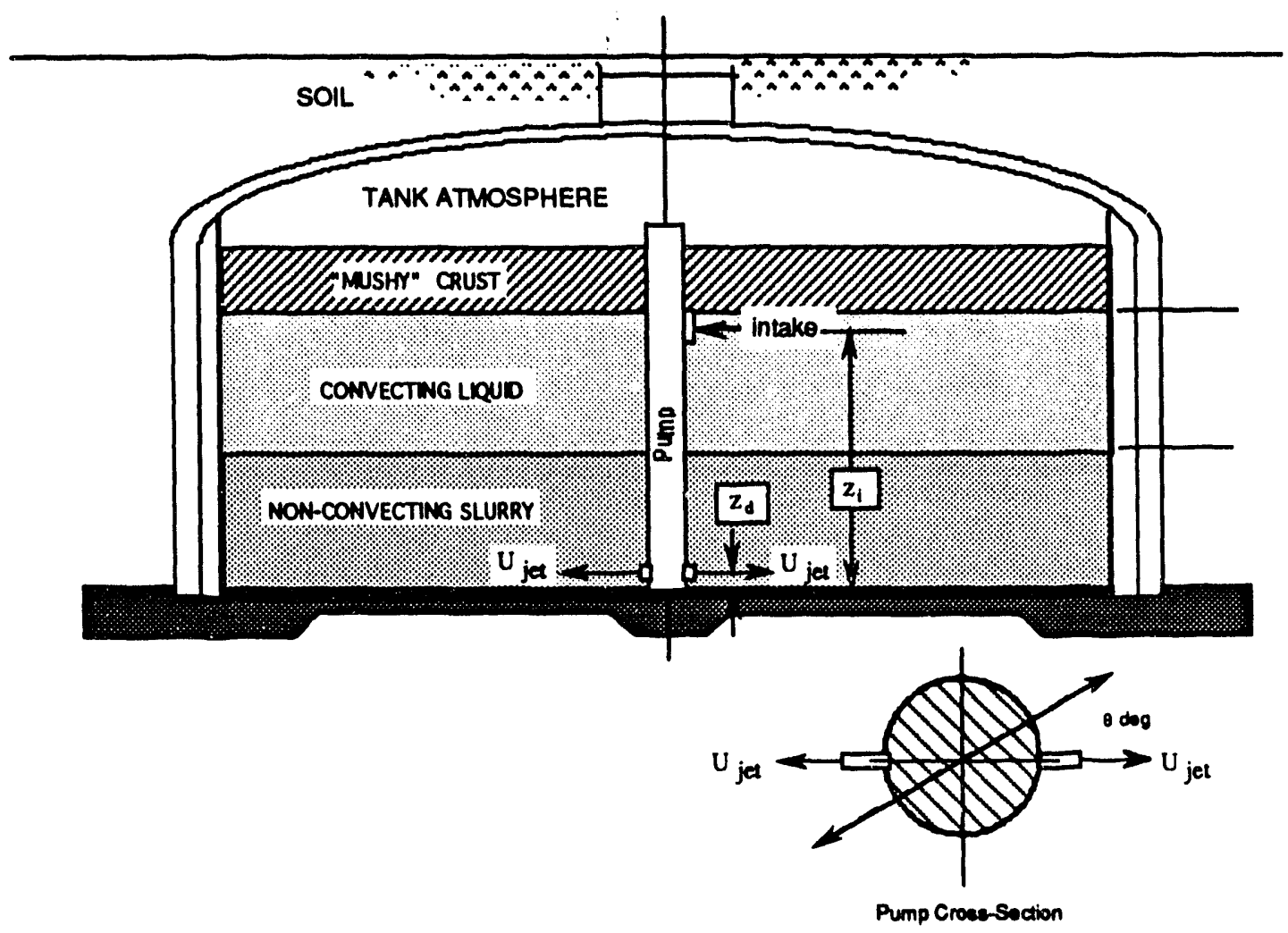

Figure 2.4. Horizontal Jet Arrangement (Two Opposing Jets) 


\subsubsection{Material Mobilization and Recirculation}

In the previous discussion, we have used the terms "mobilization" and "fluidization." Both terms refer to conditions existing when the particles that form the non-convecting slurry are in motion in that layer--but that are no: mixed throughout the tank. For the solid particles to be circulated to the top of the convecting region near the pump intake that might be located at this elevation, the circulation velocity of the convecting liquid layer would need to be greater than the settling velocity of the solid particles.

Observation of the synthetic waste settling experiments (Allemann and Hinkle(a)) suggests that the settling velocity of the solid particle may be on the order of 0.001 to $0.0001 \mathrm{ft} / \mathrm{sec}$. Using this value, a pump would need to supply 4.5 cfs just to levitate the solid material (on the average). Two three-in. diameter jets, operating continuous!y with discharge velocity of $125 \mathrm{ft} / \mathrm{sec}$ would supply $3.9 \mathrm{cfs}$. The average vertical flow over the diameter of the tank would be about $8.6 \times 104 \mathrm{ft} / \mathrm{sec}$, which is less than the particle settling velocity. On the other hand, the particle settling velocity observed in the experiments is subject to a substantial error range. The slowest settling materials are those visually observed in the experiments. If there are larger, or more dense particles, the settling velocity of this material would be substantially faster, making recirculation less probable. It is reasonable to expect that in Tank 241-SY-101 there is a range of particle sizes and densities, with the possibility of attached bubbles. Therefore, it is likely that some recirculation will occur with a two pump operation but that the majority of the material will simply fluidize.

(a) This report is a draft document by R. T. Allemann and K. D. Hinkle. 1991. Work Becord Book for Waste Slurry Tests. Pacific Northwest Laboratory, Richland, Washington. 


\subsection{Numerical Modeling}

The rationale for conducting either numerical or physical modeling of the various jet mixing concepts under consideration for Tank 241-SY-101 is primarily to predict, evaluate and test concept feasibility and guide prototypic design. Such information is invaluable to equipment design and operation, giving guidance to the range of parameters required to achieve desired results and diminishing the possibility of unexpected behavior that may compromise the design and operational effectiveness.

Physical models are used to produce physical behavior at convenient reduced scale so that comprehensive experimental information can be obtained under laboratory conditions. This not only reduces experimental costs but also permits intensive testing under controlled and instrumented conditions. Juch testing is usually conducted for either or both of two purposes: 1) to produce information that can be scaled to prototypic dimensions and 2) produce information useful for development, evaluation, and verification of a numerical model that is to be used for predicting prototypic behavior.

For physical model results to be scalable to prototypic size, the model must reproduce the important physical phenomena under conditions required for geometric, kinematic, and dynamic similarity. That is, the important physical phenomena must bear the same relative influence in the prototype as in the model. These conditions are usually difficult to achieve in complex systems and similarity distortion is usually unavoidable. The complicating factors in Tank 241-SY-101 are the presence of solid particles that can be suspended, settle, and form a slurry that might be difficult to mobilize and the presence of trapped gases in this slurry layer. Additionally, viscosity is a function of solid particle concentration and also is, perhaps, non-Newtonian. Because of these influences, results that can be reliably scaled to prototype conditions may be difficult to obtain.

Numerical modeling, on the other hand, relies on mathematical interpretation of physical phenomena and has no difficulty with scale. The question of similarity, which must also be achieved in a numerical model, is implemented through a mathematical description of physical processes. How well this can be achieved is then a measure of the numerical model's simulation accuracy.

Therefore, numerical models must rely to an extent on so-called constitutive, or empirical, relationships. These relationships are mathematical descriptions of phenomena that cannot be modeled from "first principles" or that would otherwise be impractical to compute. They include fluid stress-strain (Stokes viscosity) and viscosity behavior that is a function of concentration, particle settling, etc. In all cases, these relationships must be supported by experimental data. 
High-level numerical iluid dynamic models are based on the fundamental equations that govern fluid flow and associated transport phenomena. Empirical correlations are used only when a particular process cannot be practically described with a more fundamental relationship. Every attempt is made to make such correlations universal so that they have validity over a wide range of applications. As an example, the $k-\varepsilon$ turbulence model used by the TEMPEST code requires a set of 7 empirical constants. This set of constants was developed by the Imperial College in London, U.K. during the early 1970s. Since the inclusion of the turbulence model into the code, TEMPEST has applied this set of constants for all turbulent flow computations. Verification data presented later in this section illustrates how well these constants apply.

Unfortunately, universal constitutive relationships and empirical correlations are not available for all situations. In Tank 241-SY-101, the physical nature and behavior of the solid particles are largely unknown and probably unique. Thus it may be necessary to develop new empirical correlations for viscosity and solid settling dynamics that are specific to the material in Tank 241-SY-101 but independent of scale. In the absence of reliable and complete prototype data, physical testing using material stimulants becomes important to the development of these relationships or the determination of empirical constants that are needed by existing constitutive relationships. Once the numerical model is successful in predicting the physical behavior of scale model tests, it can be confidently used to predict prototype behavior.

\subsection{The TEMPEST Computer Code}

The TEMPEST fluid dynamics computer code(a) simulates the time-dependent, 3-dimensional equations of turbulent momentum, heat and mass transport. It uses a state-ofthe-art $k-\varepsilon$ turbulence model that has demonstrated exceptional precision in simulating jetinduced flow and mixing. TEMPEST can accommodate up to 9 mass species (liquids, gases, or solids), and non-Newtonian power law fluids.

TEMPEST is based on a finite-volume approach to numerical fluid mechanics and can accommodate Cartesian, cylindrical, polar, or generalized orthogonal coordinates systems.

\subsubsection{TEMPEST T2 Equation Set}

TEMPEST, Version T2, implements the integral form of the fundamental conservation laws; (see nomenclature in Table 3.1):

(a) This report is a draft document by D. S. Trent and L. L. Eyler. 1993. IEMPEST - A Computer Program for Three-Dimensional. Time-Dependent Computational Fluid Dynamics: Theory Manual. Version T, Mod 3. Pacific Northwest Laboratory, Richland, Washington. 
Table 3.1. Nomenclature

Vector quantilies:

$\begin{array}{ll}\mathbf{U} & =\text { velocity } \\ \mathbf{F} & =\text { force } \\ \mathbf{n} & =\text { unit surface normal }\end{array}$

Terisor quantities:

$x_{i} \quad=i_{\text {th }}$ space coordinate, $i=1,2,3$

$U_{1}=$ velocity component, ith coordinate direction

$g_{i}=$ gravitational component, ith coordinate direction

$\dot{\gamma}_{i j}=$ rate of strain tensor

\section{Varlables:}

$t=$ time

$\mathrm{A}=$ area

$\mathrm{V} \quad=$ volume

$P \quad=$ pressure

$T=$ = temperature

$\mathrm{Q} \quad=$ heat

$\mathrm{G}=$ mass concentration, ith species

$\mathrm{C}_{\text {vil }}=$ volumetric concentration

$\mathrm{C}_{\text {vamax }}=$ maximum soliós volumetric concentration

$\mathrm{C}_{\mathrm{va}}=$ solids packing factor

$V_{p i}=$ particle settling velocity, $i^{\text {th }}$ species

$v_{\infty} p=$ terminal velocity of a settling particle

s $=$ source term

k $\quad=$ turbulent kinetic energy

e $\quad=$ internal energy

h $=$ enthalpy

Sk = turbulent kinetic energy source term

$\mathfrak{S}_{\mathbf{E}}=$ = turbulent kinetic energy dissipation source term

$P_{k} \quad=$ turbulent kinetic energy production

$G_{k} \quad=$ turbulent kinetic energy stratification sink

$M=$ non-Newtonian power law coefficient

$\mathcal{N}=$ non-Newtonian power law exponent

$\varepsilon \quad=$ turbulent kinetic energy dissipation

$\rho=$ density

$\mu \quad=$ molecular dynamic viscosity

$\mu_{\theta} \quad=$ effective dynamic viscosity 


$$
\begin{array}{ll}
\mu_{0} & =\text { base viscosity of supernatant } \\
\mu_{T} & =\text { turbulent dynamic viscosity } \\
\mu_{m i x} & =\text { mixture dynamic viscosity } \\
\mu_{N} & =\text { non-Newtonian dynamic viscosity } \\
\tau & =\text { shear stress }
\end{array}
$$

\section{Constants:}
a $=$ constant, concentration dependent viscosity
b $\quad=$ constant, concentration dependent viscosity
d $\quad=$ constant, concentration dependent viscosity
$\mathrm{C}_{\mu} \quad=k-\varepsilon$ turbulence model constant
$C_{\varepsilon 1}=k-\varepsilon$ turbulence model constant
$C_{\varepsilon 2}=k-\varepsilon$ turbulence model constant
$\mathrm{C}_{\varepsilon 3}=k-\varepsilon$ turbulence model constant
$\sigma_{k} \quad=$ turbulent Schmidt number, turbulent kinetic energy
$\sigma_{\varepsilon} \quad=$ turbulent Schmidt number, turbulent kinetic energy dissipation

\section{Subscripts:}

i = tensor index, ith coordinate direction

j = tensor index, summation index

h = thermal energy

$G_{i} \quad=$ mass species, $C_{i}$

$T=$ turbulent

$k \quad=$ turbulent kinetic energy

$\varepsilon \quad=$ turbulent dissipation

s $\quad$ settling

$\operatorname{mix}=$ mixture

$v \quad=$ volumetric basis

$\mathrm{N} \quad=$ non-Newtonian

vR $=$ volume ratio

$\infty p=$ steady state

- Conservation of mass

$$
\frac{\partial}{\partial t} \int_{\omega} \rho d V+\int_{c} \rho(U \cdot \hat{n}) d A=0
$$


- Conservation of momentum (Newton's second law)

$$
\frac{\partial}{\partial t} \int_{c \nu} \rho e d V+\int_{c} \rho h(U \cdot \hat{n}) d A=\frac{\delta Q}{\delta t}+s_{e}
$$

- Conservation of energy (18t law of thermodynamics)

$$
\frac{\partial}{\partial t} \int_{\omega} \rho d V+\int_{\omega} \rho(U \cdot \hat{n}) d A=0
$$

- Conservation of turbulent kinetic energy, $k$

$$
\frac{\partial}{\partial t} \int_{\infty} \rho k d V+\int_{\omega} \rho k(U \cdot \hat{n}) d A=s_{k}
$$

- Conservation of turbulent kinetic energy dissipation, $\varepsilon$

$$
\frac{\partial}{\partial t} \int_{\infty} \rho \varepsilon d V+\int_{\sigma} \rho \varepsilon(U \cdot \hat{n}) d A=s_{\varepsilon}
$$

- Conservation of species, $C_{i}(i=1,9)$

$$
\frac{\partial}{\partial t} \int_{\infty} c_{i} d V+\int_{\infty} c_{i}(U \cdot \hat{n}) d A=s_{c_{i}}
$$

TEMPEST solves the above equations for a single-phase fluid having "bulk" or "mixture" properties.

\subsubsection{Constitutive Relationships}

Material state equations, and other constitutive relationships are as fol.'ows:

- Equation of state

$$
\rho=f\left(P, T, C_{i}\right)
$$

- $\quad K-\varepsilon$ Turbulence model

Turbulent viscosity, $\mu_{T}$, is computed using the Prandtl-Kolmogorov hypothesis as follows:

$$
\mu_{T}=c_{\mu} \rho \frac{k^{2}}{\varepsilon}
$$


Turbulent kinetic energy, $k$, and dissipation, $\varepsilon$, are computed as follows:

Turbulent kinetic energy, $k$

$$
\begin{aligned}
& \frac{\partial \rho k}{\partial t}+\frac{\partial}{\partial X_{j}}\left(\rho U_{j} k\right)=\frac{\partial}{\partial X_{j}}\left(\frac{\mu_{T}}{\sigma_{k}} \frac{\partial k}{\partial X_{j}}\right)-\rho \varepsilon+S_{k} \\
& S_{k}=P_{k}+G_{k} \\
& P_{k}=\mu_{T}\left(\frac{\partial U_{i}}{\partial X_{j}}+\frac{\partial U_{j}}{\partial X_{i}}\right)\left(\frac{\partial U_{i}}{\partial X_{j}}\right) \\
& G_{k}=\frac{\mu_{T}}{\rho \sigma_{T}}\left(8_{i} \frac{\partial \rho}{\partial X_{i}}\right)
\end{aligned}
$$

Dissipation of turbulent kinetic energy, $\varepsilon$

$$
\begin{aligned}
& \frac{\partial \rho \varepsilon}{\partial t}+\frac{\partial}{\partial X_{j}}\left(\rho U_{j} \varepsilon\right)=\frac{\partial}{\partial X_{j}}\left(\frac{\mu_{T}}{\sigma_{\varepsilon}} \frac{\partial \varepsilon}{\partial X_{j}}\right)+\frac{1}{k}\left(S_{\varepsilon}-\rho C_{\varepsilon 2}\right) \varepsilon \\
& S_{\varepsilon}=\mathrm{C}_{\mathrm{e} 1} P_{k}+\mathrm{C}_{\mathrm{e} 3} G_{k}
\end{aligned}
$$

\subsubsection{Rheology Model}

The rheological model constructed for TEMPEST approximates the viscosity of nonNewtonian fluids and slurries with the following considerations:

1. The fluid may have a Ostwald-Dewaele power law form (Bird et al 1960),

$$
\mu=m \dot{\gamma}^{n-1}
$$

where $m$ is the power law coefficient, $\dot{\gamma}$ is the rate-of-strain tensor, and $n$ is the power law exponent. The rate-of-strain tensor is defined in terms of the second invariant, the strain tensor, $\gamma$, as 


$$
\dot{\gamma}=\sqrt{\gamma}
$$

where

$$
\gamma=\frac{1}{2}\left(\dot{\gamma}_{11}^{2}+\dot{\gamma}_{22}^{2}+\dot{\gamma}_{33}^{2}\right)+\dot{\gamma}_{23}^{2}+\dot{\gamma}_{13}^{2}+\dot{\gamma}_{12}^{2}
$$

The strains, $\dot{\gamma}_{i j}$, are defined by

$$
\dot{\gamma}_{i j}=\left(\frac{\partial u_{i}}{\partial x_{j}}+\frac{\partial u_{i}}{\partial x_{i}}\right)
$$

2. Concentration of particulate material, $\mathrm{C}_{\mathrm{vs}} \mathrm{i}$

$i=1,2,3 \ldots$ number of solid species

3. Packing factor ratio of solids, $C_{\mathrm{vR}}$

$C_{V R}$ is the ratio of solids volumetric packing to the maximum packing fraction,

$$
c_{v R}=\frac{\sum_{i} c_{v s i}}{c_{v s \max }} ; \quad 0 \leq C_{v R} \leq 1
$$

where $\mathrm{C}_{\mathrm{v} s \max }$ is the maximum solids volume fraction (in the absence of gas)

\subsubsection{Particle Settling Model}

Two forms for the particle "hindered" settling velocity are provided in TEMPEST as user options. The particle settling model used for the simulations discussed in this report is given by Eq. (3.17a). A more realist hindered settling model is given by Eq. (3.17b). The two options are as follows:

Option 1. Conservative estimate - high fall settling velocity

$$
\begin{array}{ll}
v_{p}=v_{\text {osp }}, & 0 \leq C_{v} \leq 0.8 C_{v \text { max }} \\
v_{p}=5 v_{\text {oop }}\left(1-C_{v} / C_{v \text { max }}\right) & C_{v}>0.8 C_{v \text { max }}
\end{array}
$$


Option 2. Perry and Green hindered settling model (Perry and Green 1984)

$$
v_{p}=v_{\infty p}\left(1-C_{v R}\right)^{n}
$$

where $v_{\infty} p$ is the particle terminal velocity in clear liquid. The exponent $n=4.35$. The terminal settling velocity, set by input for the current computations and based on observation using material "simulant" (Allemann and Hinkle, Draft Report 1991), is $v_{\infty} p=10^{-4} \mathrm{ft} / \mathrm{sec}$. This value is low enough that for the safety computations particle settling has essentially no impact on the pump test simulation results because of the short test duration. Option 1 is called a conservative model, because, for the same terminal velocity, particles will descend more rapidly in a concentrations gradient according to Eq. (3.17a) than that prescribed by Eq. (3.17b). TEMPEST predicts less efficient mixing using Eq. (3.17a), because it is more difficult to keep the particles suspended (i.e., the particle fall out of the suspending liquid faster).

\subsection{Model Testing and Verification}

Over the past 10 years or so, versions of the TEMPEST code have been used to simulate a wide variety of fluid dynamic and heat and mass transfer problems. Numerous verification and data comparison studies have been conducted. A portion of this work has been documented in Trent and Eyler (1991)((a)), and other studies have been documented in various sponsored research reports and published papers. A standard set of test simulations is maintained to test new and modified versions of the code as it evolves with new and improved capability.

In this section, TEMPEST modeling features that are relevant to proper simulation of Tank 241-SY-101 jet mixing and tank circulation are rested. Because of time and funding constraints, this testing was limited to noding studies required to obtain proper resolution of the jet mixing behavior and material concentration gradients. Previous testing has been conducted to establish solids concentration dependent viscosity and is also illustrated. Comparisons with scale model tests (Fort et al. 1992) are planned but have not been completed at this time.

All computational fluid dynamic computer codes require that the modeled region be discretized with a grid system or, alternatively, divided into a collection of finite volumes, as is

(a) Trent, D. S., and L. L. Eyler. 1991. TEMPEST - A Computer Program for ThreeDimensional Time-Dependent Hydrothermal Analysis, Volume 2, Assessment and Verification Results. Version N, Mod 33. PNWD-1536, Vol. 2 Rev. 1, Battelle, Pacific Northwest Laboratories, Richland, Washington. 
the case with TEMPEST. In addition to proper mathematical description of the governing equations and other correlation models, the accuracy of results depends on how well the phenomena can be resolved on the grid systern used.

If we could solve the partial differential equations that govern the fluid flow "exactly", we would obtain what is called the "exact" solution, and therefore we could determine the flow properties at any "point" in space and time for the flow system. When we solve the finite volume equations numerically, we determine the flow properties at "discrete" points in space and time or in a space-time averaged sense for the finite volume. Thus, we are dealing with an approximation of the flow field that is dependent to a large extent on how many of these volumes or grid points we use to structure the region and therefore how small they are. Because the values we compute are the average for that volume, the smaller the volume, the closer the average is to the point value. Therefore, the numerical simulation of a fluid region can lead to the use of many thousands of finite volumes, each of which results in one or more aigebraic equations.

The proper size of the finite volumes required for accurate resolution is related to the magnitude of spatial gradients that exist in the flow field rather than to the relative physical size of the modeled region. Thus, if the conditions in Tank 241-SY-101 were fairly uniform, only a few hundred finite volumes, or grid points, would be needed to accurately describe the physical behavior numerically. However, we know that conditions in the tank are reasonably uniform only during the quiescent period before an upset event. During the "roll-over" period, the flow behavior is apparently very chaotic and large gradients in both space and time are certain to exist.

In the case of jet mixing, very large gradients will occur in the vicinity of the jet discharge. This requires that the finite volumes, or grid structure, must have sizes on the same order as the jet nozzle diameter. This is a requirement not because we need to know the properties in the vicinity of jet discharge but because the mixing dynamics and circulation in the overall tank will be incorrect if the jet discharge is not properly modeled. For instance, if the grid structure is too coarse, the jet will be "numerically diffused" during the computation, overestimating the near-field entrainment, and thus dissipating the jet's kinetic energy at too short a distance from the discharge. This representation would yield grossly inaccurate mixing and circulation patterns in the overall tank. Such a situation is a kin to modeling the jet with a much larger diameter and a much smaller discharge velocity. Thus, if the near-field dynamics of the jet discharge are not properly modeled, erroneous results will be produced giving a false picture of the jet mixing effectiveness.

The following section dealing with jet simulations is intended to give modeling guidance to TEMPEST users for setting up jet as well as to verify and illustrated the code's capability for modeling jet mixing. Additionally, we wish to find a reasonable compromise between simulation accuracy and the minimum number of computational cells required. 


\subsubsection{Momentum Jets}

One concept for jet mixing is to use horizontal jets, discharging at high velocity $(60$ to $125 \mathrm{f} / \mathrm{sec}$ ) through an orifice having diameters in the range of 1.5 to $3.0 \mathrm{in}$. As mentioned previously, a grid size on the order of the jet diameter is required to achieve acceptable accuracy. Because the tank has a diameter of $75 \mathrm{ft}$ and liquid material depth of some $32 \mathrm{ft}$, an enormous number of computational cells will be needed to model the tank in three-dimensions. The jet discharge has the smallest dimensions but the largest velocity gradients of any flow feature in the tank. Thus, a grid size compromise is sought that allows adequate resolution of the jet discharge, yet does not require a number of computational cells which makes the simulation computationally impractical from the standpoint of the required computer time.

The primary consideration for the number of computational cells needed in a jet simulation is consideration of the "zone of flow establishment" and how accurately this zone must be modeled to obtain accurate downstream results. This does not mean that details of the flow distribution must be produced accurately in the zone of flow establishment. It only means that this initial region must be modeled in a manner such that the downstream established flow regime will be reproduced with reasonable accuracy where the majority of the entrainment, mixing, and resulting tank circulation occurs.

Figure 3.1 illustrates the flow regimes in the near-field of a jet discharge. For a momentum jet, the zone of flow establishment extends approximately 6.2 diameters downstream. This is the zone (the distance) that is required for the effect of shear forces acting between the emanating jet and the ambient fluid to reach the jet centerline. Downstream from this point, the jet flow transitions to the zone of established flow, which is a self-similar region, having characteristic Gaussian-shaped velocity profiles.

In the zone of flow establishment, the centerline velocity, $V_{c l}$, will vary only slightly from the discharge velocity. In the zone of established flow, the centerline velocity decreases inversely proportional to the downstream distance, $z$.

As illustrated in Figure 3.2, experimental data for momentum jet centerline velocity correlated by

$\begin{array}{lll}V^{*}=1 & Z^{*} \leq 6.2 & \text { (zone of flow establishment) } \\ V^{*}=6.2 / Z^{*} & Z^{*}>6.2 & \text { (zone of established flow) }\end{array}$




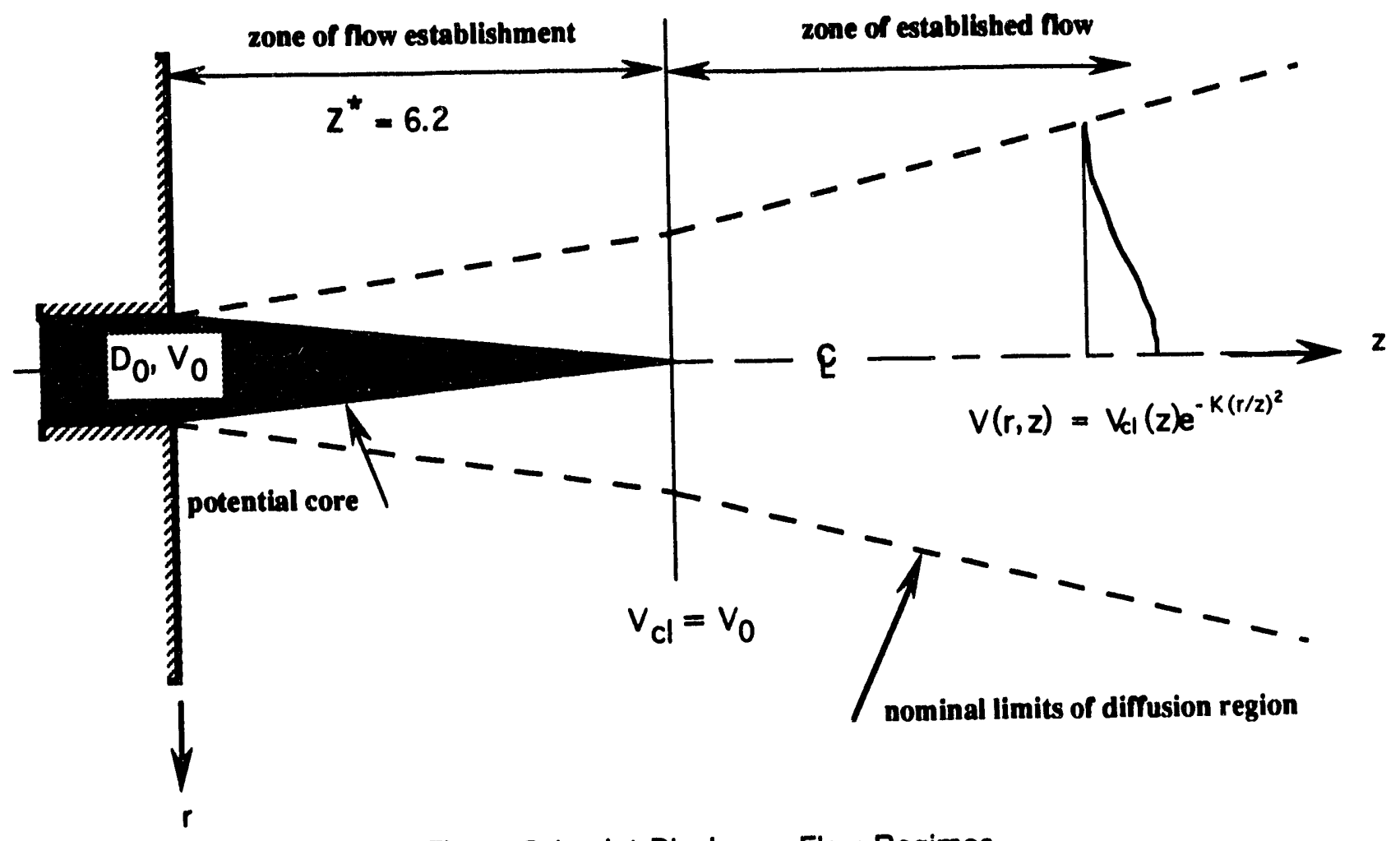

Figure 3.1. Jet Discharge Flow Regimes

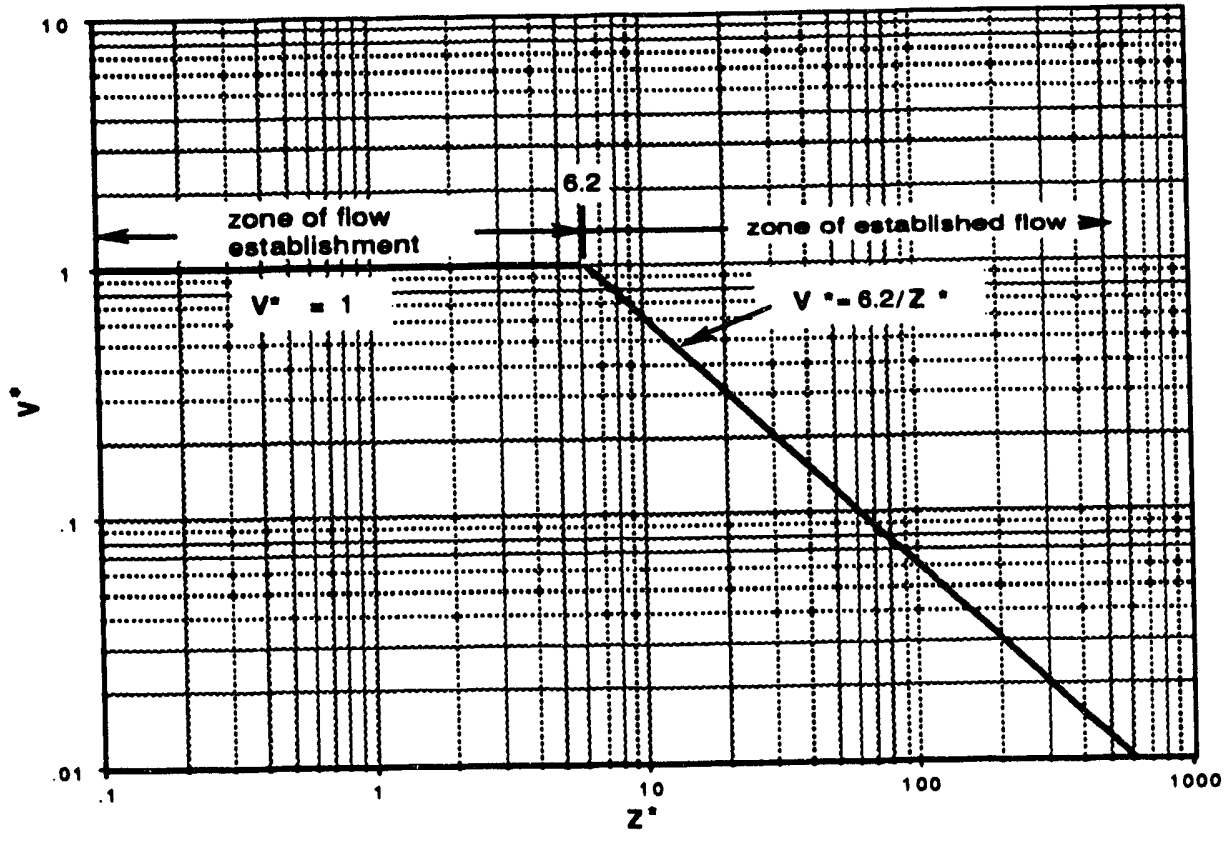

Figure 3.2. Centerline Velocity of a Momentum Jet 


$$
\text { where } \begin{aligned}
Z^{*} & =z / D_{0} \\
R^{*} & =r / D_{0} \\
V^{*} & =V_{C} / V_{0} \\
D_{0} & =j e t \text { orifice diameter } \\
V_{0} & =j e t \text { discharge velocity } \\
r & =j e t \text { radial coordinate } \\
Z & =\text { jet axial coordinate }
\end{aligned}
$$

The lateral distribution of downstream velocity has a Gaussian profile, given by

$$
V(r, z)=V_{c l}(z) \theta^{-K(r / z)^{2}}
$$

\begin{tabular}{|c|c|c|}
\hline Case $A$ (5 radial cells) & Case 8 ( 3 radial cells) & Case $C$ (1 radial cell) \\
\hline (total cells $=55 \times 40)$ & (total cells $=23 \times 27$ ) & (total cells $=30 \times 27)$ \\
\hline A.9 9 axial cells & $\begin{array}{ll}\text { B.1 } & 1 \text { axial cell } \\
\text { B.2 } & 2 \text { axial cells } \\
\text { B.6 } & 6 \text { axial cells }\end{array}$ & $\begin{array}{ll}\text { C.1 } & 1 \text { axial cell } \\
\text { C.2 } & 2 \text { axial cells } \\
\text { C.4 } & 4 \text { axial cells } \\
\text { C. } 6 & 6 \text { axial cells }\end{array}$ \\
\hline
\end{tabular}

where the experimentally determined entrainment coefficient, $K=77$ (Abraham 1963).

Several test cases were executed to determine the minimum acceptable grid structure for the potential core. Two-dimensional cylindrical coordinates were used to model a $10^{\circ}$ segment of symmetry of the round jet. The TEMPEST k- $\varepsilon$ turbulence model was used with the standard set of constants. These case are summarized in Table 3.2 and the grid structures are illustrated in Figure 3.3.

Table 3.2. Momentum Jet Test Case Summary

As given in Table 3.2 and illustrated in Figure 3.3, the number of "radial" cells is the number used to model the radius of the jet orifice, and the number of axial cells is the number used to model the length of the "zone for flow establishment" (the potential core).

\section{Case A}

Case A.9 uses five computational cells to model the core in the radial direction and nine in the axial direction. The total number of cells used in the simulation was $55 \times 40=2200$. This is a "fine" node case which is expected to give good results. Figure 3.4 illustrates the centerline profile of downstream velocity compared to the data correlation, Eq. (3.18) and (3.19). As shown in Figure 3.4, the results are in excellent agreement with the data correlation, and it appears that this node structure gives results as accurate as required. 


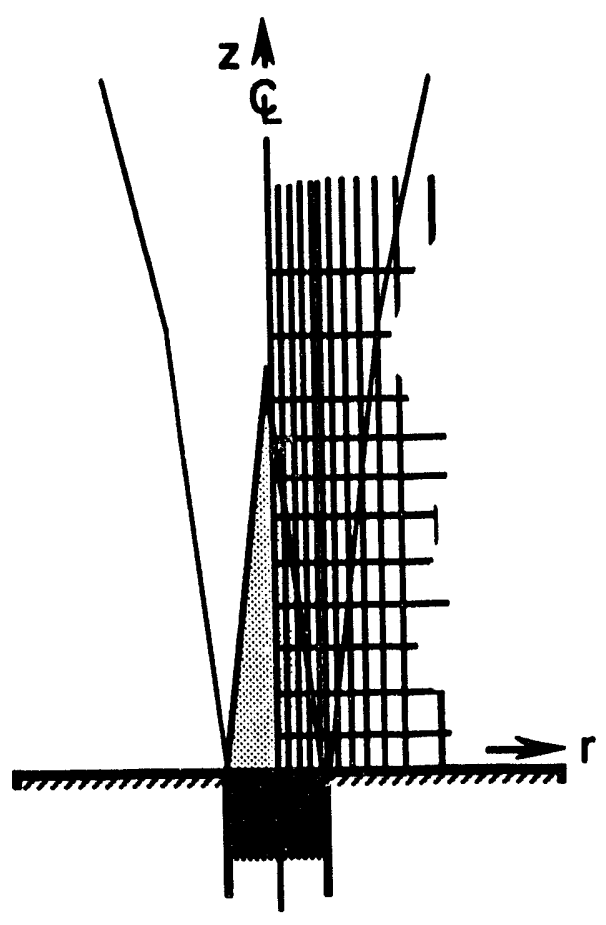

5 radial cells, 9 axial cells Case A.9
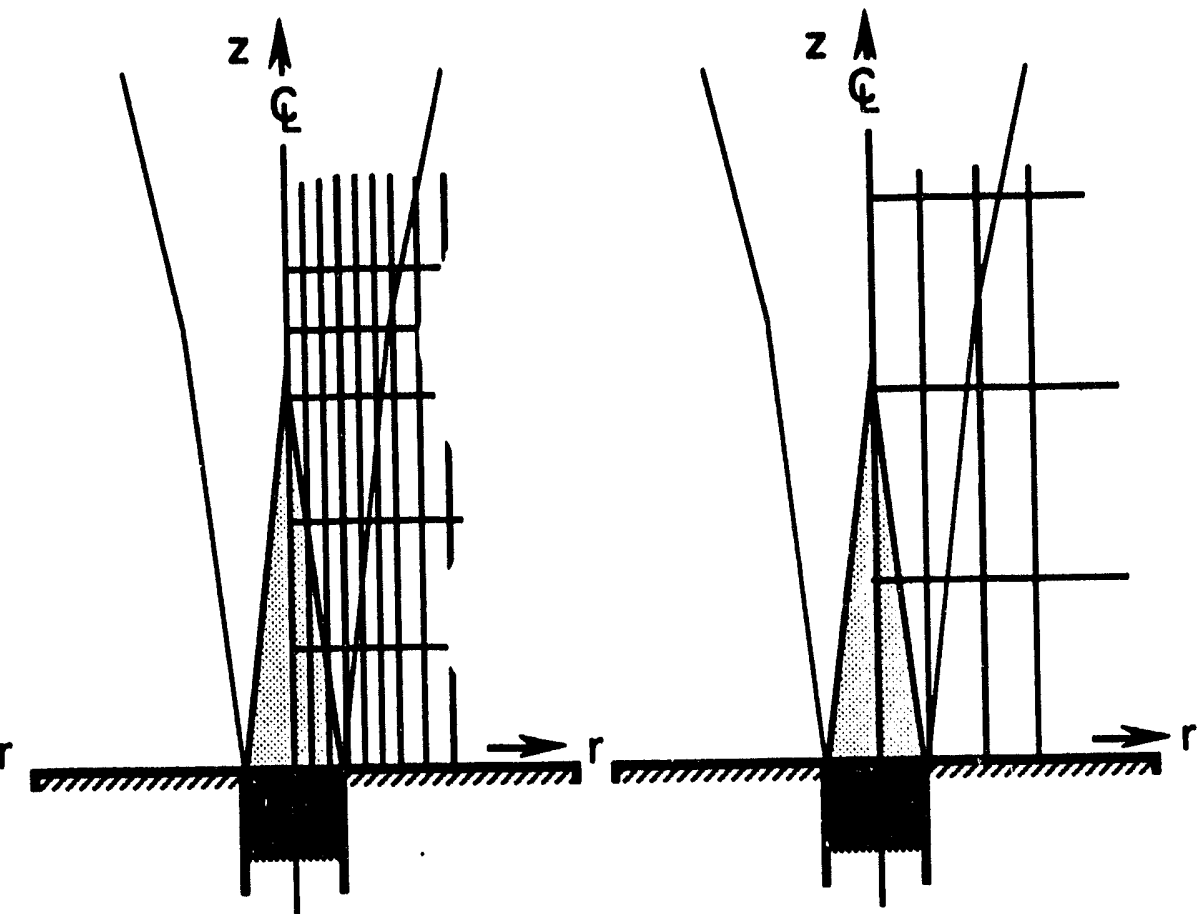

3 radial cells, 3 axial cells 1 radial cell, 2 axial cells Case B.3

Figure 3.3. Jet Core Computational Cell Structure

Figure 3.5 illustrates the Gaussian shaped lateral profiles of the jet's axial velocity, $V(r, z)$, at several downstream locations, as predicted by TEMPEST.

Figures 3.6 through 3.9 are color representations of a fully developed jet flow field computed by TEMPEST and included for qualitative illustration. Figure 3.6 illustrates the magnitude of downstream velocity where red depicts high velocity and dark blue is axial velocity near zero. The white line is a contour of velocity that is near zero and thus defines the nominal outer edge of the jet. The zone of flow establishment is shown at an expanded scale in Figure 3.7. The jet discharge orifice is at the bottom of the figure and the white contour line again defines the edge of the jet influence. Where the white contour "necks" is where the zone of flow establishment ends.

Figures 3.8 and 3.9 illustrate the magnitude of lateral velocity, which is the agent for entraining material into the jet stream. In Figure 3.8, blue indicates a negative flow, or liquid being entrained into the jet stream. The darker the blue, the higher the entrairinent velocity. Red indicates positive lateral velocity, or liquid flow away from the jet centerline, and green indicates regions of very low flow. Thus, the very center of the jet is green (not seen near the jet discharge because of graphics resolution). As the jet flow move downstream, the jet flow field spreads and the centerline velocity decreases because of entrainment. This also means that 


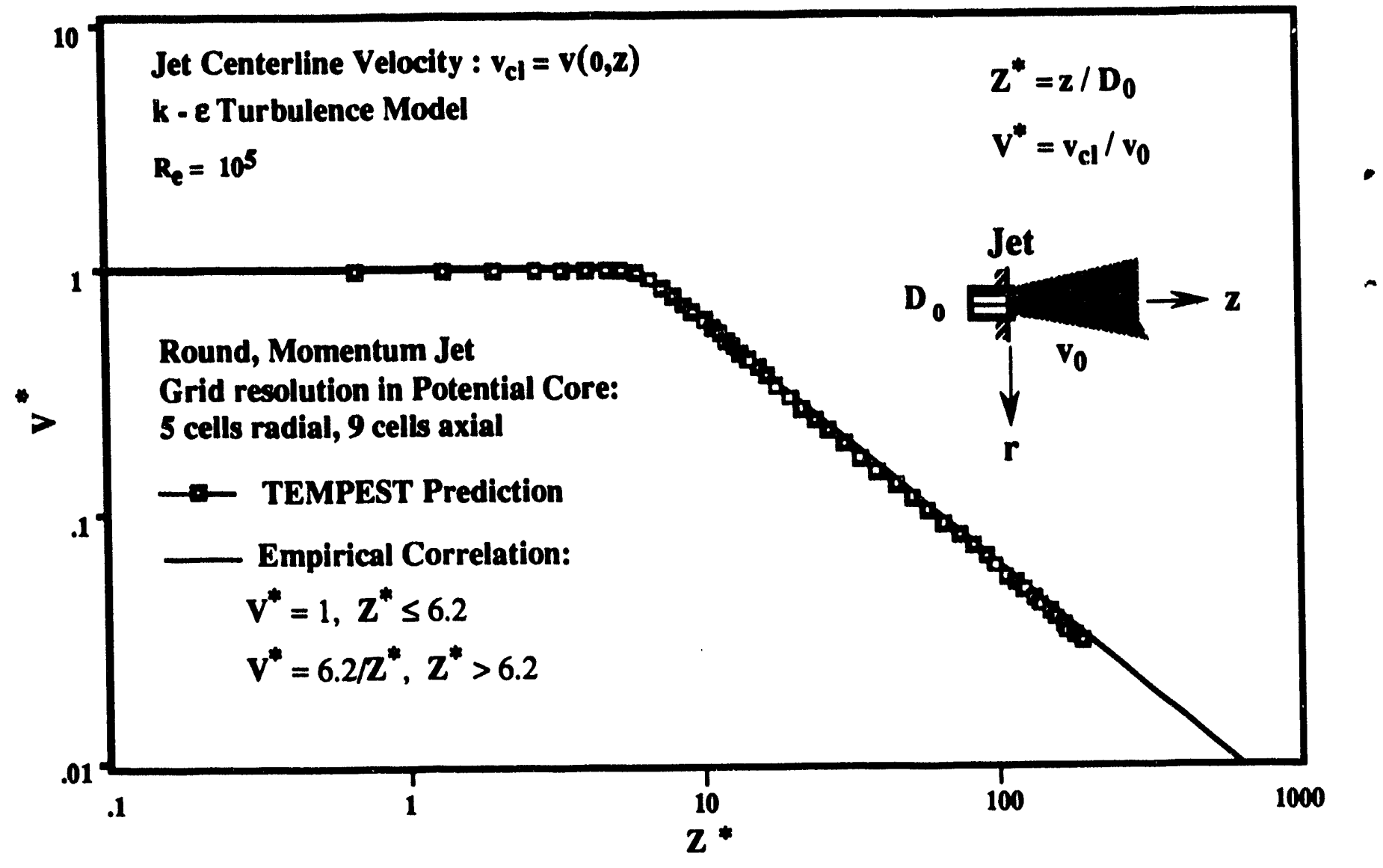

Figure 3.4. Momentum Jet Test: Case A.9

the original jet liquid is flowing away from the centerline. At some point in the radial direction, this positive velocity becomes zero. At radial distances beyond this point, liquid is being entrained into the jet and the flow is in the negative radial direction. The white contour line defines this "stagnation" line and illustrates the boundary of liquid that has emanated from the jet. Figure 3.9 illustrates lateral velocities in the zone of flow establishment, where again the white contour is the lateral velocity stagnation line. In this graphic, only two colors ara used: red indicates positive flow and blue indicates negative flow. Where the contour changes slope is where the flow establishment zone ends and the established flow zone begins.

\section{Case B}

As mentioned above, TEMPEST produces an excellent resolution of a momentum jet with a fine grid system. Unfortunately, using a grid with this high degree of resolution for practical application in tank simulations would lead to an enormous number of computational cells and a severe computational time-step limitation. To reduce the computer time requirements, a smaller number of computational cells were used. Therefore, the test simulations of Case B were conducted to investigate reducing the number of radial computational cells in the radial 


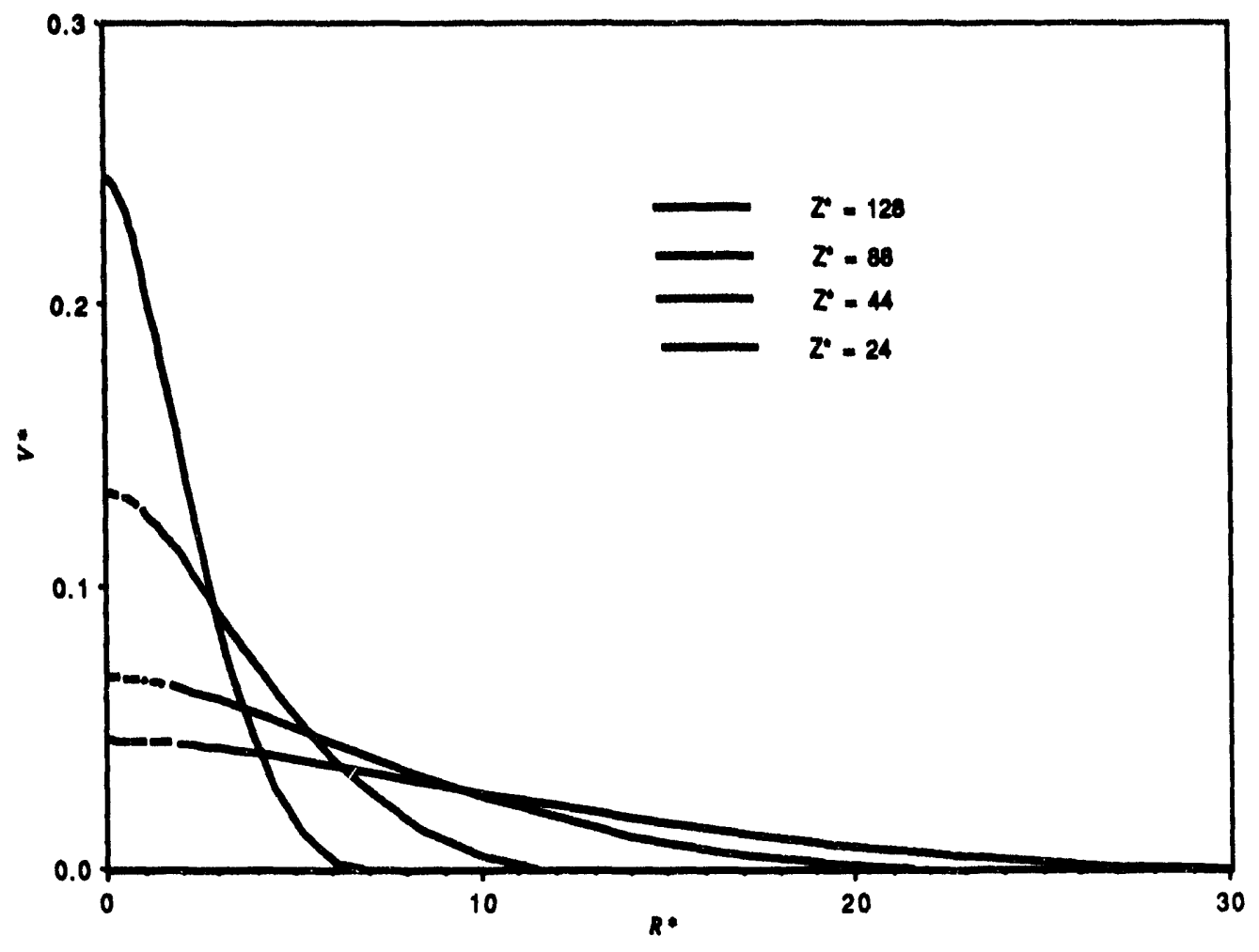

Figure 3.5. Momentum Jet Axial Velocity Distributions (Case A.9)

direction from 5 to 3. These results are illustrated in Figure 3.10a, 3.10b and 3.10c. These figure reveal that accuracy is severely compromised in the downstream region unless about 6 cells are used in the axial direction (Figure 3.10a, Case B.6). Using only two axial cells (Figure 3.10b, Case B.2) or one axial cell (Figure 3.10c, Case B.1) give unacceptable results.

\section{Case C}

The simulation testing entitled Case $C$ investigates an even coarser representation of the zone of flow establishment. Four tests were conducted with one radial cell for the jet orifice and one, two, four and six axial cells in the zone of flow establishment (refer to Table 3.2 and Figure 3.3). In this, case acceptable results were obtained in the downstream "fully developed flow" region for all four tests. In each test, the computed centerline velocity is underestimated in the transition region. However, in the region 20 to 200 diameters downstream, the computed results are acceptable as is shown in Figure 3.11(a, b, c, and d). 


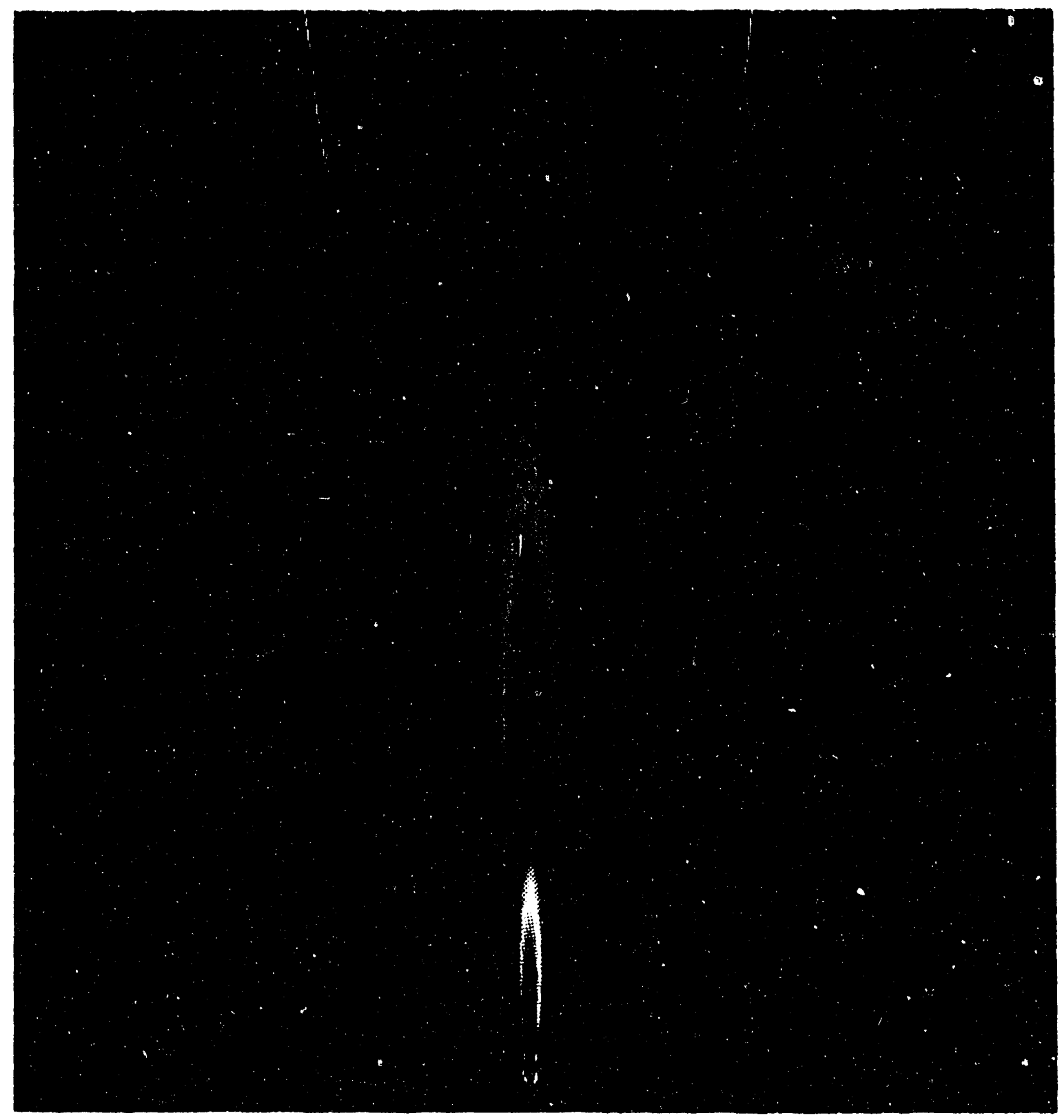

Figure 3.6. Downstream Velocity: Red $=$ High Velocity, Blue $=$ Low Velocity, and White $=$ Zero Velocity 


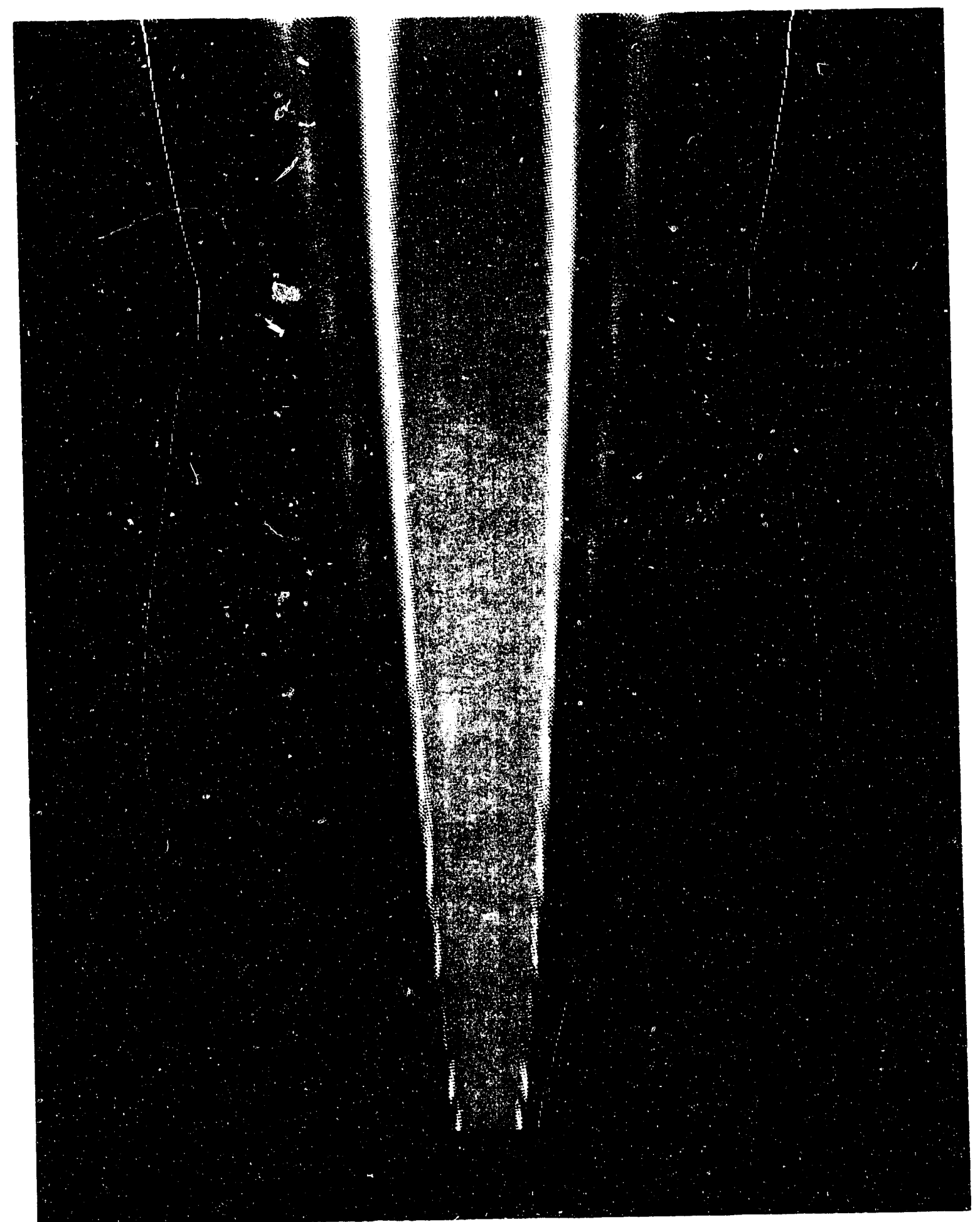

Figure 37. Downstream Velocity (Expanded Scale) Red = High Velocity. Blue = Low Velocity. and White $=$ Zero Velocity 


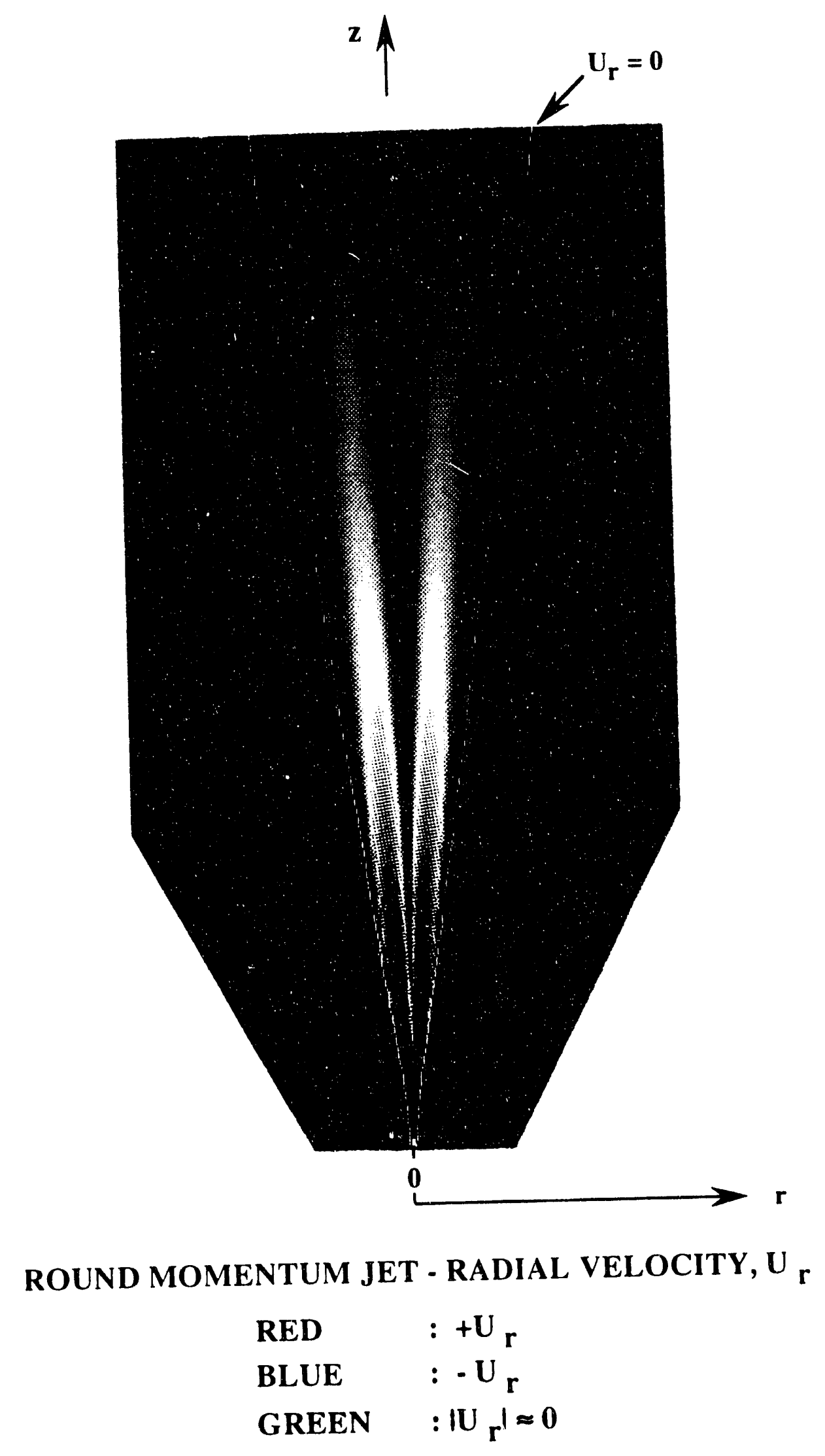

Figure 3.8. Magnitude of Lateral Velocity Showing: Red $=$ High Positive Velocity, Blue $=$ High Negative Velocity, and Green $=$ Very Low Flow 


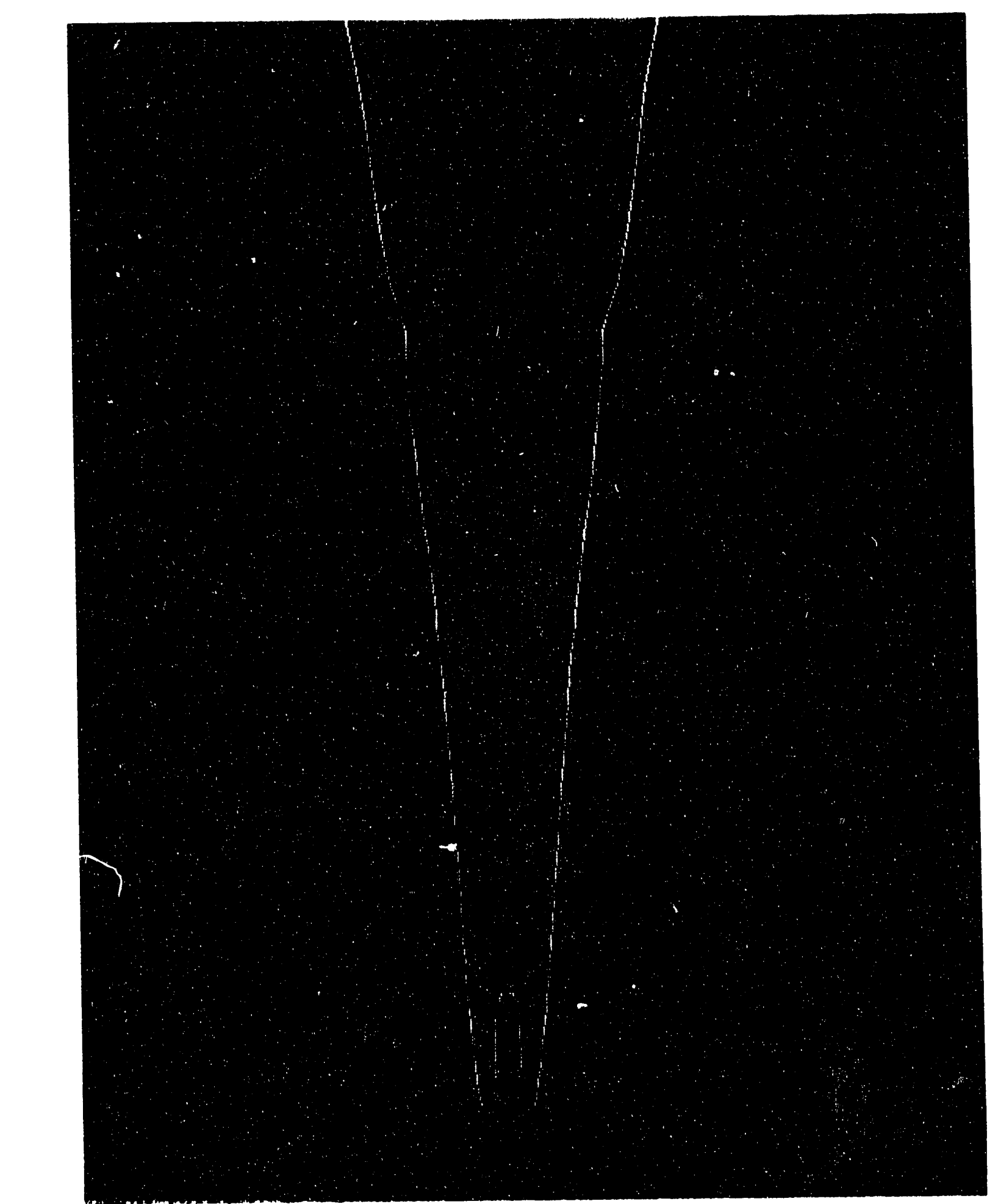

Figure 3.9. Magnitude of Lateral Velocity Showing: Red = Positive Flow and Blue $=$ Negative Flow 


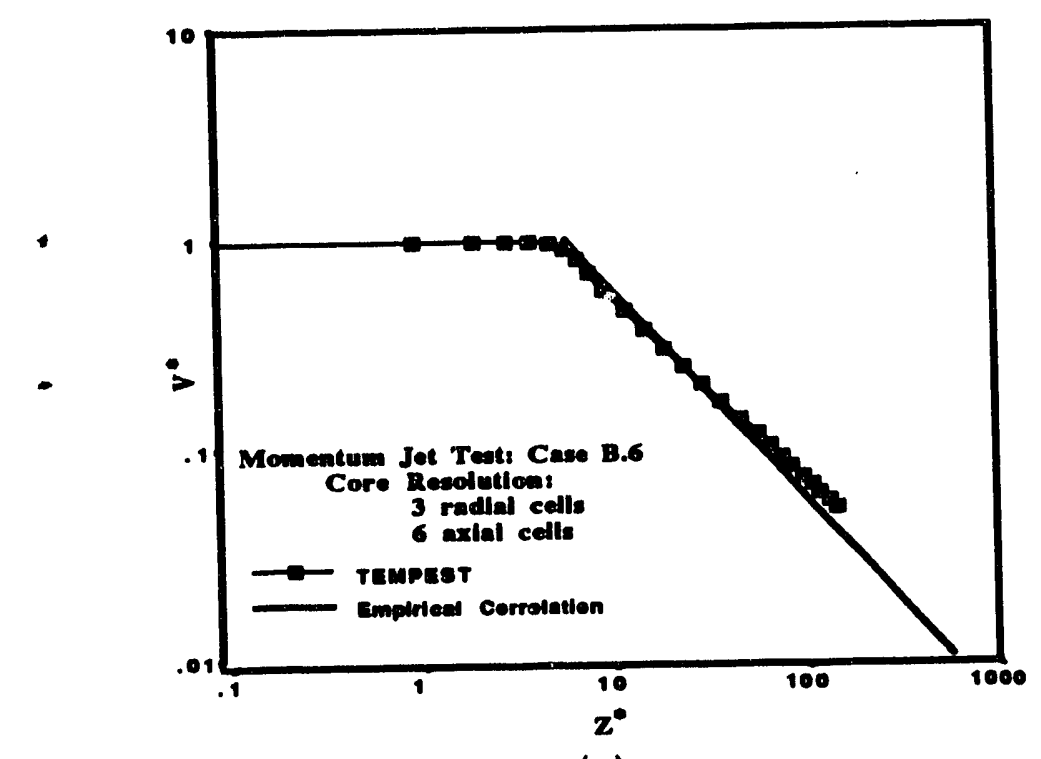

(a)

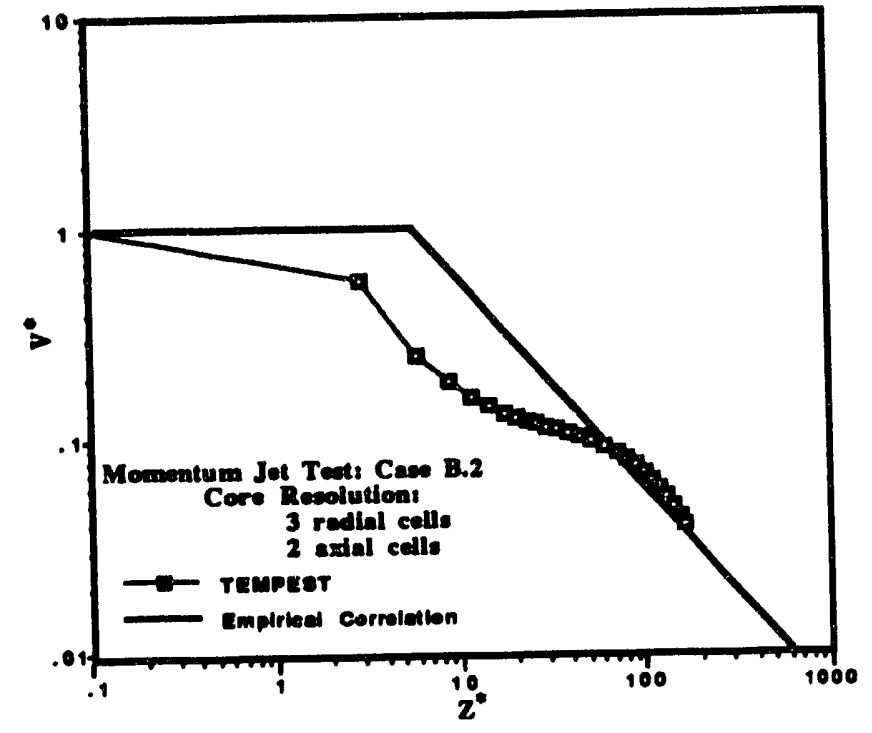

(b)

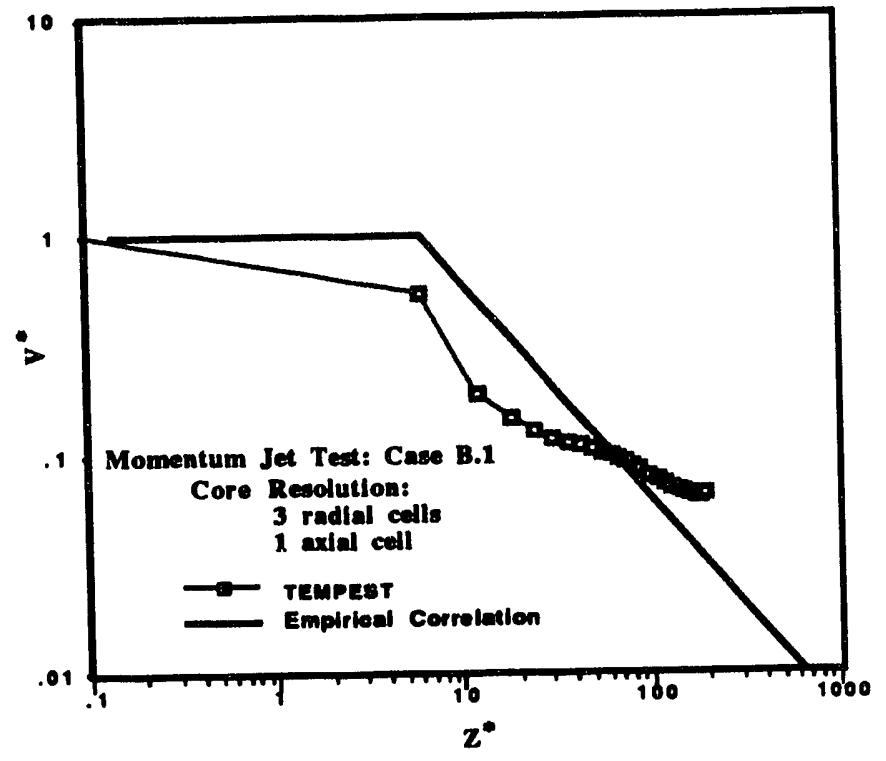

(c)

Figure 3.10. Case B; Computed Momentum Jet Centerline Velocity Using Three Radial Cells in the Zone of Flow Establishment 


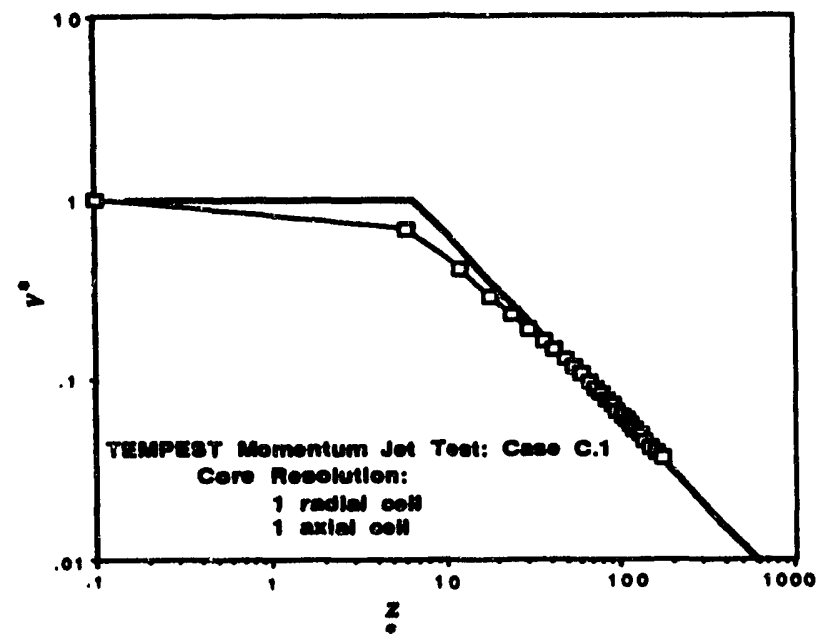

(a)

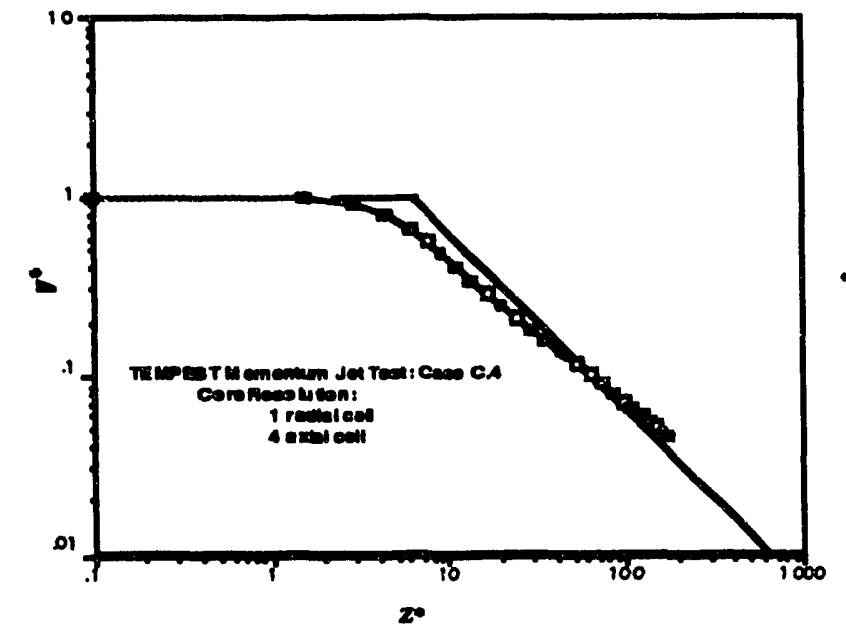

(c)

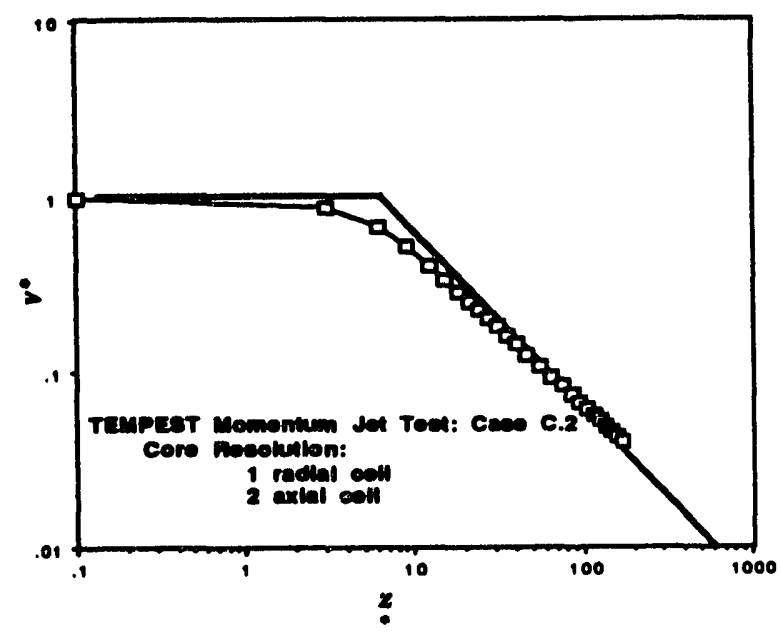

(b)

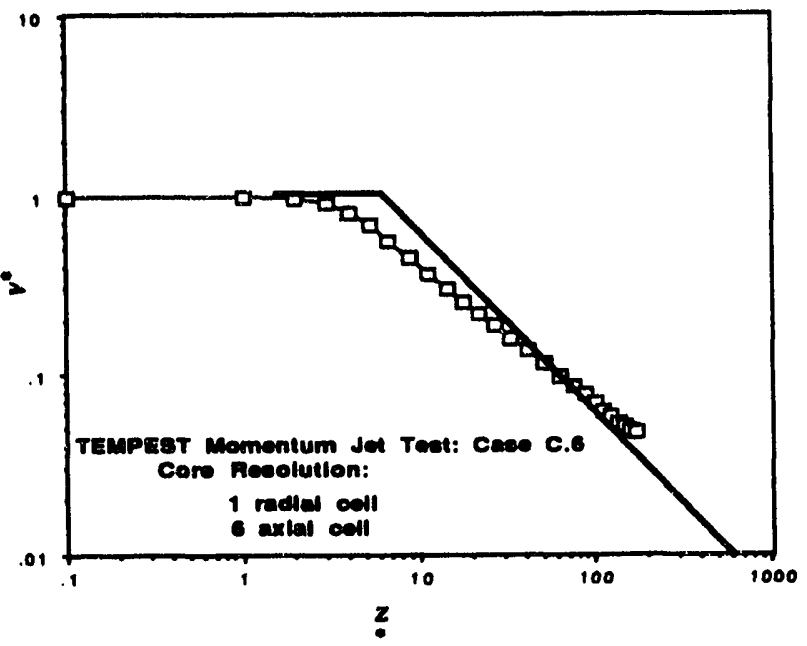

(d)

Figure 3.11. Case C; Computed Momentum Jet Centerline Velocity Using one Radial Cell in the Zone of Flow Establishment

These results indicate, however, that increasing the number of axial cells in the zone of flow establishment does not improve the accuracy, but in fact, diminishes the accuracy somewhat. This trend is observed in comparing Figures 3.11 ( $a$ and $b$ ) with Figures 3.11 (c and $d)$. Without further investigation, it is felt that the best results will be obtained when the grid 
resolution is consistent along each space coordinate. This observation indicates that it is possible to model the jet zone of flow establishment with one radial cell and one axial cell and expect to obtain acceptably accurate results.

\subsubsection{Momentum Jet Using the Tank Coordinate System}

The previous jet flow verification studies indicated that accurate results can be obtained using one radial cell in the jet core. This verification was done using cylindrical coordinates conforming to round jet geometry. This next step in the verification process tests the codes capacity to produce accurate jet flow results using a coordinate system that conforms to the tank geometry rather than to the jet geometry. A three-dimensional model $(r-\theta-z)$ is used where the $z$ is vertical.

Figure 3.12 illustrates the grid system used by TEMPEST for computations involving two horizontal jets. Because the two jets discharge as a mirror image of each other, the system can be modeled with a $90^{\circ}$ section of symmetry. Note that the models jet cross-section is $1 / 2$ of the actual jet cross section and must be approximated as a segment of vertical cylinder having the
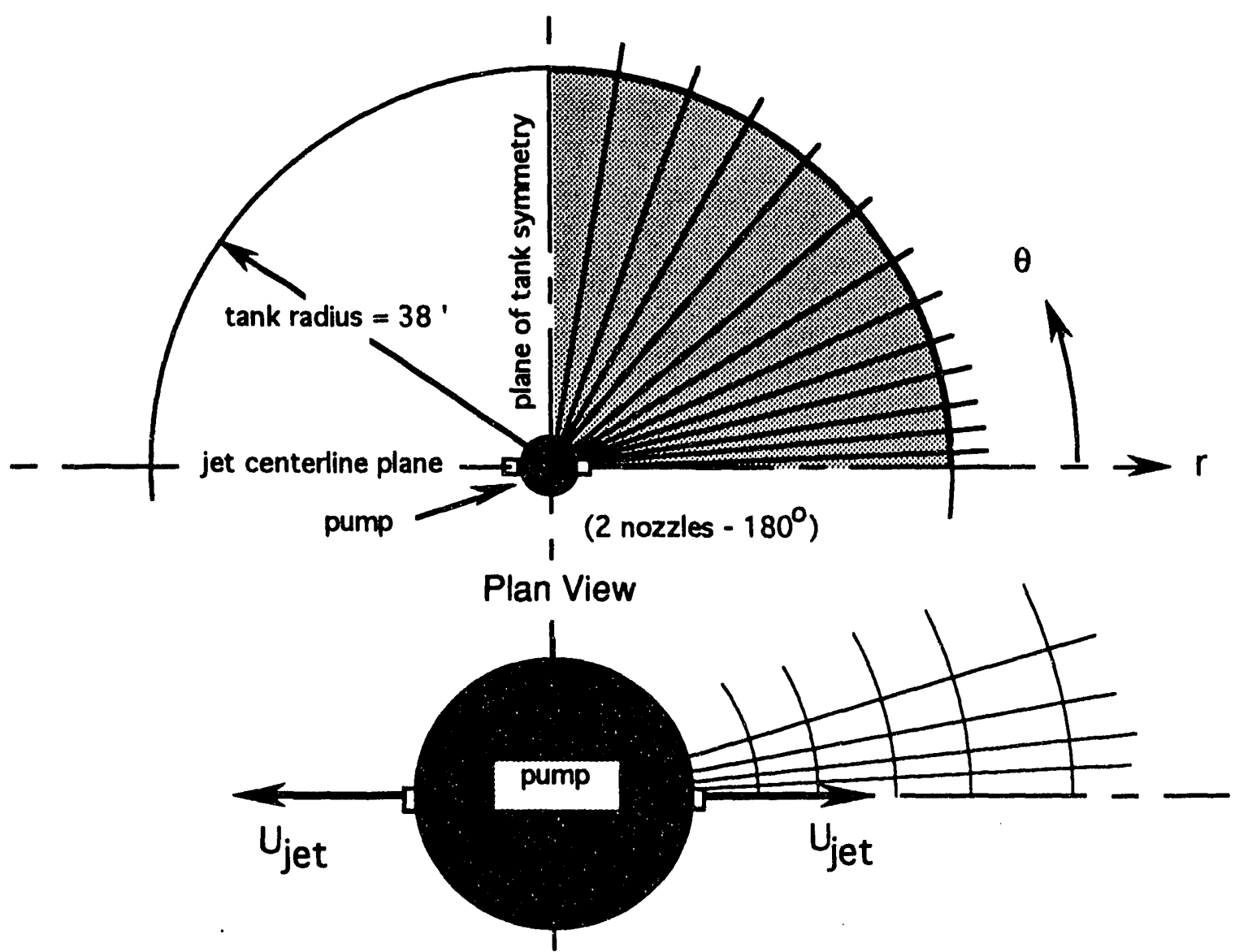

Figure 3.12. Plan View of Computational Grid System ( $r-\theta$ plane) 
area of $A_{j}=r_{0} \Delta \theta \Delta Z$, where $r_{0}$ is the radius from the pump centerline to the jet nozzle, $\Delta \theta$ is the grid azimuthal angle, and $\Delta Z$ is the grid vertical increment at the jet nozzle.

Therefore, the grid angle, $\Delta \theta$, and the vertical increment, $\Delta Z$, must be adjusted such that

$$
r_{0} \Delta \theta \Delta Z=\left(\pi \mathrm{r}^{2}\right) / 2
$$

In this case, the jet "zone of flow establishment" has the coarse noding comparable to that of test Case C. 1 above ( 1 cell wide and 1 cell in the direction of flow). Even with the use of this coarse noding to model the jet discharge, over 14,000 computational cells are required for simulation of the tank $(27 \times 35 \times 15$, including boundary cells).

Figure 3.13 illustrates the centerline velocity distribution for this test compared the empirical correlation for a round jet having an equivalent discharge area. As can be observed, the velocity is somewhat under-predicted at distances 4 to 20 diameters downstream ( 1 to $5 \mathrm{ft}$ ), but otherwise the prediction is quite accurate. Thus, in spite of the rough approximations required to model the jet in the tank geometry, we obtain results that are quite accurate.

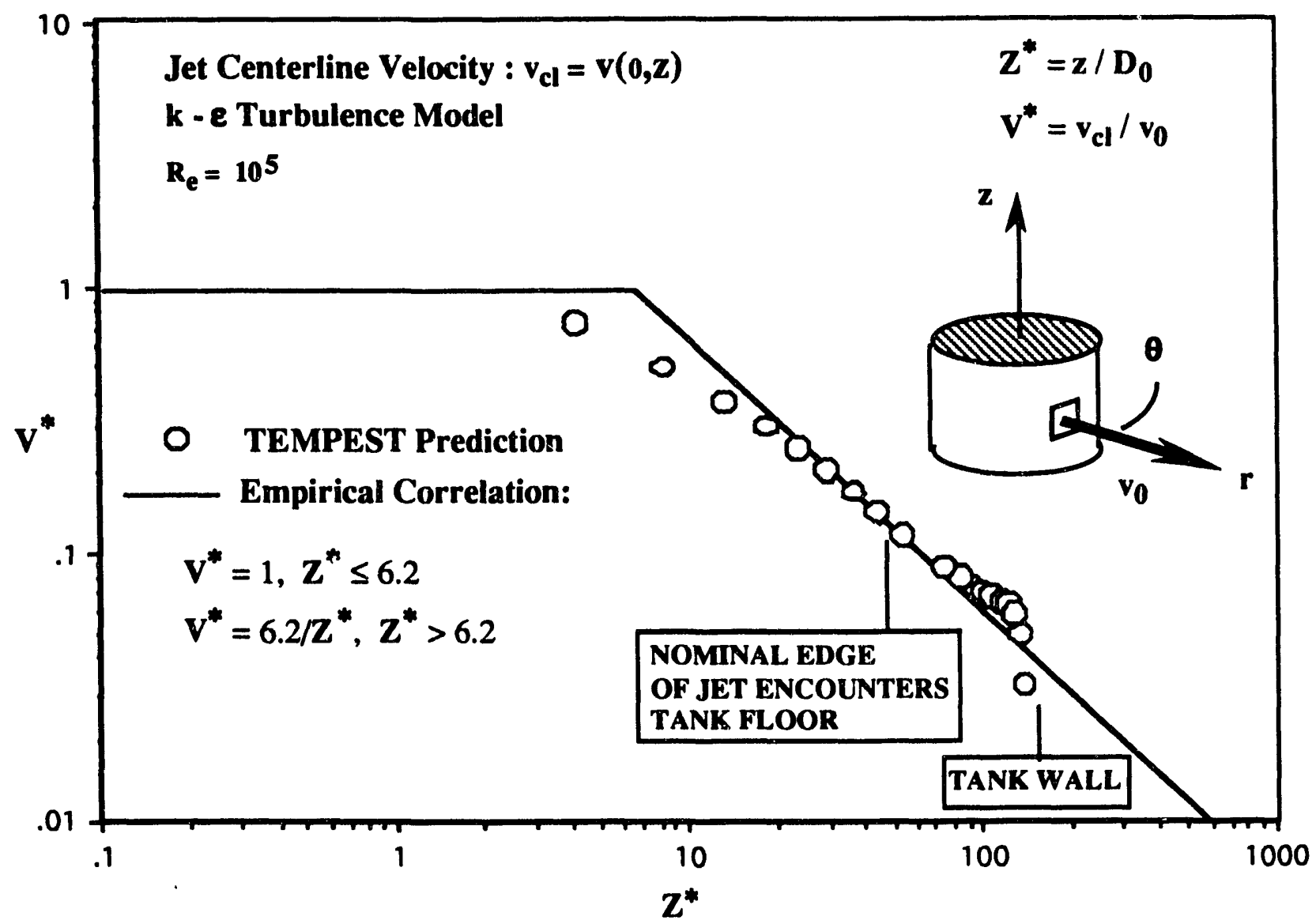

Figure 3.13. Computed Momentum Jet Centerline Velocity Using Tank Coordinates 


\subsection{TEMPEST Jet Mixing Simulations}

TEMPEST simulations of jet mixing were performed for jets configured in both vertical and horizontal orientations in the Tank 241-SY-101 geometry. In these initial studies, the TEMPEST models did not include the effects of the gas on the predicted flow physics. A report to be published at a later date will address TEMPEST simulations that will include the effects of trapped gases on jet mixing effectiveness. In each of the following sections, only a brief discussion of the modeling results is provided. A few representative cases are discussed in more detail.

\subsection{Vertical Jets}

The applicability of the TEMPEST computer code for use in modeling jet mixing in Tank 241-SY-101 was demonstrated for a downward vertical jet orientation (Figure 4.1) over a range of jet operating conditions and geometries. Two-dimensional TEMPEST models were developed to simulate the mixing process in Tank 241-SY-101 for different jet flow rates, nozzle diameters, discharge locations, intake locations, and computation grid sizes. A summary of the 14 cases investigated are provided in Table 4.1. The objective of this set of cases was to demonstrate and evaluate the possible use of centrally located vertical jets as well as the effectiveness of computer modeling of jet mixing and to gain an understanding of the jet forces required to levitate particles that form the non-convecting slurry in the tank. A brief description of the cases investigated is provided, along with a more detailed presentation of a few representative cases.

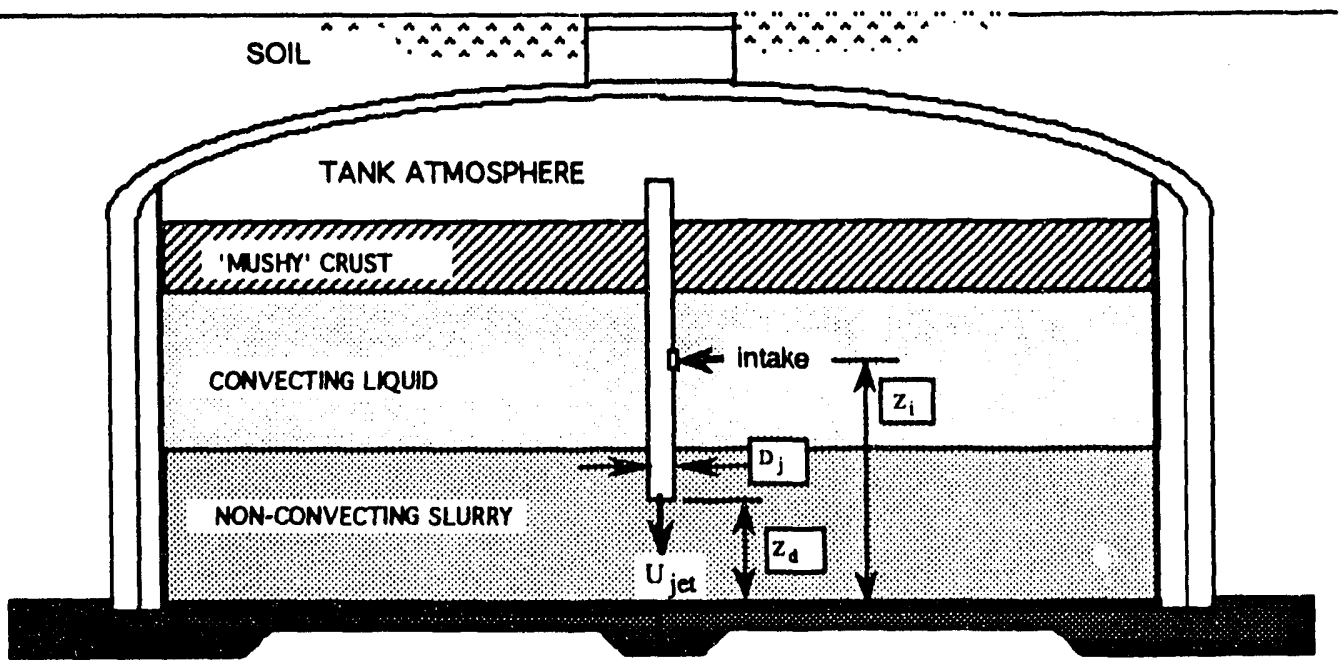

Figure 4.1. Vertical Jet and Draft Tube Arrangement 
要尊 "I

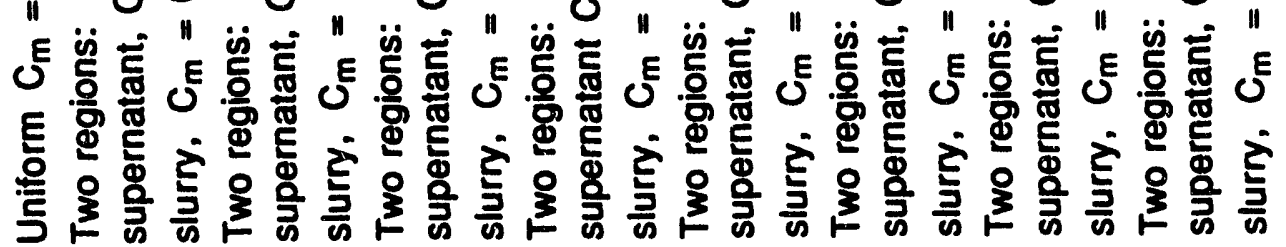

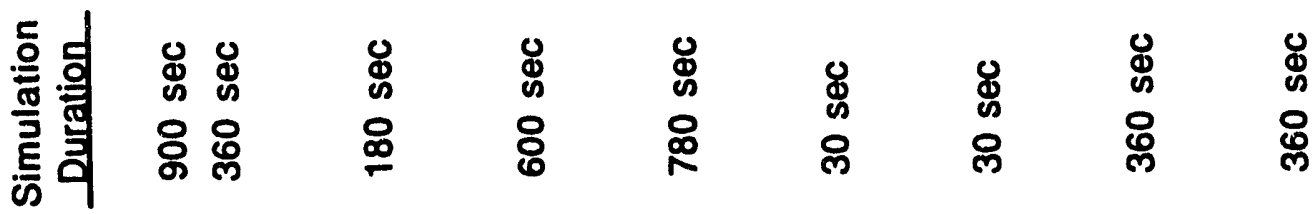

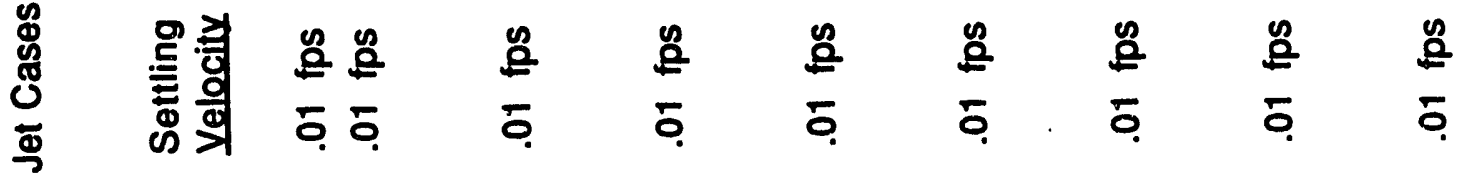

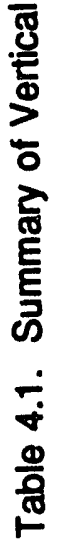

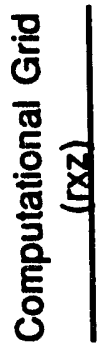

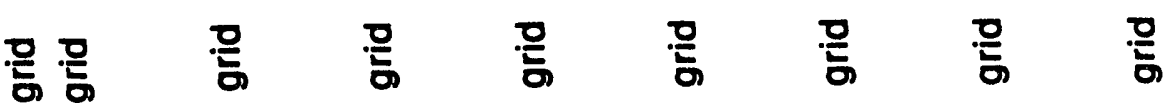

ชิ

กัฒ

N

$\stackrel{N}{\aleph}$

ஜू

வे

$\underset{X}{X}$

$\stackrel{N}{x}$

产

$\begin{array}{lll}\infty & \infty & \infty\end{array}$

$=\infty$

$\mp$

$\mp \quad \mp$

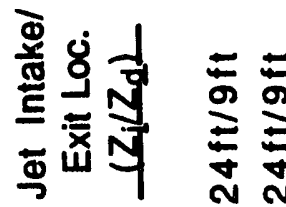

$\frac{5}{2} \quad \frac{5}{\frac{5}{5}}$

营

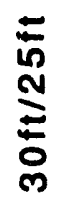

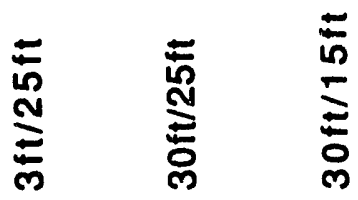

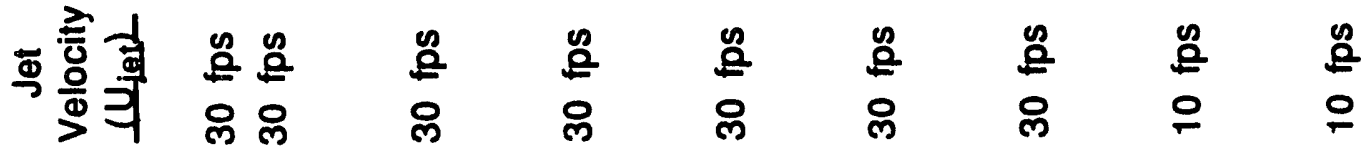

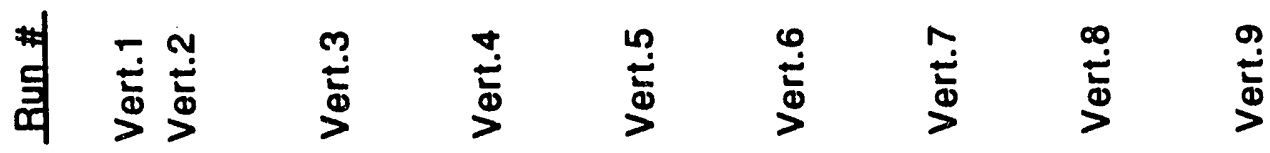




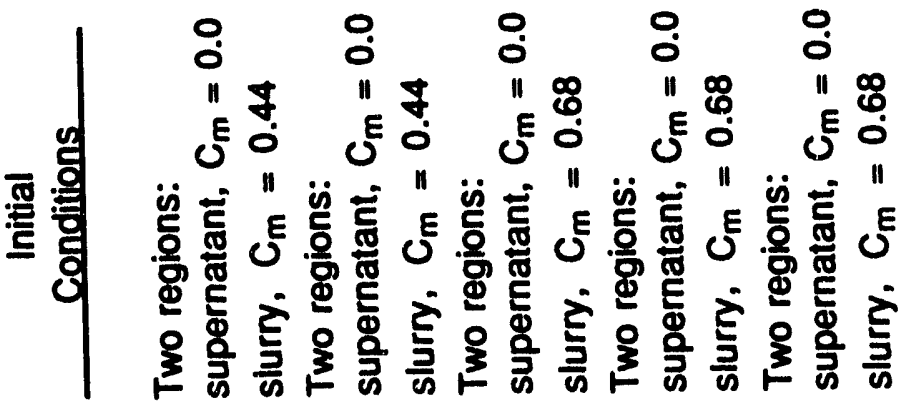

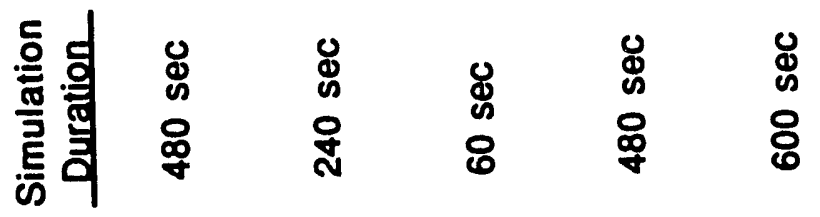

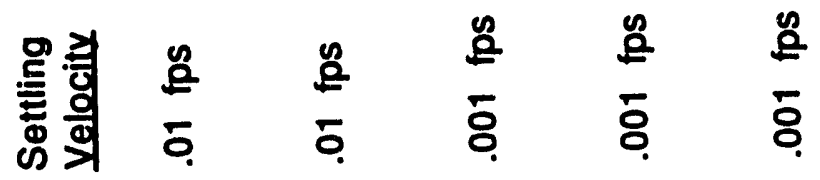

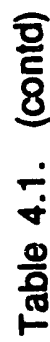

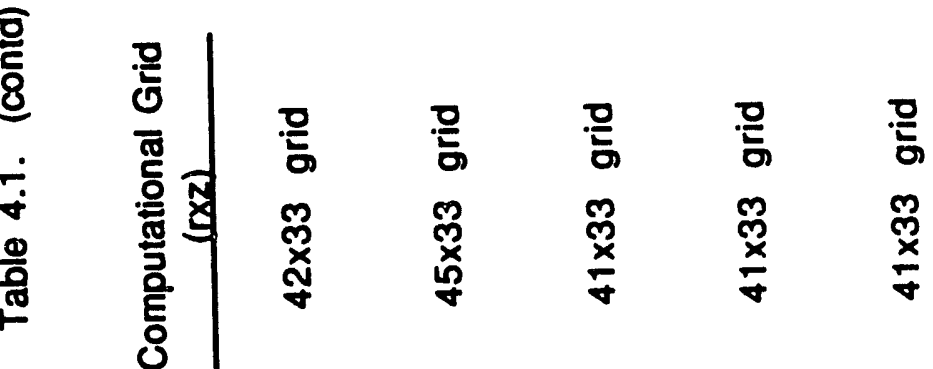

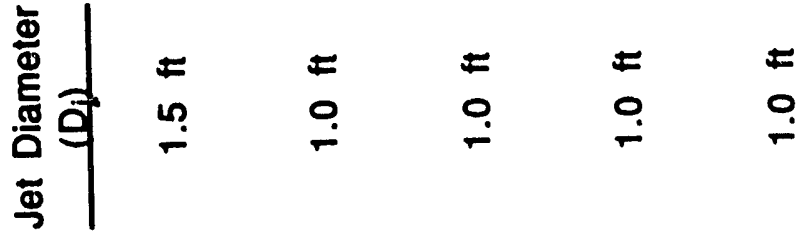

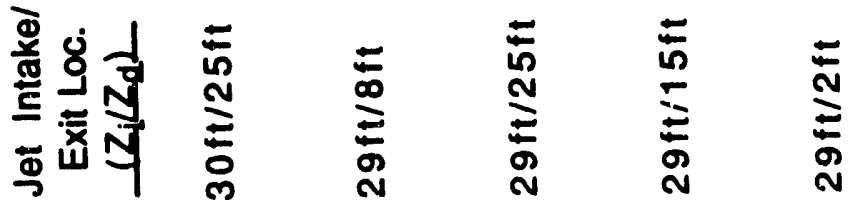

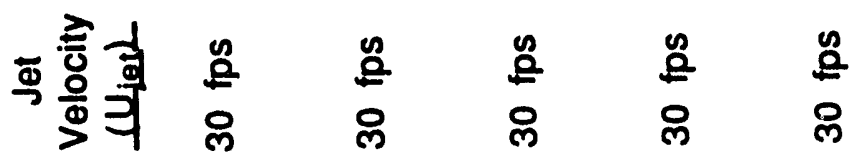

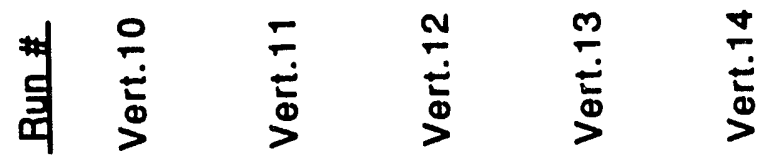




\subsubsection{Case \#1: Vert. 1}

Case \#1: Vert. 1 represents the initlal model developed to study vertical jet mixing in Tank 241-SY-101. This case modeled a 3-ft diameter centrally located jet with a nozzle exit located $9 \mathrm{ft}$ from the tank bottom with a jet nozzle velocity of $30 \mathrm{ft} / \mathrm{sec}$. The fluid was recirculated via an intake located $8 \mathrm{ft}$ under the top of the convecting layer. The tank was assumed to be uniformly mixed (post-burp) at the beginning of the computer simulation. The purpose of this case was to investigate whether the jet forces in this configuration would be sufficient to maintain the suspension of the particles throughout the tank after a GRE has fully mixed the tank. The simulation was carried out $600 \mathrm{sec}$ in time.

At the time this first case was completed, little was known about the properties of the particles that formed the non-convecting slurry in the tank. Therefore, it was necessary to assume values for the particle density $\left(143 \mathrm{lb} / / t^{3}\right)$, the unhindered particle settling velocity $(0.01 \mathrm{ft} / \mathrm{sec})$, the volumetric concentration $\left(C_{v}\right)$ of particles in the tank $(0.12)$ and the convecting fluid viscosity $(0.016 \mathrm{lbm} / \mathrm{ft} \mathrm{sec})$. A detailed TEMPEST computational grid structure with $750.5-\mathrm{ft}$ cells in the radial direction and $600.5-\mathrm{ft}$ cells in the vertical direction modeled a $1 / 2$ symmetry $2-d$ section of the tank (Figure 4.2 ).

TEMPEST contours of $C_{v}$ are presented for $15,60,120,240,480,600$, and $900 \mathrm{sec}$ in Figures 4.3 to 4.9. Corresponding velocity vector plots are provided in Figures 4.10 to 4.16 .

In Figure 4.3, the contours of $C_{v}$ after 15 sec of simulation time show that the tank was still uniformly mixed. The velocity vectors at $15 \mathrm{sec}$ (Figure 4.10 ) indicate that the jet entrains fluid near the tank center and proceeds to sweep along the tank bottom to the wall before being directed upward. This is expected, as the fluid that makes up the jet is at approximately the same density as the fluid in the bottom of the tank, resulting in negligible buoyancy effects.

As the simulation progresses to $60 \mathrm{sec}$, the particles began to settle slowly, as seen in Figure 4.4; however, in general the tank is still well mixed at this time. The velocity distribution has changed somewhat, with the recirculation region moving upward (Figure 4.11).

At $120 \mathrm{sec}$ of simulation time, the effect of the flow field on $C_{v}$ (Figure 4.5) becomes more pronounced. A ridge of slightly higher concentration material has formed along the outer wall. It appears that the flow field has reached a quasi steady-state (Figure 4.12) as very little changes in the flow pattern from the 60 to 120 sec can be seen.

Confirmation that the velocity field has reached an quasi steady-state is displayed in the Figures 4.13 (240 sec), 4.14 (480 sec), 4.15 (600 sec), and 4.16 (900 sec). Even though the velocity vector field approaches a steady-state after $60 \mathrm{sec}$, the contours of $C_{v}$ are still 


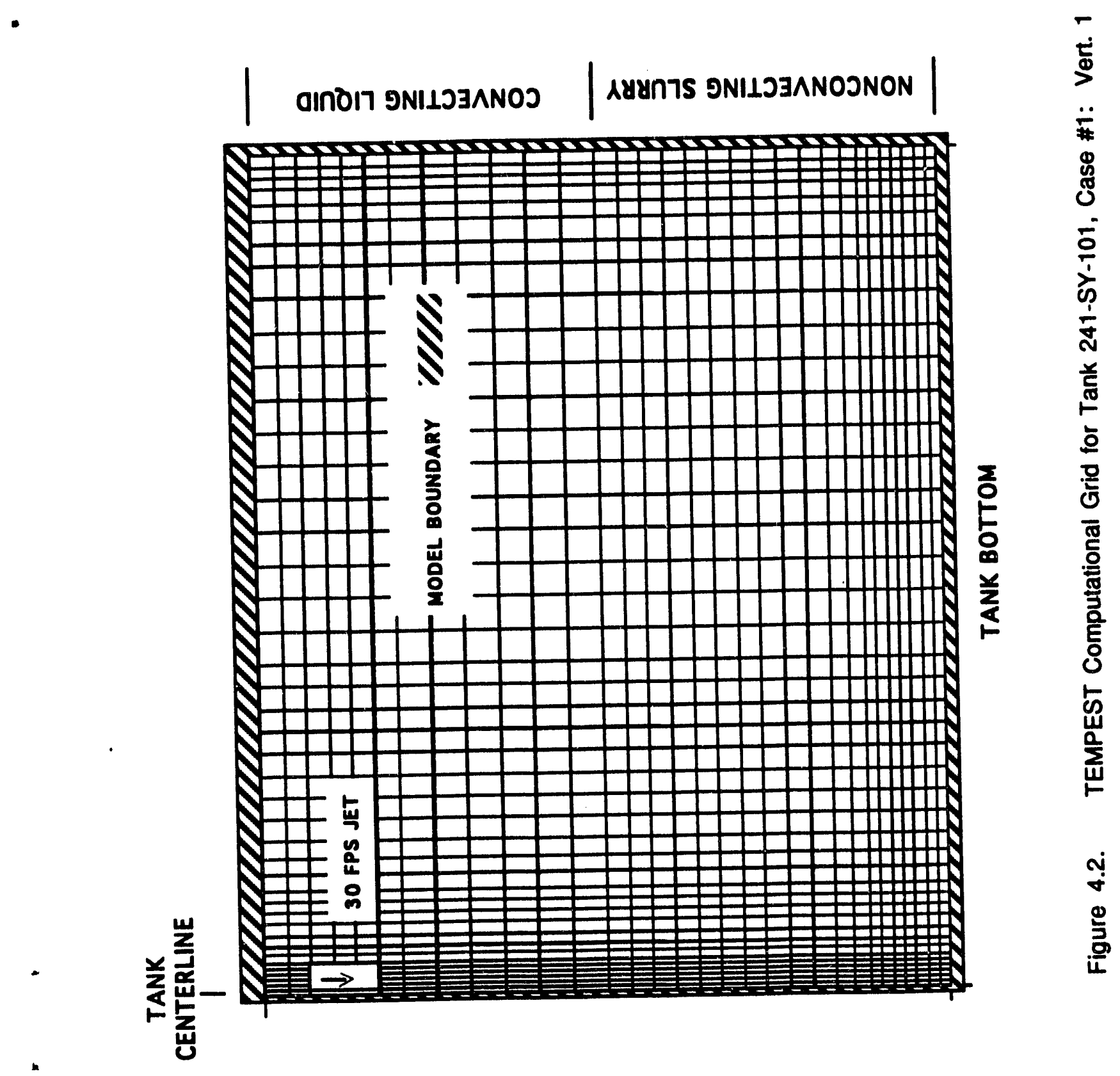



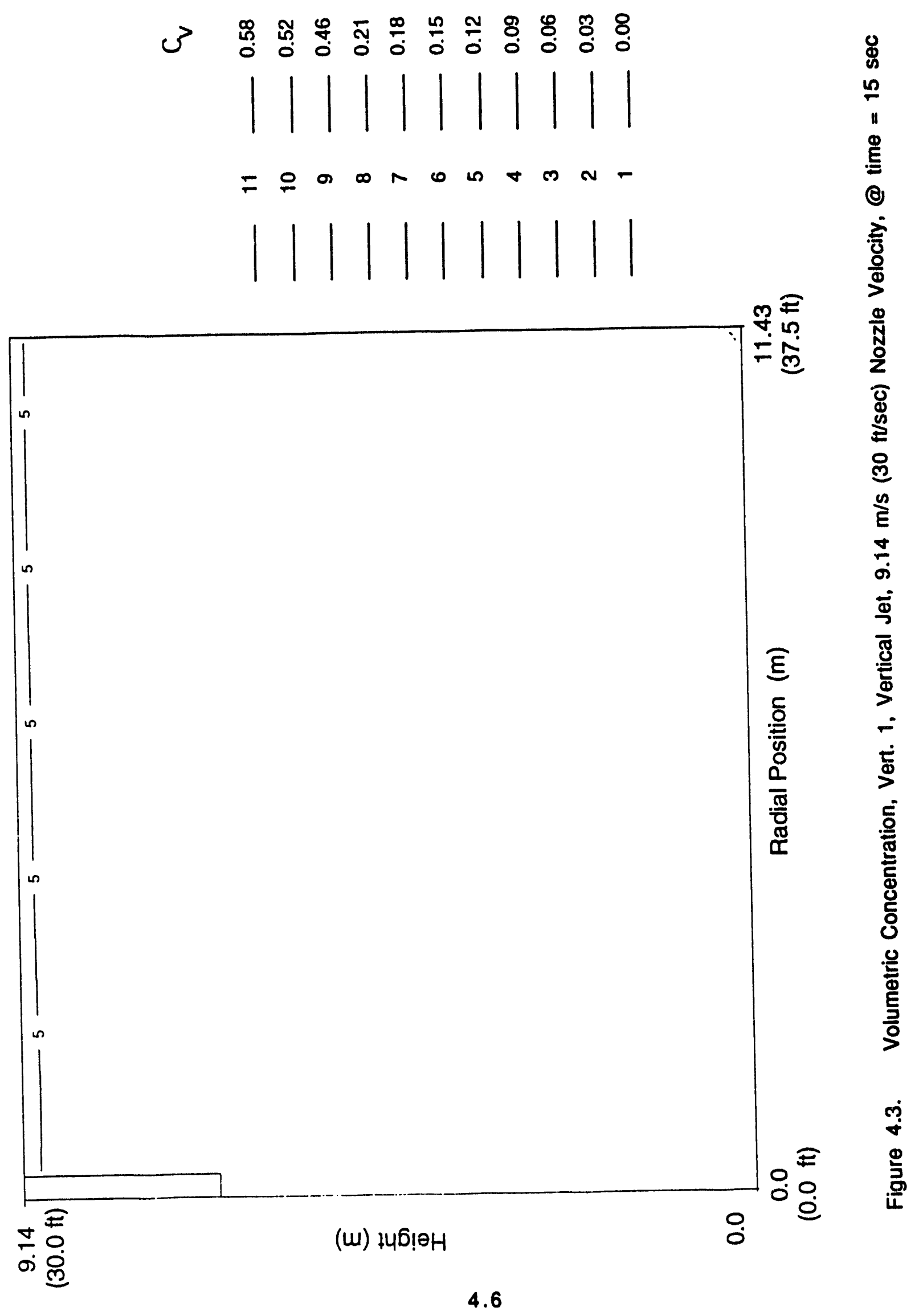


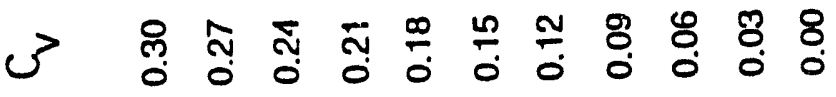

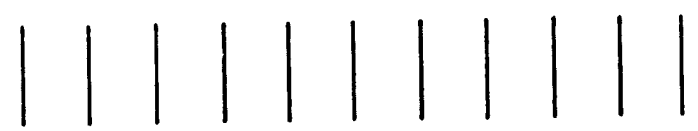

$$
\begin{aligned}
& =00 \infty \pi 0 n+\infty n-
\end{aligned}
$$
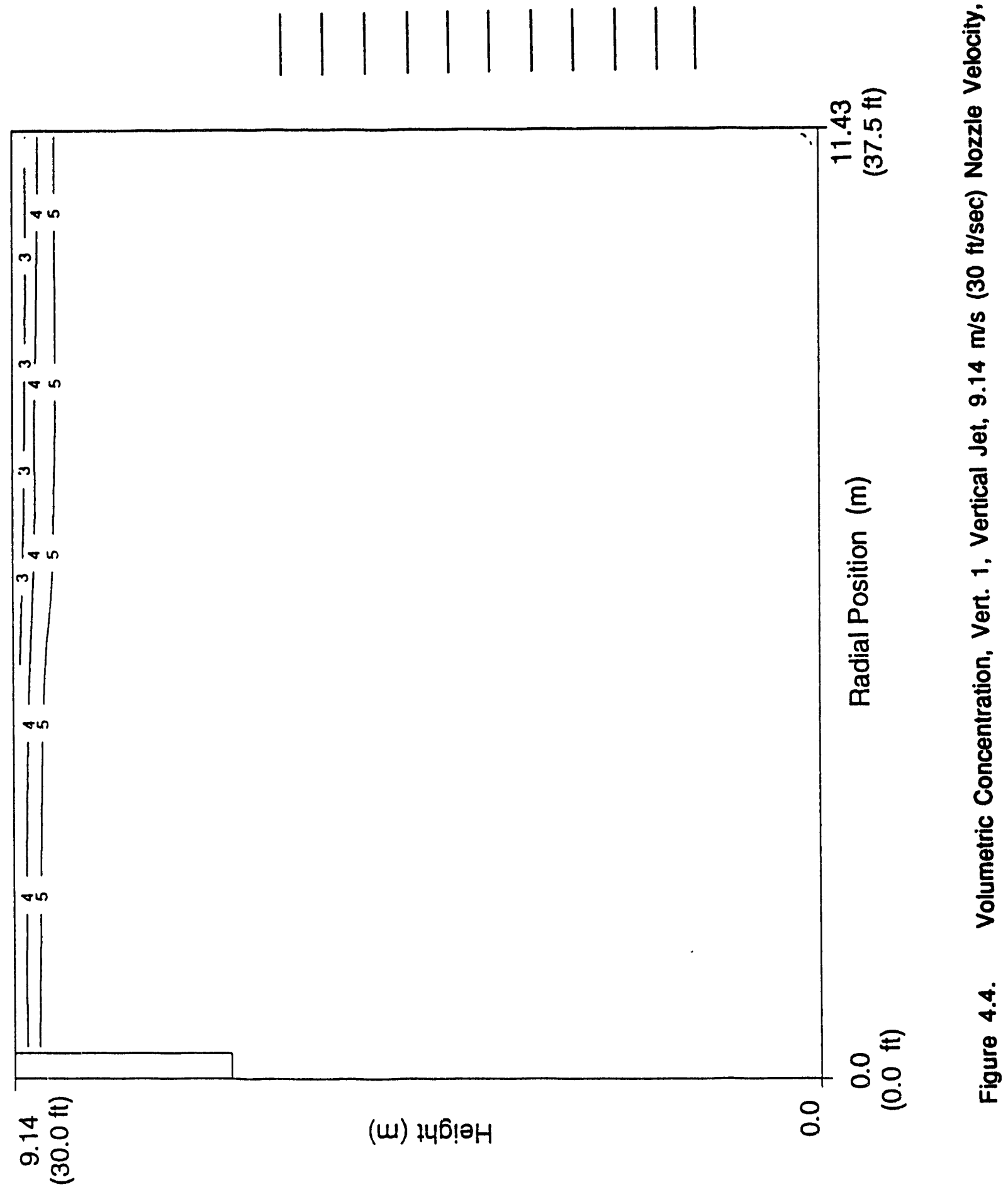


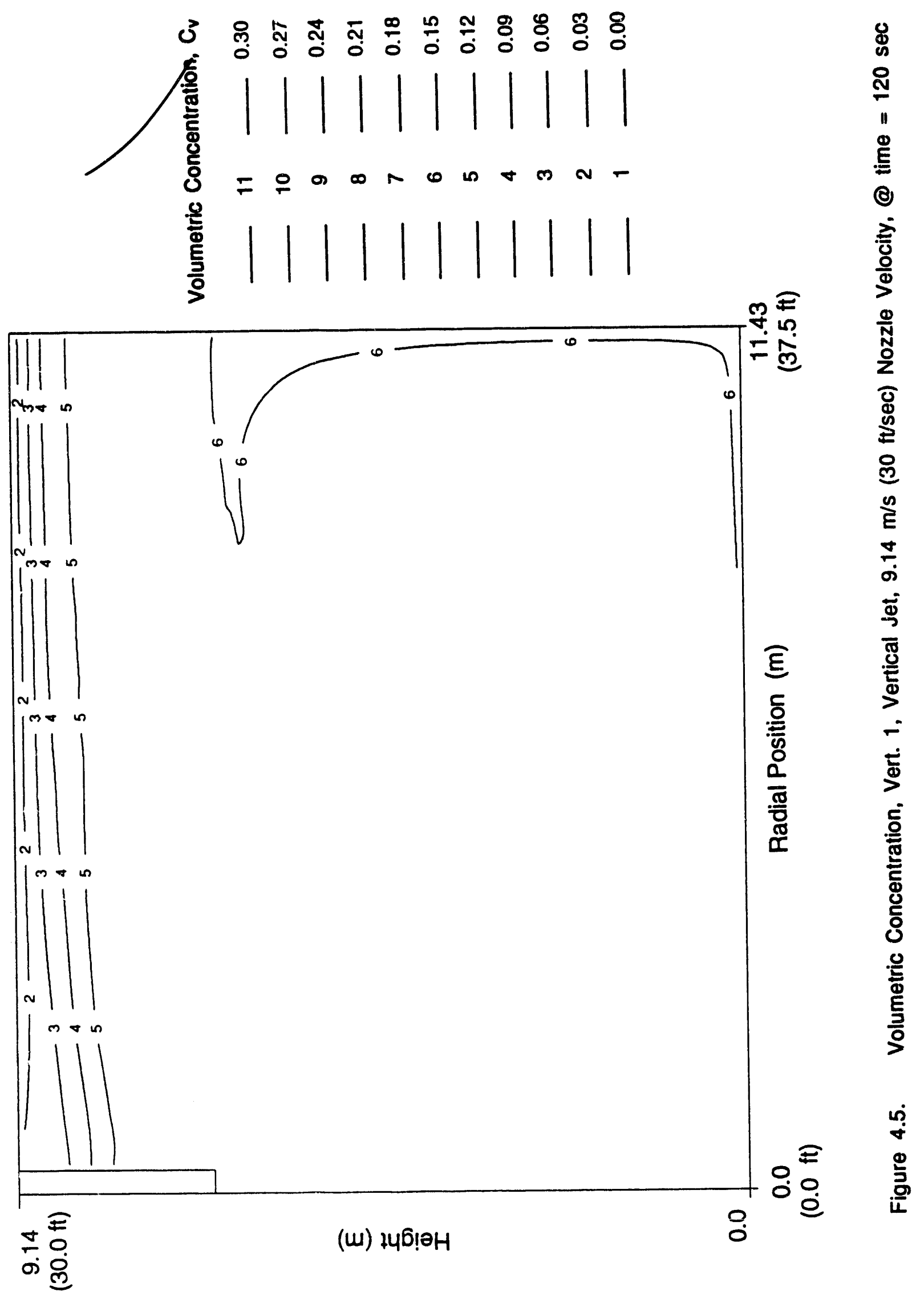




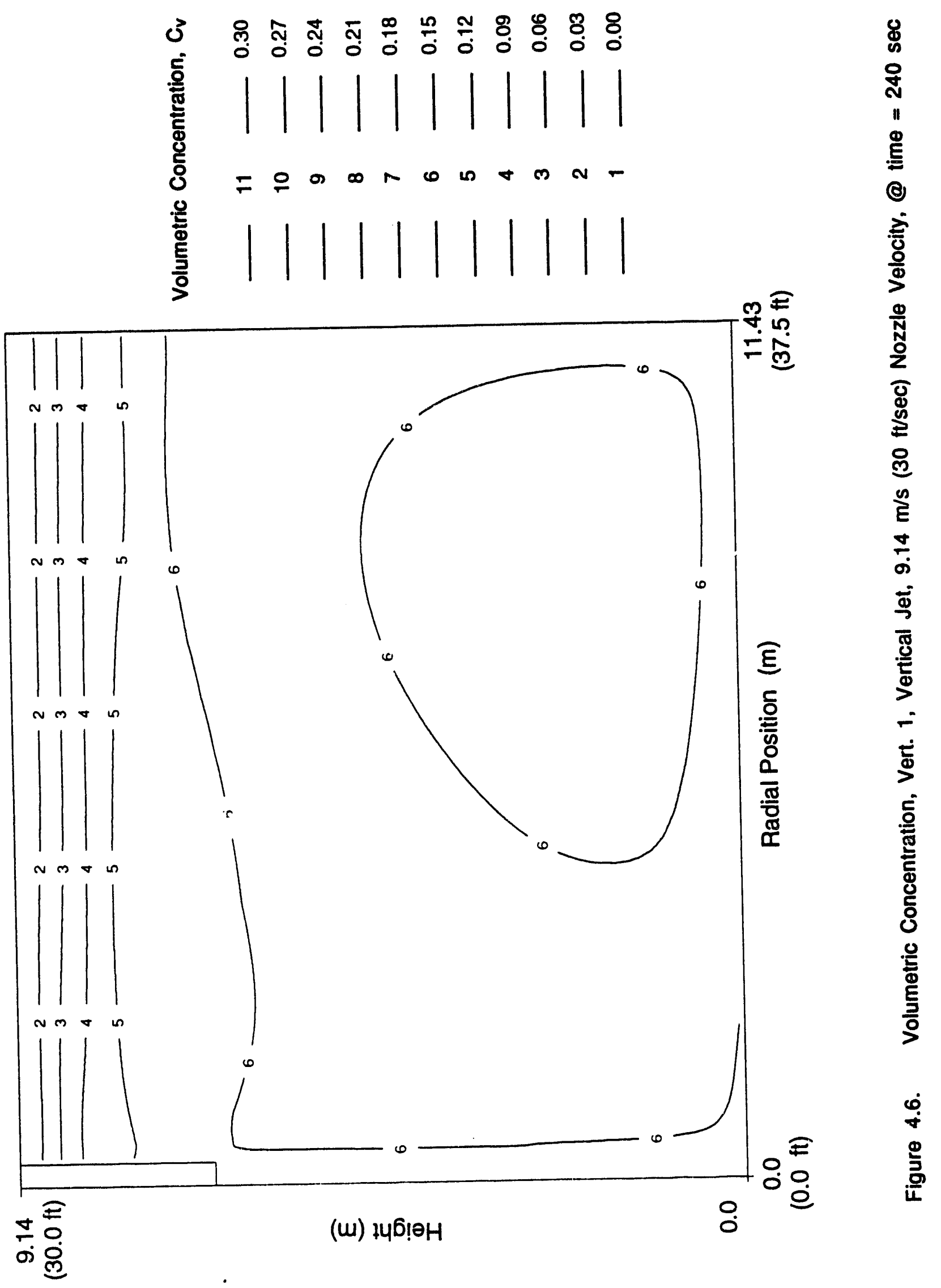




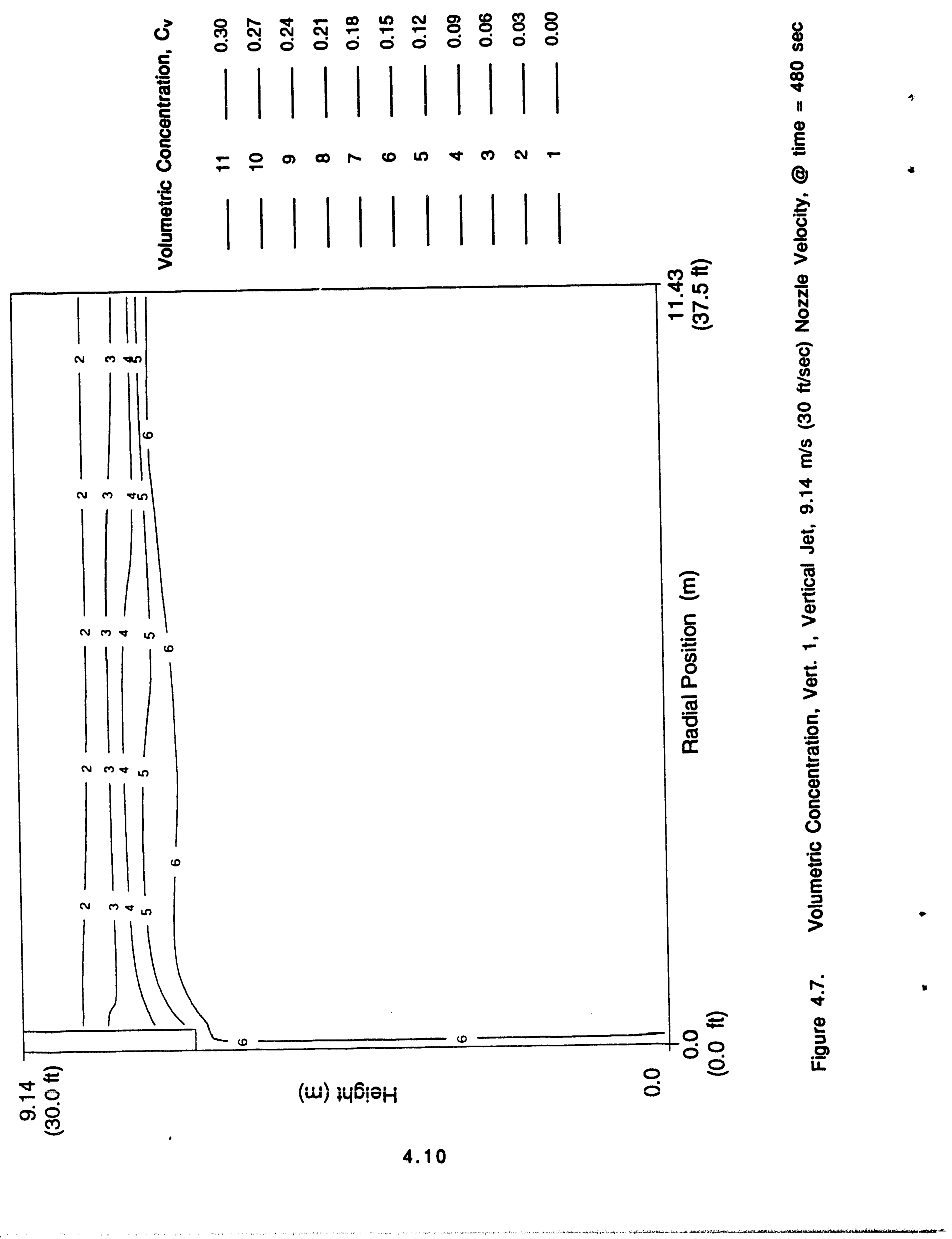




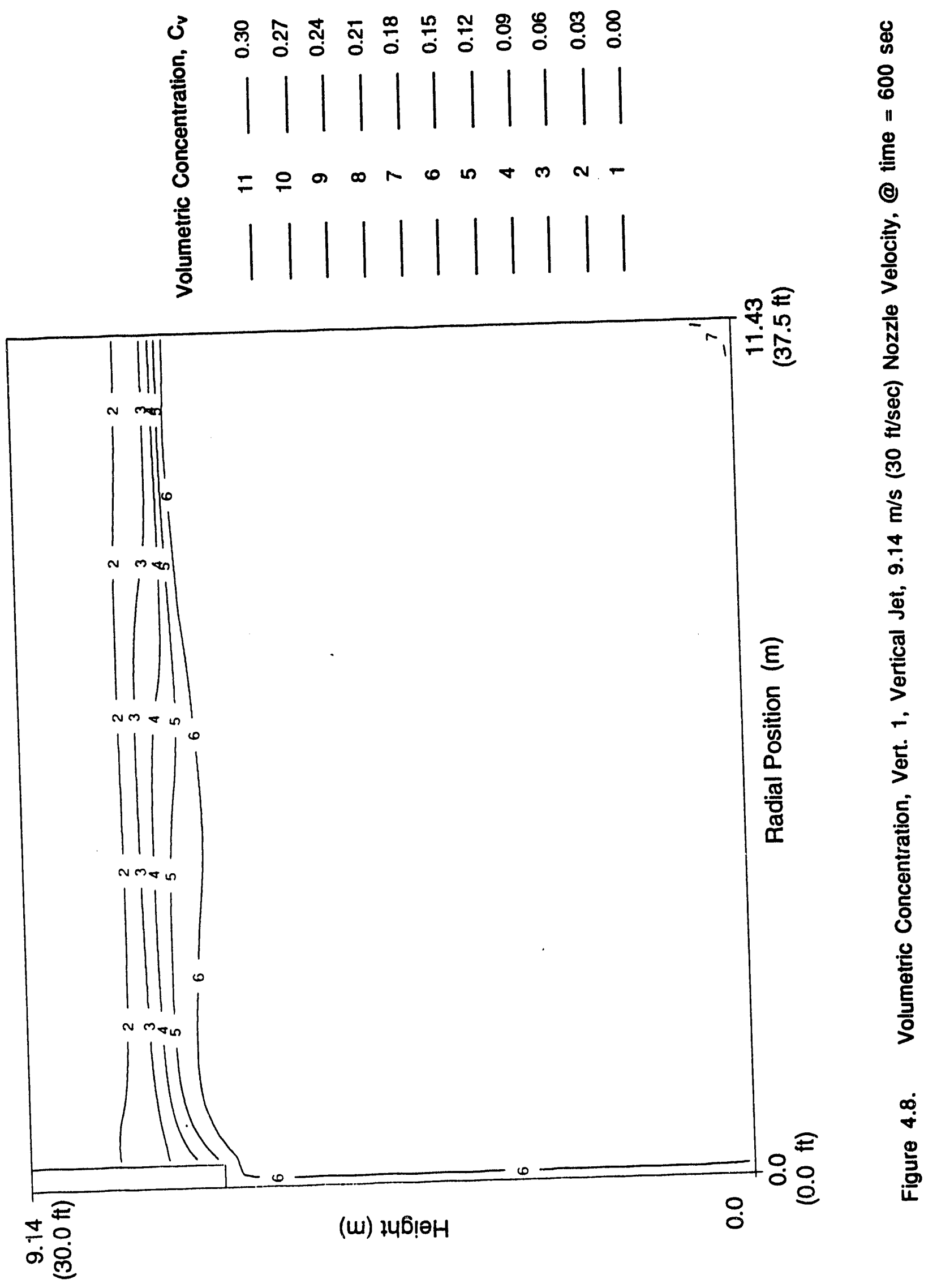




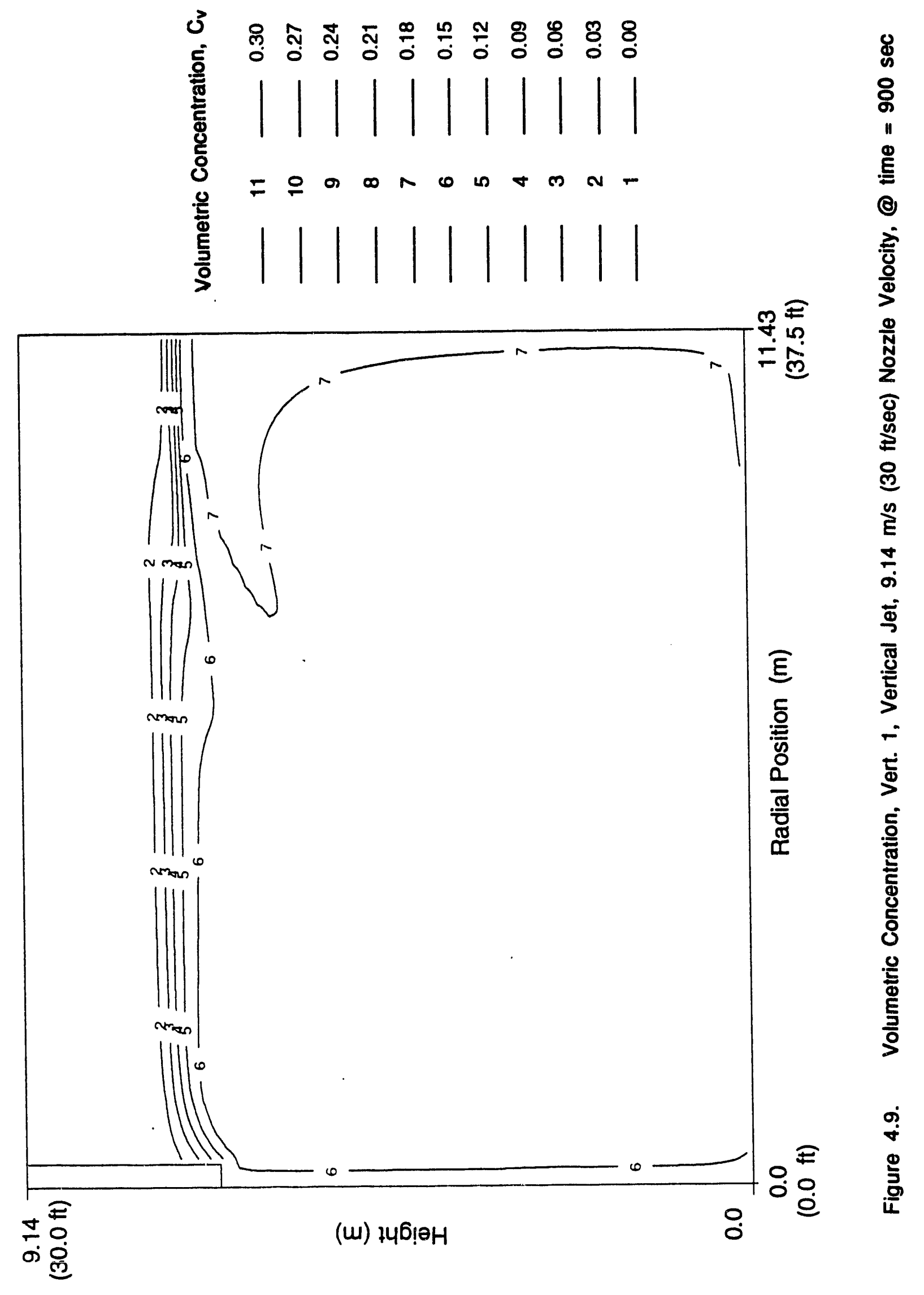




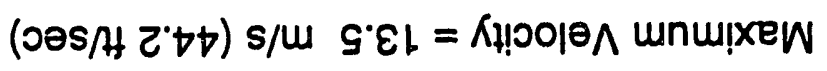

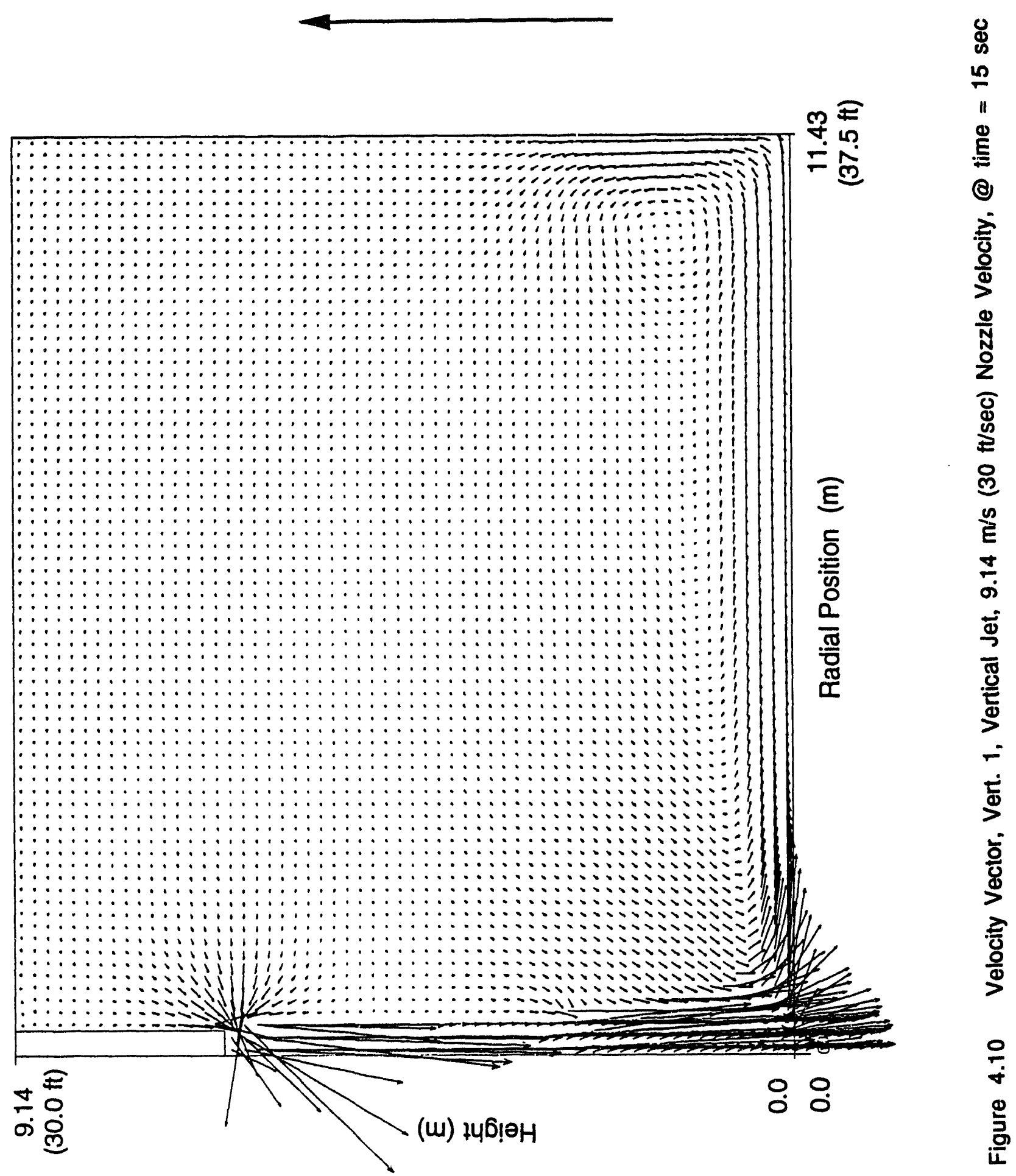




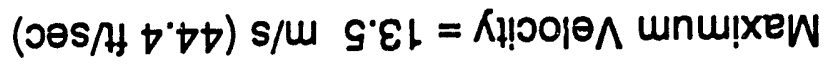

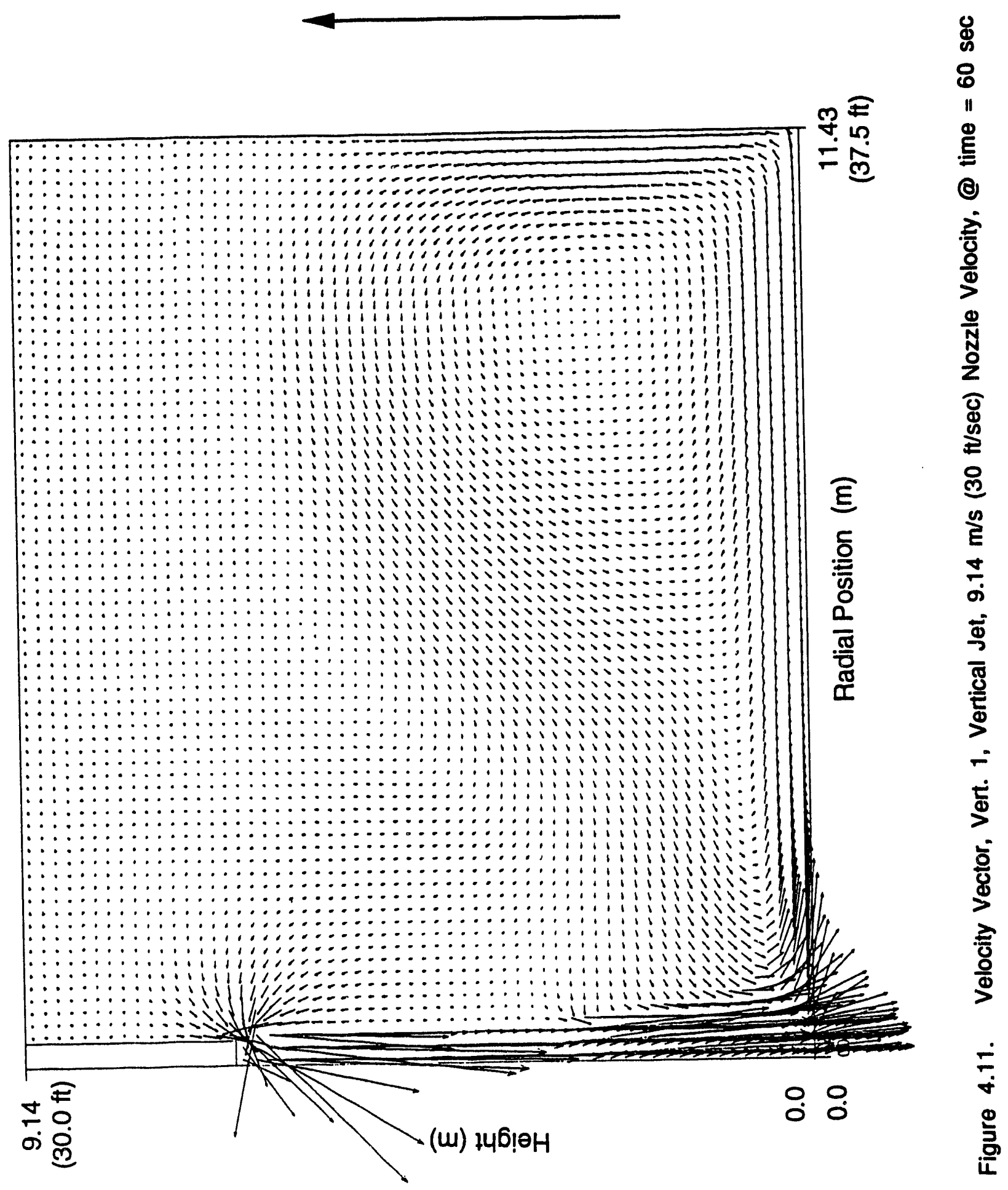




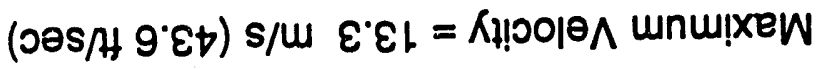

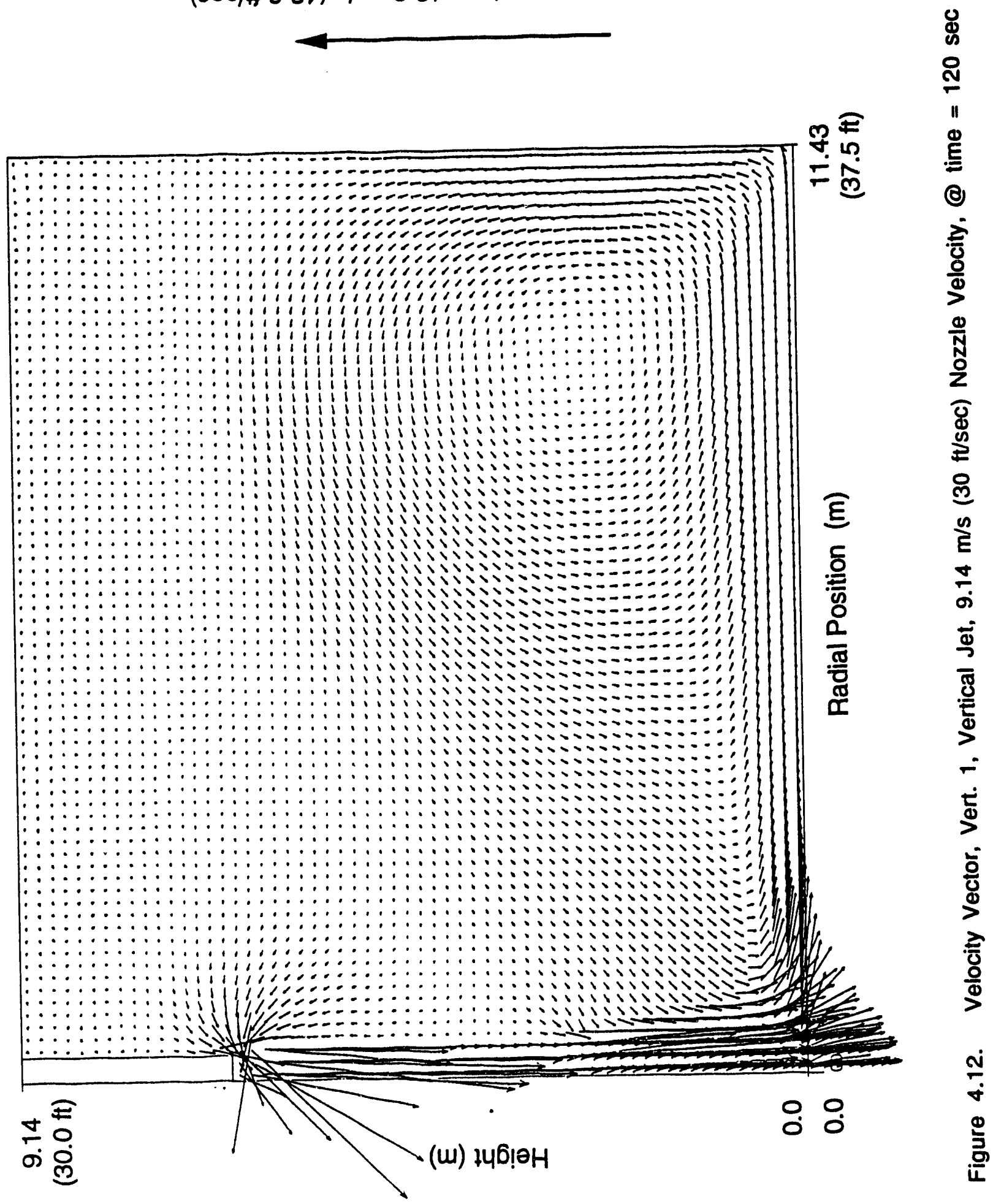




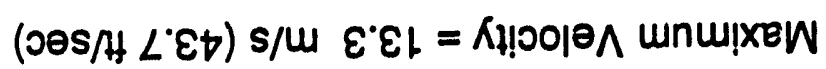

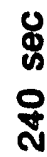

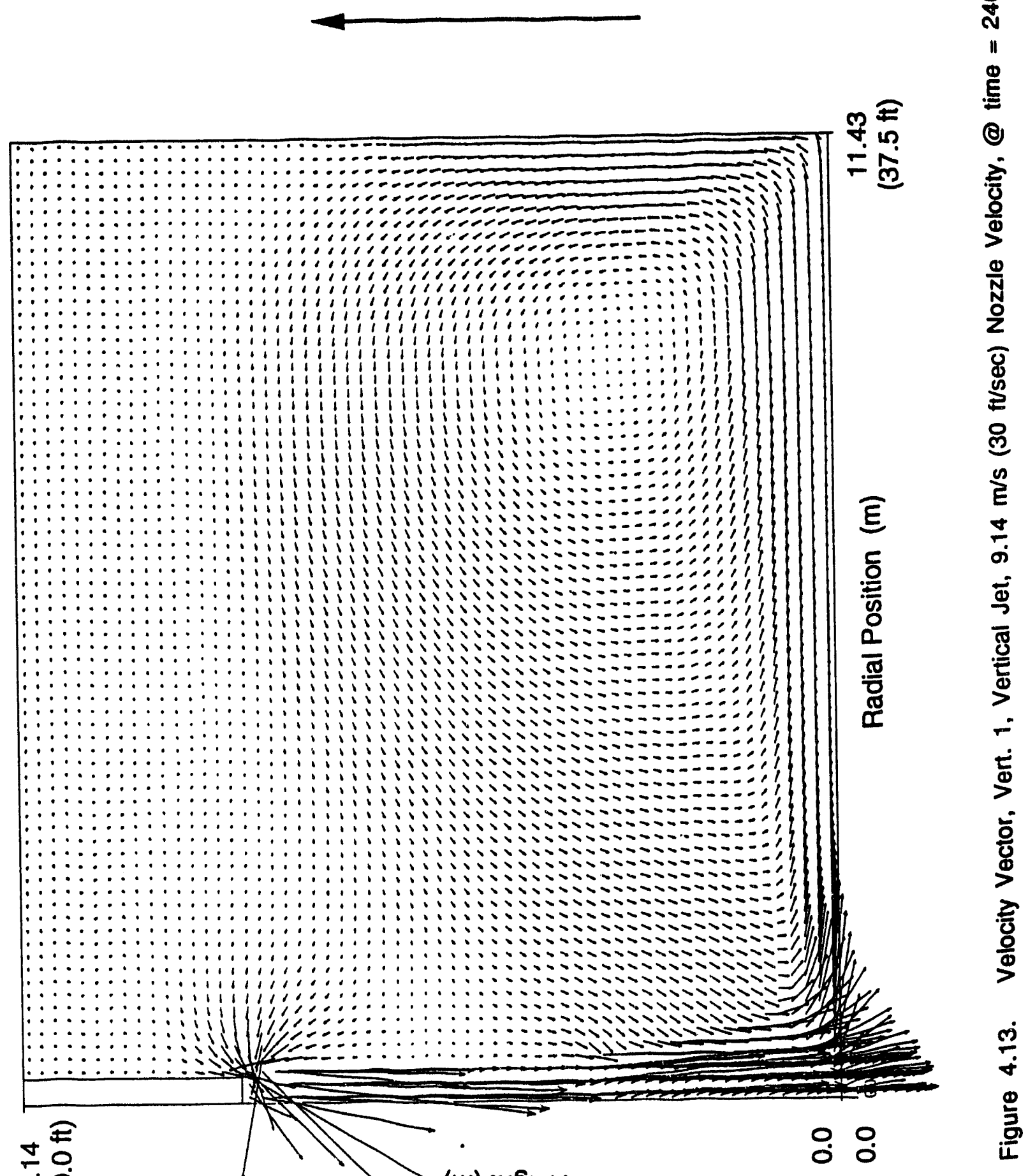




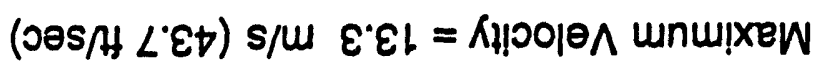

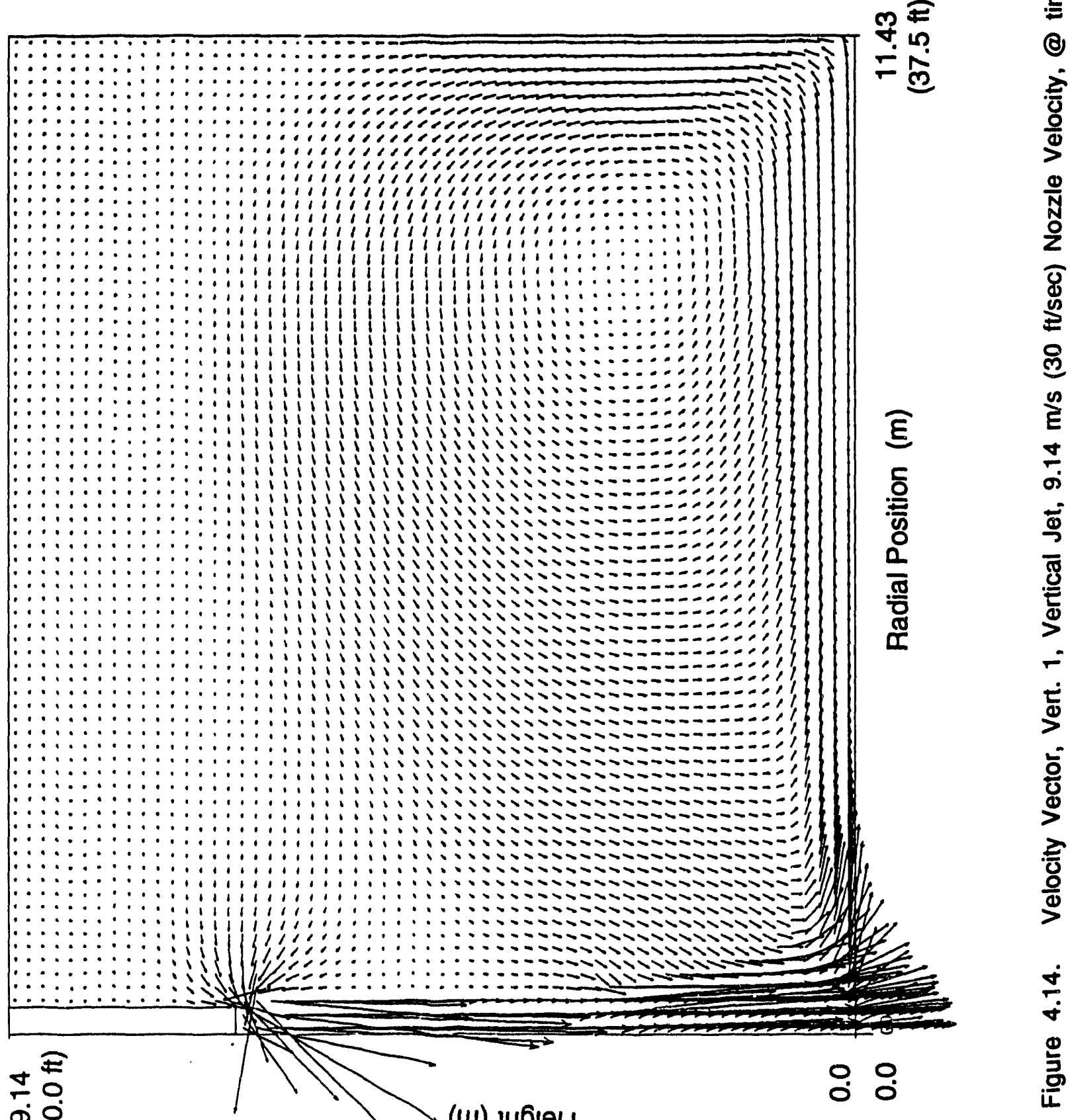

(3)

के

(w) $146 !$ 


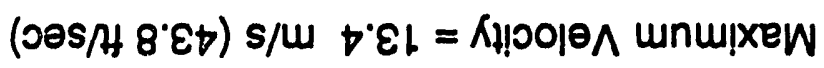

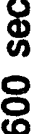

$m$

皇

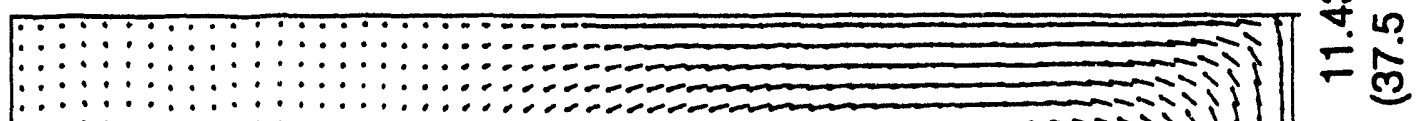

(8)

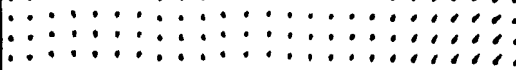

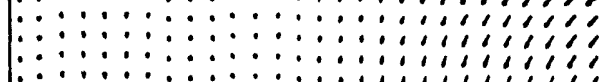

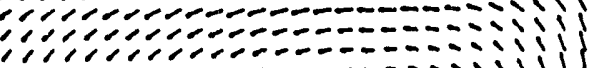

(n)

$\because: \because:$

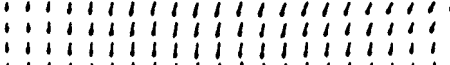

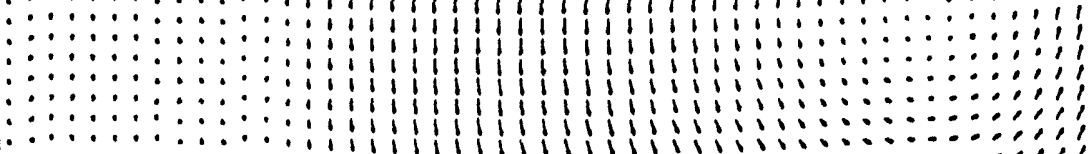

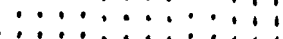

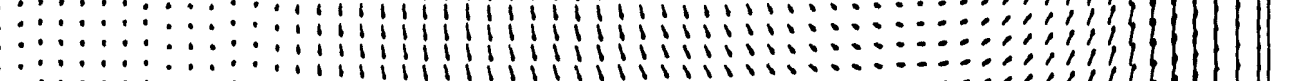

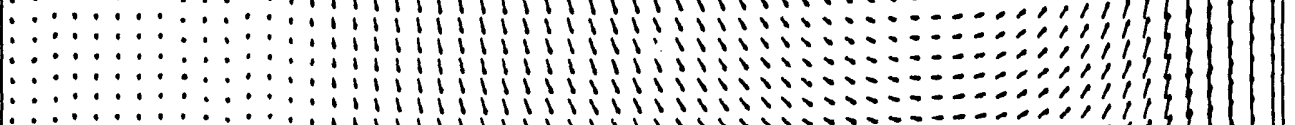

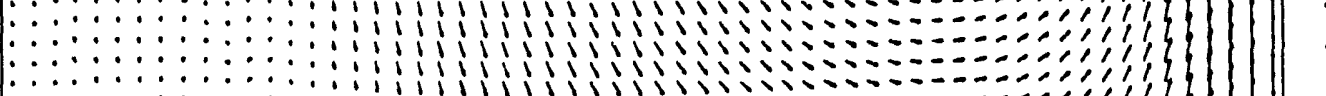

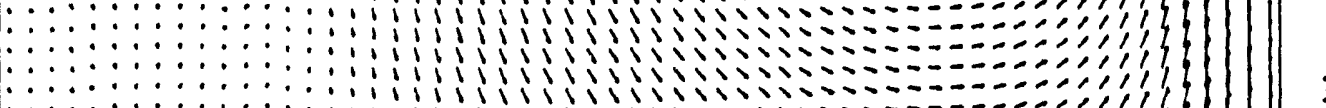

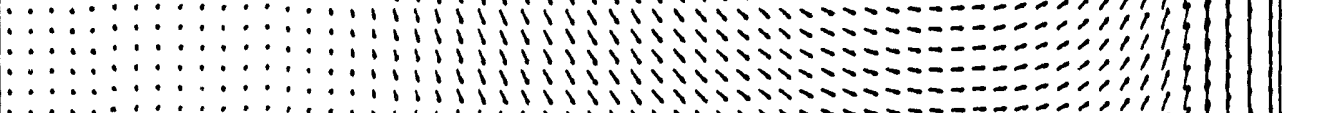

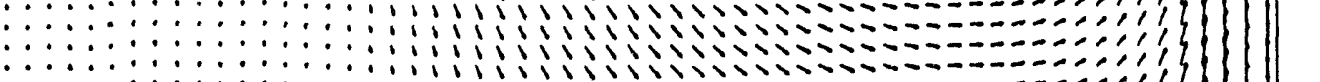

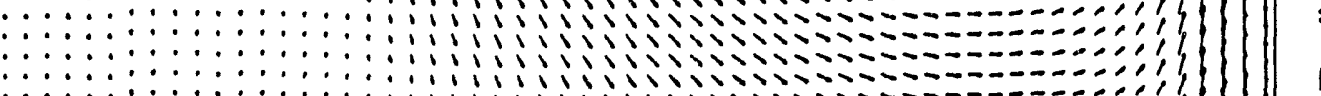

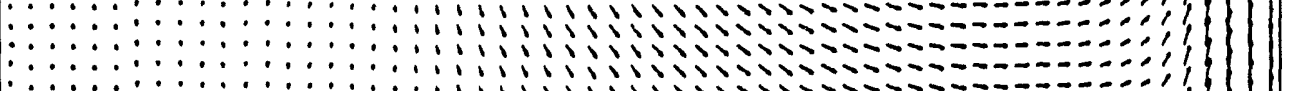

ह $\quad \stackrel{0}{E}$

C $\quad \frac{2}{\dot{2}}$

के

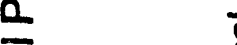

帚

(1)

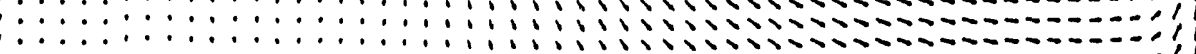
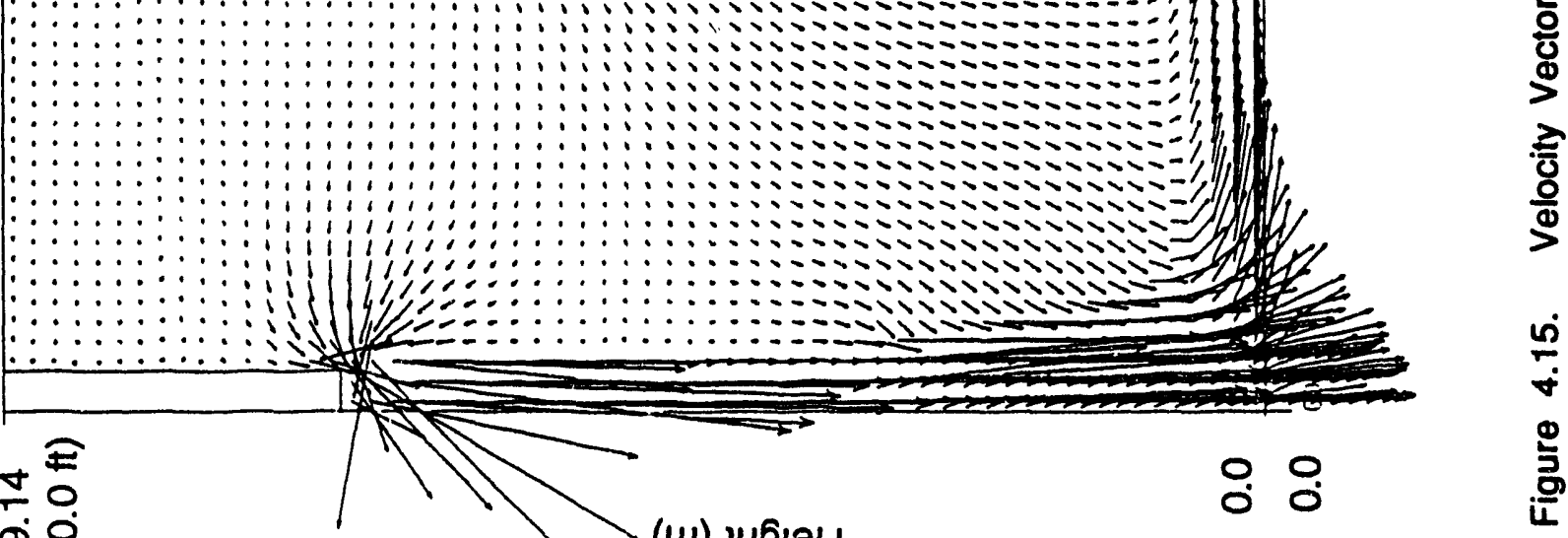

बं ्ल

(w) $+46 \hat{1} \theta \mathrm{H}$ 


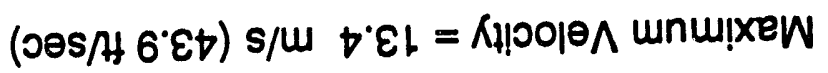

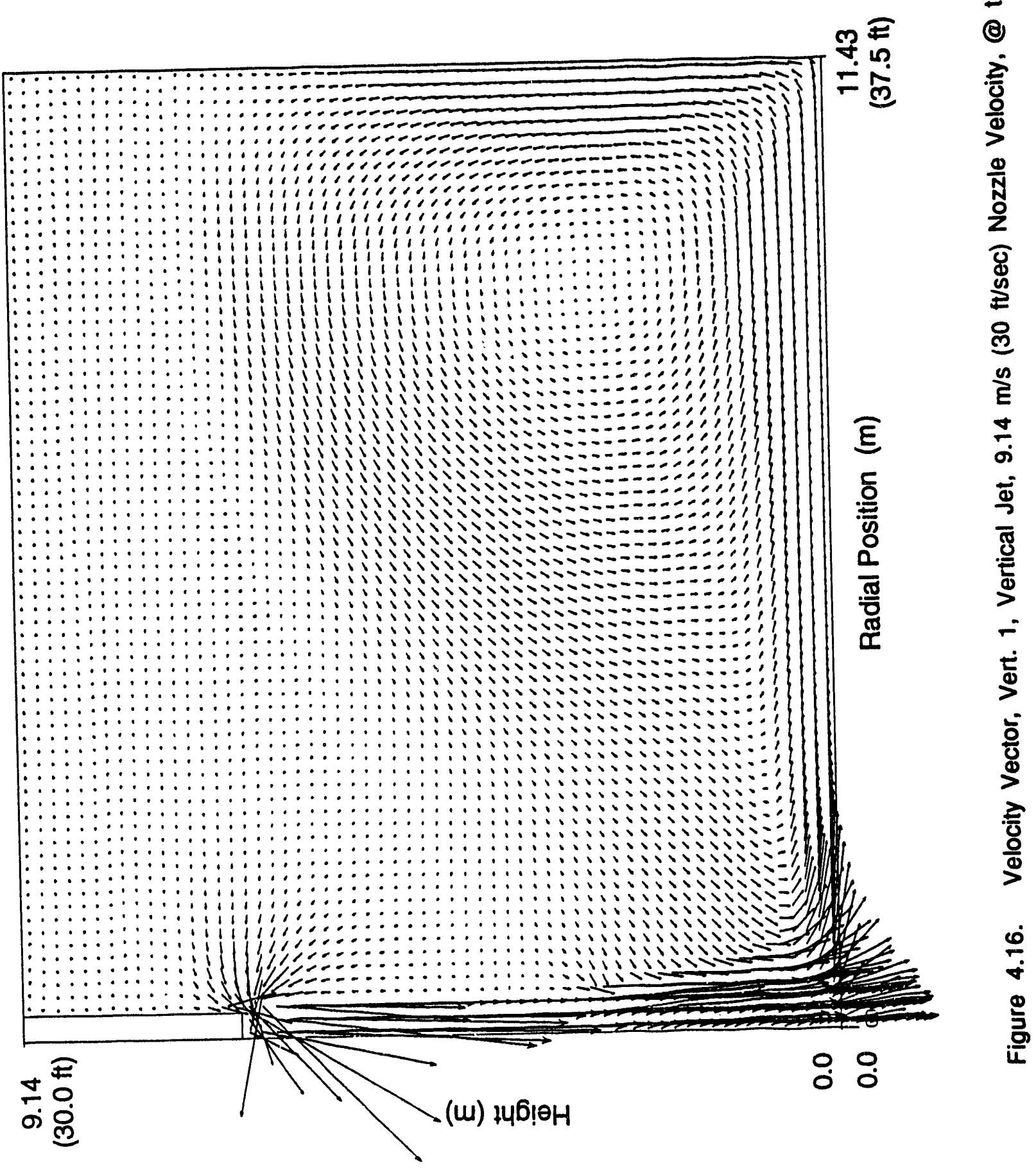


changing, as seen in Figures 4.6 (240 sec), 4.7 (480 sec), 4.8 (600 sec), and 4.9 (900 sec). After $900 \mathrm{sec}$, the peak value of $C_{v}$ has increased from the initial uniform value of 0.12 to slightly over 0.18 . It is not possible to extrapolate from the TEMPEST results at 900 sec to the eventual steady-state distribution of $C_{v}$. The simulation would have to continued in time until the distribution of $\mathrm{C}_{v}$ is stationary.

Computer simulation of the initially fully mixed tank has shown that a 30 fps vertical jet with the assumed material properties and constitutive relationships cannot maintain a fully mixed condition.

\subsubsection{Cases \#2-4: Vert. 2 - Vert. 4}

Cases \#2-4: Vert. 2 - Vert. 4 used the same geometry and slurry parameters as the first case but with different initial conditions. The tank was initialized with mixed pre-GRE conditions. A 15-ft layer of convecting liquid over a 15-ft layer of non-convecting slurry was chosen for the initial solids distribution condition of the tank. The $\mathrm{C}_{v}$ of the slurry was initialized at 0.24 and the convecting layer was assumed to be clear of particles $\left(C_{v}=0.0\right)$.

In the Vert. 2 simulation, the tank contents were mixed to a uniform concentration from the tank bottom up to the jet intake located $8 \mathrm{ft}$ from the top of the convecting layer after $360 \mathrm{sec}$ of jet mixing.

The computer time requirements for this simulation were such that an effort to increase the time step in the model was undertaken in Vert. 3. To accomplish this, a model was developed that did not recirculate fluid from the top of the tank into the jet. Instead, clear liquid was provided from an infinite source at $30 \mathrm{fps}$ at the jet nozzle, and fluid from the tank was allowed to exit the tank at the top of the model. This case was carried out 180 sec. The results at that time indicated less mixing throughout the tank than was desired. To increase the mixing in the tank, Vert. 4 was carried out with the 9-ft jet exit raised to $25 \mathrm{ft}$ from the tank bottom. The tank contents were mixed; however, at some time in the simulation, particles from the slurry reached the upper portion of the tank and began exiting the system, resulting in a particle mass loss of $68 \%$ of the initial amount after $600 \mathrm{sec}$. Hence it was determined that a closed system was required, even at the expense of computer time.

\subsubsection{Case \#5: Vert. 5}

Case \#5: The objective of the Vert. 5 study is to determine the impact of jet intake and jet exit vertical locations on the mixing effectiveness. Mass was conserved for this case using a recirculation model with a pump intake placed $2 \mathrm{ft}$ from the top of the convecting layer. The jet exit was located $25 \mathrm{ft}$ from the tank bottom and the jet nozzle velocity was $30 \mathrm{fps}$. The initial conditions again assumed a 15- $\mathrm{ft}$ layer of convecting liquid over a 15- $\mathrm{ft}$ layer of nonconvecting slurry. Contours of $C_{v}$ are presented in Figures 4.17 to 4.23 which represent the 


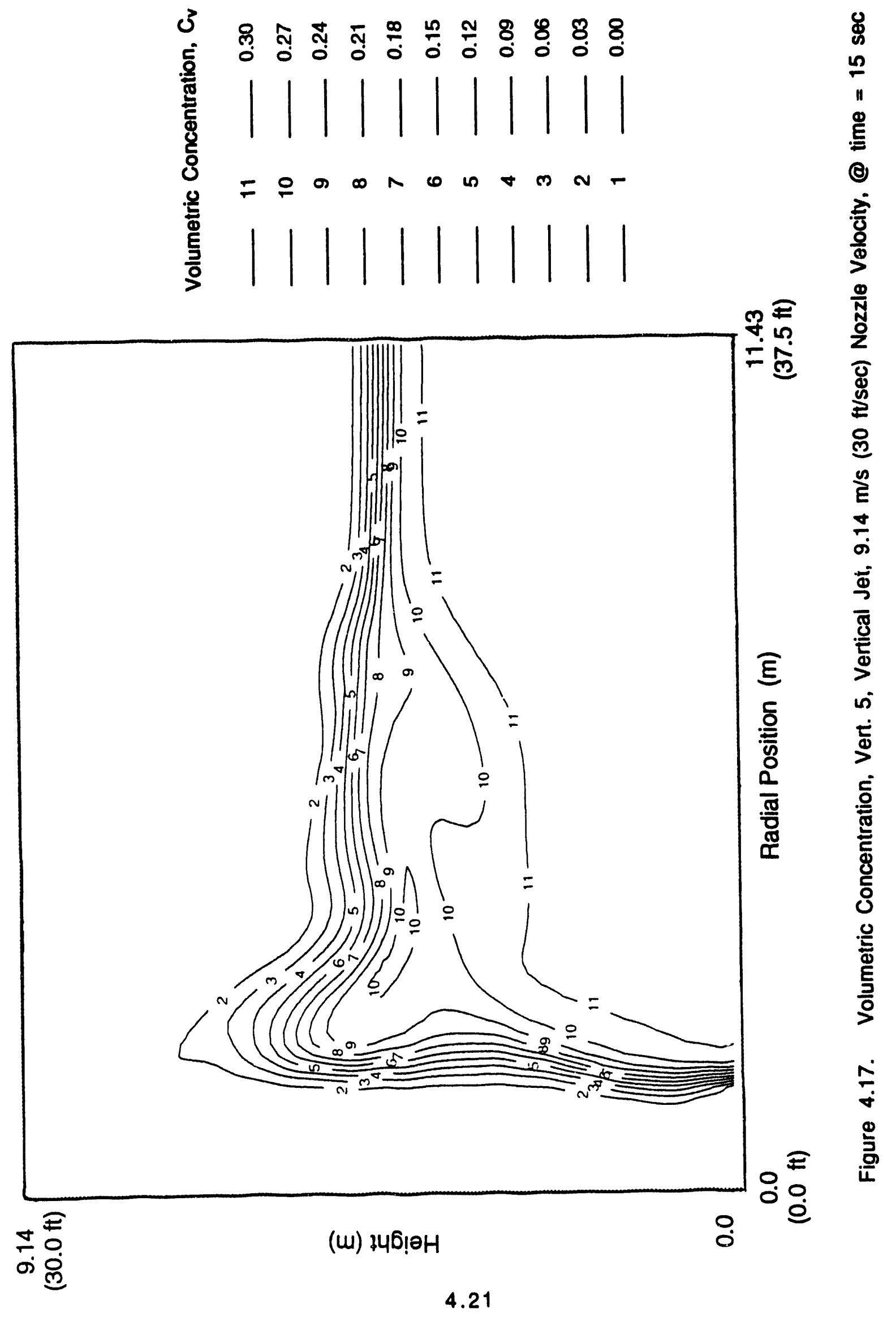




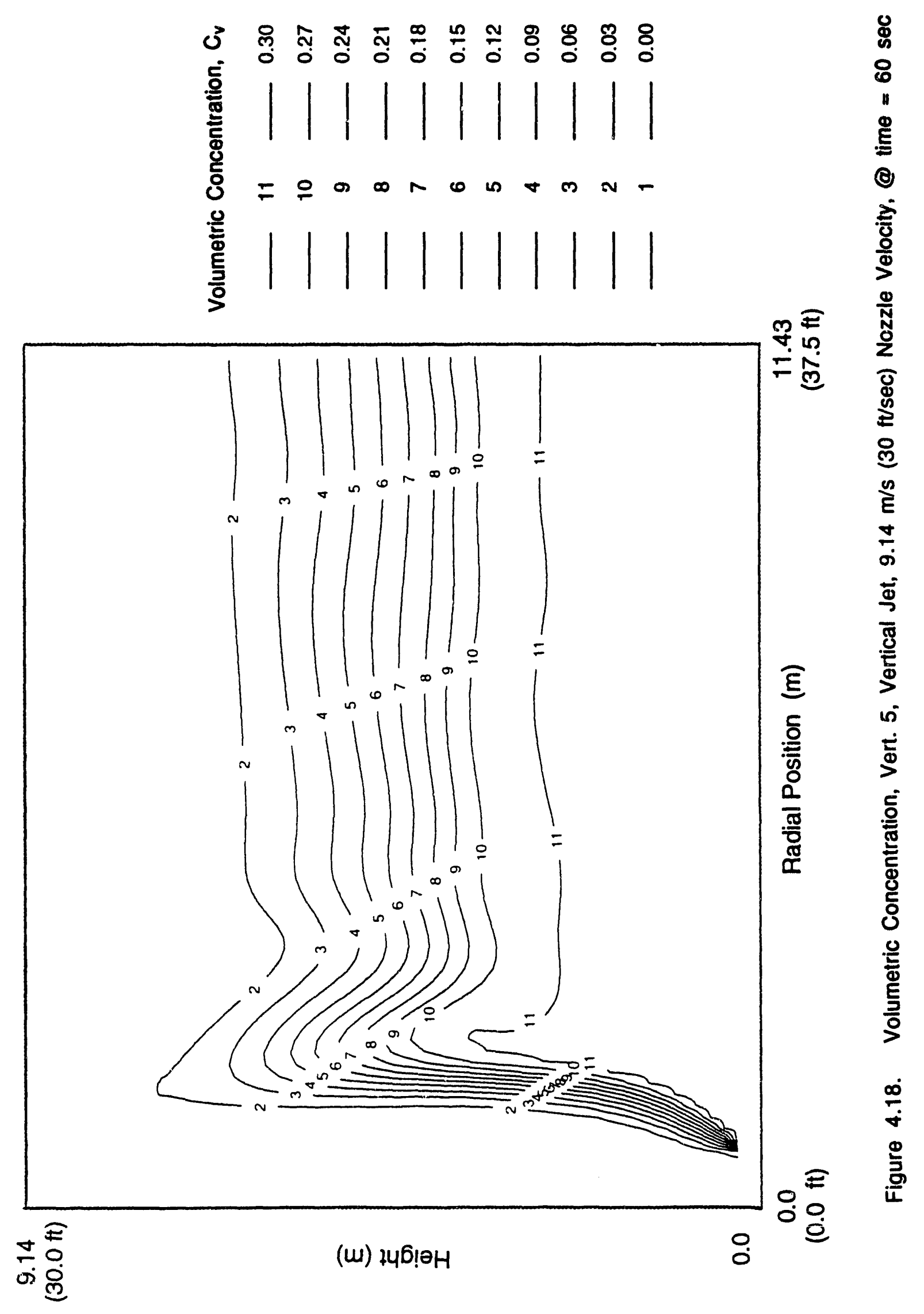




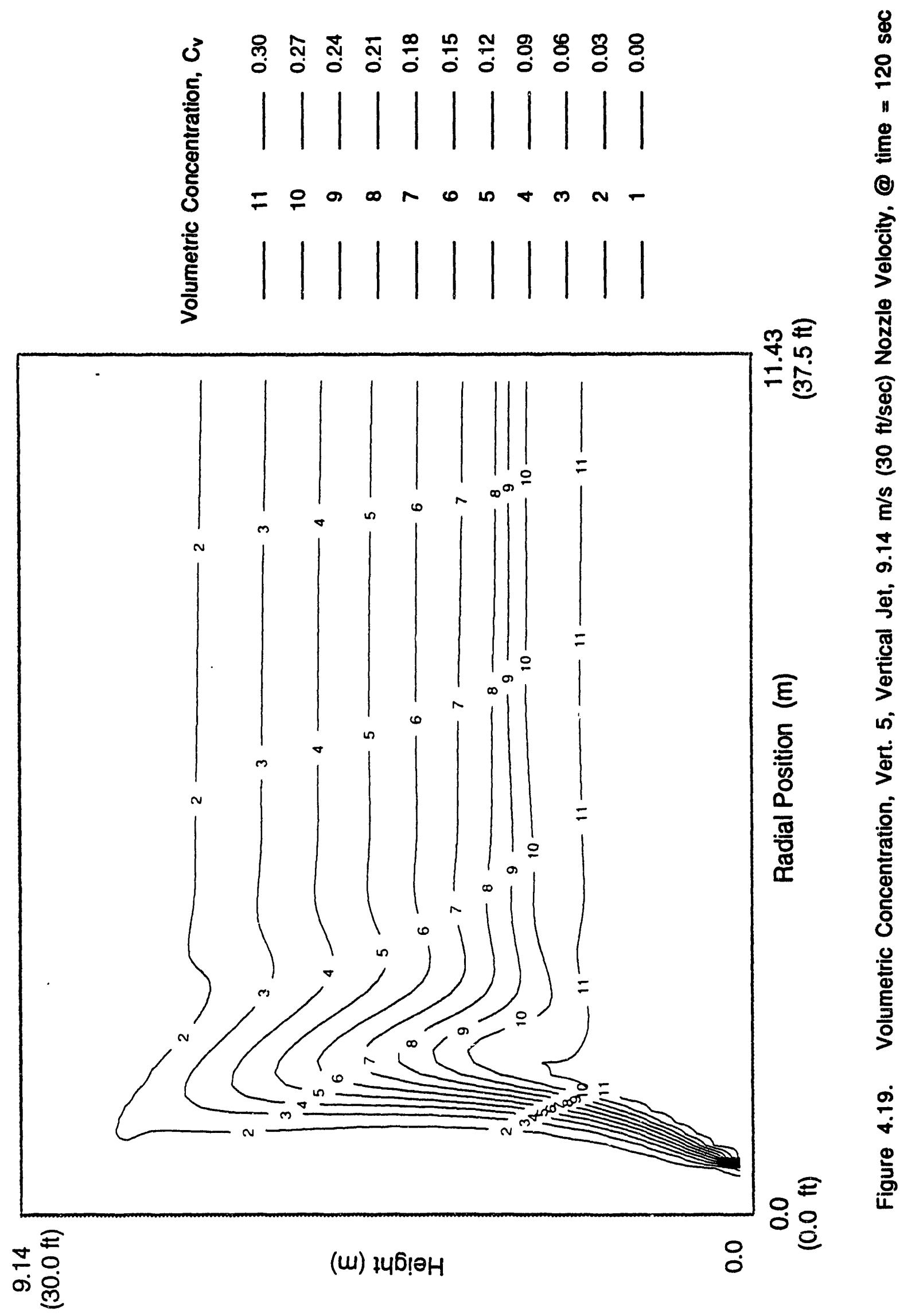




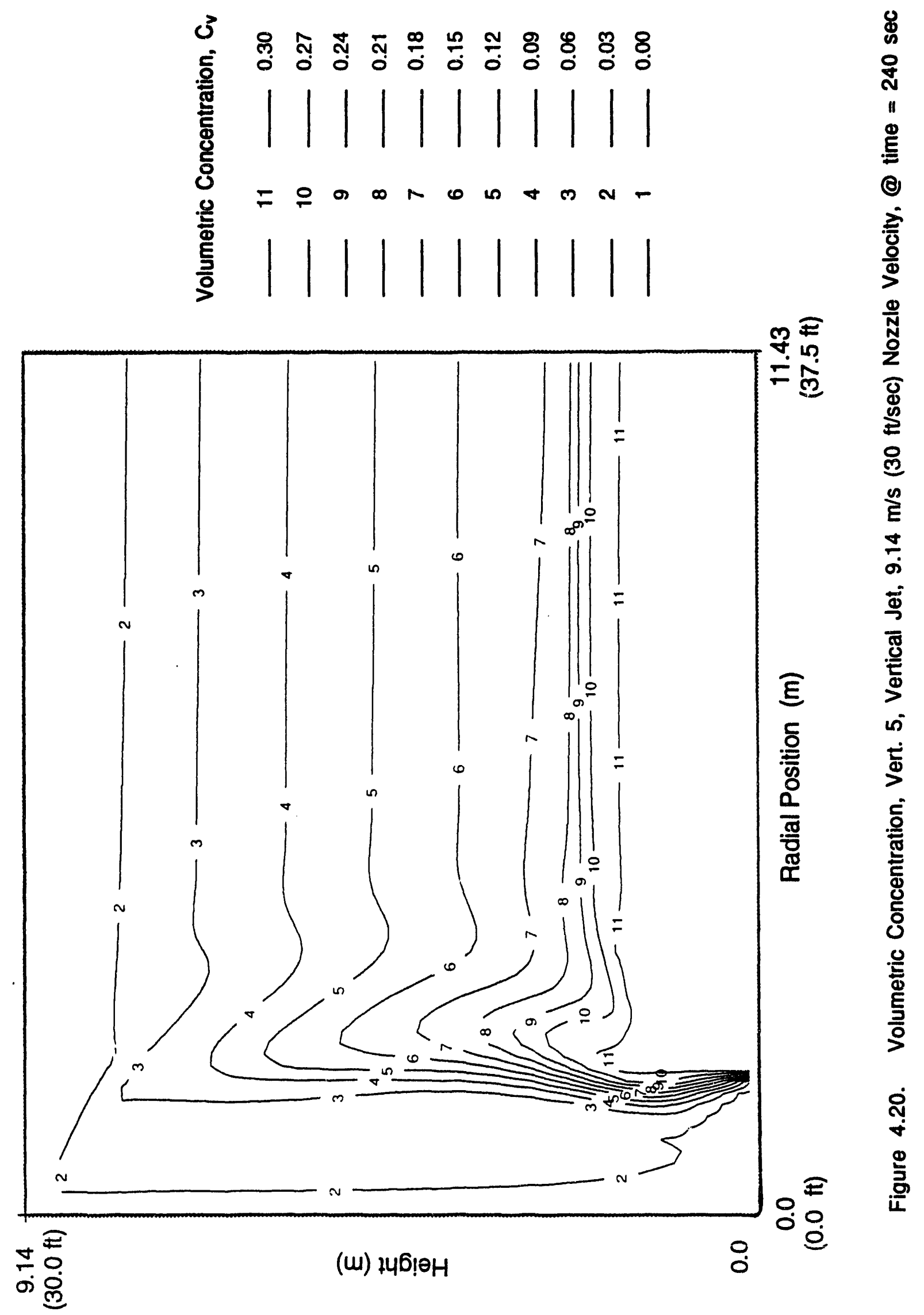




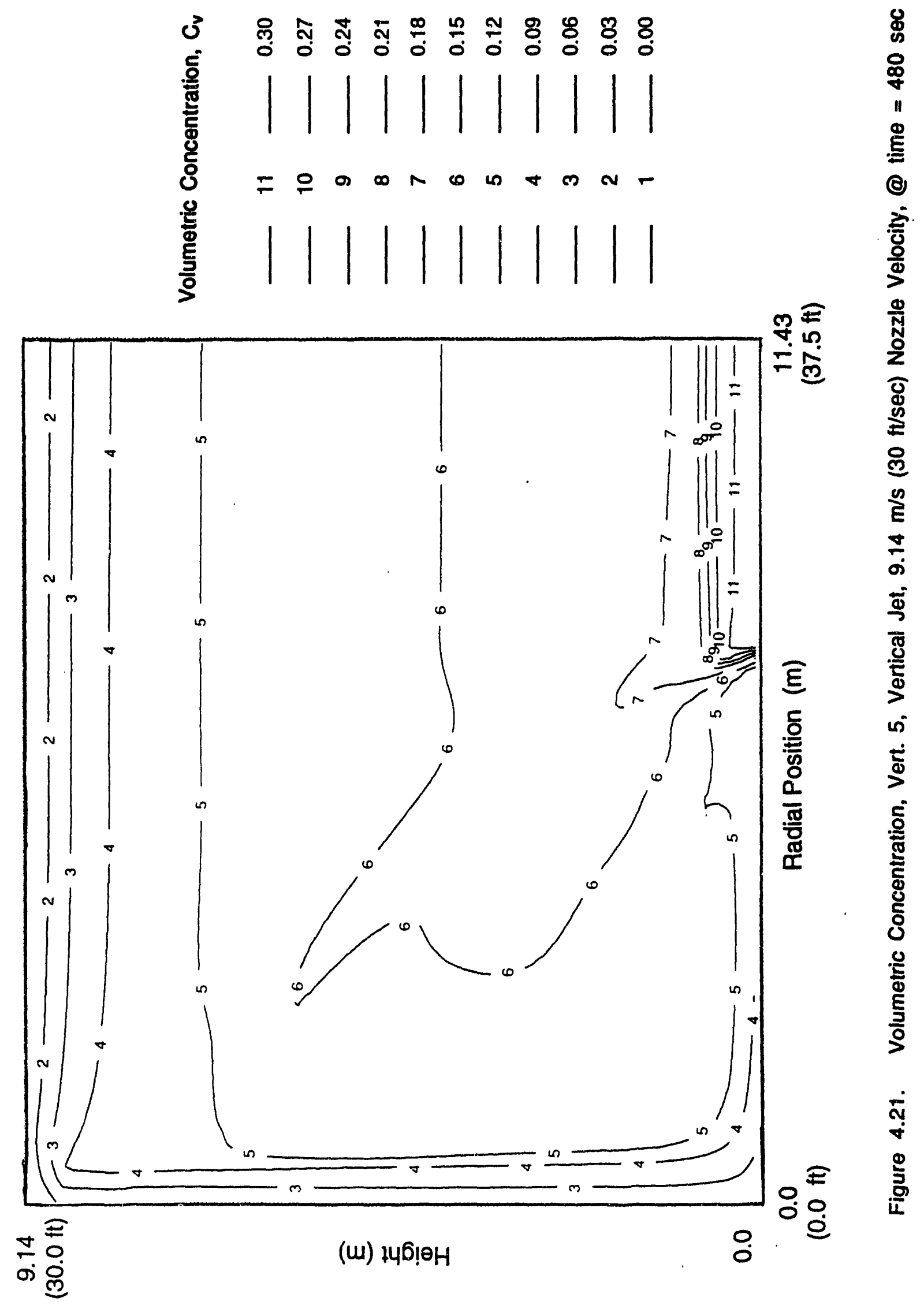



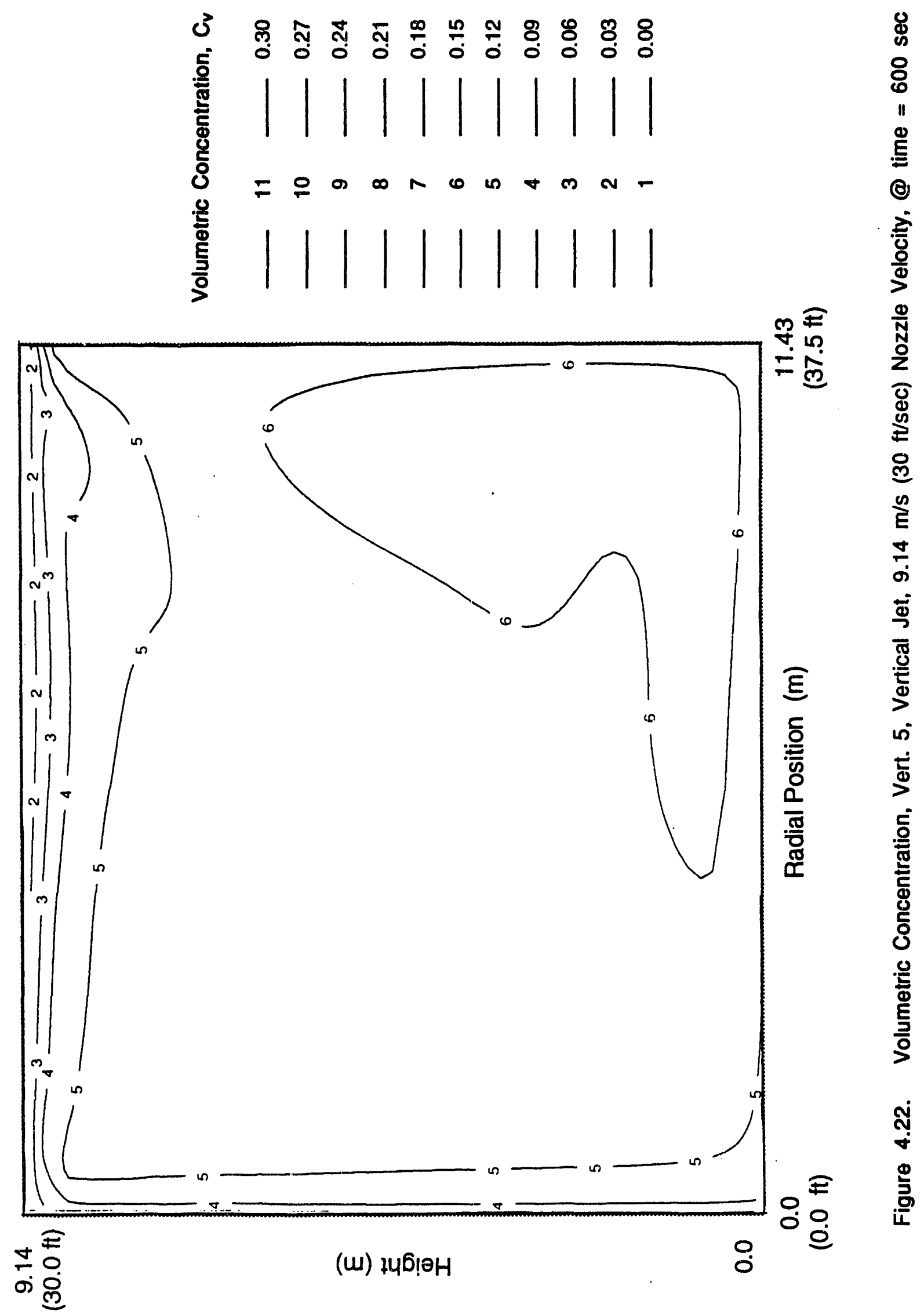


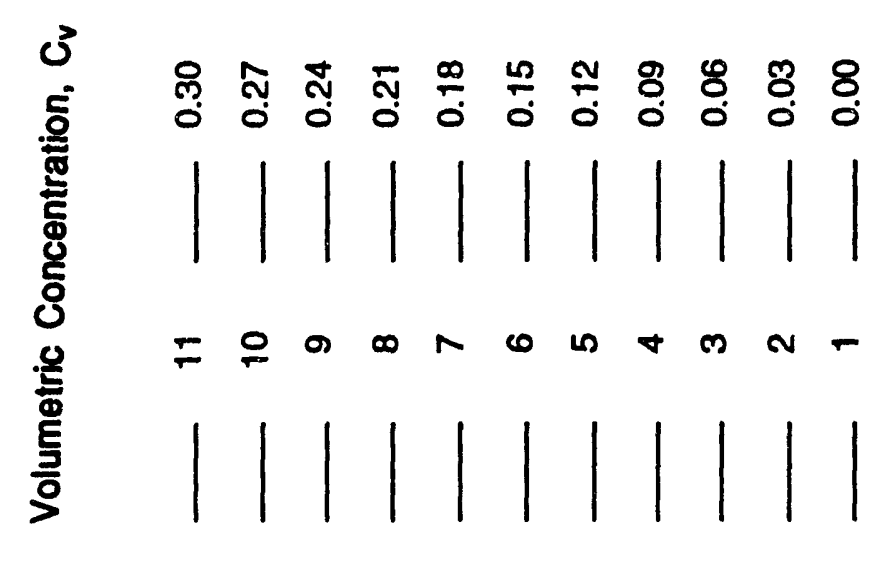

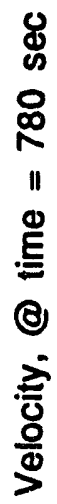

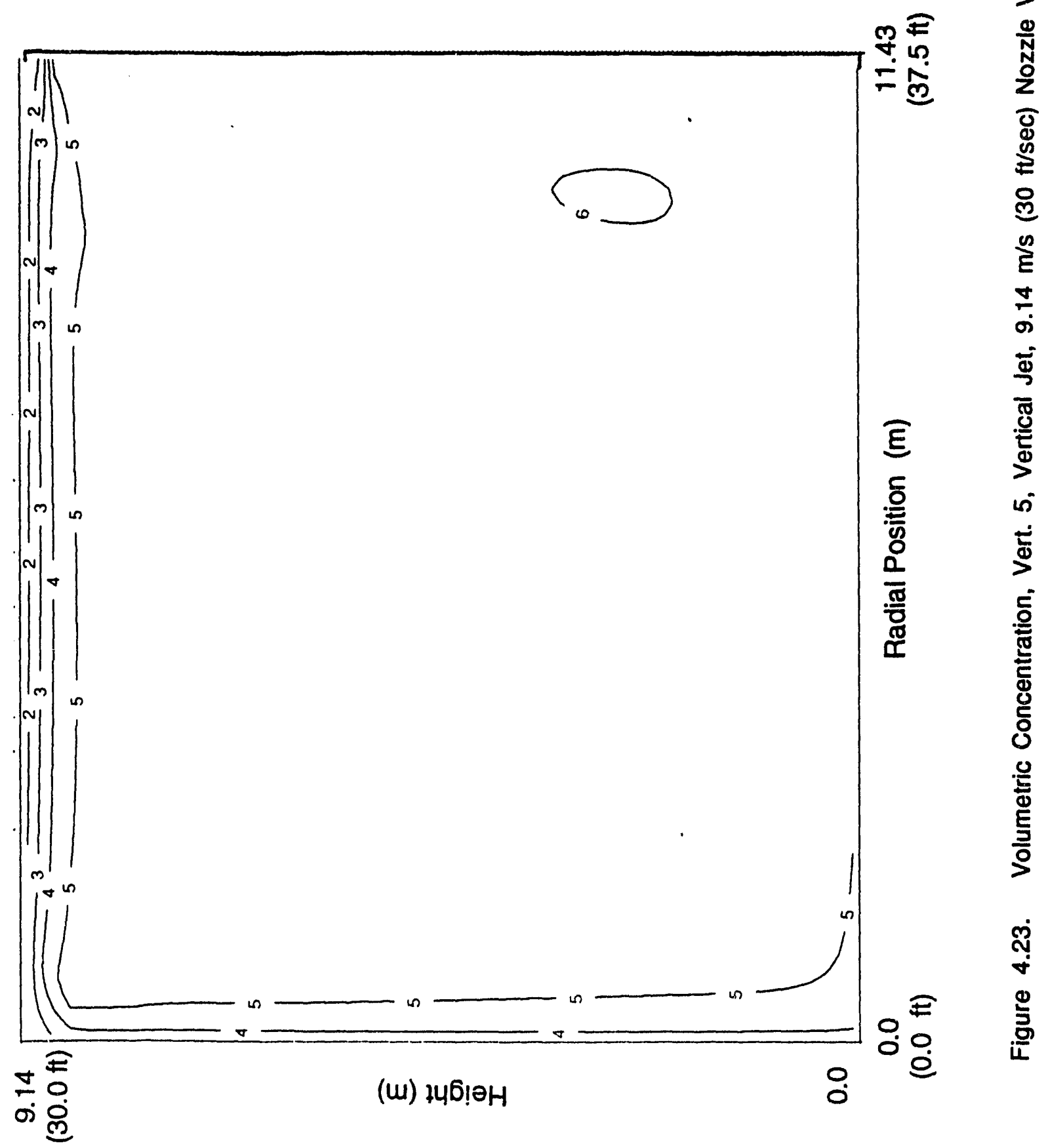


state of the tank at $15,60,120,240,480,600$, and 780 sec. In this case, the jet scoured only the region directly below the jet (Figure 4.17). As the simulation proceeded in time, the slurry region was eroded away by the jet forces along the bottom of the tank. By 780 sec (Figure 4.23), the majority of the tank was below $C_{v}=0.15$, with $C_{v}=0.12$ being the fully mixed state. The velocity vectors are displayed for the same time points in Figures 4.24 to 4.30. The scouring of the slurry region can best be seen in Figure 4.28 (480 sec) where the flow field is shown hitting the edge of the slurry at approximately $24 \mathrm{ft}$ from the tank center at which time the flow is redirected up and radially inward. By 600 sec (Figure 4.29), the flow field had become fairly steady and the tank approached a uniform mixture.

An important finding from this simulation is that the jet exit and intake locations have a substantial effect on the ability of the vertical jet to mix the tank. In this configuration $\left(Z_{i}=30 \mathrm{ft}, Z_{d}=25 \mathrm{ft}\right)$, the jet mixing was such that the resultant mixture is fairly uniform, whereas, when the jet exit and intake were lower $\left(Z_{i}=24 \mathrm{ft}, Z_{d}=9 \mathrm{ft}\right.$ case Vert. 1), the jet was unable to maintain a uniform mixture.

\subsubsection{Cases \#6 and 7: Vert. 6 and Vert. 7}

Cases \#6 and 7: Another effort to reduce the computation time requirements of the runs was initiated via a grid study, Vert. 6 and Vert. 7 to determine the minimum computational grid resolution that could be employed while maintaining acceptable accuracy in the predictions. The results from Vert. 5 at 30 sec were used as the maximum grid size case and two new cases were investigated with decreased grid sizes. Vert. 6 consisted of the same geometry and operating conditions as Vert. 5 with a grid reduced from $75 \times 60$ computation cells to $43 \times 31$ cells. This results in a saving in computational requirements of $70 \%$. The grid size was reduced further to $36 \times 22$ cells in case Vert. 7, which reduces the computational requirements to $18 \%$ of the $75 \times$ 60 case. A comparison of the results for each case at $30 \mathrm{sec}$ are provided in Figures 4.31 (75 $x$ $60), 4.32(43 \times 31)$, and $4.33(36 \times 22)$. A comparison of $C_{v}$ contours for the three cases indicates that the $43 \times 31$ grid model compares reasonably well with the $75 \times 60$ grid model. The contours of $C_{v}$ predicted on the coarsest grid $(36 \times 22)$ have significant differences, indicating a loss of accuracy in the predictions.

The $43 \times 31$ grid was selected as the most economical with acceptable accuracy for the vertical jet cases. 


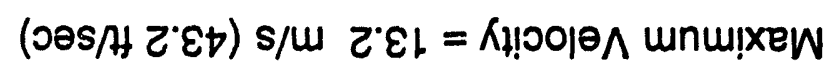

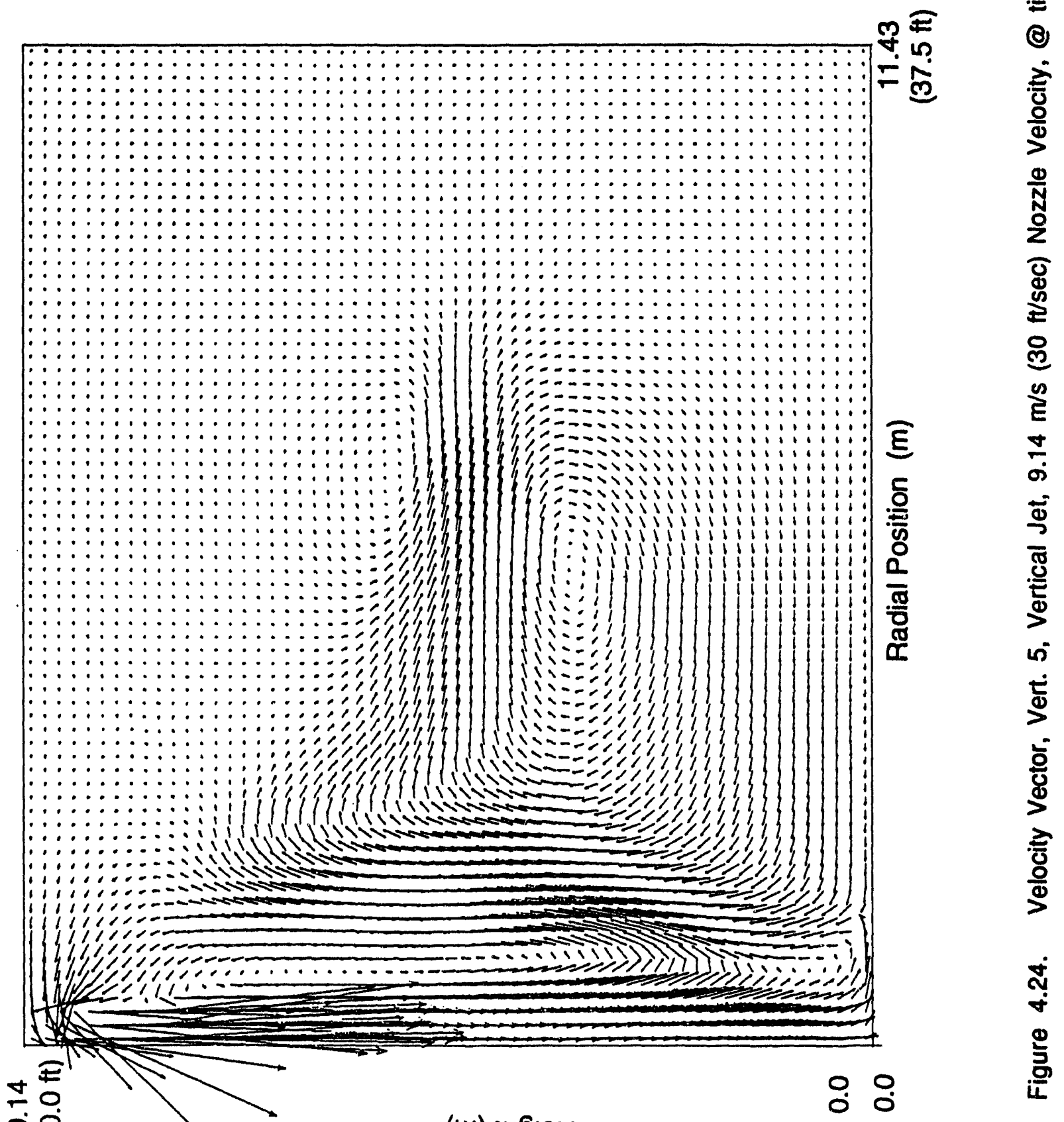

कं ्.

(w) $+46 ! 10 \mathrm{H}$ 


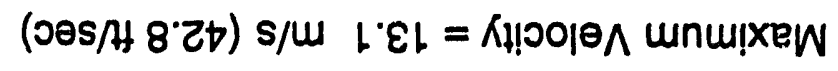

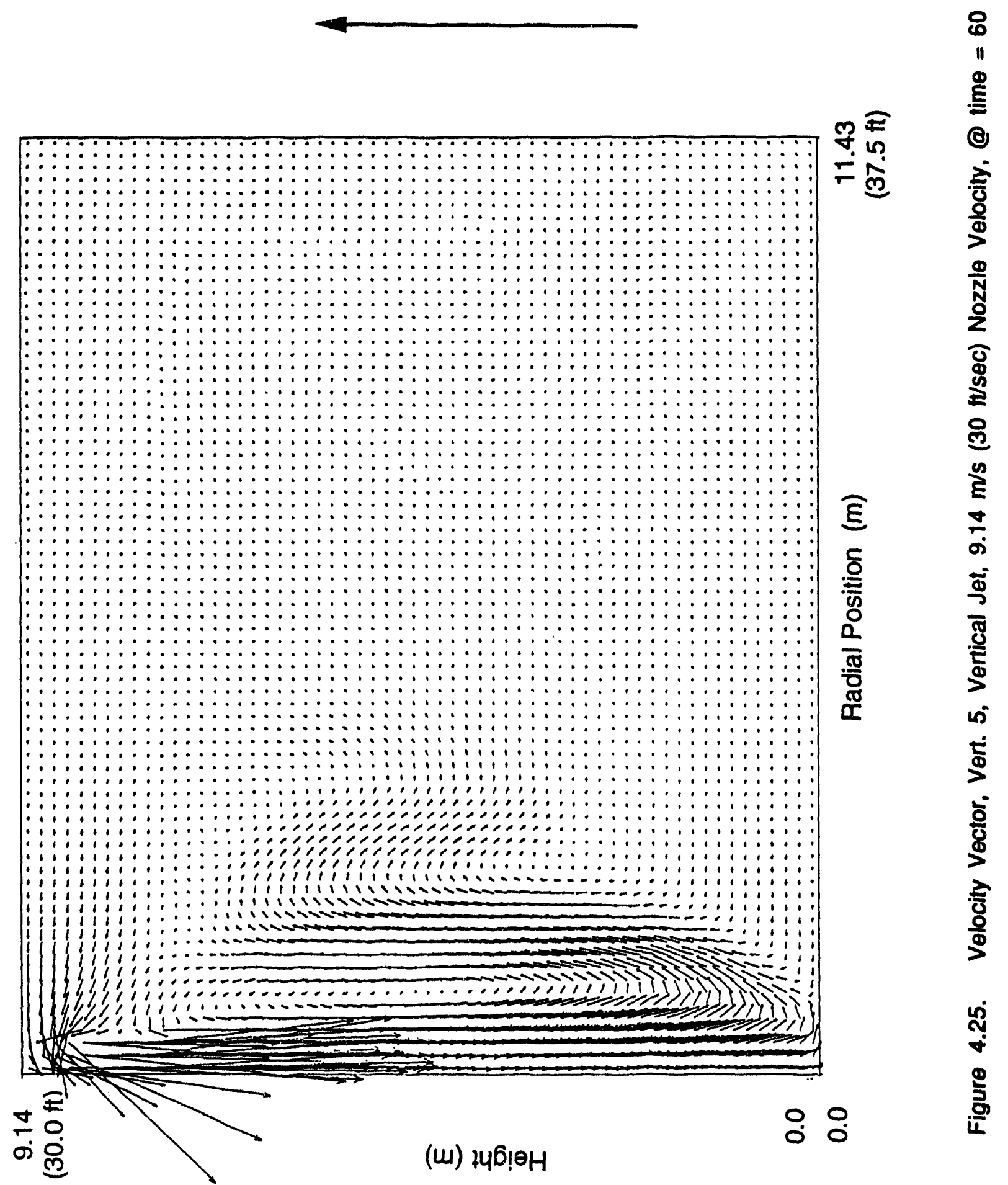




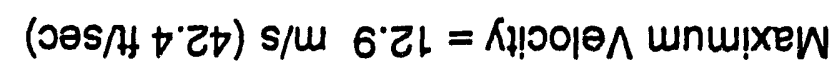

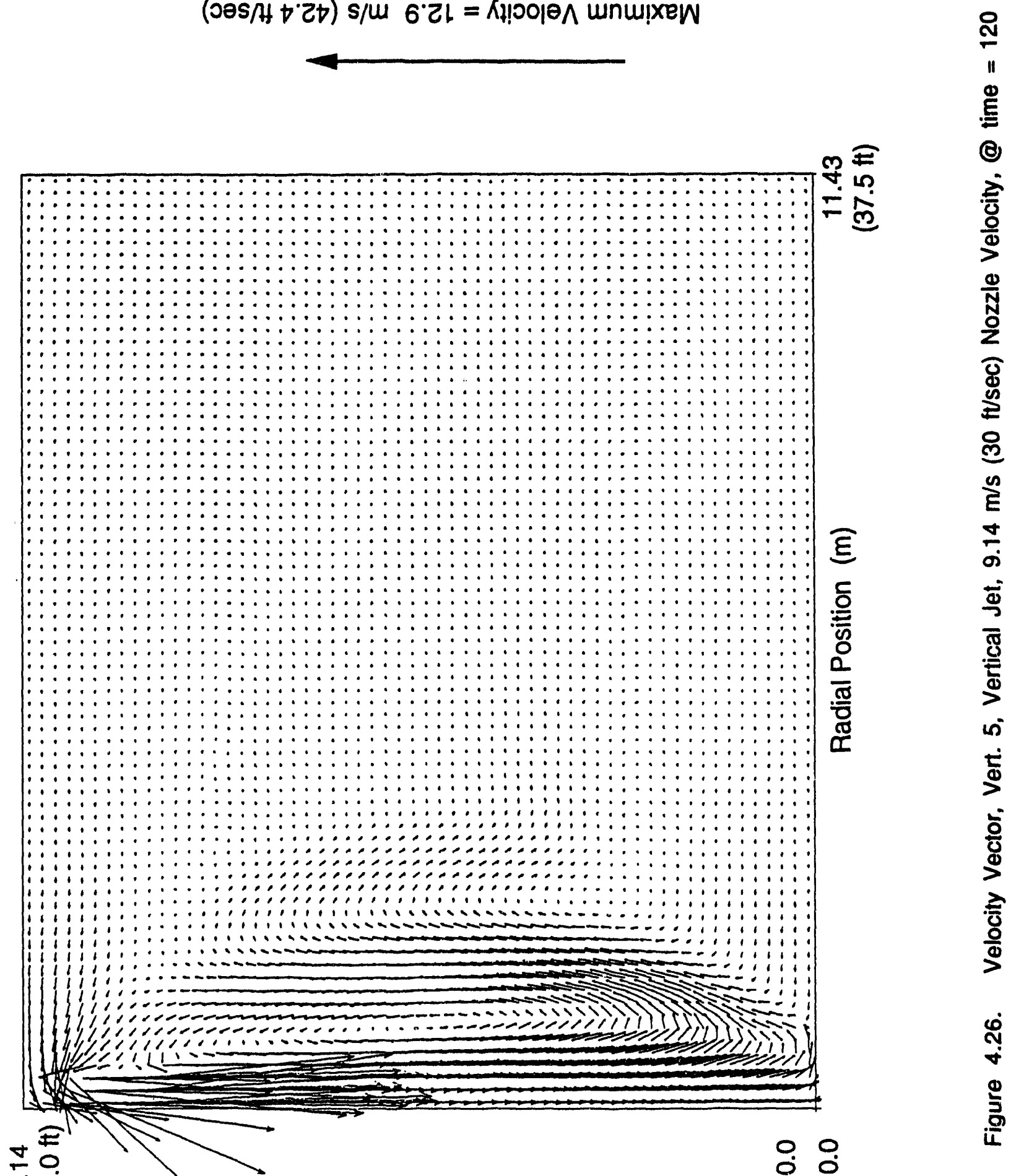

के

(w) $746 !$ 


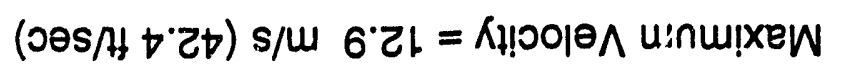

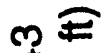

$\stackrel{\text { II }}{\text { II }}$

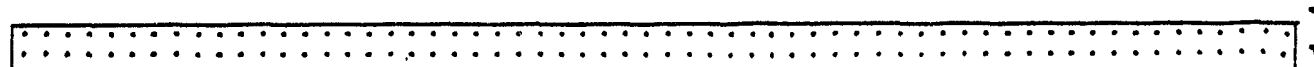

$\stackrel{-10}{2}$

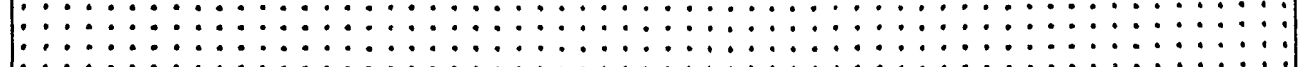

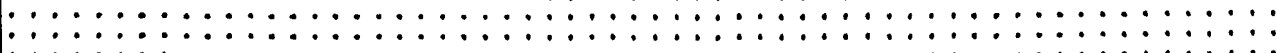

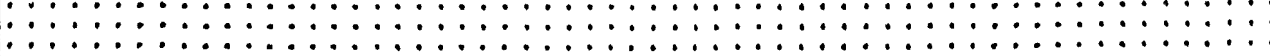

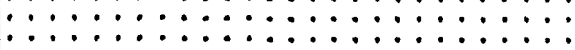

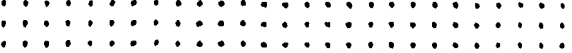

$\because:::::::::: 20$

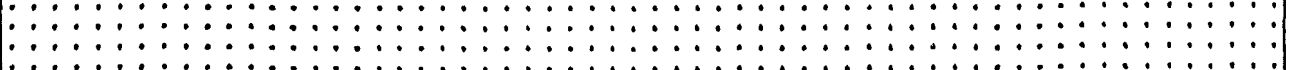

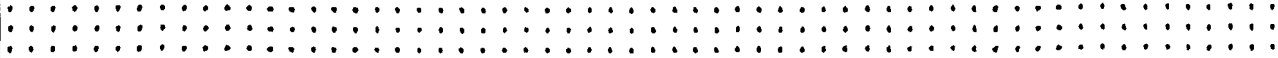

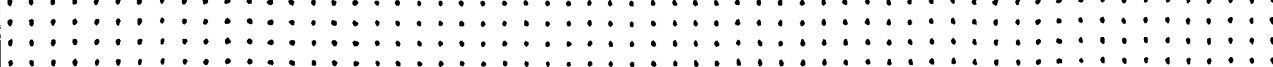

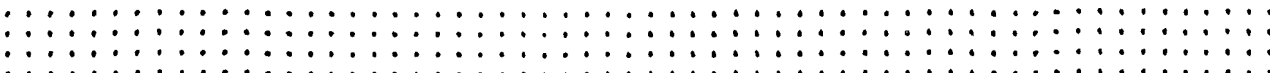

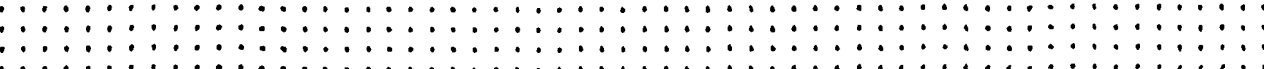

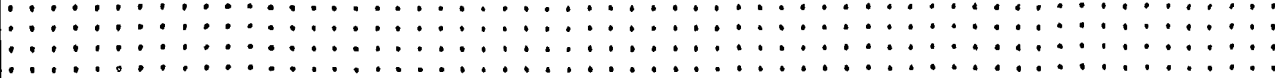

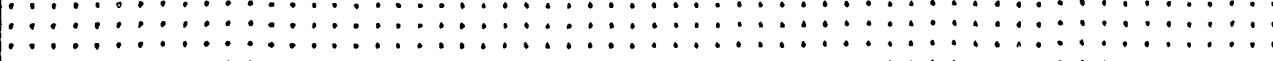

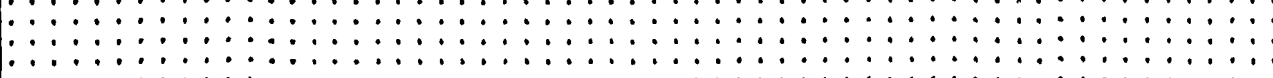

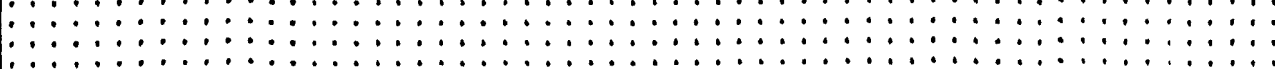

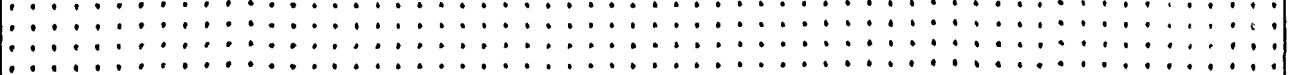

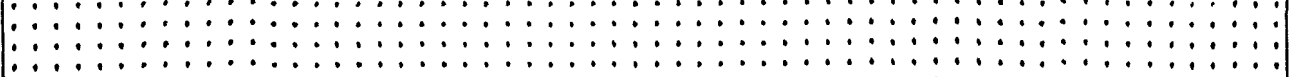

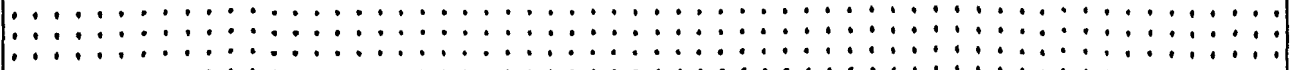

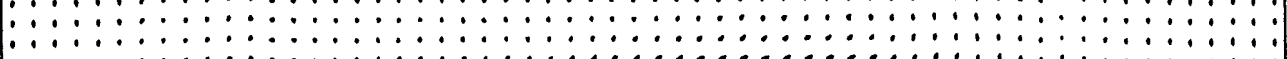

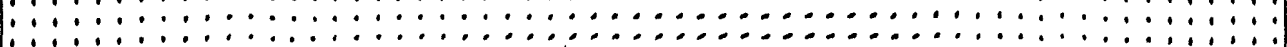

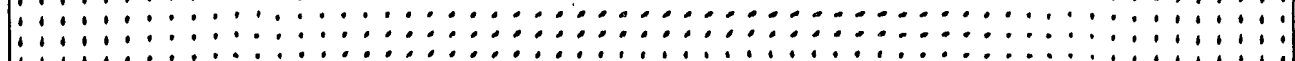

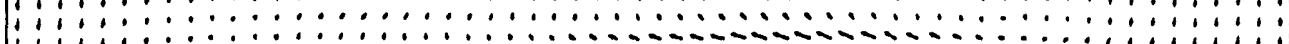

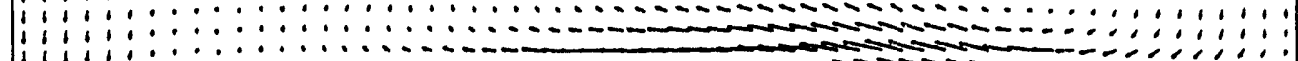

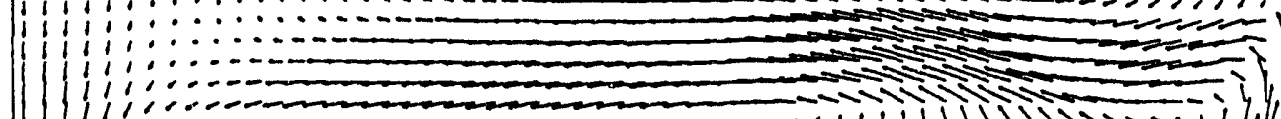

$=\hat{n}$

(w) $446 !$ 


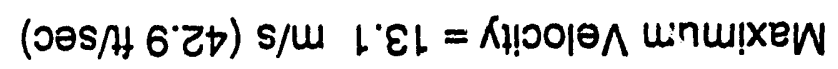

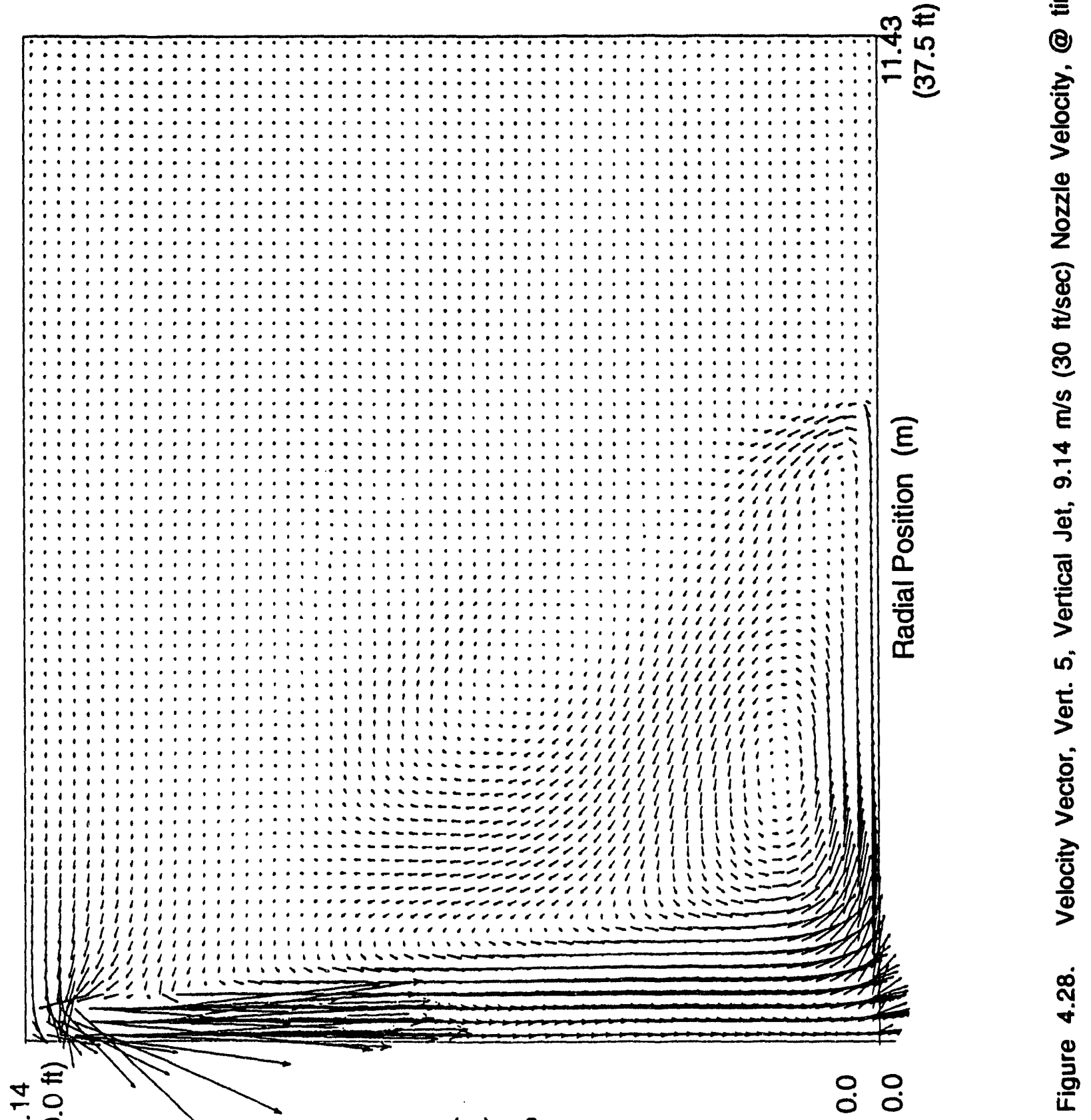

के @्:

(u) $+46 ! \div$ 


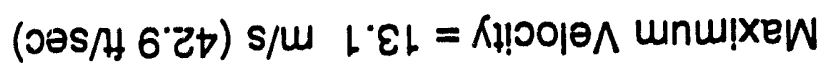

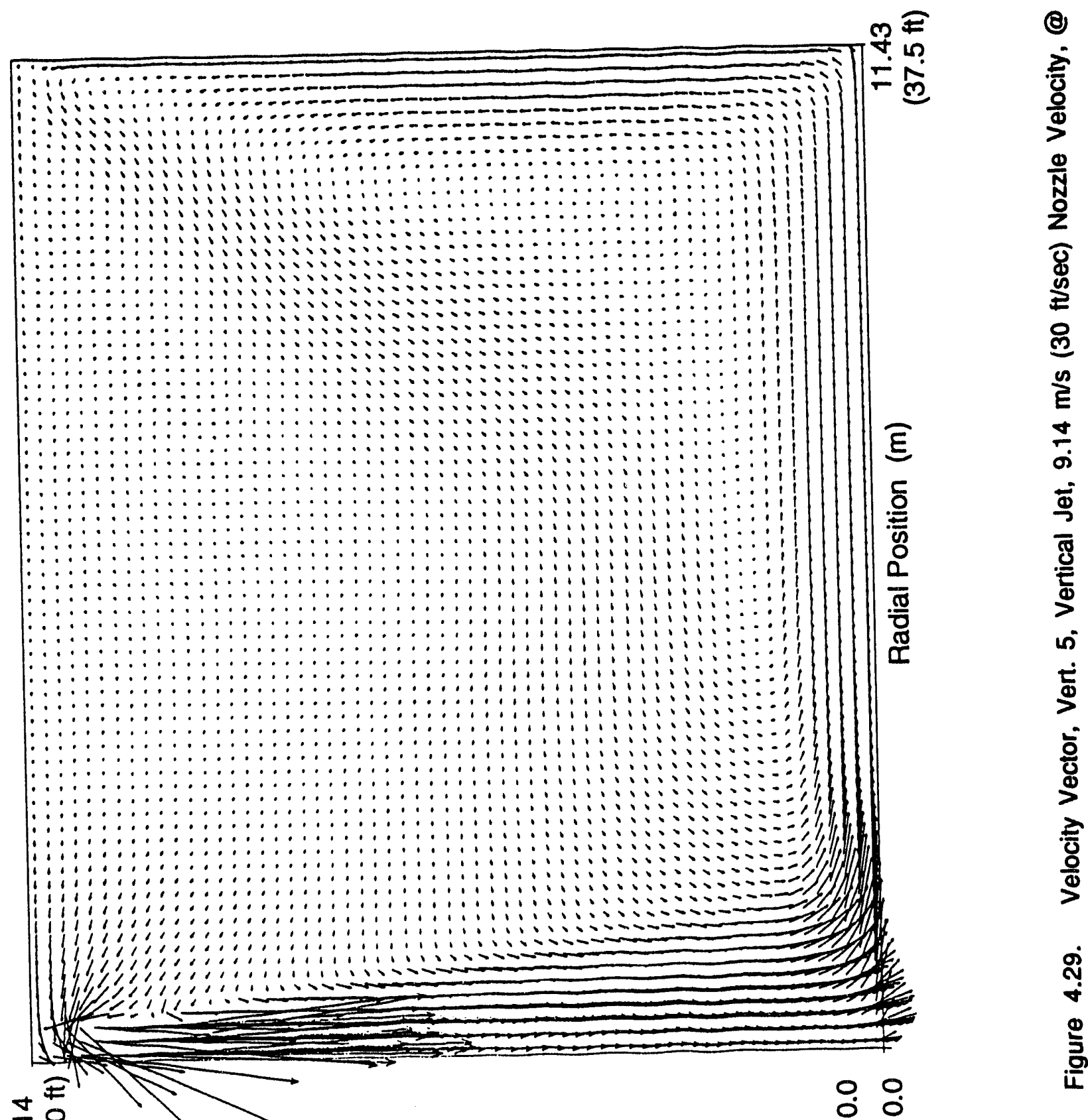

कृ

(w) $+46 ! \mathrm{\theta} \theta \mathrm{H}$ 


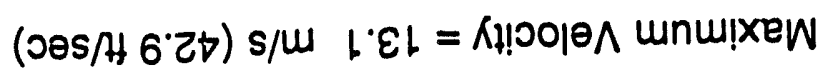

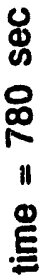

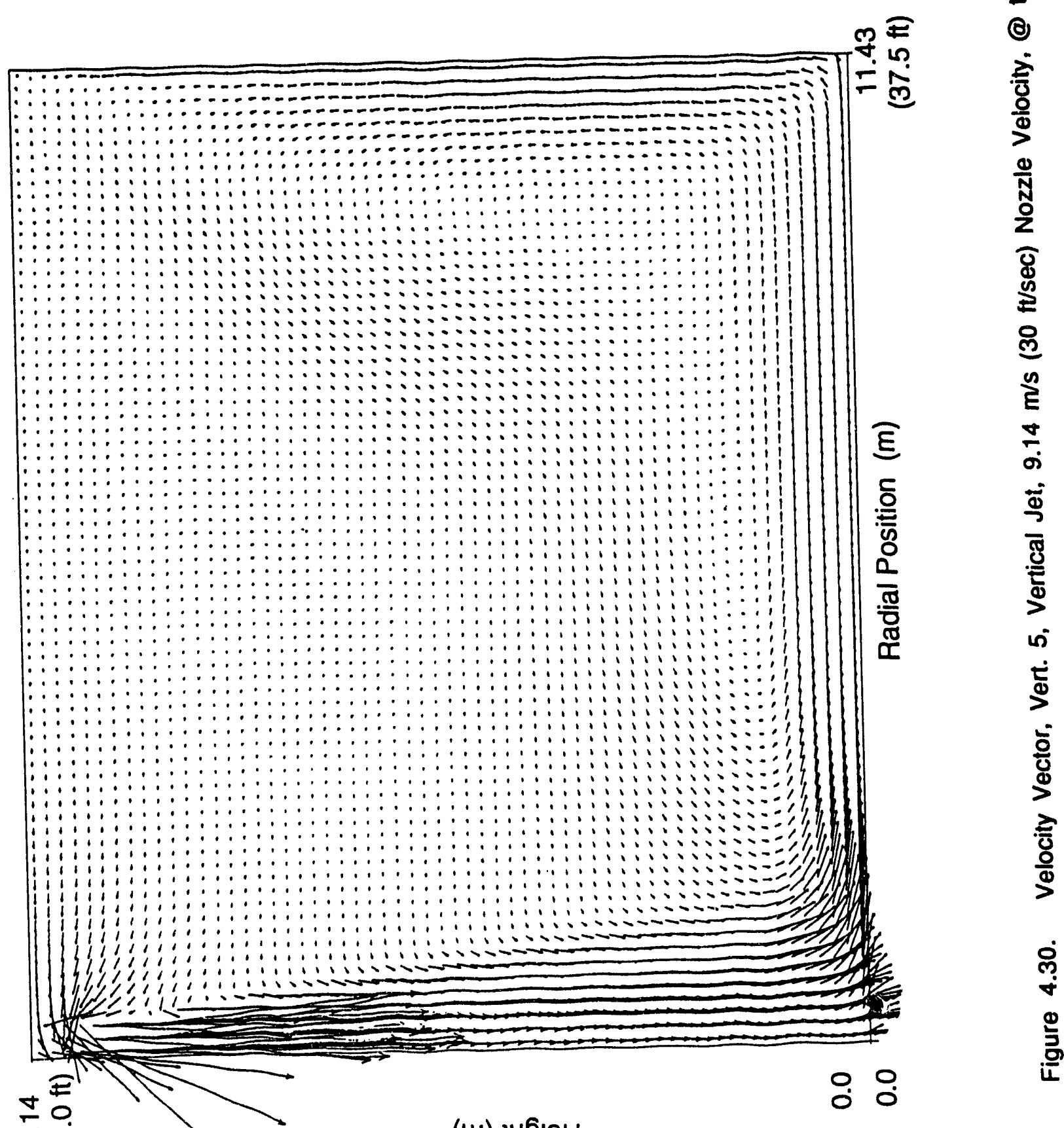

(u) 1466 

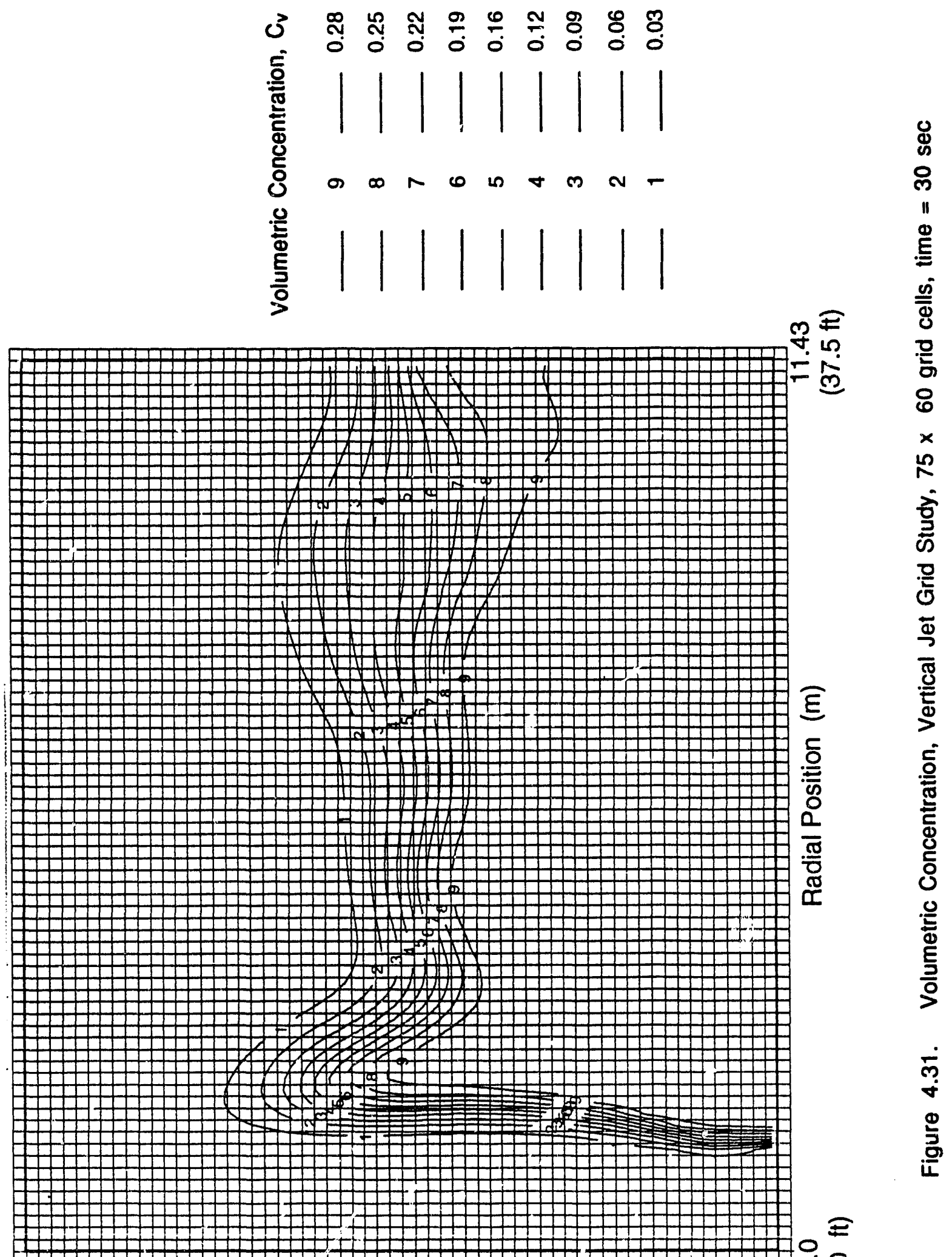

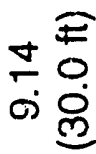

(u) 746 !아

웅 

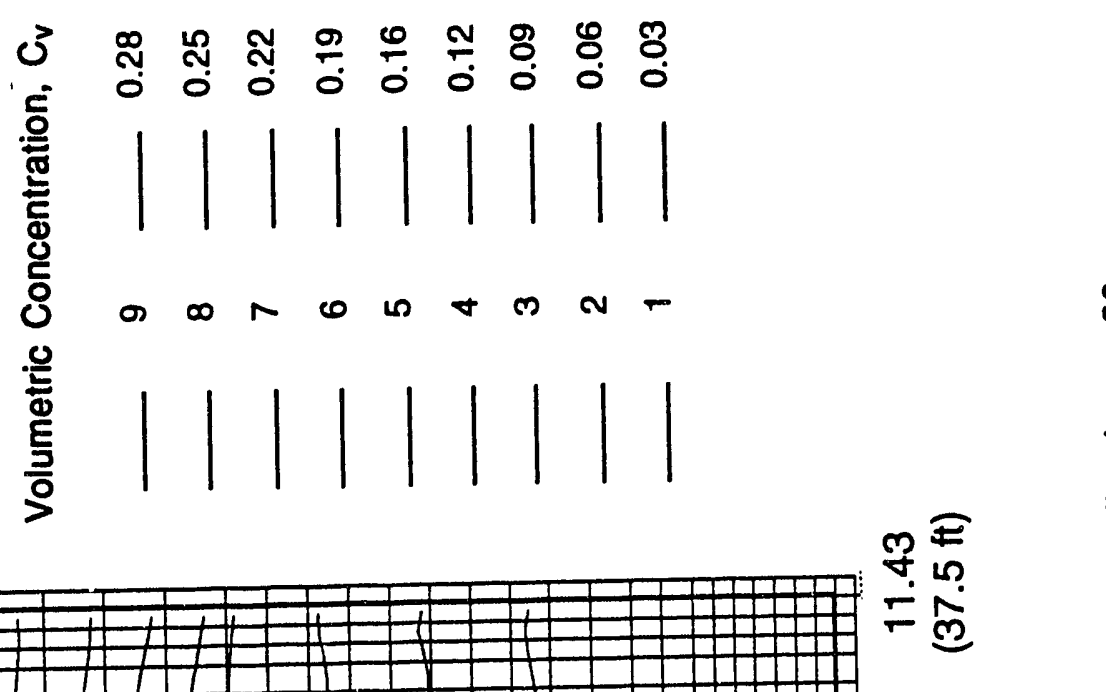

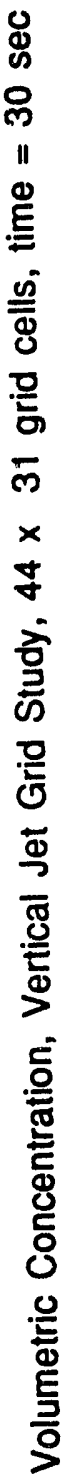
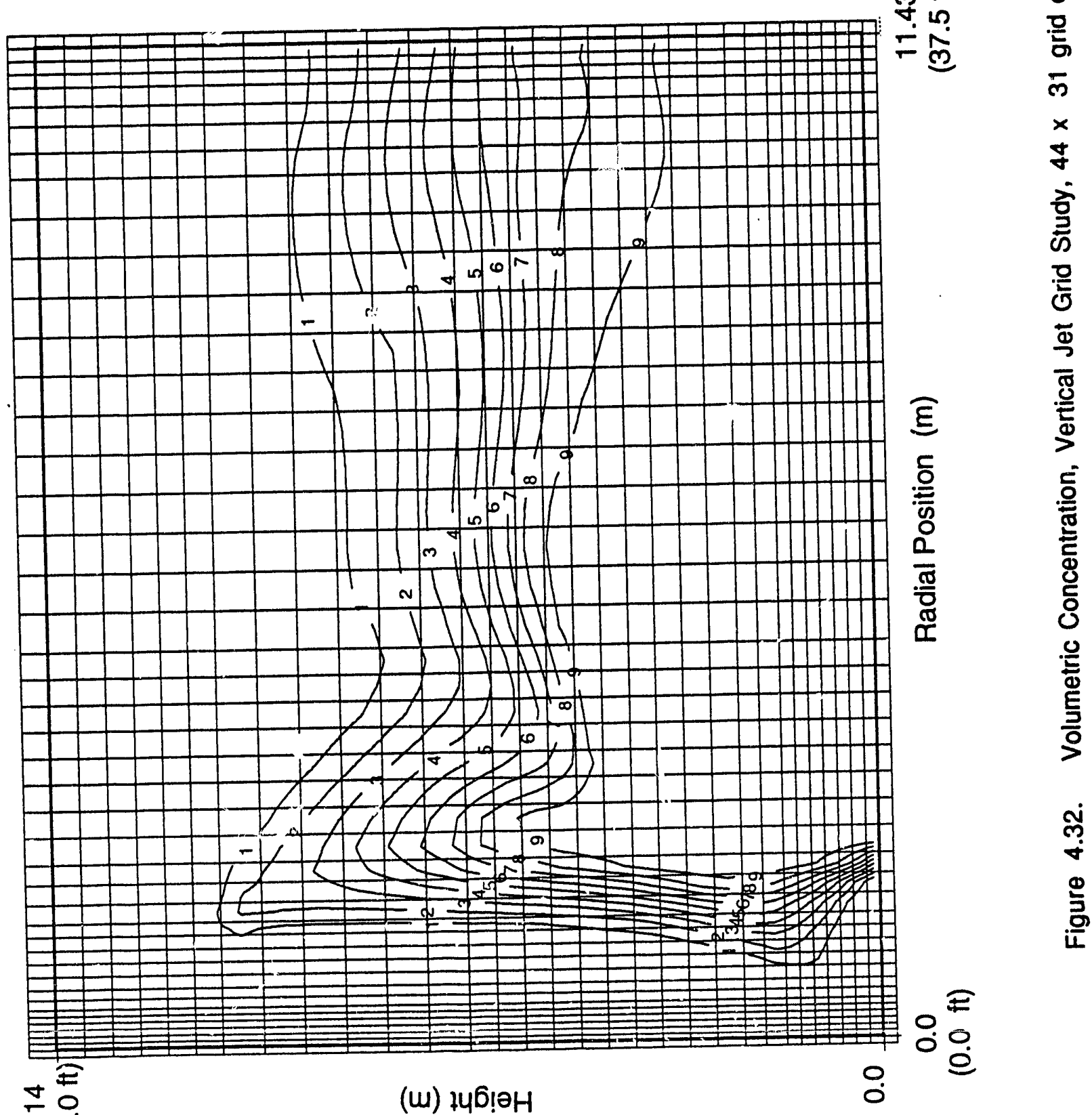

: 


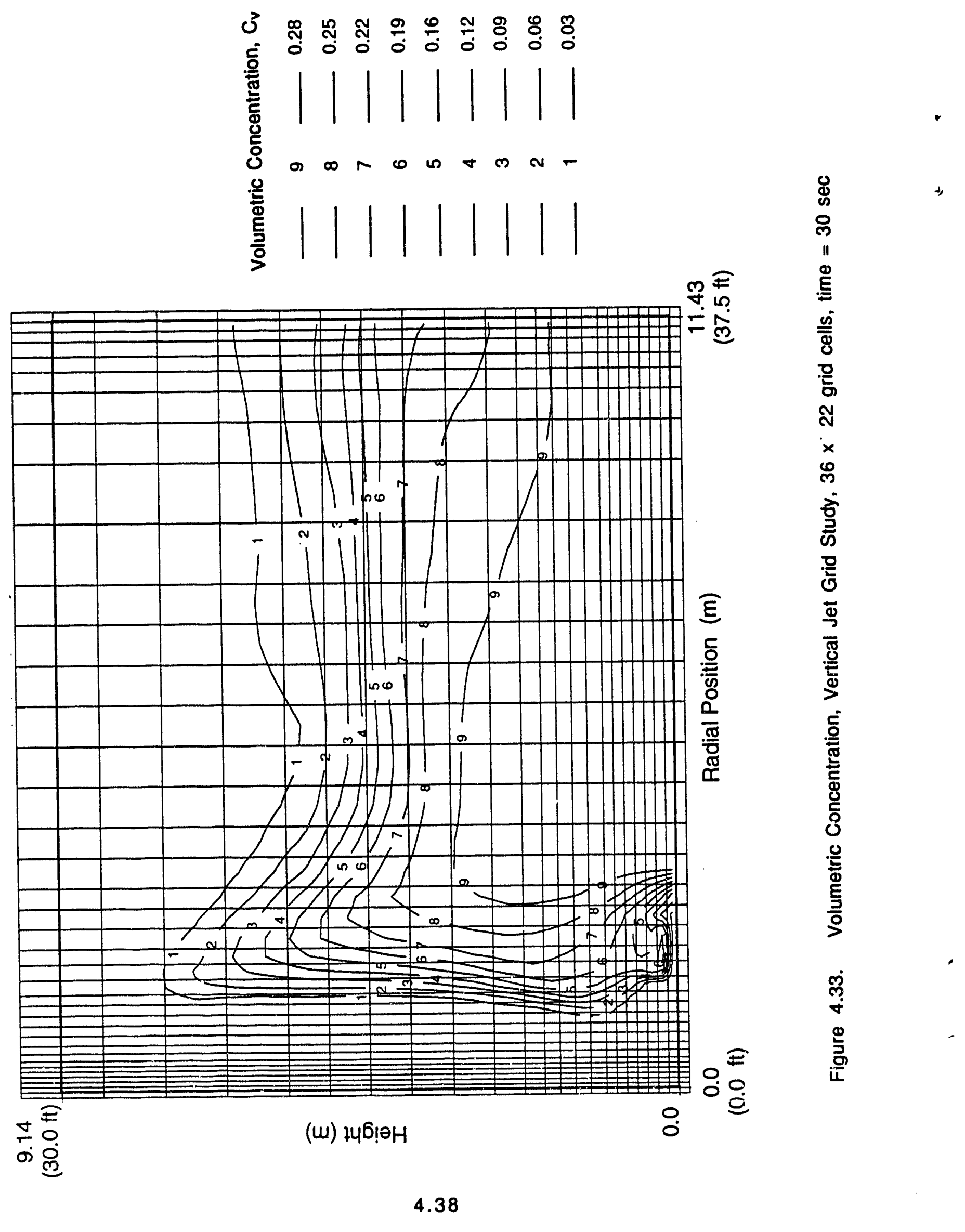




\subsubsection{Cases \#8-10: Vert. 8 - Vert. 10}

The next three cases were designed to investigate different jet nozzle sizes and velocities in an attempt to search for a lower more realistic flow rate while still providing sufficient mixing in the tank. The results from the Vert. 5 simulation indicated that the tank could be mixed fairly uniformly with a jet configuration defined by a $30-\mathrm{ft} / \mathrm{sec}$ discharge, a $3.0-\mathrm{ft}$ diameter jet, with the jet intake $30 \mathrm{ft}$ from the tank bottom, and the jet exit $25 \mathrm{ft}$ from tank bottom. This corresponds to employing a pump capable of providing $Q=(\pi / 4)^{\star} d^{2} V_{\text {jet }}=$ $\left.(\pi / 4)^{*} 9.0^{*} 30\right)=212 \mathrm{ft}^{3} / \mathrm{sec}$, or $95,152 \mathrm{gal} / \mathrm{min}$. This large flow rate was used as a starting point based on early modeling efforts when little was known about the material properties.

Case Vert. 8 was similar to Vert. 5 with the exception of the nozzle velocity, which was lowered from 30 fps to 10 fps. The jet was unable to penetrate the slurry more than a few feet under the jet. The jet exit was then lowered from $25 \mathrm{ft}$ to $15 \mathrm{ft}$ above the tank bottom for case Vert. 9. TEMPEST predictions from this case reflected a slight increase of the depth of penetration into the slurry, with the mixing remaining insufficient. Lastly, for case Vert. 10, the velocity was raised back to $30 \mathrm{fps}$, the jet exit was relocated back to $25 \mathrm{ft}$ from the tank bottom, and the jet diameter was reduced from 3.0 to $1.5 \mathrm{ft}$. In this case, the jet was able to penetrate to within a few feet of the tank bottom after $480 \mathrm{sec}$. There was still a layer of high concentration slurry a few feet in depth all along the tank bottom.

Based on the Vert. 8 - Vert. 10 studies, it is concluded that decreasing the jet flowrate by 3 to 4 times, whether it be through lowering the discharge velocity or via a reduced jet diameter, results in poor mixing of the settled tank contents.

\subsubsection{Case \#11: Vert. 11}

The objective of this case was to investigate the performance of a vertical draft tube configuration suggested in Babad et al. (1992) and illustrated in Figure 4.34. In this case, it was postulated that the entrainment into the vertical draft tube might enhance circulation in the tank resulting in increased mixing of the slurry region compared to the plain vertical jet. The 1 -ft diameter jet ended $5 \mathrm{ft}$ from the top of the convecting layer with a 2-ft diameter draft tube beginning 1 -ft further down ( $6 \mathrm{ft}$ from the top of the convecting layer) and ending $8 \mathrm{ft}$ from the bottom of the tank. This case was simulated for $24 n \mathrm{sec}$ of mixing. Instead of increasing the recirculation throughout the tank, this model predicted minimal mixing of the slurry region. A recirculation pattern was established near the tank center which had not expanded outward after $240 \mathrm{sec}$. Other draft lube configurations may have been more effective, but based on these results the vertical draft tube was not investigated further. 


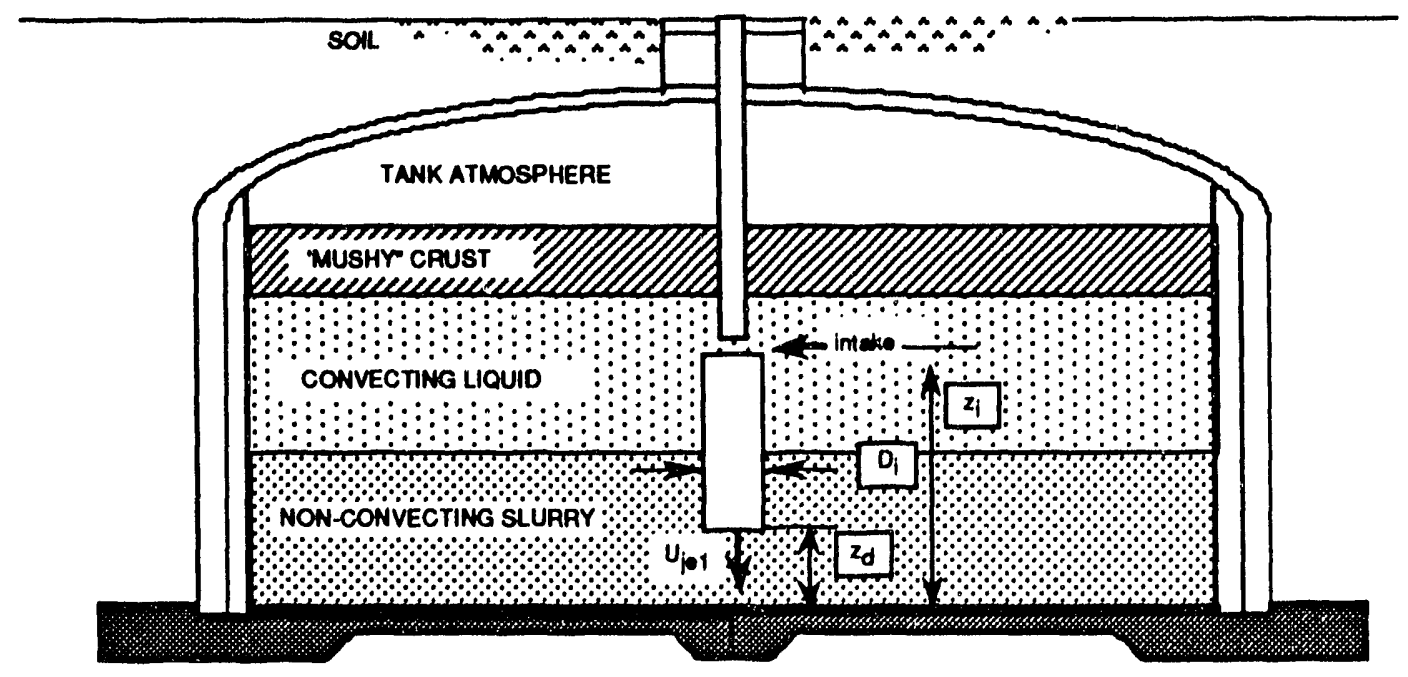

Figure 4.34. Vertical Draft Tube Arrangement

\subsubsection{Case \#12: Vert. 12}

At this point in our investigation, more information on densities and slurry $C_{v}$ became available (Bryan et al. 1991). The new particle density information used in all the following cases was 115 . $\mathrm{lb}_{\mathrm{m}} / \mathrm{ft}^{3}$, and the convecting liquid density was changed to $90.5 \mathrm{lb}_{\mathrm{m}} / \mathrm{ft}^{3}$. The initial slurry $C_{v}$ was therefore changed to 0.54 . The $41 \times 33$ numerical grid was employed to investigate the same basic geometry as Vert. 5 with the exception that the jet diameter was reduced from 3 to $1 \mathrm{ft}$. This case was run out only $60 \mathrm{sec}$. Figures 4.35 to 4.37 present $C_{v}$ contours for 5,15 , and 60 sec. The jet initially penetrated the slurry region to reach the tank bottom (Figure 4.35); however, as the contours from 15 and $60 \mathrm{sec}$ indicate, the jet exit height appeared to be located too high for this configuration. This conclusion is supported by the velocity vector results displayed in Figures 4.38 to 4.40 for the same times.

\subsubsection{Cases \#13 and 14: Vert. 13 and Vert. 14}

Cases \#13 and 14: These last two vertical jet cases, Vert. 13 and Vert. 14 were extensions of Vert. 12. Case Vert. 13 investigated the effect of lowering the jet exit from 25 to $15 \mathrm{ft}$ from the bottom of the tank for the 1-ft diameter jet configuration. Little improvement in the mixing resulted from this change; therefore, the jet was lowered further to $2 \mathrm{ft}$ from the bottom of the tank. This change had a significant effect on the mixing as is shown in the $C_{v}$ contours presented in Figures 4.41 to $4.47(5,60,120,240,360,480$, and $600 \mathrm{sec})$. By locating the jet exit close to the bottom of the tank, the jet flow encounters the bottom and is redirected out radially with a minimum of fluid entrained during its downward phase. This lack of entrainment inhibits any vertical recirculation pattern from being established near the tank center 


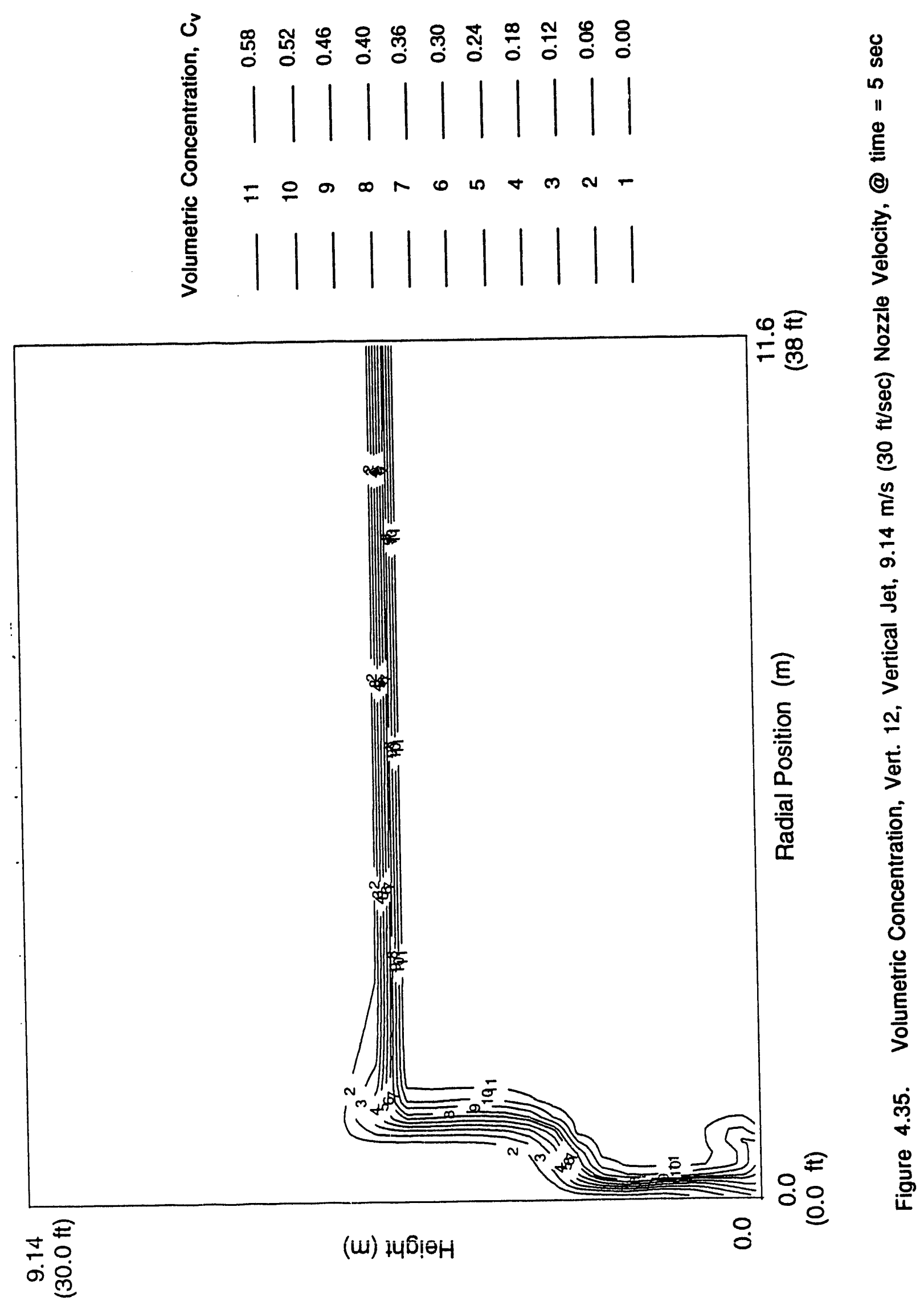




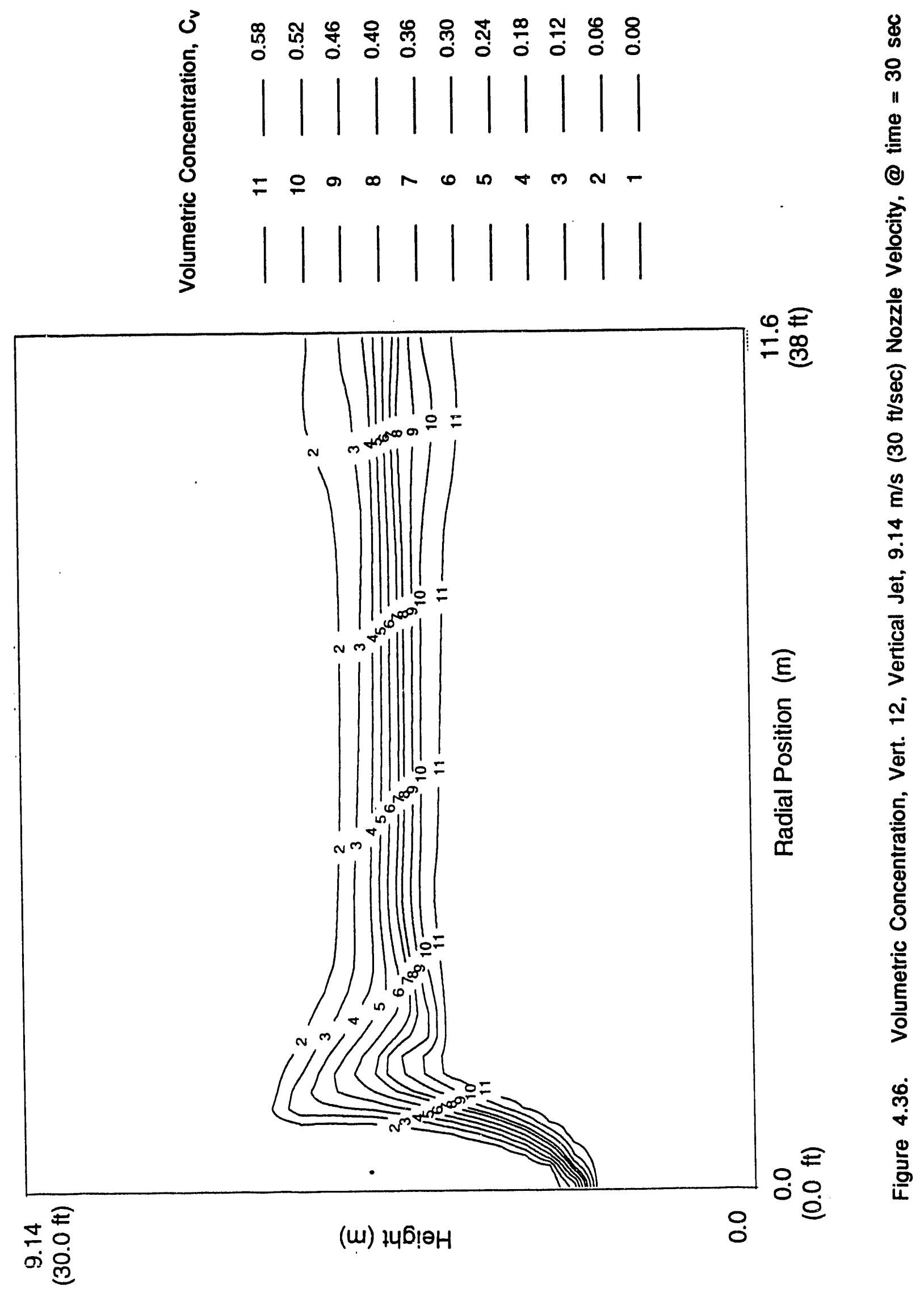




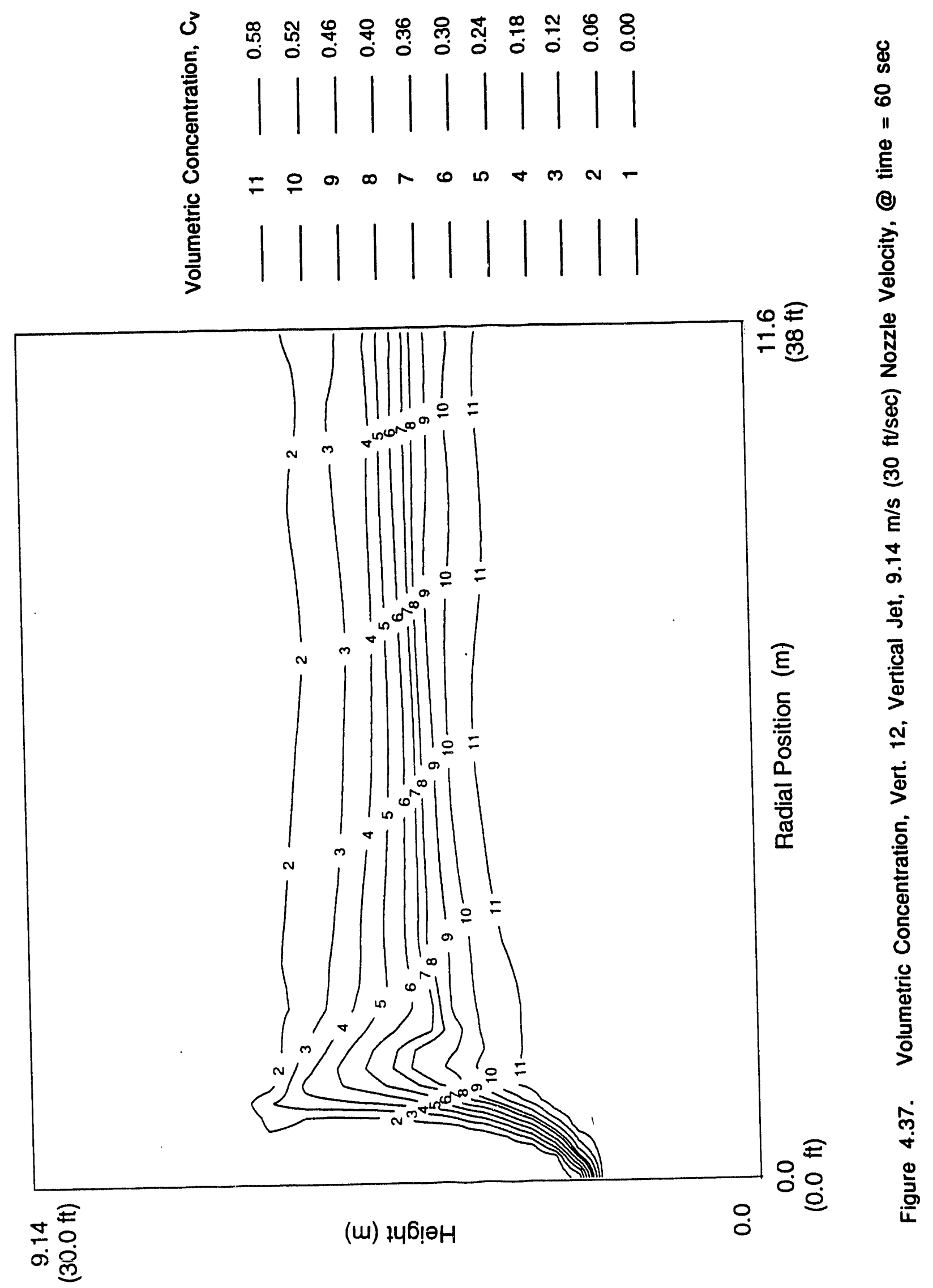




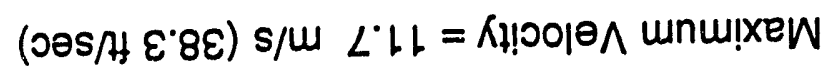

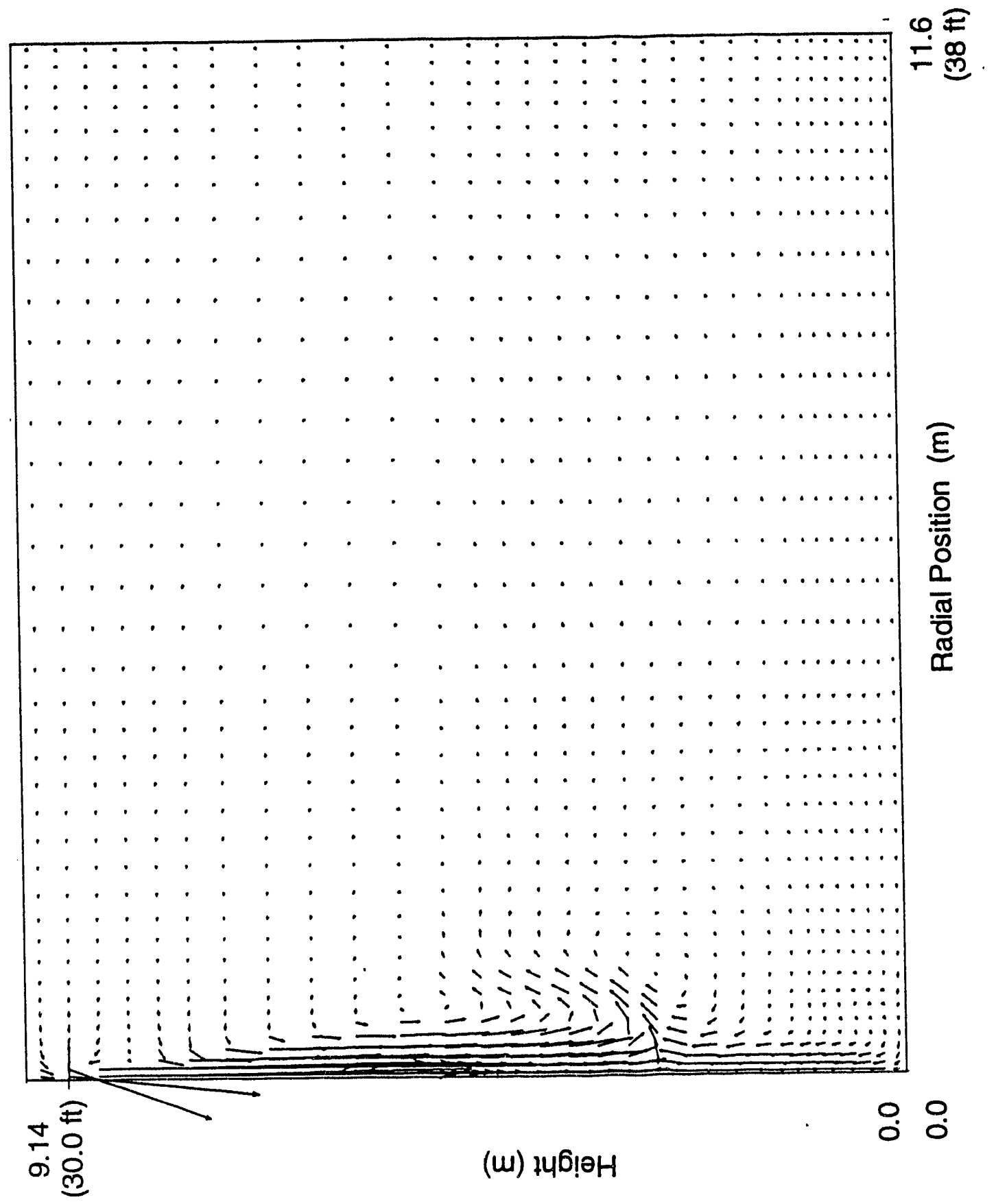

(e)

흥

$\frac{0}{N}$

导

으

है

$\pm$

Фं

.

กับ

宓 
(วәs/H $\varepsilon .8 \varepsilon) s / m L L L=\Lambda ! ! 00 \mid \theta \wedge$ unu!XeW

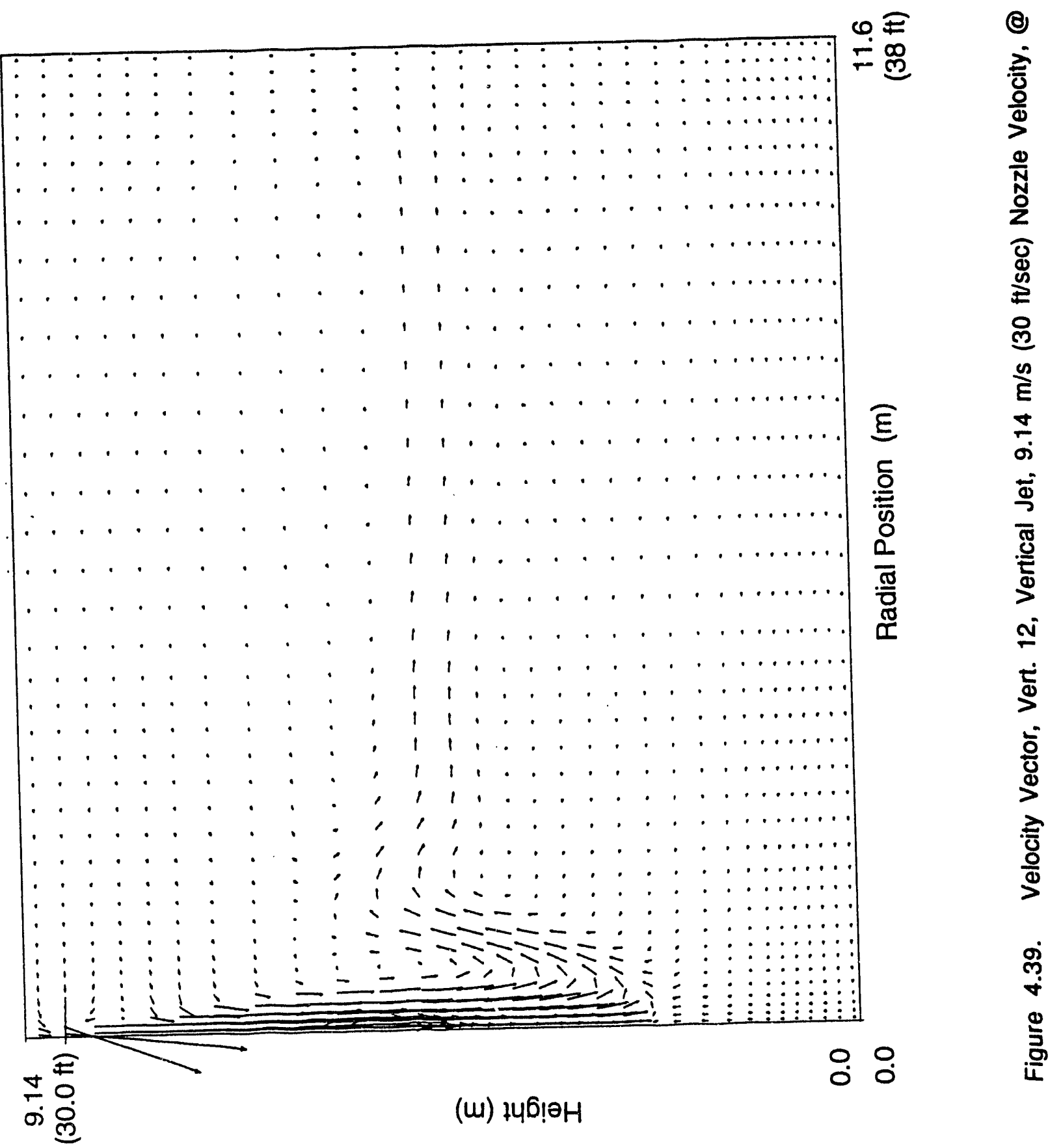




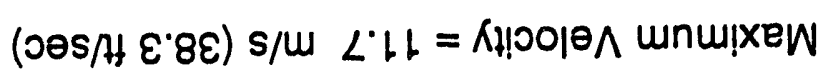

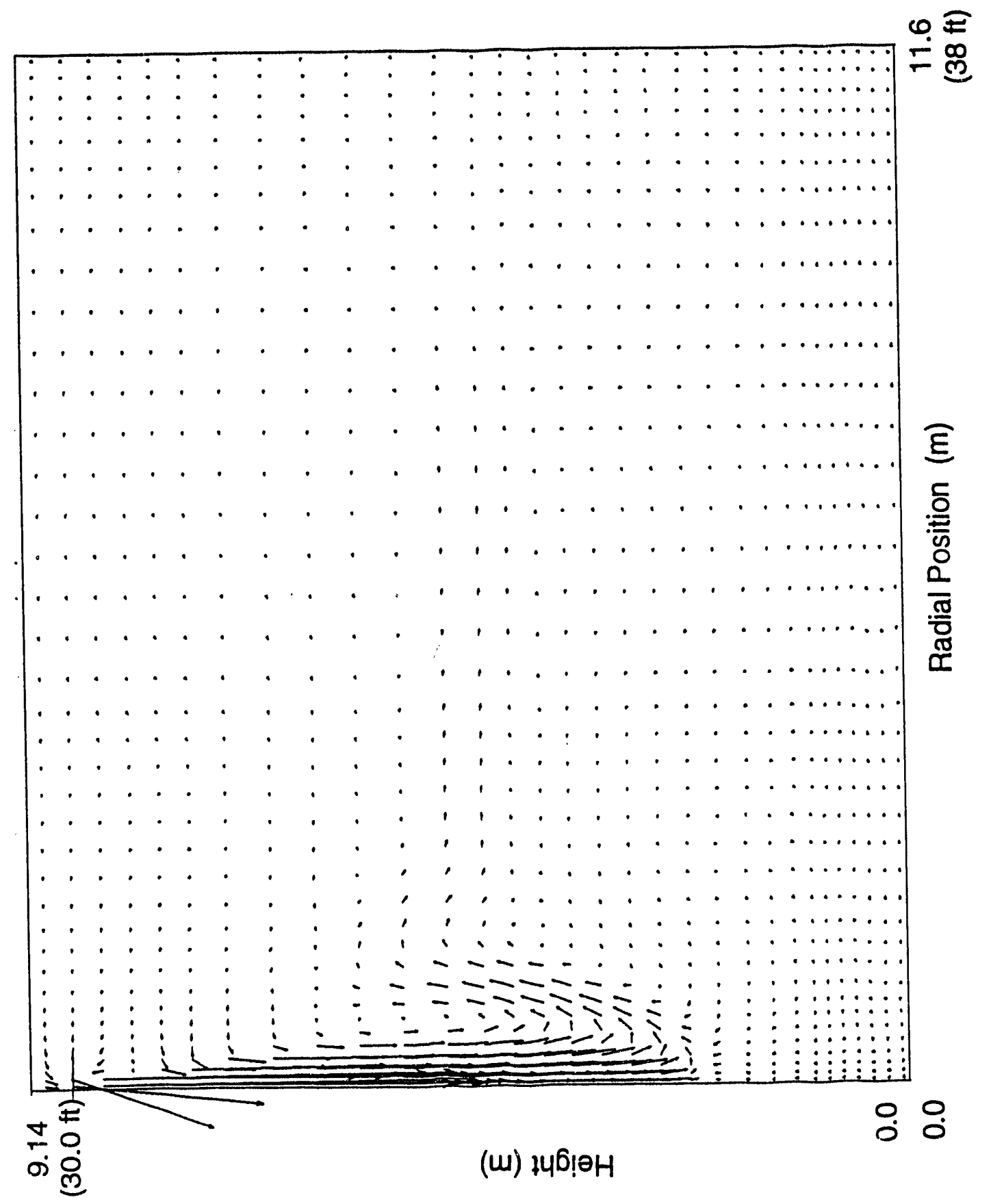

(C)

$\frac{3}{\frac{0}{0}}$

产

ब్

우

है

$\frac{\nabla}{\dot{\sigma}}$

$\dot{\Phi}$

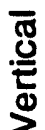

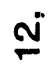

市

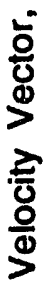

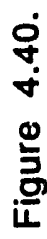

के

(w) $246 !$ 


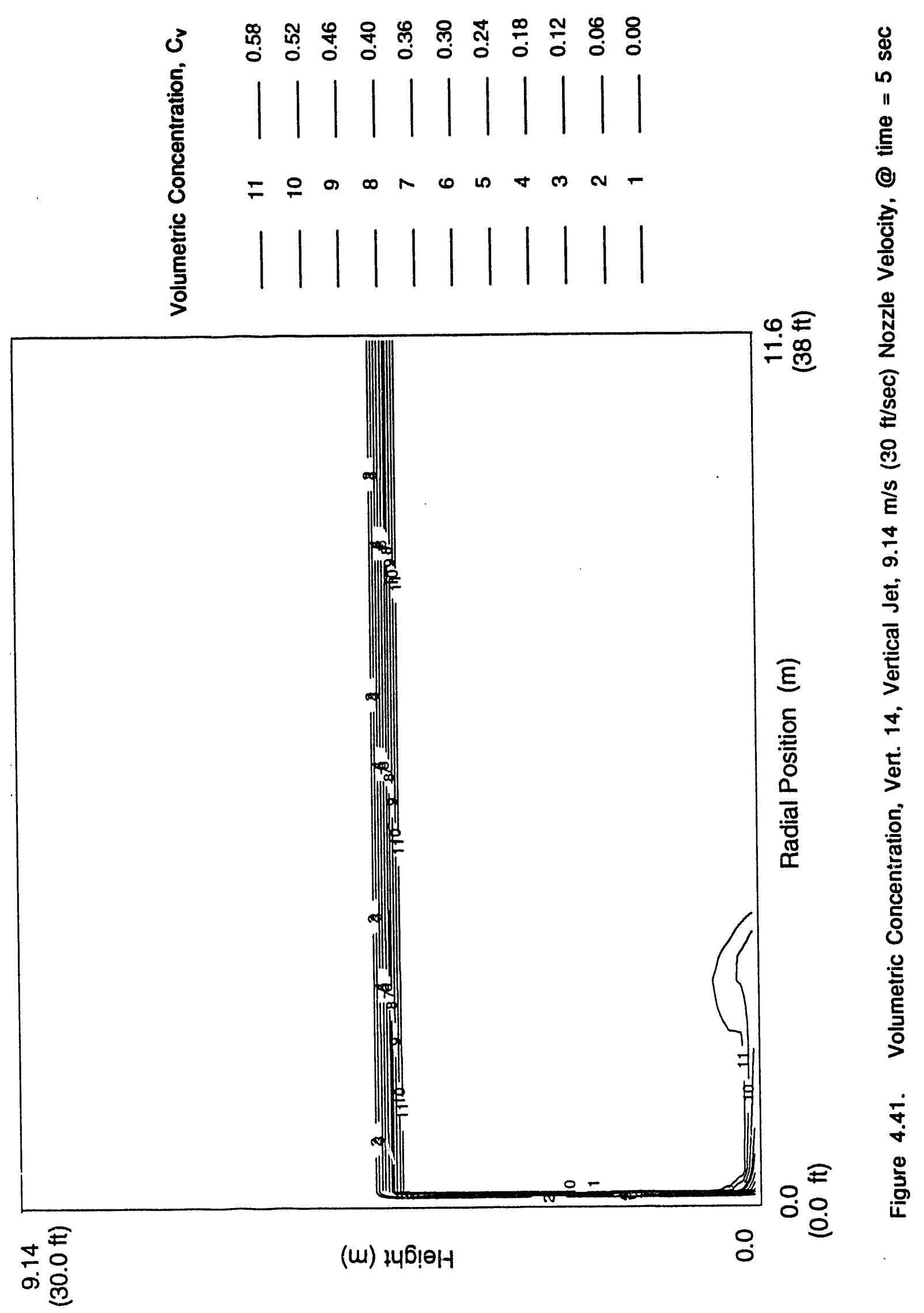




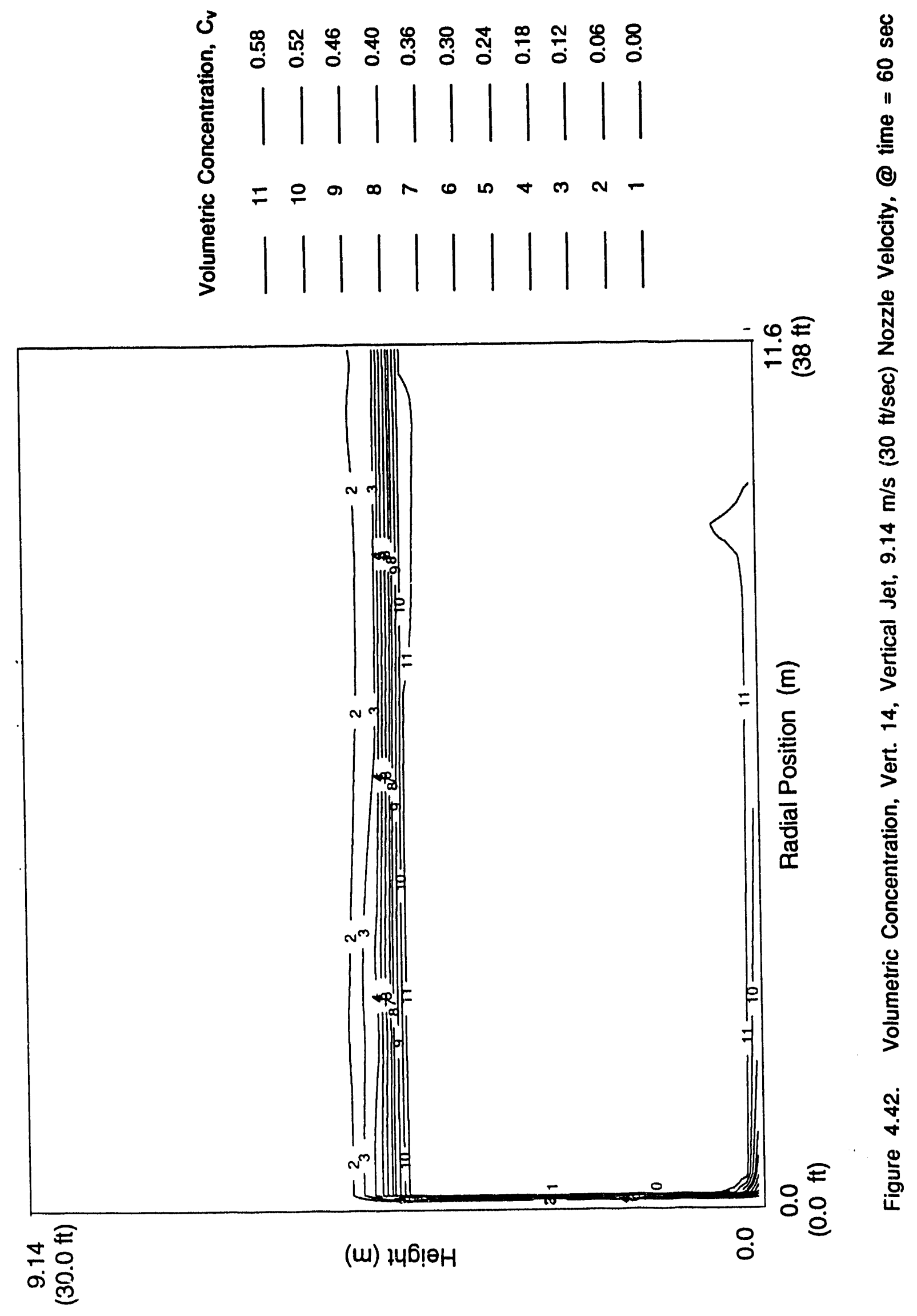




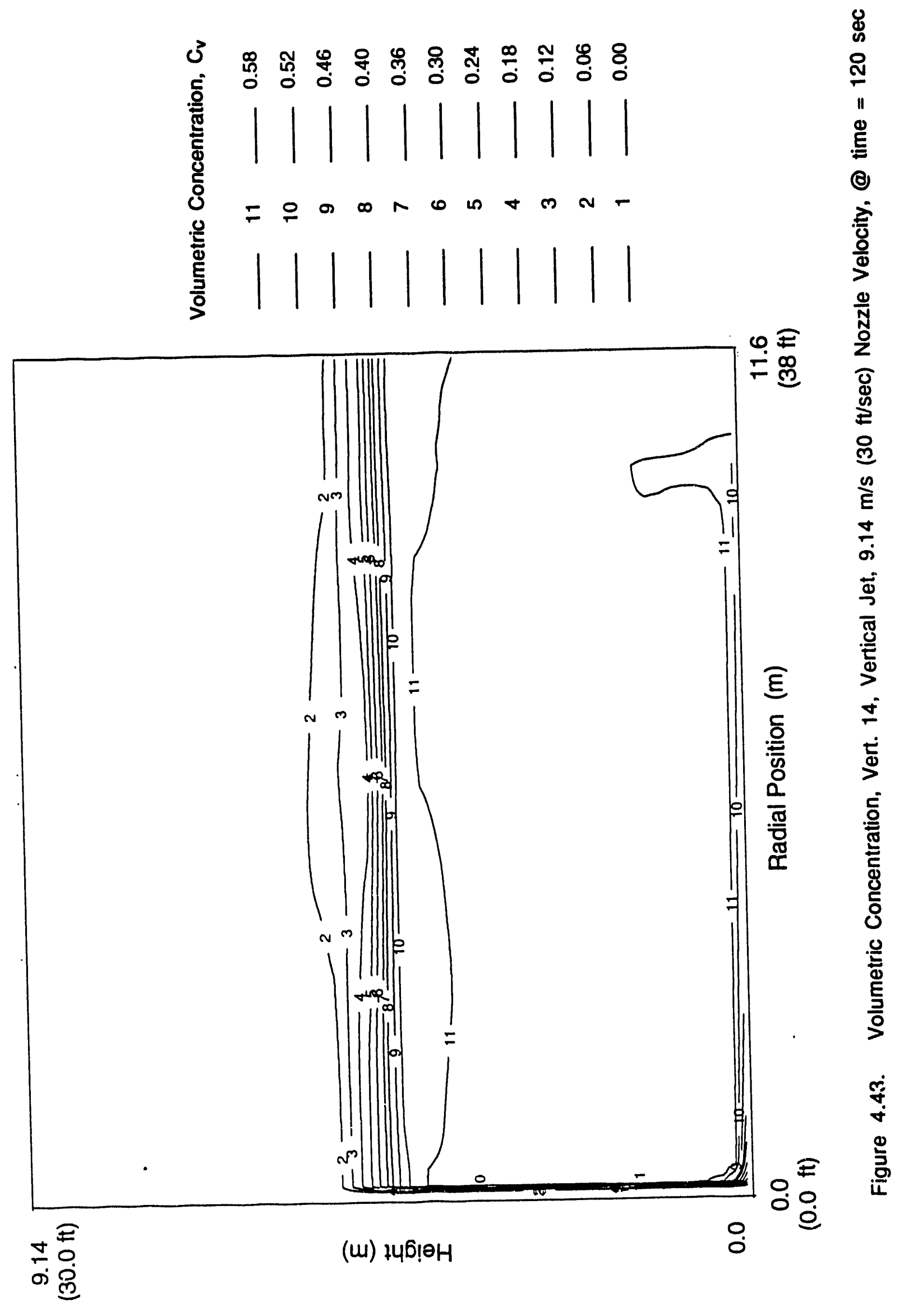



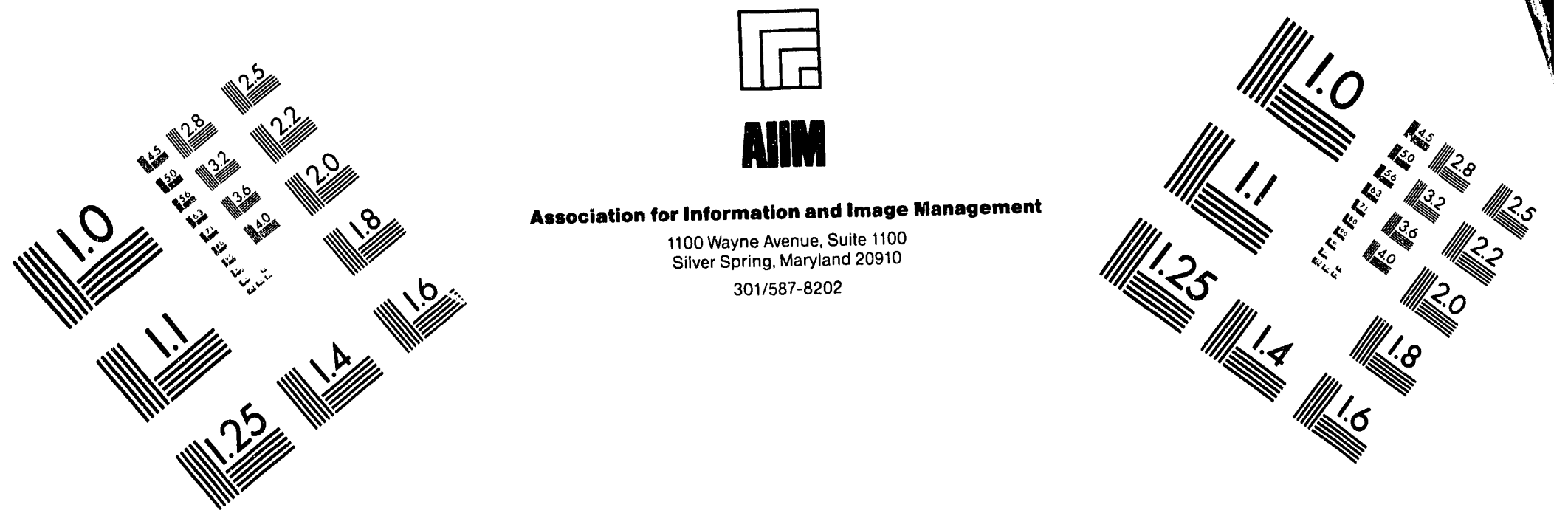

\section{Centimeter}

$\begin{array}{llllllllllllllll}1 & 2 & 3 & 4 & 5 & 6 & 7 & 8 & 9 & 10 & 11 & 12 & 13 & 14 & 15 & \mathrm{~mm}\end{array}$

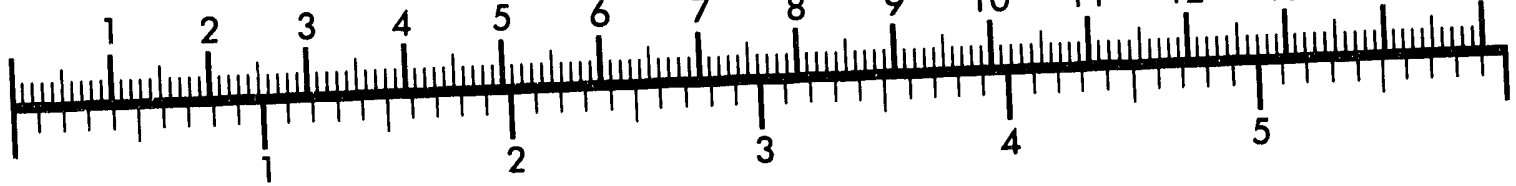
Inches
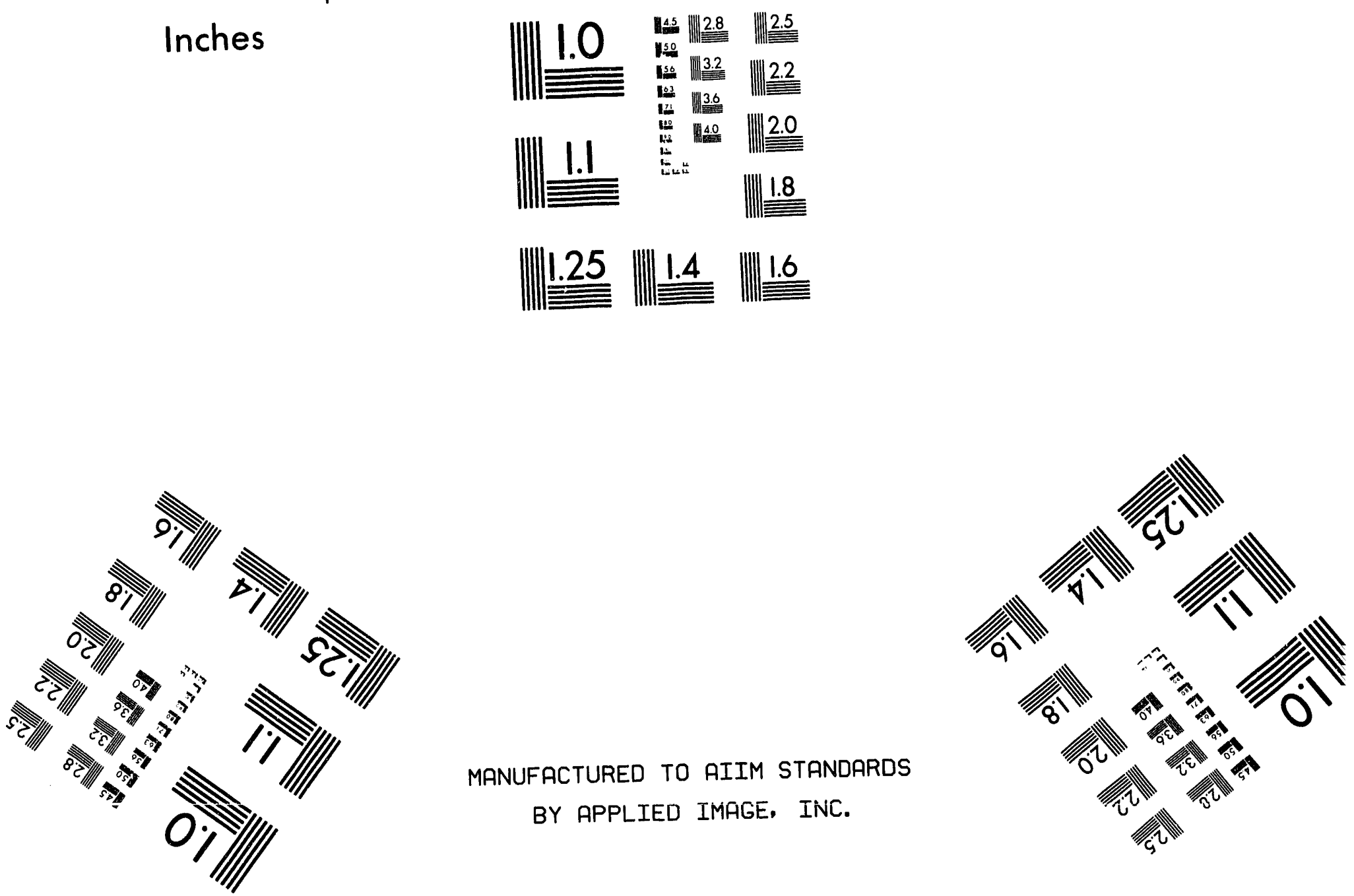

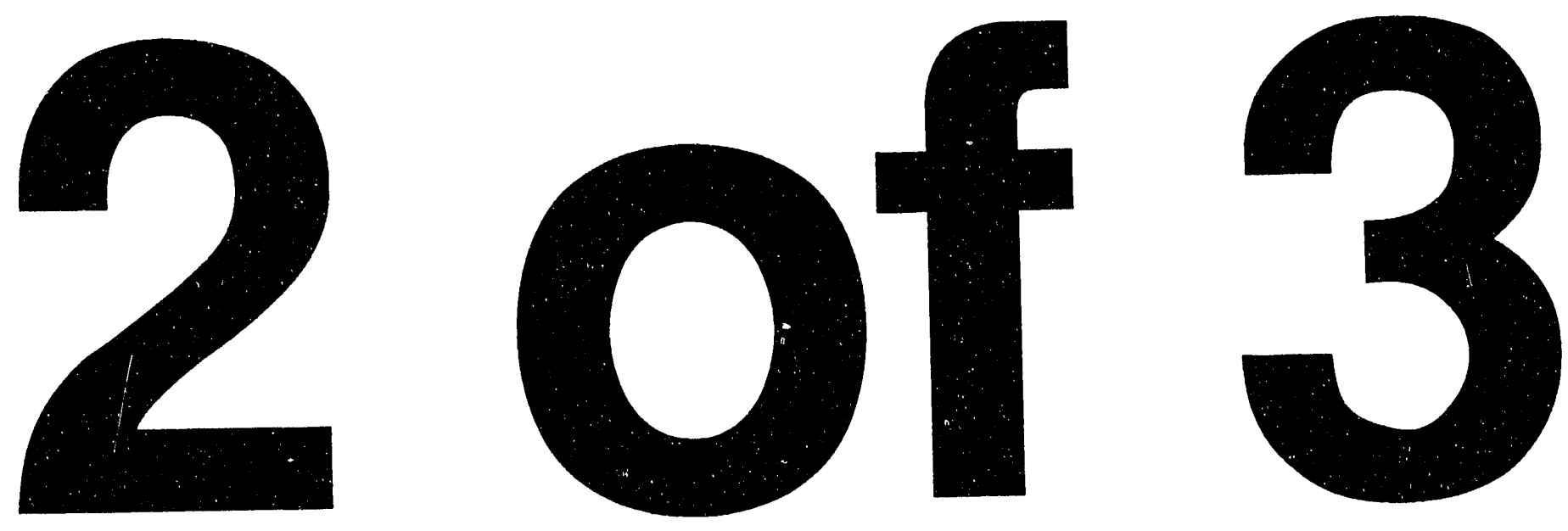


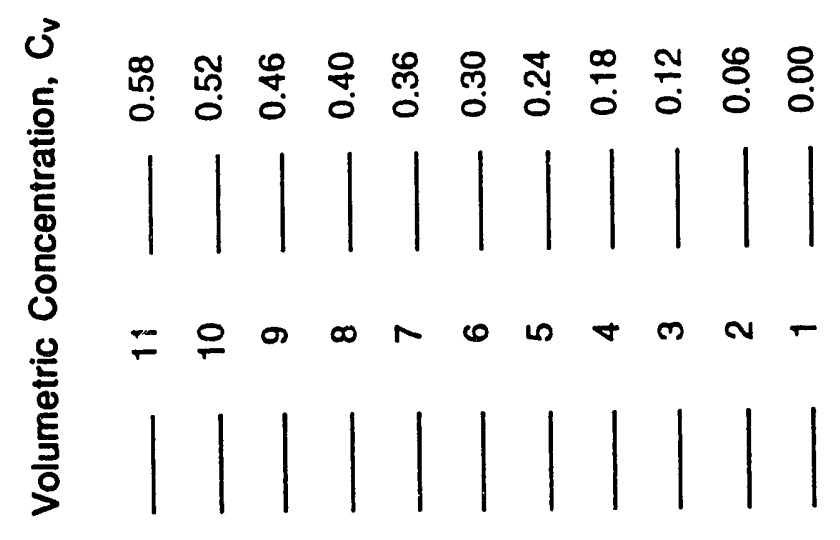

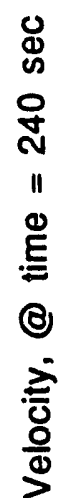

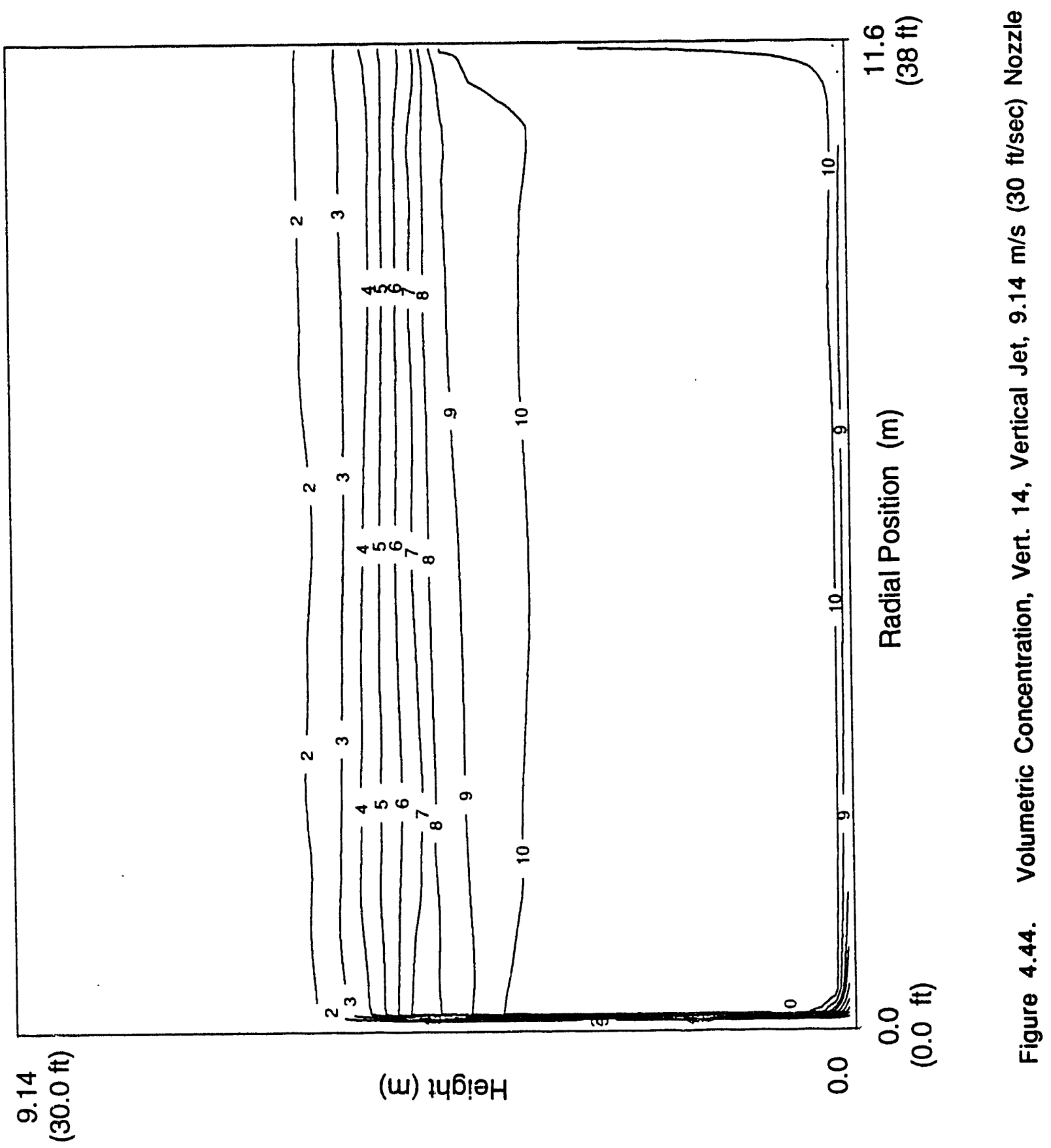




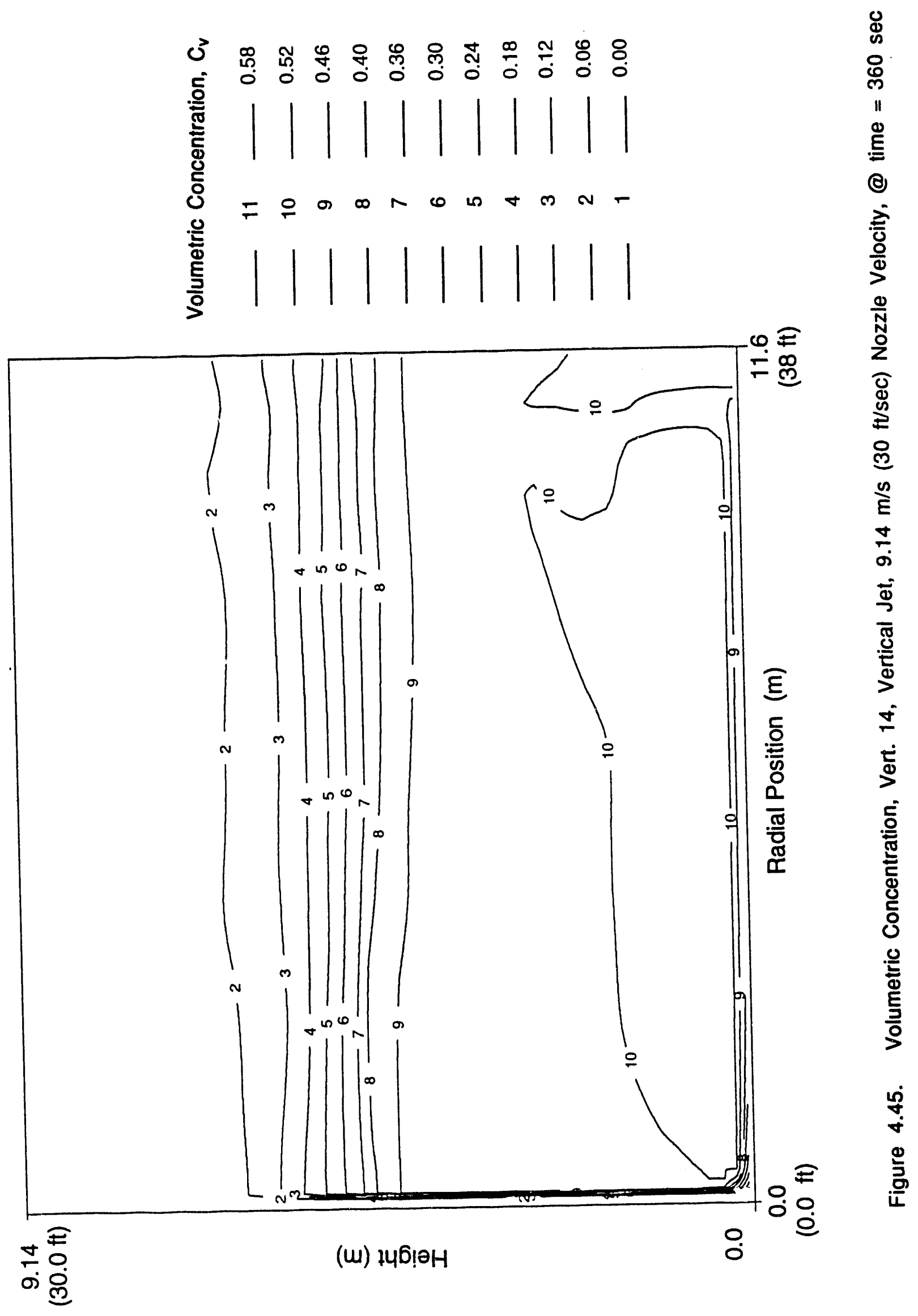




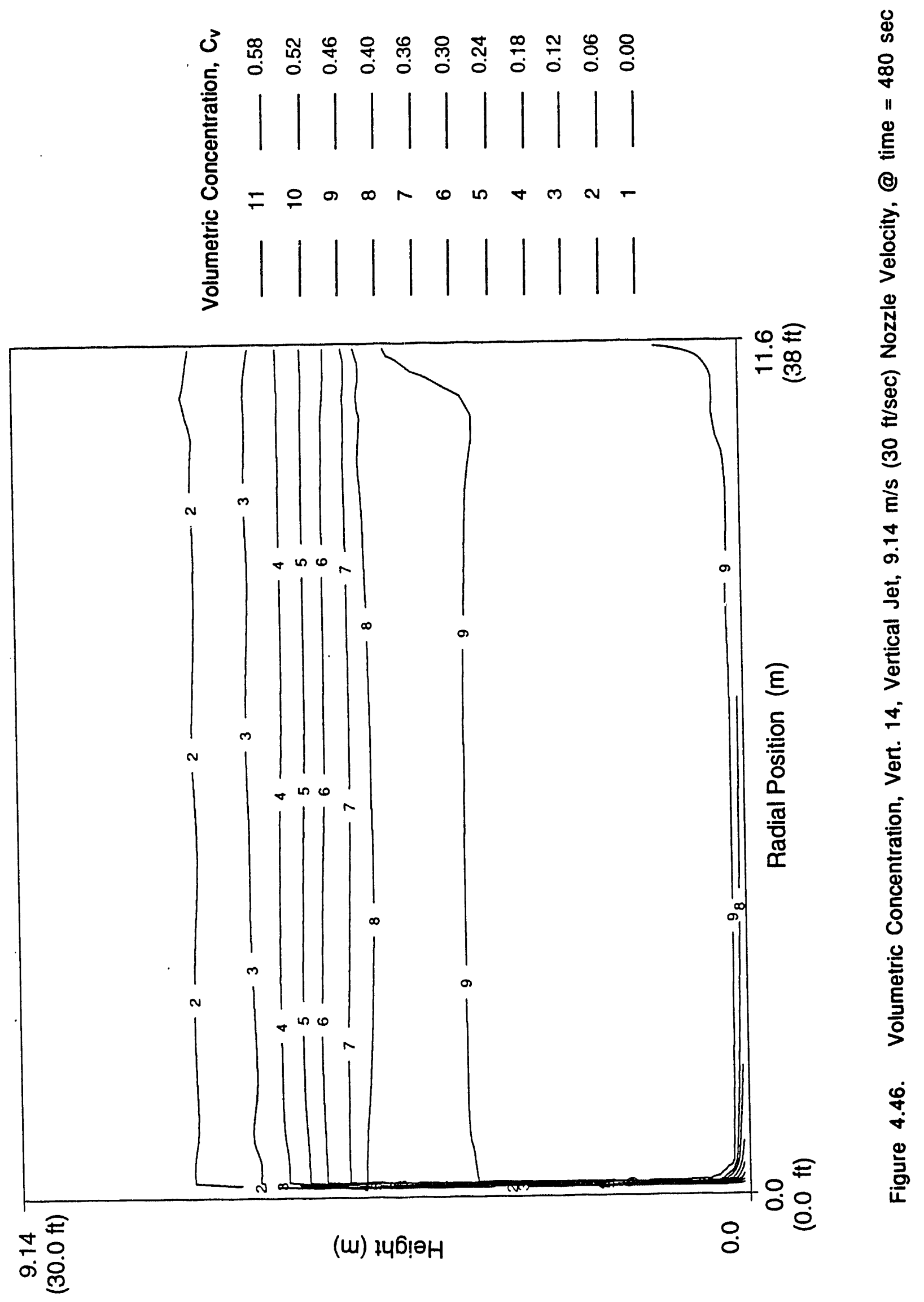




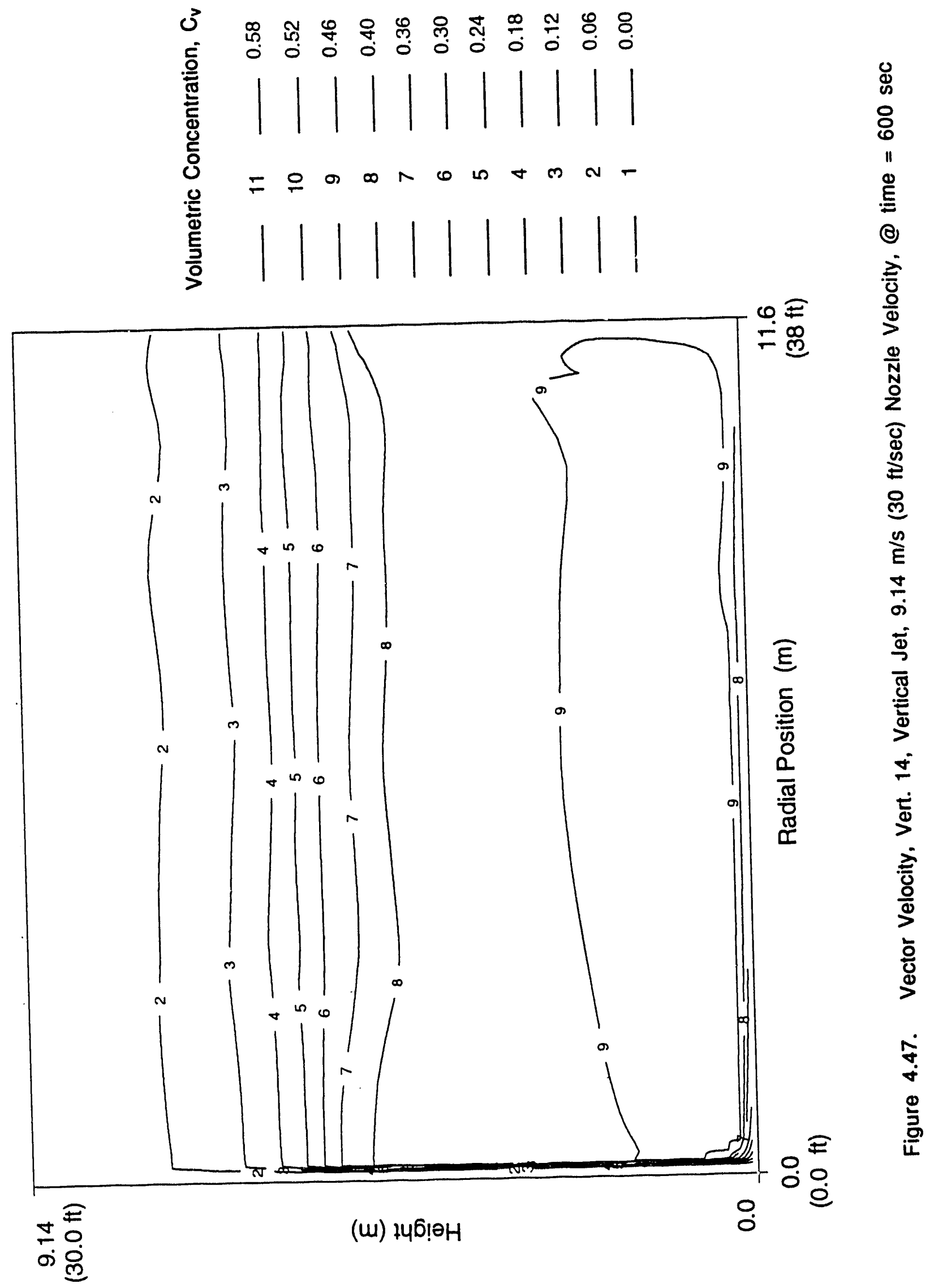


and allows the jet to have significant momentum as it is turned and proceeds in the radial direction. In reality, it is possible that the jet would rise upward due to buoyancy forces (the fluid in the jet having a notably lower density). However, in using a 2-dimensional model (assuming a plane jet), the jet must remain attached to the floor as no material is available to replace the space that would be vacated as the jet moved upward. This will be true if the jet momentum is high enough to dominate the buoyancy forces as the jet moves outward along the tank bottom to the wall. The same time sequences $(5,60,120,240,360,480$, and $600 \mathrm{sec})$ are presented in Figures 4.48 to 4.54 for the velocity vectors.

TEMPEST studies of jet mixing using a downward vertical jet have shown that with a sufficient volumetric flow rate the slurry region can be mobilized and mixed with the convecting layer located directly above. The problem with this approach is that extremely high jet flow rates are required to achieve the desired mixing. As an example, Case Vert. 5, in which TEMPEST predicted a fully mixed tank, was simulated using a 3.0-ft dia jet with a 30 -fps nozzle velocity. This equates to a flow rate of $95,152 \mathrm{gal} / \mathrm{min}$. The effectiveness of using horizontal jets with discharges on the order of $5,800 \mathrm{gal} / \mathrm{min}$ is discussed in the following section.

\subsection{Horizontal (Radial) Jets}

The cases investigated are presented in Table 4.2 at the end of Section 4.0. Two geometries were modeled using 3-d TEMPEST models. Three simulations of a $90^{\circ}$ sector of the tank (Figure 3.12) were carried out with two opposed fixed horizontal 2.6-in. diameter jets with nozzle velocities of 15,45 , and $87 \mathrm{ft} / \mathrm{sec}$, along with a simulation of a $180^{\circ}$ sector of the tank that incorporated a scheme of jet pulsing and incremental rotation of the jet to sweep along the tank bottom.

\subsubsection{Horiz. 1, Horiz. 2, and Horiz. 3}

The objective of these first three simulations was to study the effectiveness of horizontal jets in mobilizing the slurry region. Three jet discharge velocities were investigated.

Contours of particle concentration at $15 \mathrm{sec}$ into jet operation are presented in Figures 4.55 to 4.57 for $15 \mathrm{ft} / \mathrm{sec}, 45 \mathrm{ft} / \mathrm{sec}$, and $87 \mathrm{ft} / \mathrm{sec}$. The contours are provided at the vertical plane through the jet centerline. While the $15 \mathrm{ft} / \mathrm{sec}$ jet in Horiz. 1 (Figure 4.55 ) has little impact at $15 \mathrm{sec}$, the $45 \mathrm{ft} / \mathrm{sec}$ jet in Horiz. 2 (Figure 4.56) has influence radially outward past the midpoint of the tank. In Horiz. 3, (Figure 4.57), the $87 \mathrm{ft} / \mathrm{sec}$ jet has reached on the interface between the slurry and the convecting layer and impinged on the tank outer wall.

The three cases are displayed in Figure 4.58 to 4.60 after $240 \mathrm{sec}$ of jet operation. For that simulated time, it is observed that the $15 \mathrm{ft} / \mathrm{sec}$ jet in Horiz. 1 (Figure 4.58) has a 


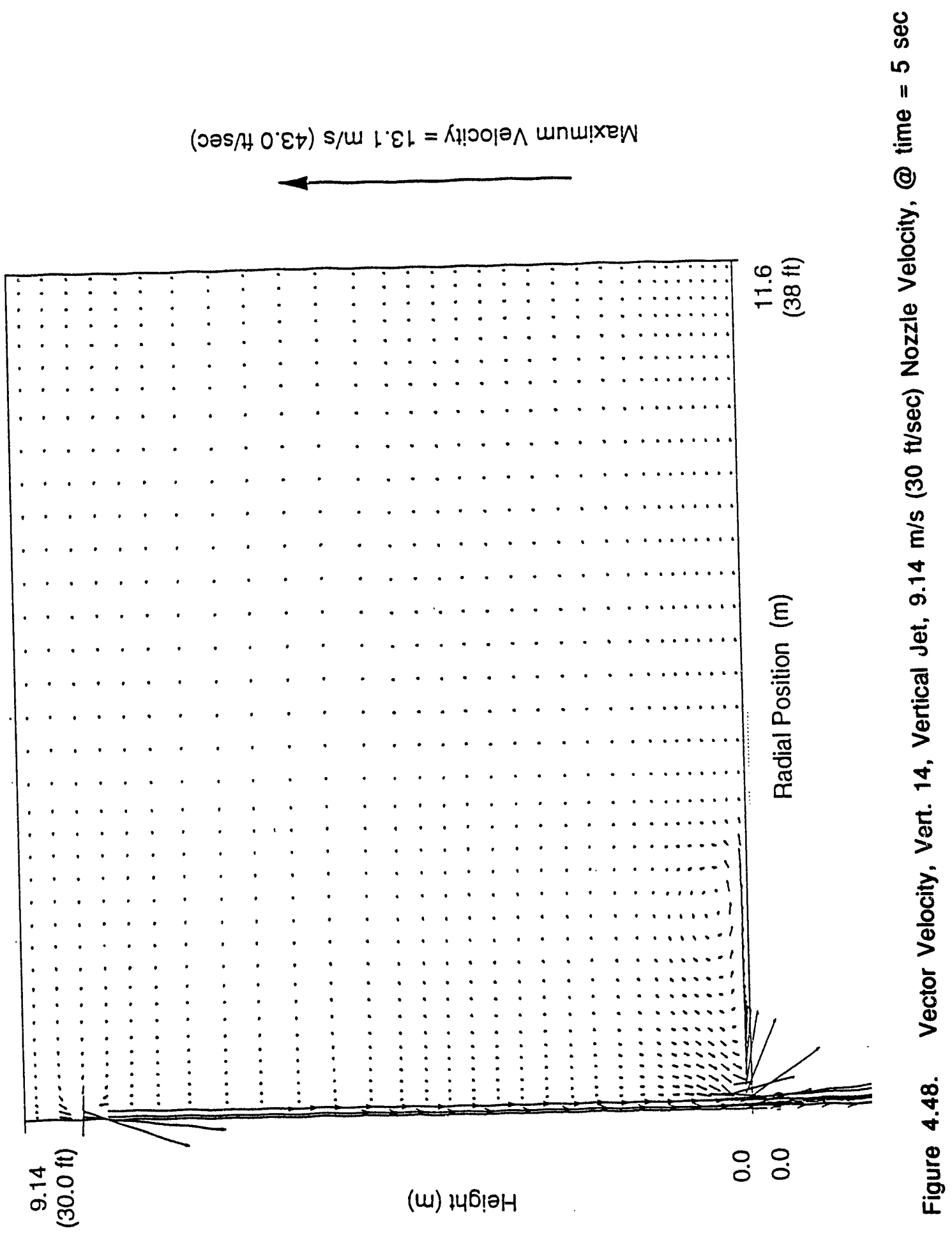




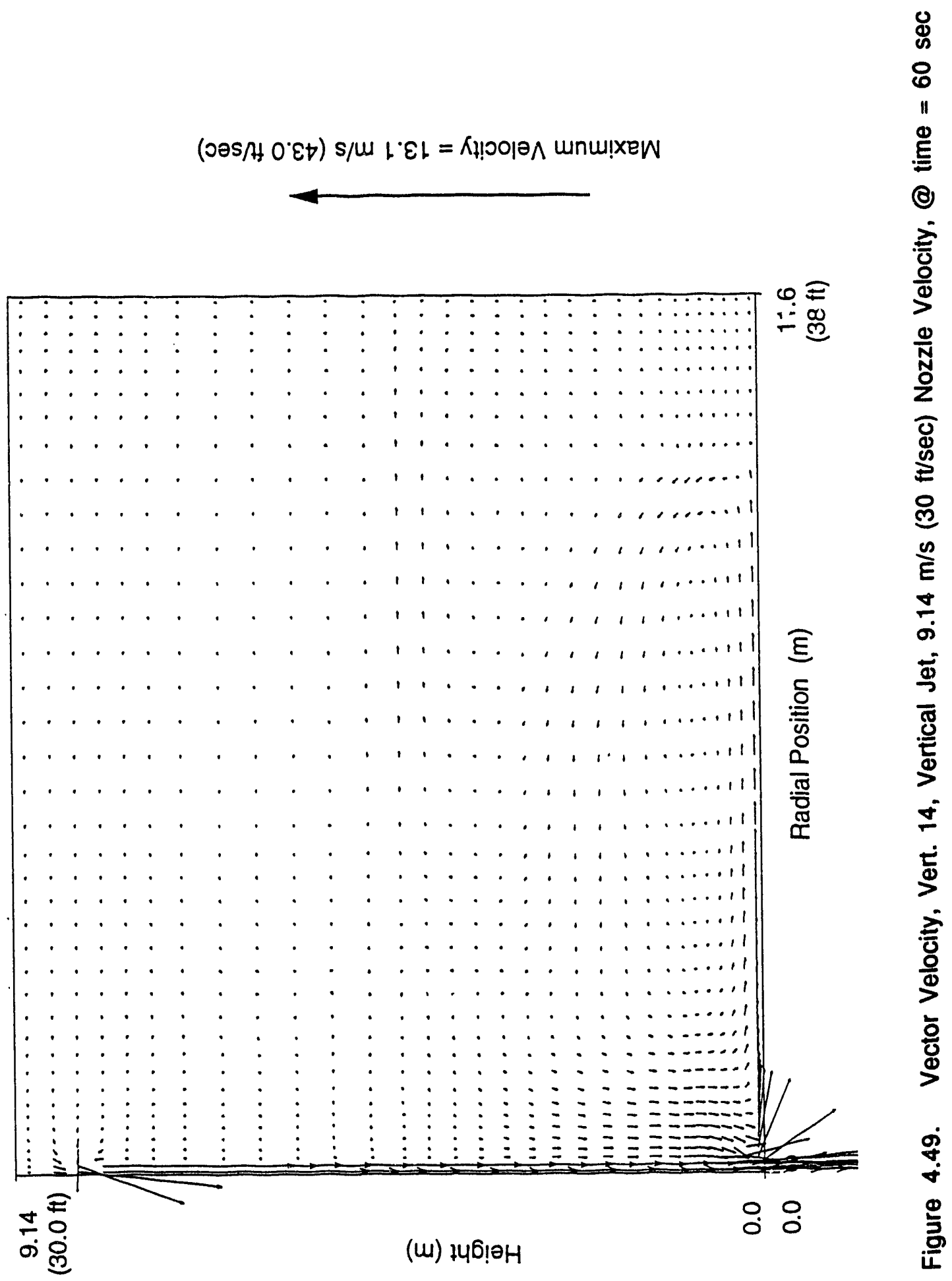


年

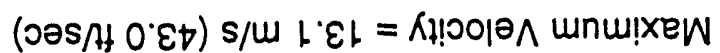

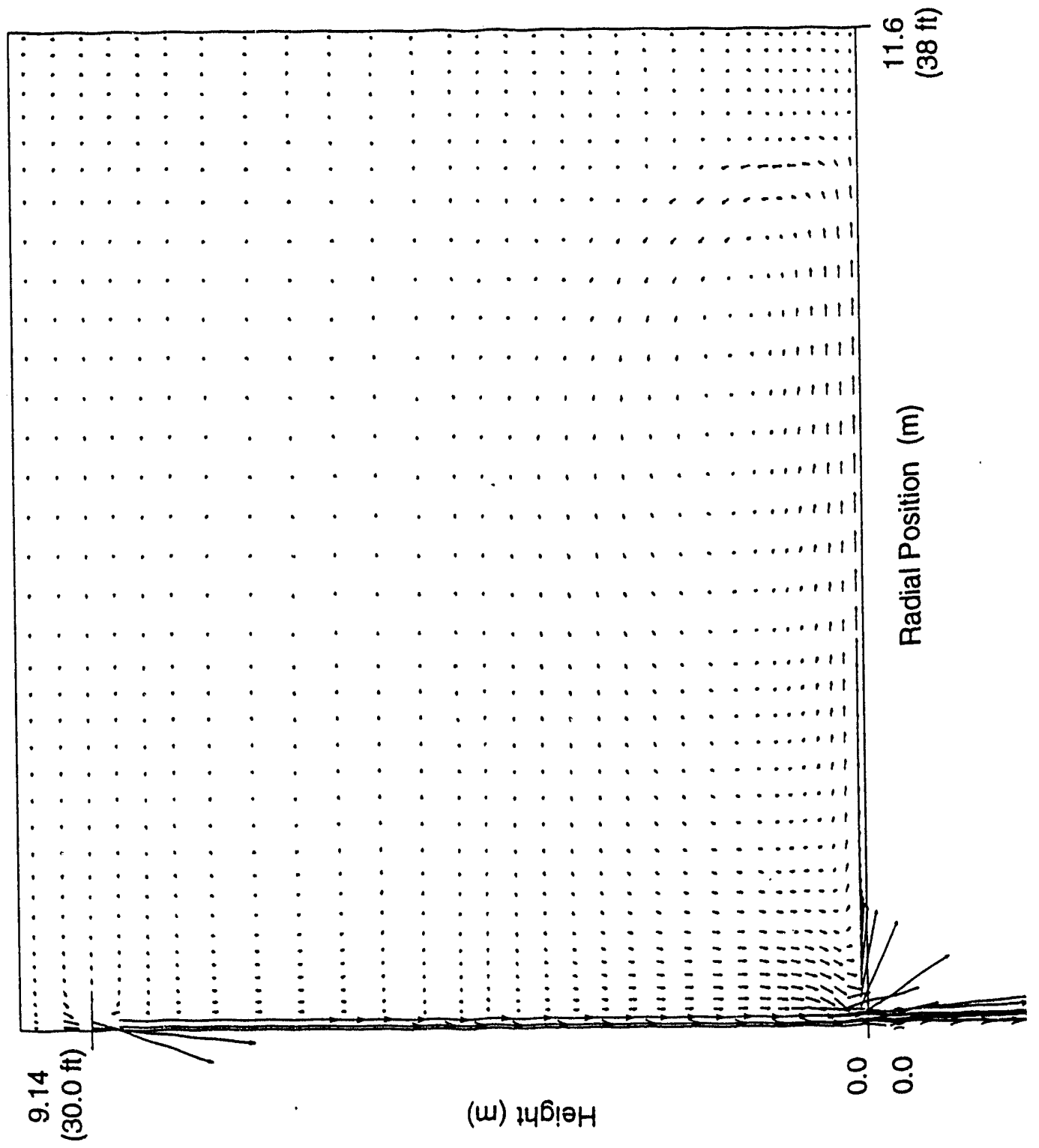




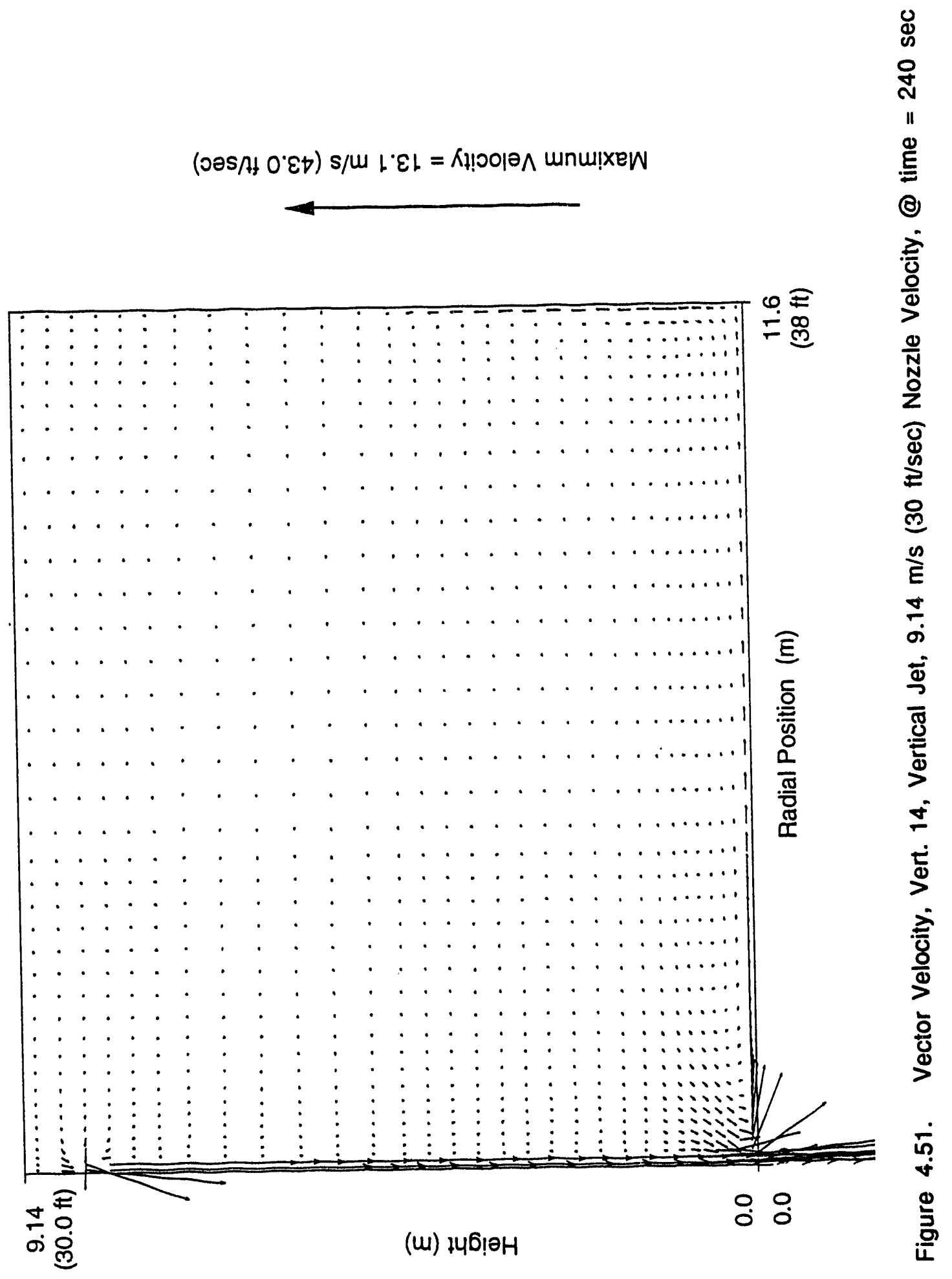




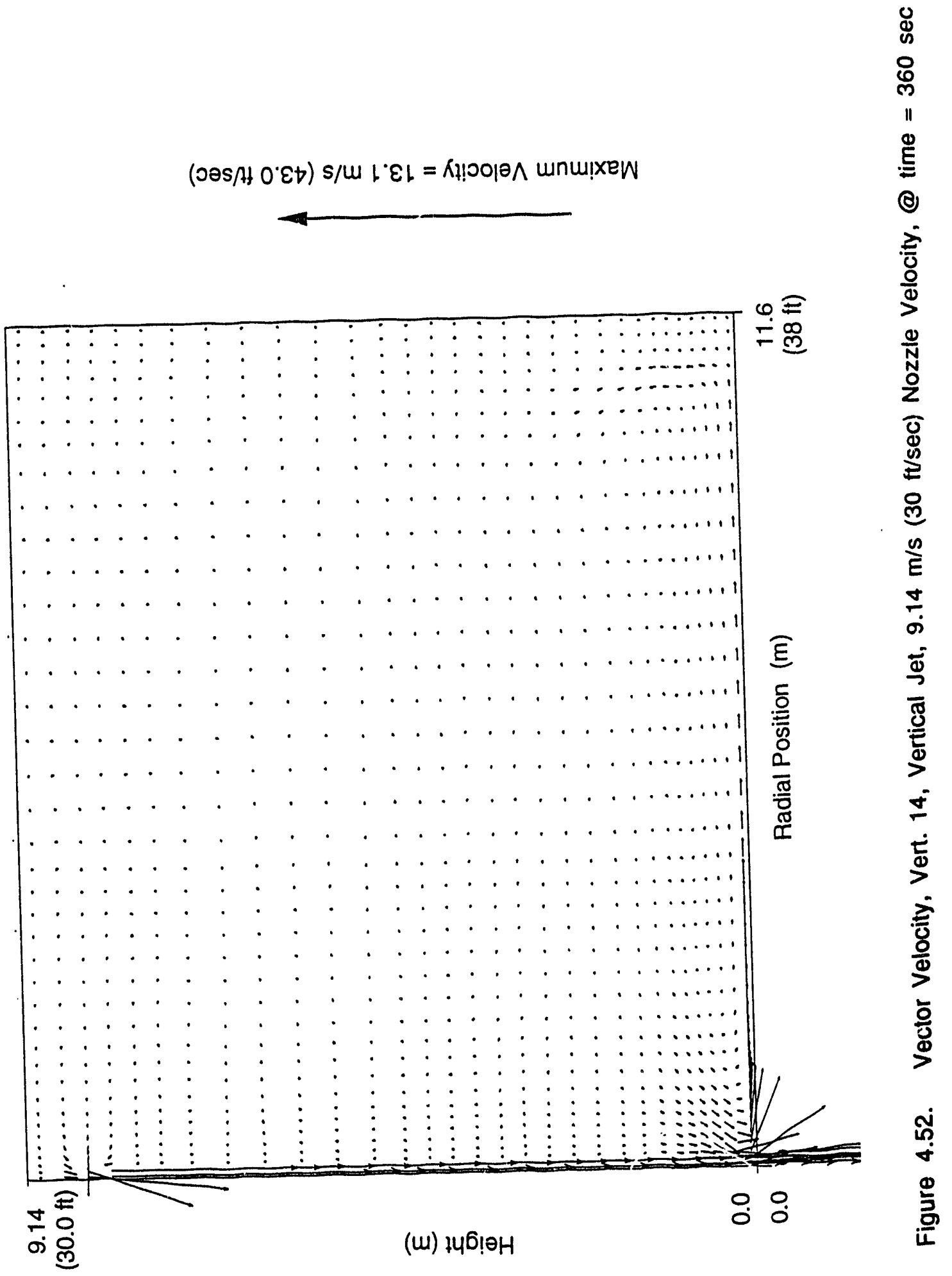




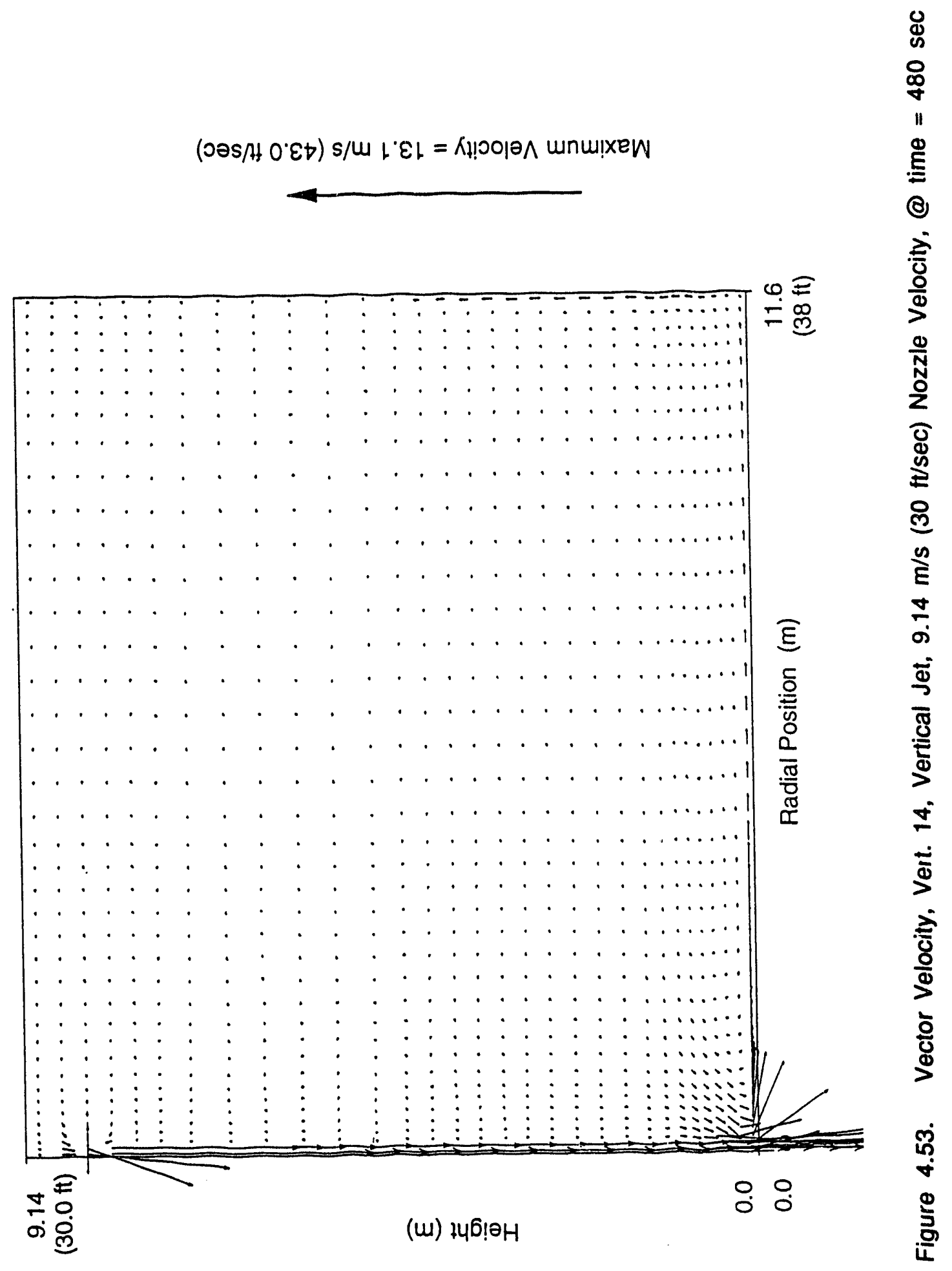




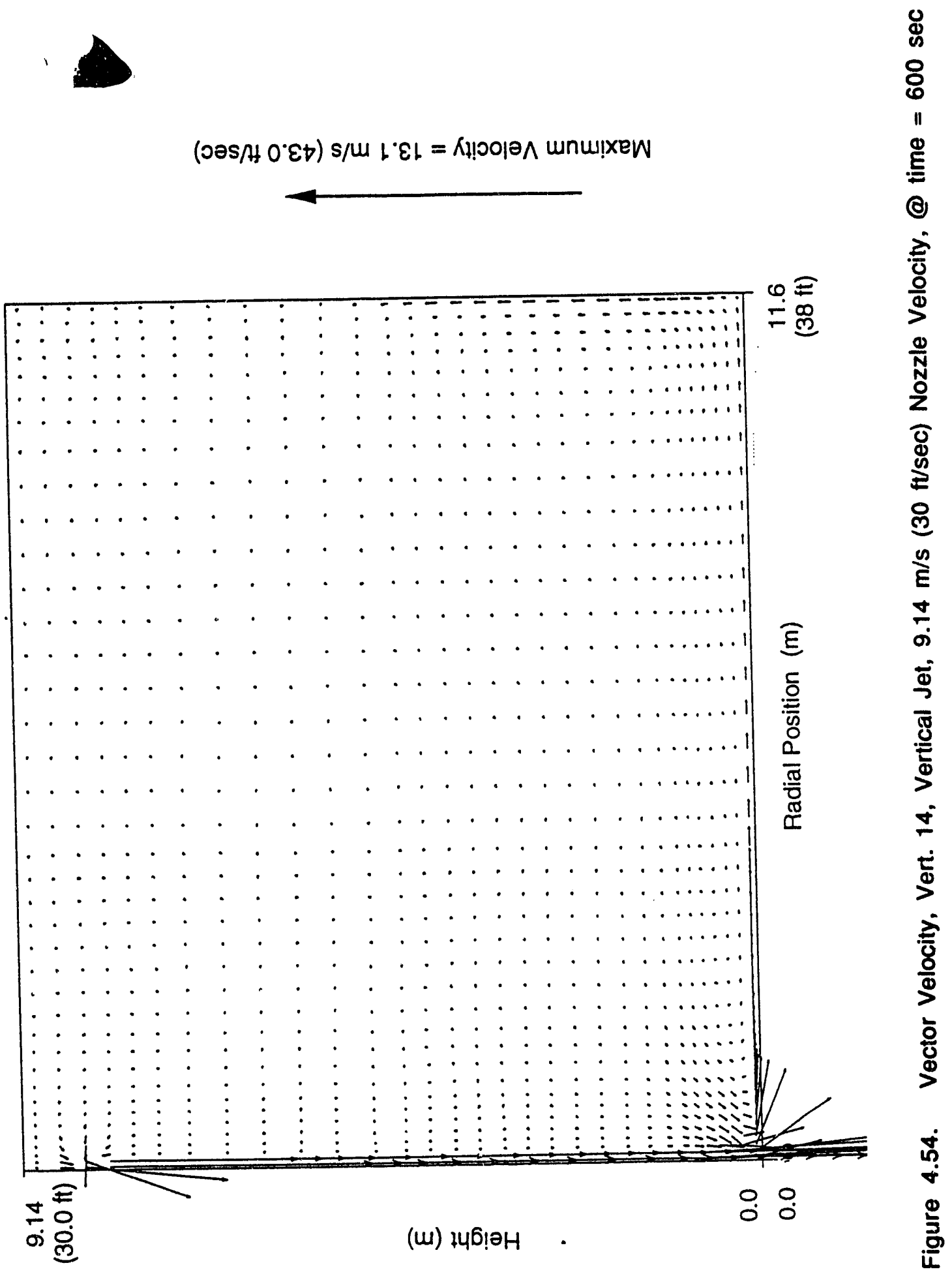




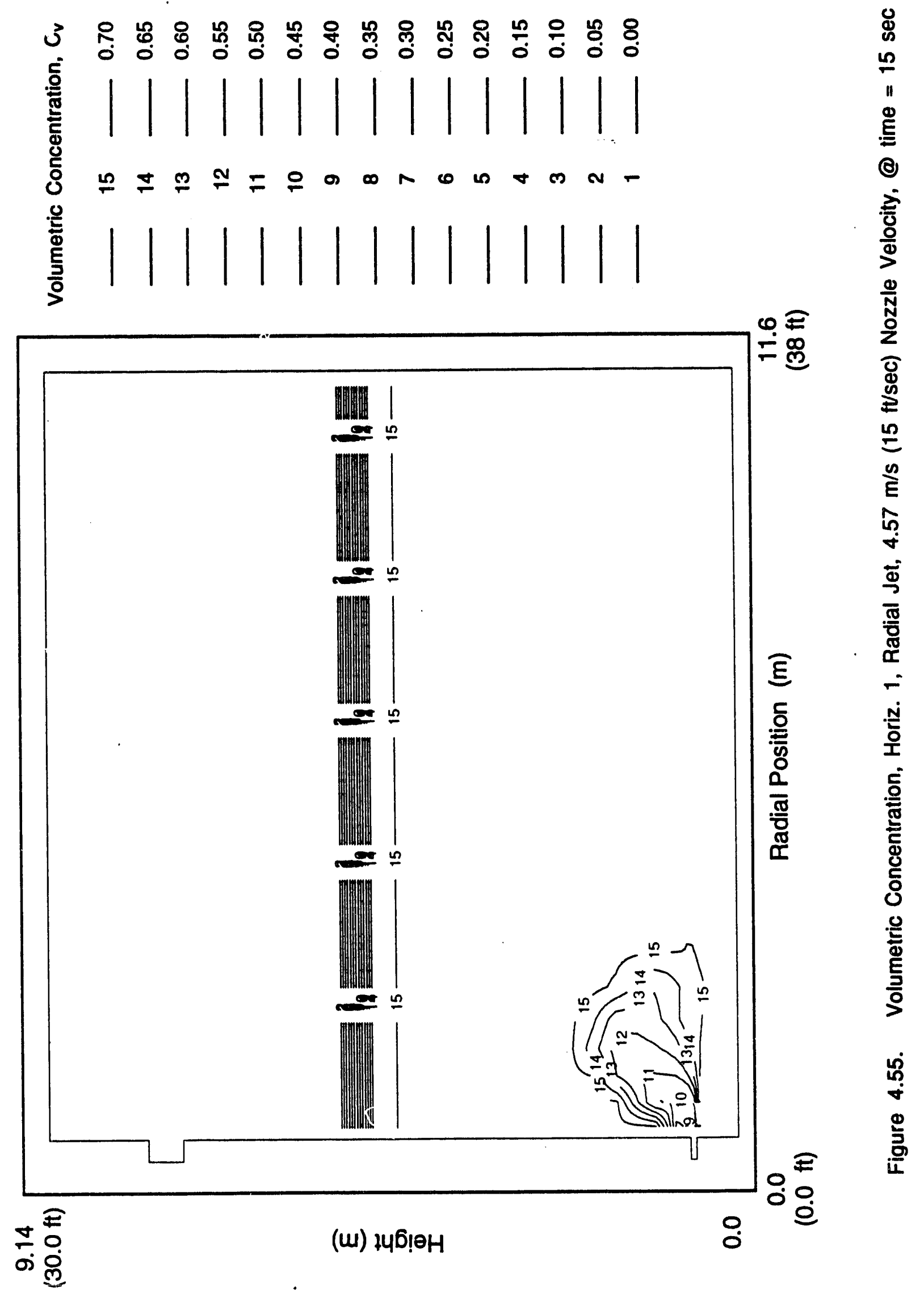




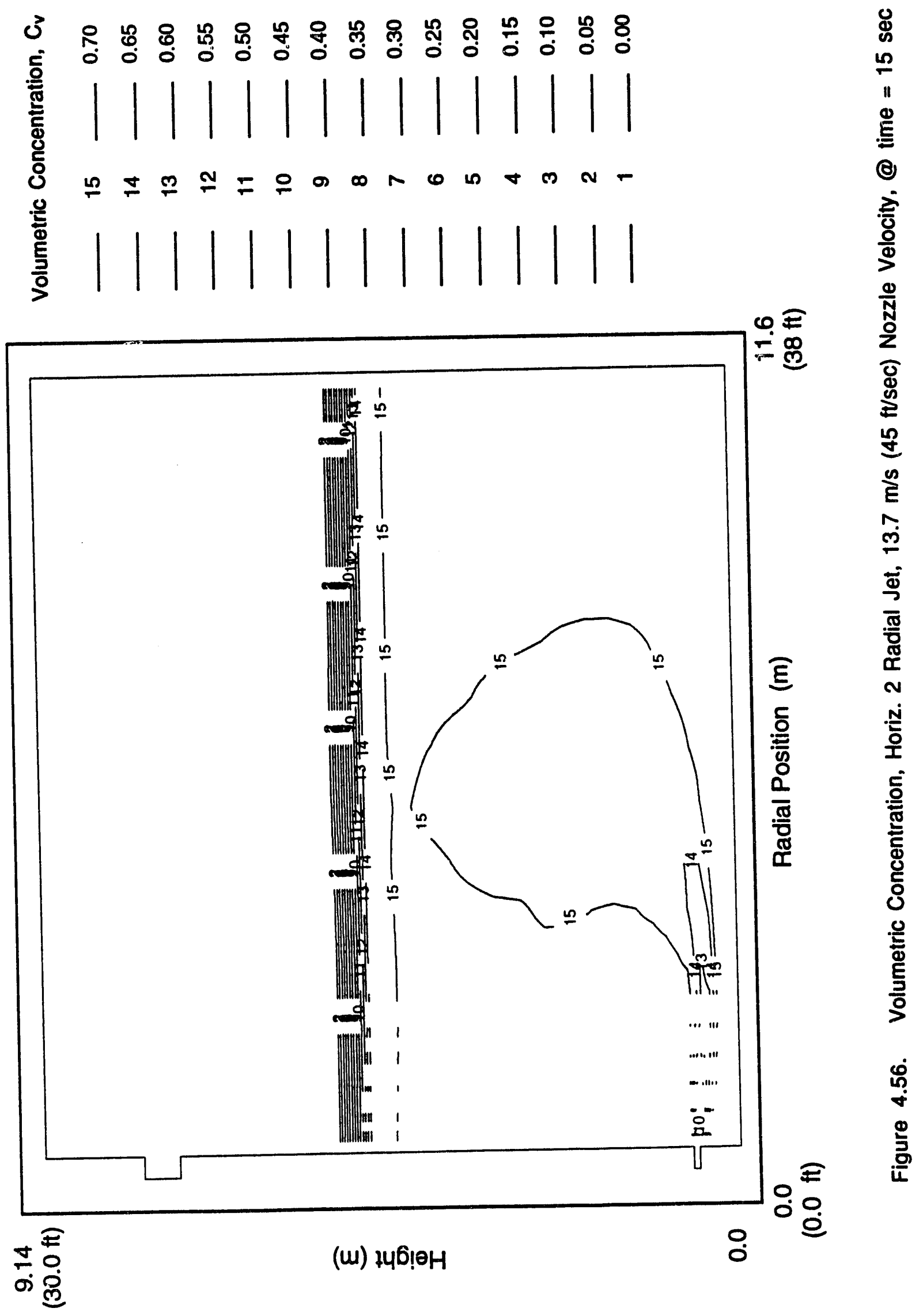




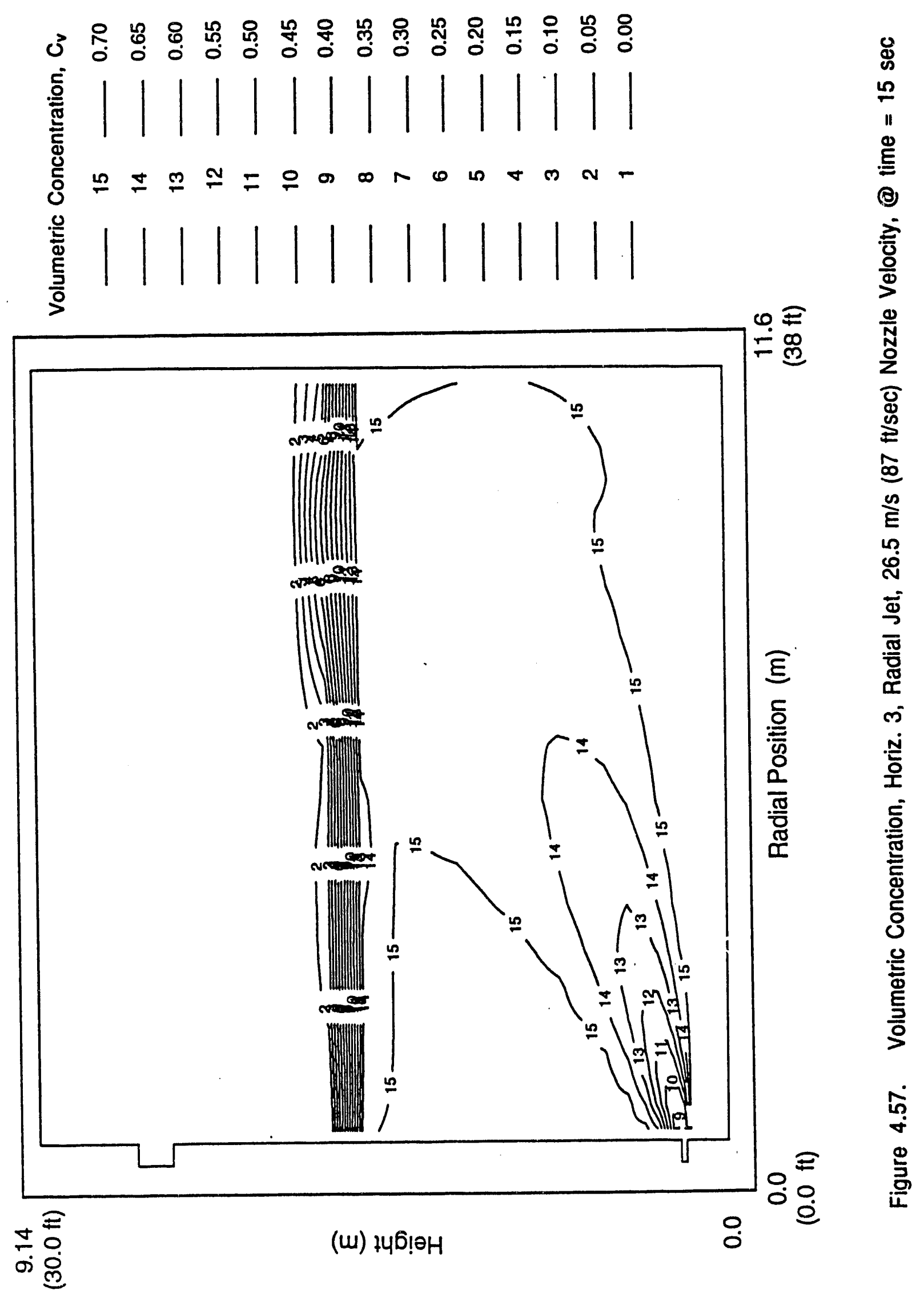




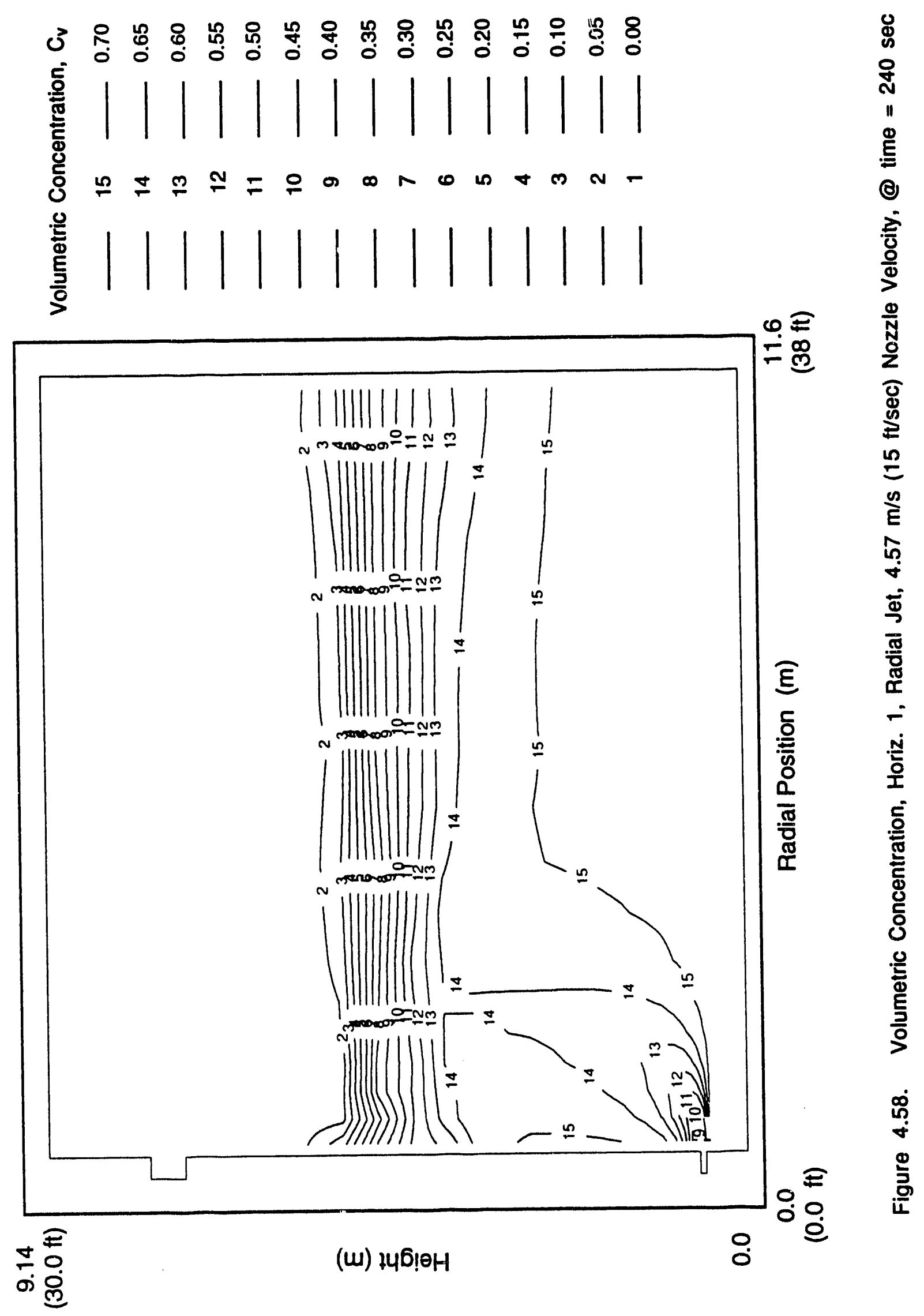




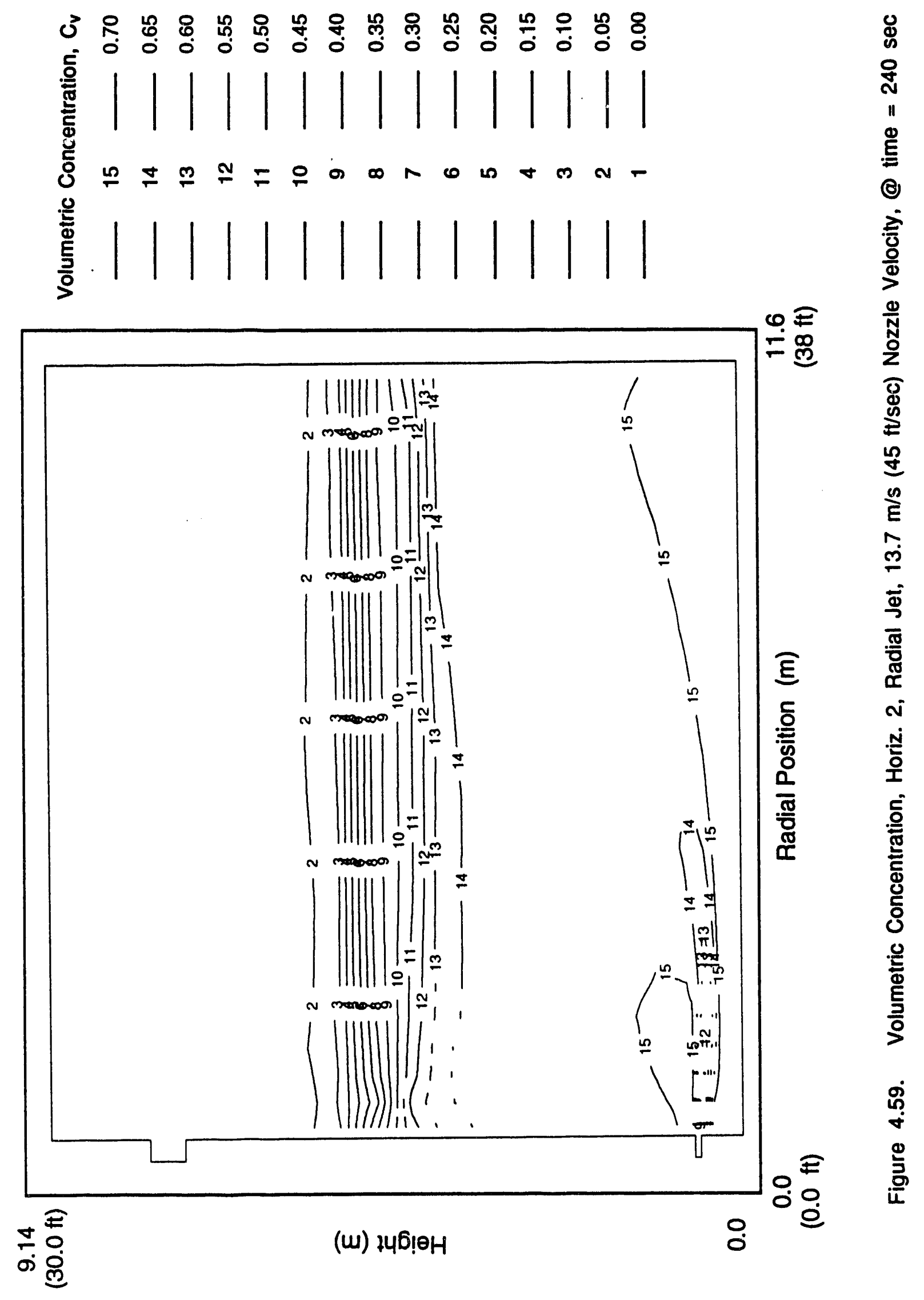




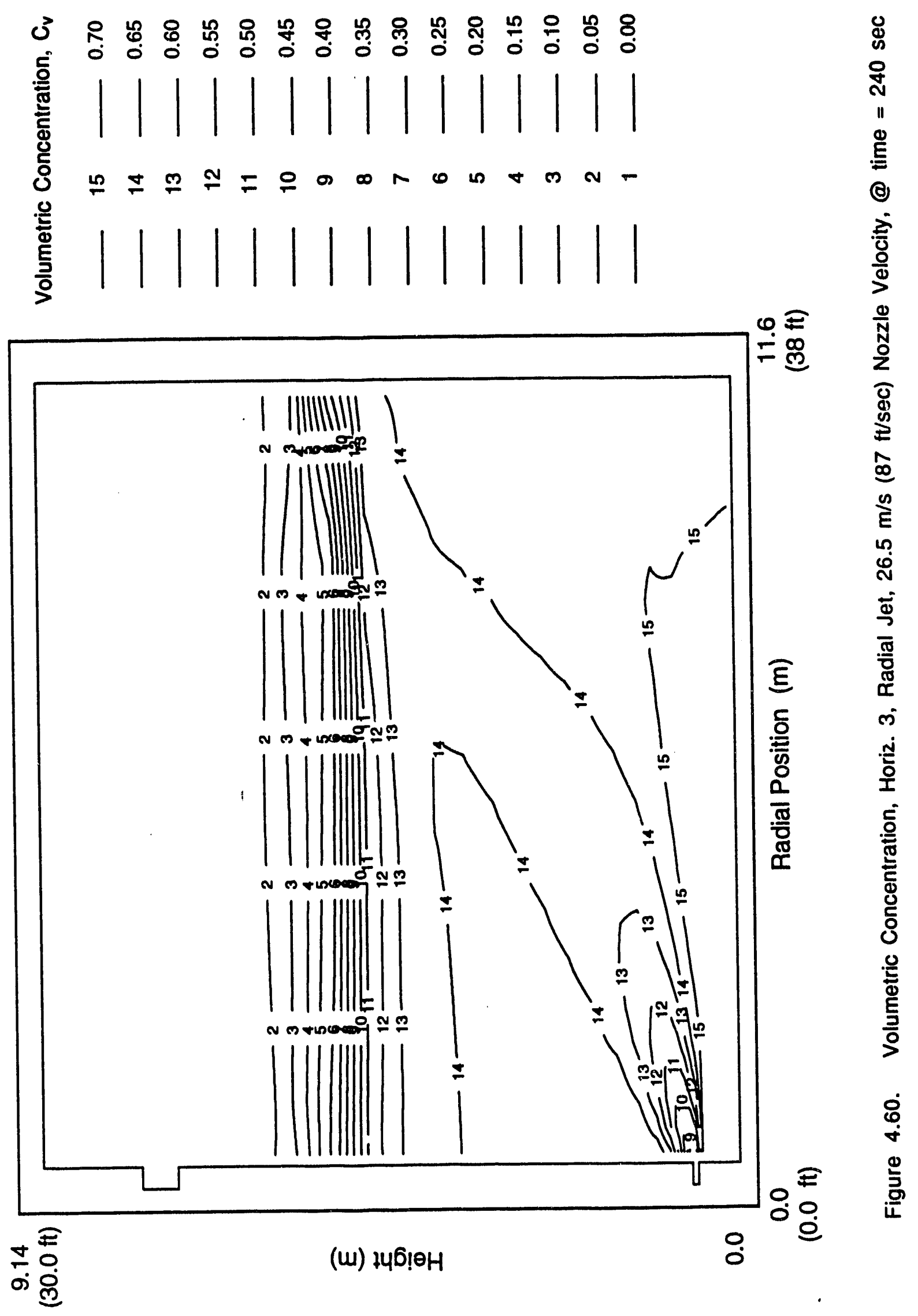


significant bank of high concentration slurry yet to be fluidized. The $45 \mathrm{ft} / \mathrm{sec}$ jet in Horiz. 2 has fluidized the slurry in front of the jet somewhat (Figure 4.59); however, mobilization of the particles in the slurry appears to be very slow. Horiz. 3, the $87-\mathrm{ft} / \mathrm{sec}$ jet, has fluidized much of the slurry region, but circulation of the slurry material remains slow.

From these first three cases, it is concluded that fluidization of the fluid slurry with 15to $87-\mathrm{ft} / \mathrm{sec}$ horizontal jets through a 2.6-in. diameter nozzle does not appear to be feasible.

This approach may be used if mobilization is acceptable; however, the impact the horizontal jets is limited to a small area in front of the discharge location. For this reason, another simulation (horiz. 4) was carried out for a $180^{\circ}$ sector with the jets rotating about the vertical axis in an effort to influence all areas of the tank.

\subsubsection{Horiz. 4}

Leaving the opposed jets in a single location is not the most effective approach for mobilizing or fluidizing the slurry region in the tank. Horiz. 4 was designed to investigate the impact of incremental rotation of the jet, thereby providing a better coverage of the entire tank. In this study, the jet was operated for a $90 \mathrm{sec}$ pulse at one station, followed by a 180-sec period with no jet operation. After this $270 \mathrm{sec}$ cycle, the jet was operated at the next azimuthal station. Stations were located every $30^{\circ}$ for a total of 6 positions. The duration of this simulation was, therefore, $6 \times 270=1620 \mathrm{sec}$.

TEMPEST velocity vectors and particle concentration contours are provided for a $180^{\circ}$ sector model of Tank 241-SY-101 in Figures 4.61 to 4.156. As there are numerous figures from this simulation, a figure summary is provided in Table 4.3. Temporal information is provided for four times in each jet operation cycle. Information is provided once near the start of each 90-se $\%$ jet pulse, next near the end of each jet pulse, again near the start of the nopulse period, and finally, at near the end of the no-pulse period. This logic is followed for each of the 6 pulse cycles. For each time "snapshot," views are presented for vertical and horizontal planes in the tank. The vertical plane passes through the center of the jet nozzle, and the horizontal plane is provided at the vertical elevation of the jet nozzle. Velocity vectors and particle concentration contours are provided for each view.

Using jet rotation is a more effective method of suspending the settling slurry throughout the tank. It is observed that significant convection patterns exist $180 \mathrm{sec}$ after jet pumping has been terminated. However, it is also observed that after 6 cycles of jet operation the concentration of particles in the slurry region is still within $92 \%$ of the initial value at the jet nozzle vertical level (Figure 4.156). 


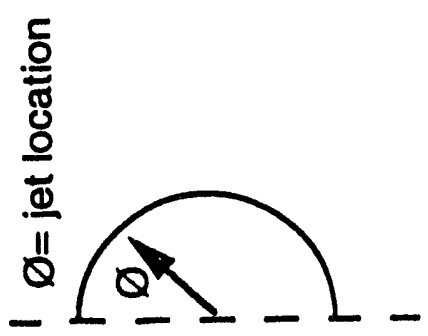

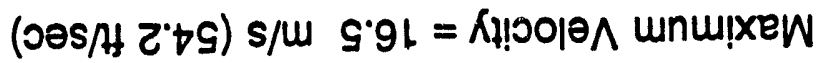

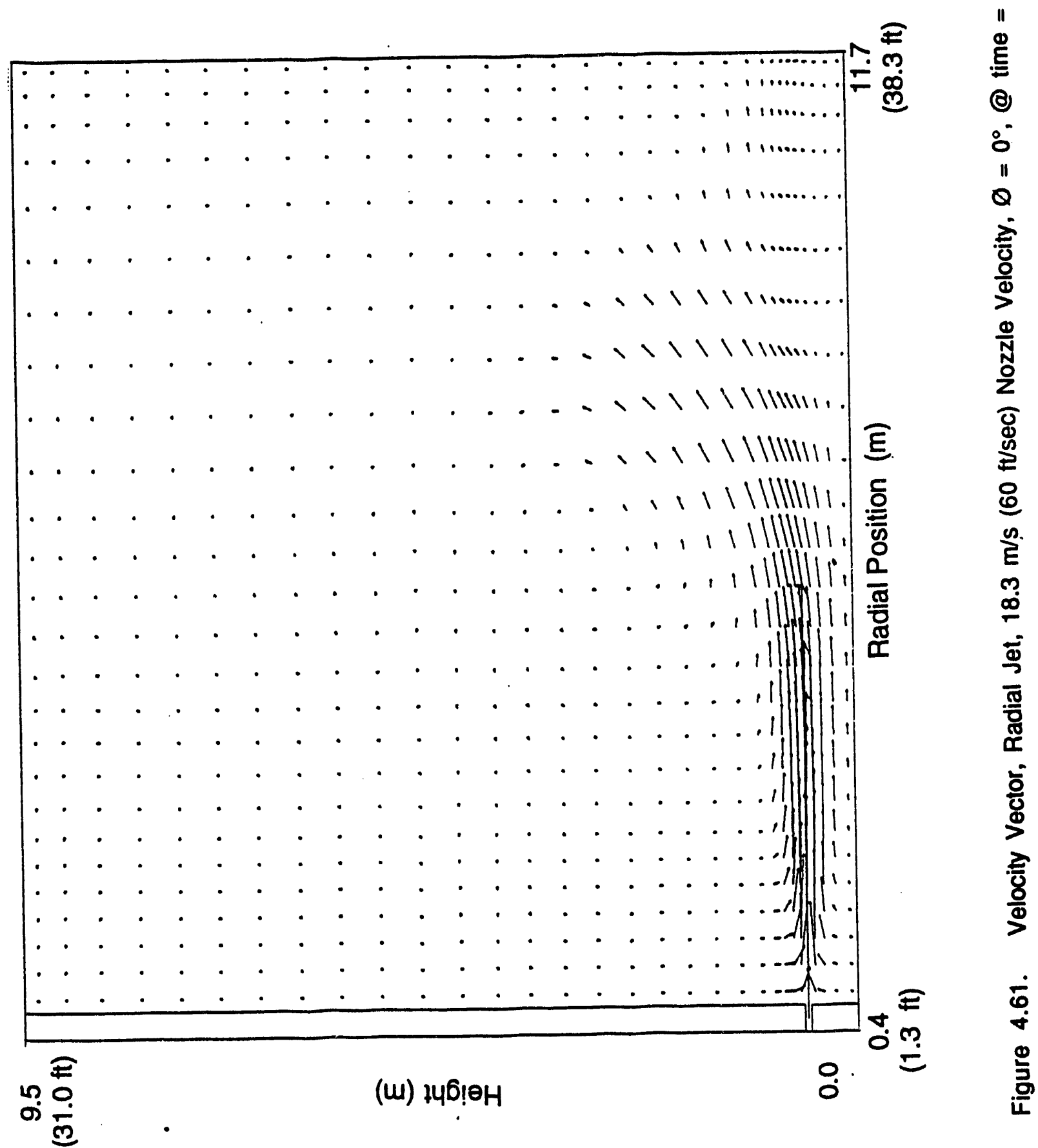




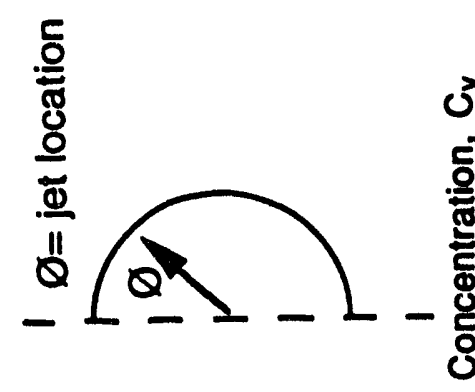

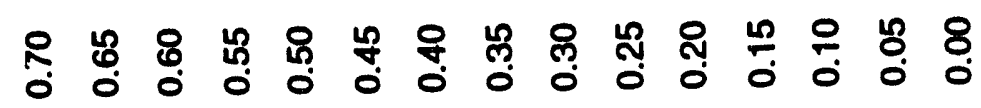

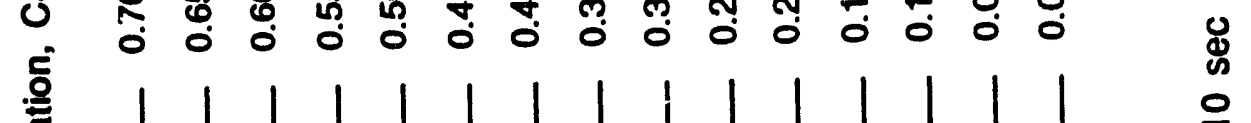

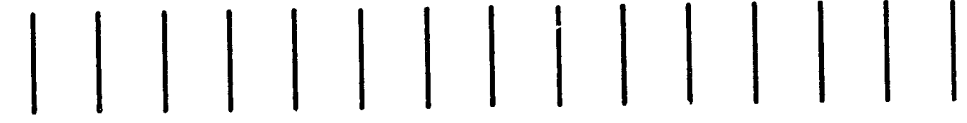

$n \pm M N=$ N

을
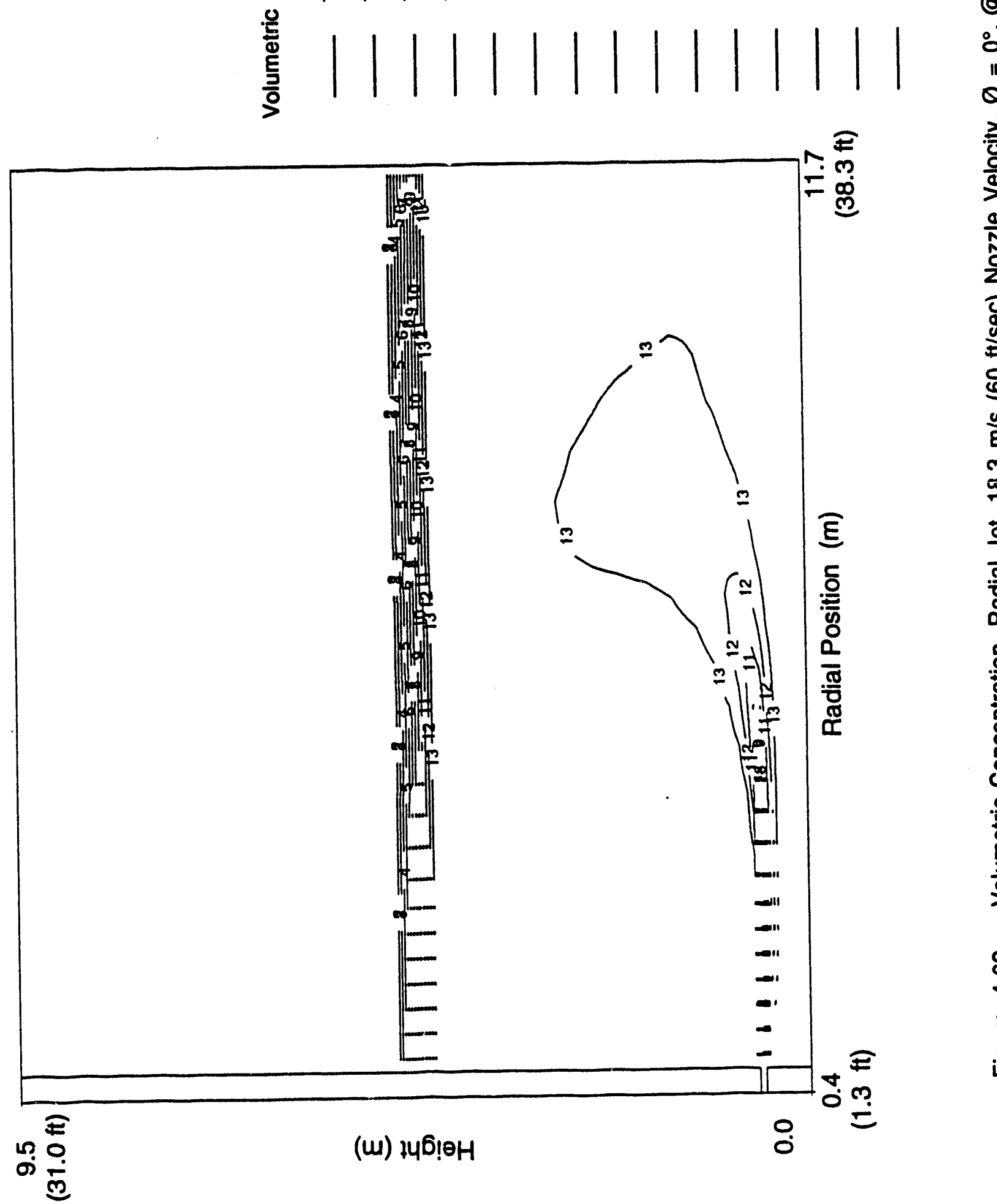

응

$\Phi$

은

ত্ষ

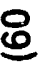

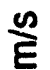

$\infty$

$\varpi$

Ф

要 


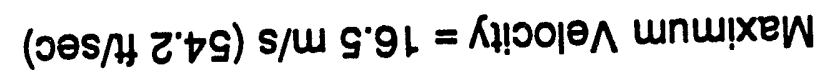

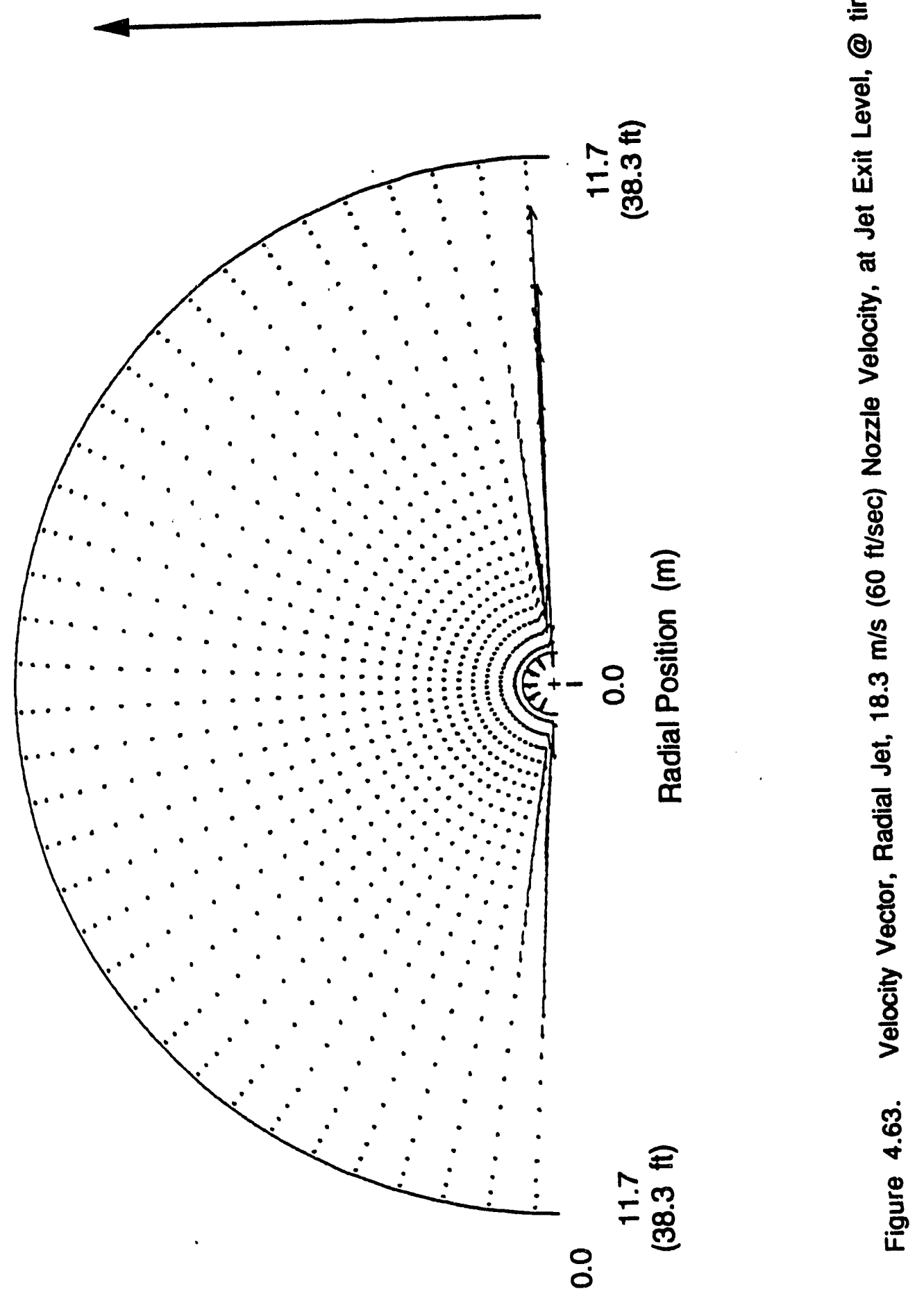



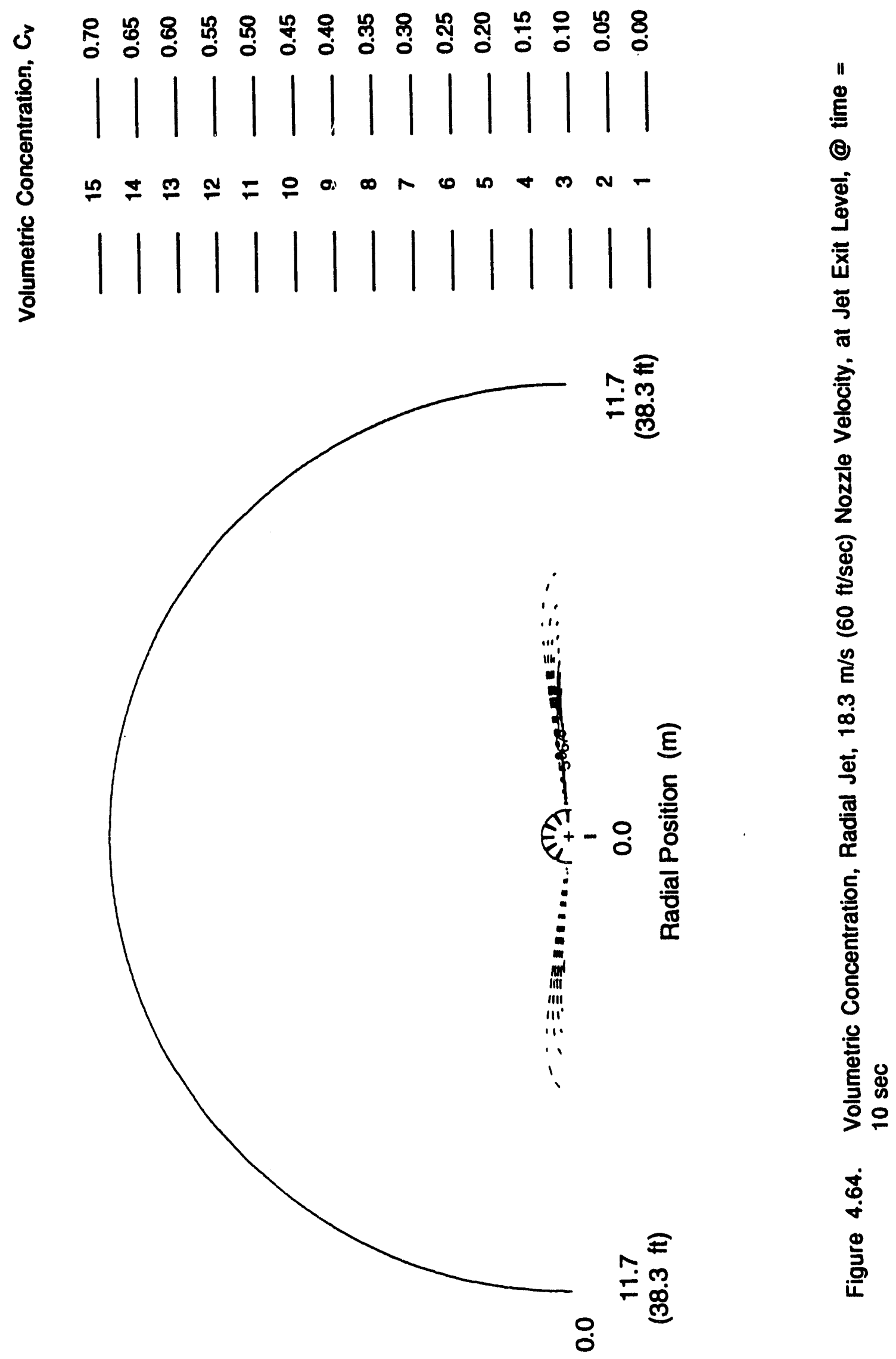


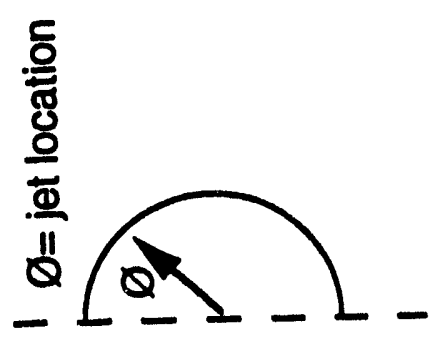

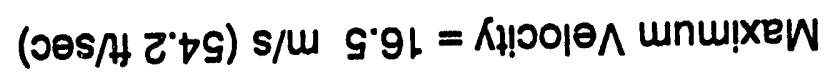

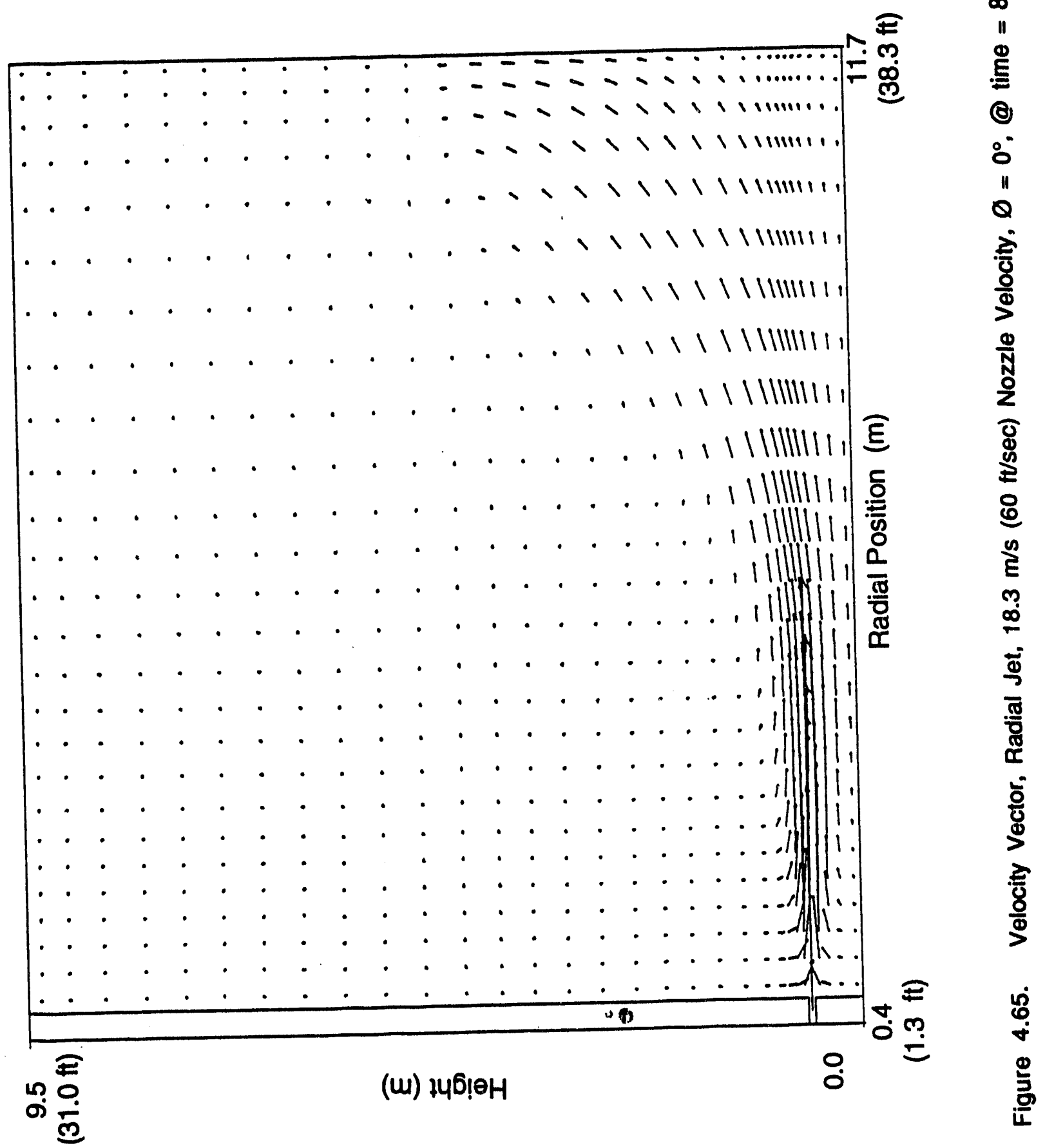



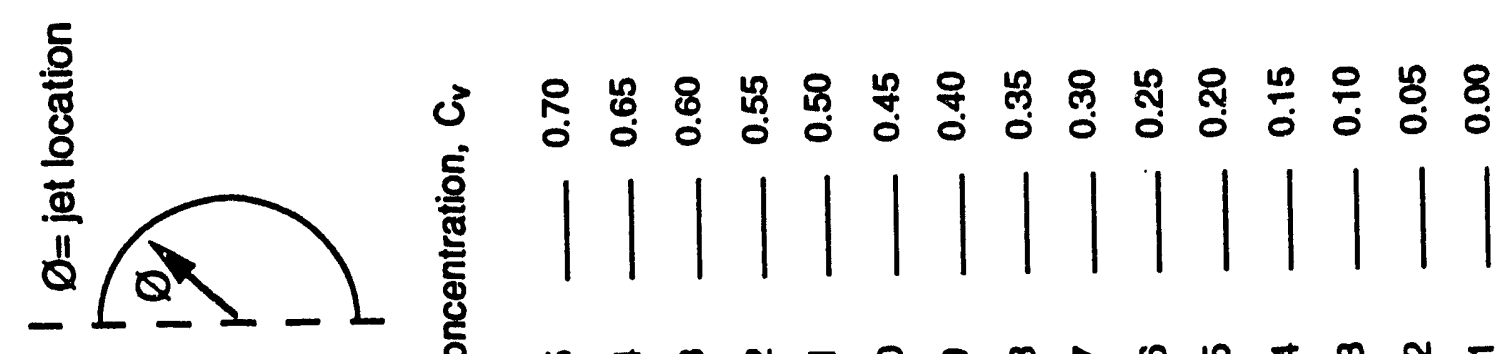

I
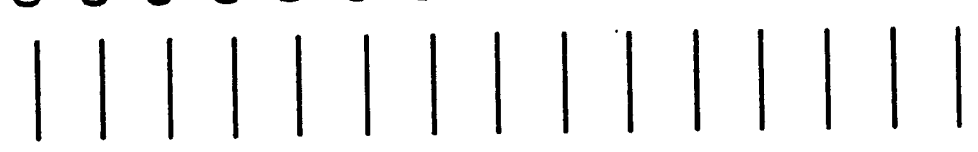

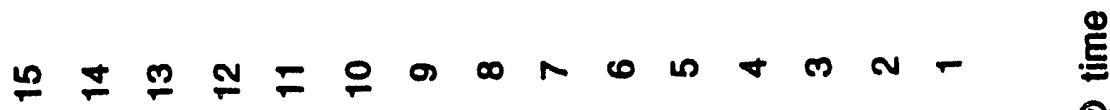

온

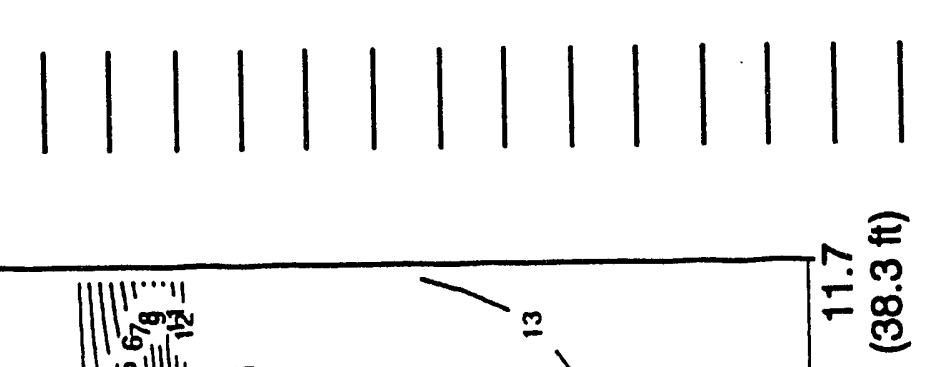

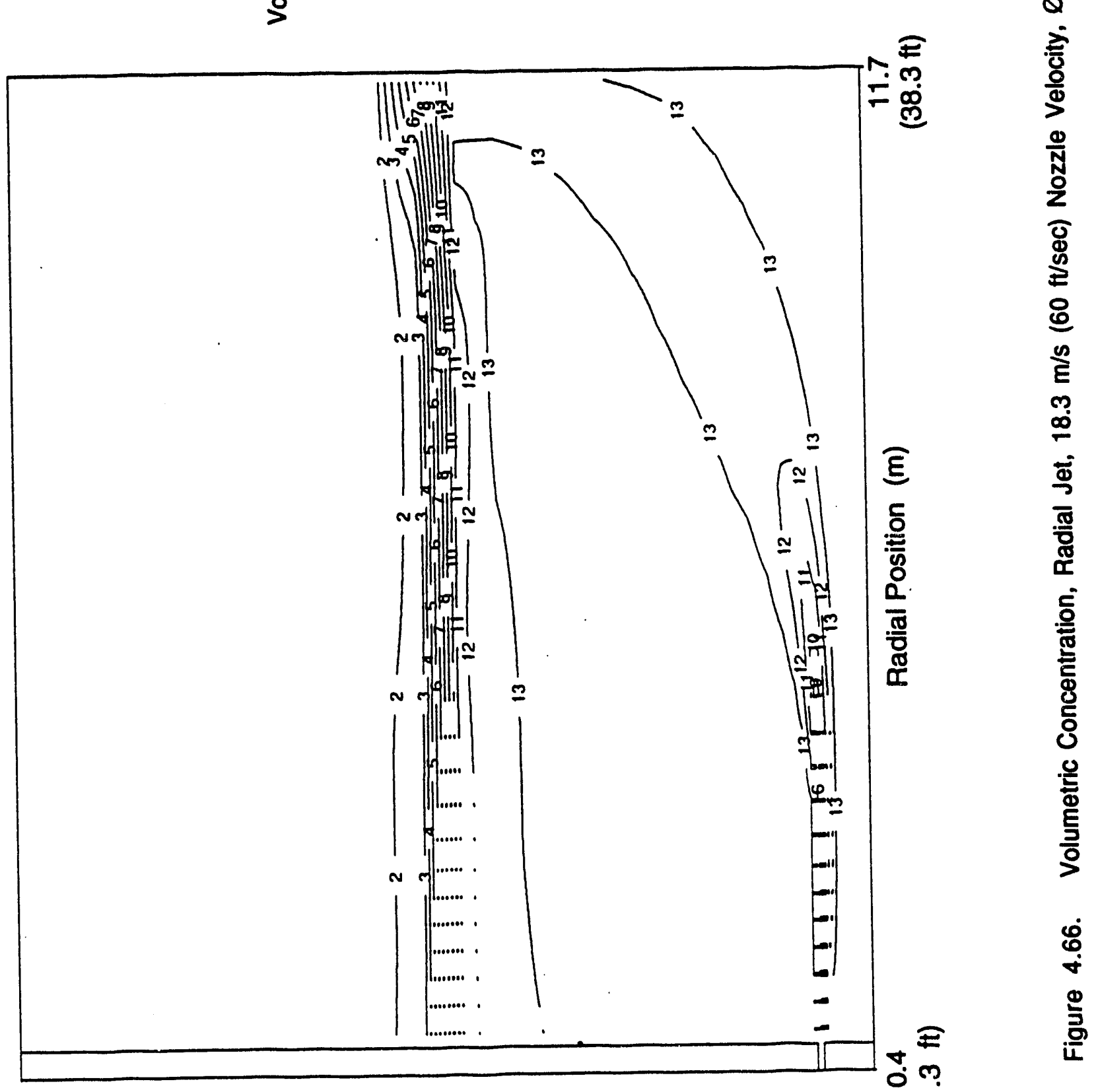

ஸึ

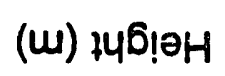

$0 \stackrel{0}{0}$ 


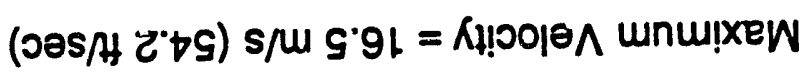

\&
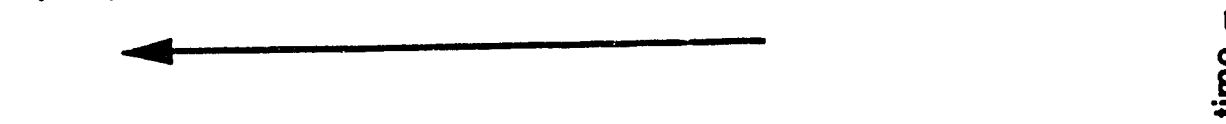

(8)

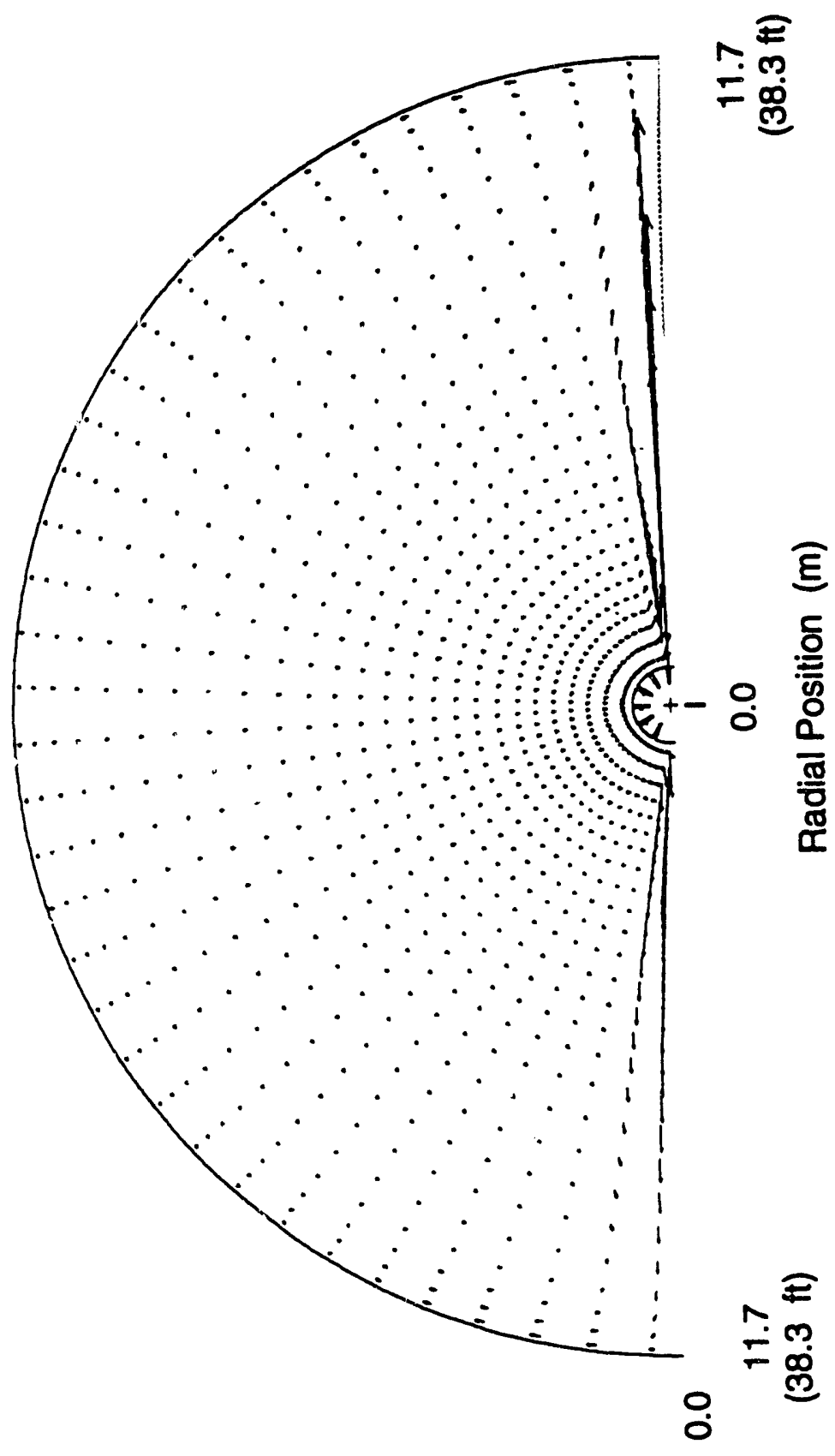

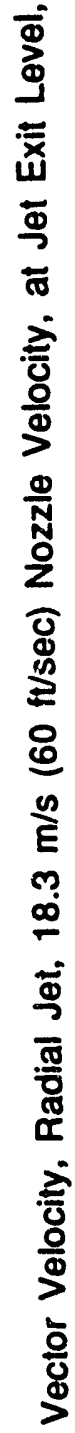

ஸั
$\stackrel{+}{0}$
$\stackrel{9}{5}$
은 

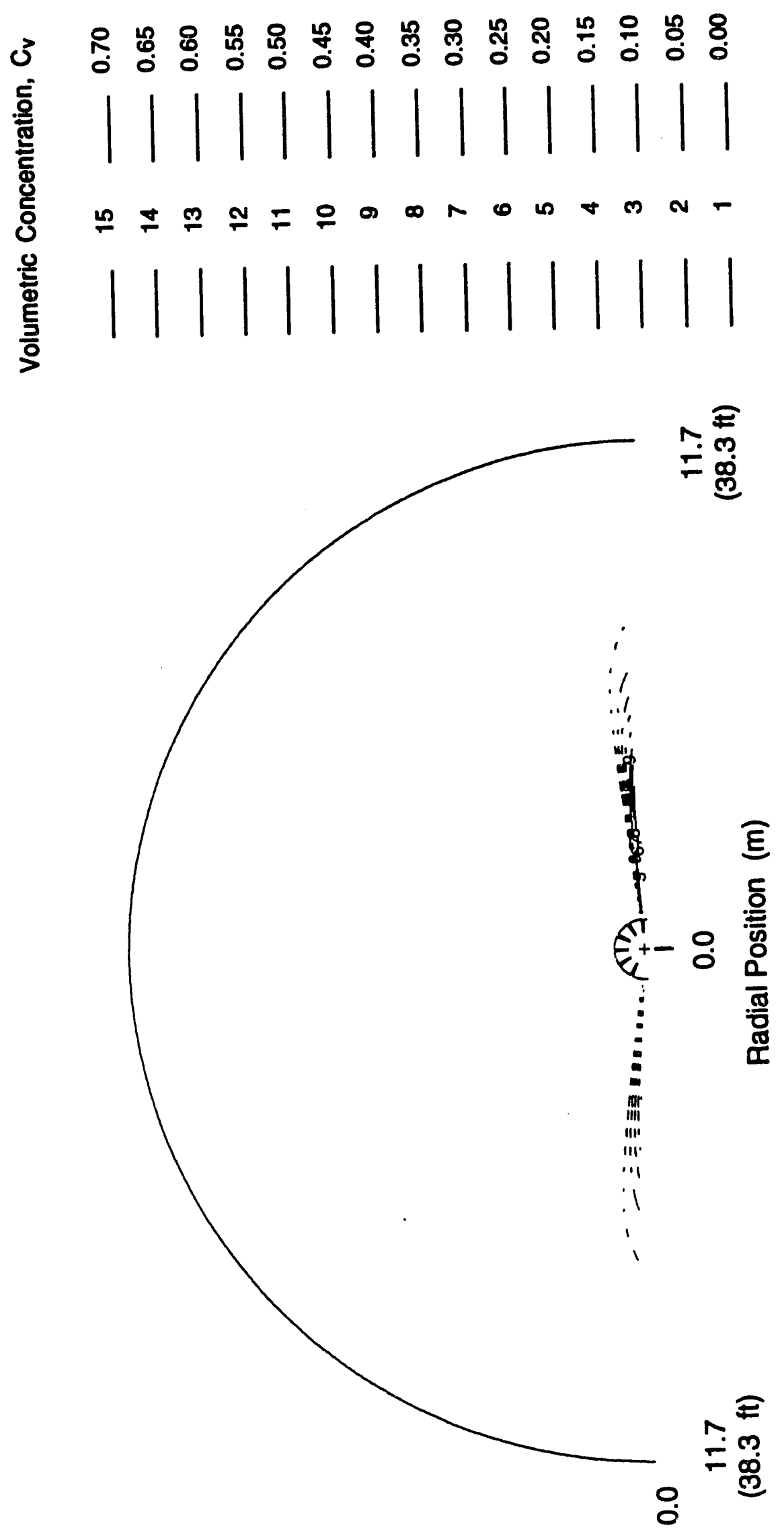

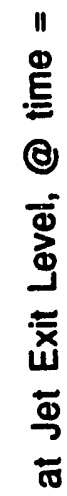




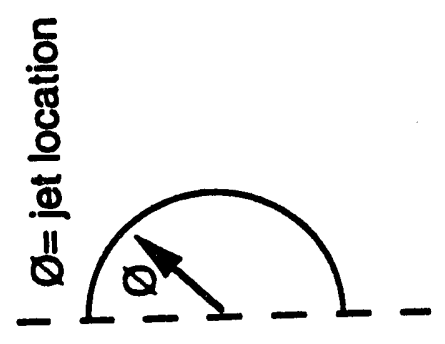

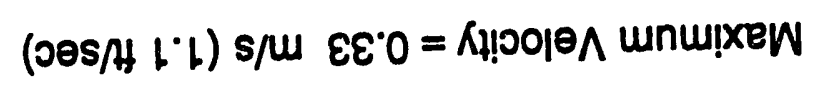

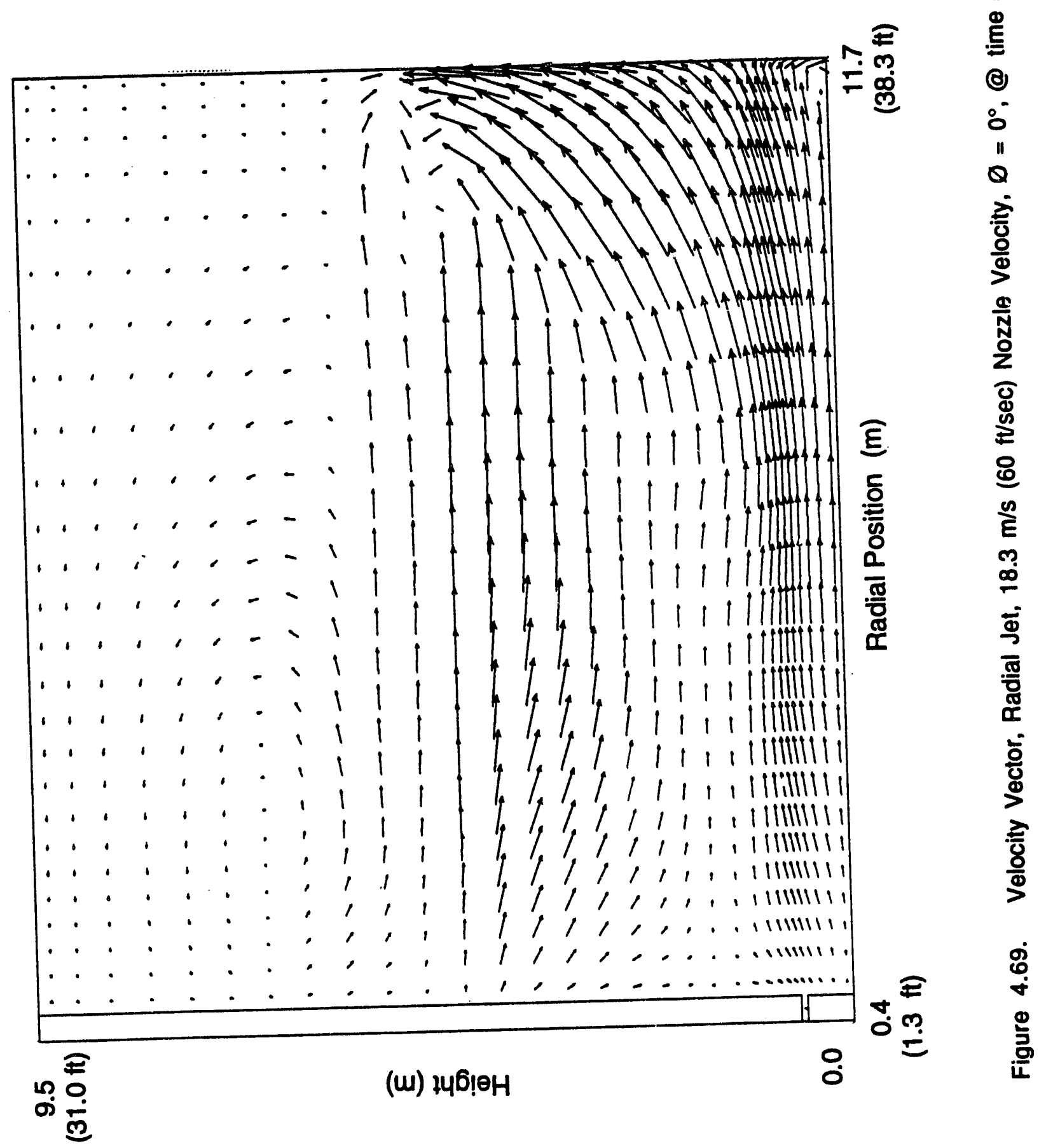



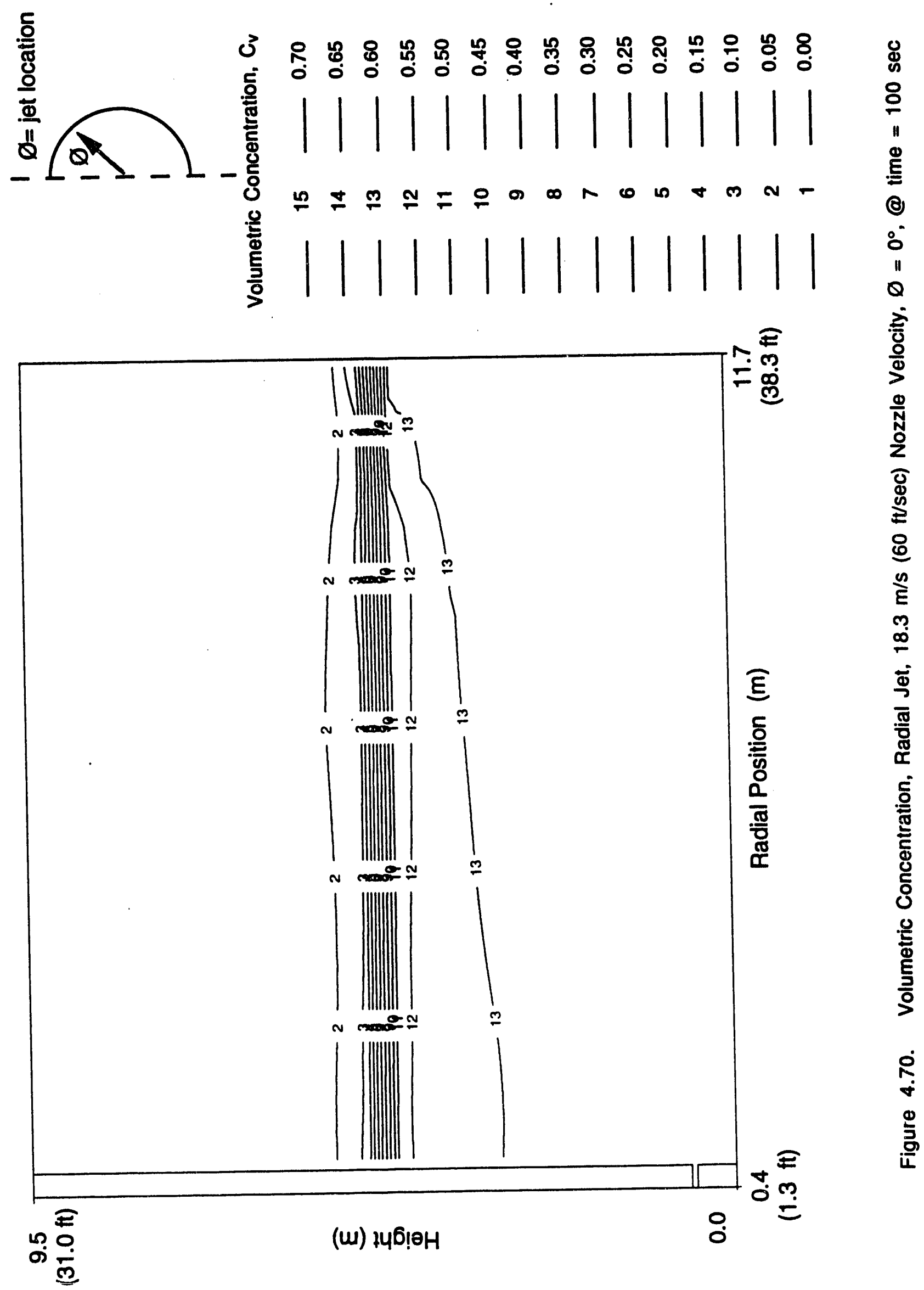


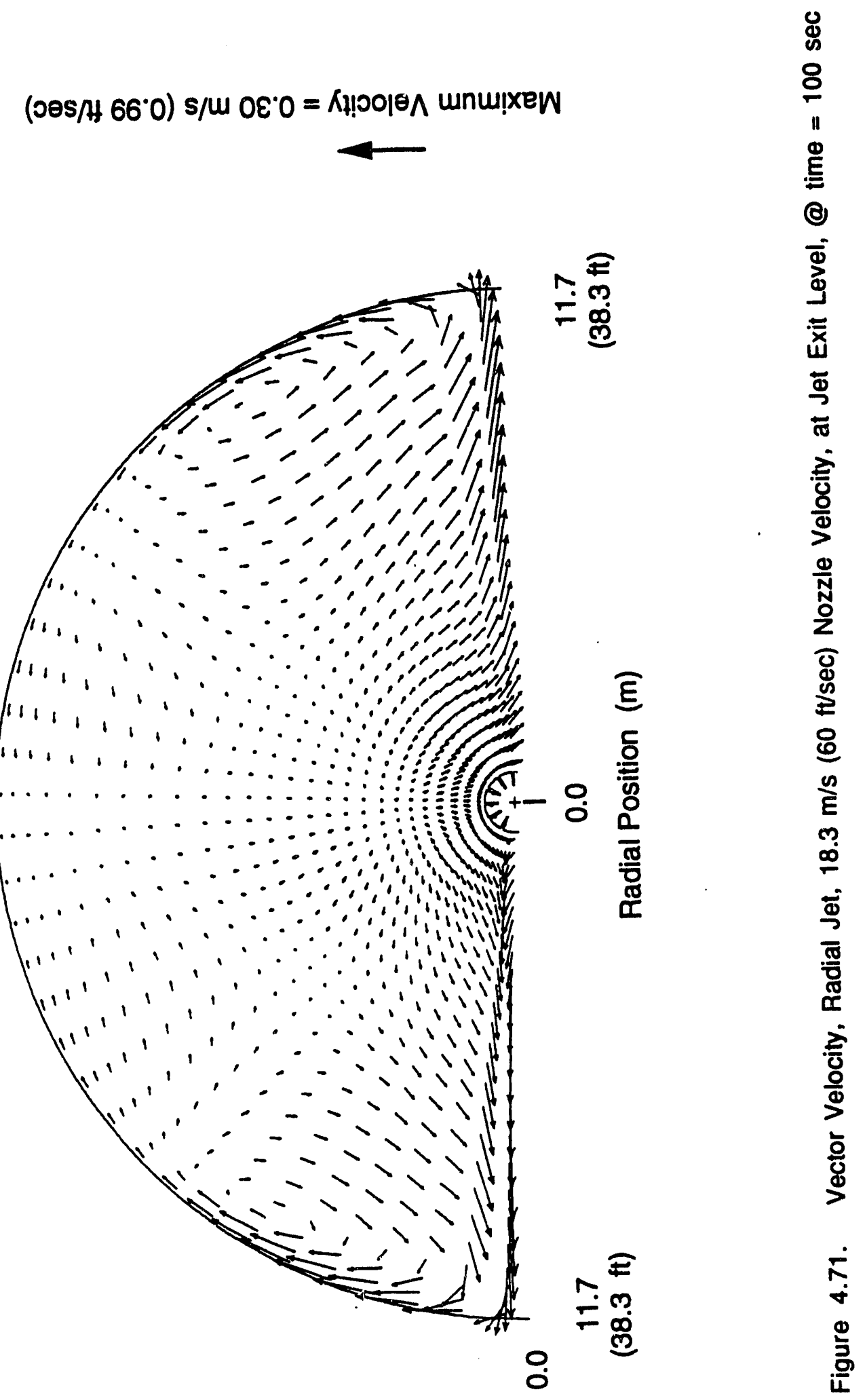



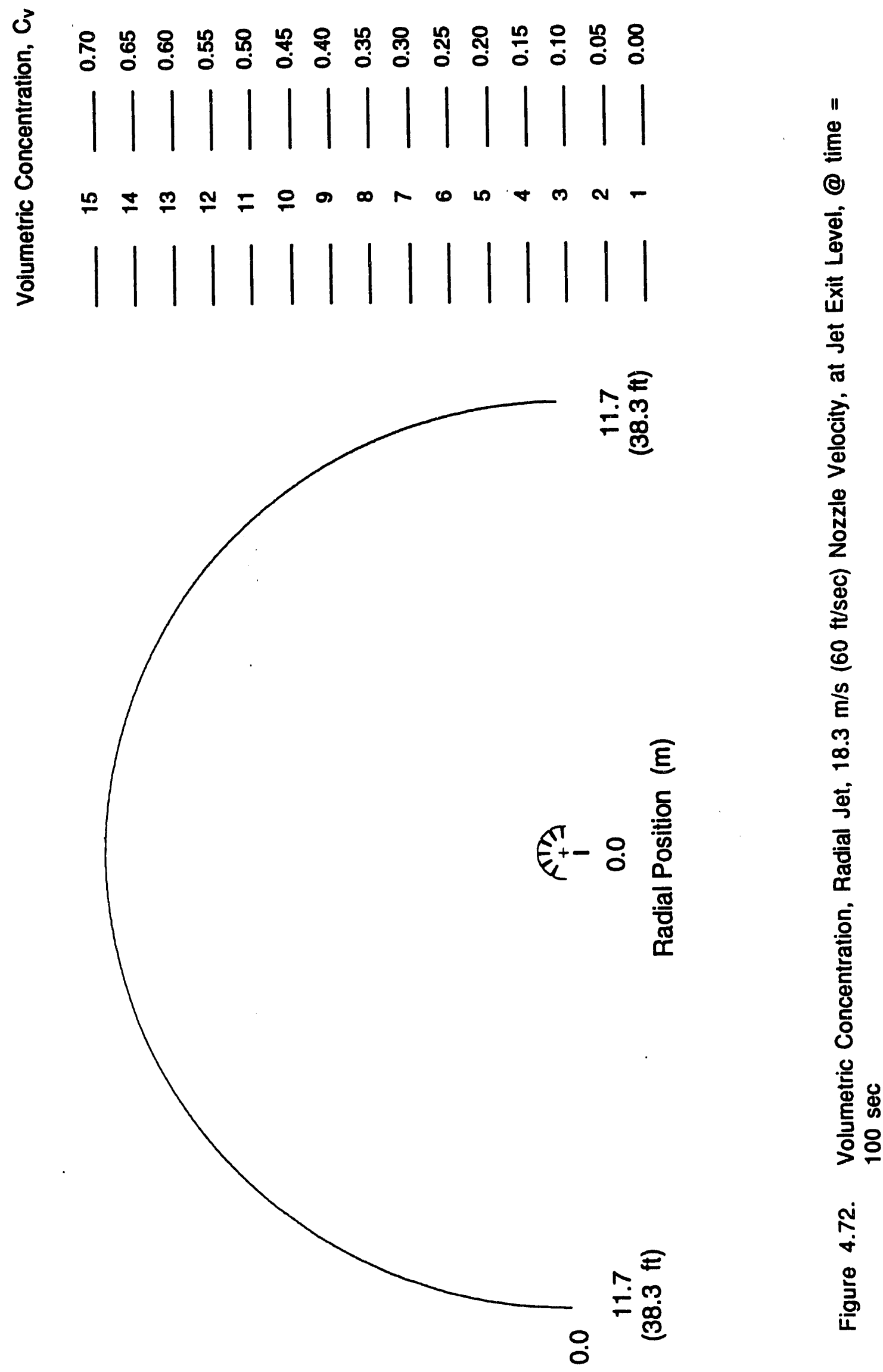

4.80 


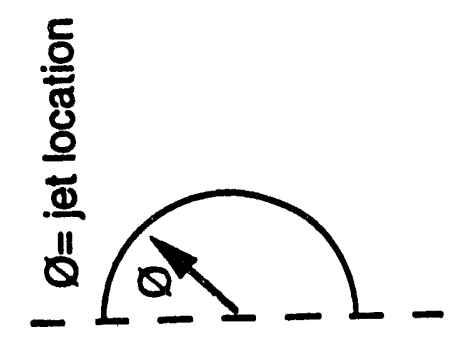

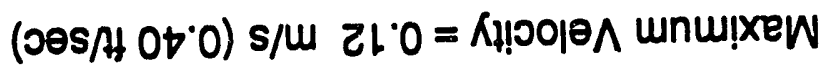

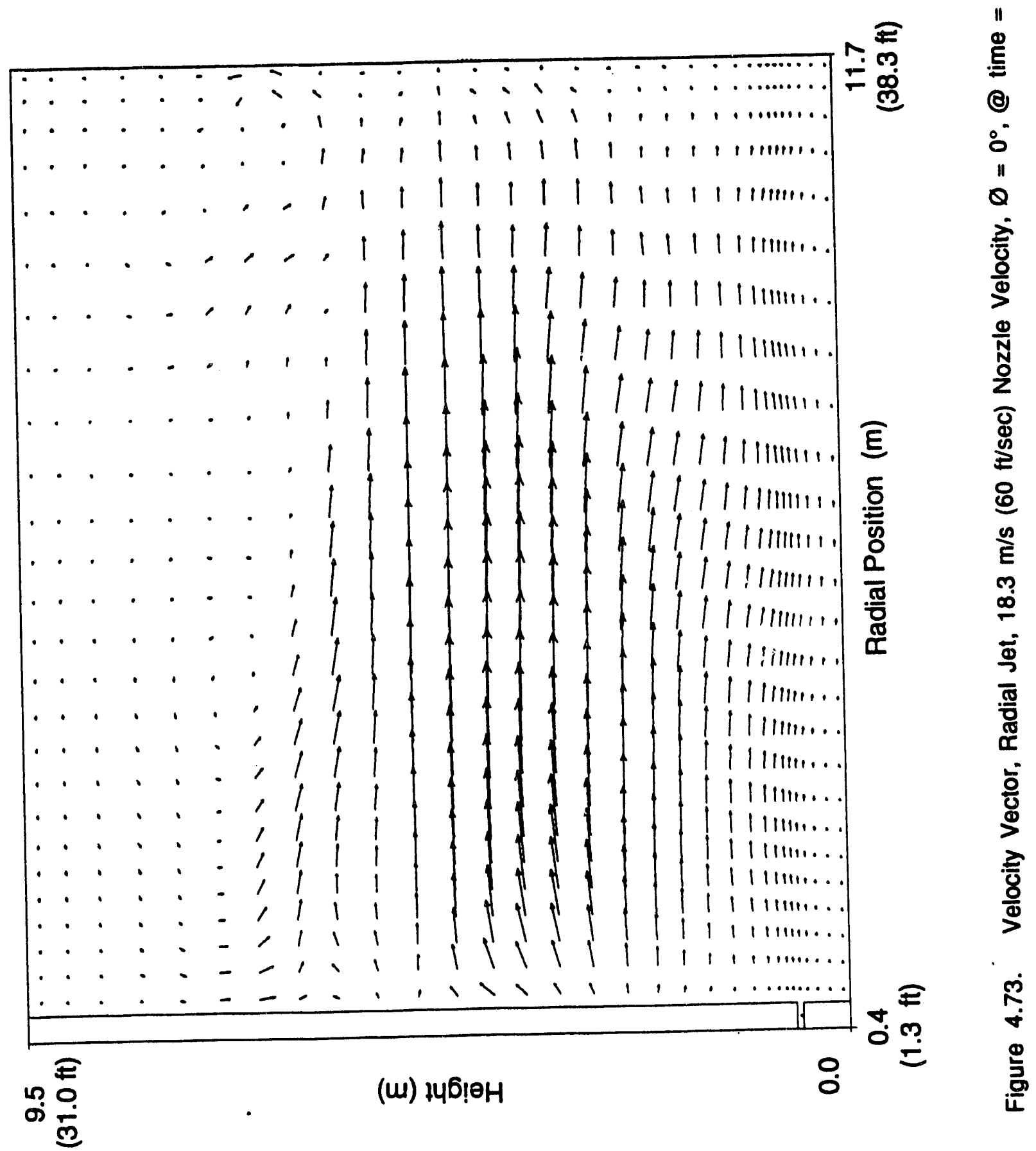



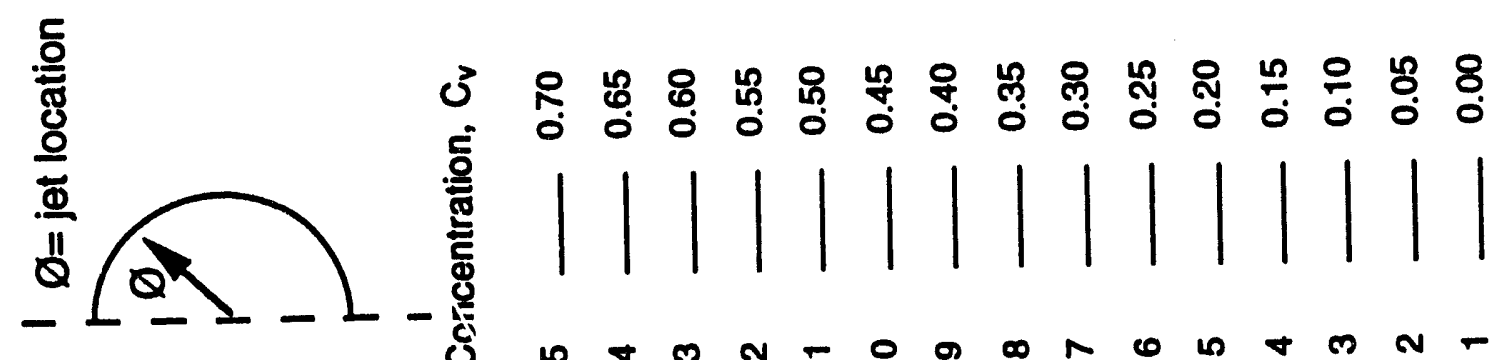

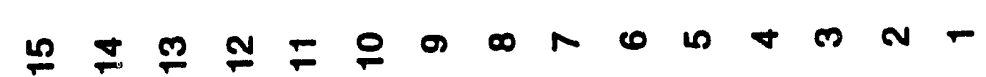

를

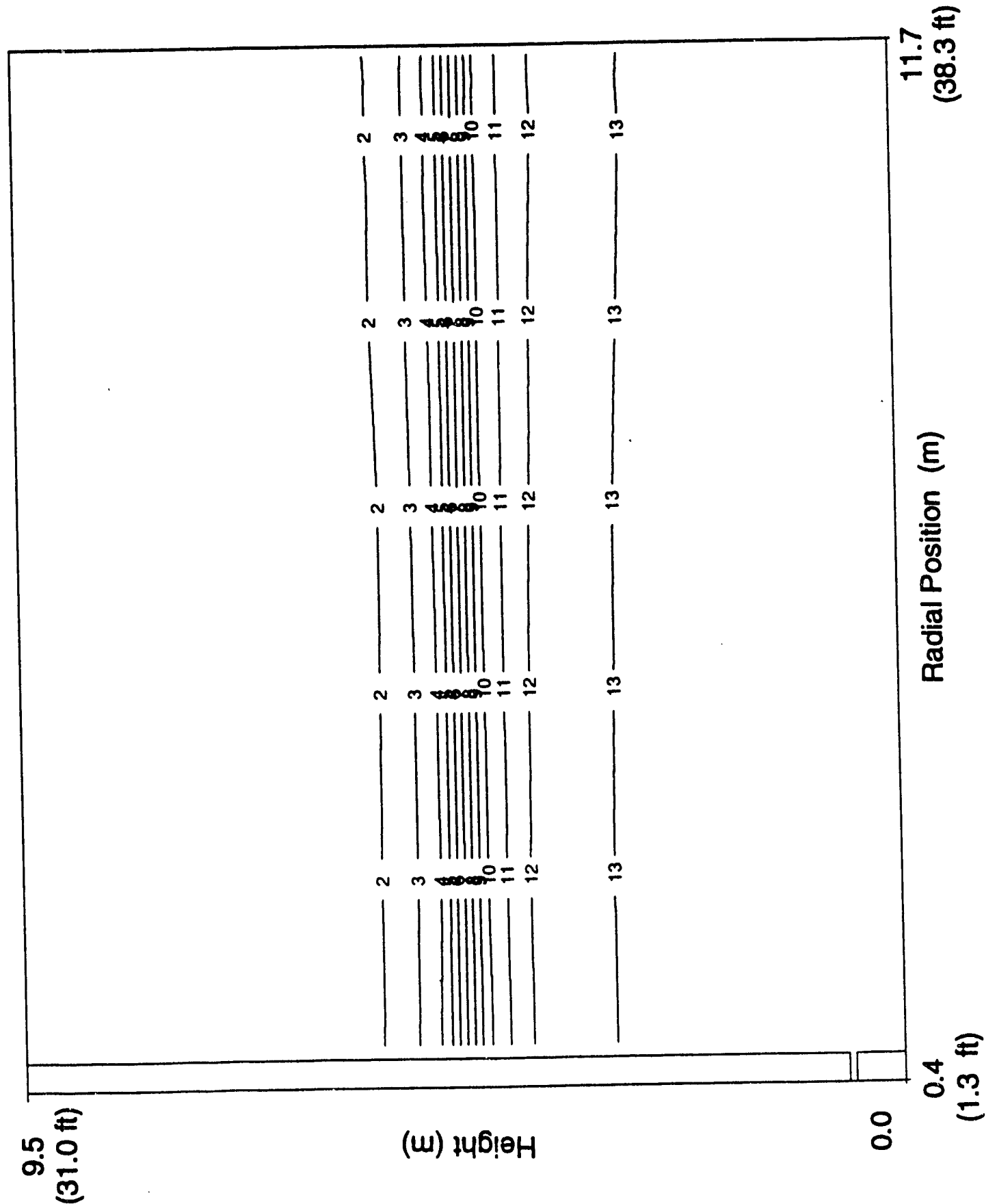

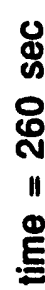

()

$\therefore$

11

$Q$

:

$\frac{\Phi}{\mathrm{N}}$

ఫ్d

\&

$\stackrel{\infty}{a}$

m 


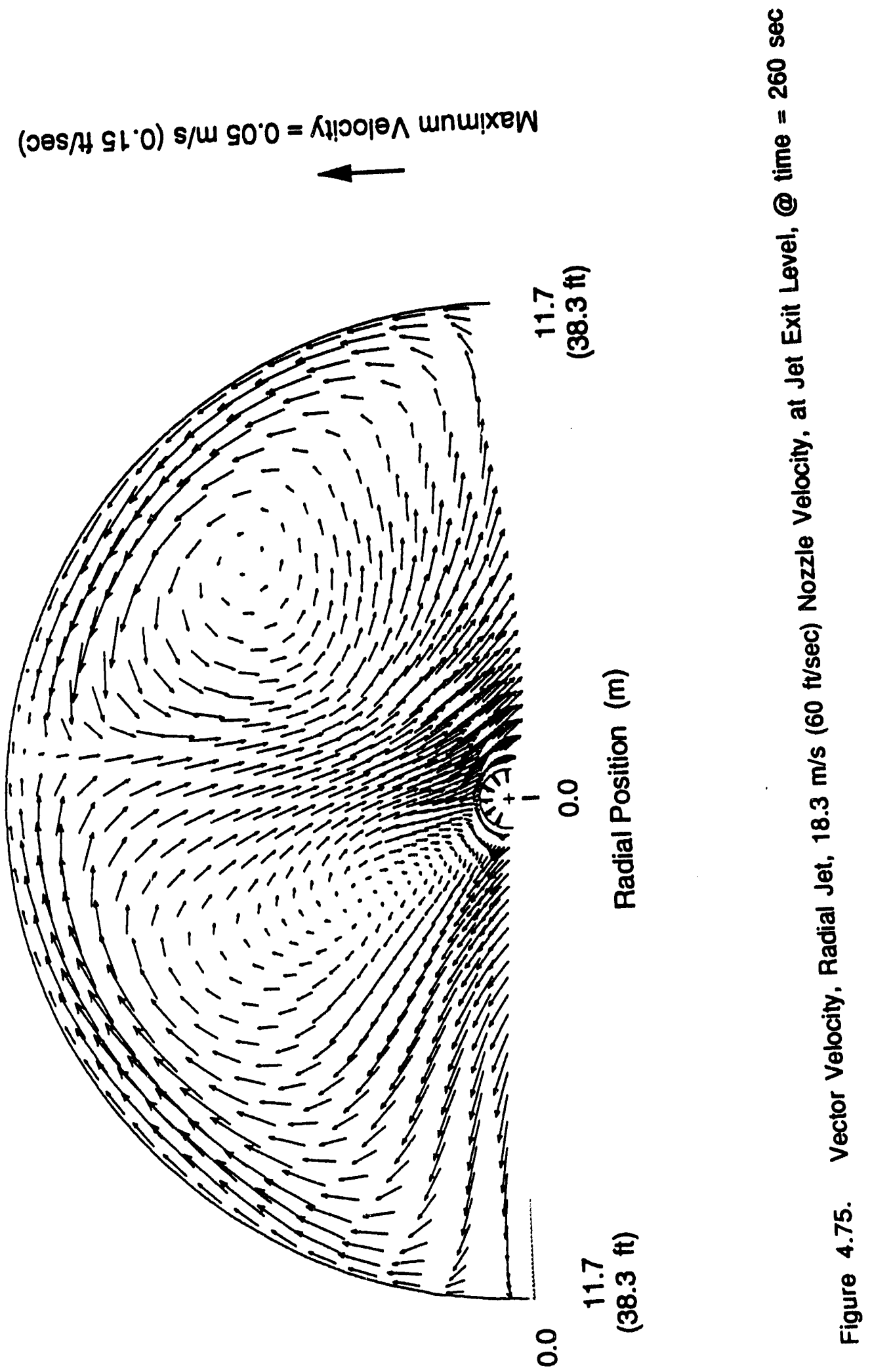




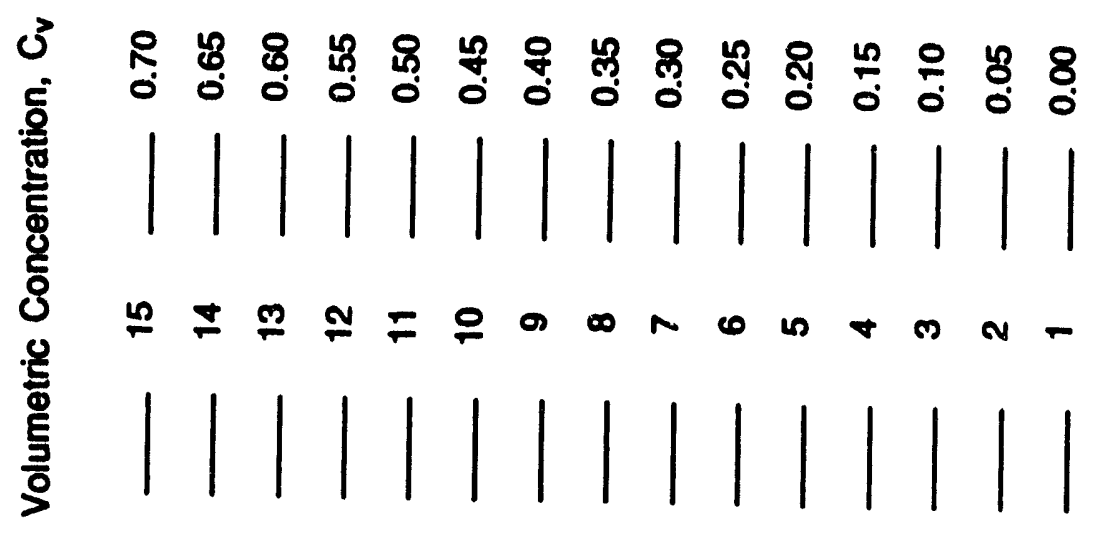

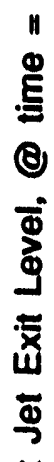

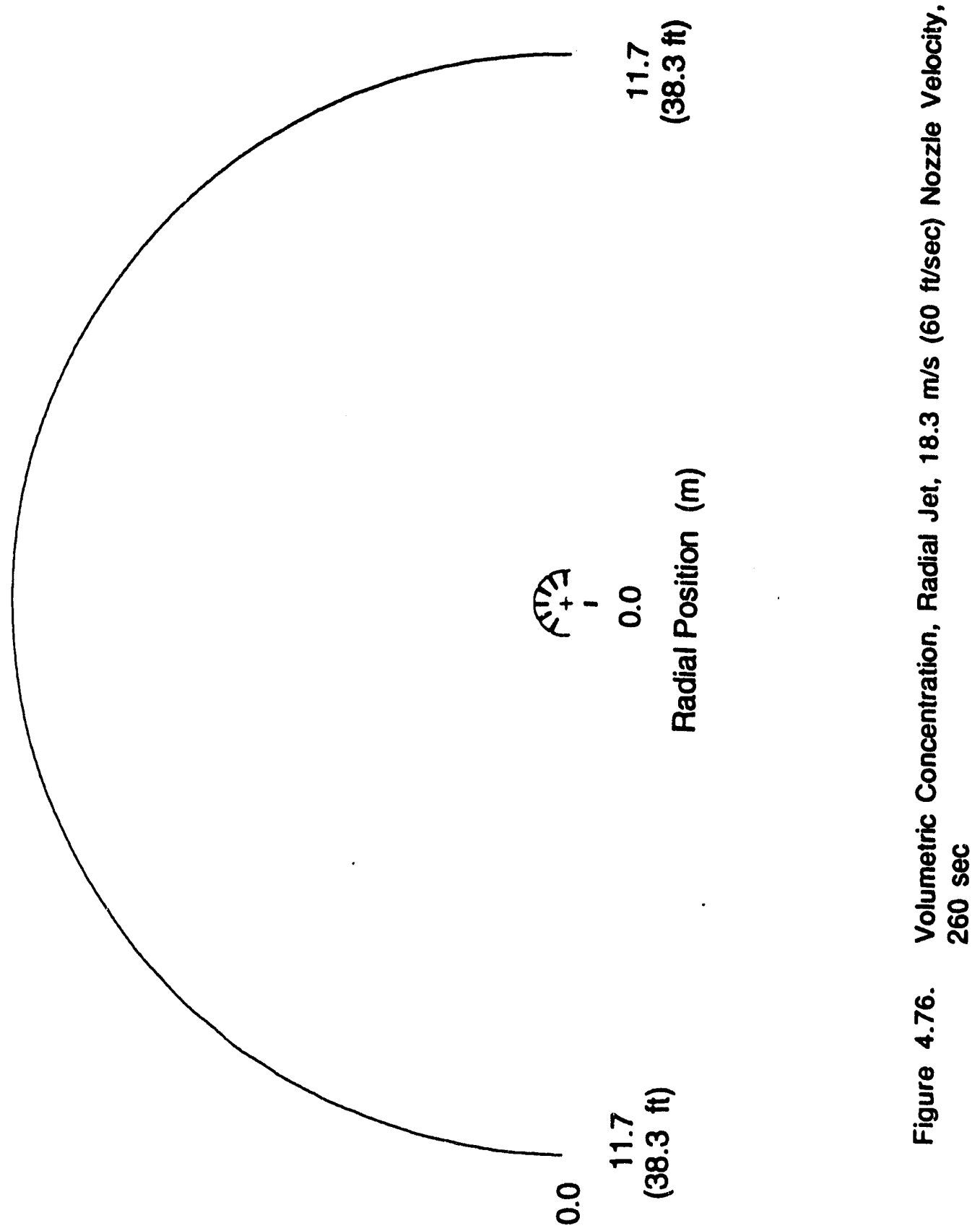




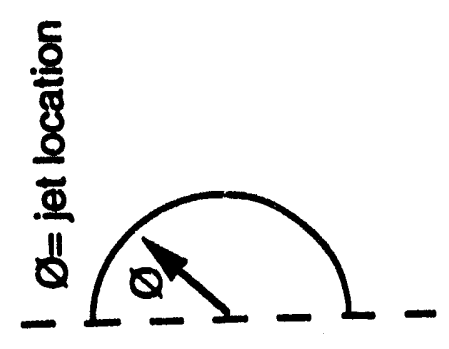

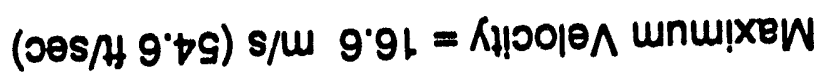

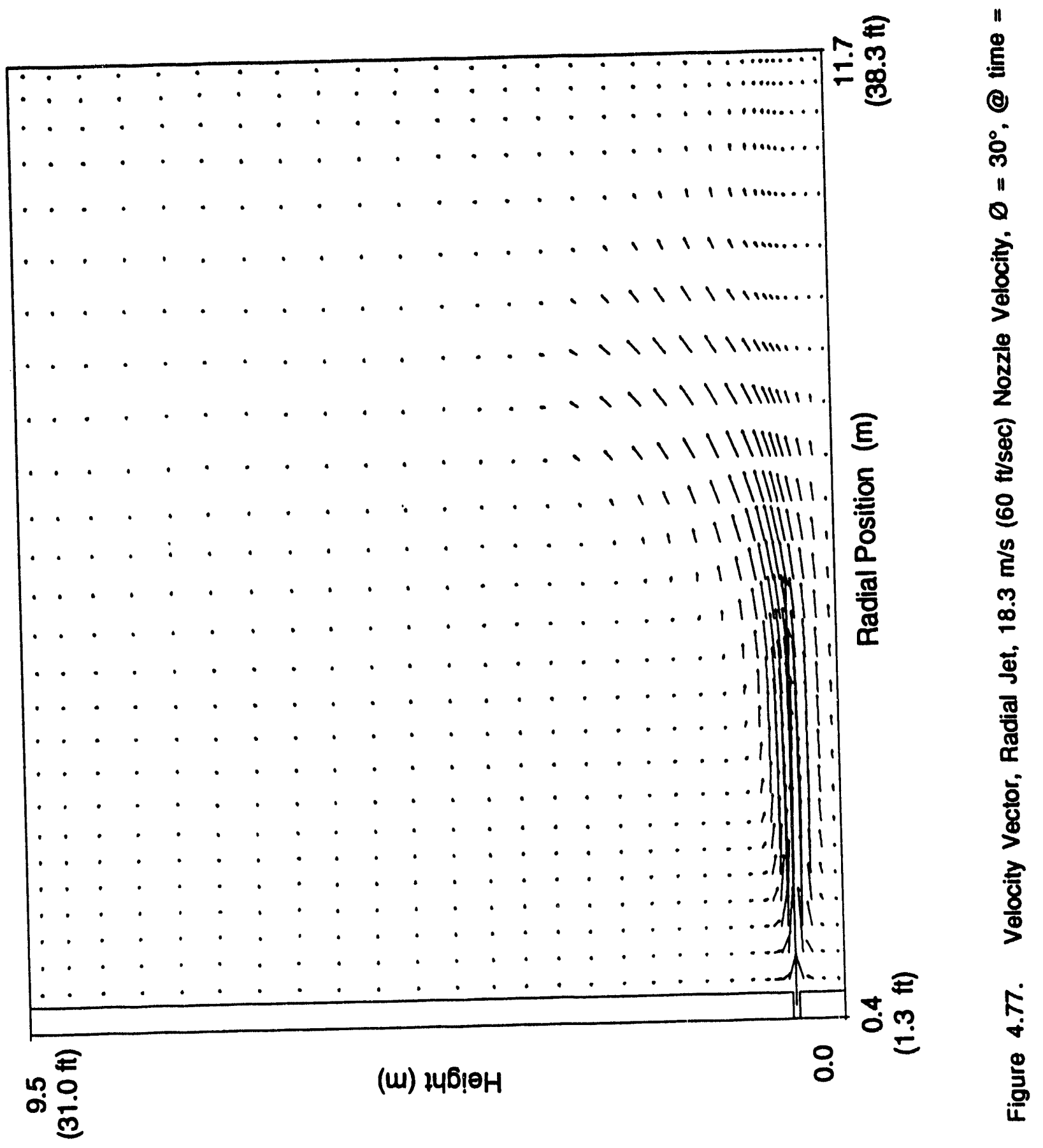




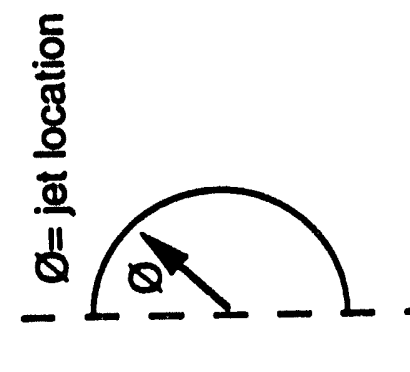

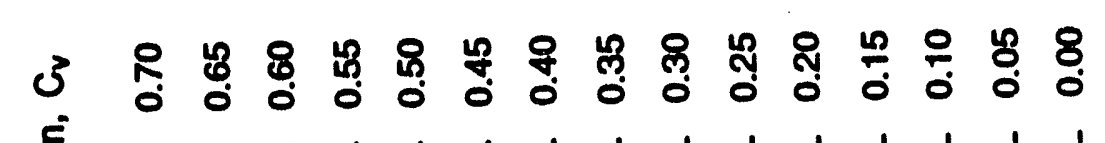

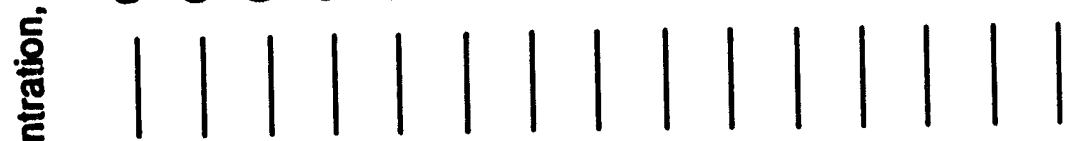

ญ్

怘

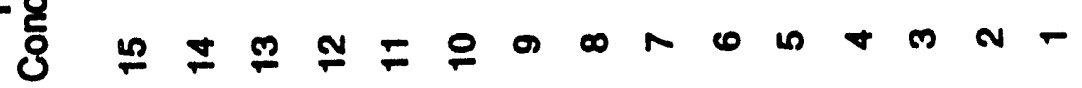

옳
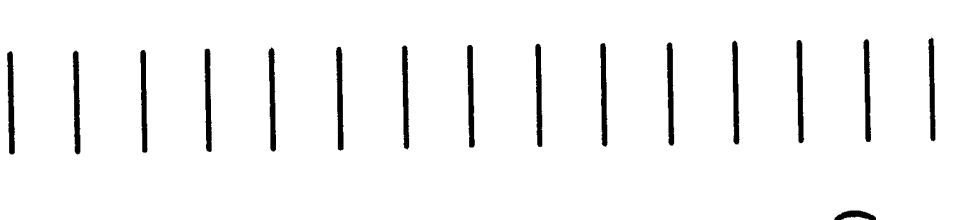

()

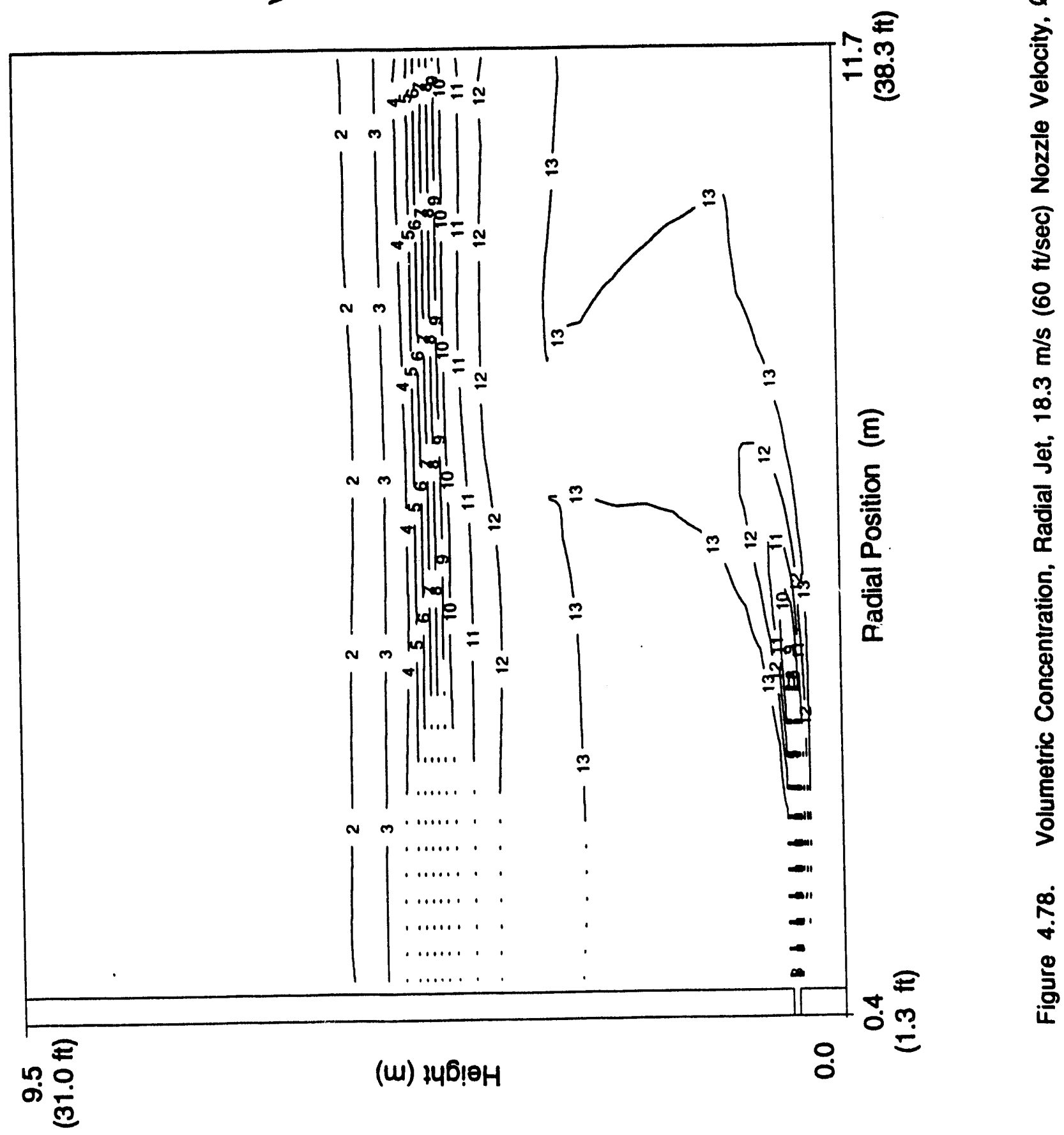




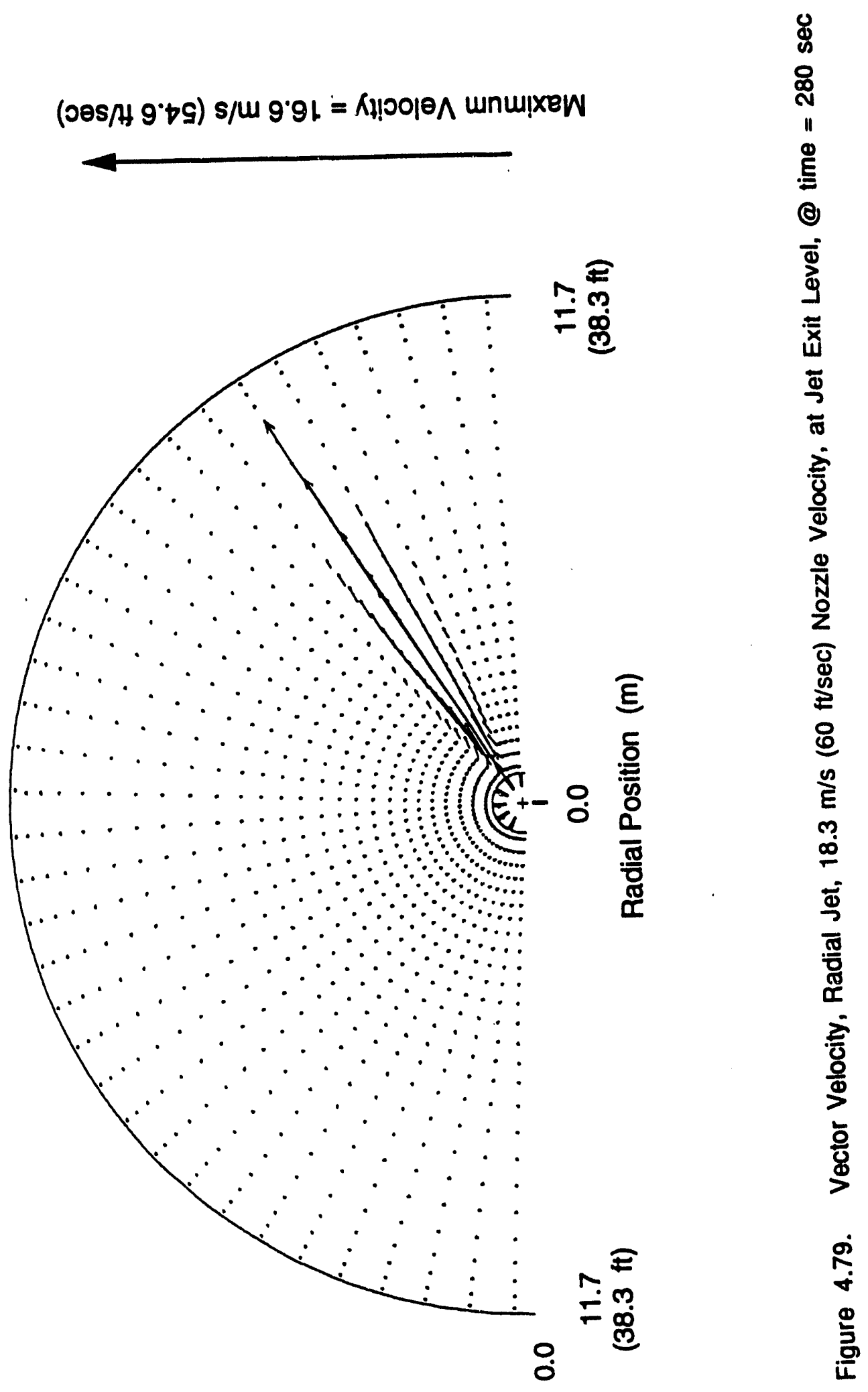



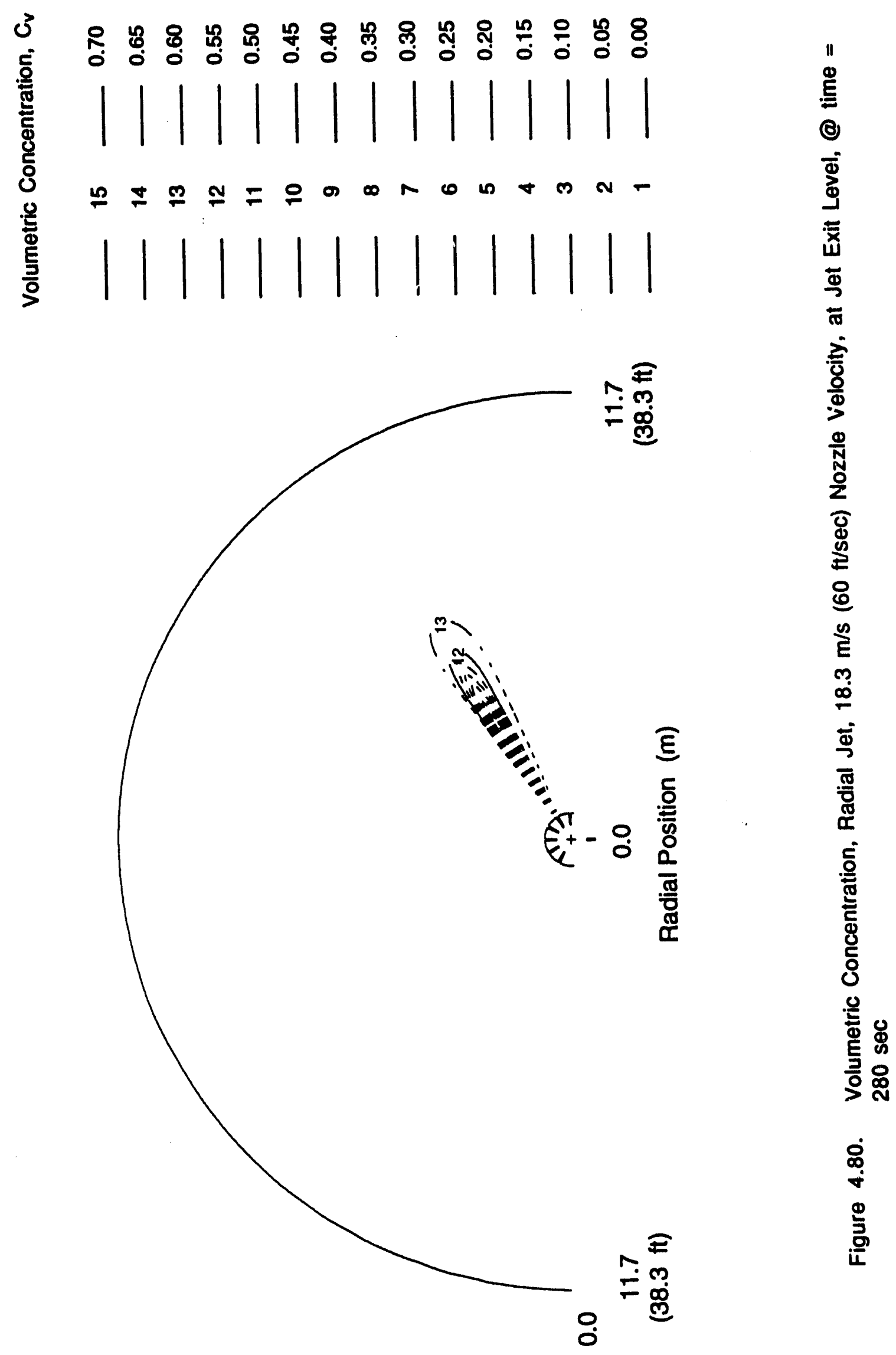


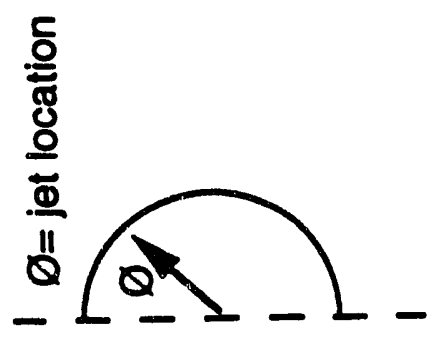

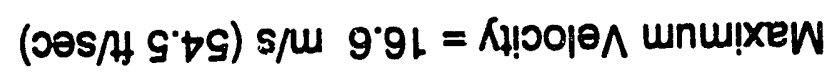

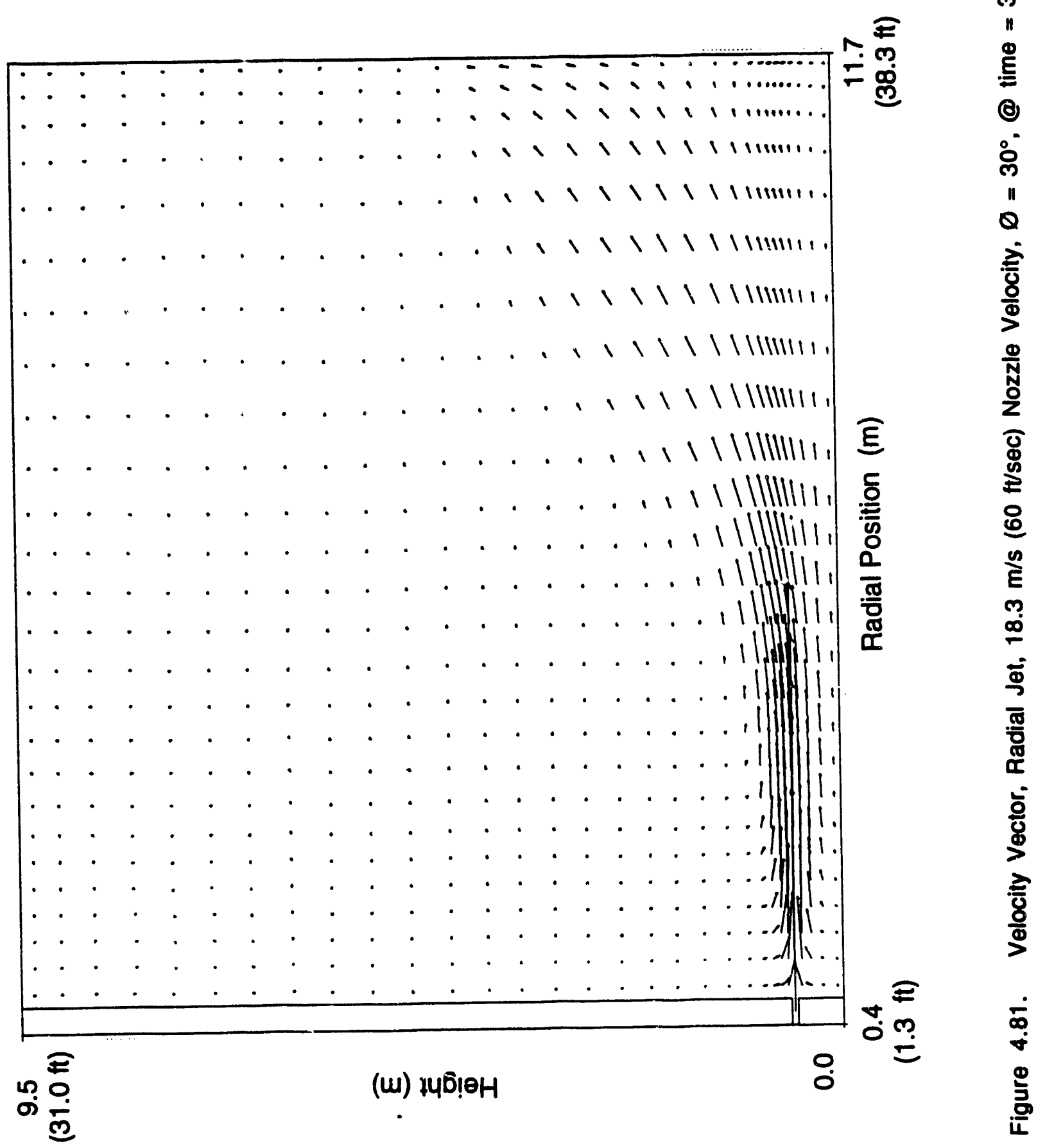



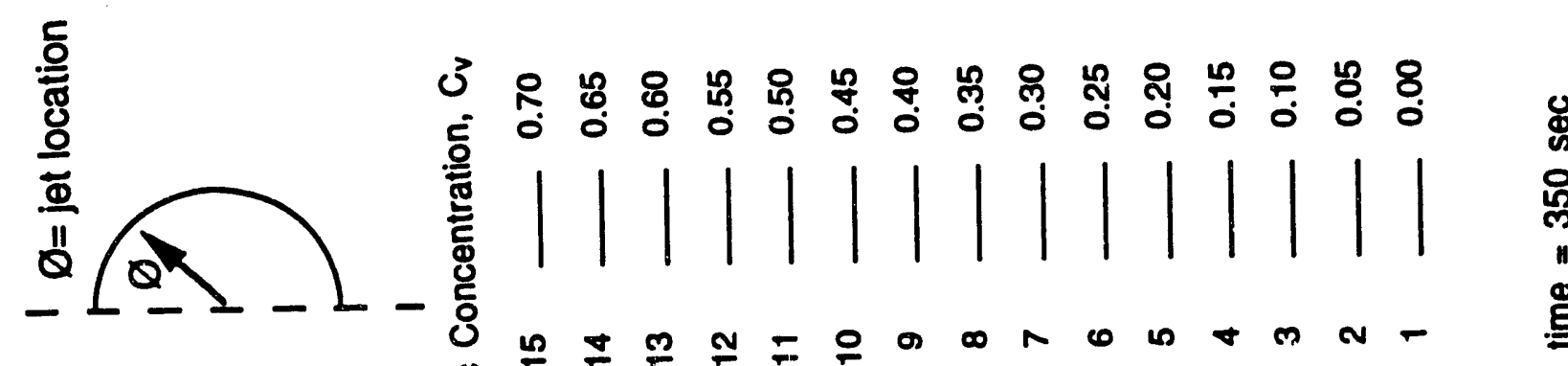

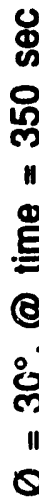

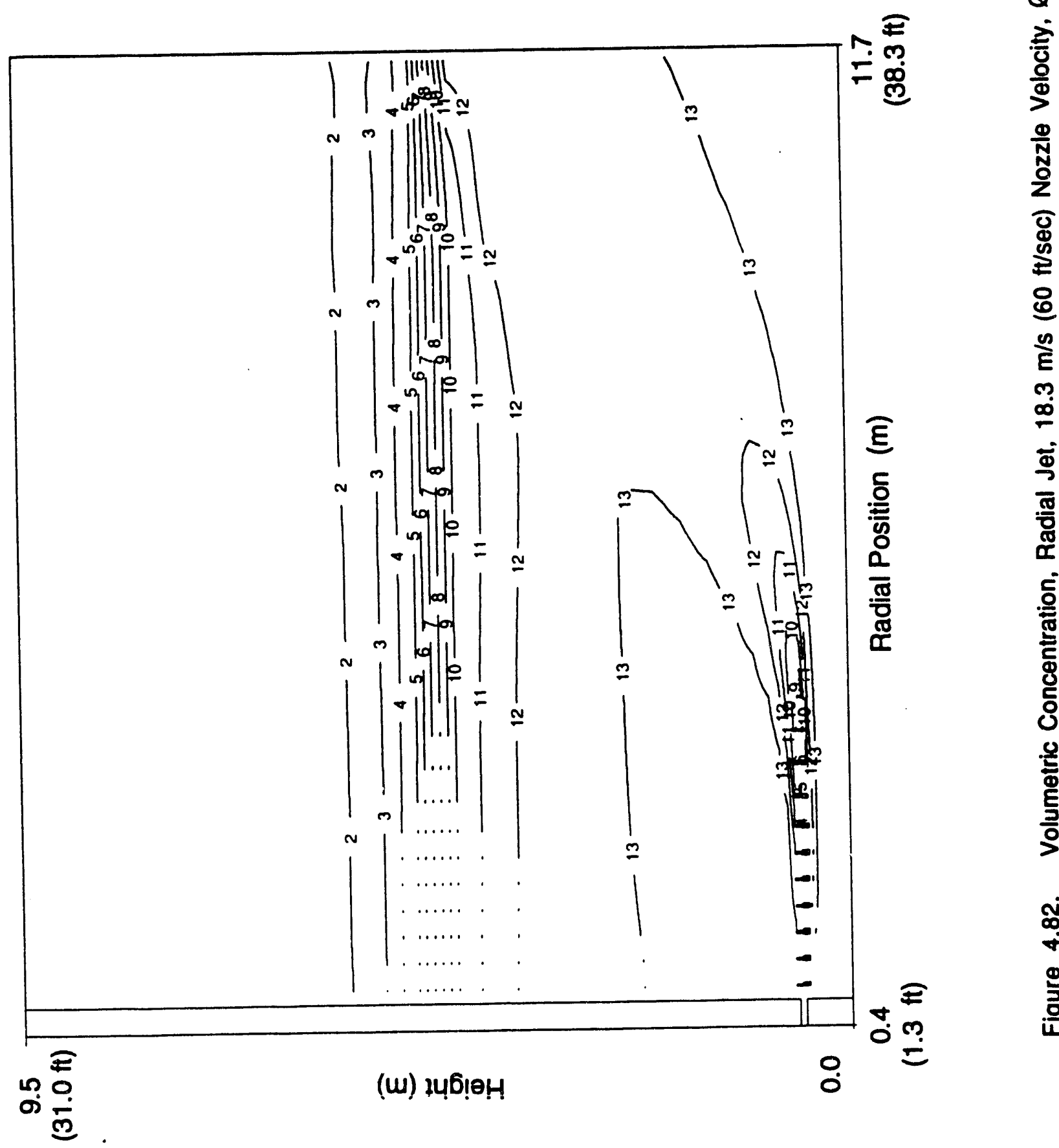




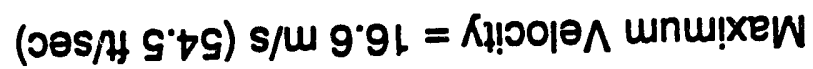

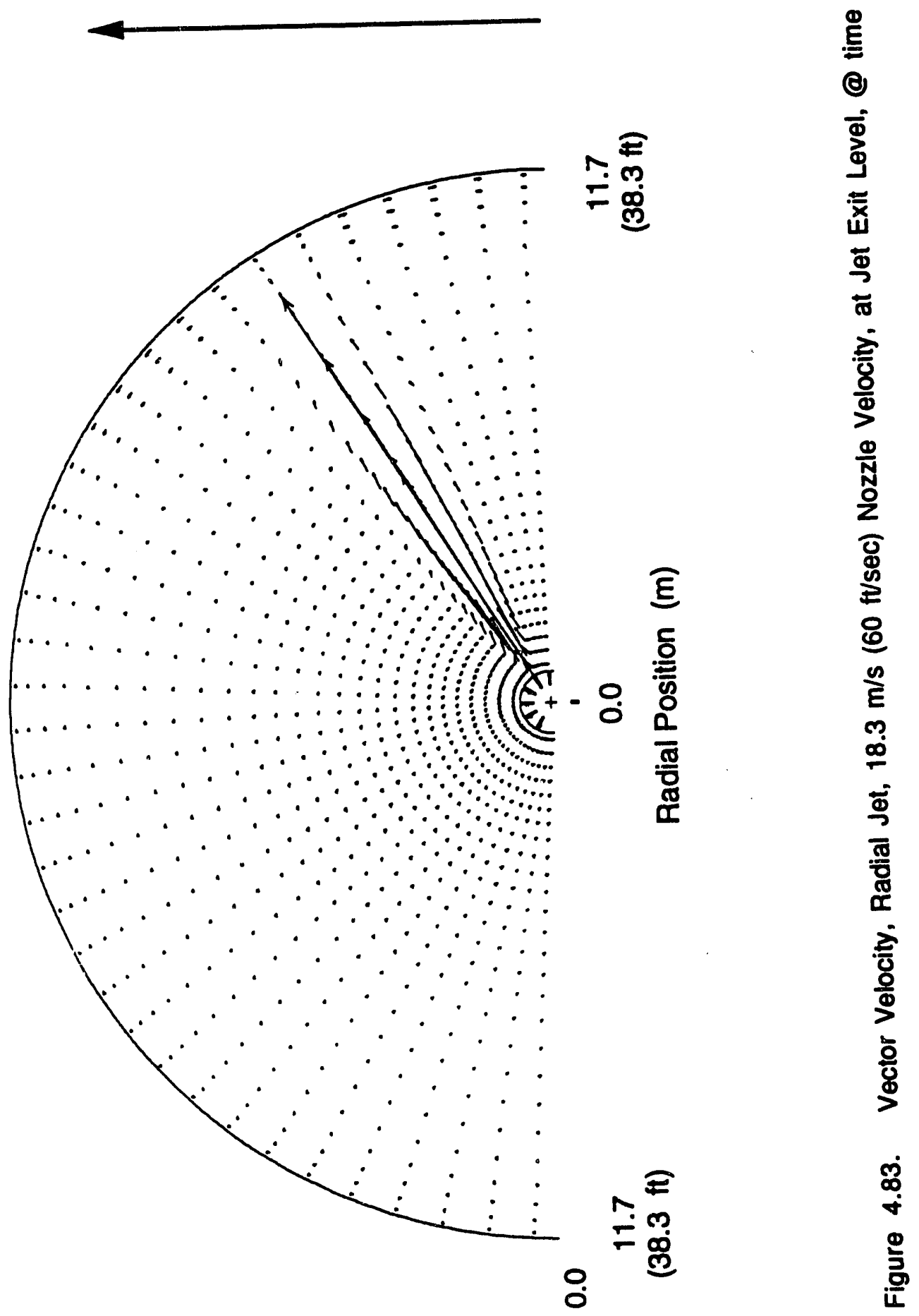




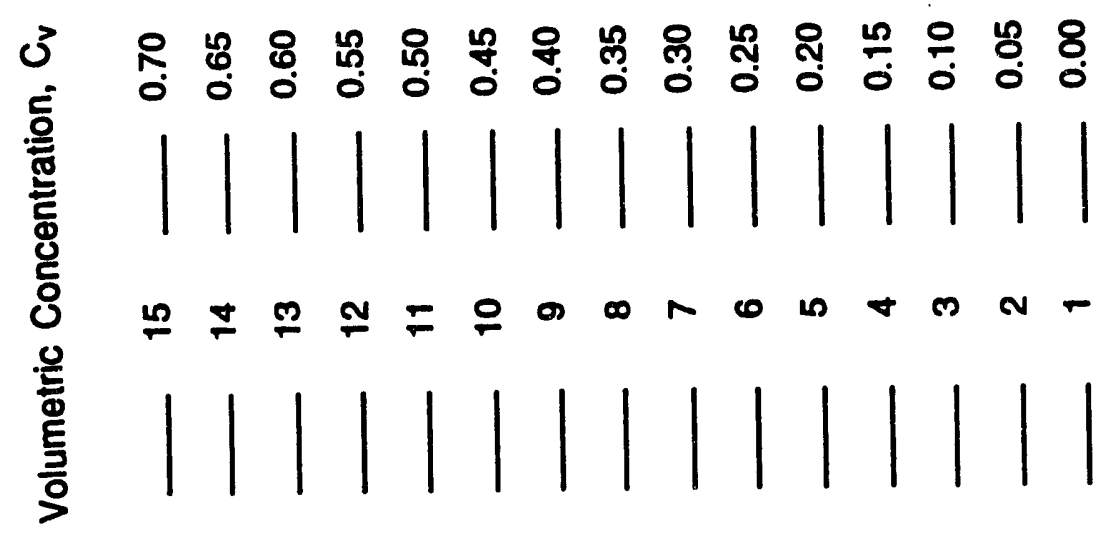

올

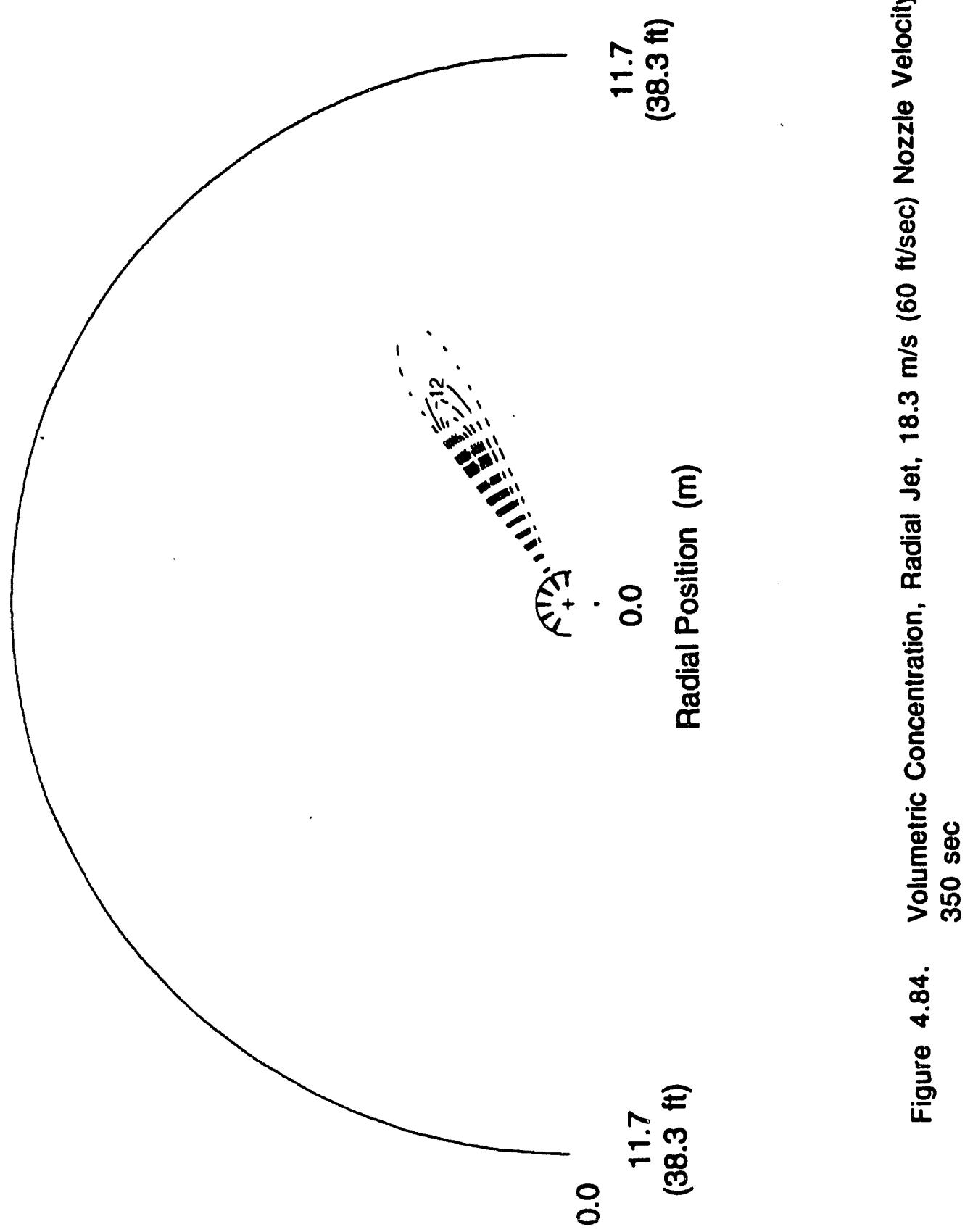




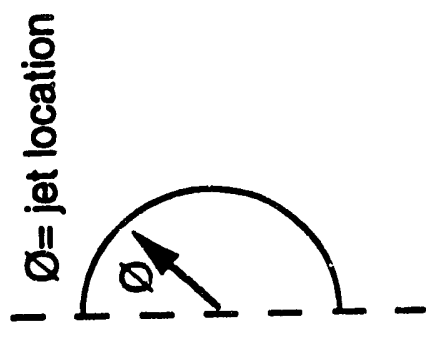

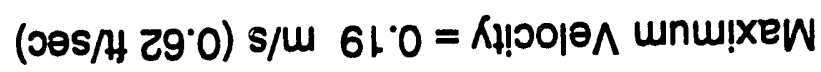

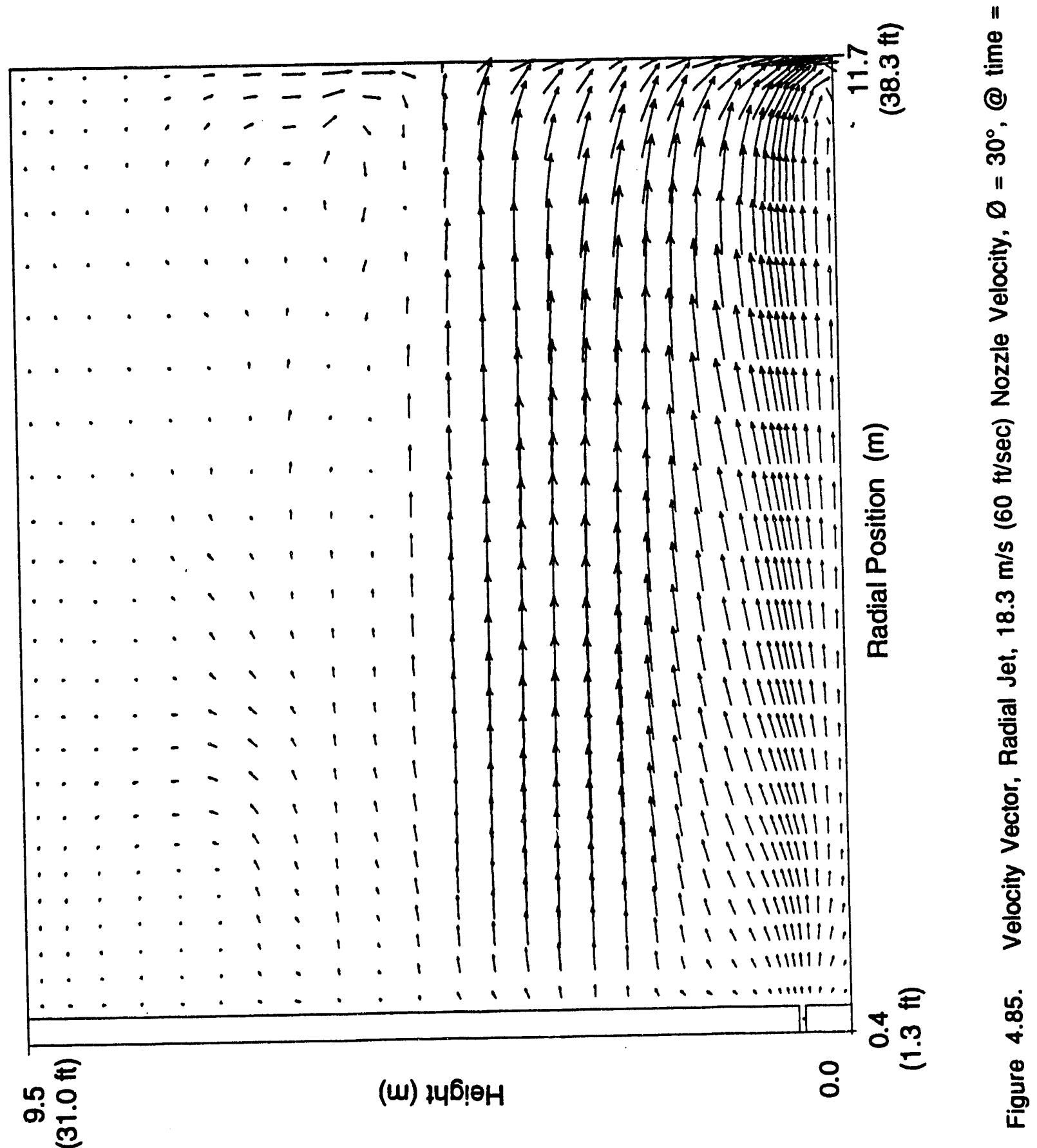



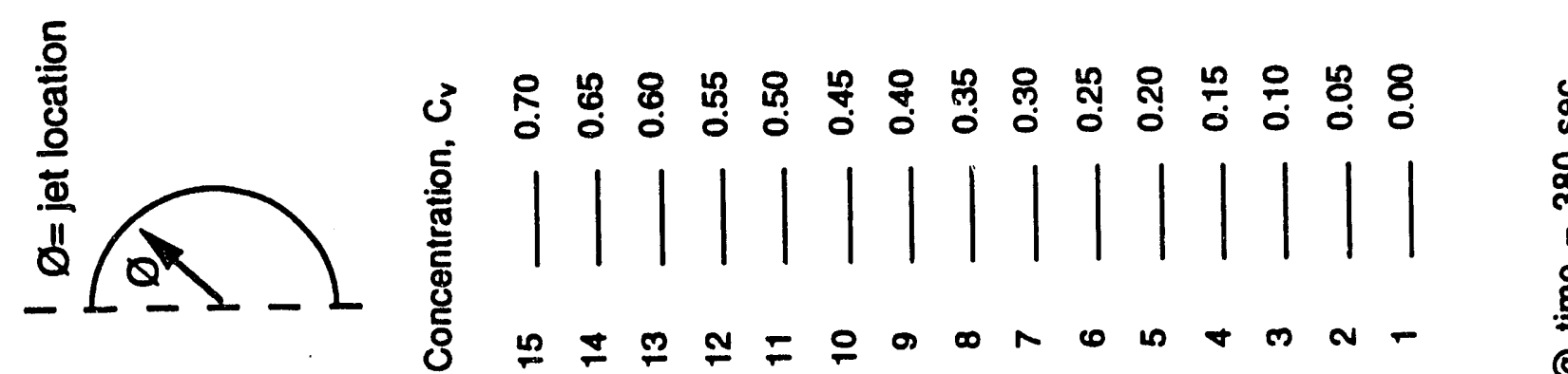

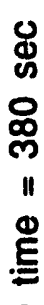

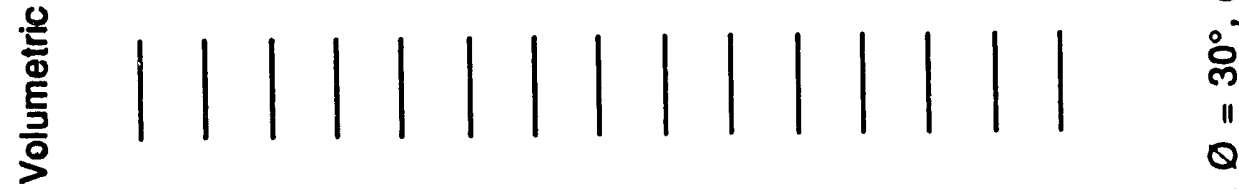

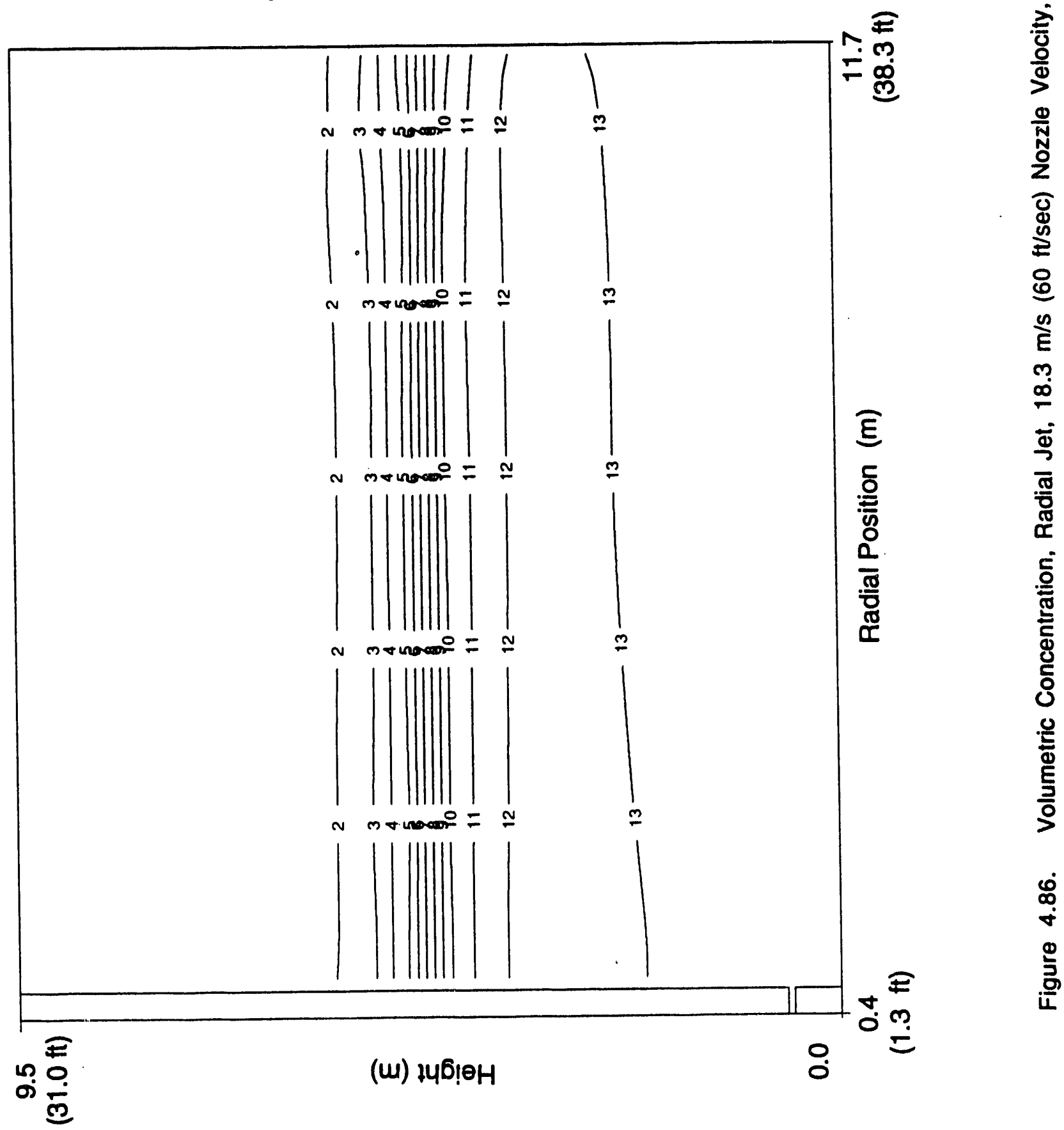




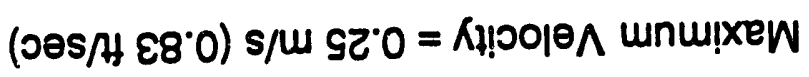

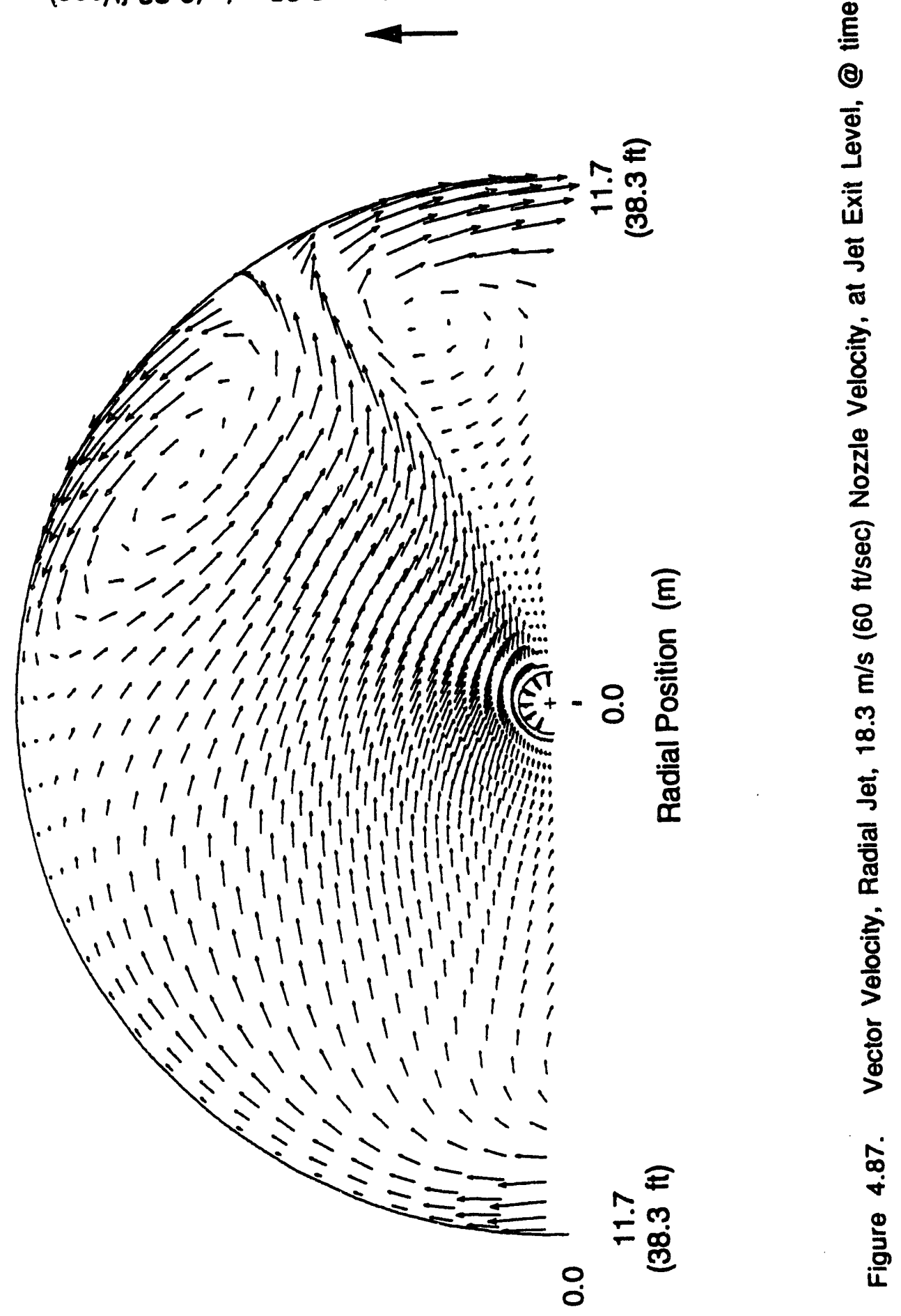




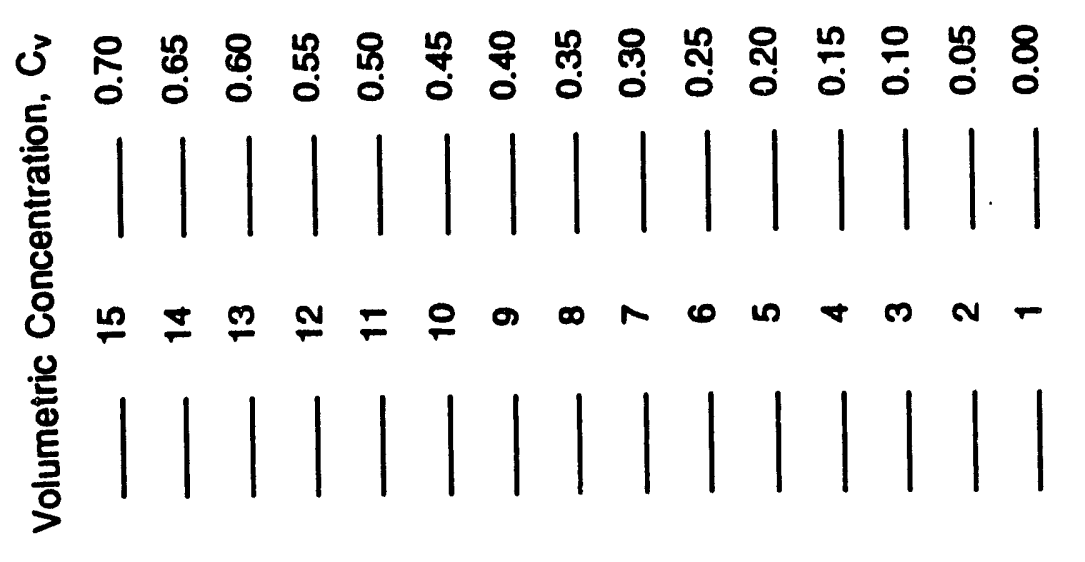

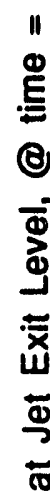

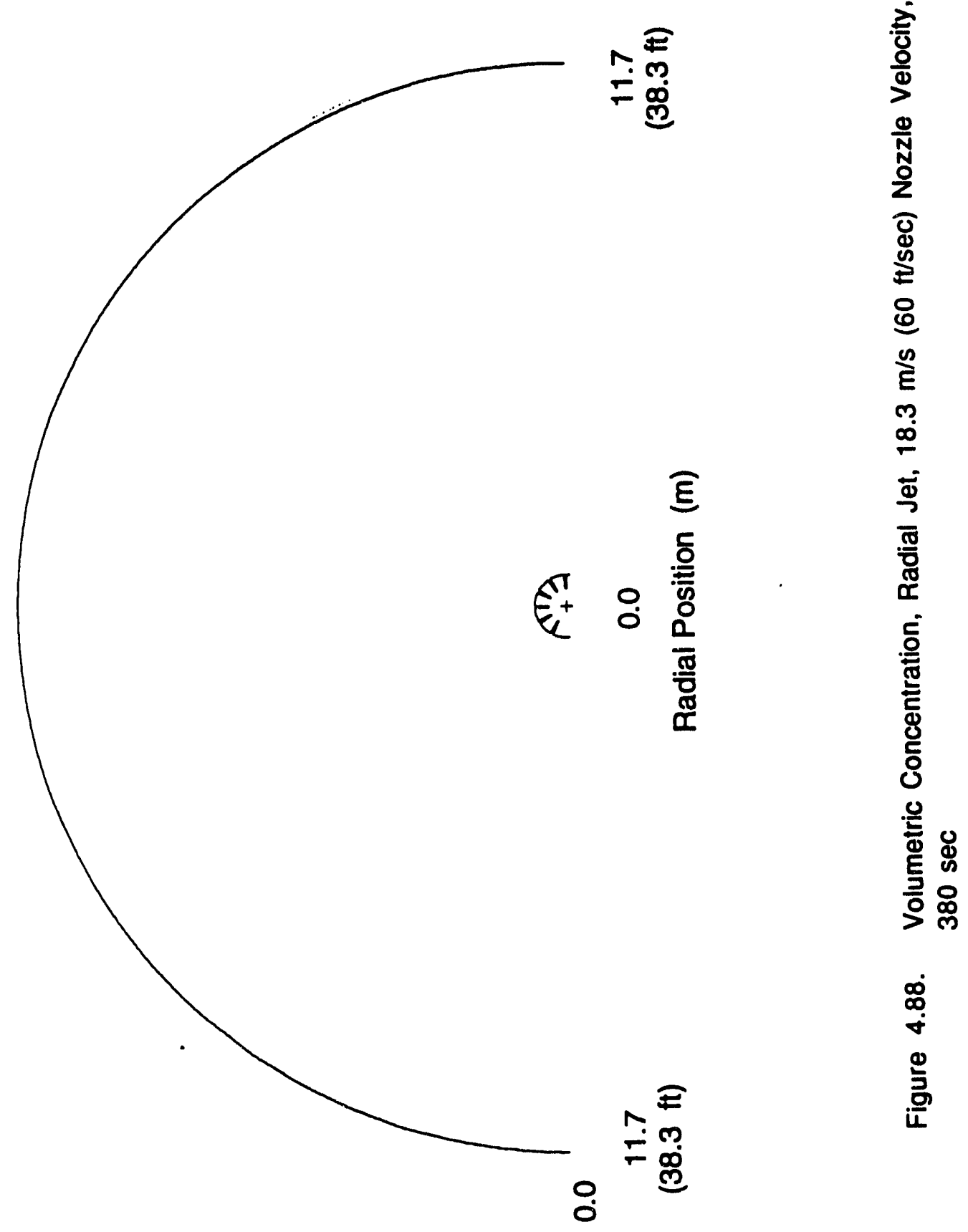

4.96 


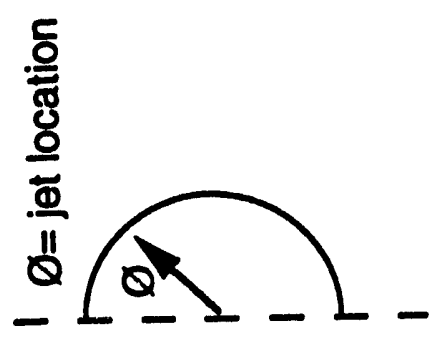

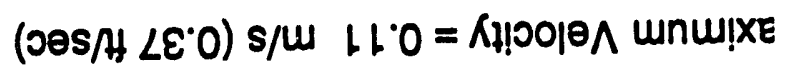

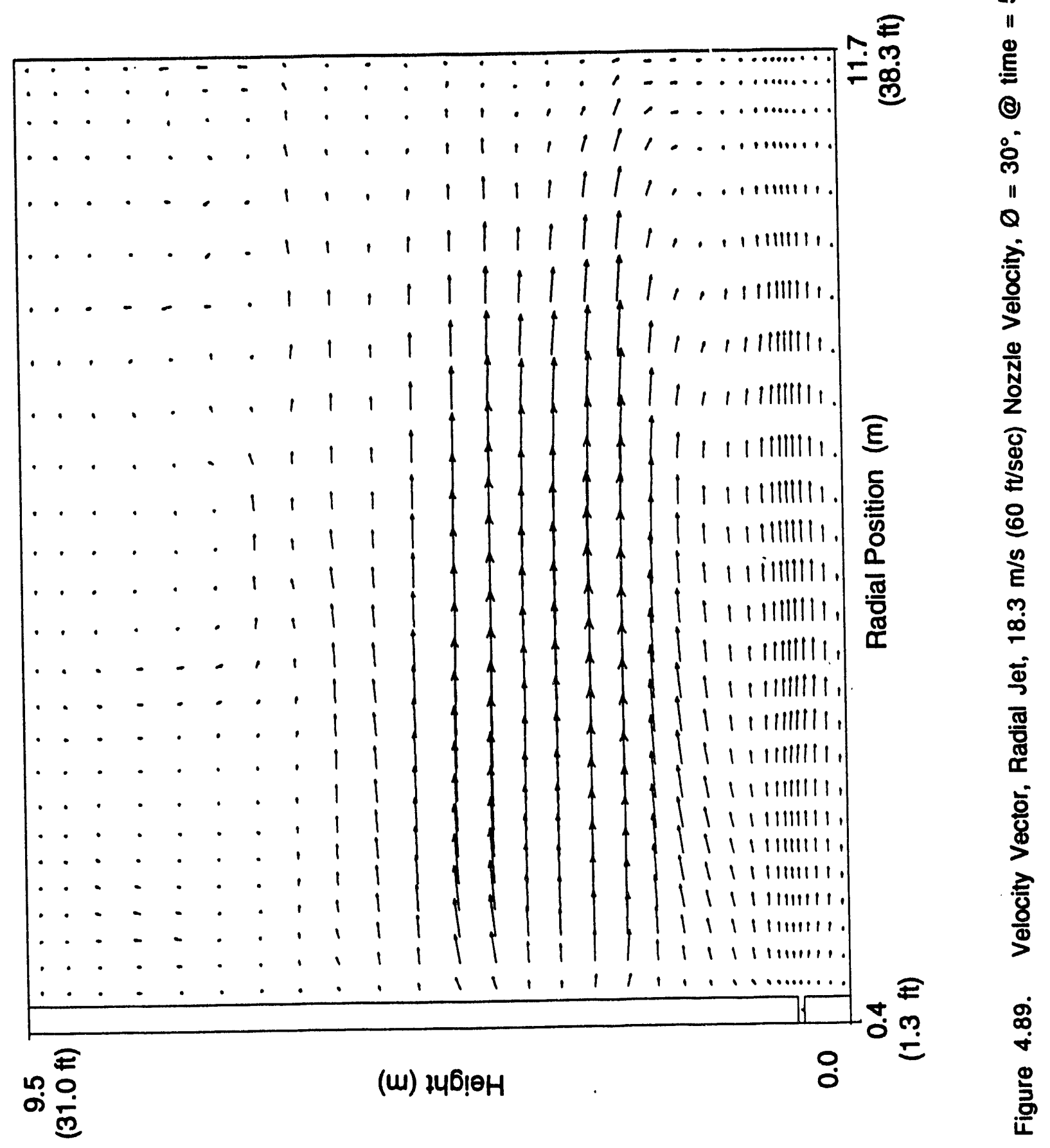




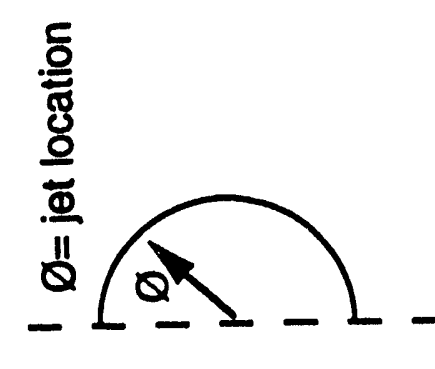

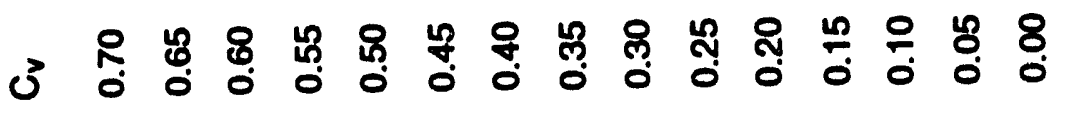
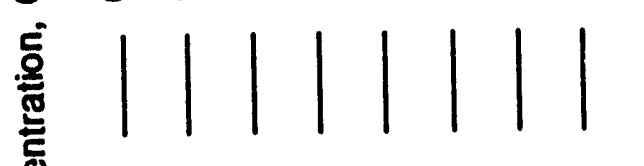

|| 11

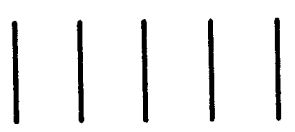

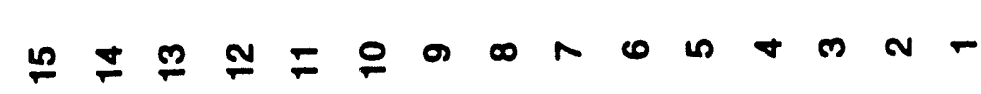

을

111111
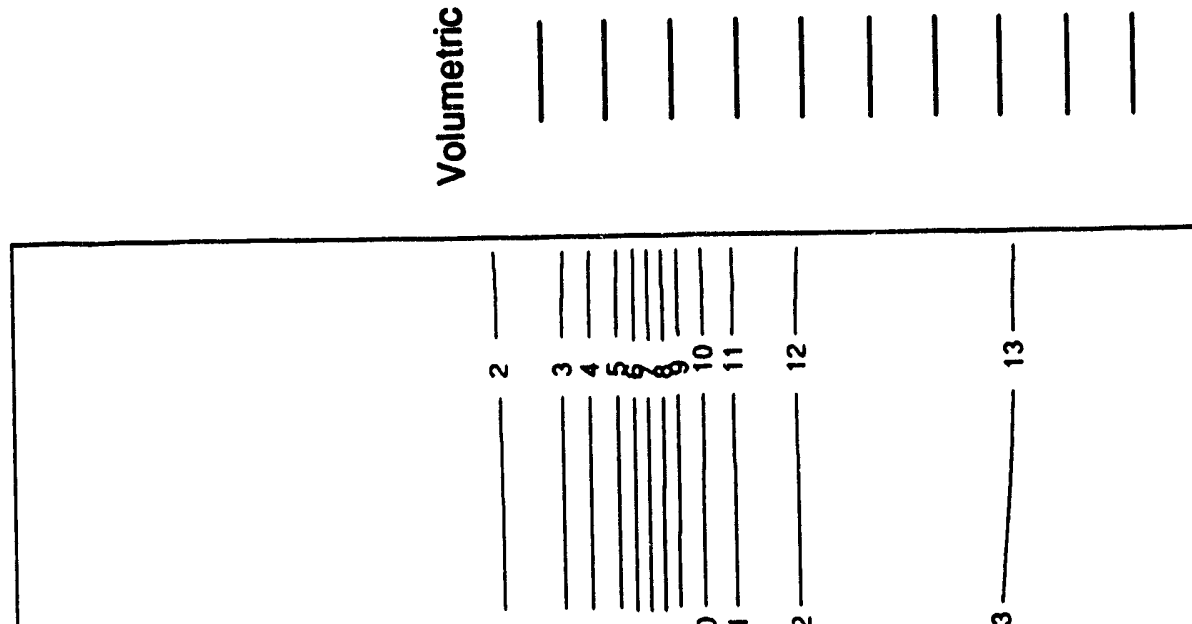

N $m \rightarrow \sin 200=$ N

N

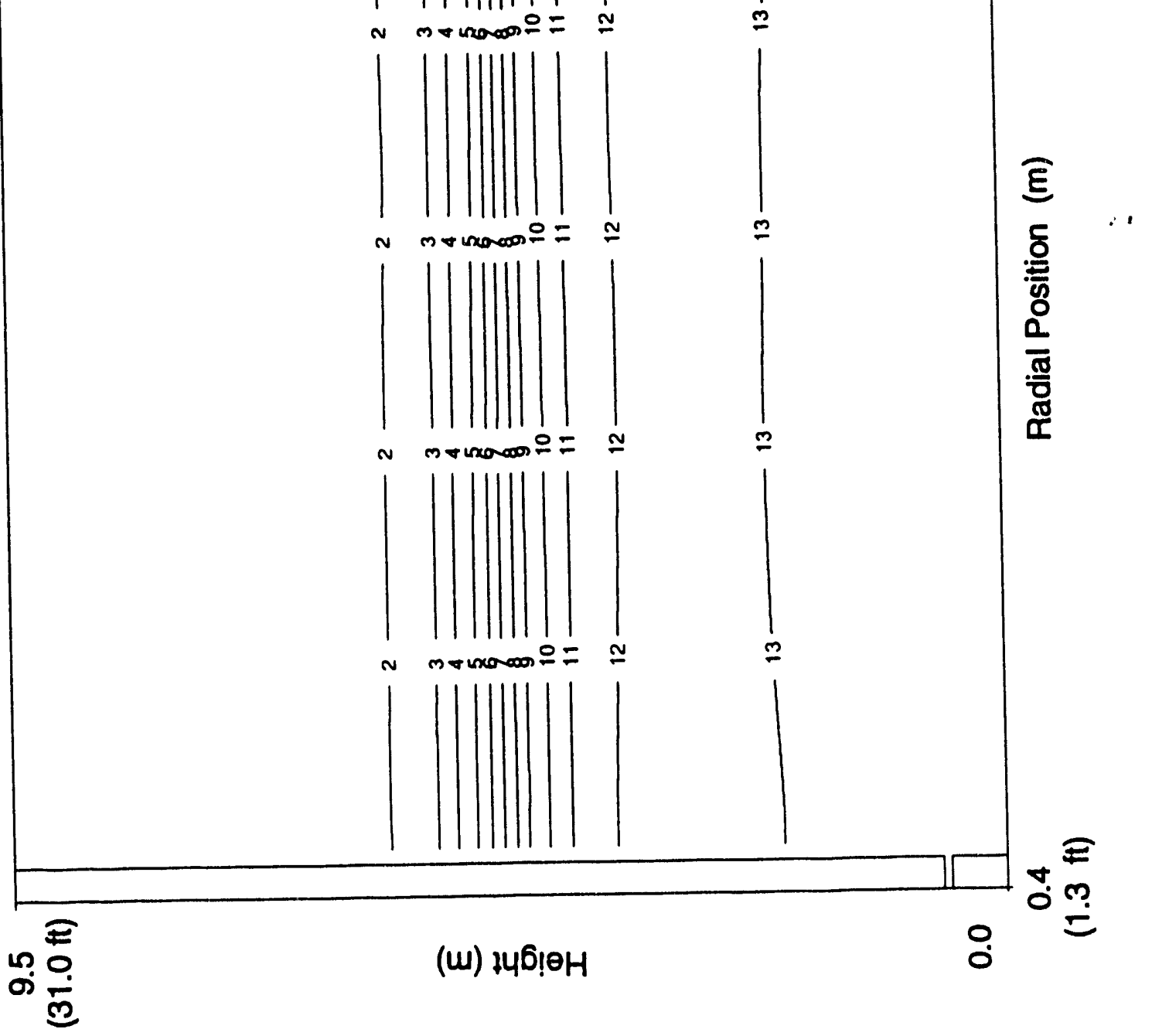

a mosenoso $=$

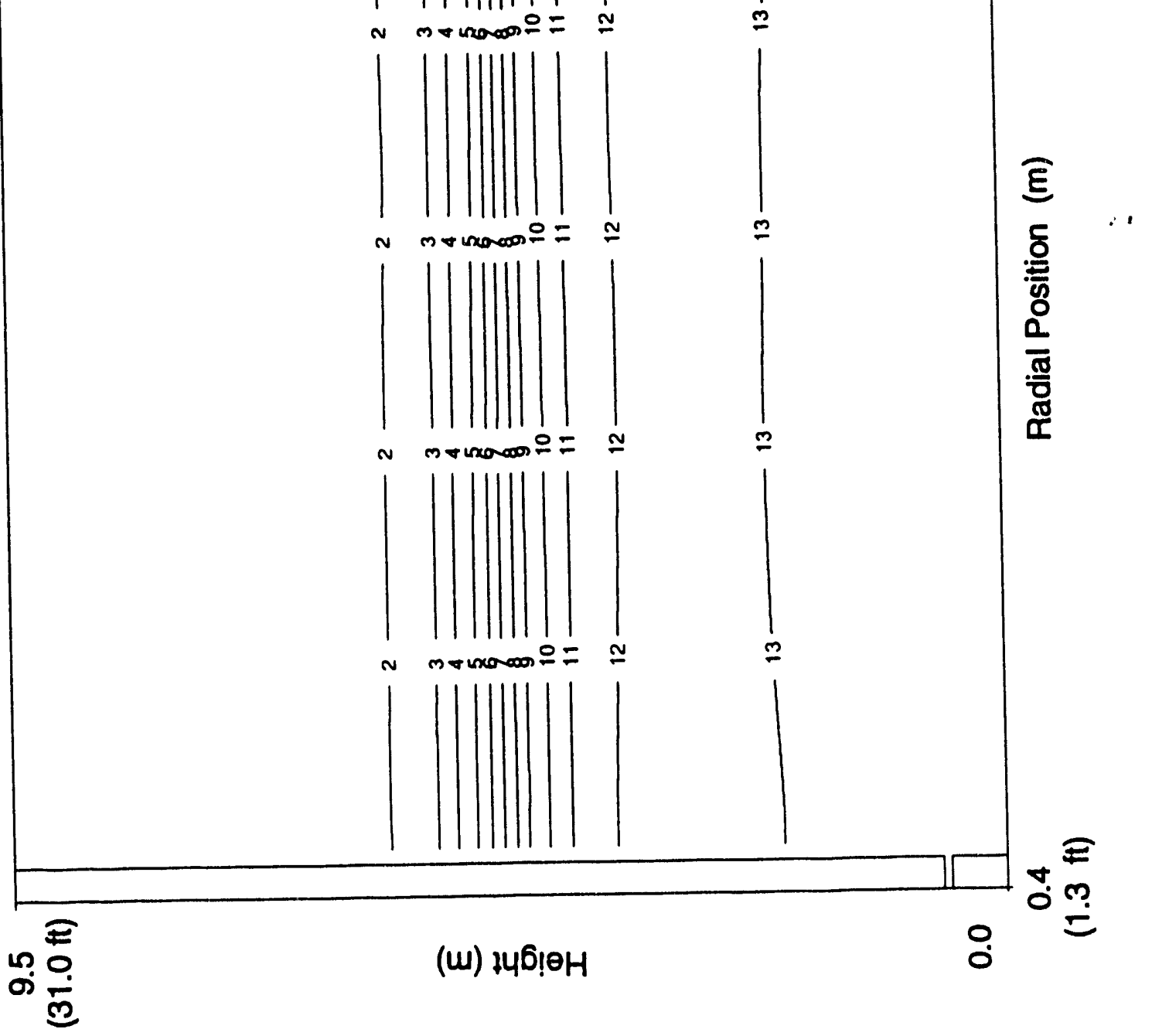

n

monacoso: $=$
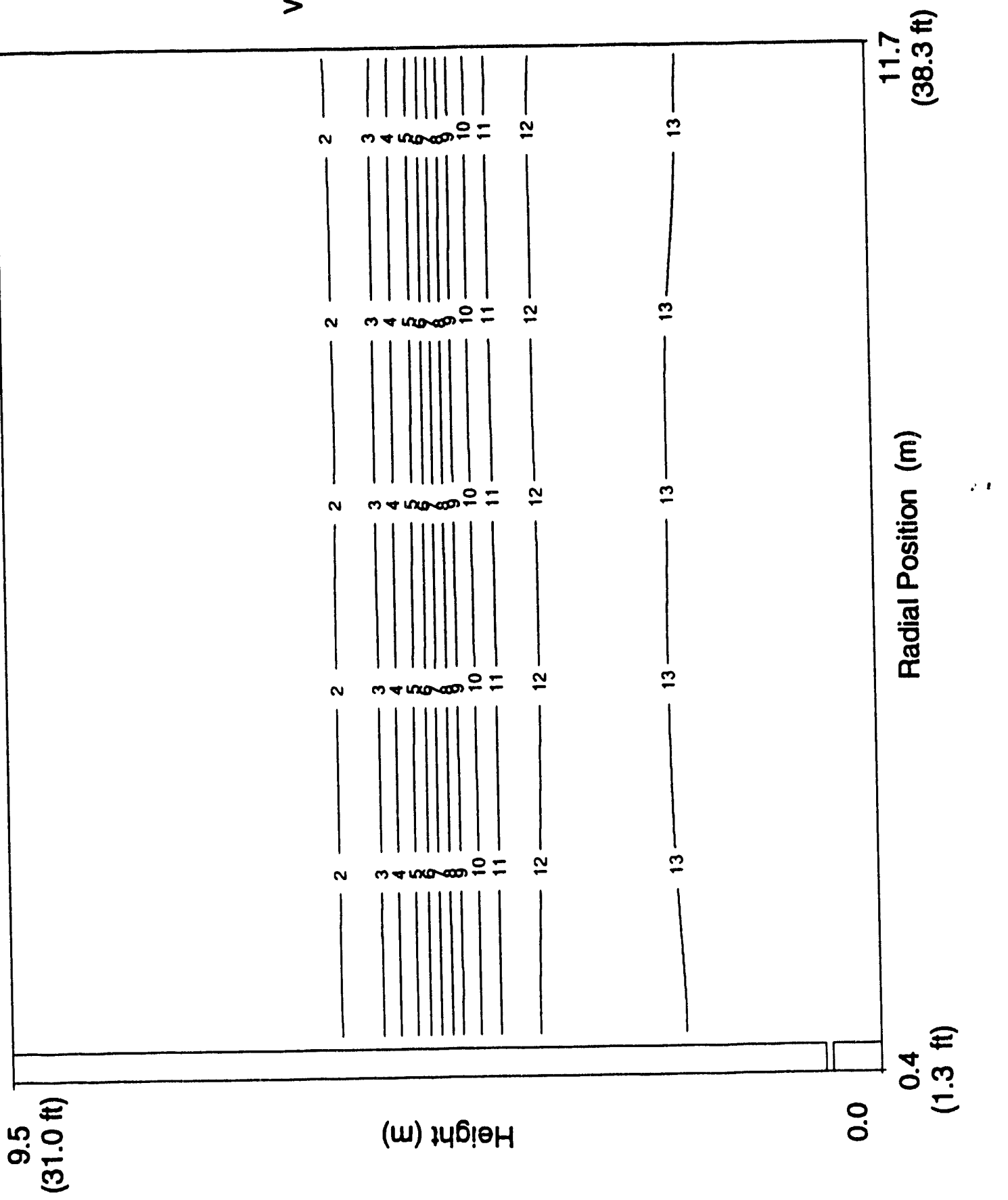

Q 


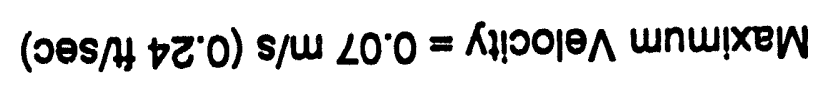

\begin{tabular}{l}
8 \\
8 \\
\$ \\
11 \\
.5 \\
\hline
\end{tabular}

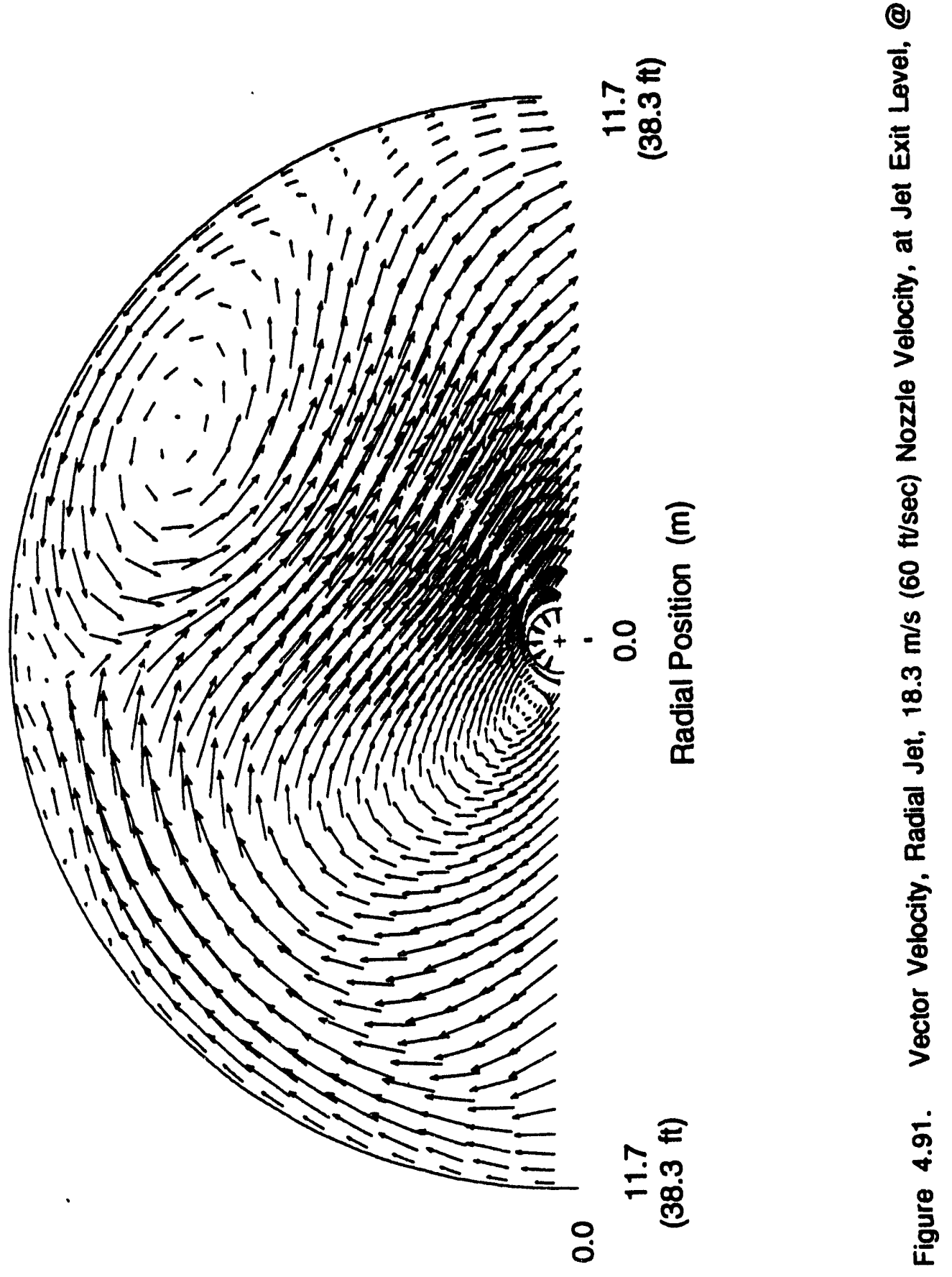



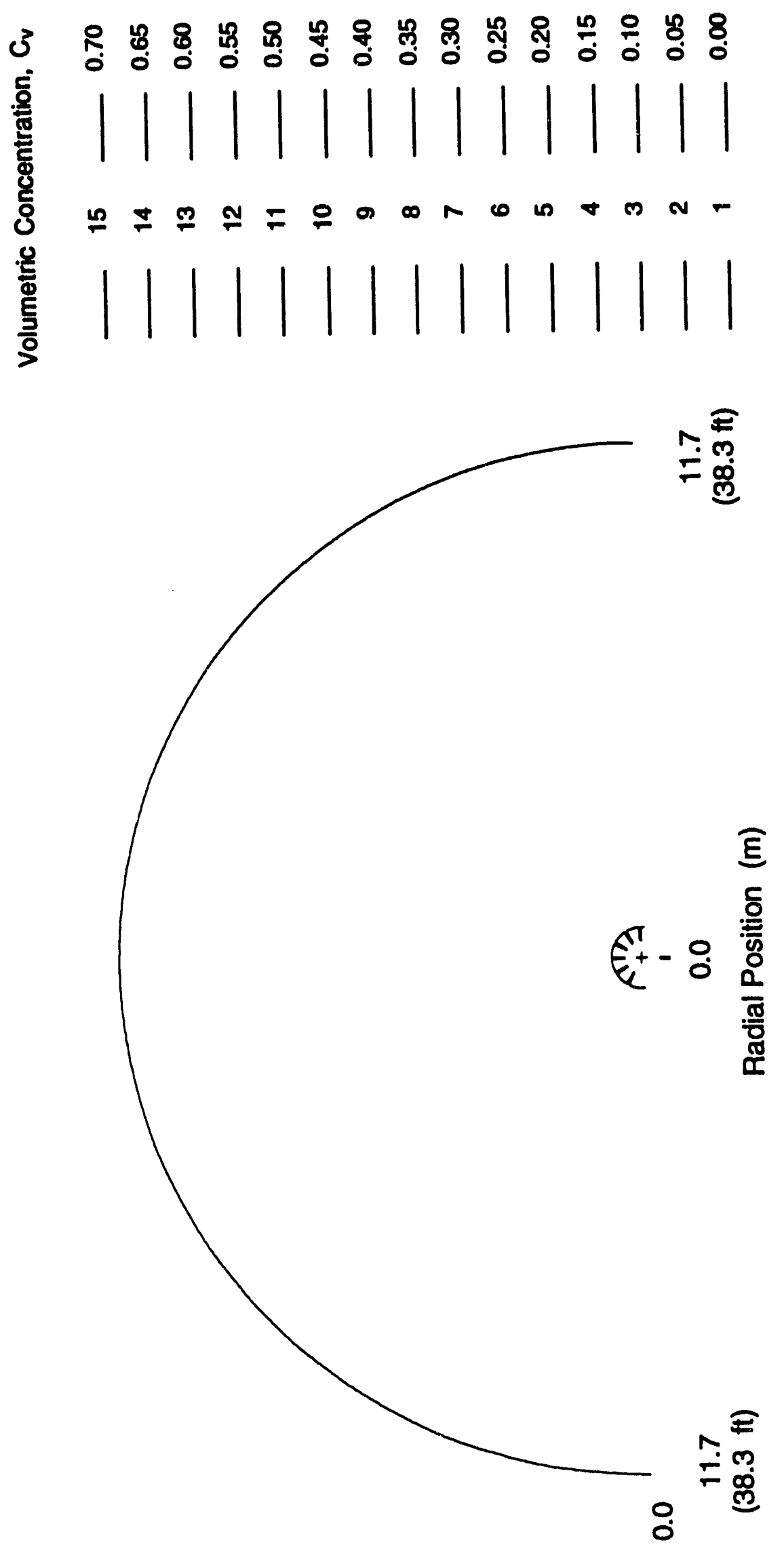

")

홍

N.

ত্

8

है

क

ఫึ

중

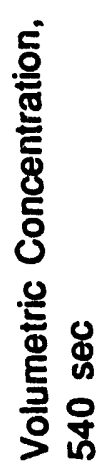

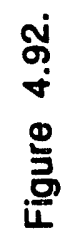




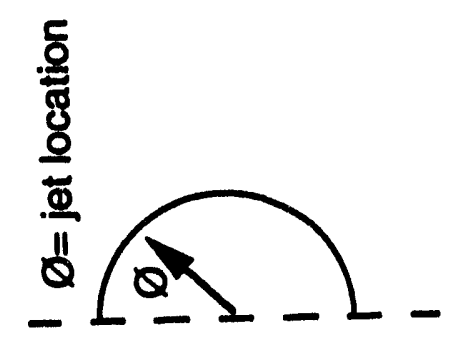

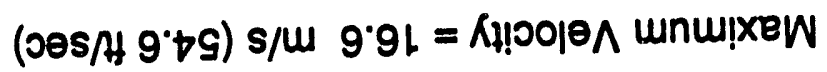

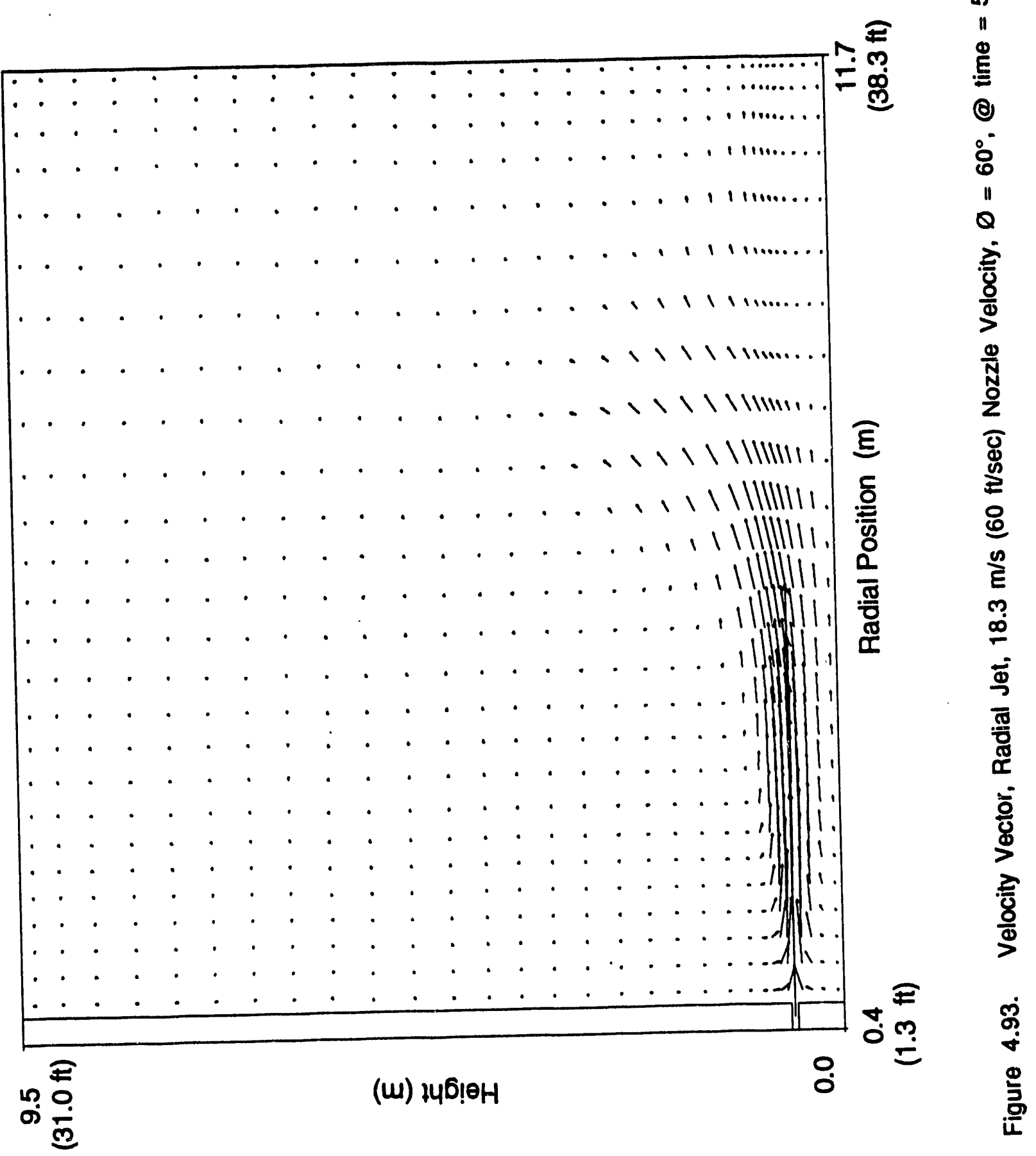




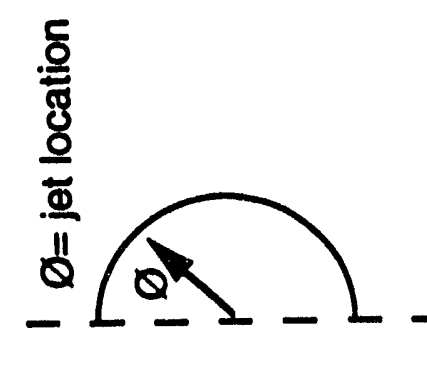

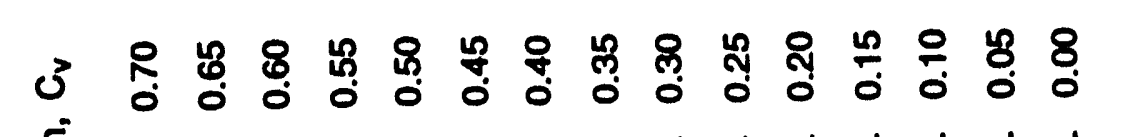

咘

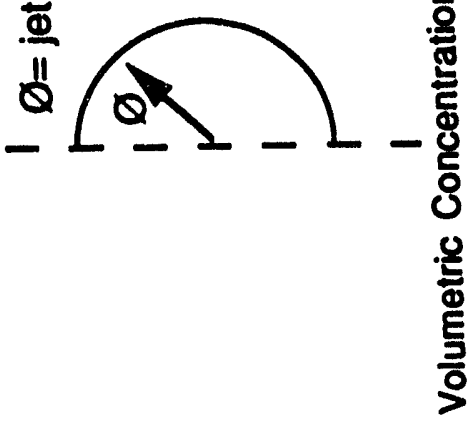
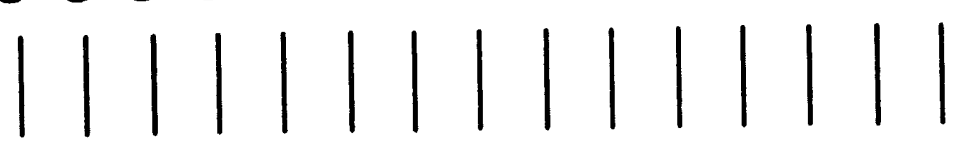

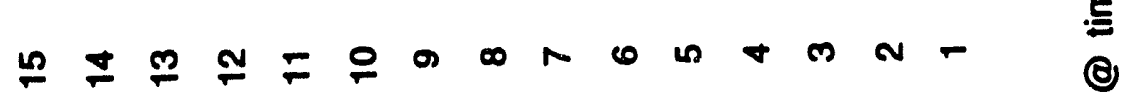
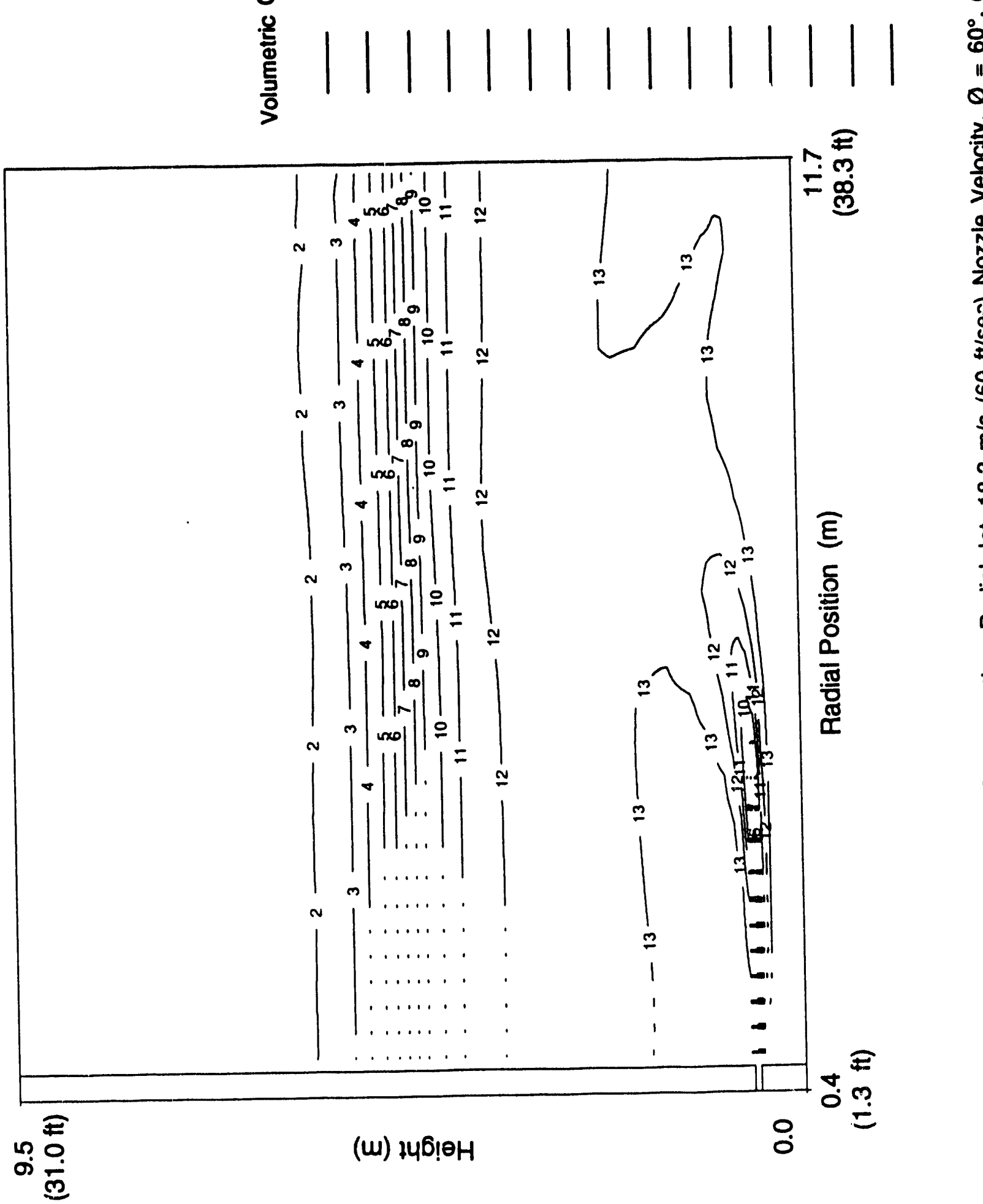

를

$:$

Q

产

$\frac{\Phi}{\mathrm{N}}$

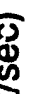

8 


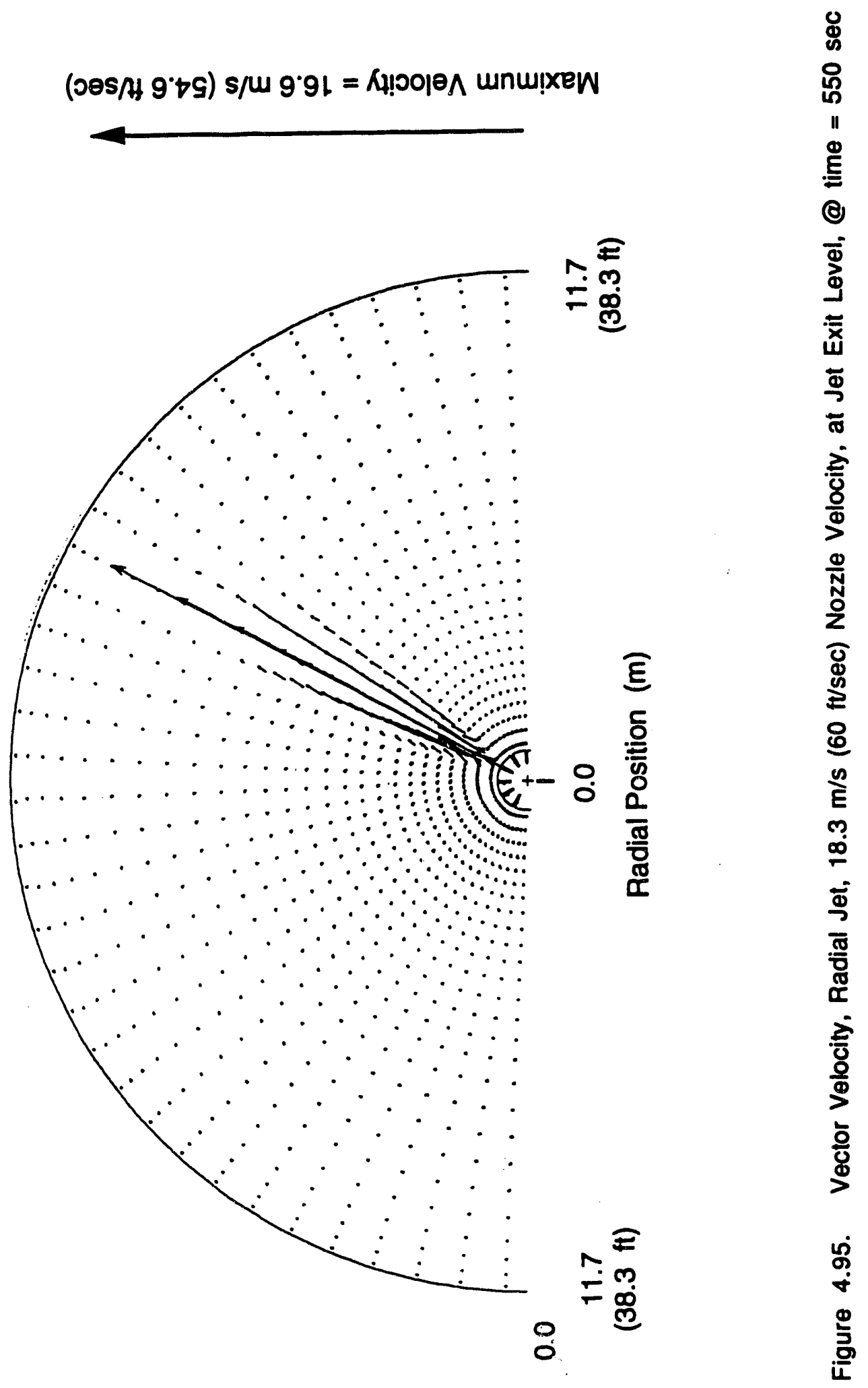



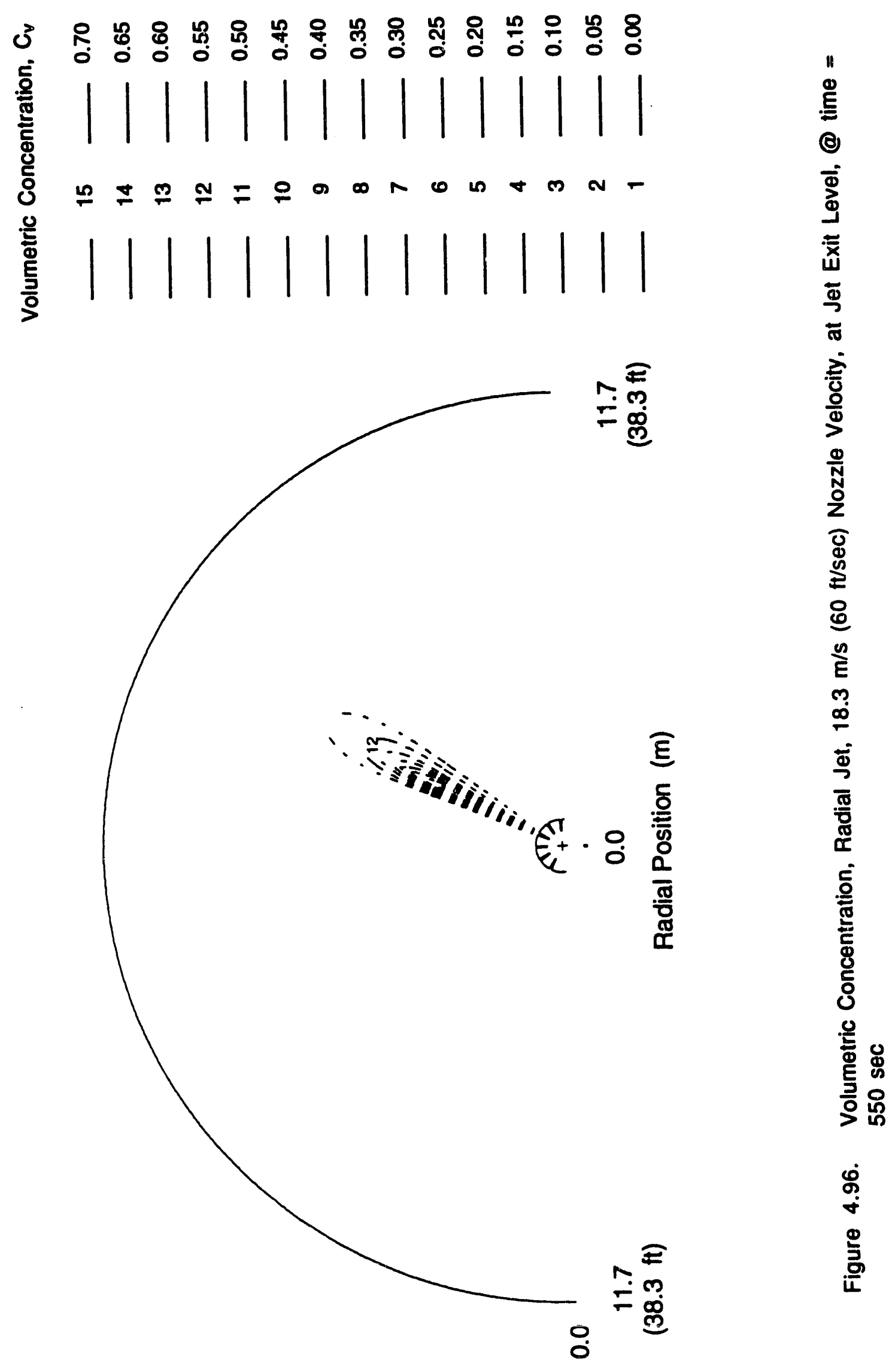

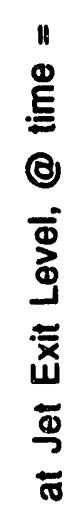




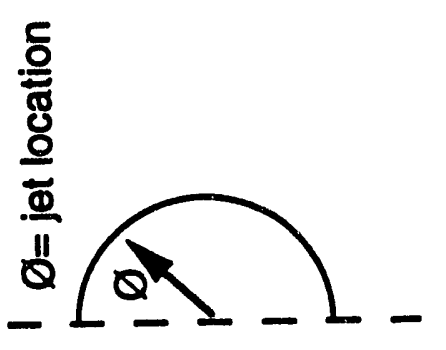

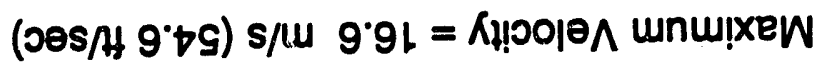

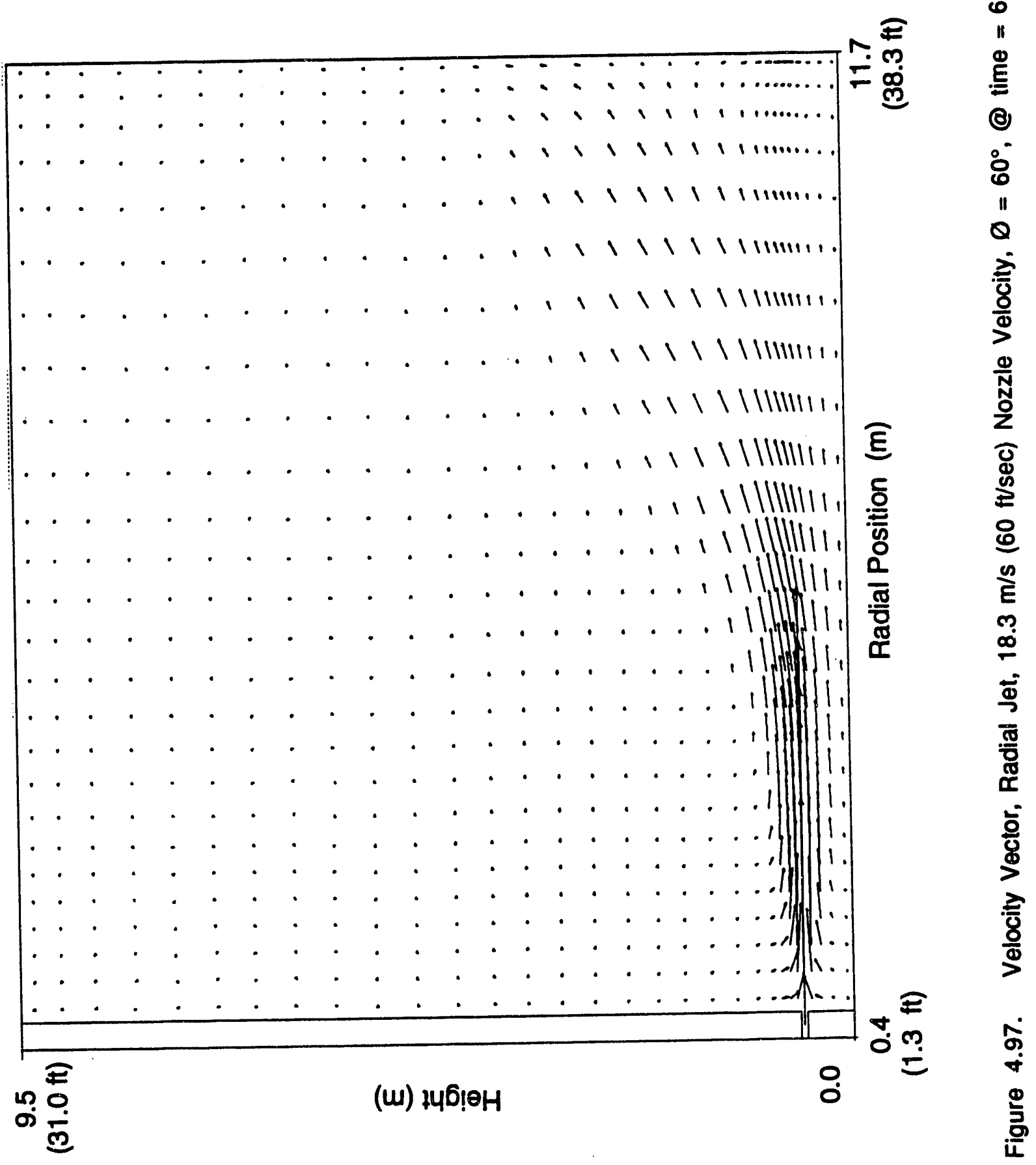




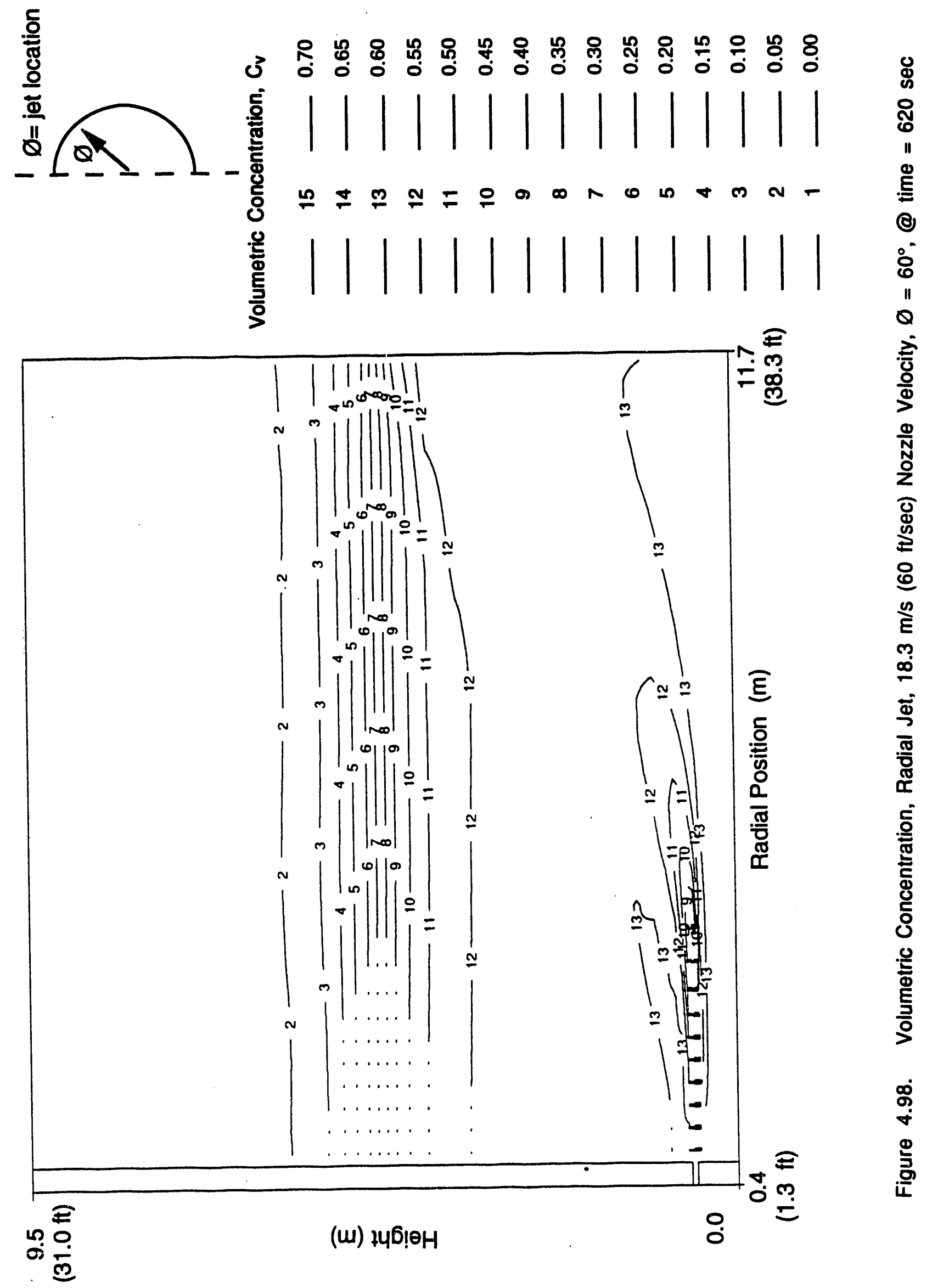




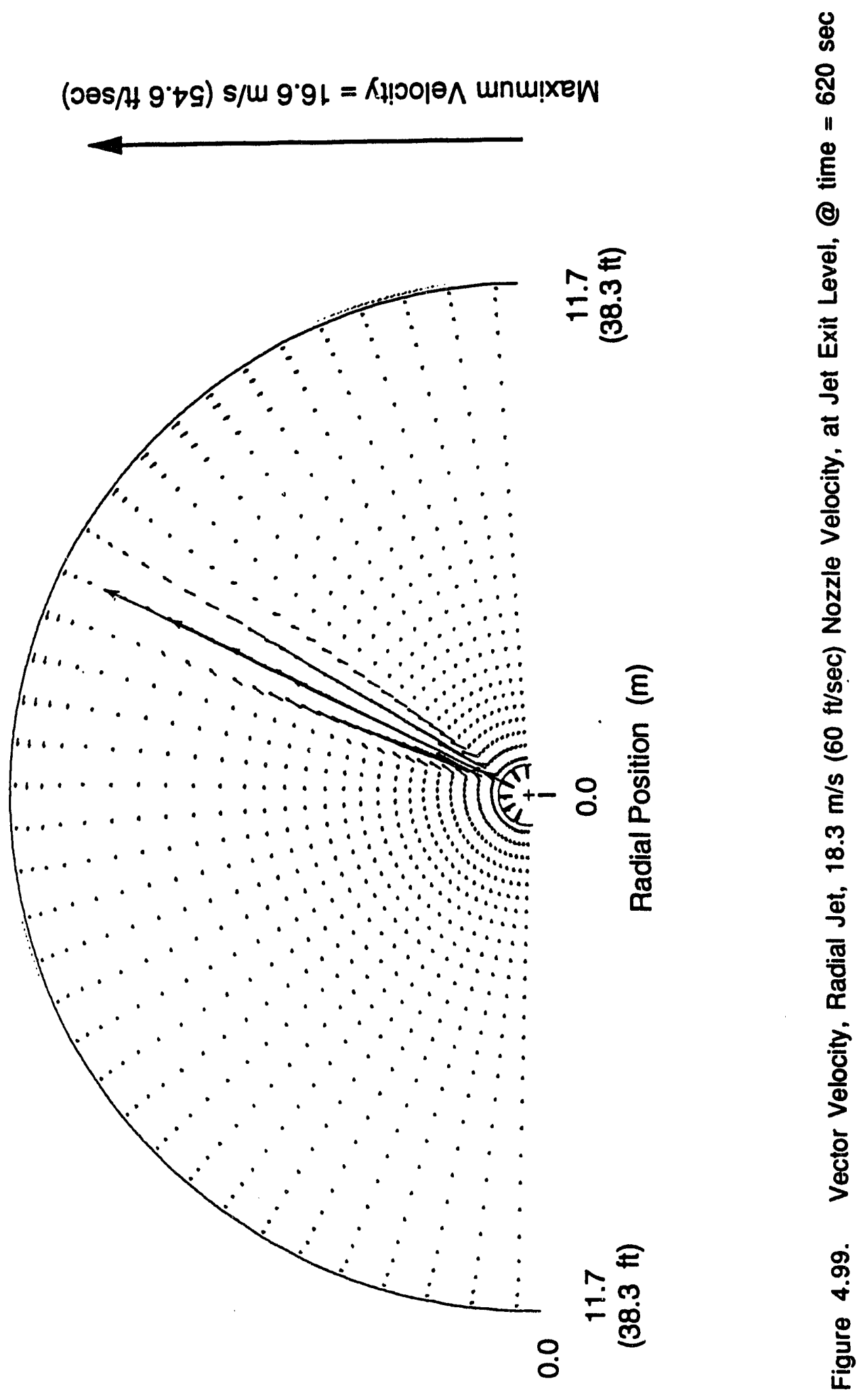



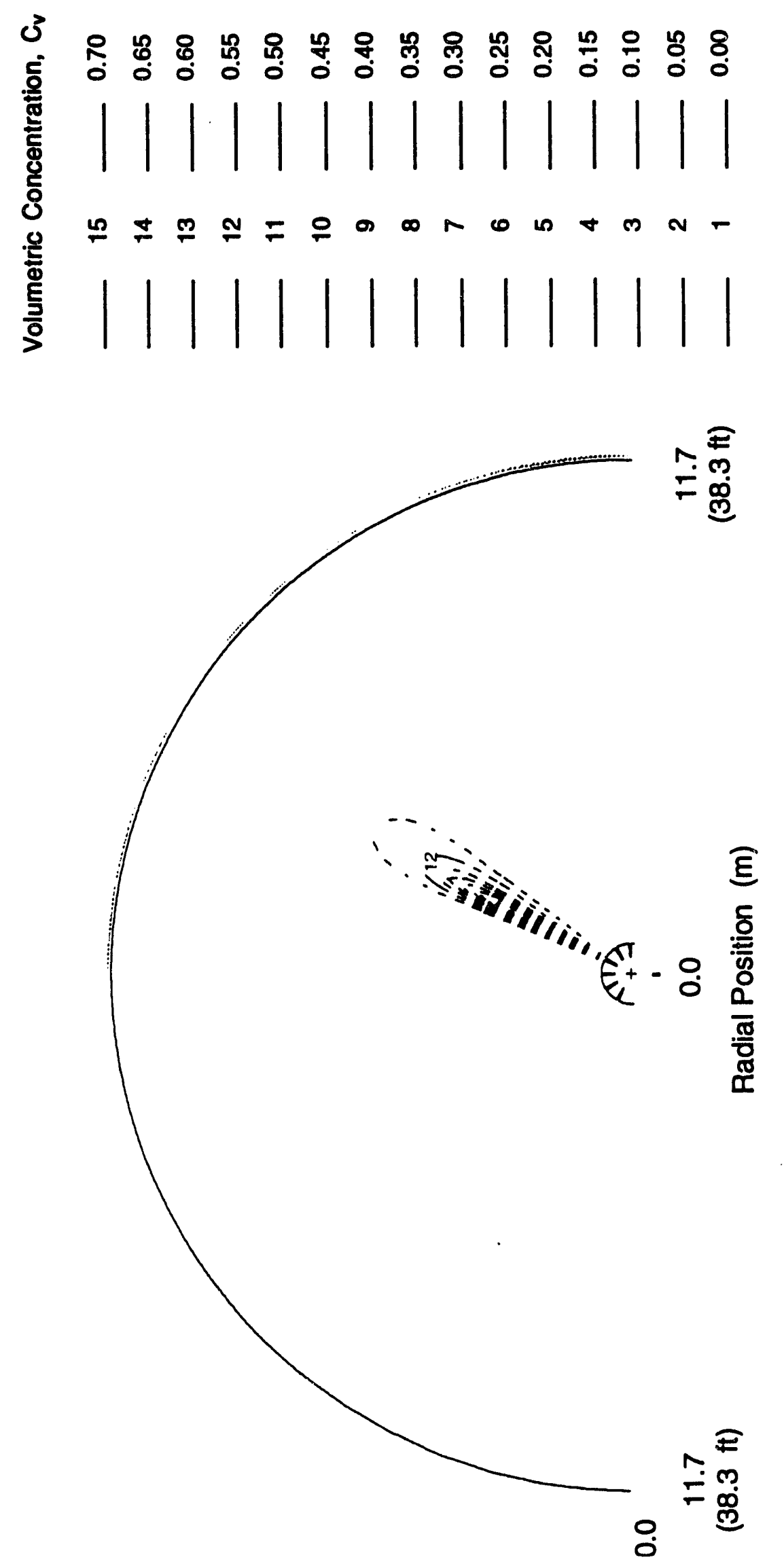

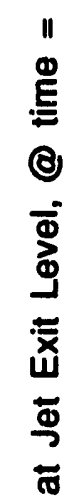

흥

\begin{tabular}{l} 
N \\
N \\
\hline
\end{tabular}

ర్

$\stackrel{\mathscr{N}}{2}$

:

है

$\infty$

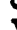




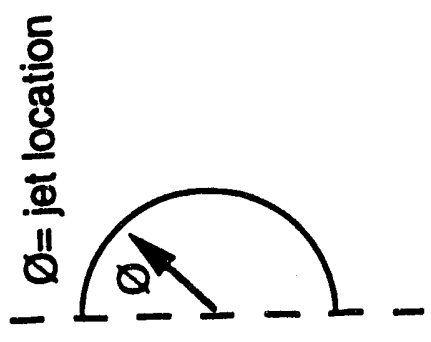

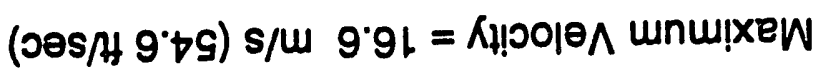

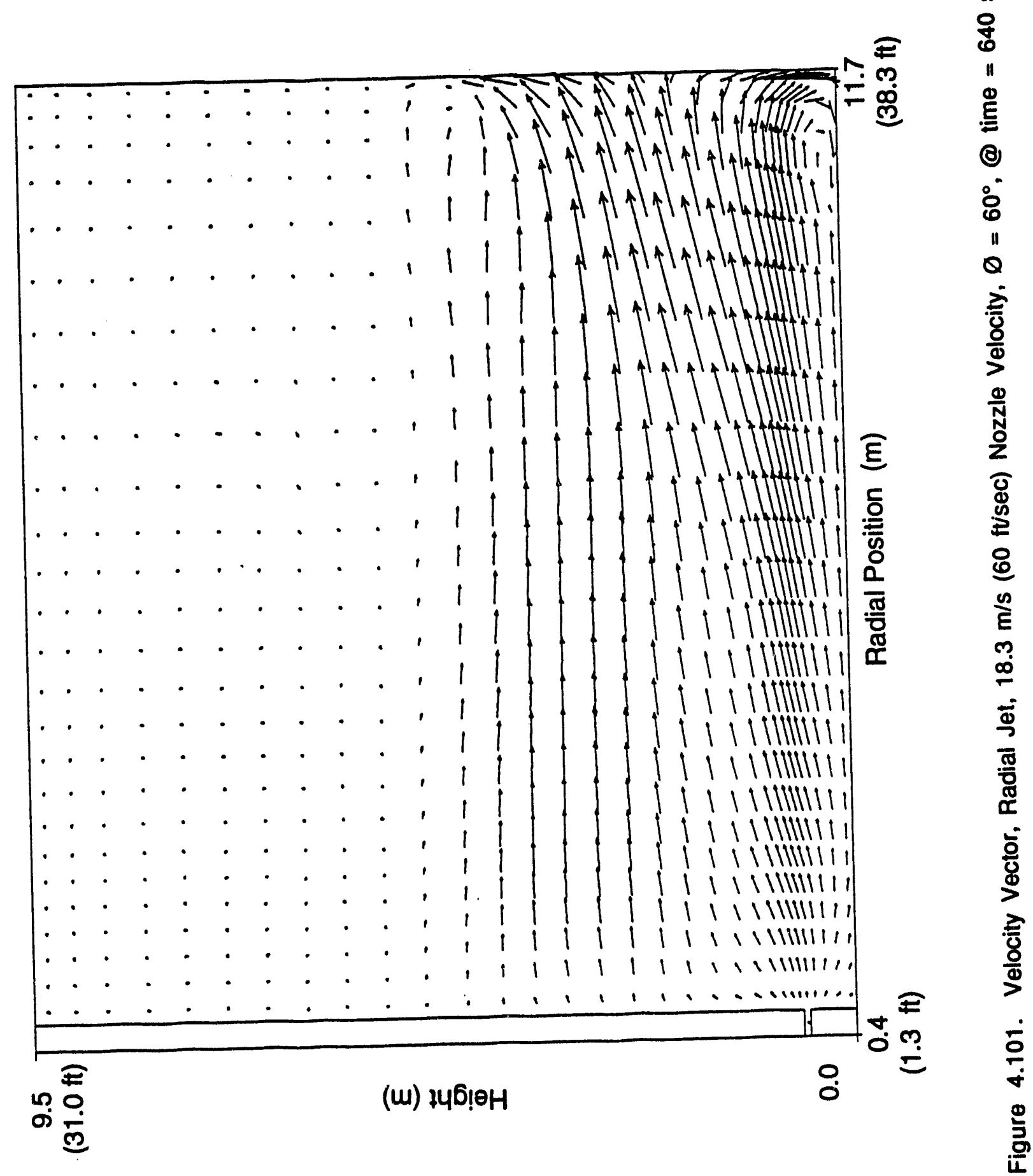



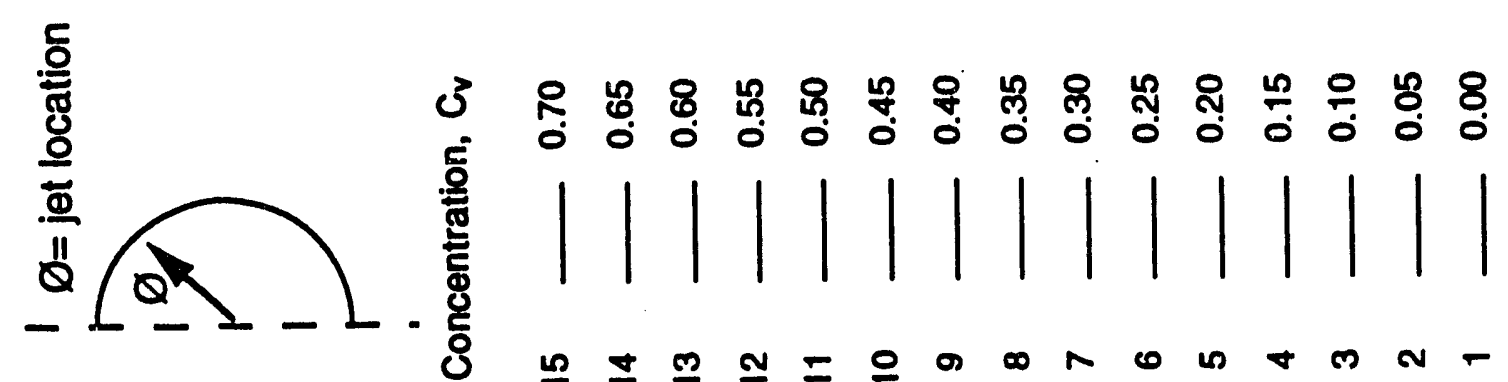

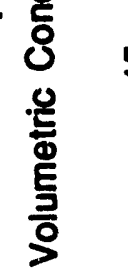

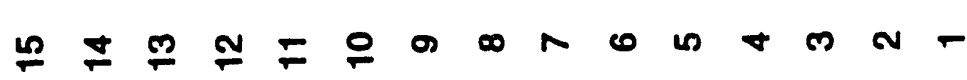

\&

를

(C)
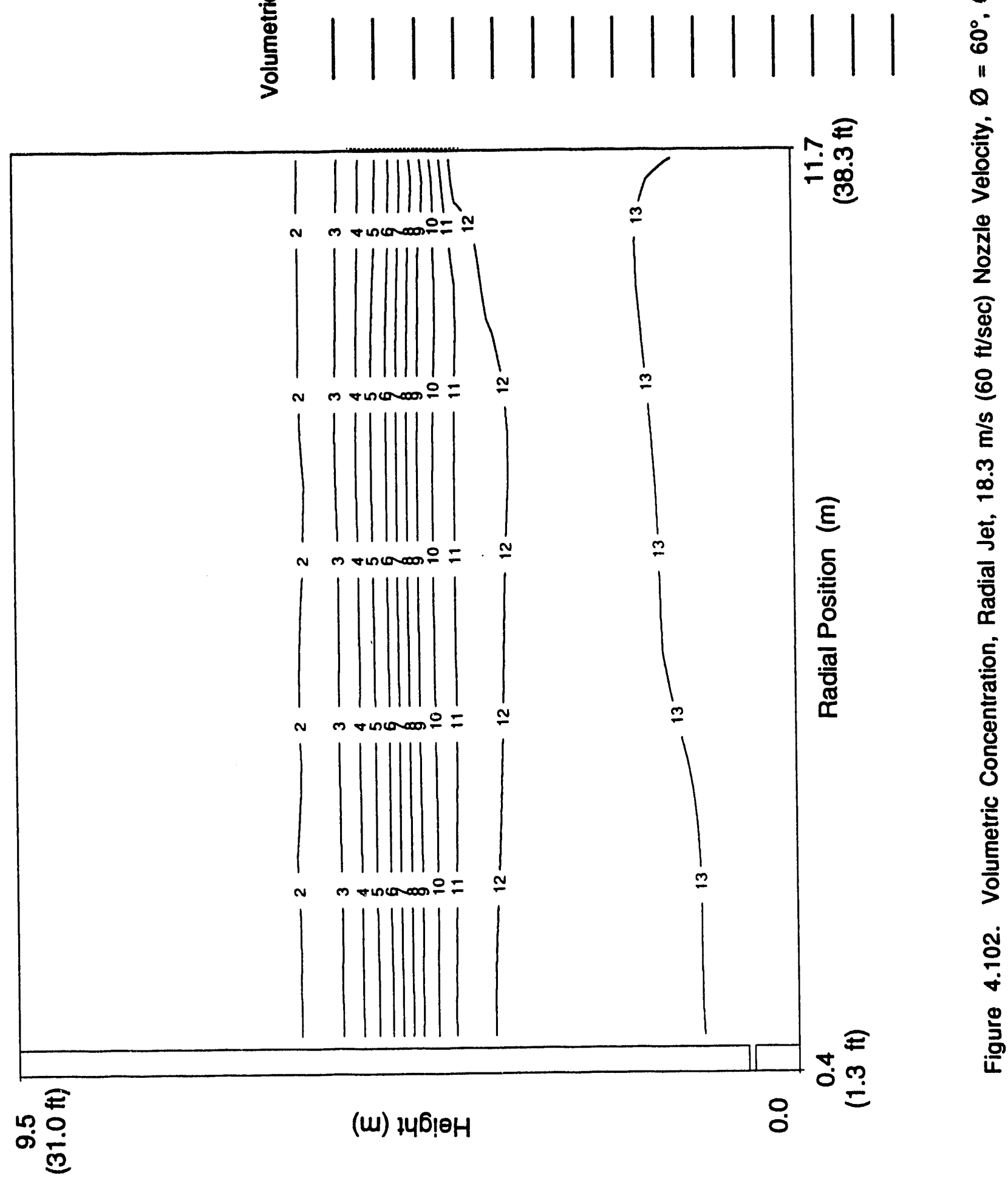

ஜ

" 


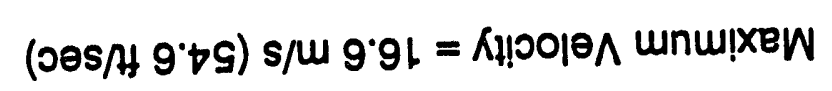

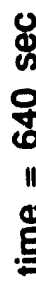

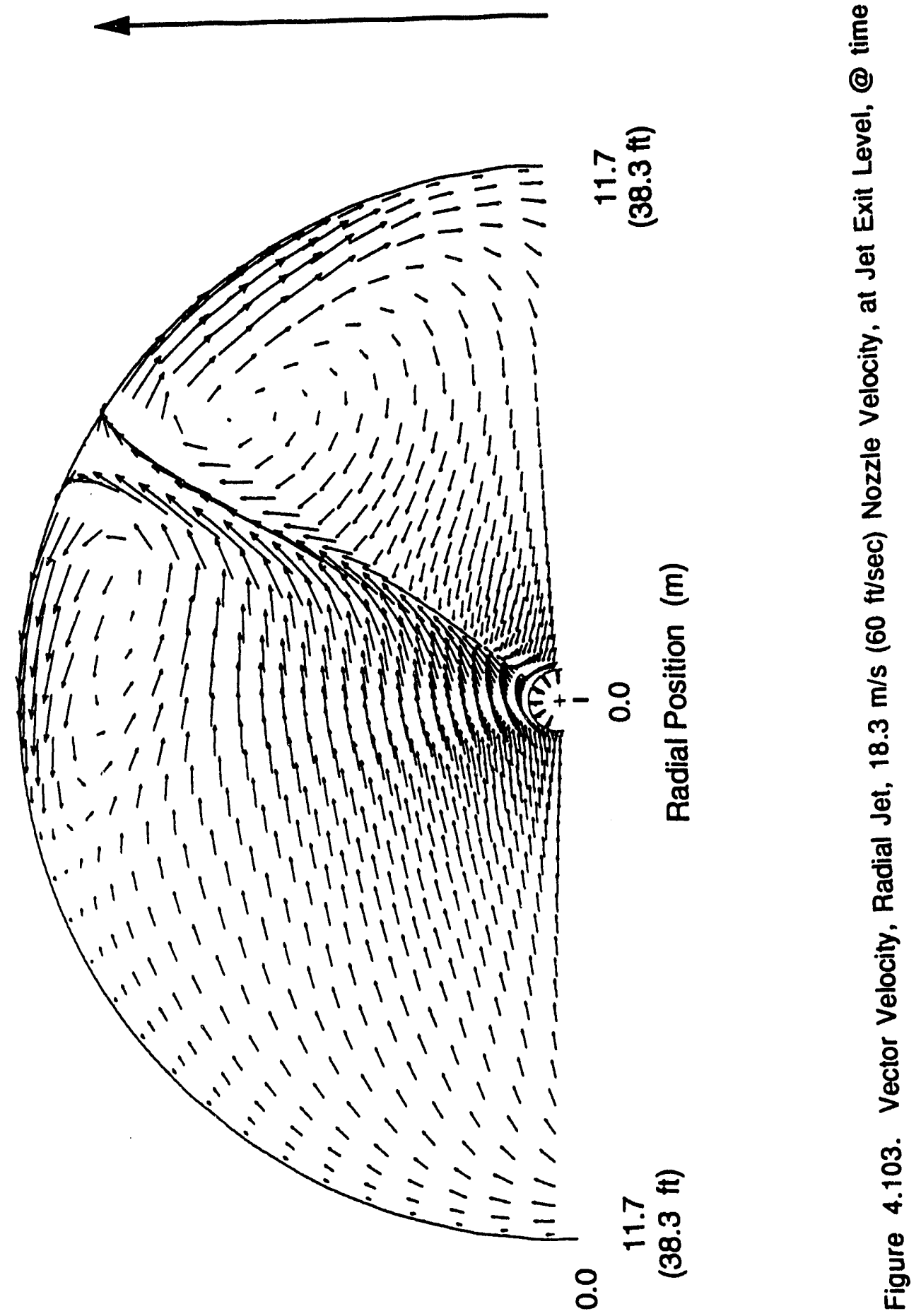



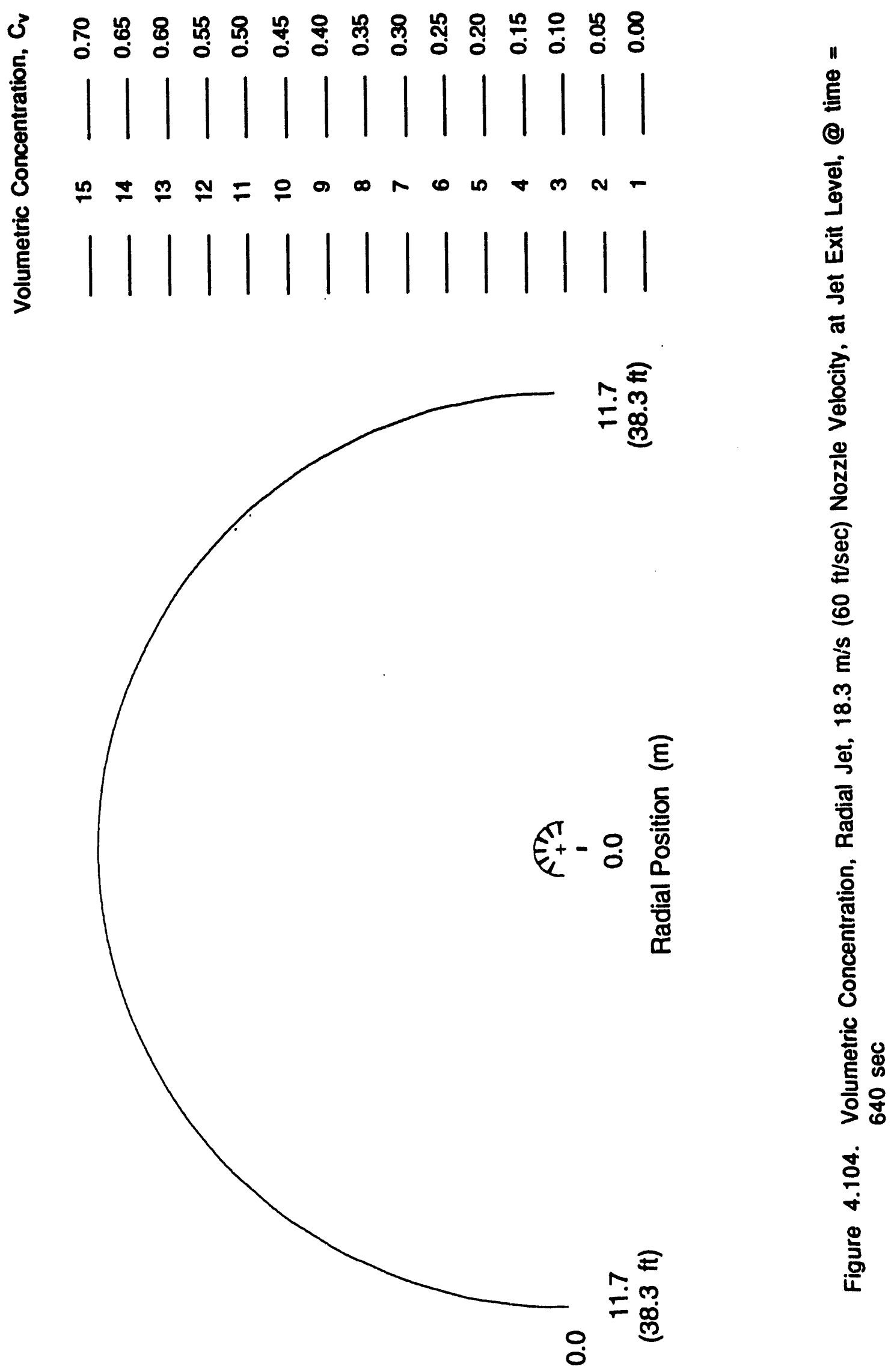


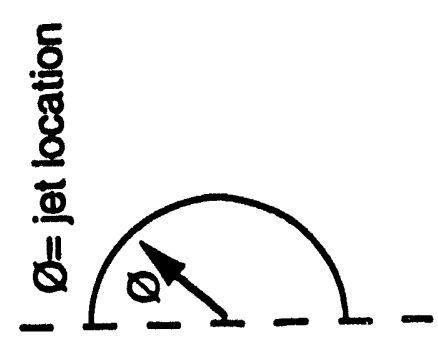

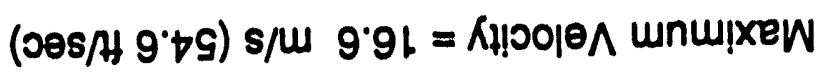

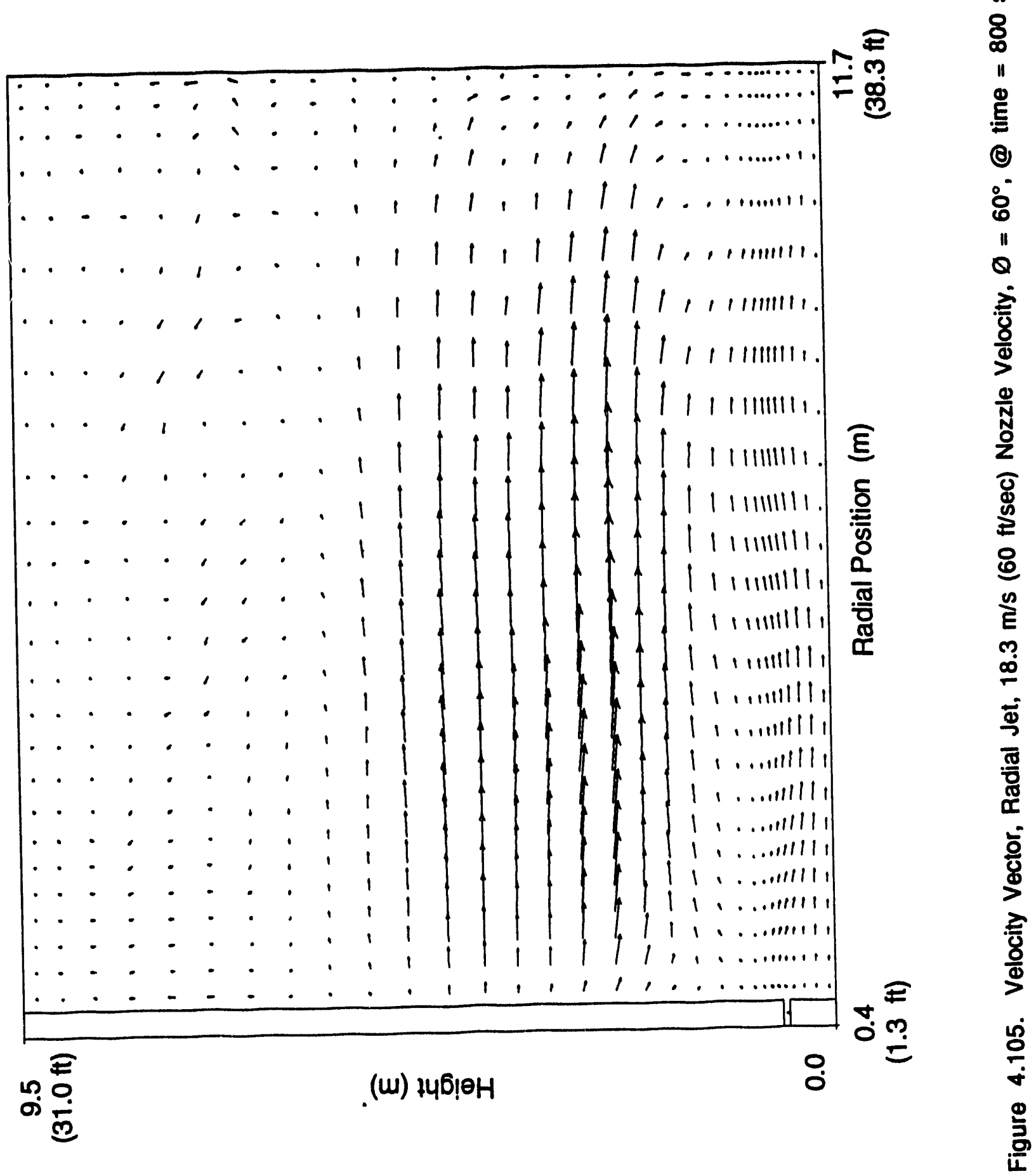



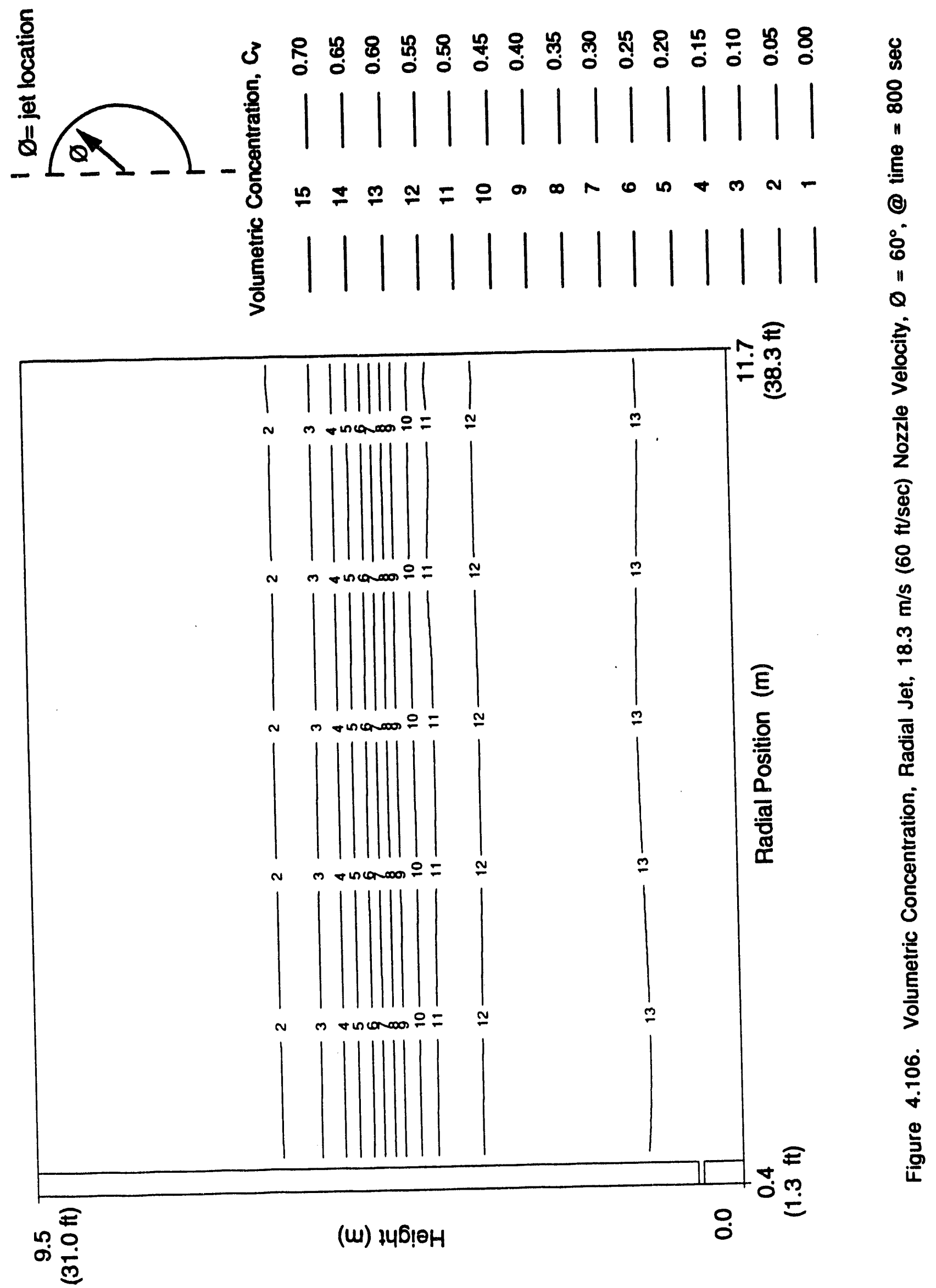


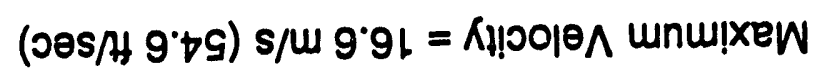

8

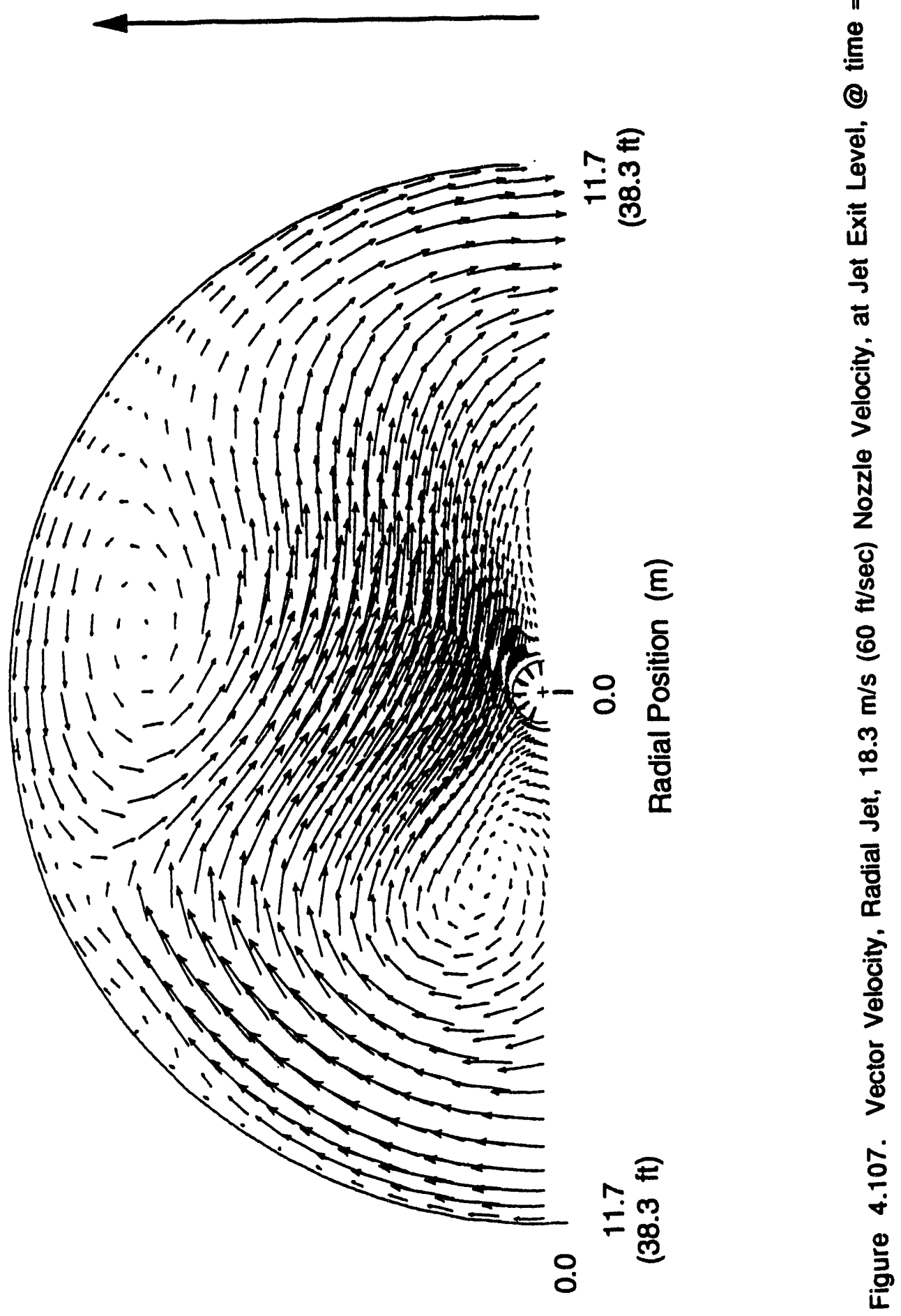




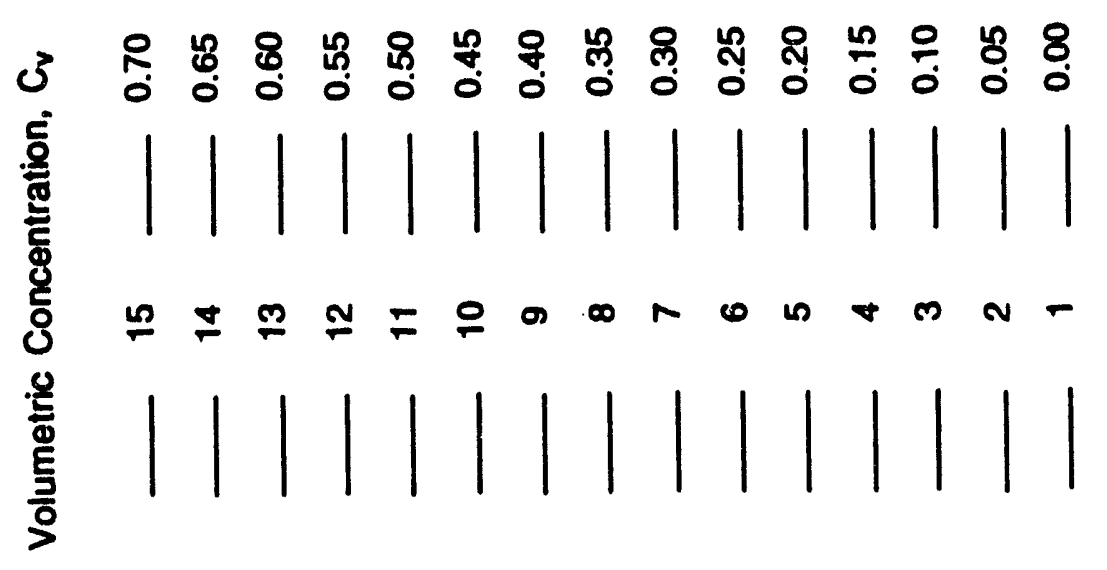

है

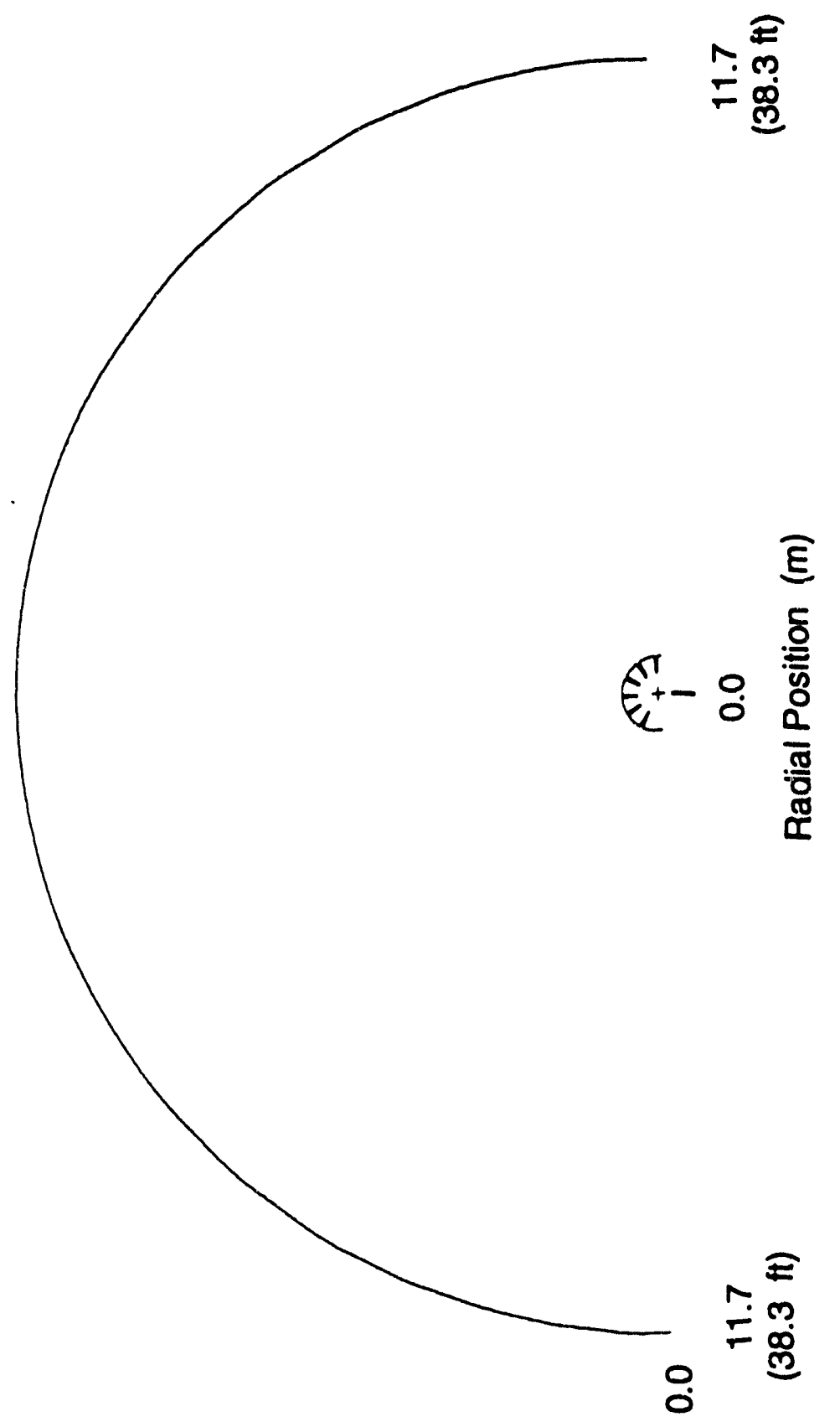

ํํำ

N

ठ্

8

है

$\infty$

๘)

带

을

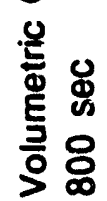

$\stackrel{\infty}{\circ}$

온 


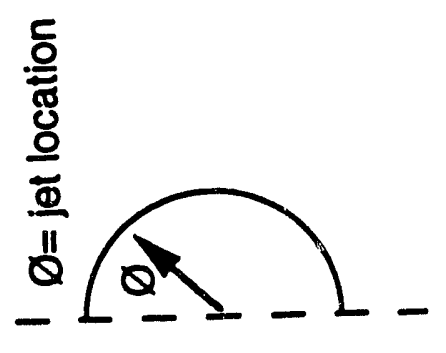

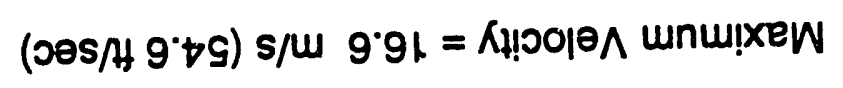

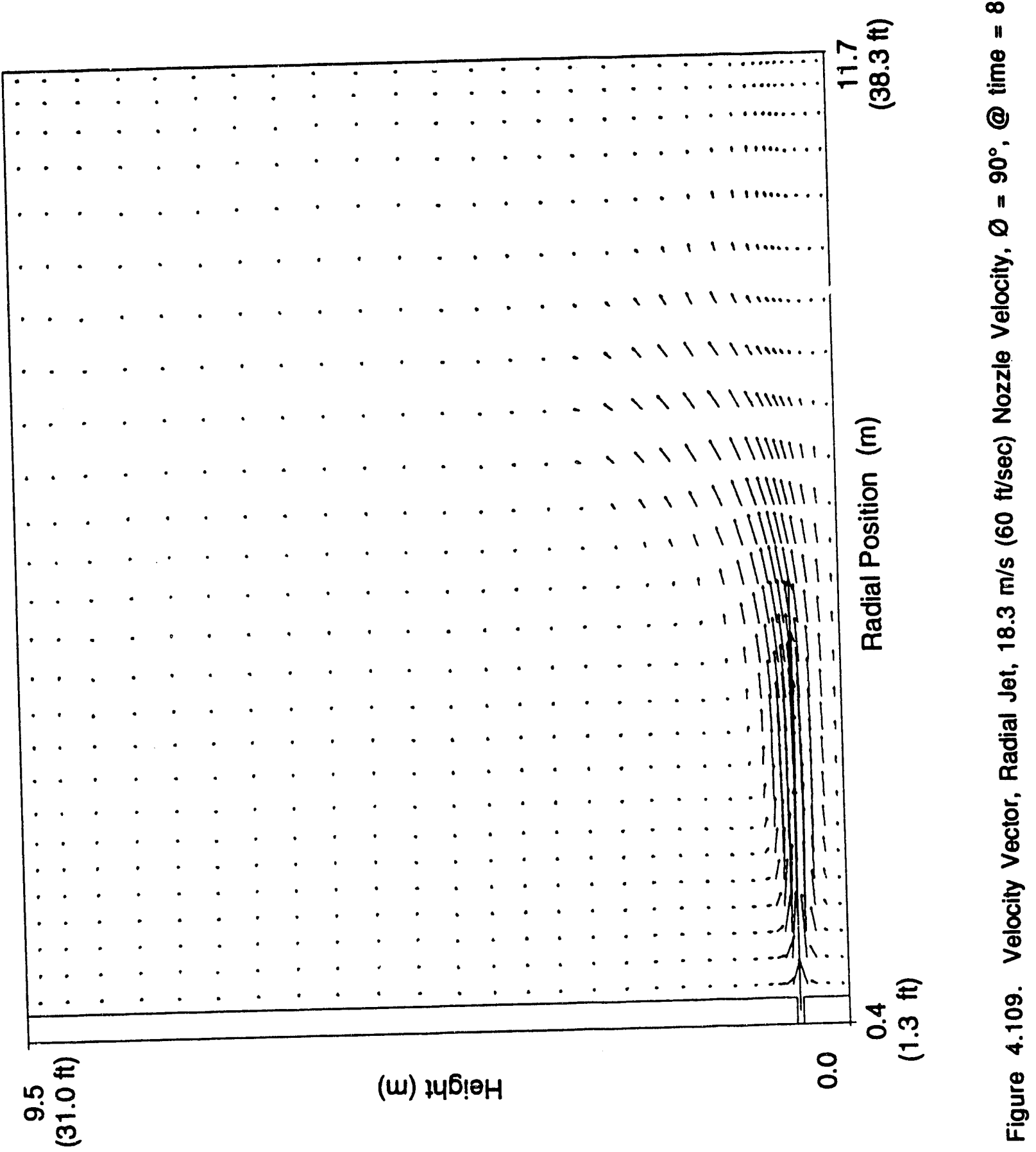




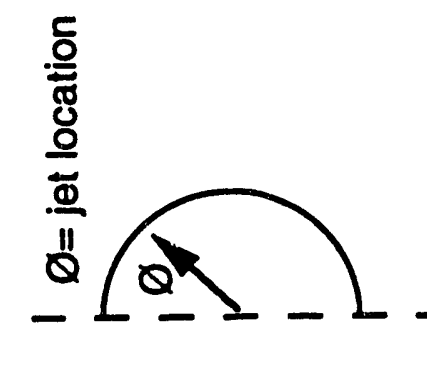

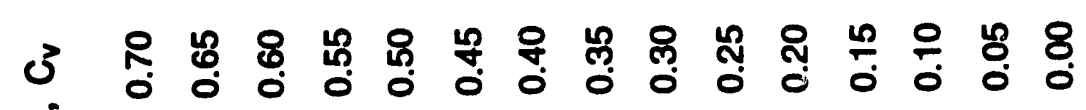

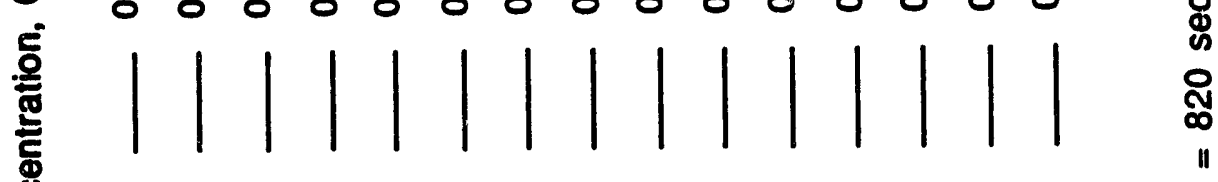

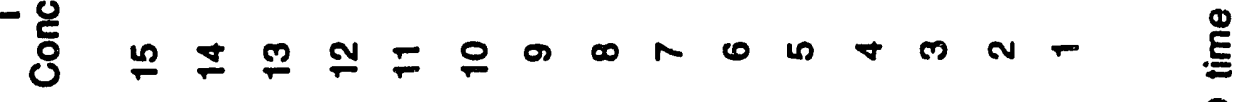

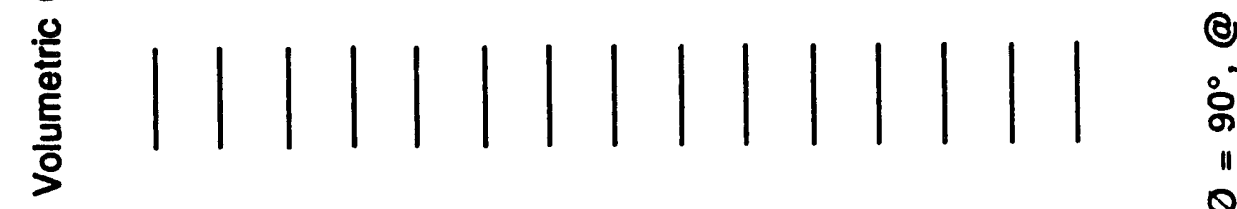

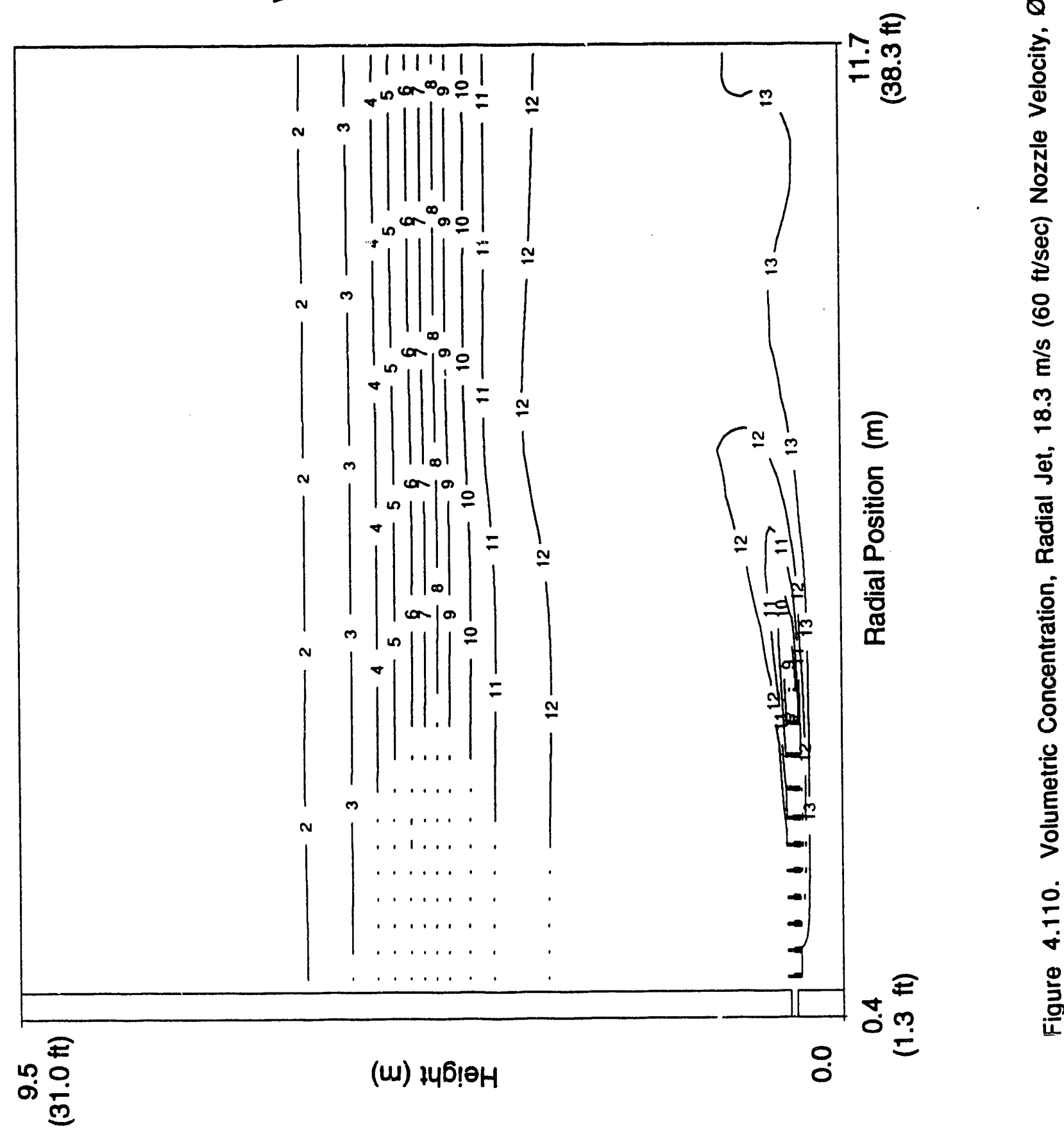




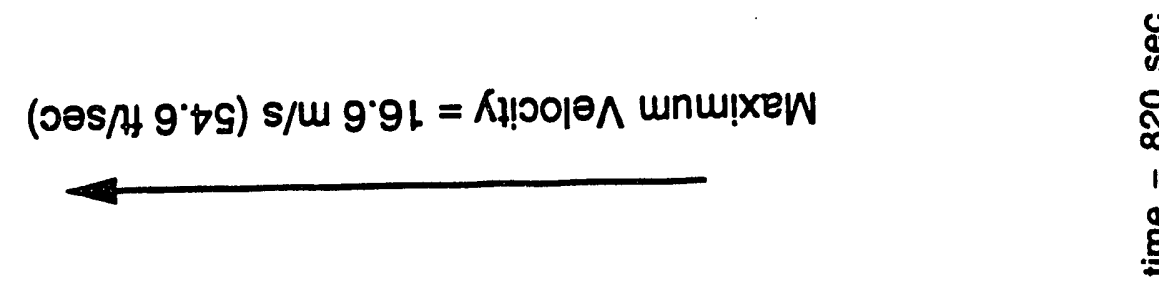

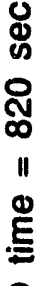

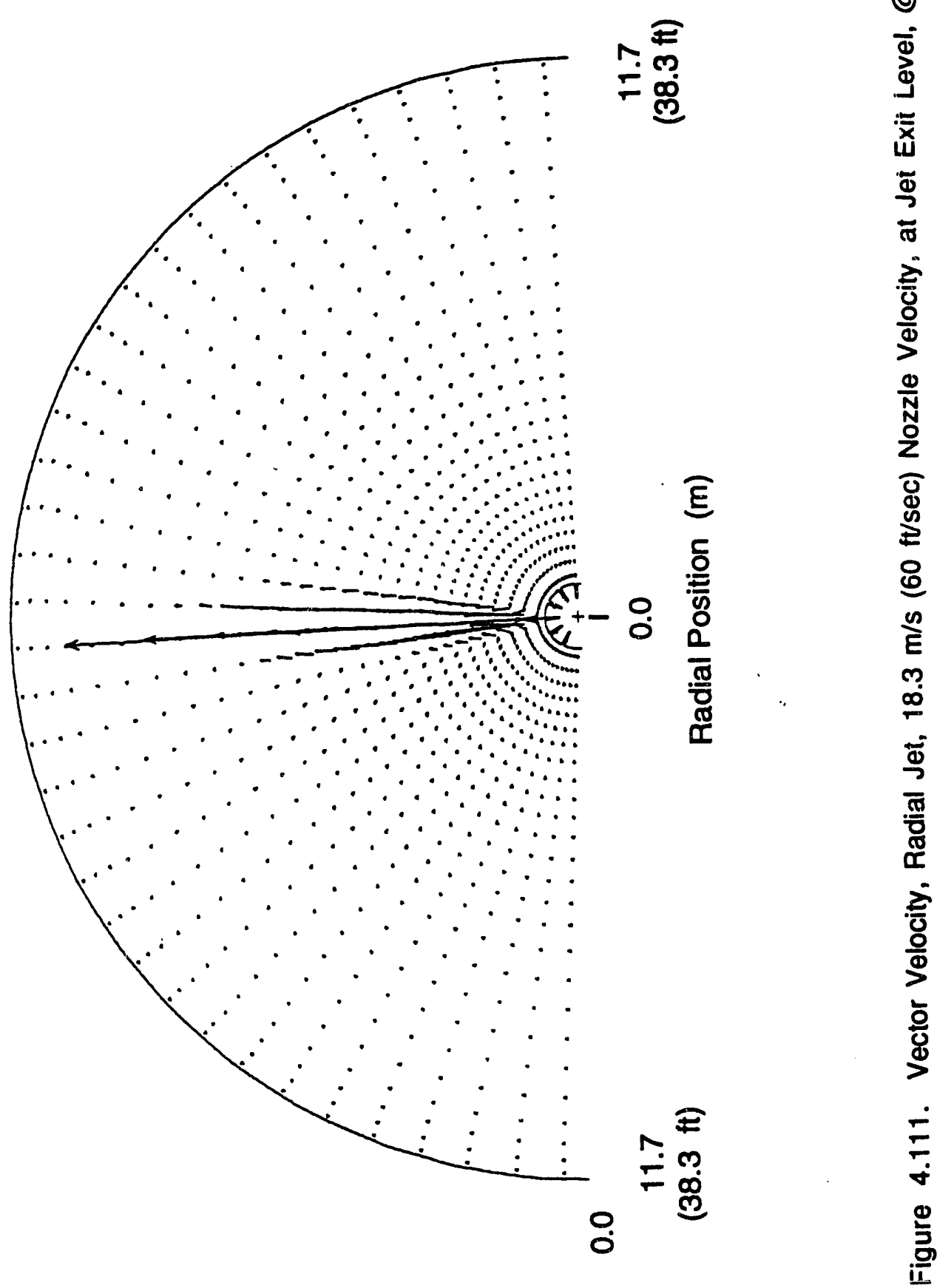



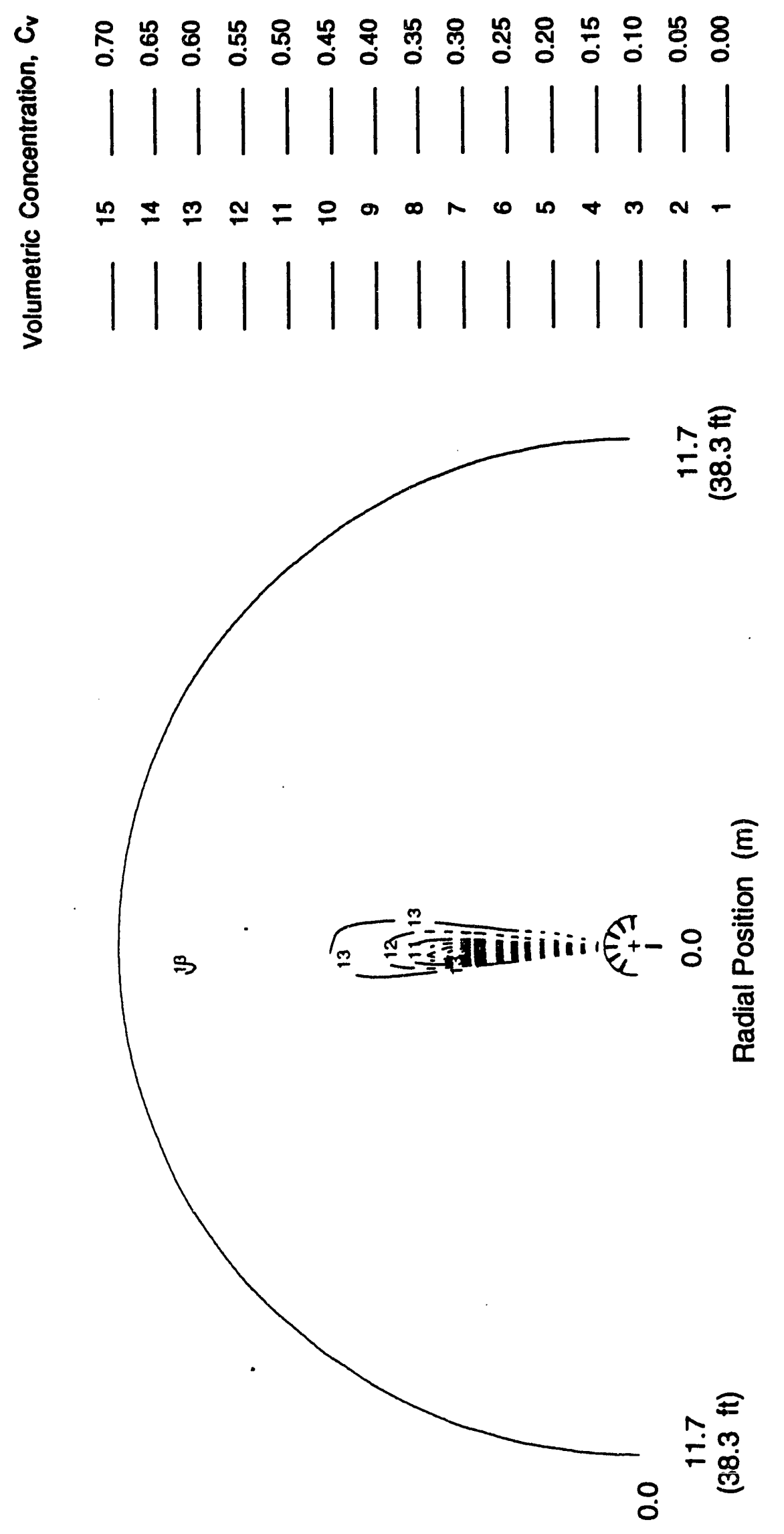

है

离 


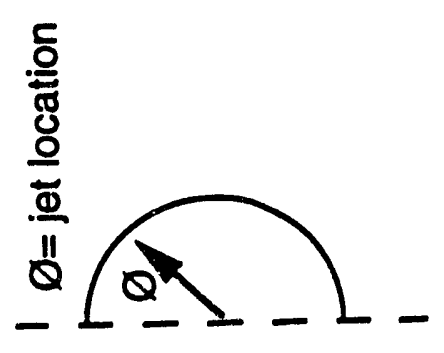

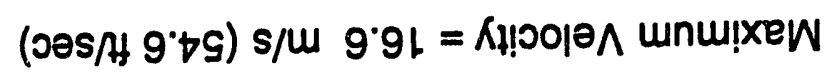

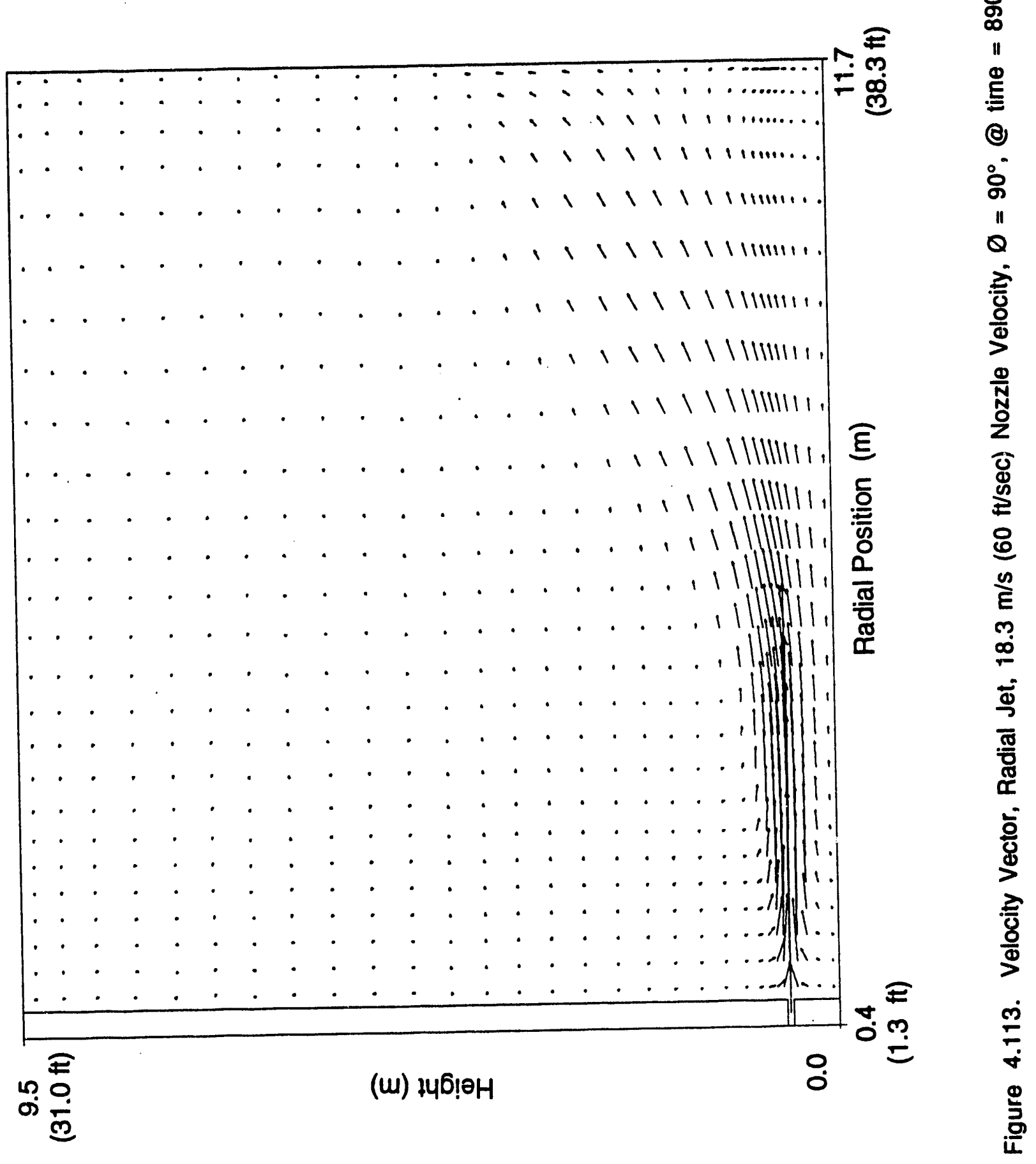




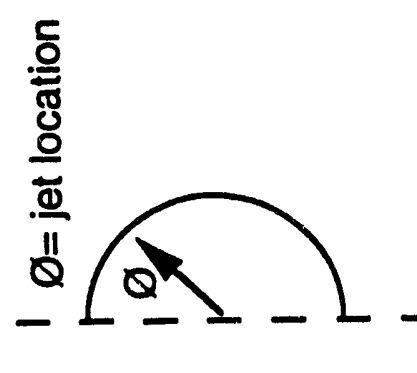

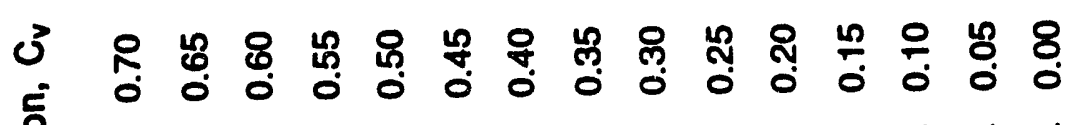

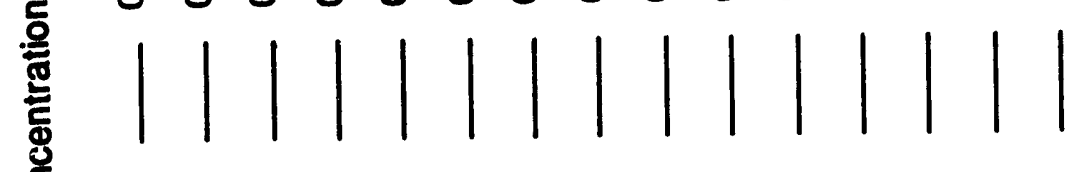

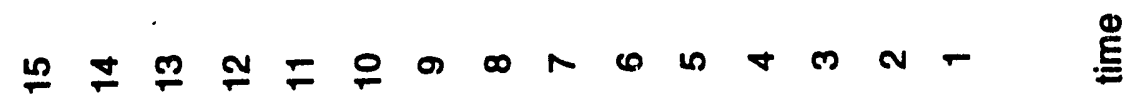

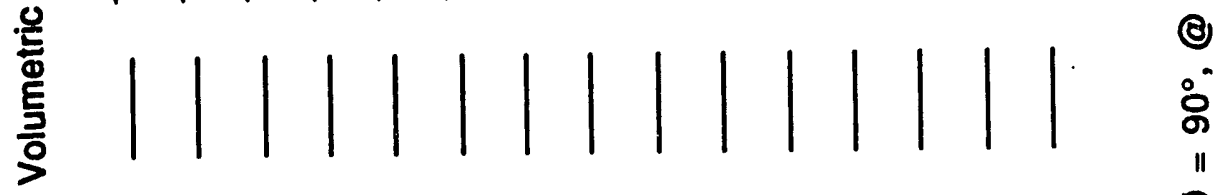

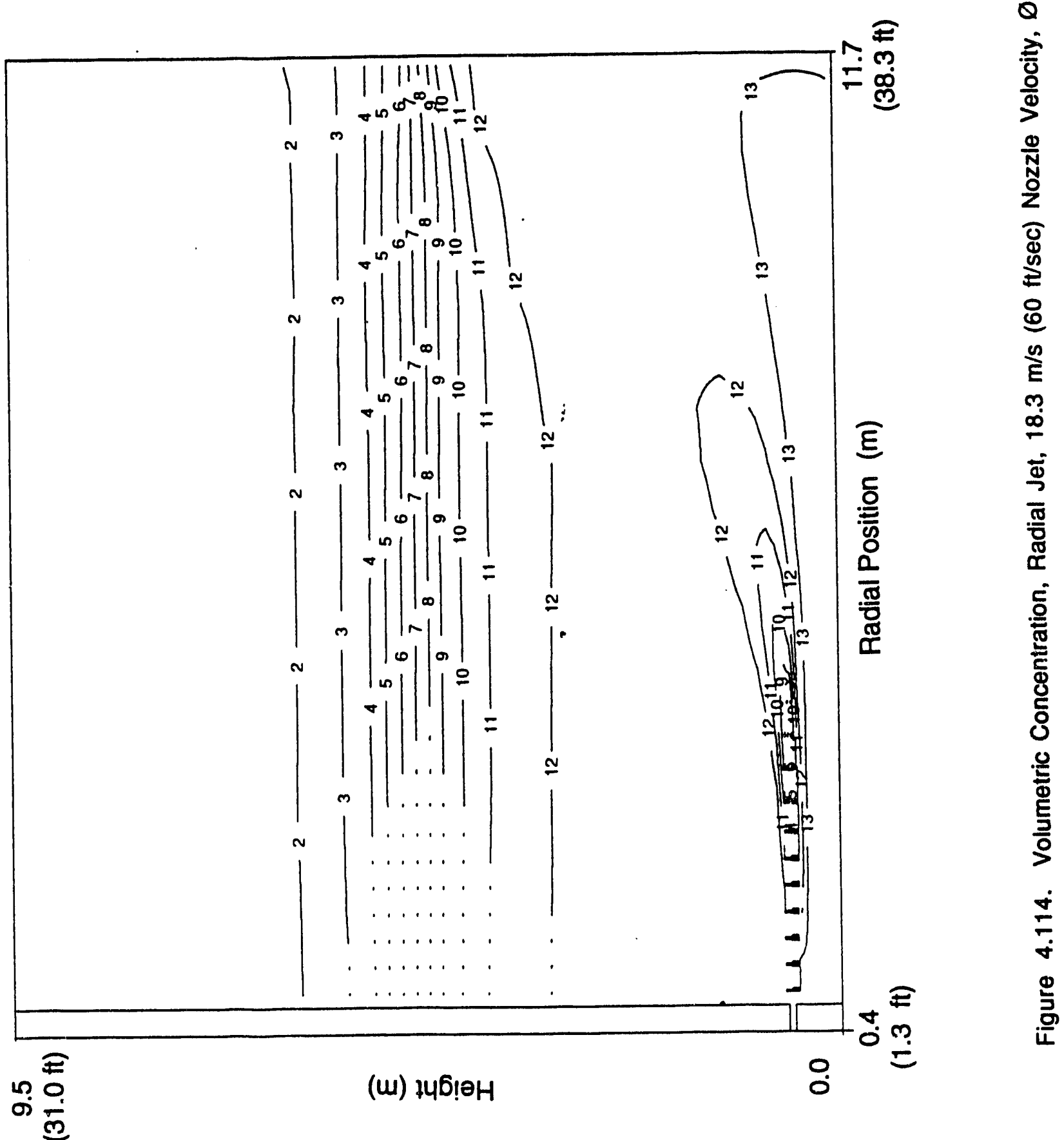




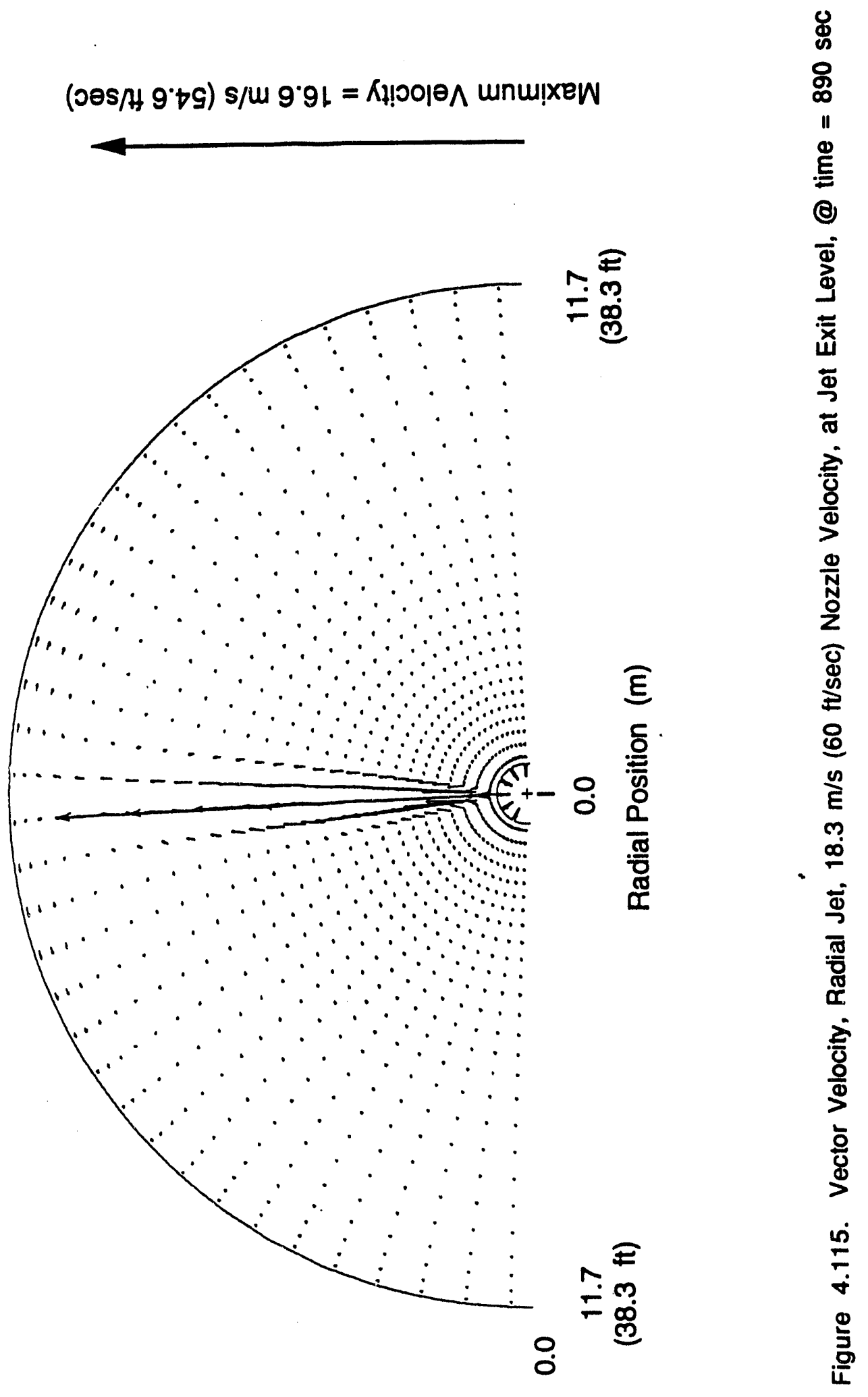




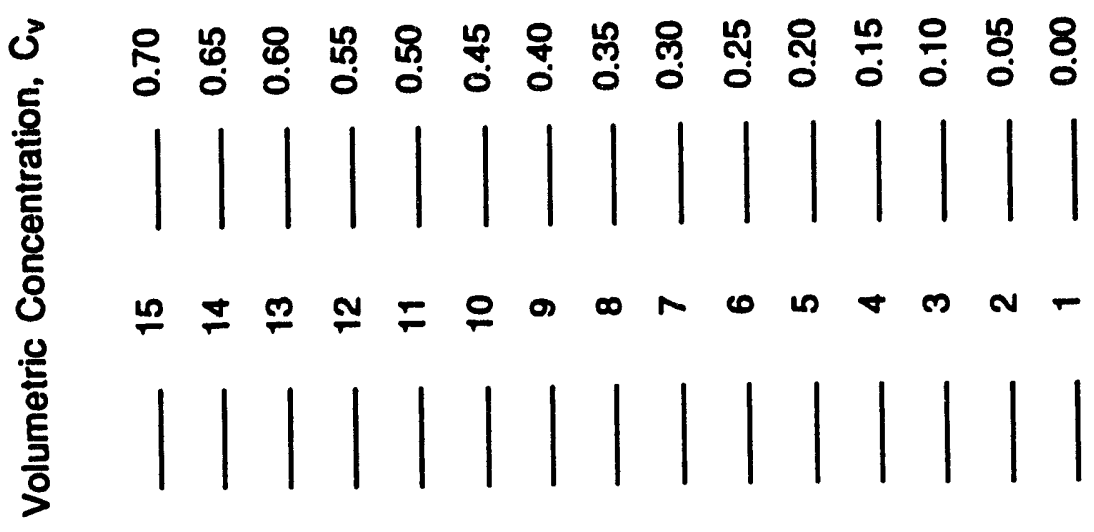

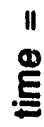

(C)

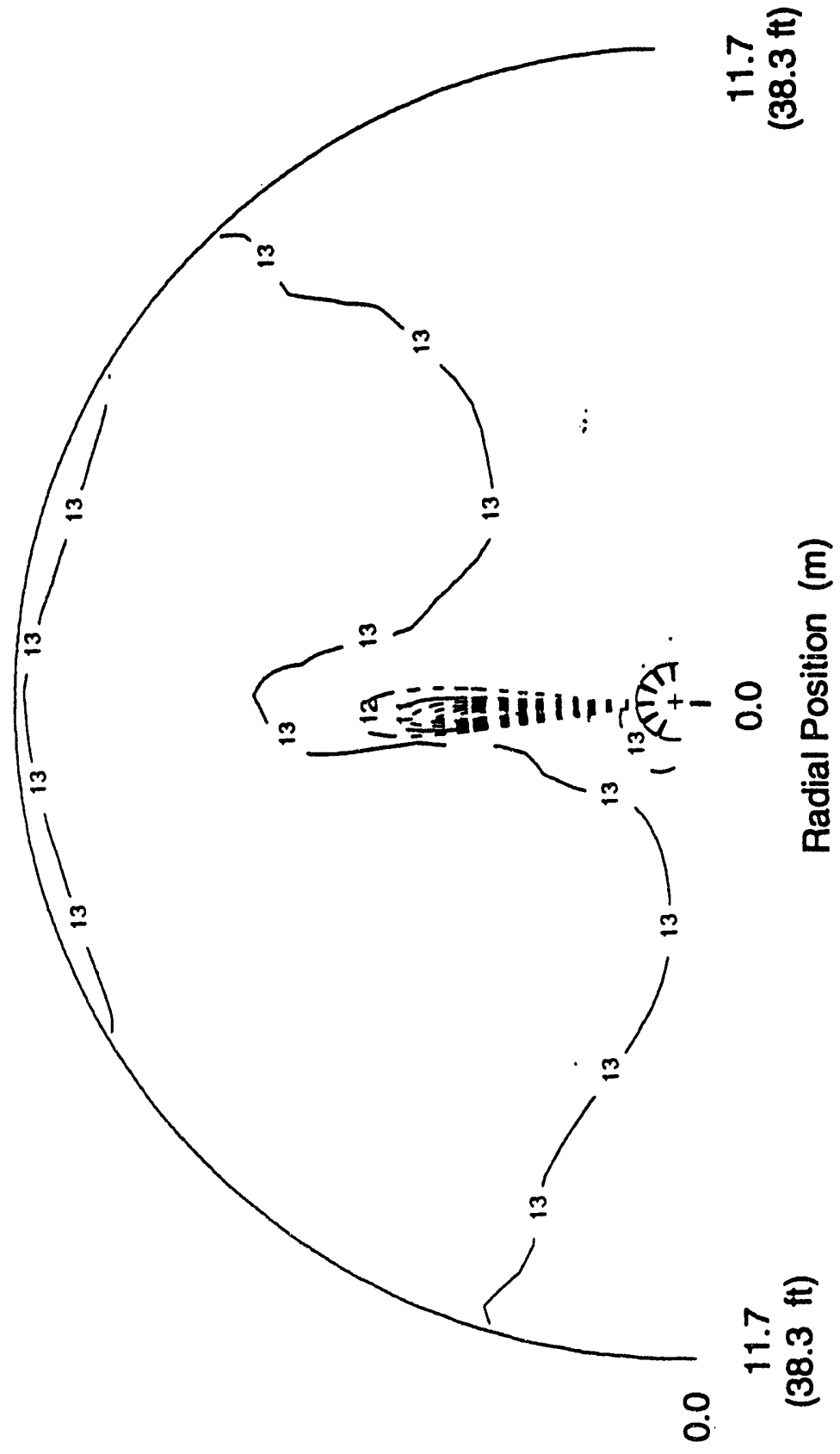

สั

응

N

ত্

8

E

m

ธิ

흠

రั

은

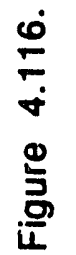




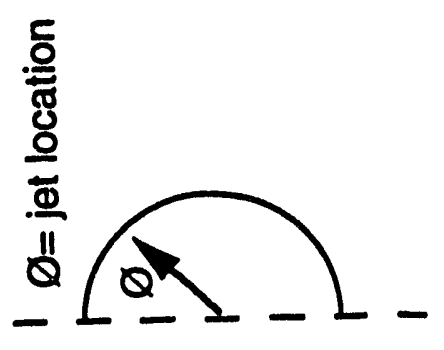

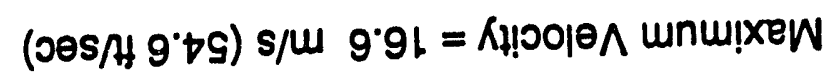

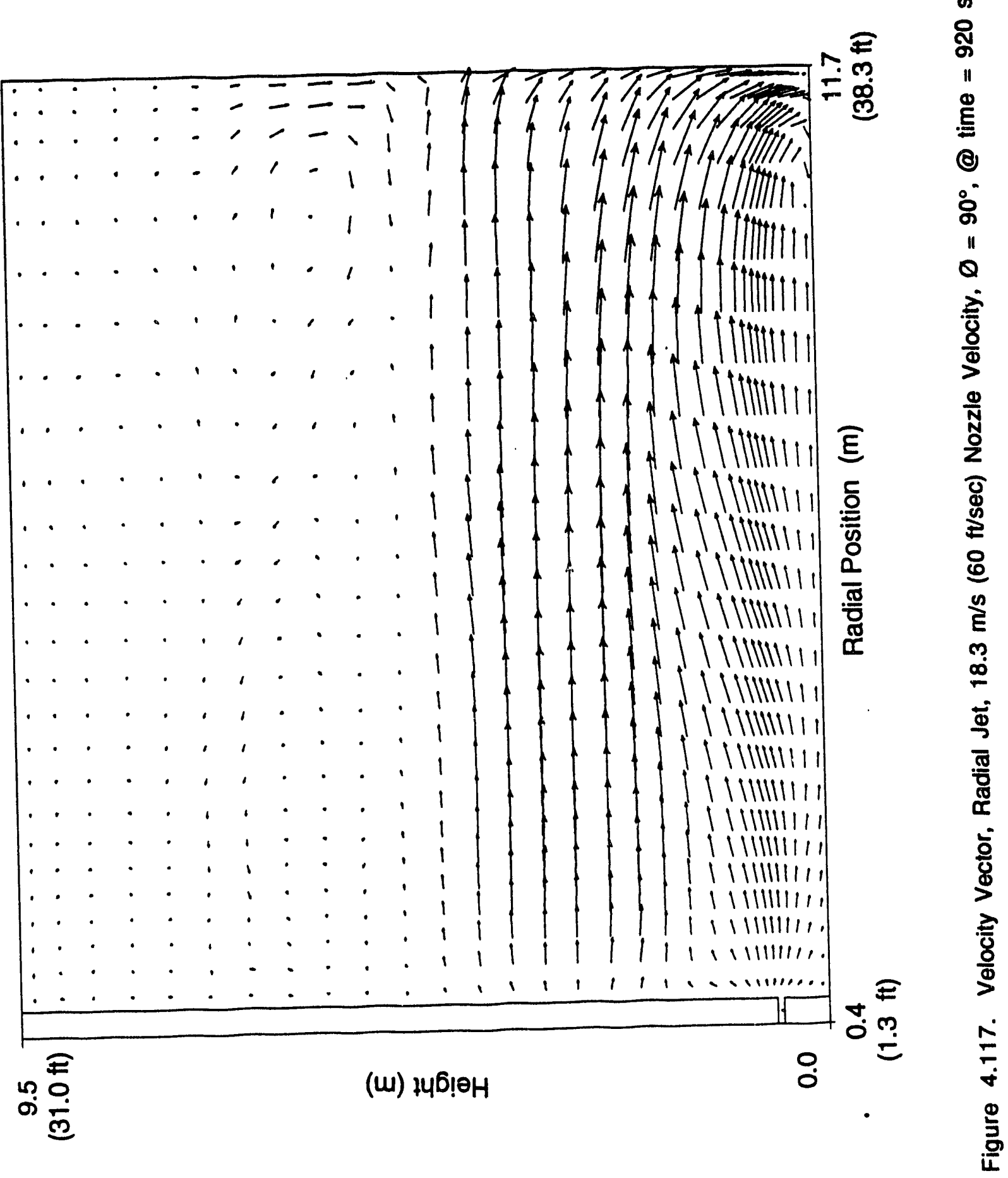



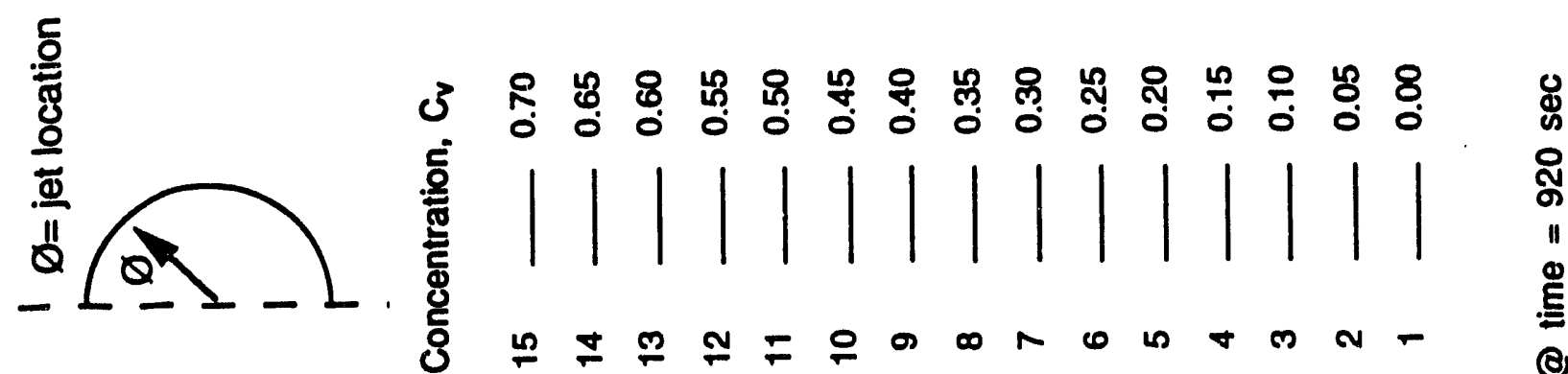

옿

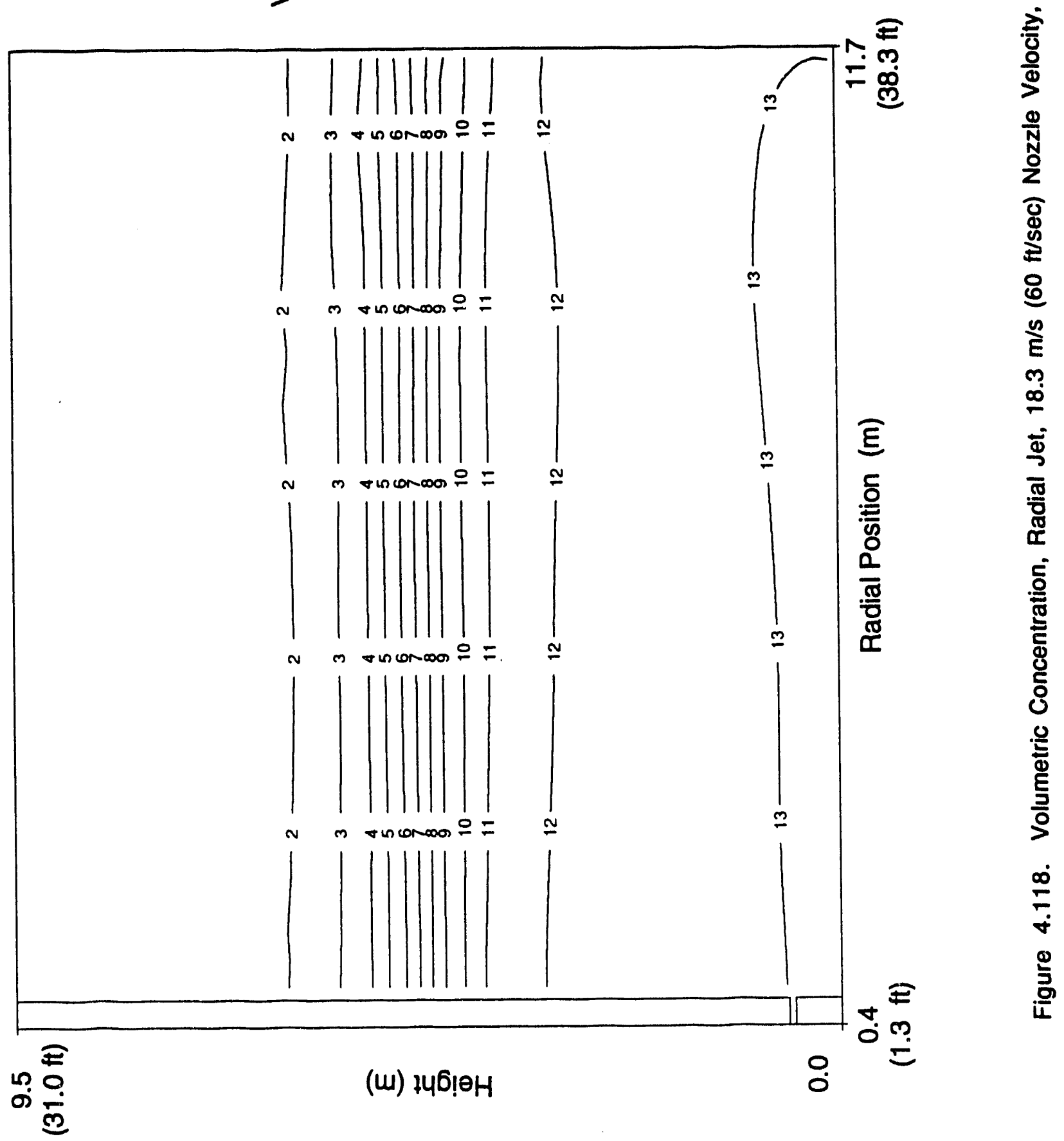




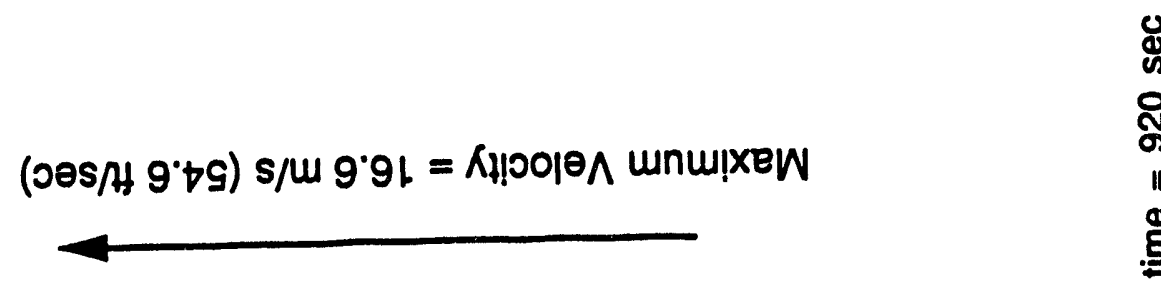

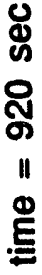

()

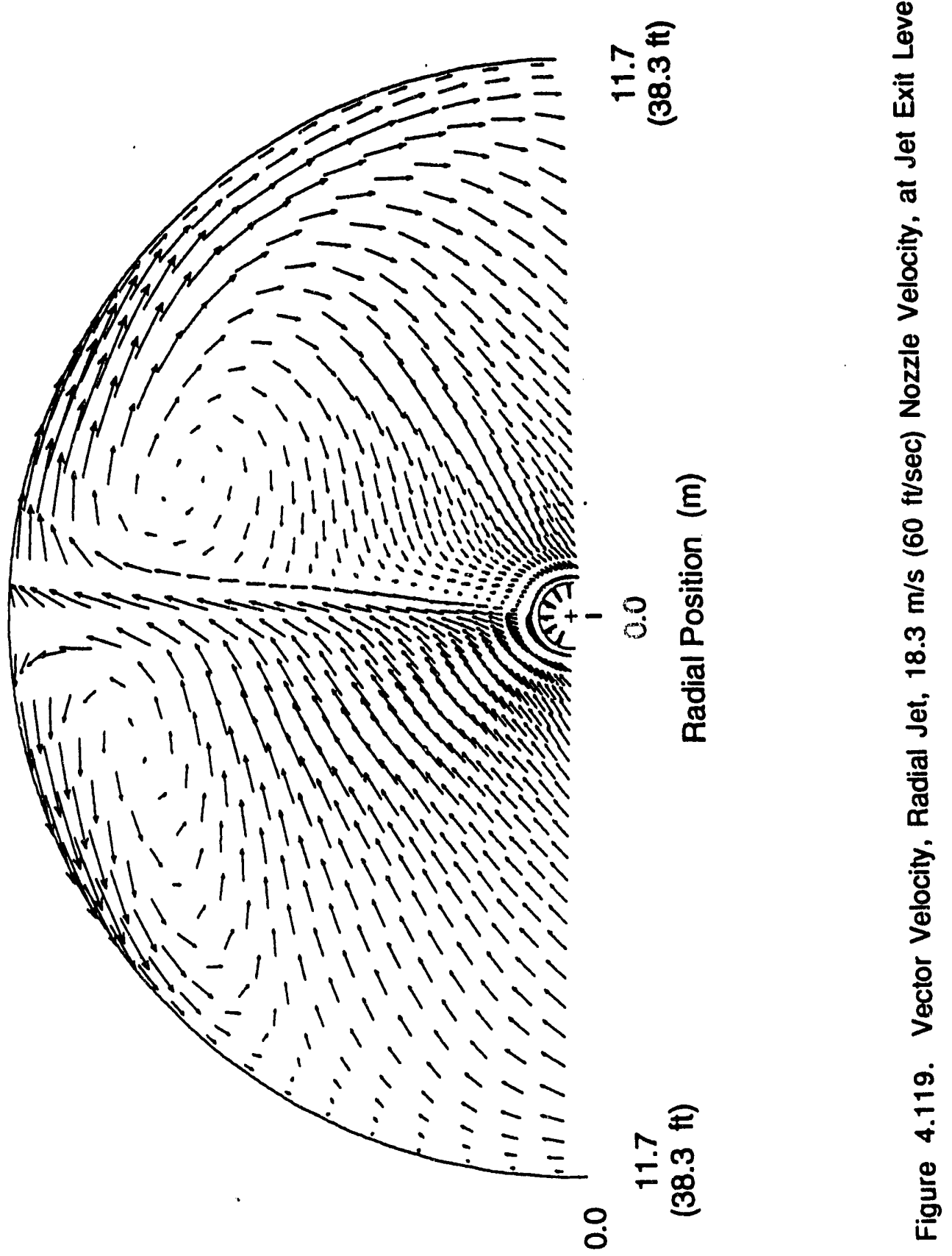




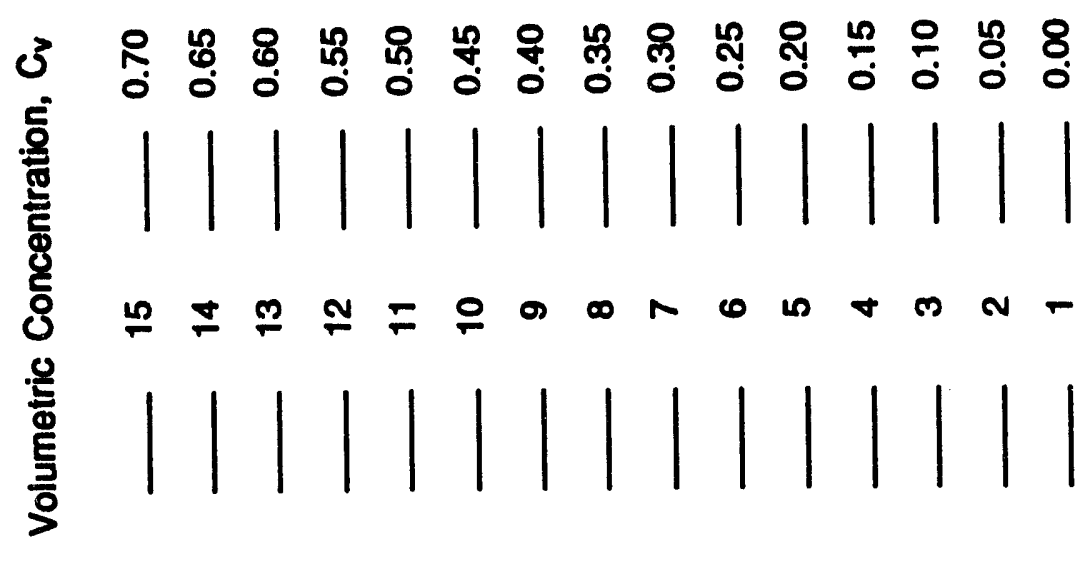

(1)

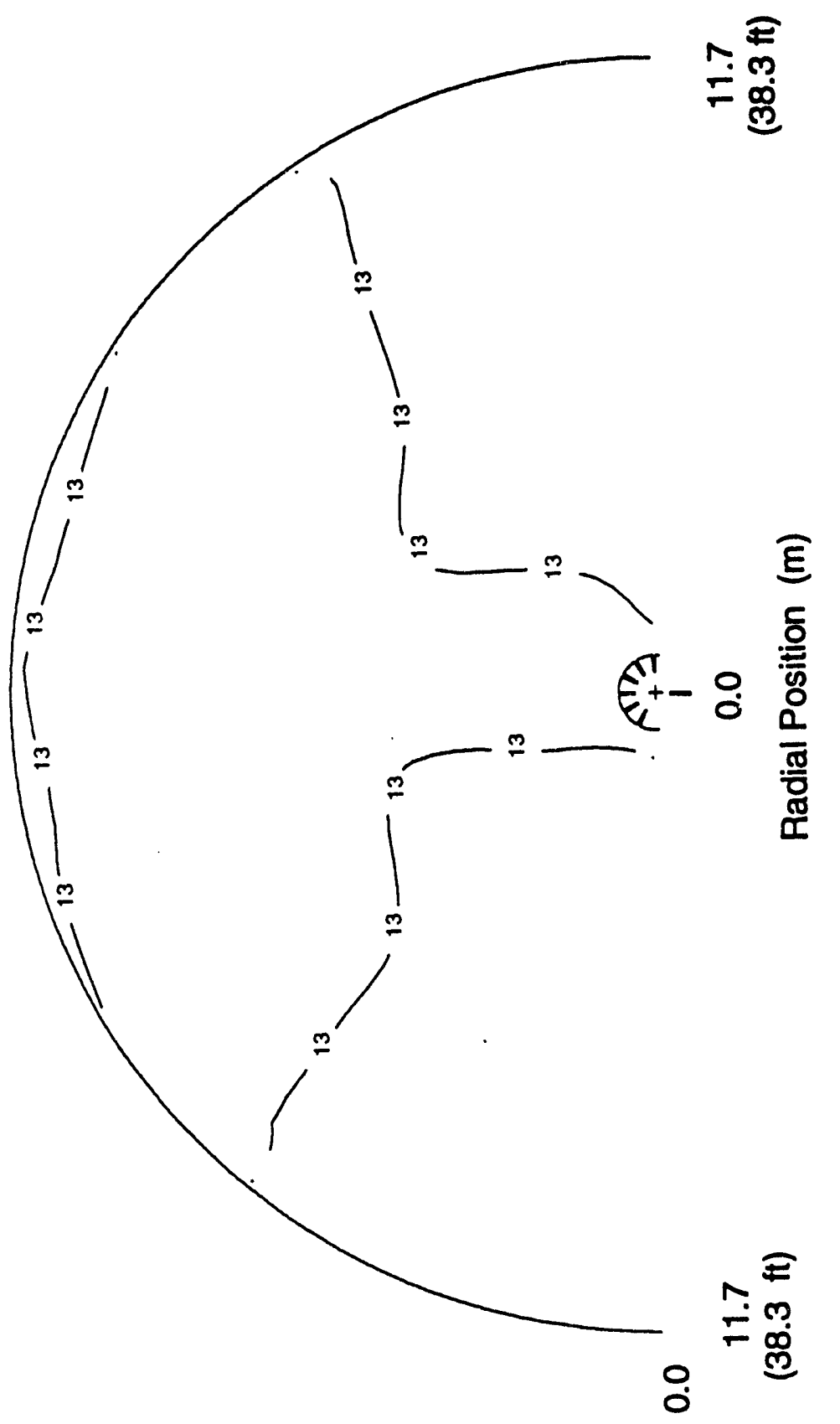

응

$\frac{N}{N}$

ฮ্ষ

王

8

है

$\infty$

Фे

흄

들

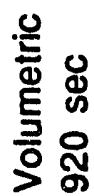

ণ

额 


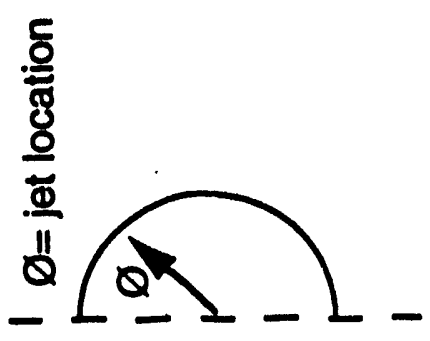

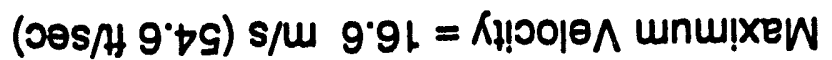

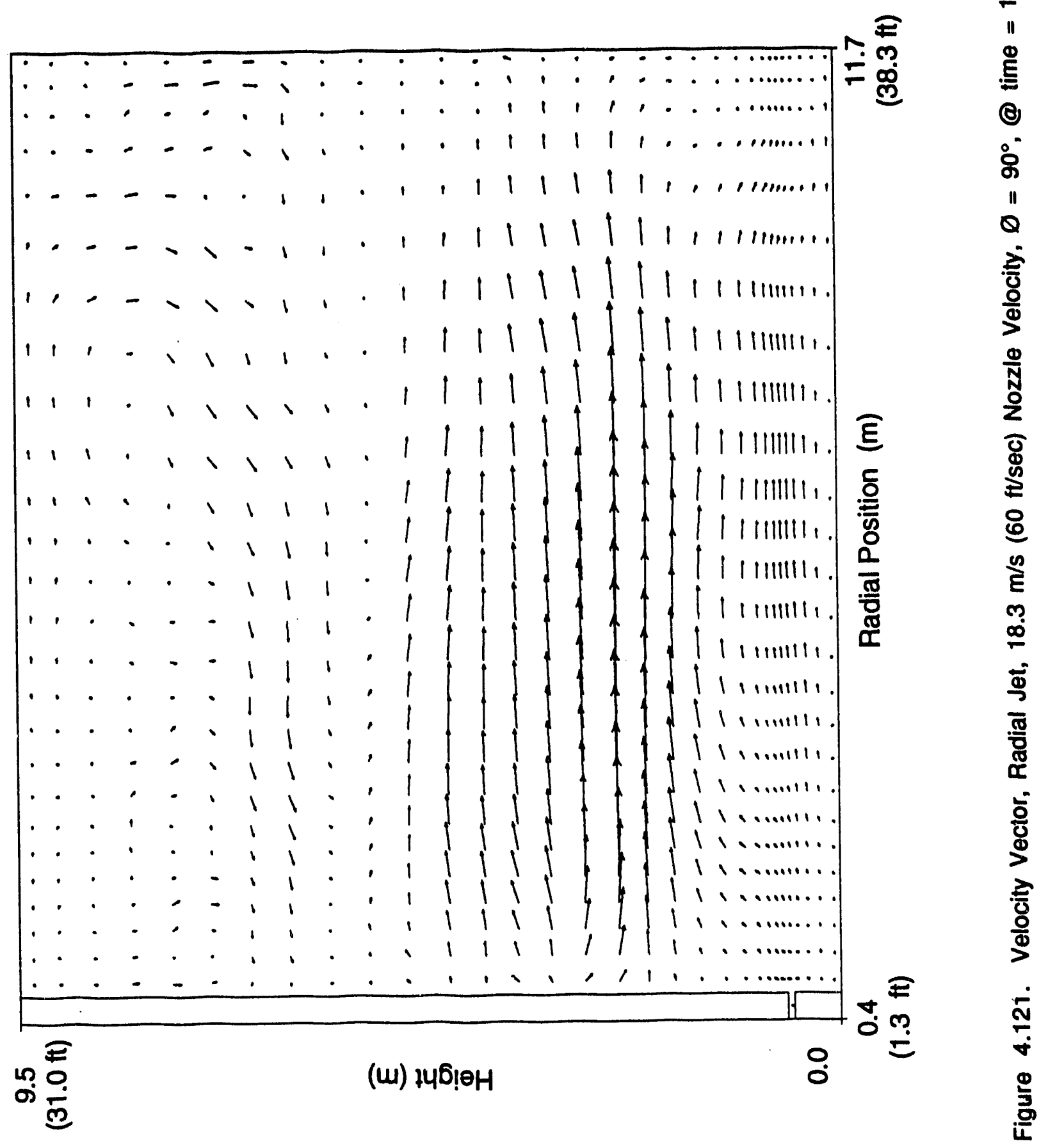




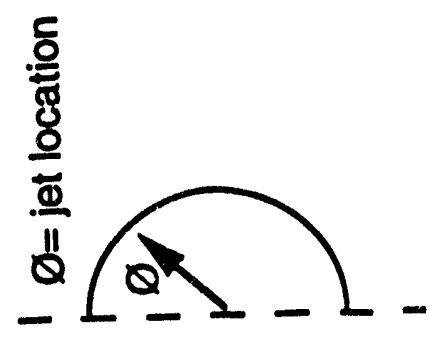

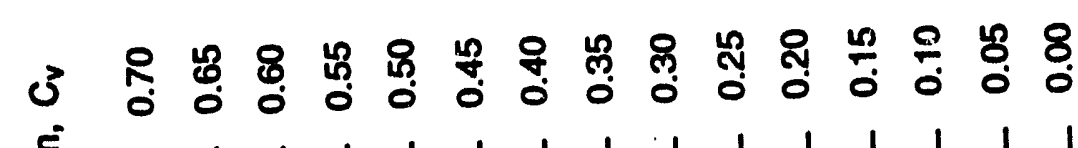

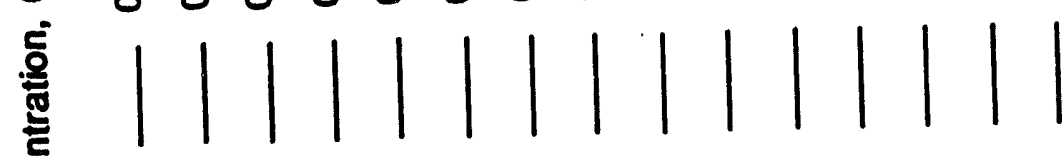

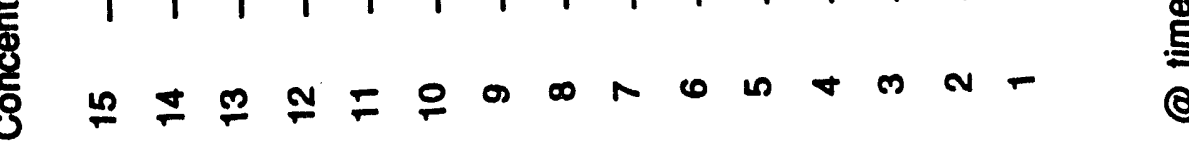

$$
\begin{aligned}
& 0 \\
& \text { 옳 } \\
& \text { Е } \\
& \text { 응 }
\end{aligned}
$$

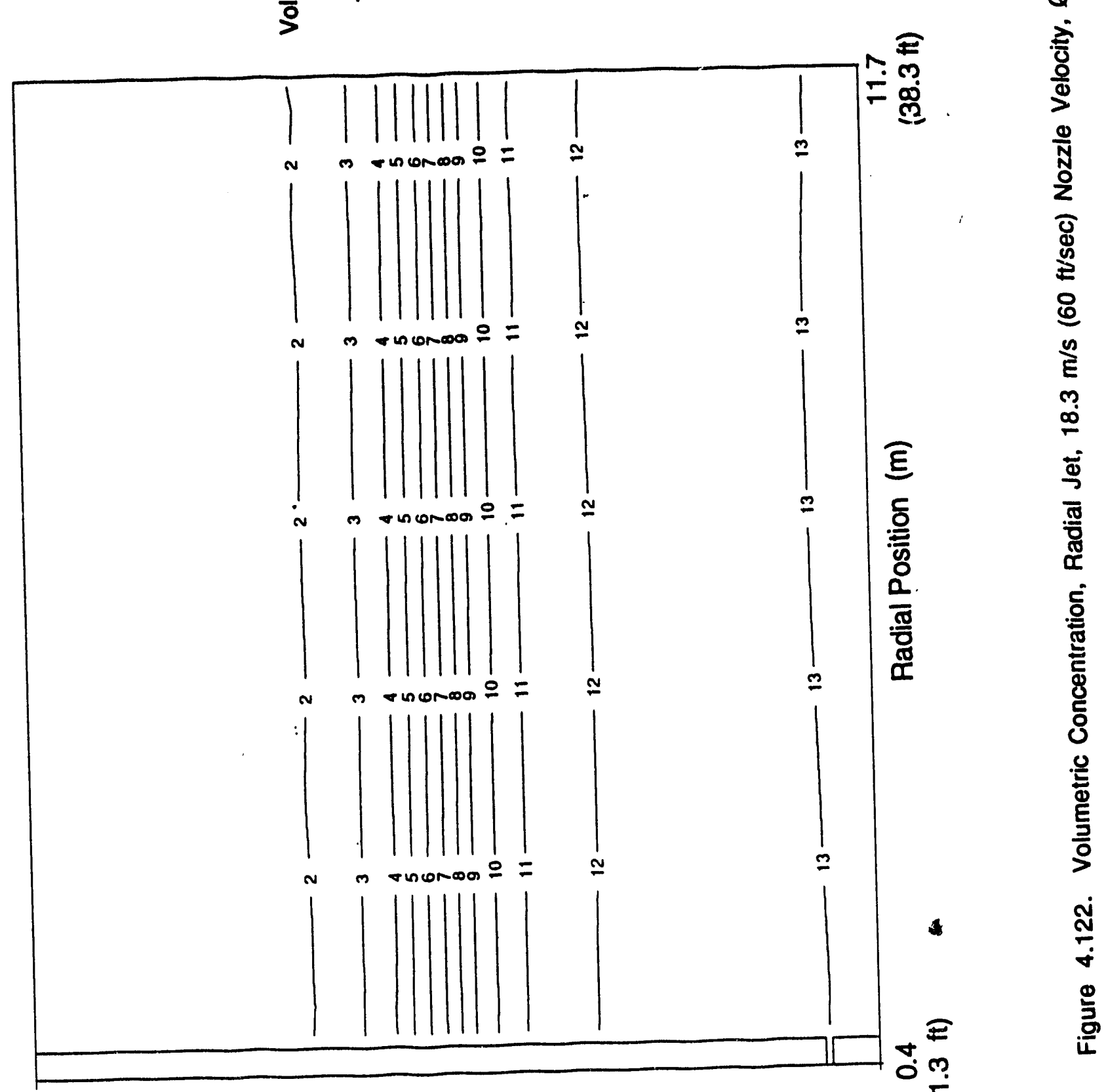

(w) $346 ! ! \theta H$ 


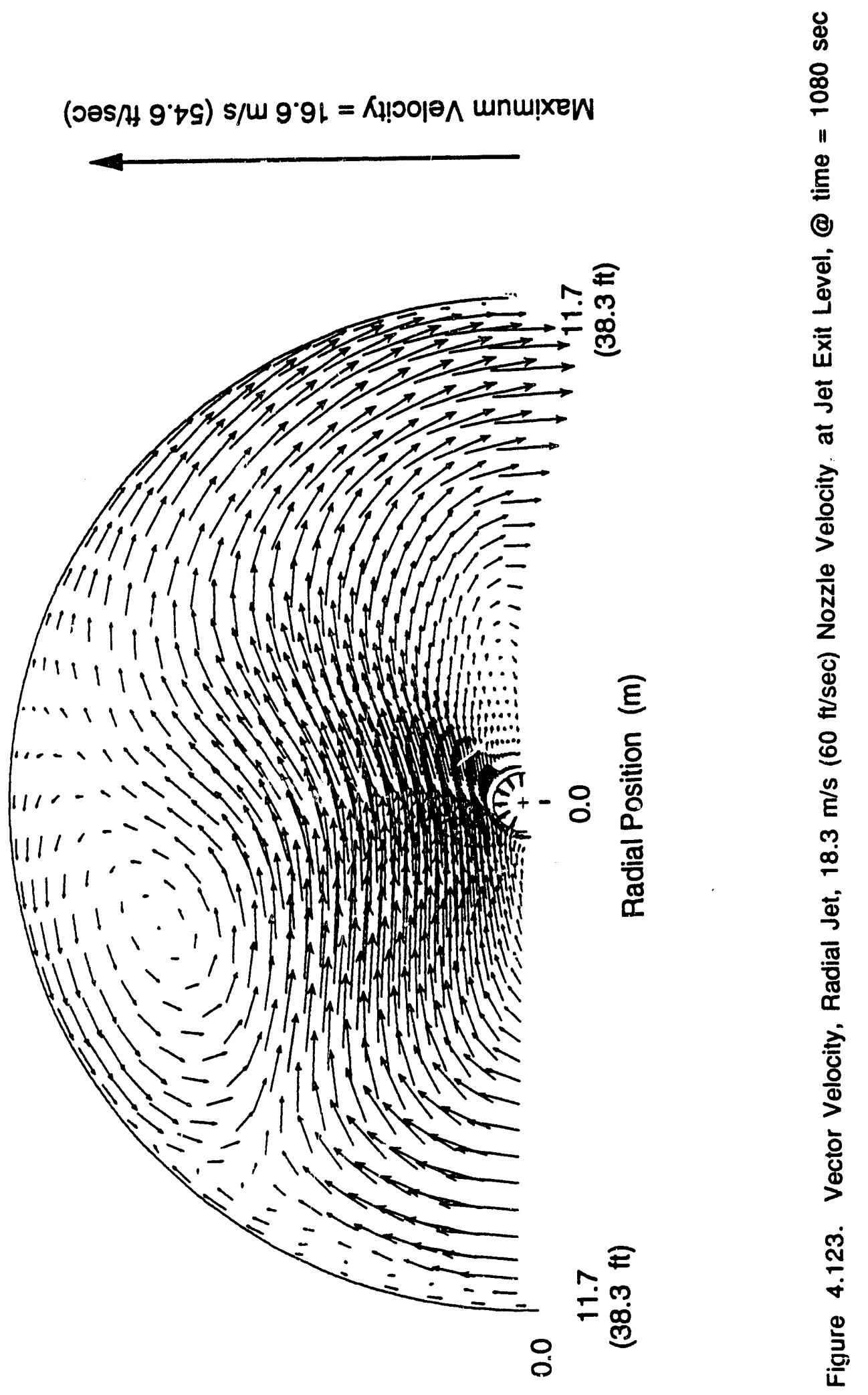



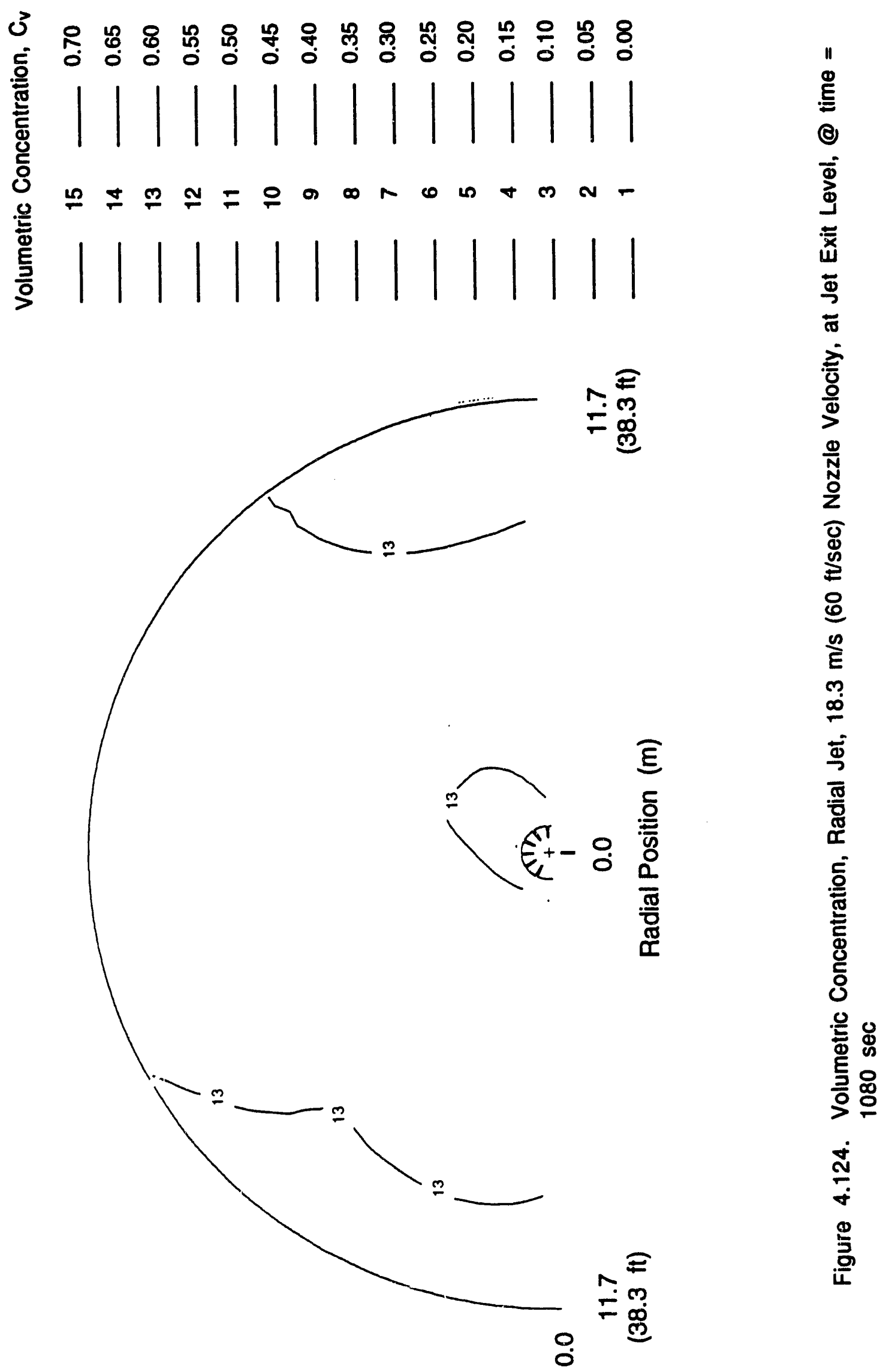


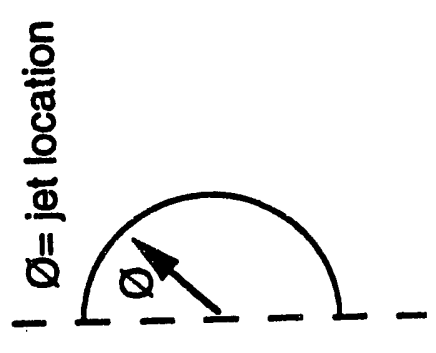

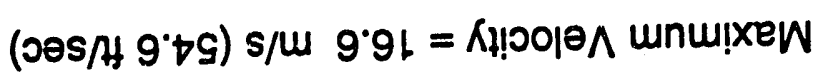

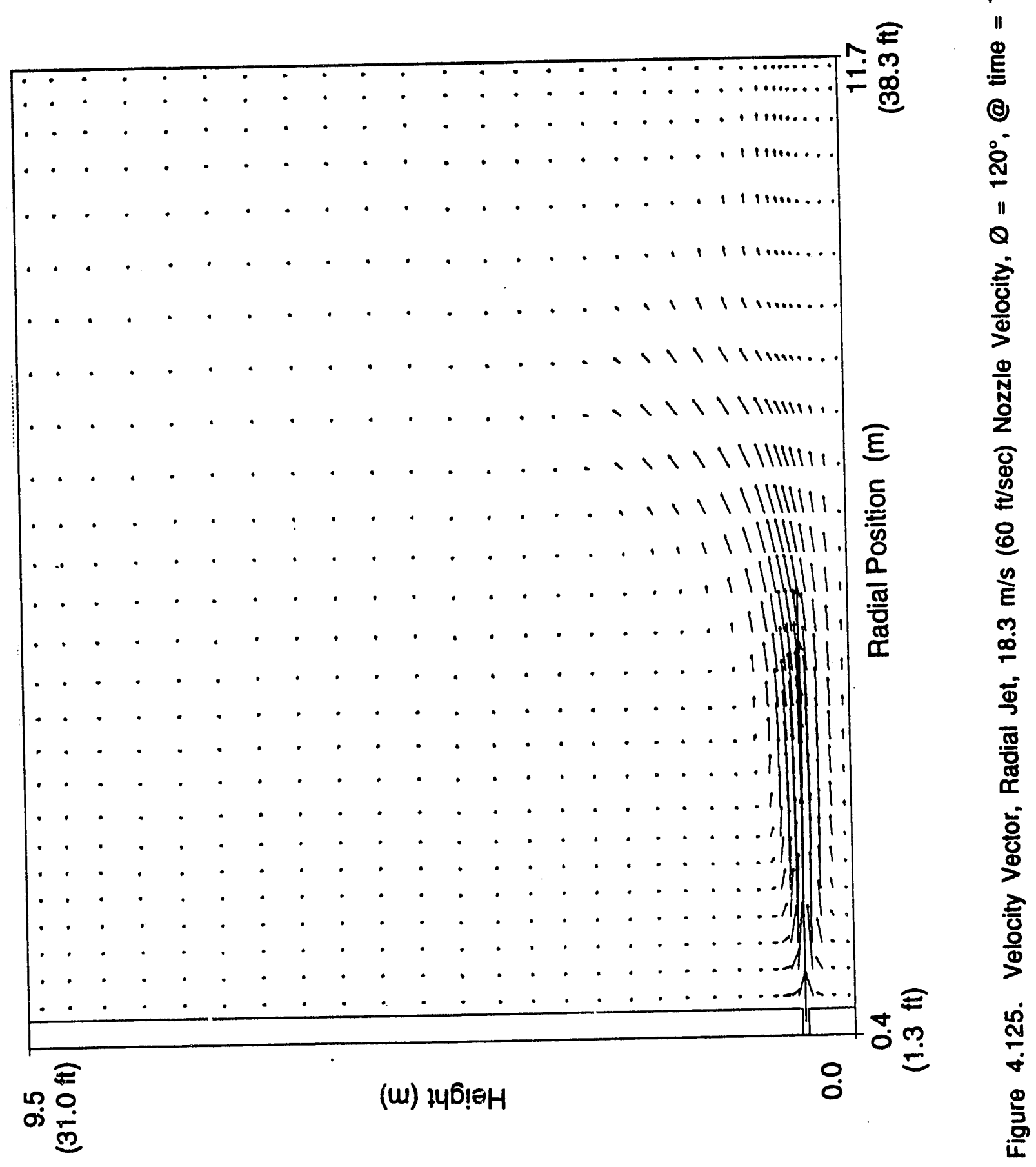



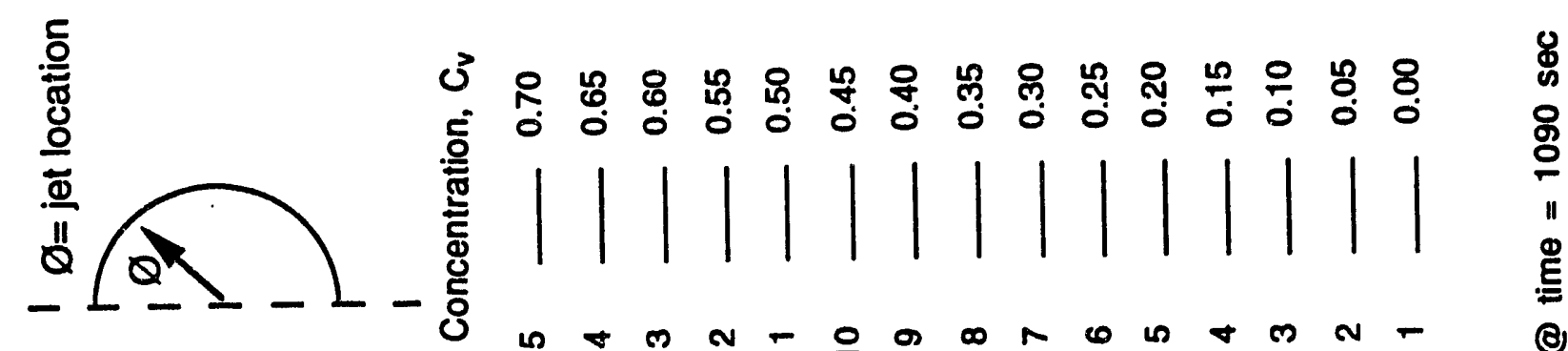

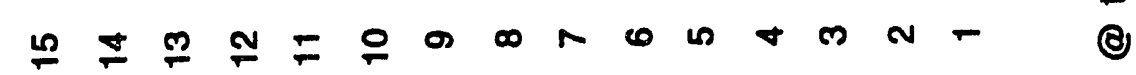

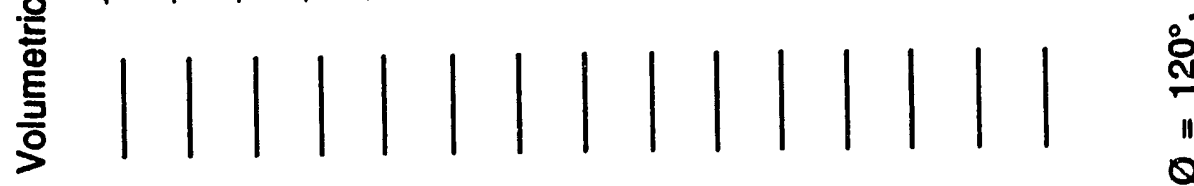

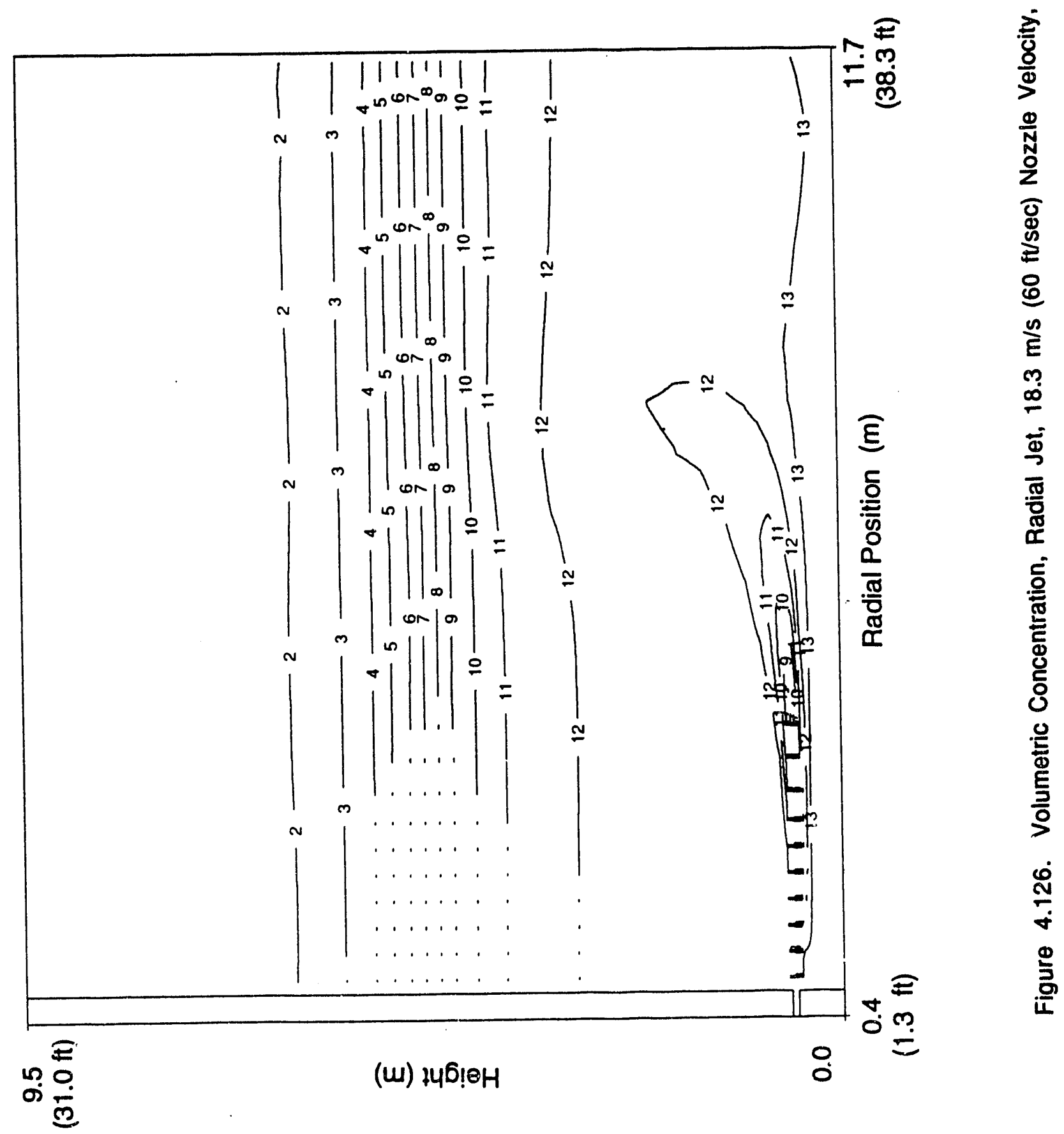




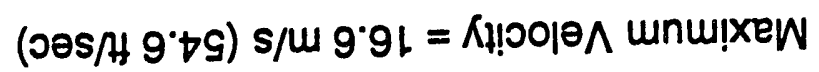

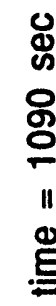

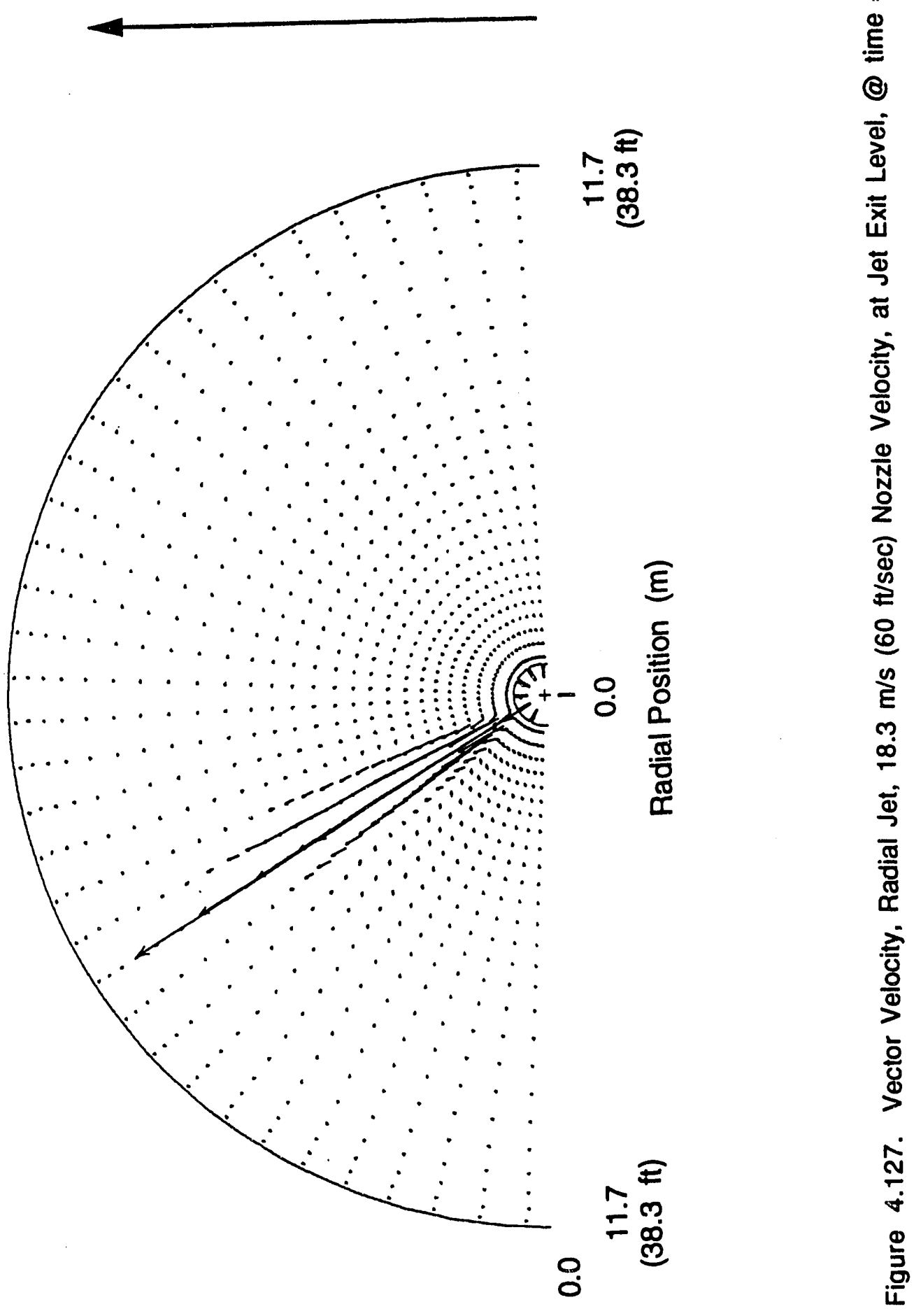



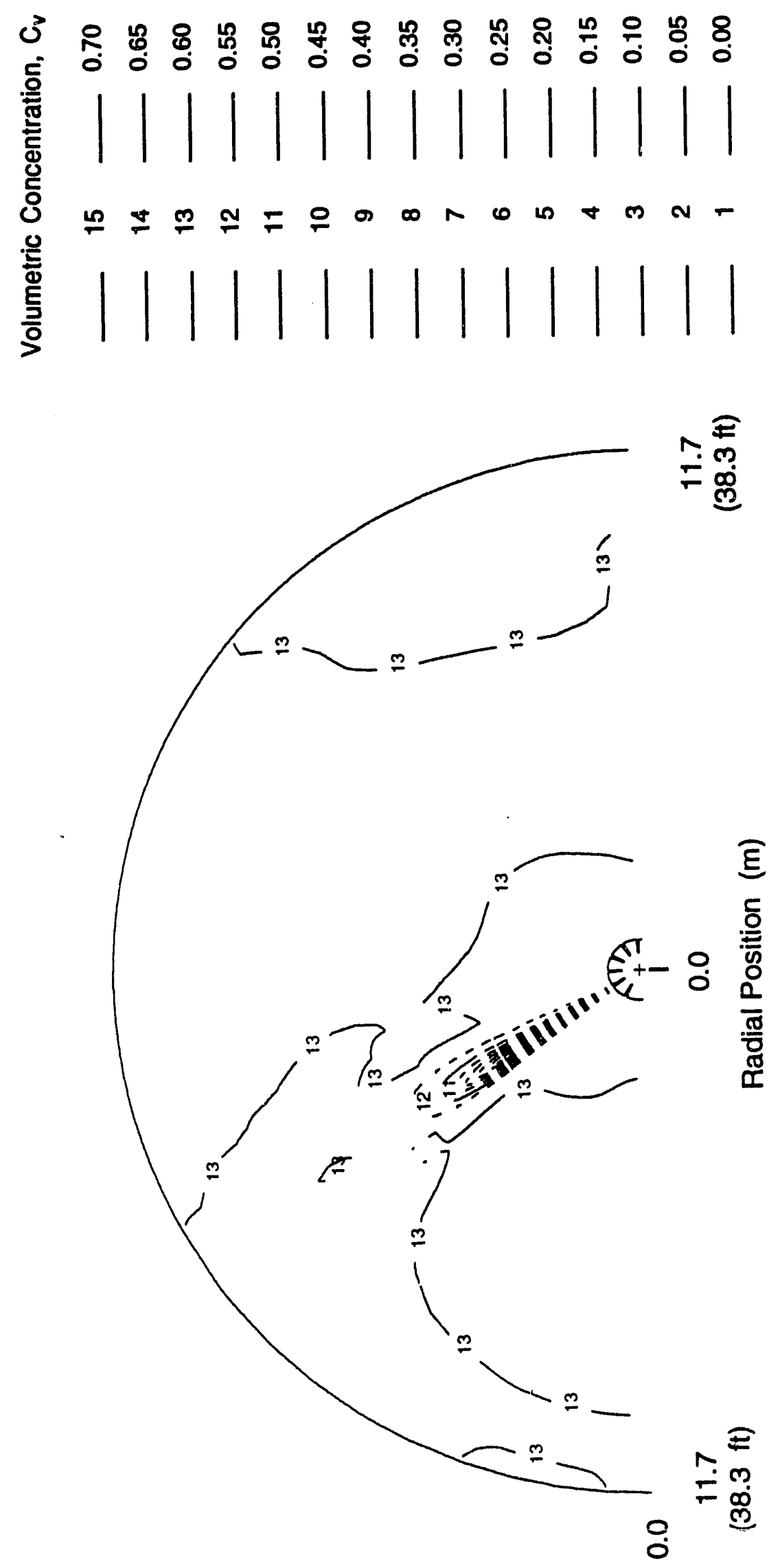

吕

(C)

Ф)

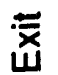

ప

ธั

응

N

은

임

ڤ

0

E

क

ธ్

짐

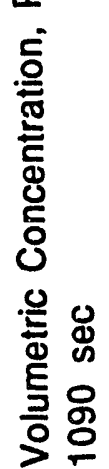

$\stackrel{\infty}{N}$

옥 


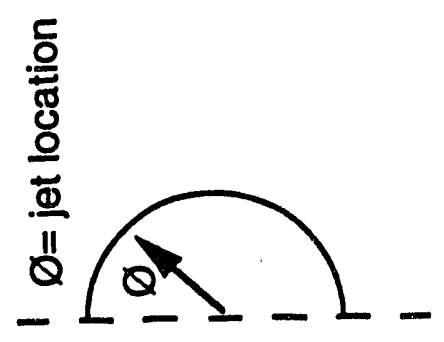

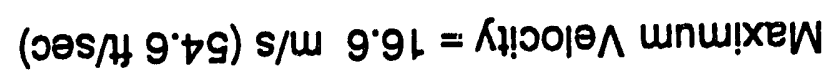

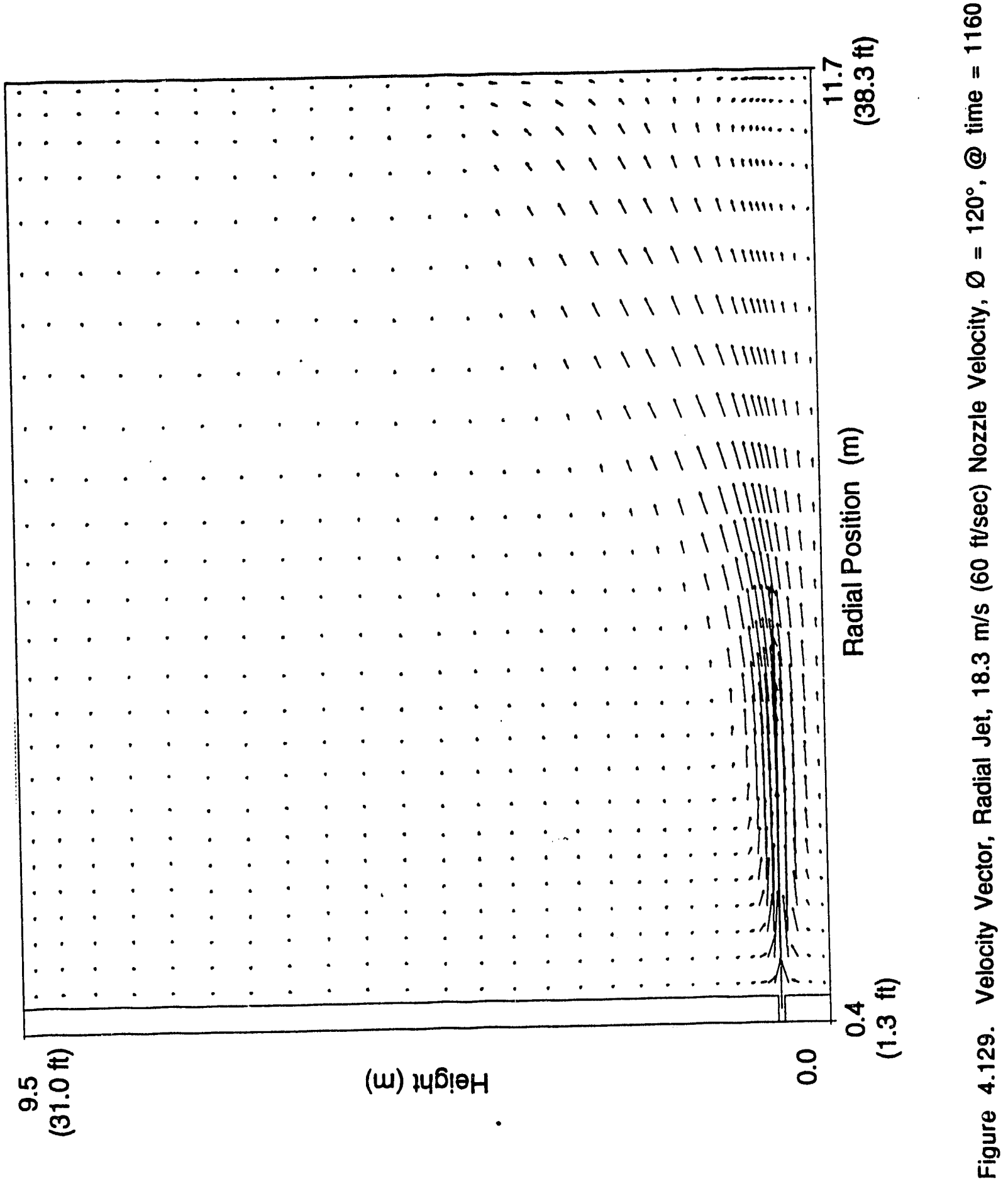



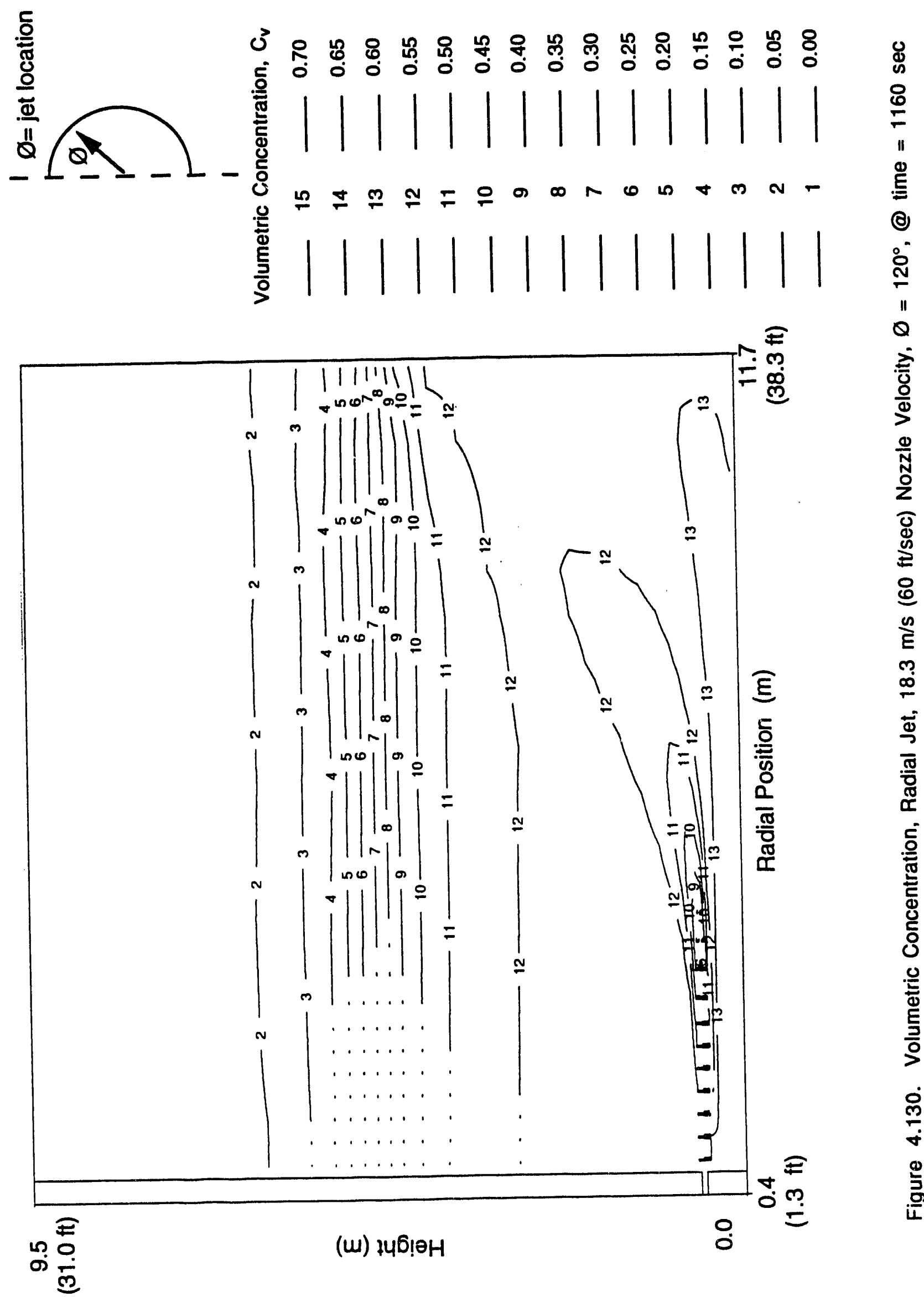


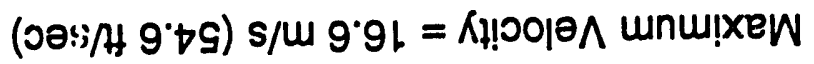

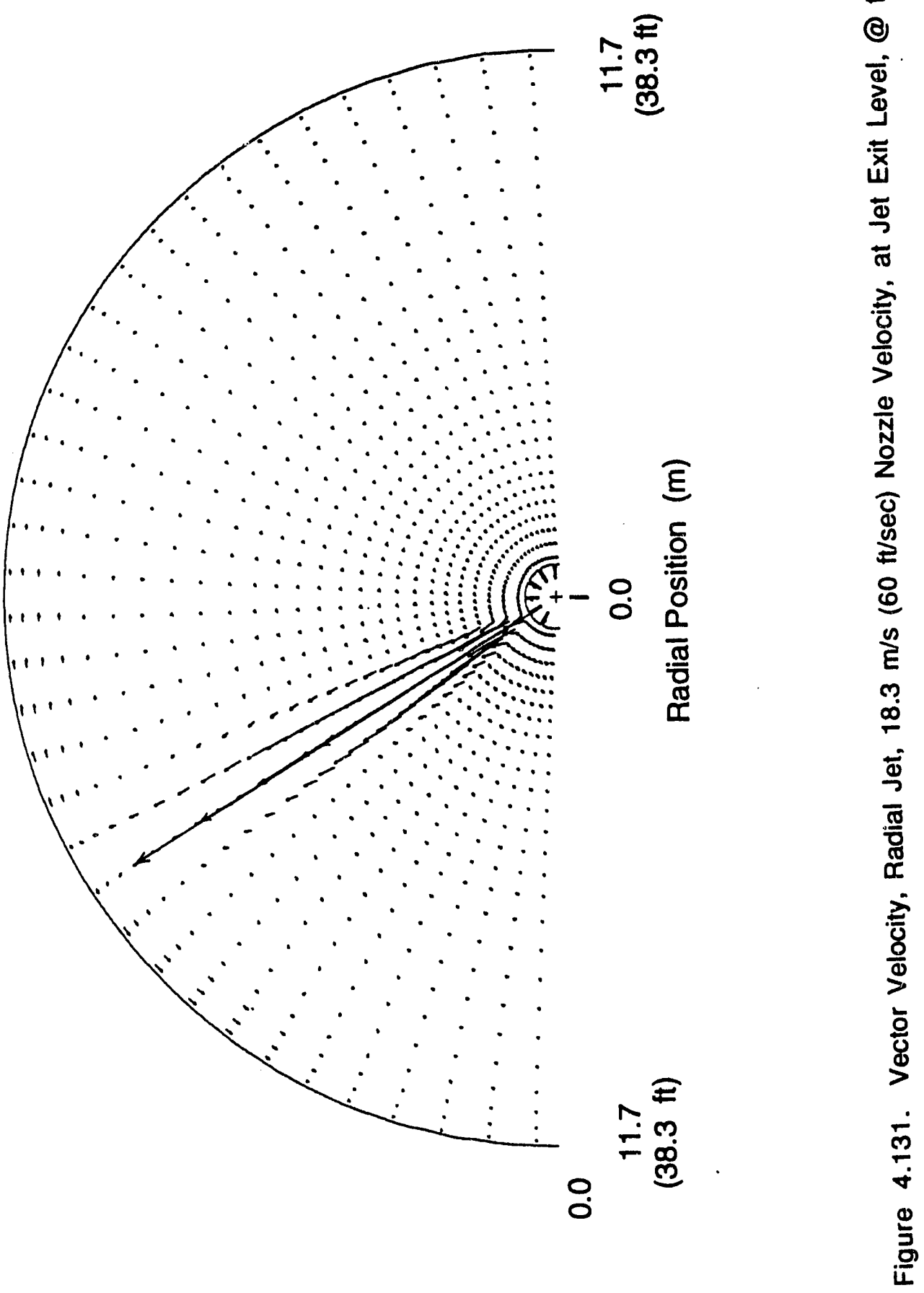



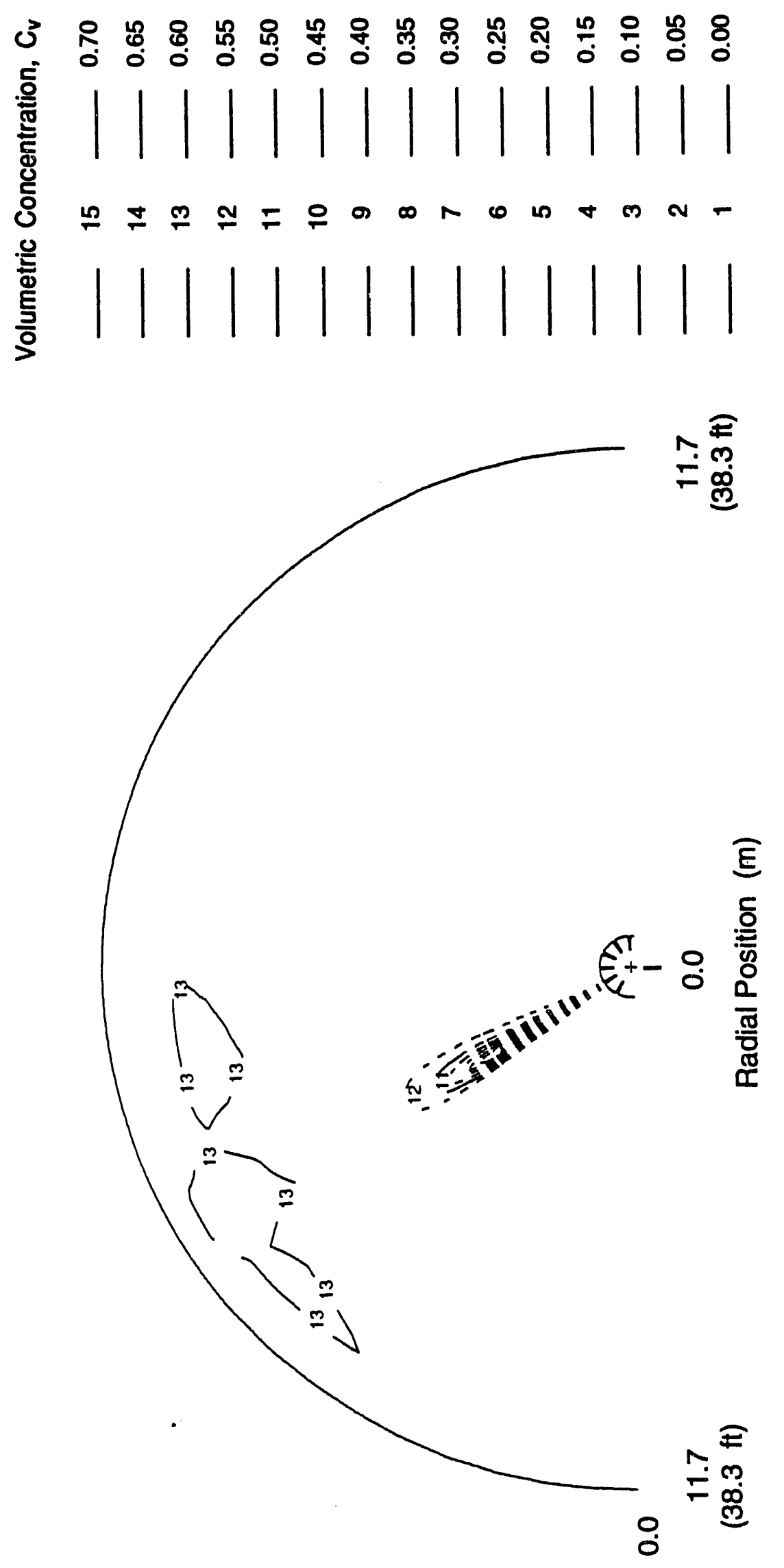

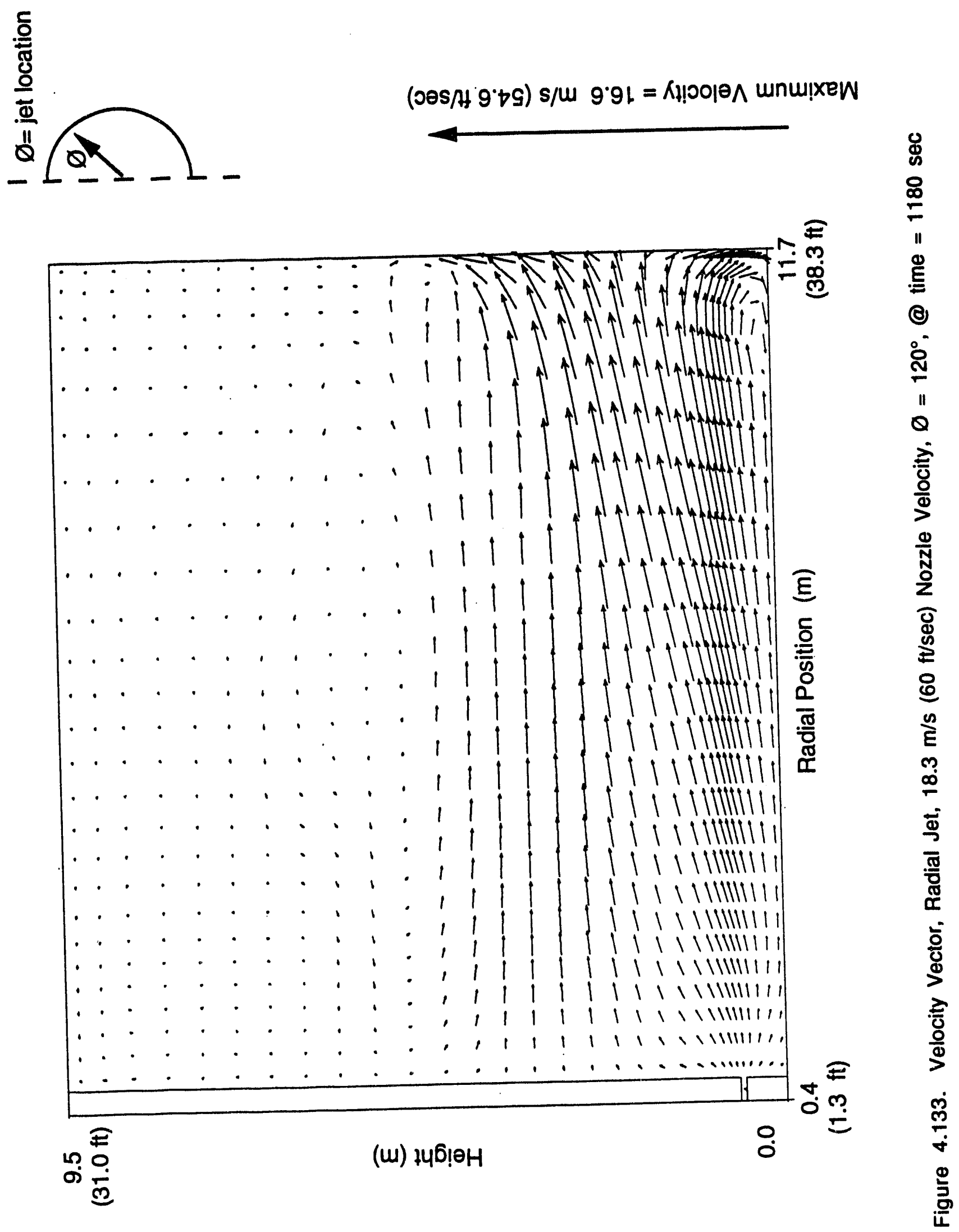


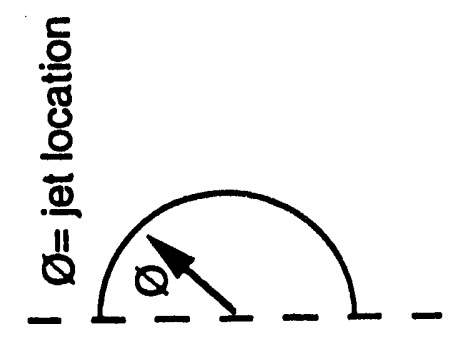

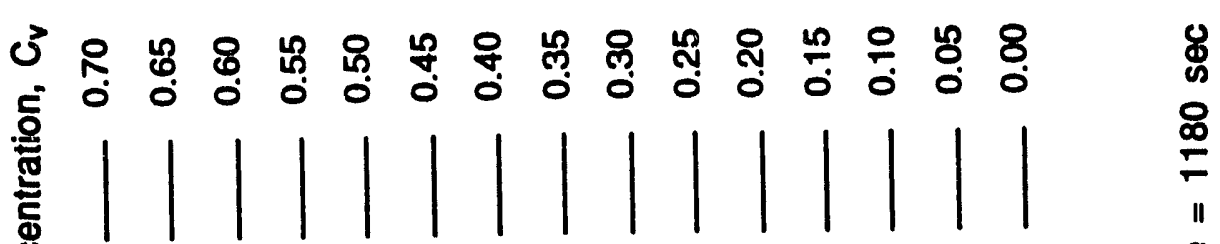

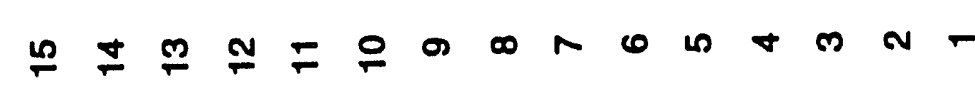

$\stackrel{\infty}{\underline{E}}$

옹

I
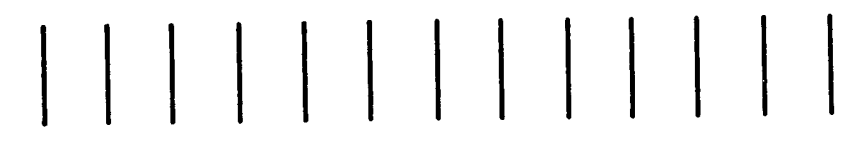

(e)

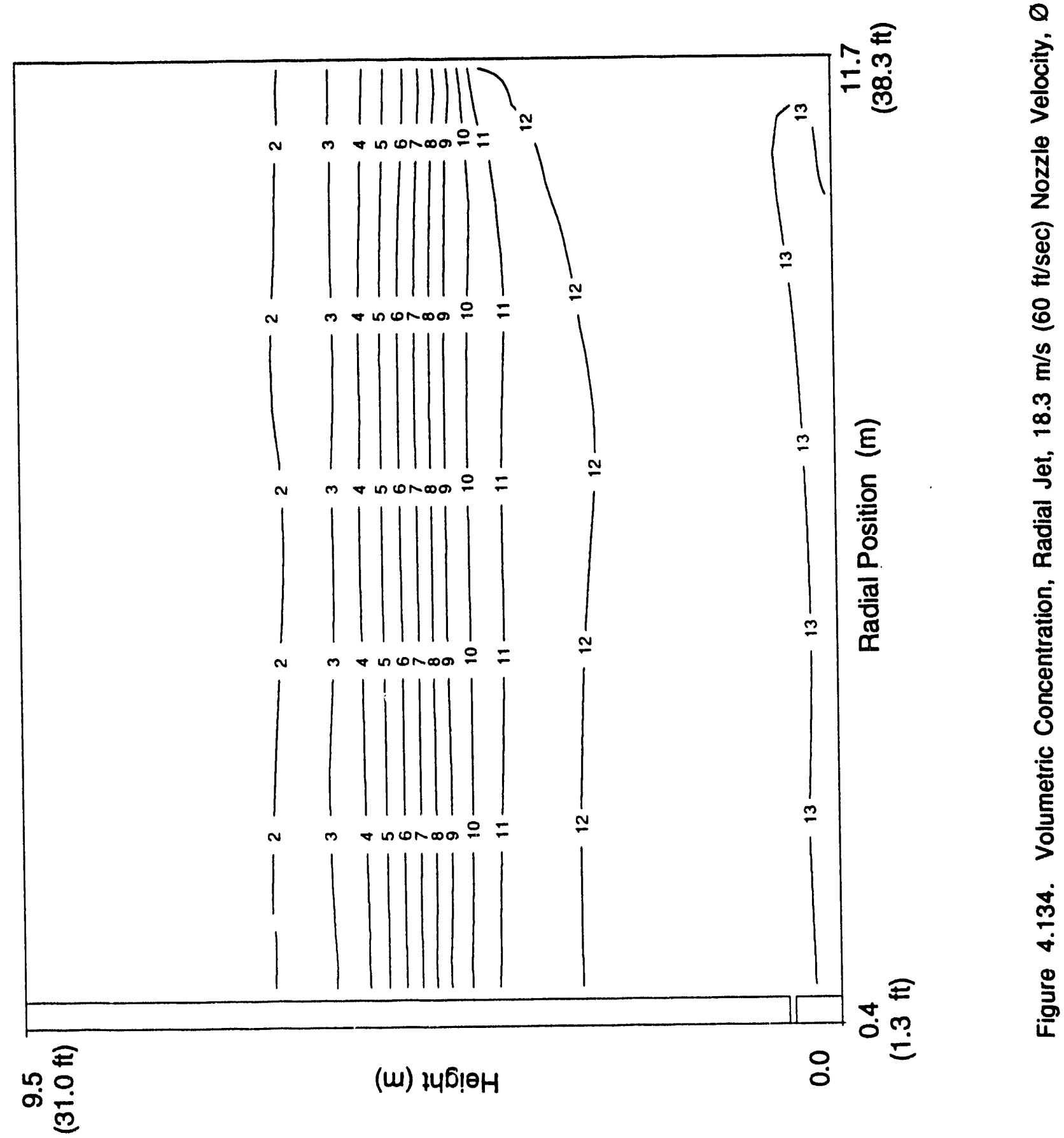




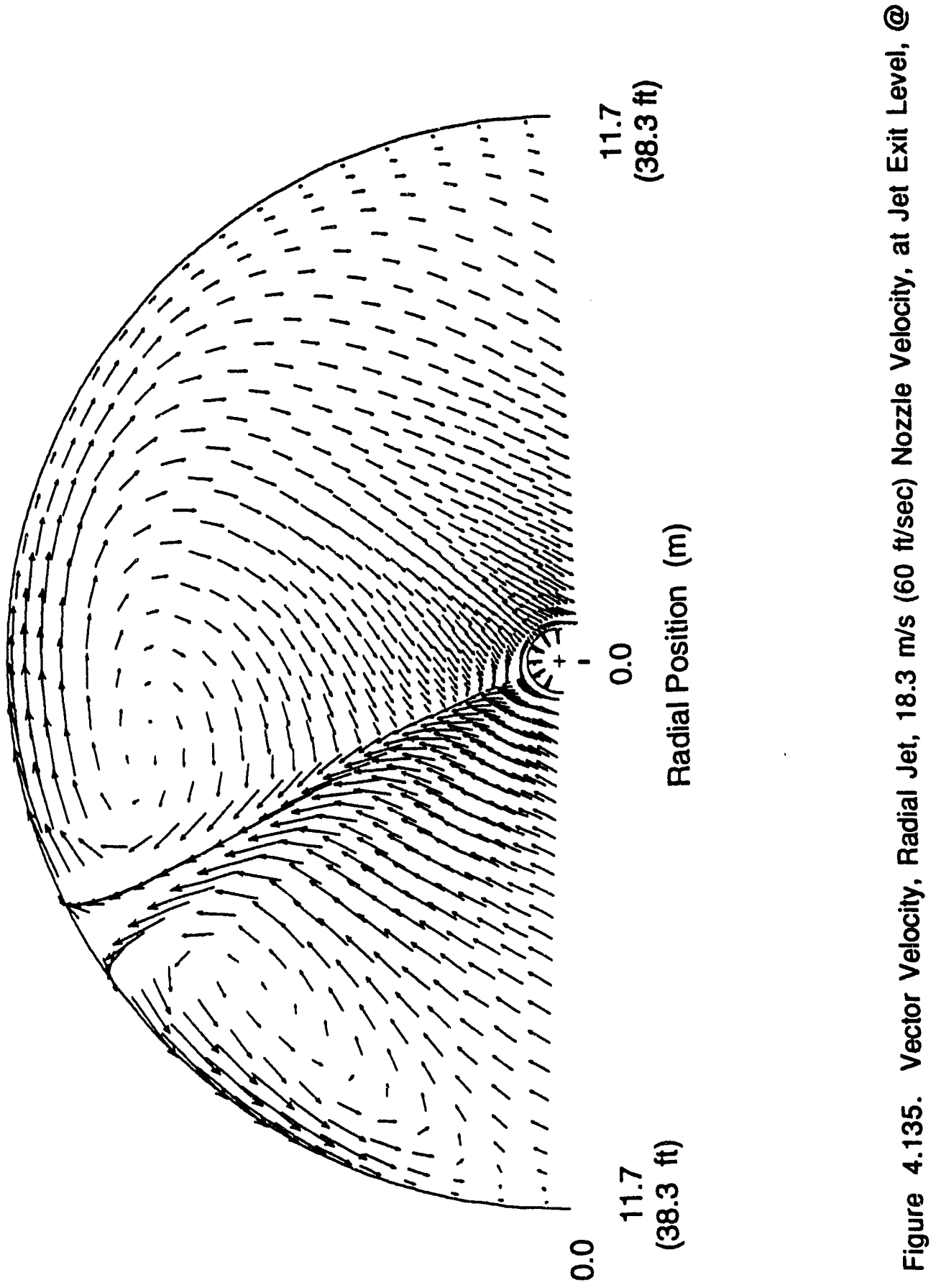



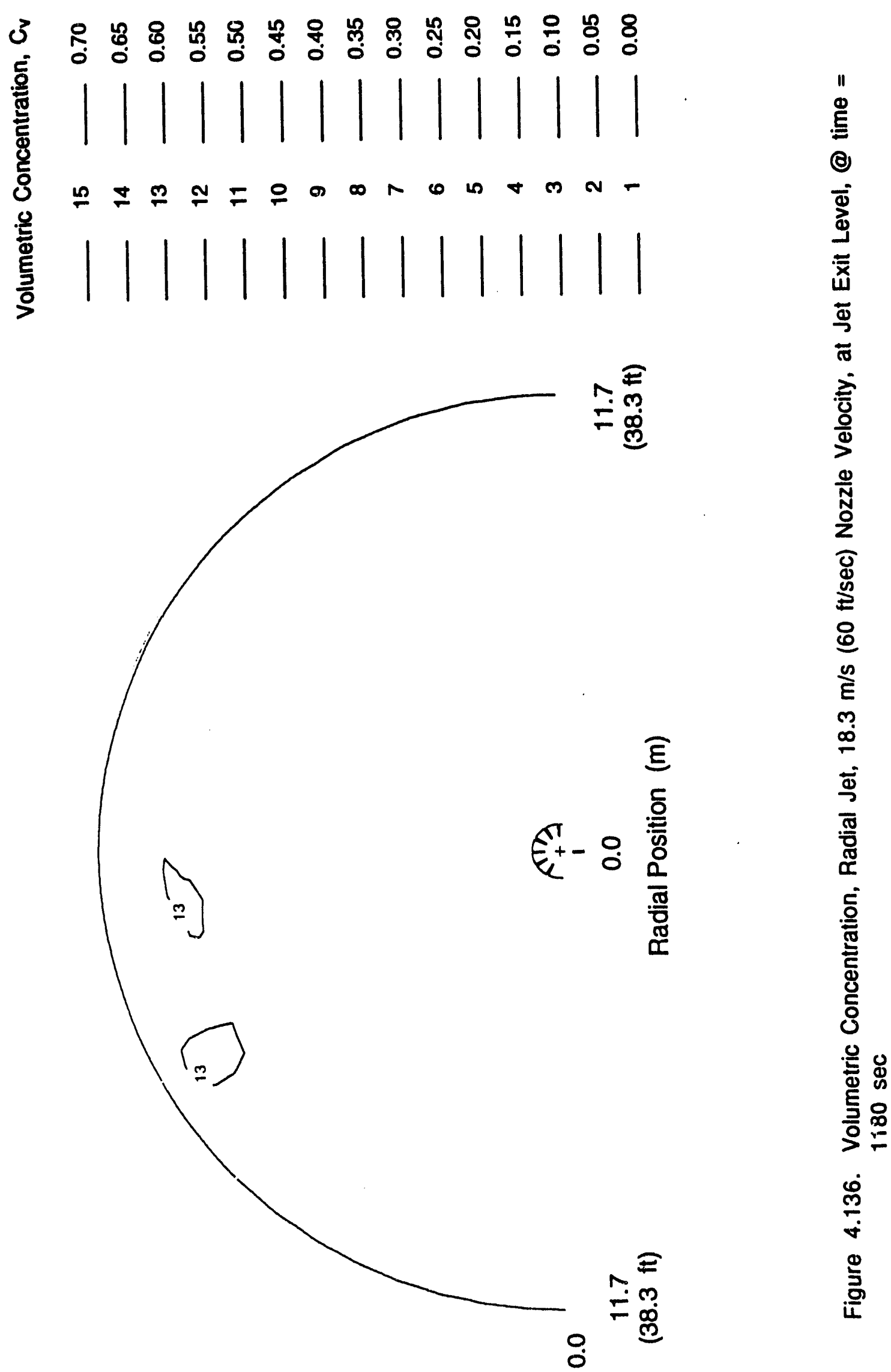

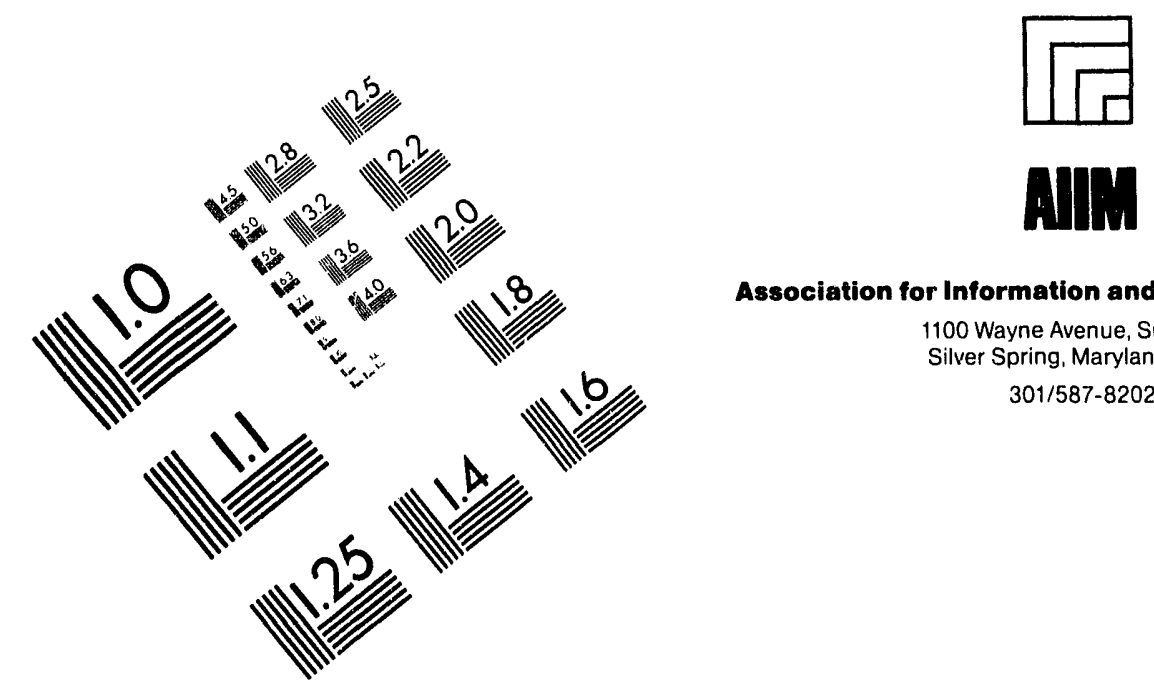

Association for Information and Image Management

1100 Wayne Avenue, Suite 1100

Silver Spring, Maryland 20910

301/587-8202

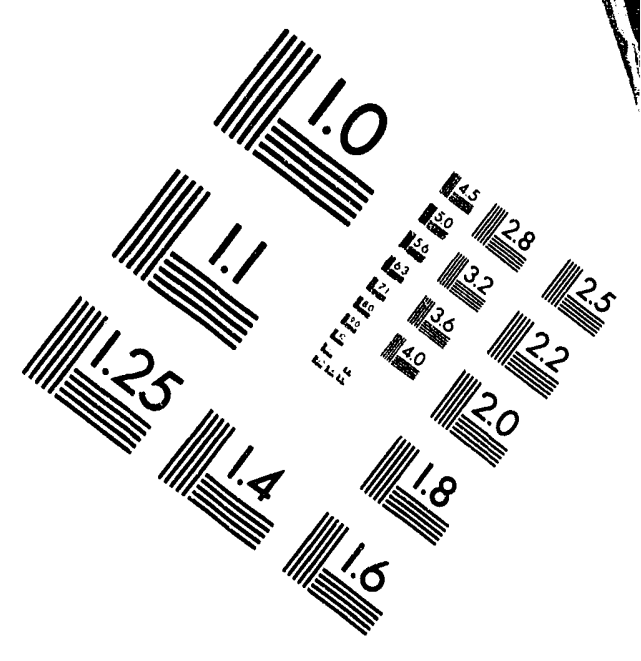

Centimeter

$\begin{array}{llllllllllllllll}1 & 2 & 3 & 4 & 5 & 6 & 7 & 8 & 9 & 10 & 11 & 12 & 13 & 14 & 15 & \mathrm{~mm}\end{array}$

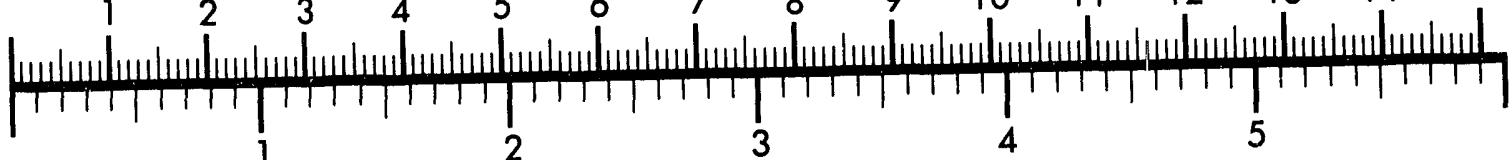
Inches
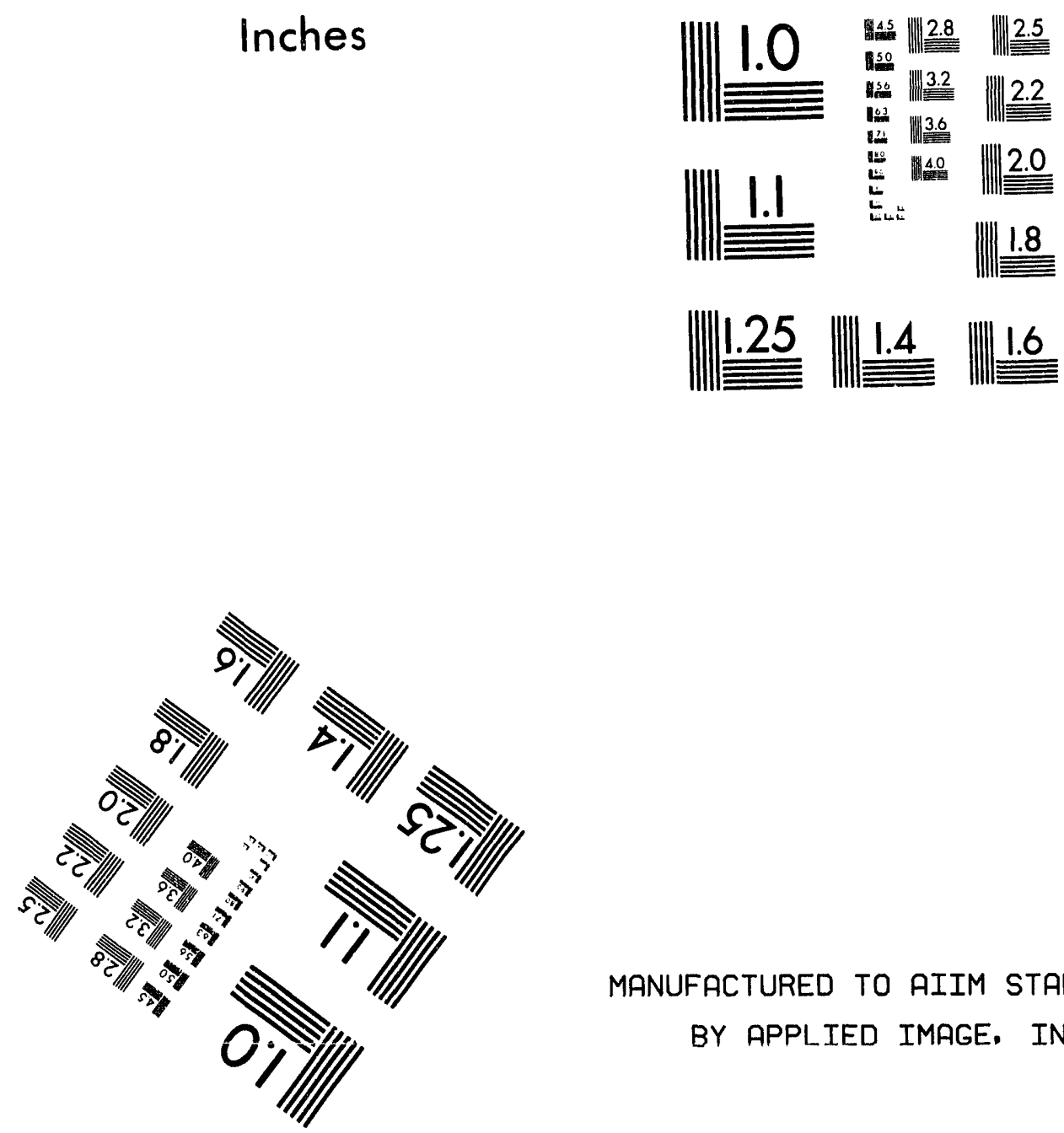

MANUFACTURED TO AIIM STANDARDS BY APPLIED IMAGE, INC.

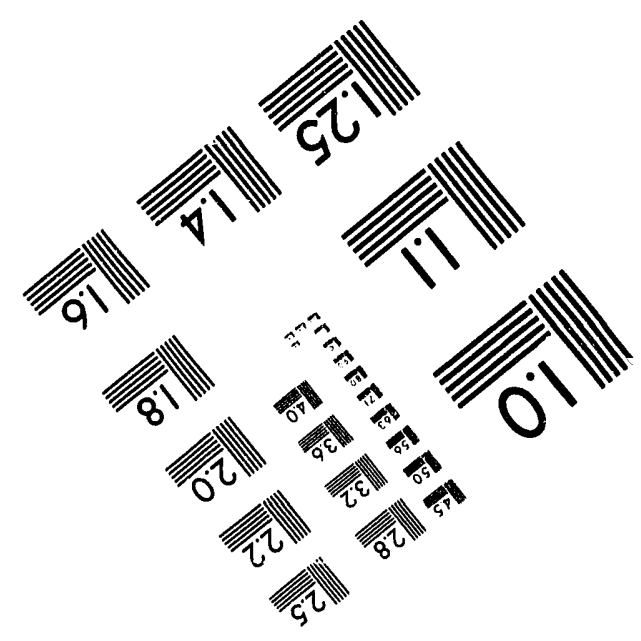



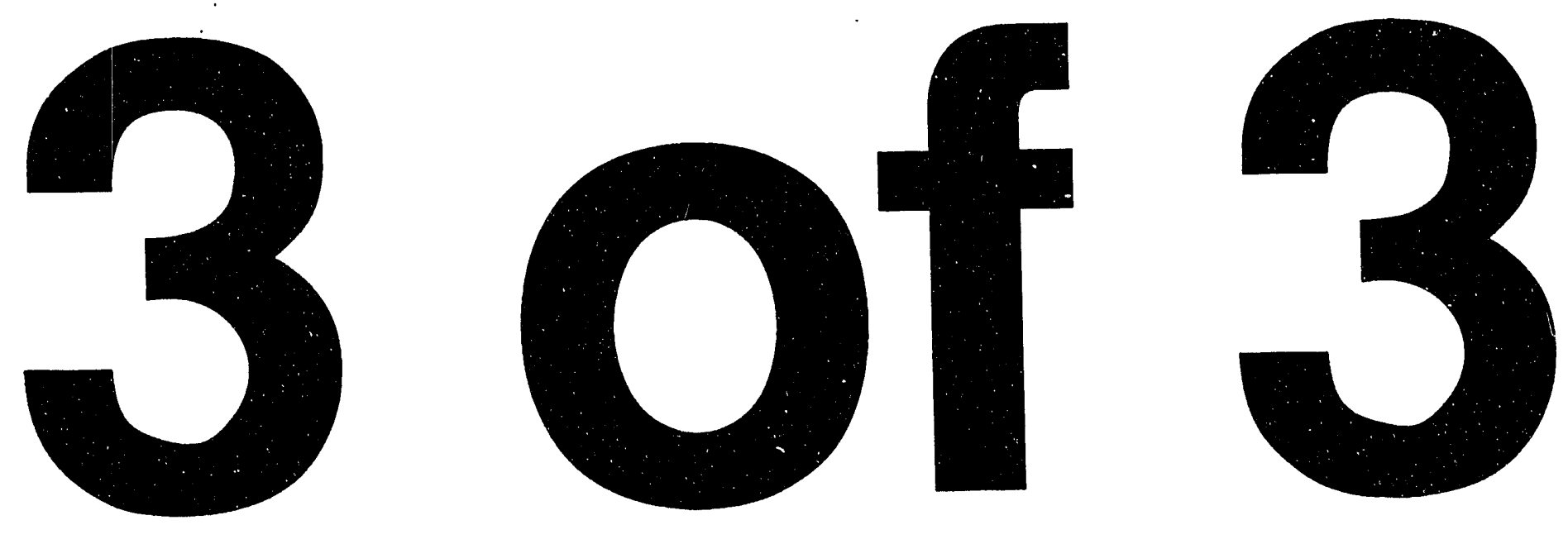


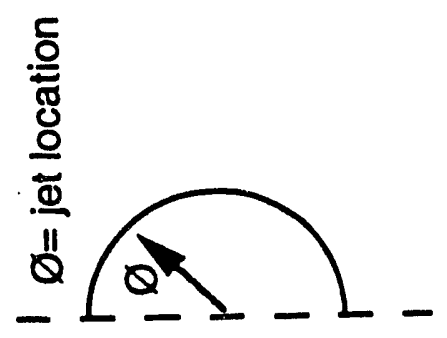

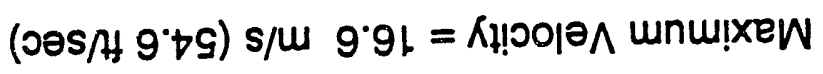

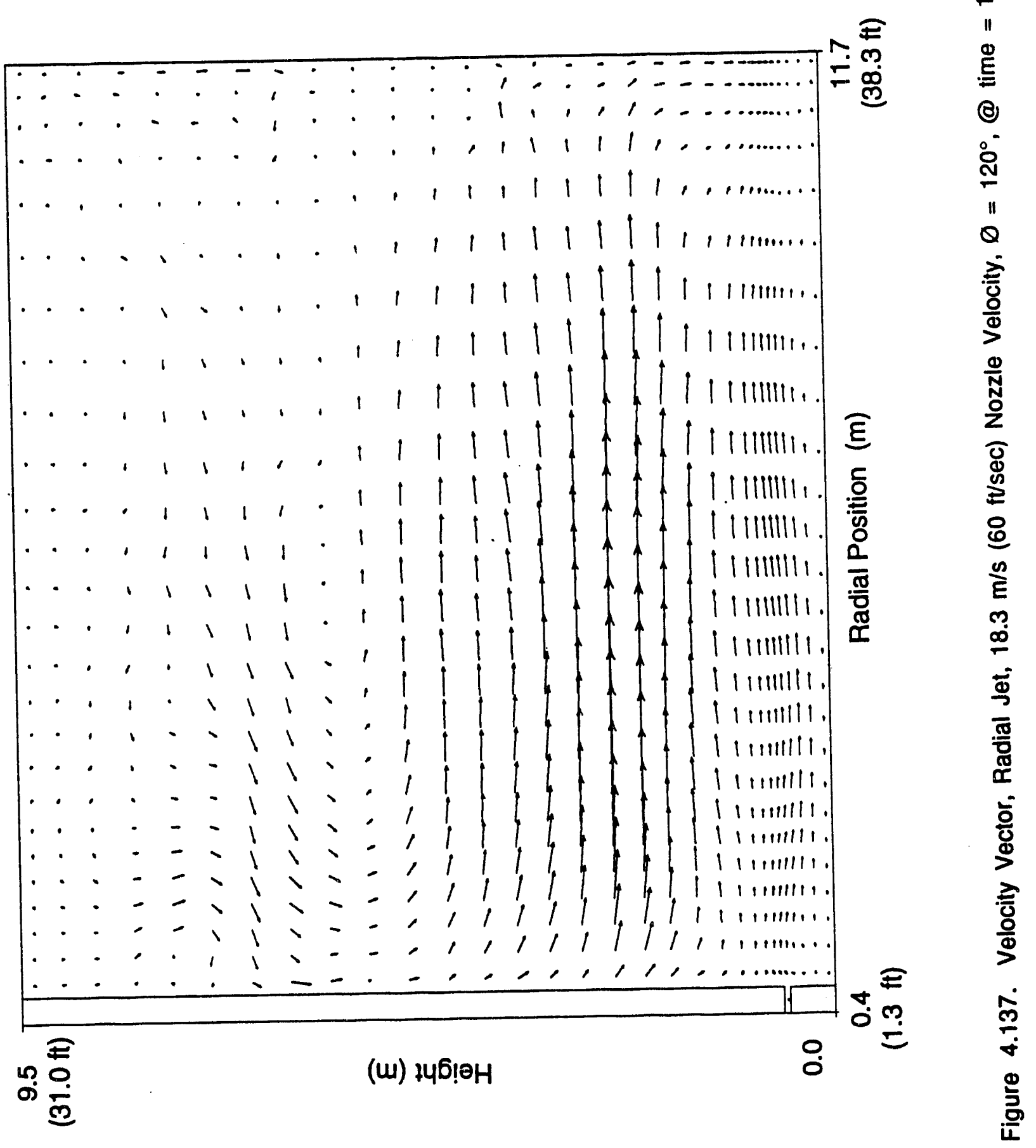




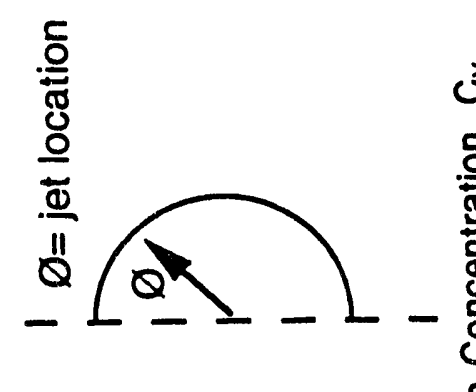

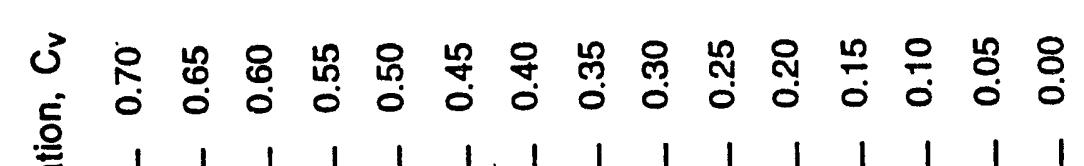

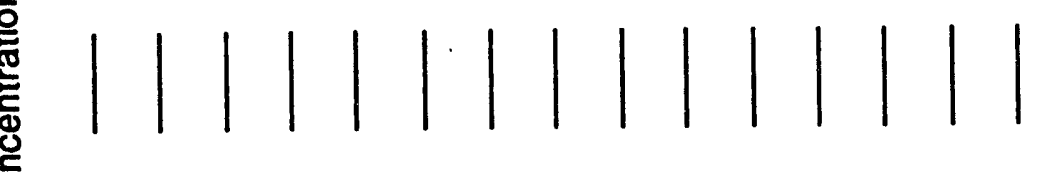

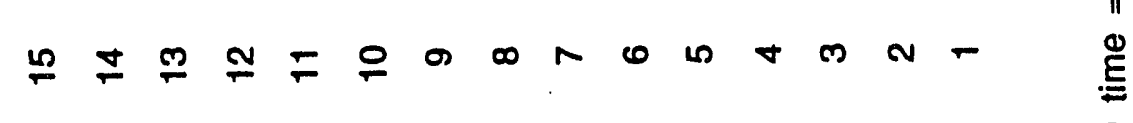

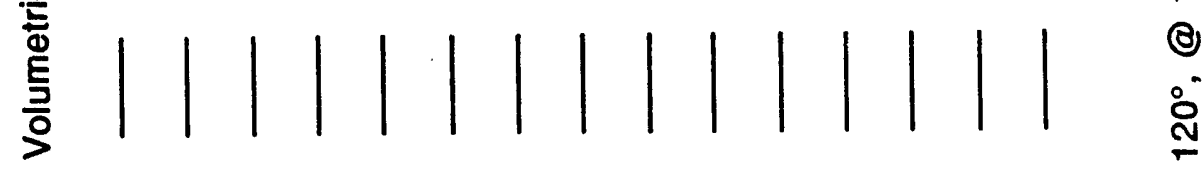

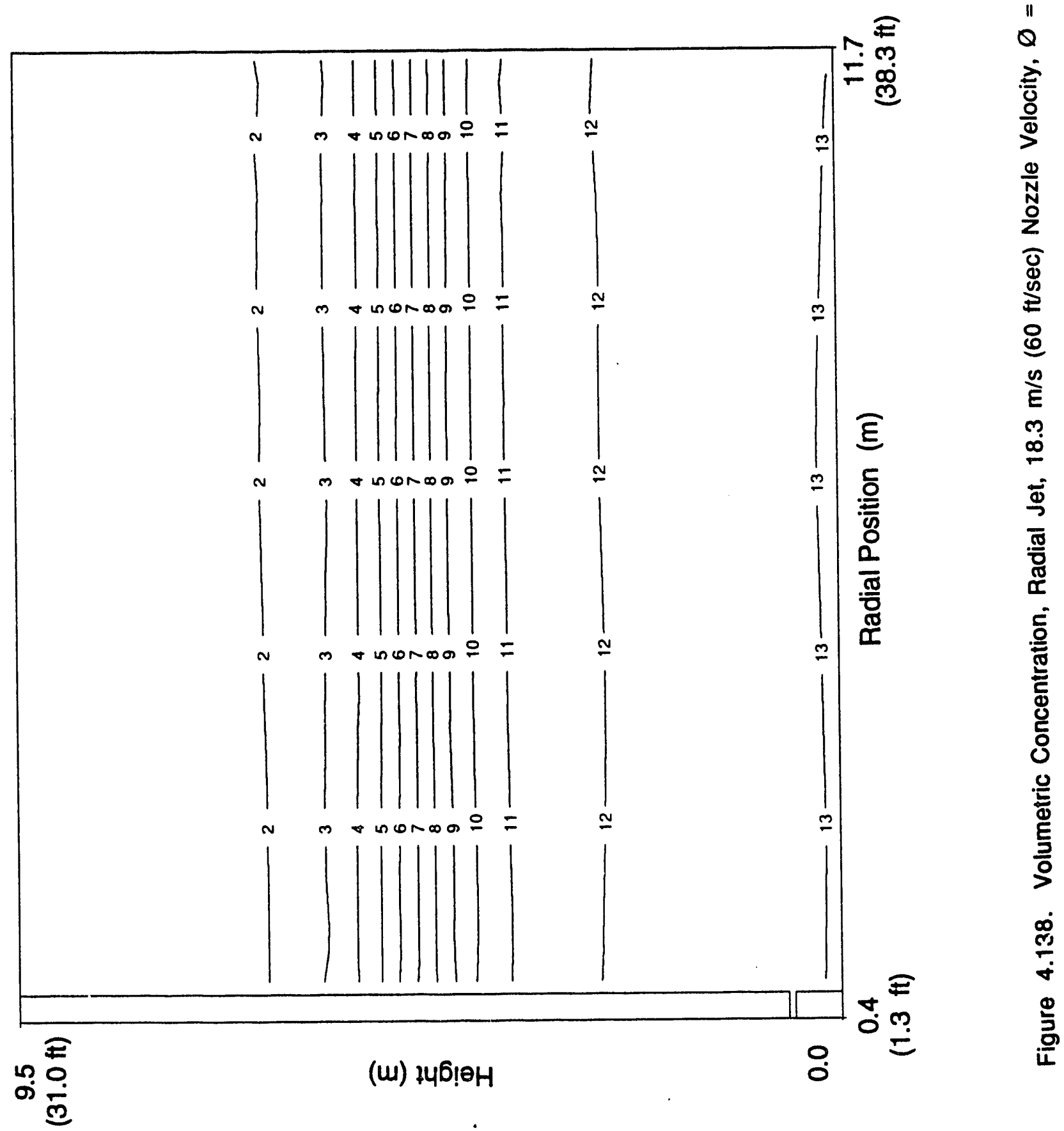




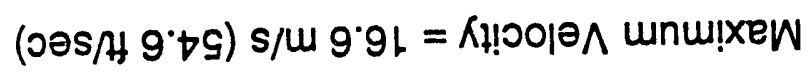

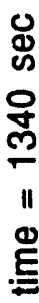

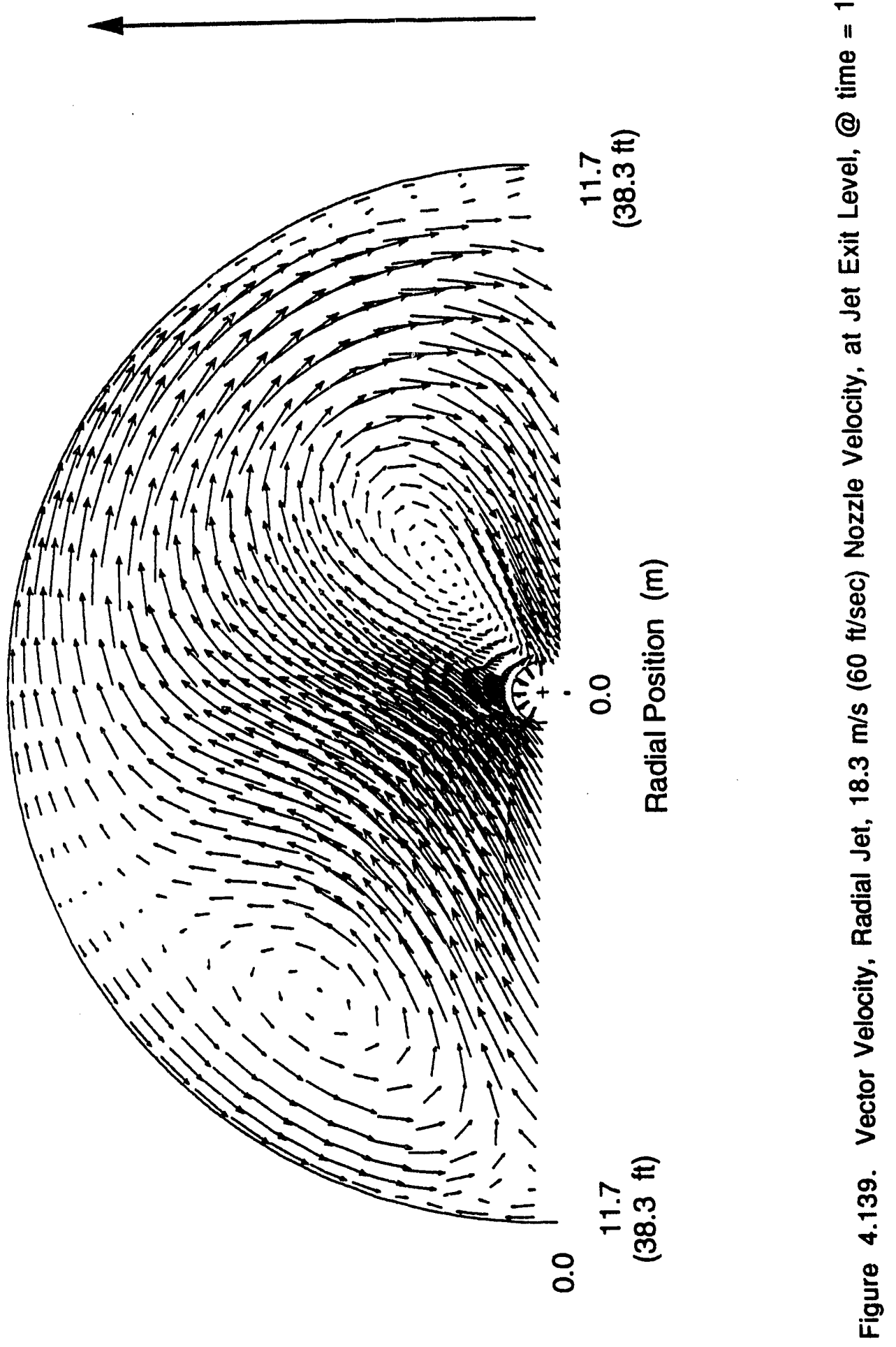




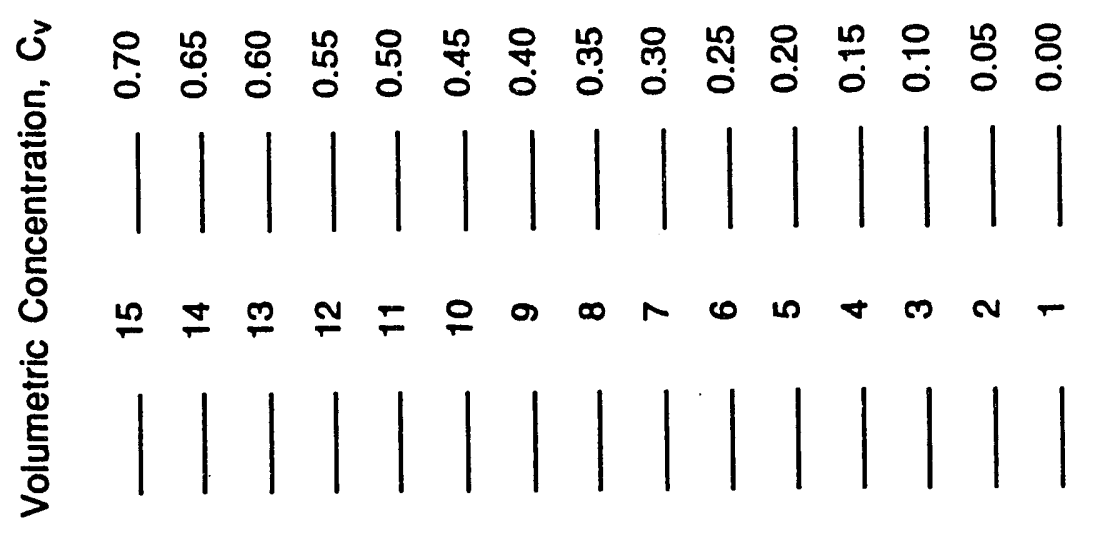

"I

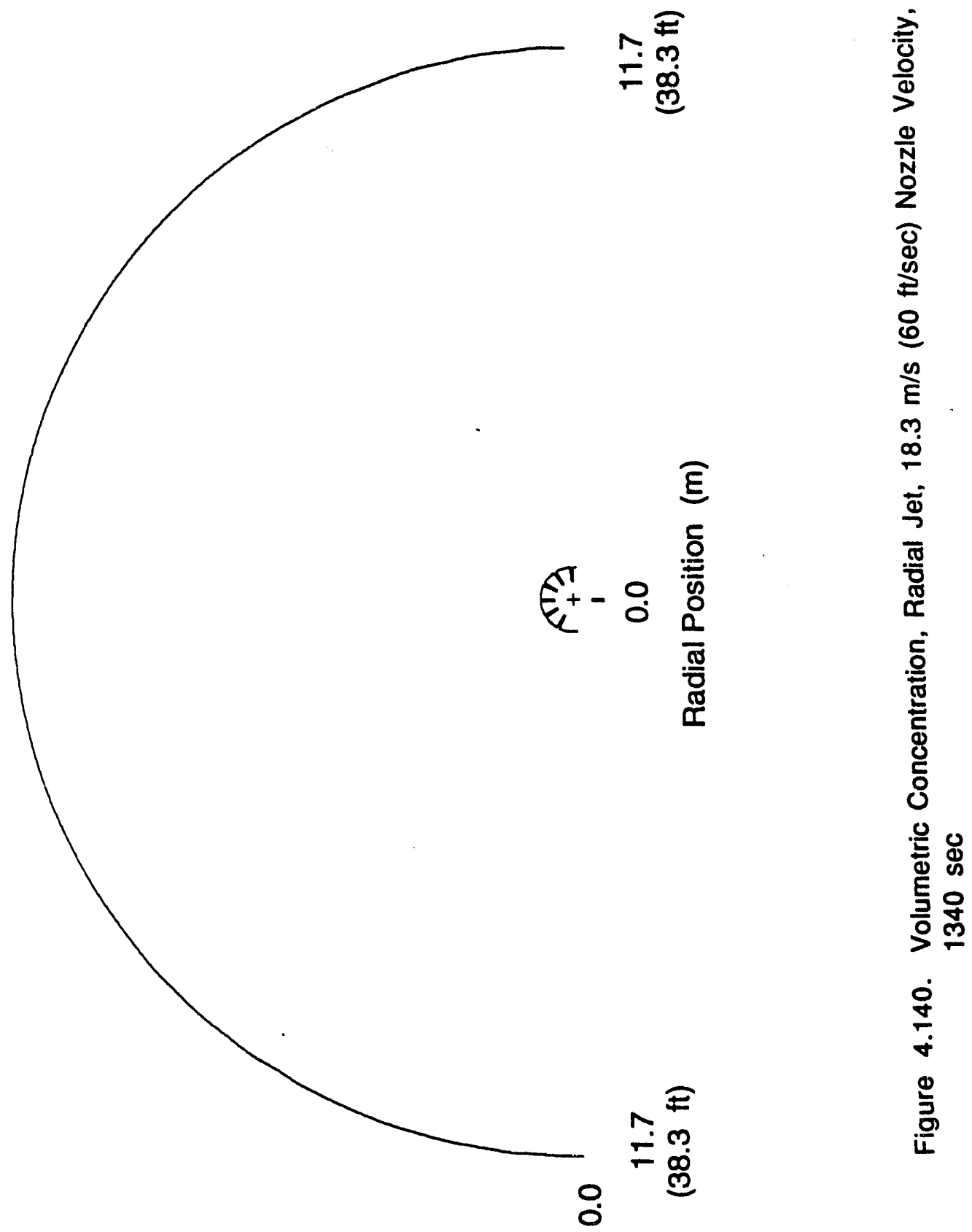

4.148 


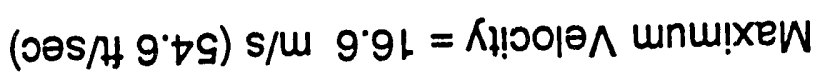
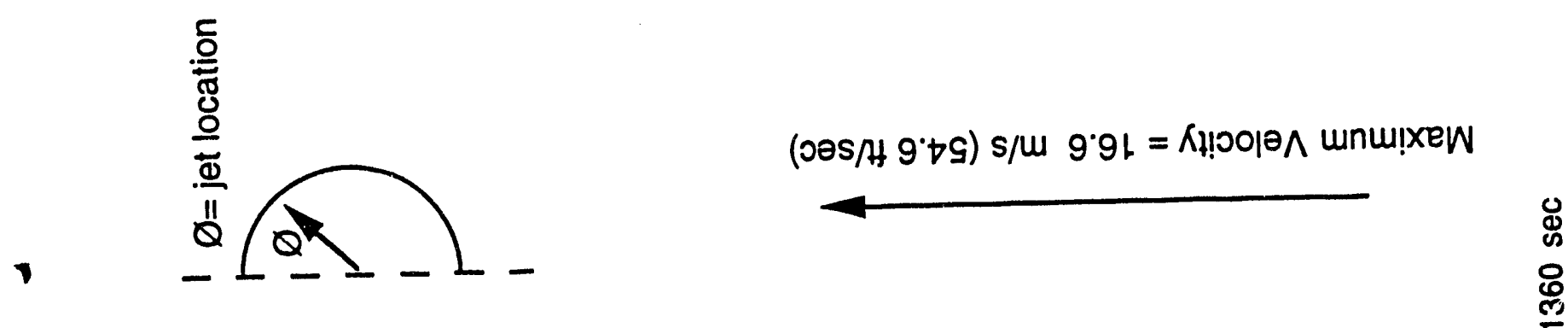

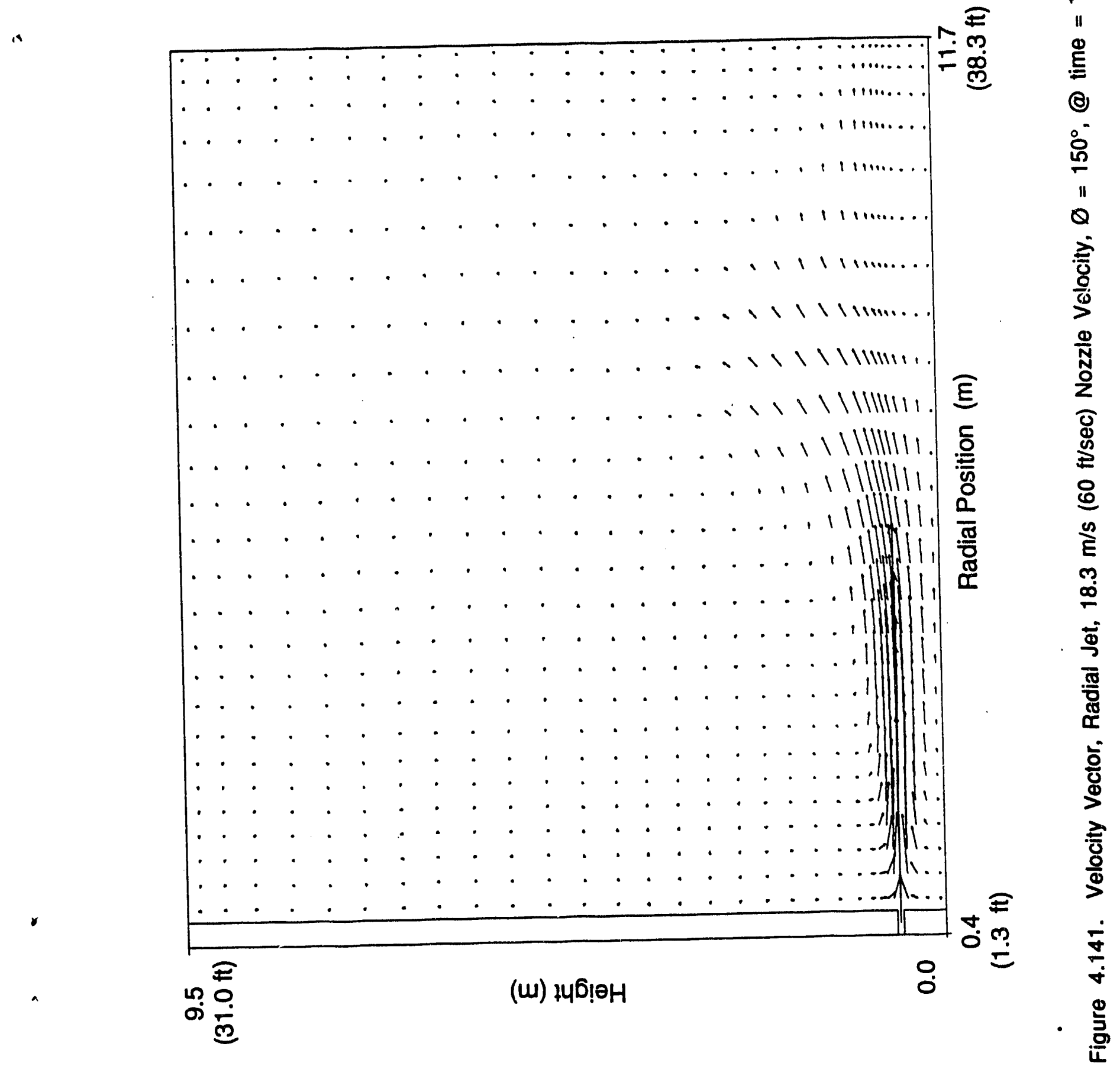




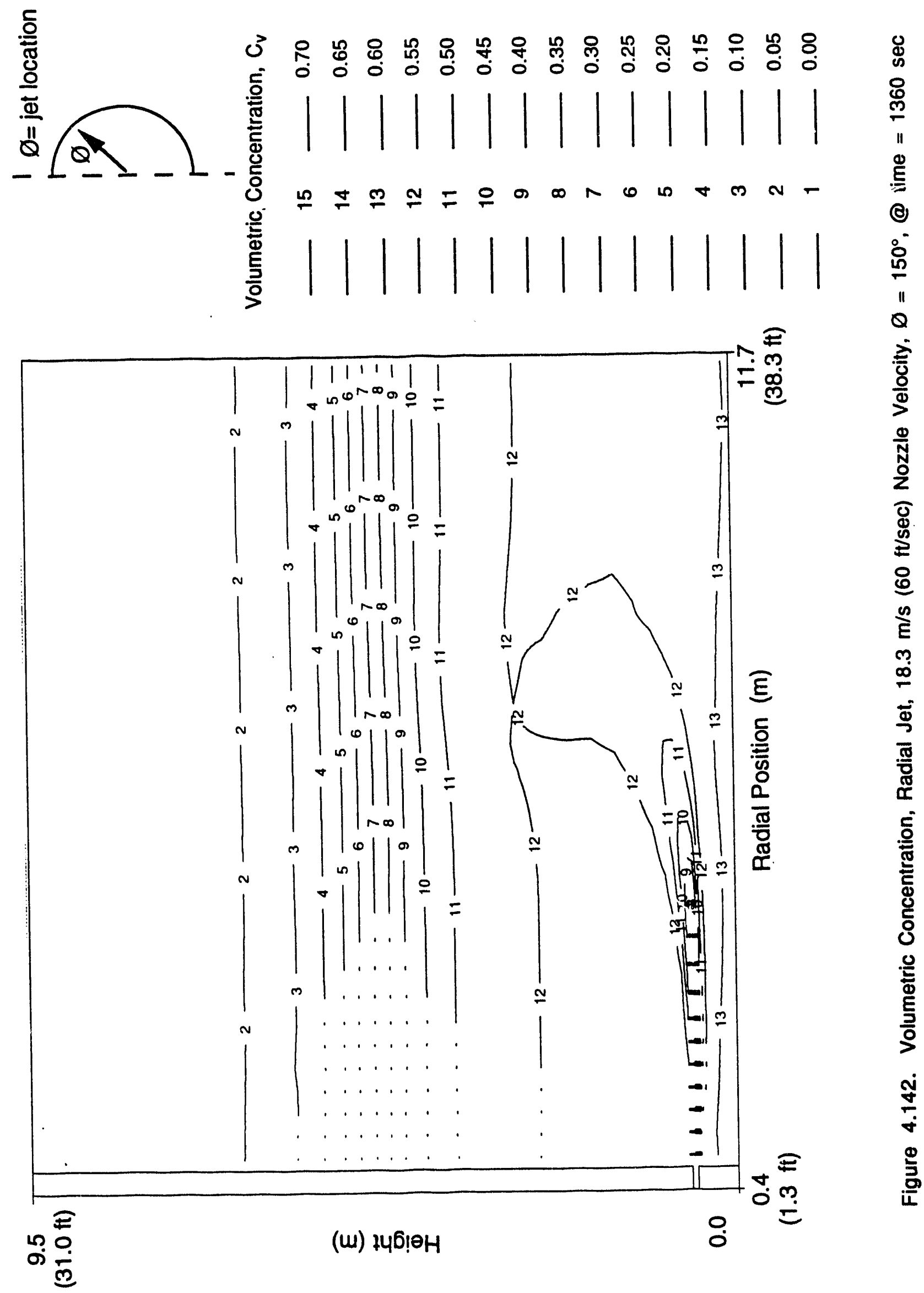




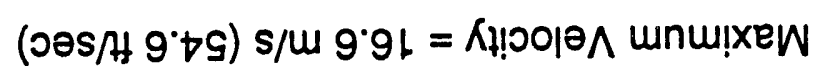

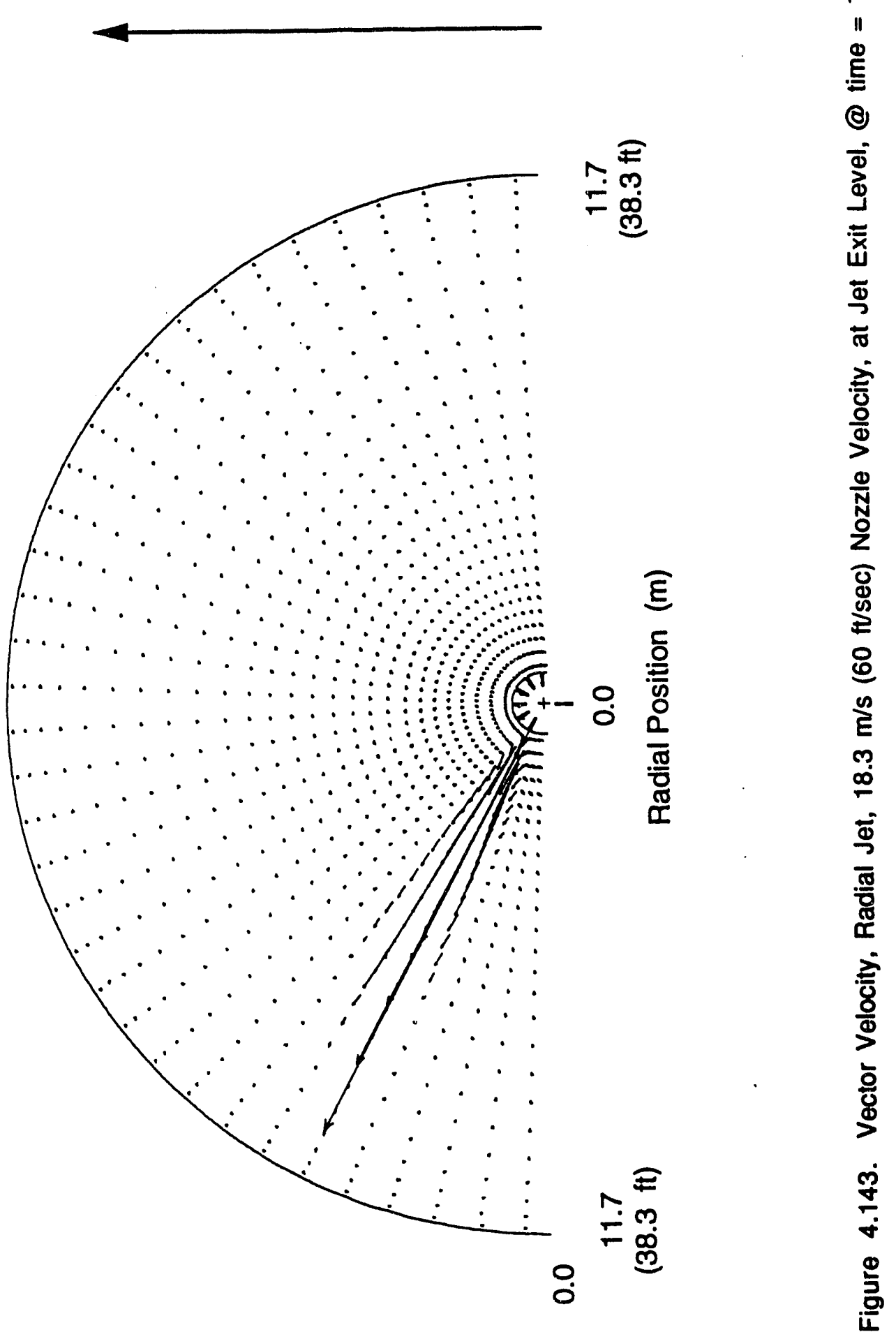




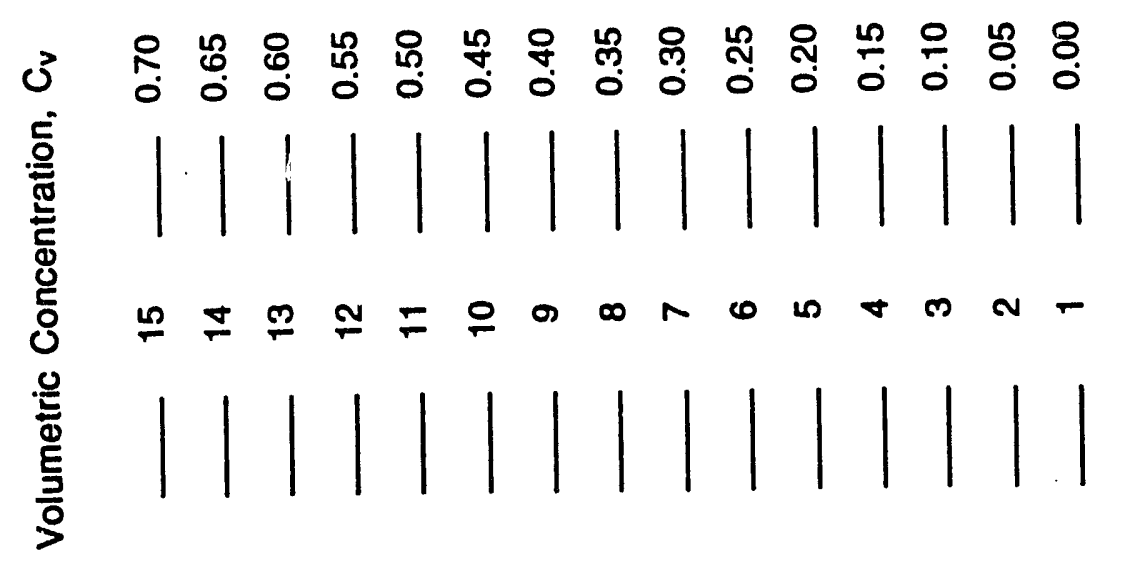

$\stackrel{\Perp}{\text { E }}$

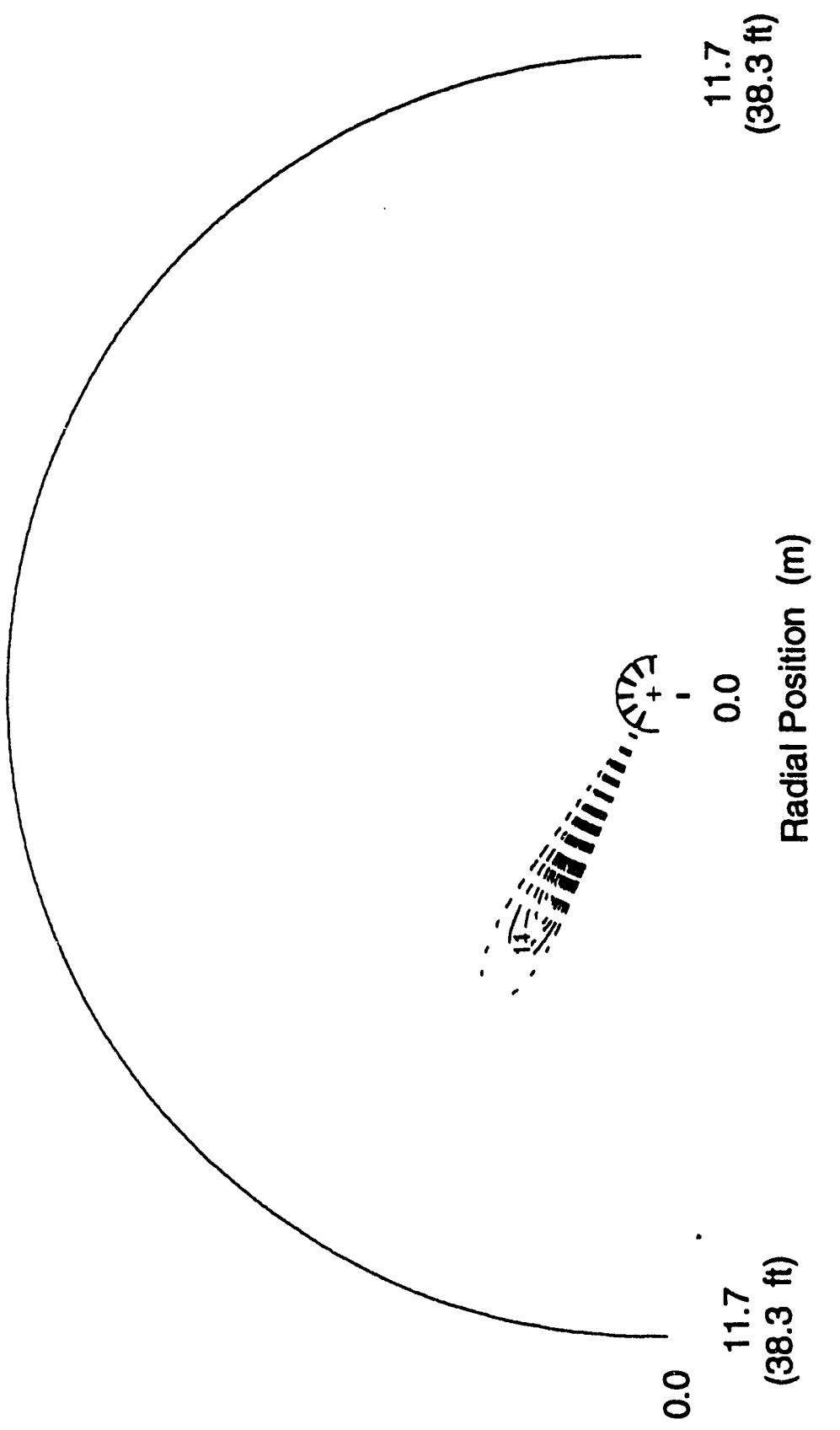

य) สั

흥

$\frac{0}{N}$

O

\&

웅

है

$\stackrel{\infty}{\infty}$

赤

뭉

סू.

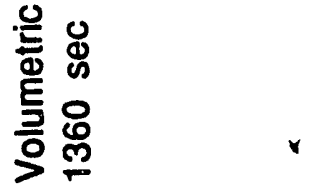




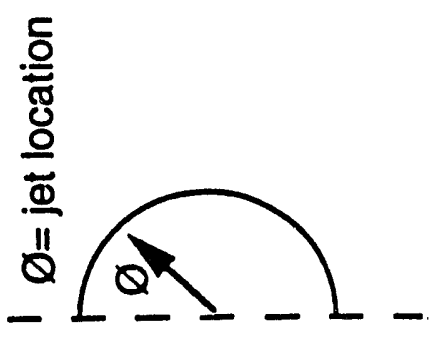

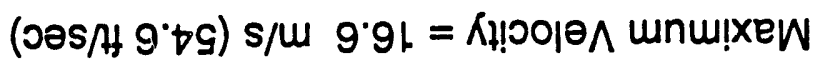

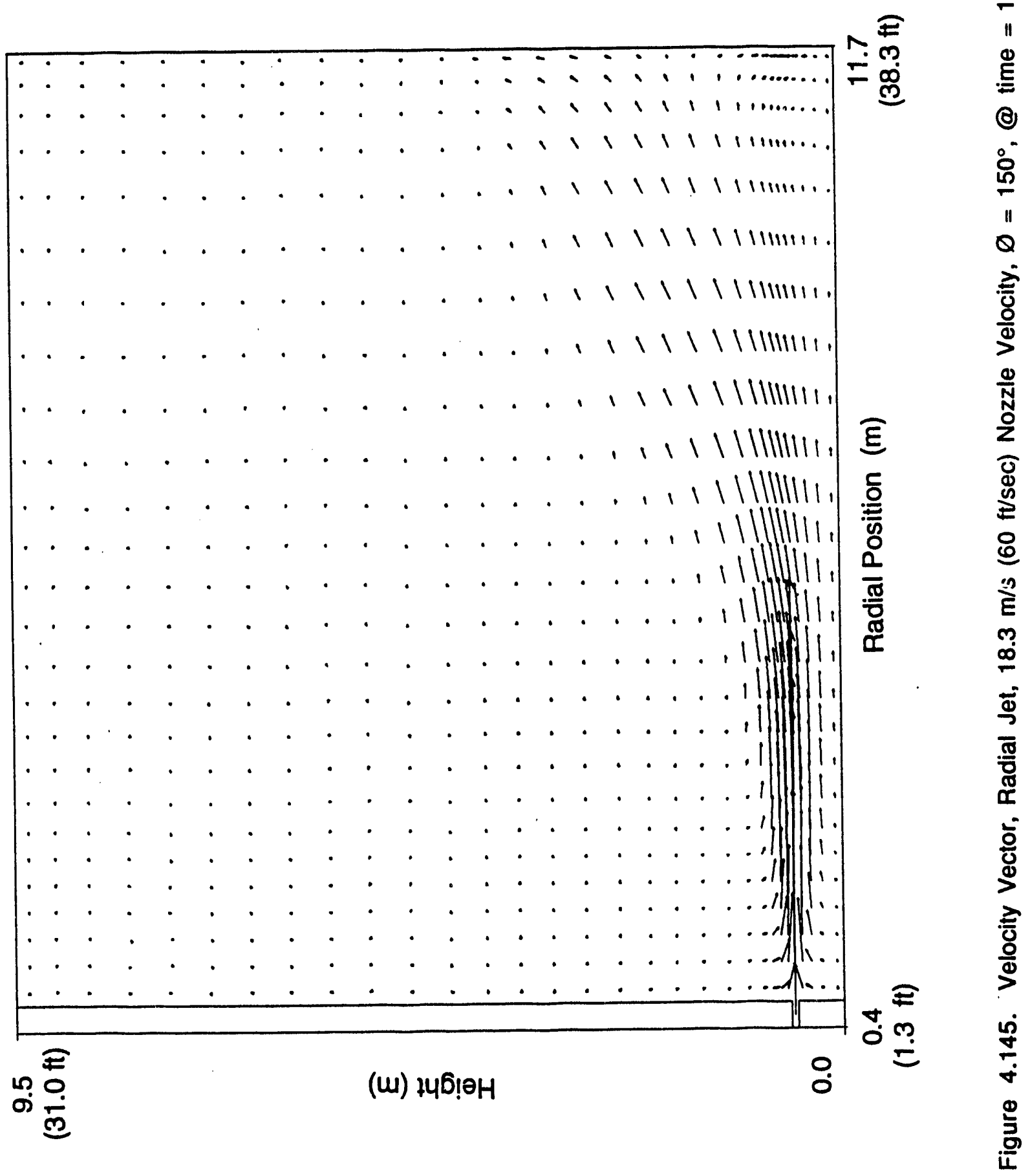




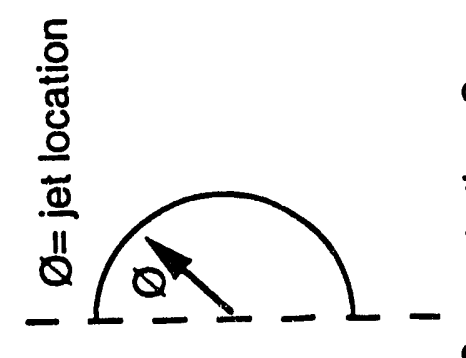

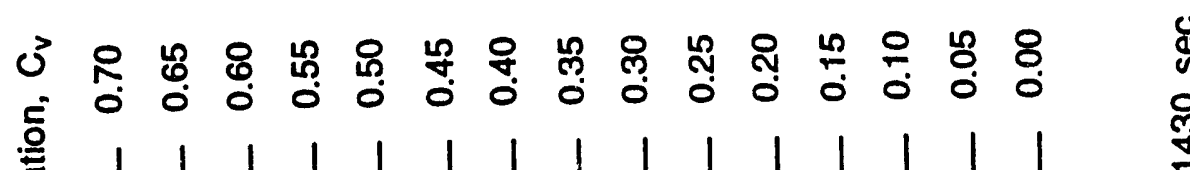

\$

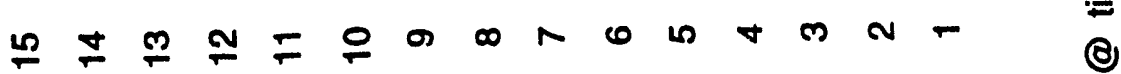
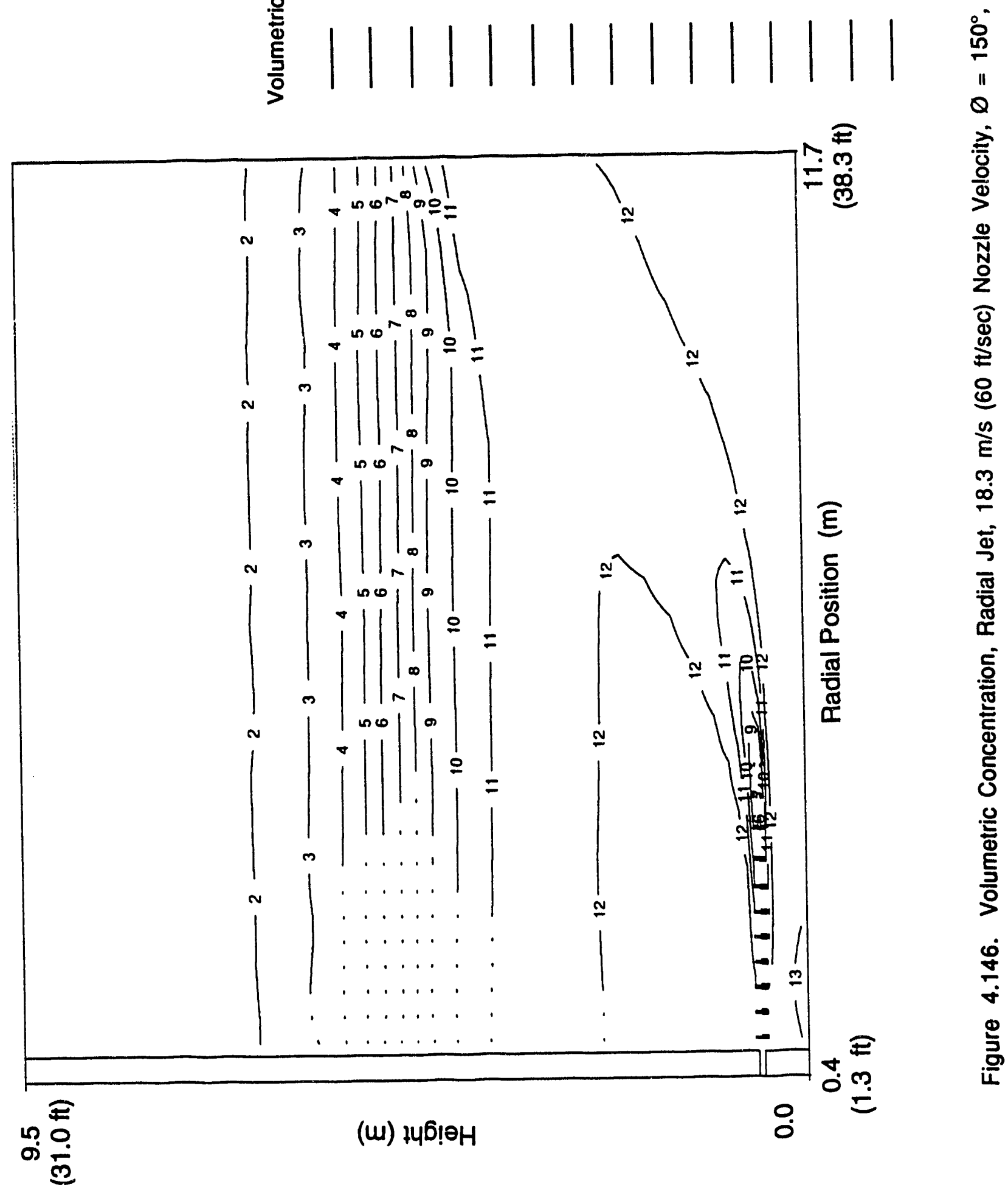


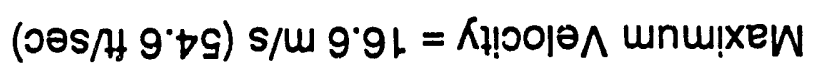

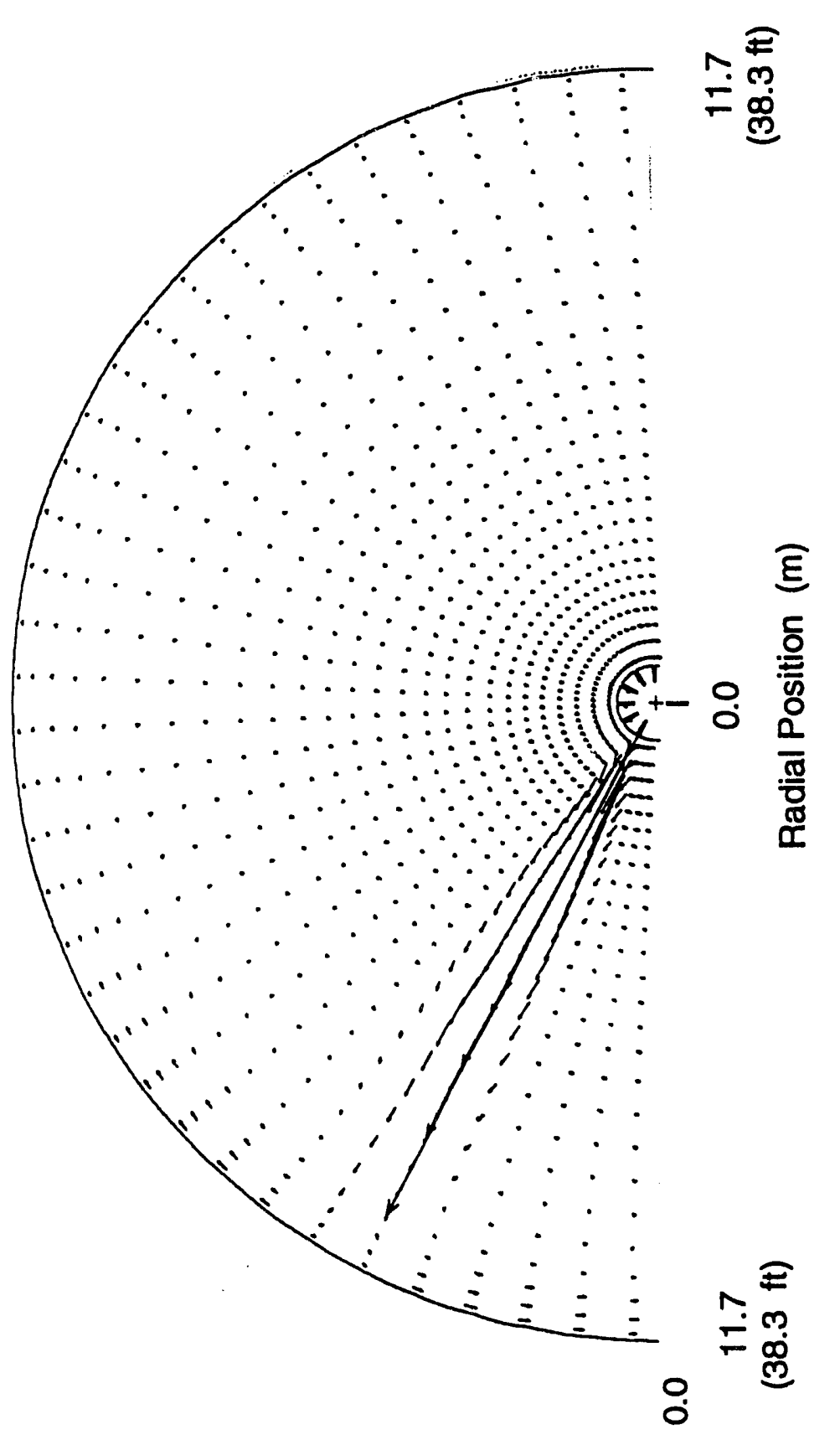

(6) 

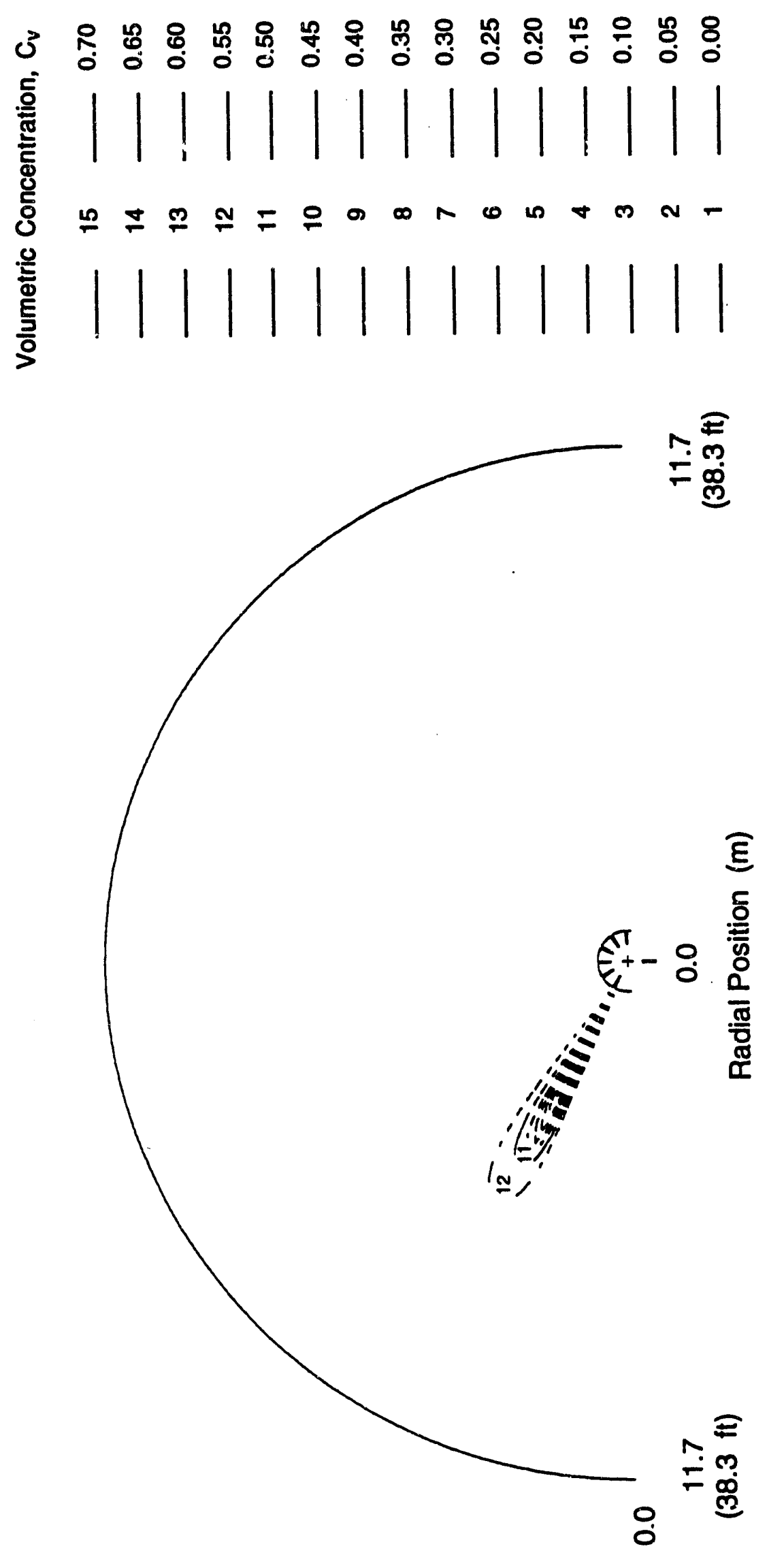

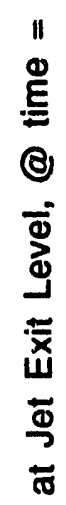

흥

4.156 


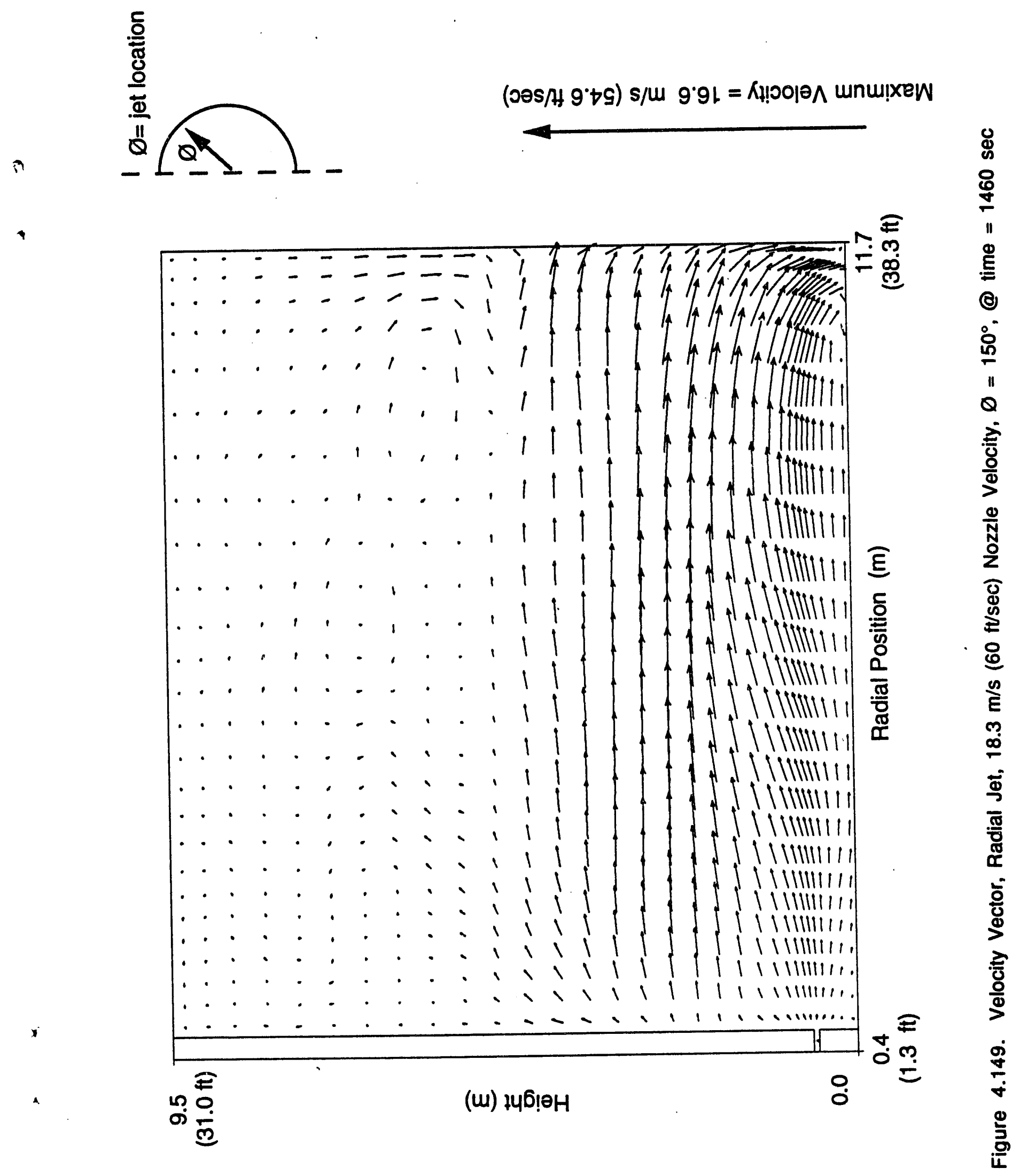



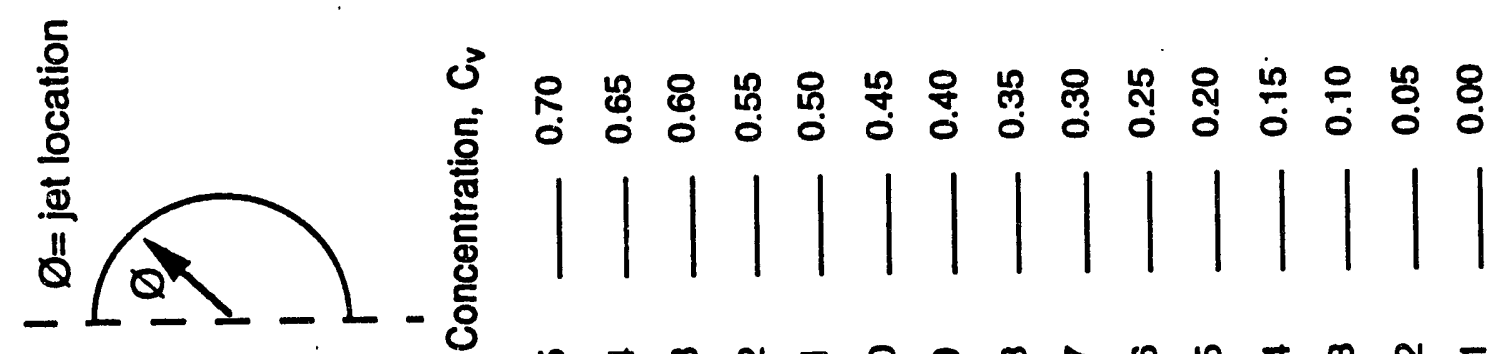

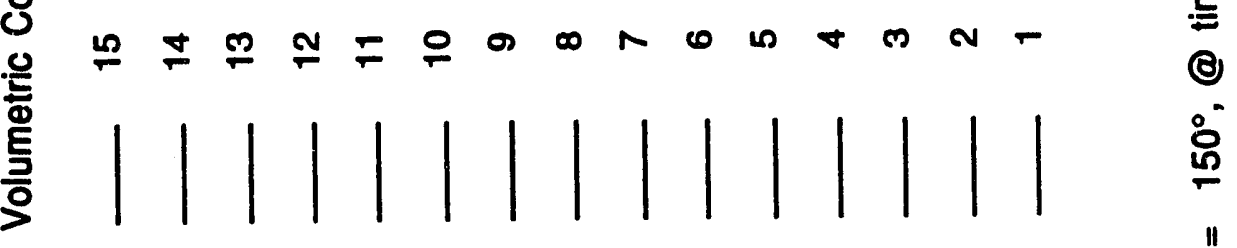

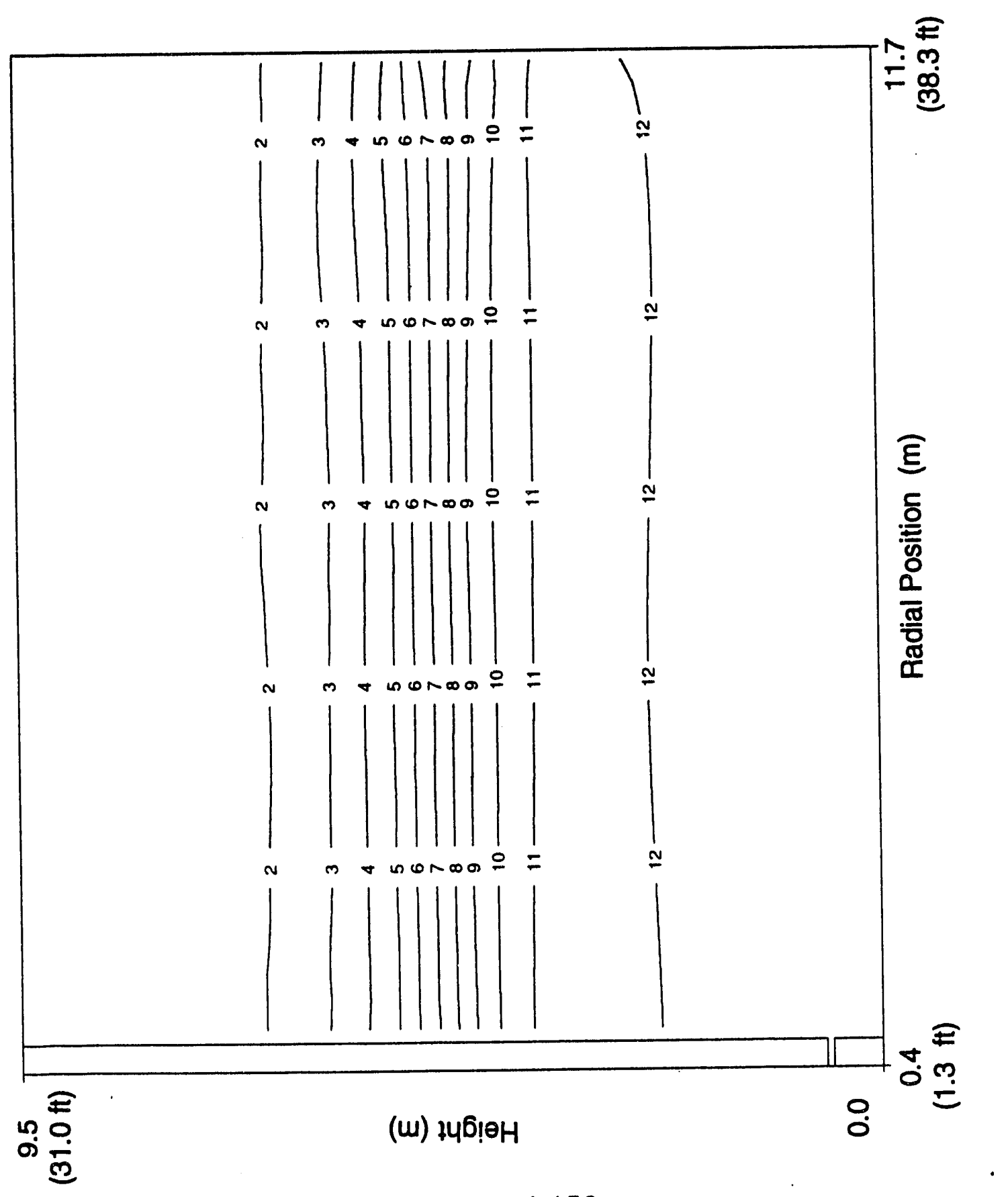

Q

응

里

త్ర

웅

E

$\infty$

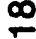

बे

즘

2

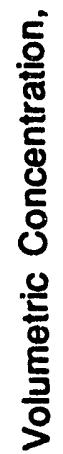

웅

논 


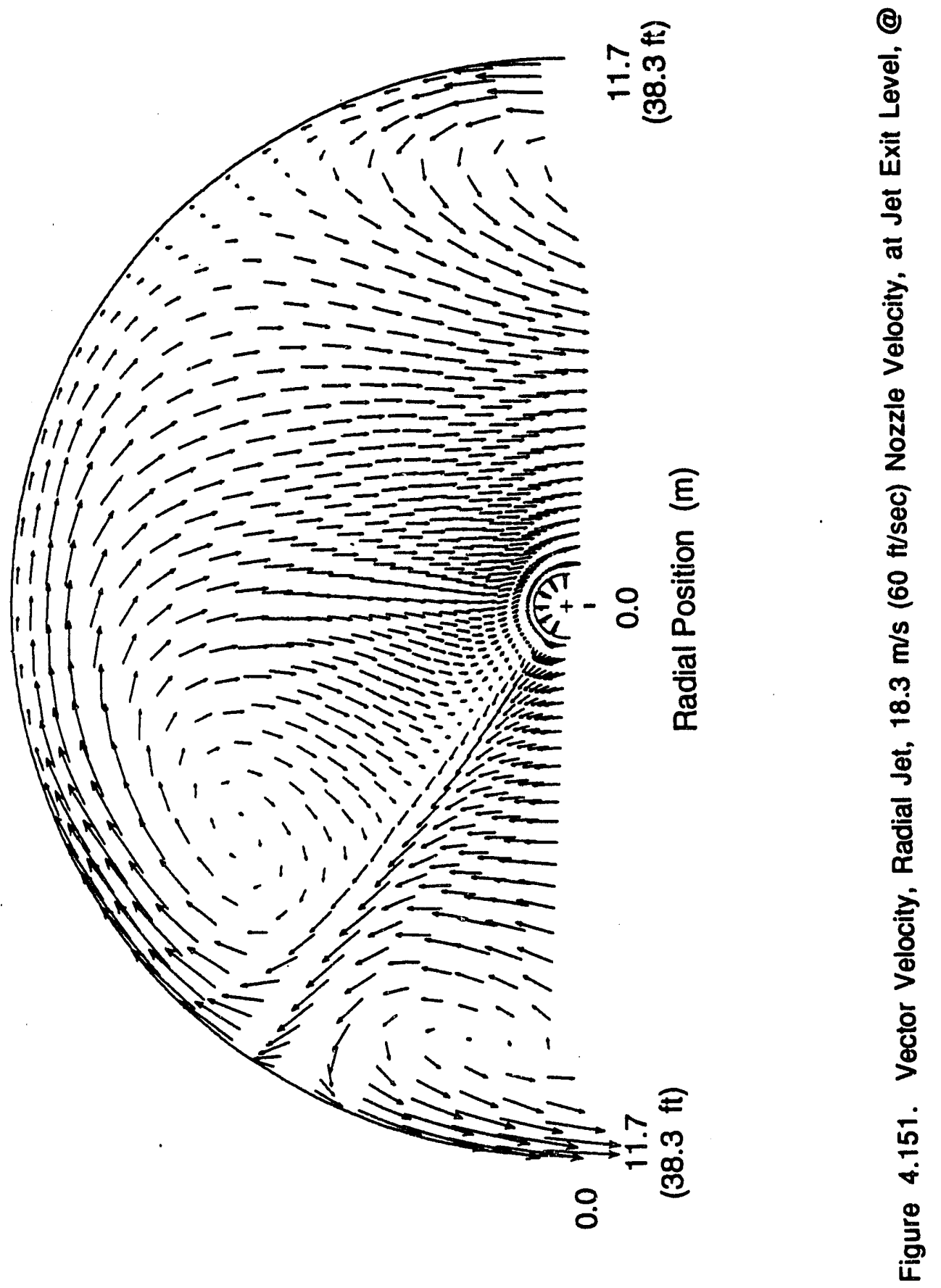




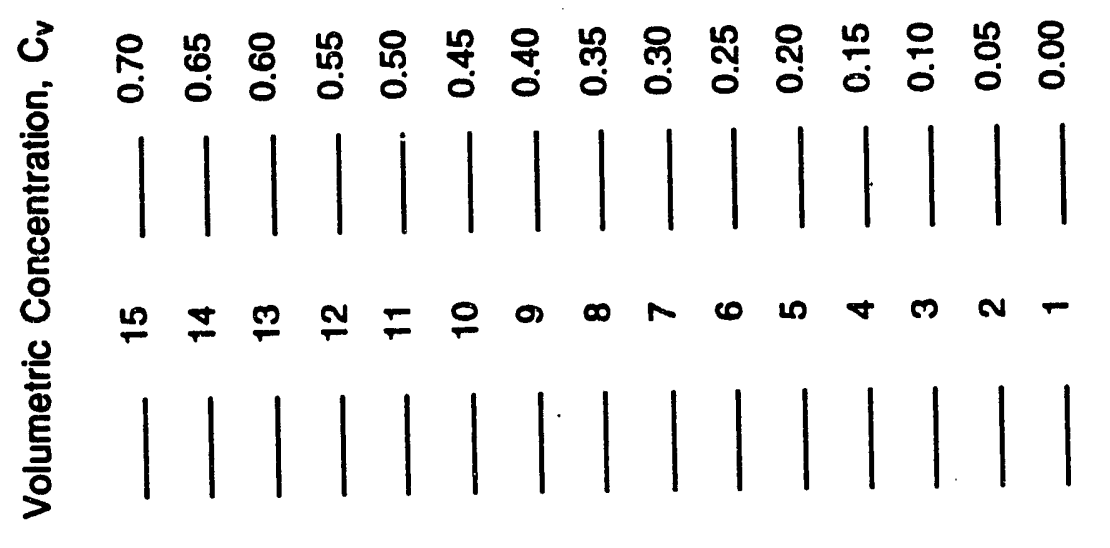

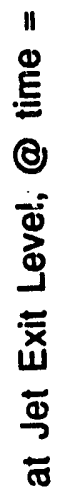

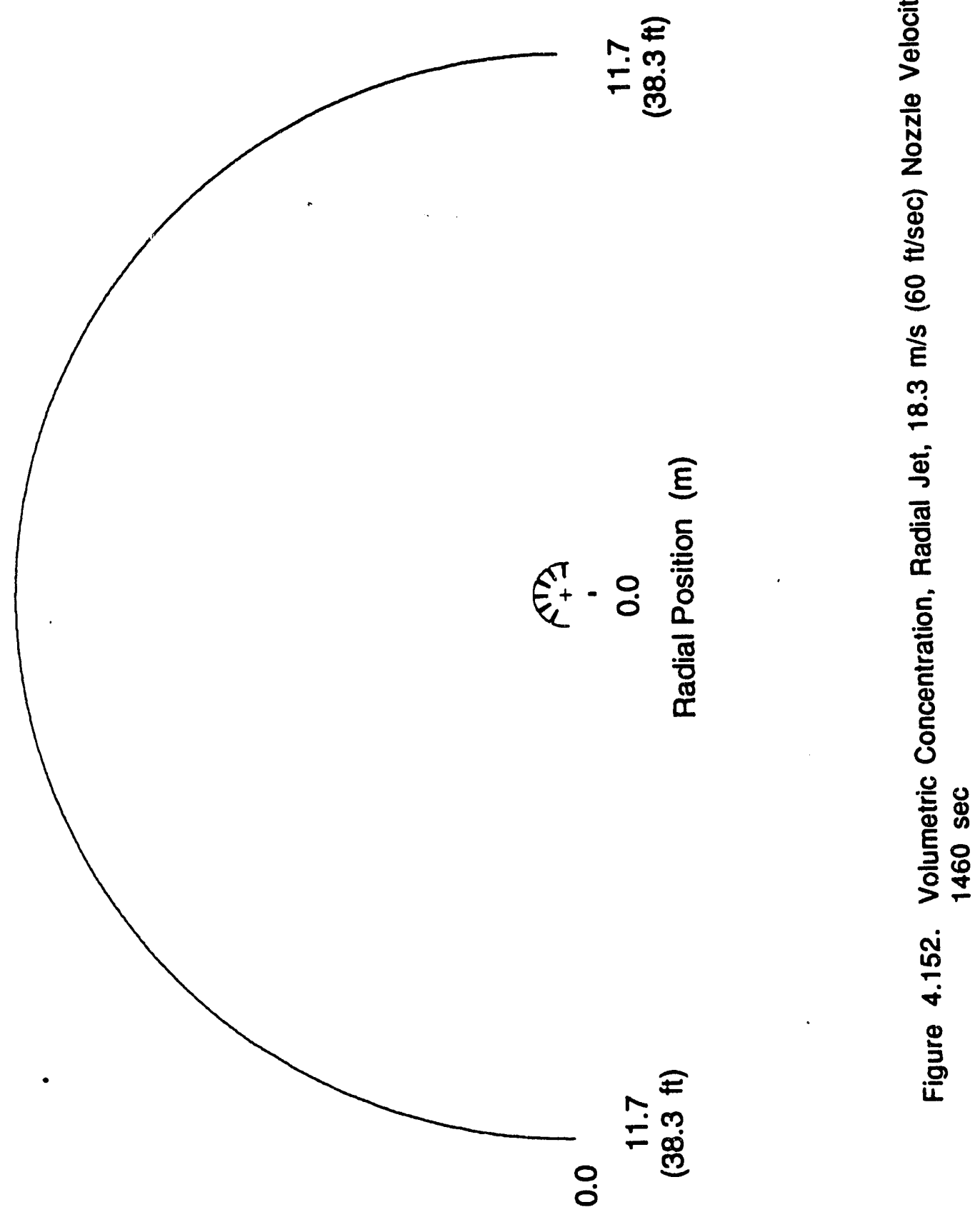




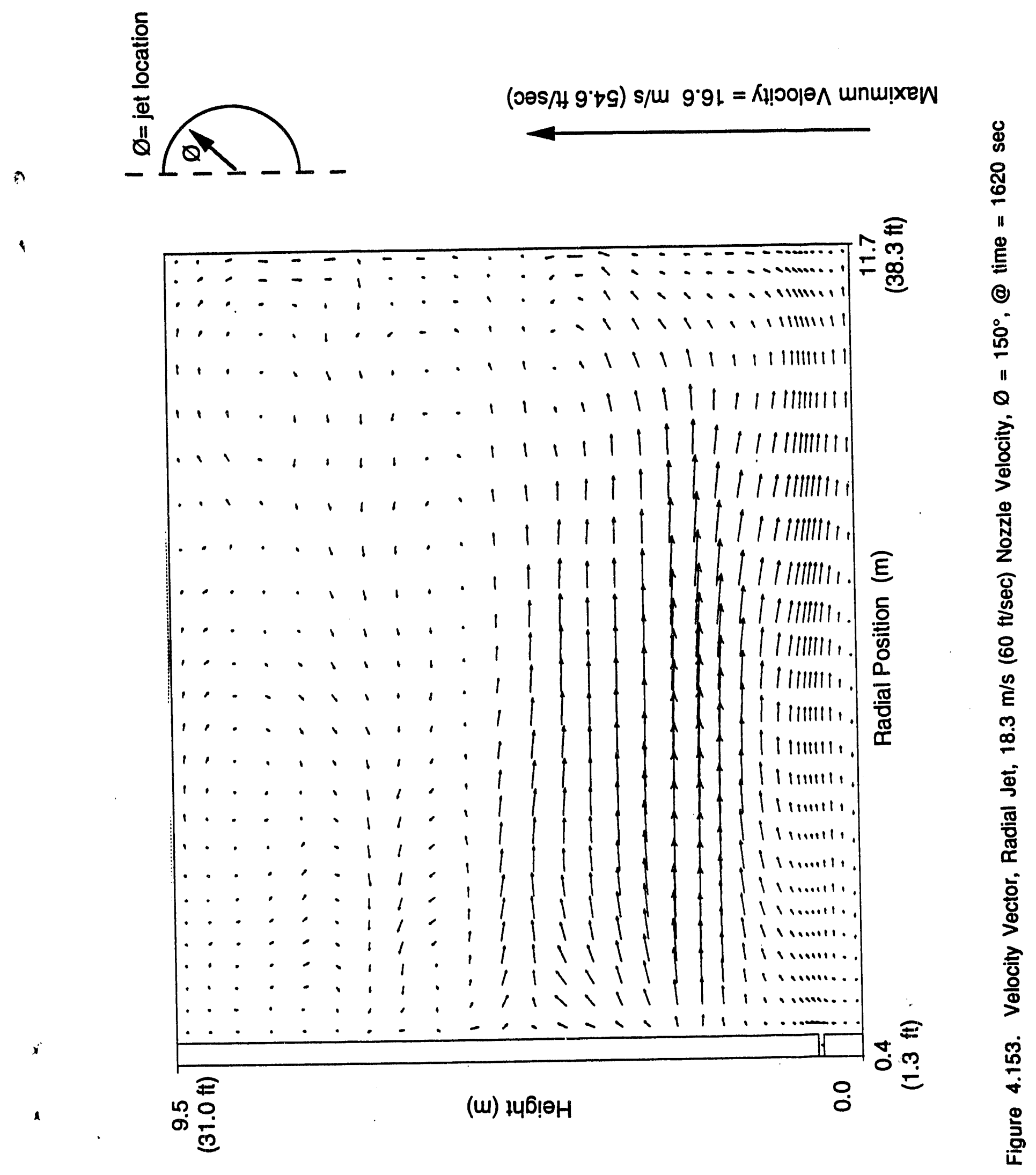



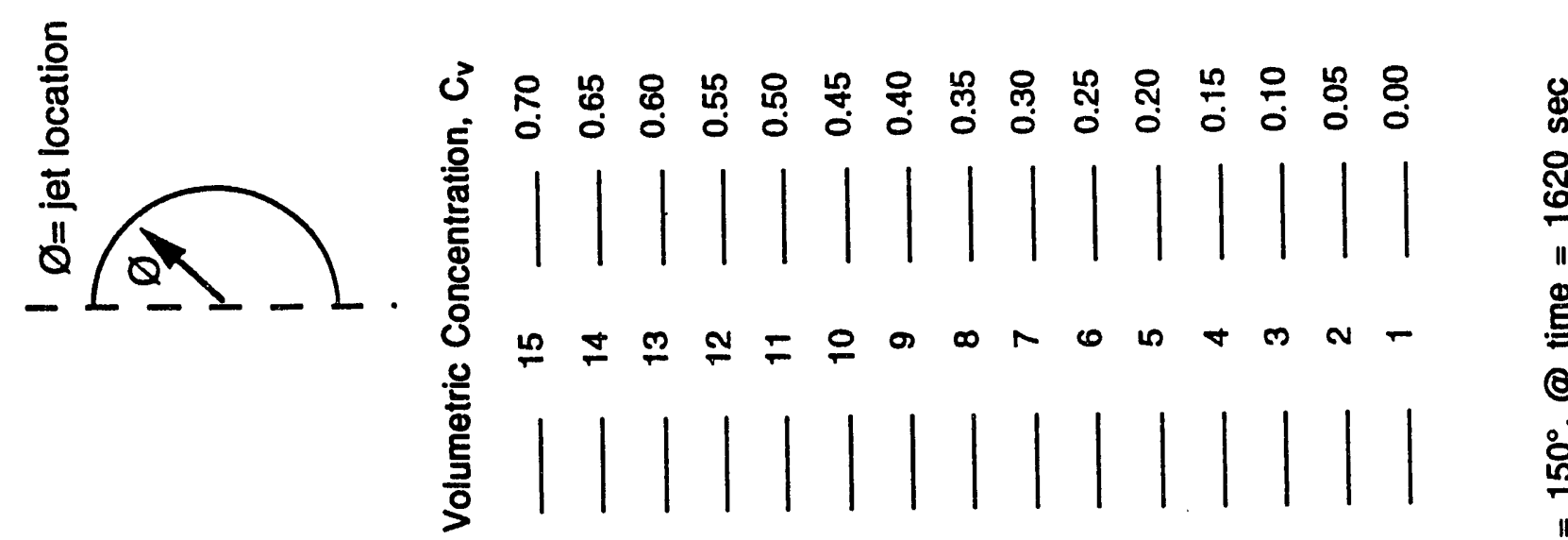

오

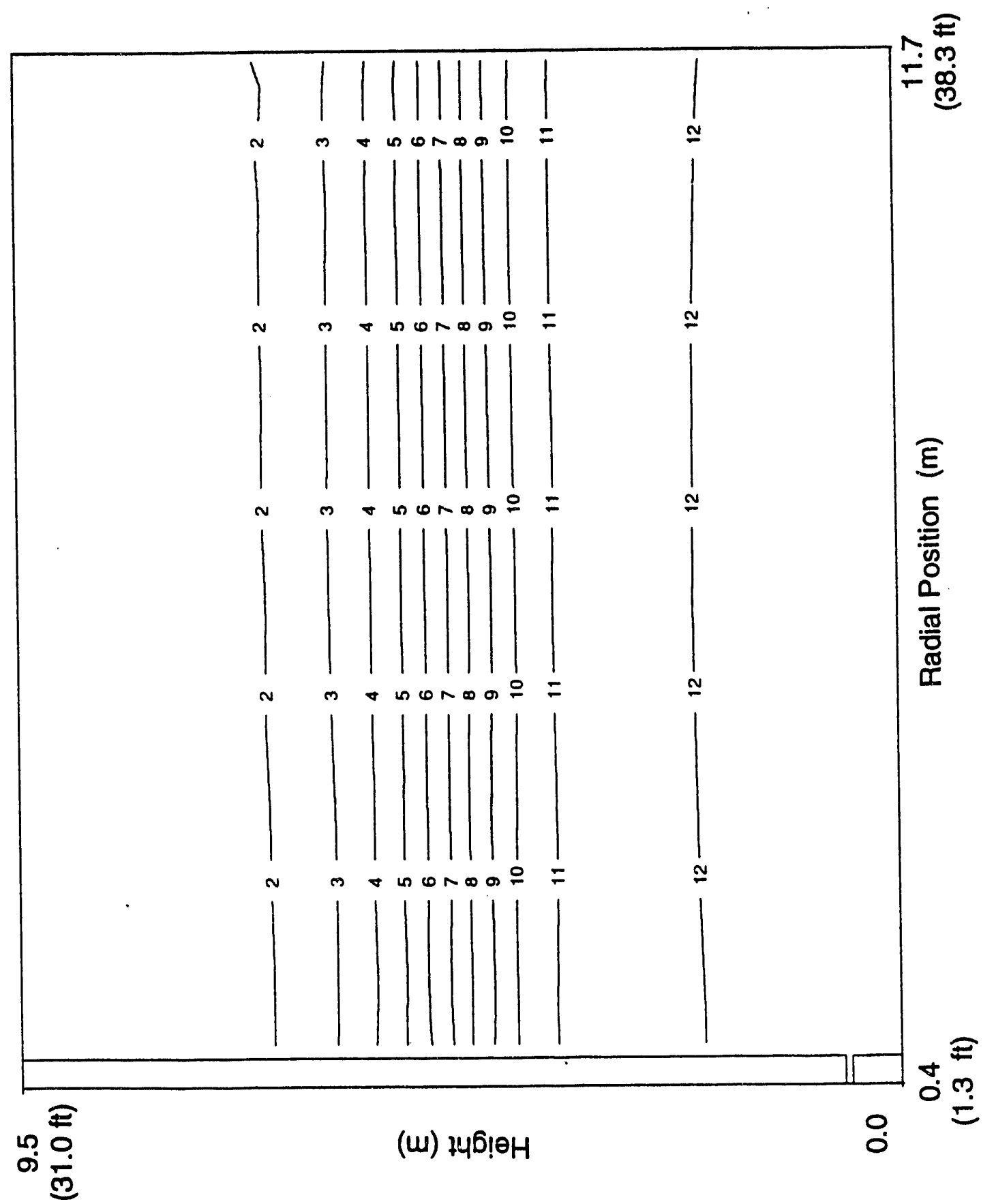

$Q$

응

$\frac{D}{N}$

을

ত্ষ

$\pm$

웅

ह

$\infty$

ธี

$\frac{9}{7}$

흠

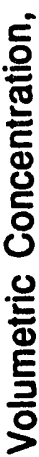

突 


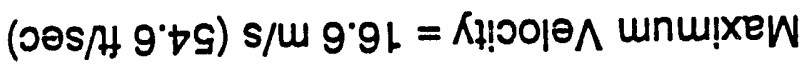




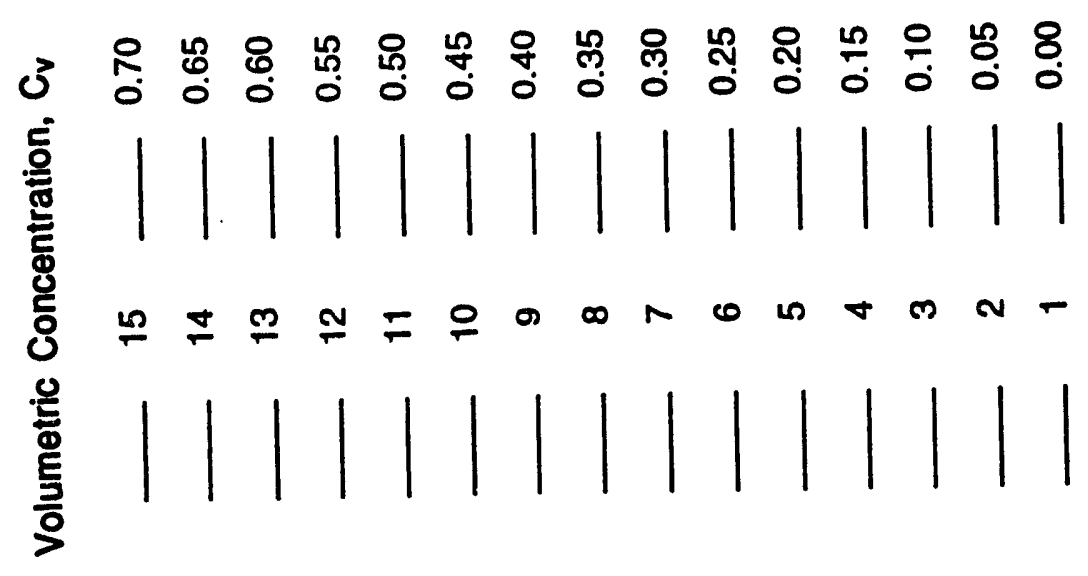

$\stackrel{\Perp}{\text { I }}$

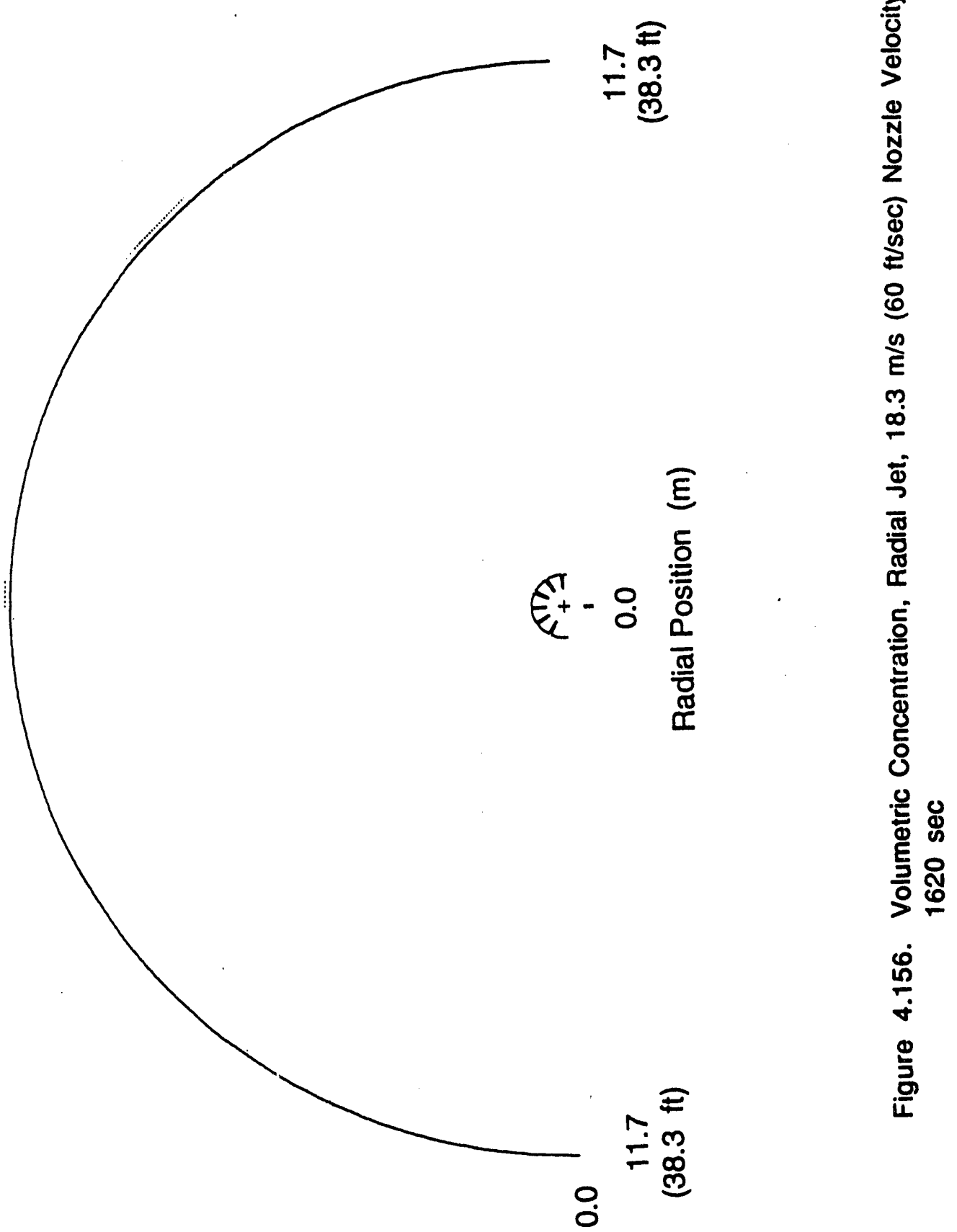

4.164 


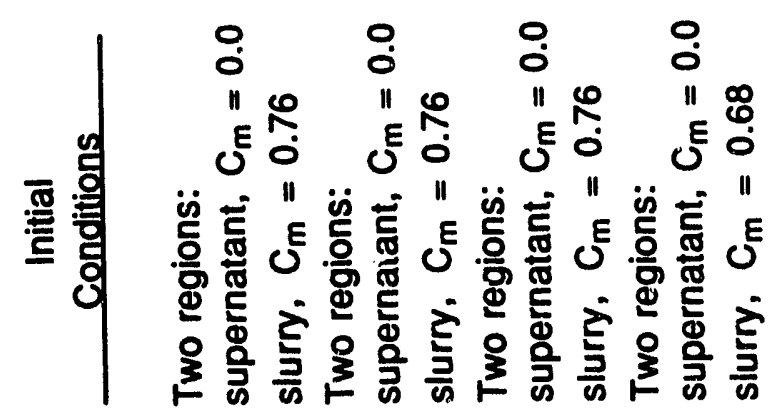

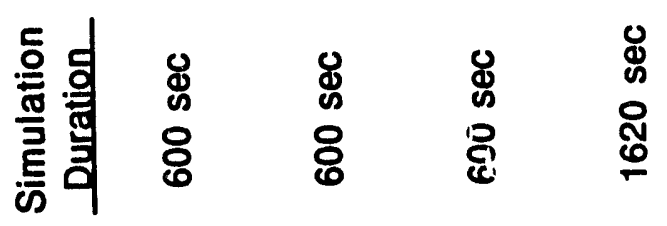

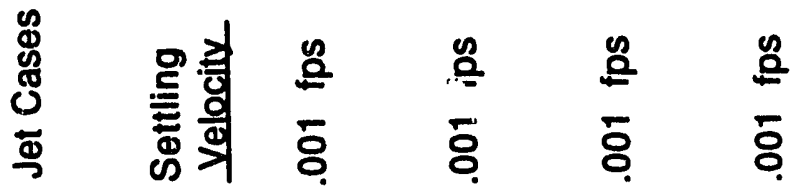

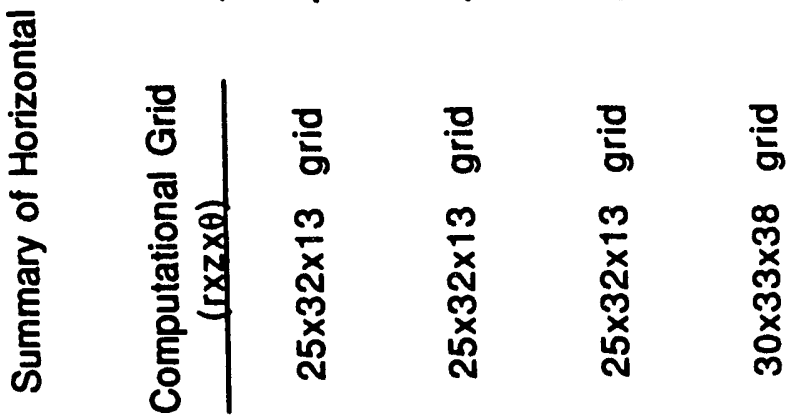

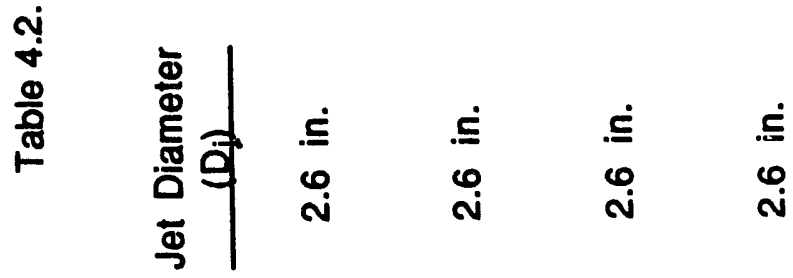

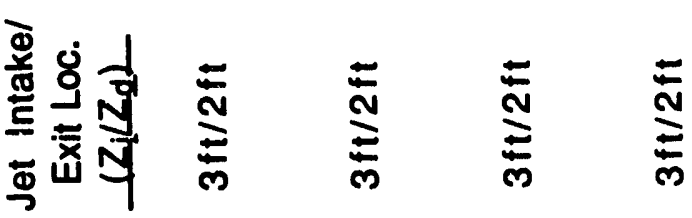

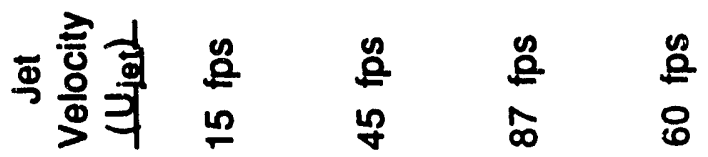

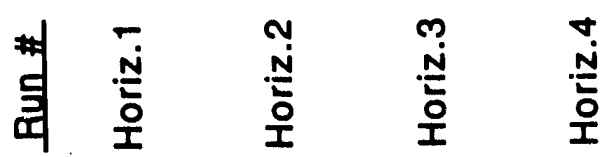


Table 4.3. Horiz. 4 Figure Index

Eiqure \# Iime (sec) Jetanale (ס) JetStatus View

Information

\begin{tabular}{|c|c|c|c|c|c|}
\hline 4.61 & 10 & $0^{\circ}$ & on & Vertical & Velocity Vectors \\
\hline 4.62 & 10 & $0^{\circ}$ & on & Vertical & Particle Concentration \\
\hline 4.63 & 10 & $0^{\circ}$ & on & Horizontal & Velocity Vectors \\
\hline 4.64 & 10 & $0^{\circ}$ & on & Horizontal & Particle Concentration \\
\hline 4.65 & 80 & $0^{\circ}$ & on & Vertical & Velocity Vectors \\
\hline 4.66 & 80 & $0^{\circ}$ & on & Vertical & Particle Concentration \\
\hline 4.67 & 80 & $0^{\circ}$ & on & Horizontal & Velocity Vectors \\
\hline 4.68 & 80 & $0^{\circ}$ & on & Horizontal & Particle Concentration \\
\hline 4.69 & 100 & $0^{\circ}$ & off & Vertical & Velocity Vectors \\
\hline 4.70 & 100 & $0^{\circ}$ & off & Vertical & Particle Concentration \\
\hline 4.71 & 100 & $0^{\circ}$ & off & Horizontal & Velocity Vectors \\
\hline 4.72 & 100 & $0^{\circ}$ & off & Horizontal & Particle Concentration \\
\hline 4.73 & 260 & $0^{\circ}$ & off & Vertical & Velocity Vectors \\
\hline 4.74 & 260 & $0^{\circ}$ & off & Vortical & Particle Concentration \\
\hline 4.75 & 260 & $0^{\circ}$ & off & Horizontal & Velocity Vectors \\
\hline 4.76 & 260 & $0^{\circ}$ & off & Horizontal & Particle Concentration \\
\hline 4.77 & 280 & $30^{\circ}$ & on & Vertical & Velocity Vectors \\
\hline 4.78 & 280 & $30^{\circ}$ & on & Vertical & Particle Concentration \\
\hline 4.79 & 280 & $30^{\circ}$ & on & Horizontal & Velocity Vectors \\
\hline 4.80 & 280 & $30^{\circ}$ & on & Horizontal & Particle Concentration \\
\hline 4.81 & 350 & $30^{\circ}$ & on & Vertical & Velocity Vectors \\
\hline 4.82 & 350 & $30^{\circ}$ & on & Verticui! & Particle Concentration \\
\hline 4.83 & 350 & $30^{\circ}$ & on & Horizontal & Velocity Vectors \\
\hline 4.84 & 350 & $30^{\circ}$ & on & Horizontal & Particle Concentration \\
\hline 4.85 & 380 & $30^{\circ}$ & off & Vertical & Velocity Vectors \\
\hline 4.86 & 380 & $30^{\circ}$ & off & Vertical & Particie Concentration \\
\hline 4.87 & 380 & $30^{\circ}$ & off & Horizontal & Velocity Vectors \\
\hline 4.88 & 380 & $30^{\circ}$ & off & Horizontal & Particle Concentration \\
\hline 4.89 & 540 & $30^{\circ}$ & off & Vertical & Velocity Vectors \\
\hline 4.90 & 540 & $30^{\circ}$ & off & Vertical & Particle Concentration \\
\hline 4.91 & 540 & $30^{\circ}$ & off & Horizontal & Velocity Vectors \\
\hline 4.92 & 540 & $30^{\circ}$ & off & Horizontal & Particle Concentration \\
\hline 4.93 & 550 & $60^{\circ}$ & on & Vertical & Velocity Vectors \\
\hline 4.94 & 550 & $60^{\circ}$ & on & Vertical & Particle Concentration \\
\hline 4.95 & 550 & $60^{\circ}$ & on & Horizontal & Velocity Vectors \\
\hline 4.96 & 550 & $60^{\circ}$ & on & Horizontal & Particle Concentration \\
\hline 4.97 & 620 & $60^{\circ}$ & on & Vertical & Velocity Vectors \\
\hline 4.98 & 620 & $60^{\circ}$ & on & Vertical & Particle Concentration \\
\hline 4.99 & 620 & $60^{\circ}$ & on & Horizontal & Velocity Vectors \\
\hline
\end{tabular}


Table 4.3. (contd)

Eloure \# IIme (sec) Jet anole (o) det Status View Information

\begin{tabular}{|c|c|c|c|c|c|}
\hline 4.100 & 620 & $60^{\circ}$ & on & Horizontal & Particle Concentration \\
\hline 4.100 & 620 & $60^{\circ}$ & on & Horizontal & Particle Concentration \\
\hline 4.101 & 640 & $60^{\circ}$ & off & Vertical & Velocity Vectors \\
\hline 4.102 & 640 & $60^{\circ}$ & off & Vertical & Particle Concentration \\
\hline 4.103 & 640 & $60^{\circ}$ & off & Horizontal & Velocity Vectors \\
\hline 4.104 & 640 & $60^{\circ}$ & off & Horizontal & Particle Concentration \\
\hline 4.105 & 800 & $60^{\circ}$ & off & Vertical & Velocity Vectors \\
\hline 4.106 & 800 & $60^{\circ}$ & off & Vertical & Particle Concentration \\
\hline 4.107 & 800 & $60^{\circ}$ & off & Horizontal & Velocity Vectors \\
\hline 4.108 & 800 & $60^{\circ}$ & off & Horizontal & Particle Concentration \\
\hline 4.109 & 820 & $90^{\circ}$ & on & Vertical & Velocity Vectors \\
\hline 4.110 & 820 & $90^{\circ}$ & on & Vertical & Particle Concentration \\
\hline 4.111 & 820 & $90^{\circ}$ & on & Horizontal & Velocity Vectors \\
\hline 4.112 & 820 & $90^{\circ}$ & on & Horizontal & Particle Concentration \\
\hline 4.113 & 890 & $90^{\circ}$ & on & Vertical & Velocity Vectors \\
\hline 4.114 & 890 & $90^{\circ}$ & on & Vertical & Particle Concentration \\
\hline 4.115 & 890 & $90^{\circ}$ & on & Horizontal & Velocity Vectors \\
\hline 4.116 & 890 & $90^{\circ}$ & on & Horizontal & Particle Concentration \\
\hline 4.117 & 920 & $90^{\circ}$ & off & Vertical & Velocity Vectors \\
\hline 4.118 & 920 & $90^{\circ}$ & off & Vertical & Particle Concentration \\
\hline 4.119 & 920 & $90^{\circ}$ & off & Horizontal & Velocity Vectors \\
\hline 4.120 & 920 & $90^{\circ}$ & off & Horizontal & Particle Concentration \\
\hline 4.121 & 1080 & $90^{\circ}$ & off & Vertical & Velocity Vectors \\
\hline 4.122 & 1080 & $90^{\circ}$ & off & Vertical & Particle Concentration \\
\hline 4.123 & 1080 & $90^{\circ}$ & off & Horizontal & Velocity Vectors \\
\hline 4.124 & 1080 & $90^{\circ}$ & off & Horizontal & Particle Concentration \\
\hline 4.125 & 1090 & $120^{\circ}$ & on & Vertical & Velocity Vectors \\
\hline 4.126 & 1090 & $120^{\circ}$ & on & Vertical & Particle Concentration \\
\hline 4.127 & 1090 & $120^{\circ}$ & on & Horizontal & Velocity Vectors \\
\hline 4.128 & 1090 & $120^{\circ}$ & on & Horizontal & Particle Concentration \\
\hline 4.129 & 1160 & $120^{\circ}$ & on & Vertical & Velocity Vectors \\
\hline 4.130 & 1160 & $120^{\circ}$ & on & Vertical & Particle Concentration \\
\hline 4.131 & 1160 & $120^{\circ}$ & on & Horizontal & Velocity Vectors \\
\hline 4.132 & 1160 & $120^{\circ}$ & on & Horizontal & Particle Concentration \\
\hline 4.133 & 1180 & $120^{\circ}$ & off & Vertical & Velocity Vectors \\
\hline 4.134 & 1180 & $120^{\circ}$ & off & Vertical & Particle Concentration \\
\hline 4.135 & 1180 & $120^{\circ}$ & off & Horizontal & Velocity Vectors \\
\hline 4.136 & 1180 & $120^{\circ}$ & off & Horizontal & Particle Concentration \\
\hline 4.137 & 1340 & $120^{\circ}$ & off & Vertical & Velocity Vectors \\
\hline
\end{tabular}


Table 4.3. (contd)

Eiqure\# Iime (sec) Jetanole (ø) Jet Status

View

4.138

4.139

4.140

4.141

4.142

4.143

4.144

4.145

4.146

4.147

4.148

4.149

4.150

4.151

4.152

4.153

4.154

4.155

4.156
1340

1340

1340

1360

1360

1360

1360

1430

1430

1430

1430

1460

1460

1460

1460

1620

1620

1620

1620 $120^{\circ}$

$120^{\circ}$

$120^{\circ}$

$150^{\circ}$

$150^{\circ}$

$150^{\circ}$

$150^{\circ}$

$150^{\circ}$

$150^{\circ}$

$150^{\circ}$

$150^{\circ}$

$150^{\circ}$

$150^{\circ}$

$150^{\circ}$

$150^{\circ}$

$150^{\circ}$

$150^{\circ}$

$150^{\circ}$

$150^{\circ}$

\section{of}

off

off

Vertical

Horizontal

Horizontal

Vertical

Vertical

Horizontal

Horizontal

Vertical

Vertical

Horizontal

Horizontal

Vertical

Vertical

Horizontal

Horizontal

Vertical

Vertical

Horizontal

Horizontal
Information

Particle Concentration

Velocity Vectors

Particle Concentration

Velocity Vectors

Particle Concentration

Velocity Vectors

Particle Concentration

Velocity Vectors

Particle Concentration

Velocity Vectors

Particle Concentration

Velocity Vectors

Particle Concentration

Velocity Vectors

Particle Concentration

Velocity Vectors

Particle Concentration

Velocity Vectors

Particle Concentration

For the properties assumed at the time of these initial TEMPEST simulations, the computer predictions of jet mixing in Tank 241-SY-101 indicate that high jet discharge flowrates would be required to fully mix the tank to a uniform consistency for both the vertical and horizontal jet configurations. It is not possible, however, to state whether the velocity distributions are sufficient to release any trapped gases that might exist. The TEMPEST simulations that address the effect of treating gases will be presented in a later report, which will include an accurate representation of the material properties in the tank. 


\subsection{Conclusions}

The objectives of this work were to verity the accuracy of the TEMPEST computer code in modeling turbulent jets and investigating the effectiveness of a series of mitigation concepts incorporating jet mixing. The following conclusions are provided:

- The accuracy of the TEMPEST computer code in modeling turbulent jets was quantified via a series of 2-dimensional simulations. Several cases were simulated to determine the minimum number of total grids cells while maintaining accuracy in the code results. In comparing the results with the empirical correlation, it was determined that 1 radial cell in the jet diameter with 1 axial node in the jet core region was sufficient. This finding was confirmed for a 3-dimensional computational grid of the Tank 241-SY-101 geometry.

- A series of 2-dimensional simulations were run to find the most economical grid size with acceptable accuracy for the grid system beyond the jet region for the vertical jet cases. The $43 \times 31$ grid was selected.

- The vertical draft tube configuration was found to be ineffectual in mixing the contents of the tank beyond a recirculation pattern established near the tank center. Based on this result, it is recommended that the draft tube mitigation concept be abandoned.

- TEMPEST studies of jet mixing using a downward centrally located vertical jet have shown that, with a sufficient volumetric flow rate, the slurry region can be mobilized and mixed with the convecting layer located directly above. The problem with this approach is that extremely high jet flow rates $(95,000 \mathrm{gal} / \mathrm{min})$ are required to achieve the desired mixing.

- Results from horizontal jet mitigation concept study indicate that high velocity jets discharging near the bottom of the tank are more effective mixing devices than vertical downward discharging jets located at the center of the tank. The TEMPEST simuiations indicate that an incrementally rotated horizontal jet located 2- to 3-ft above the tank floor appears to be the most effective jet mixing option.

- This study of mitigation concepts incorporates the best available information on the material properties for the contents of Tank 241-SY-101 at the time of the work. The accuracy of the simulations are dependent on the constitutive relations that describe the behavior of the materials found in the tank. It is, therefore, important to improve our understanding of the material properties for the range of conditions found in the tank. 


\subsection{References}

Abraham, G. 1963. Jet Diffusion in Stagnant Ambient Fluid. Delft Hydraulics Laboratory. Publication No. 29. Waterloopkundig Laboratorium, Delft, The Netherlands.

Allemann, R. T., and Z. I. Antoniak, J. R. Friley, C. E. Haines, L. M. Liljegren, and S.

Somasundarani. 1991. Collection and Analysis of Existine Data for Waste Tank Mechanistic Analysis. PNIL-7658, Pacific Northwest Laboratory, Richland, Washington.

Babad, H., J. L. Deichman, B. M. Lohnson, D. K. Lemon, and D. M. Strachan. 1992.

Mitigation/Remediation Concepts for Hanford Site Flammable Gas Generatina Waste Tanks. WHC-EP-051S, Westinghouse Hanford Company, Richland, Washington.

Bird, R. B., W. E. Stewart, and E. N. Lightfoot. 1960. Transport Phenomena. John Wiley and Sons, Inc., New York.

Bryan, S. A., L. R. Pederson, J. I.. Ryan, R. D. Scheele, and J. M. Tingey. 1991. Slurn Growth. Gas Retention and Flammable Gas Generation by Hantord Radioactive Waste Ianks: Synthetic Waste Studies. FY 1991. PNL-8169, Pacific Northwest Laboratory, Richland, Washington.

Fort, J. A., J. A. Bamberger, J. M. Bates, C. W. Enderlin, and M. R. Elmore. 1992. 1/12-Scale Physical Modelino Experiments in Suppont of Tank 241-SY-101 Hydrogen Mitiaation. PNL8476, Pacific Northwest Laboratory, Richland, Washington.

Perry, R. H., and D. W. Green. 1984. Perry's Chemical Engineers' Handbook. McGraw-Hill, New York. 


\section{DISTRIBUTION}

No. of

Copies

\section{OFFSITE}

12 DOE/Office of Scientific and Technical Information

\section{S. Abrams}

1987 Virginia

Idaho Falls, ID 83404

N. E. Bibler

Westinghouse Savannah River Co.

Bldg. 773A, Room B132

Box 616

Aiken, SC 29802

D. Campbell

102 Windham Road

Oak Ridge, TN 37830

F. N. Carlson

6965 North, 5th West

Idaho Falls, ID 83401

C. W. Forsberg

Oak Ridge National Laboratory

MS-6495, P.O. Box 2008

Oak Ridge, TN 37831-6495

6 Los Alamos National Laboratory

P.O. Box 1663

Los Alamos, NM 87545

Attn: L. H. Sullivan, K557

J. R. White, K555

S. W. Eisenhawer, K557

J. Edwards, K557

T. E. Larson, P915

K. Pasamehmetoglu, K557

J. L. Mai

723 45th Avenue

San Francisco, CA 94121
No. of

Copies

F. L. Parker

Vanderbilt University

P.O. Box 1596, Station B

Nashville, TN 37235

G. Powers

Design Science Inc.

163 Witherow Road

Sewickley, PA 15143

A. Schneider
Massachusetts Institute of Technology

Department of Nuclear Engineering

Room 24-1098

77 Massachusetts Avenue

Cambridge, MA 02139

W. W. Schulz

727 Sweetleaf Drive

Wilmington, DE 19808

D. D. Siemer

WINCO

IRC MS 2207

Idaho Falls, ID 83403

S. E. Slezak

Sandia National Laboratories

1515 Eubank NE

Division 6424

P.O. Box 5800

Albuquerque, NM 87185

W. J. Thomson

Dept. of Chemical Engineering

Washington State University

Pullman, WA 99164

Distr.1 
No. of

Copies

J. Tseng

U.S. Department of Energy

EM-35

Trevion II

Washington, D.C. 20585-0002

G. Wallis

Associate Dean

Thayer School of Engineering

Dartmouth College

Hanover, NH 03755

\section{ONSITE}

4 DOE Richland Field Office

R. F. Christensen, A4-02

R. E. Gerton, A5-21

J. M. Gray, A4-02

G. W. Rosenwald, A5-21

30 Westinghouse Hanford Company

H. Babad, B2-15

T. R. Beaver, H0-33

T. R. Benegas, H5-09

H. R. Brager, L5-03

T. M. Burke, H0-34

R. J. Cash, R2-31

C. DeFigh-Price, R2-31

J. C. Fulton, R2-31

K. A. Gasper, B3-68

M. N. Hall, H5-68

C. E. Hanson, H5-09

G. D. Johnson, L5-03

N. W. Kirch, R2-11

W. L. Knecht, H0-34

J. W. Lentsch, R2-31

R. D. Marusich, H5-32

G. J. Miskho, R2-50
No. of

Copies

C. P. Molteni, R1-51

D. Ogden, H0-34

M. A. Payne, R2-50

R. W. Reed, R1-51

D. A. Reynolds, R2-11

D. C. Richardson, R2-31

K. Sathyanarayana, H0-34

M. H. Shannon, B1-35

D. D. Stepnewski, N1-31

T. I. Stokes, H5-09

J. D. Thomson, R1-30

R. E. Vandercook, S6-07

D. D. Wodrich, R2-23

40

Pacific Northwest Laboratory

R. T. Allemann, K5-19

I. G. Choi, K7-15

J. A. Bamberger, K7-15

J. M. Bates, K 7-15

J. B. Colson, K5-10

M. R. Elmore, P7-19

C. W. Enderlin, K7-15

E. J. Eschbach, K7-15

L. L. Eyler, K7-15

J. A. Fort, K7-15

M. S. Greenwood, K2-31

M. S. Hanson, K1-51

B. M. Johnson, Jr., K5-02 (3)

M. R. Kreiter, K7-90 (3)

L. M. Liljegren, K7-15

N. J. Lombardo, K7-02

T. E. Michener, K7-15 (5)

R. D. Scheele, P7-25

D. M. Strachan, K2-44

D. S. Trent, K7-15 (5)

H. H. Van Tuyl, P7-22

G. Terroes, K7-15

Publishing Coordination

Technical Report Files (5) 

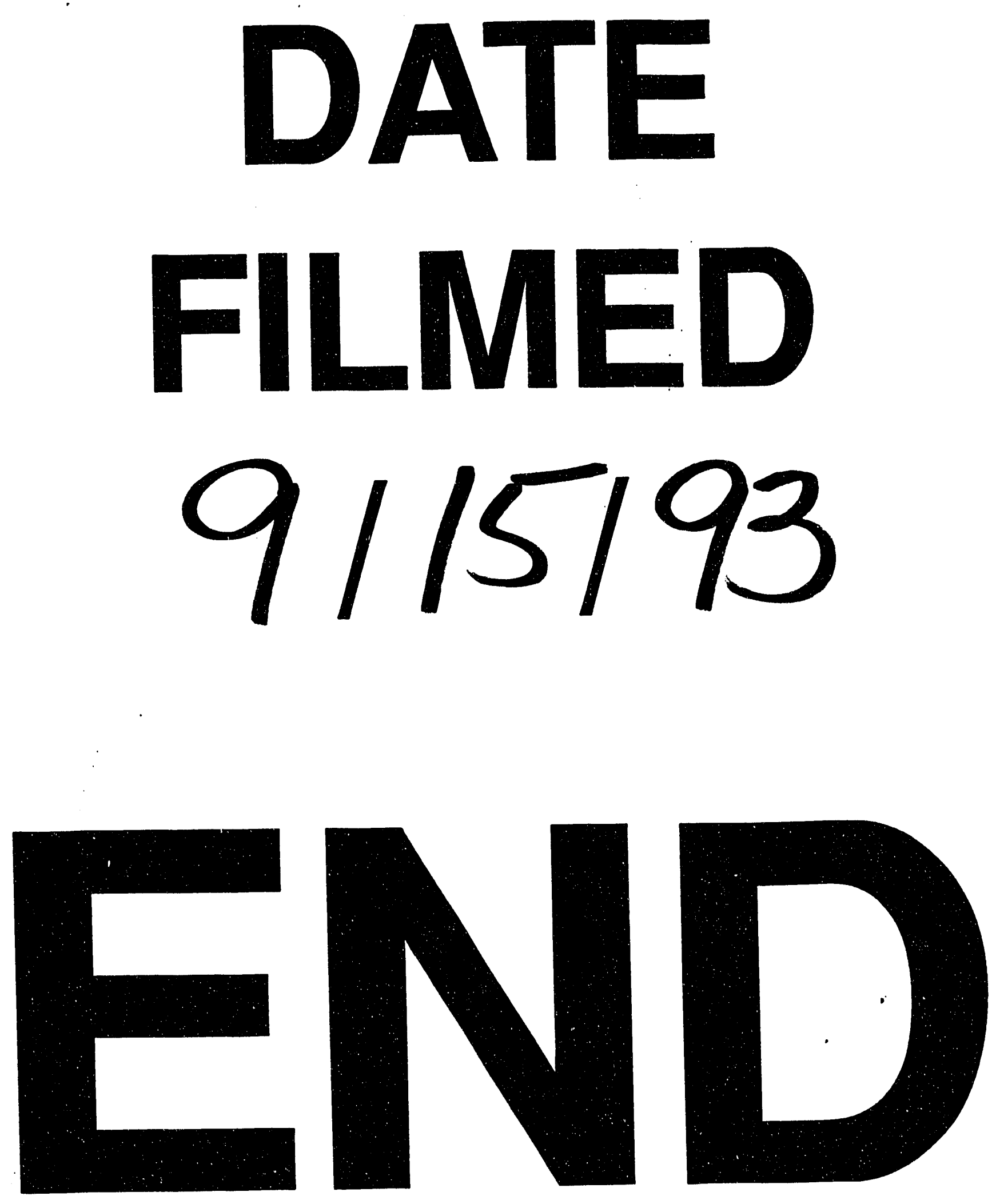
